\title{
Baldassare Scolari
}

State Martyr

Representation and Performativity of Political Violence

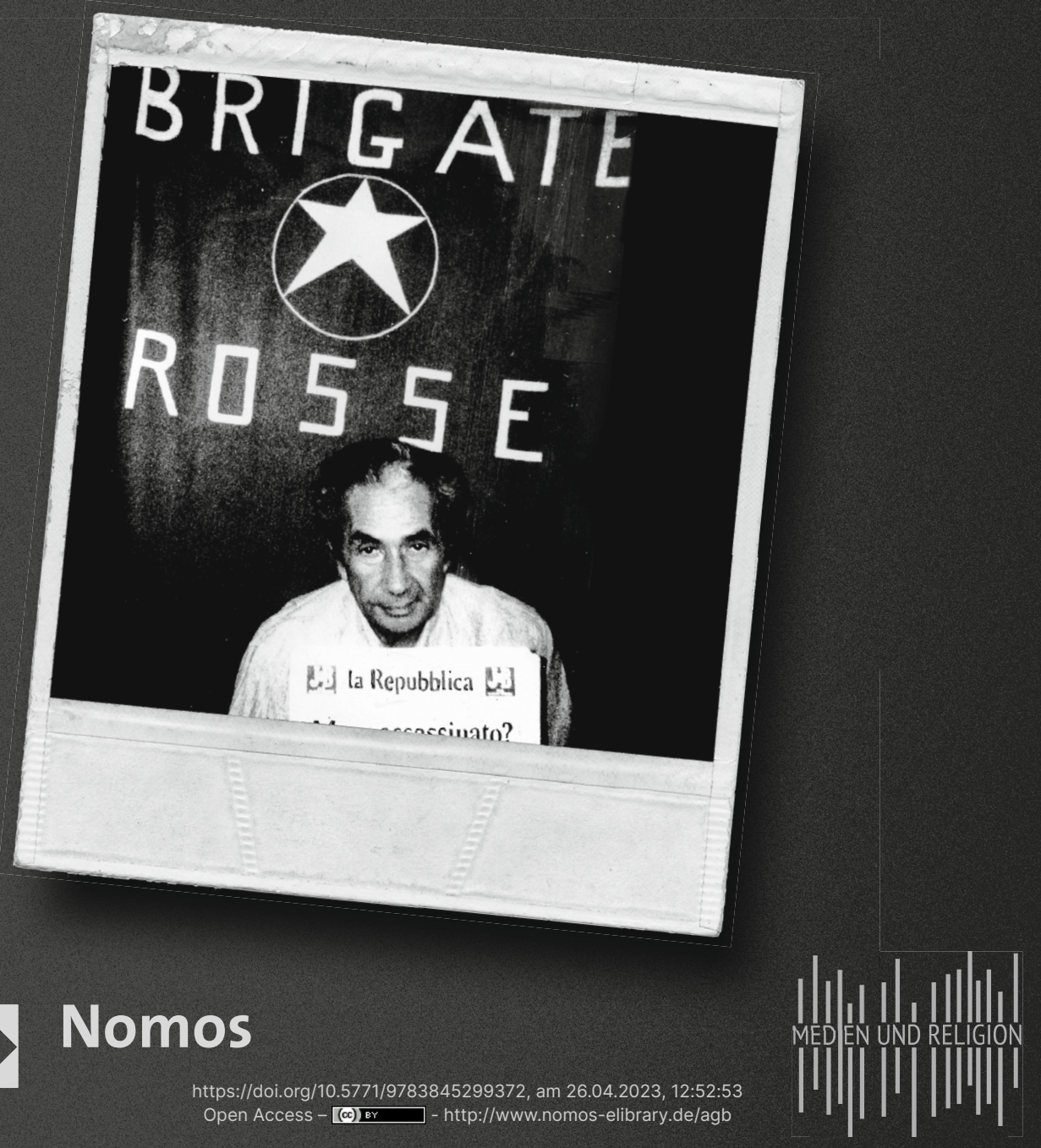


Media and Religion | Medien und Religion

edited by | herausgegeben von

Dr. Anna-Katharina Höpflinger

Ludwig-Maximilians-Universität München

Prof. Dr. Stefanie Knauss

Villanova University, USA

Dr. Marie-Therese Mäder

Ludwig-Maximilians-Universität München

Prof. Dr. Daria Pezzoli-Olgiati

Ludwig-Maximilians-Universität München

Volume $2 \mid$ Band 2 
Baldassare Scolari

\section{State Martyr}

Representation and Performativity of Political Violence

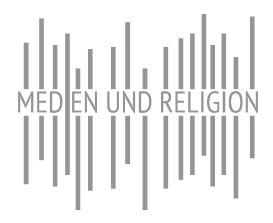


The publication was supported by the Swiss National Science Foundation (SNSF).

\section{FN TNF \\ SCHWEIZERISCHER NATIONALFONDS \\ ZUR FÖRDERUNG DER WISSENSCHAFTLICHEN FORSCHUNG}

The Deutsche Nationalbibliothek lists this publication in the Deutsche Nationalbibliografie; detailed bibliographic data are available on the Internet at http://dnb.d-nb.de

a.t.: München, Ludwig-Maximilians-Univ., Diss., 2018

ISBN 978-3-8487-5761-9 (Print) 978-3-8452-9937-2 (ePDF)

British Library Cataloguing-in-Publication Data

A catalogue record for this book is available from the British Library.

ISBN 978-3-8487-5761-9 (Print)

978-3-8452-9937-2 (ePDF)

\section{Library of Congress Cataloging-in-Publication Data}

Scolari, Baldassare

State Martyr

Representation and Performativity of Political Violence

Baldassare Scolari

$417 \mathrm{pp}$.

Includes bibliographic references and index.

ISBN 978-3-8487-5761-9 (Print)

978-3-8452-9937-2 (ePDF)

1st Edition 2019

(c) Baldassare Scolari

Published by

Nomos Verlagsgesellschaft mbH \& Co. KG

Waldseestraße 3-5 | 76530 Baden-Baden

www.nomos.de

Total Print Production:

Nomos Verlagsgesellschaft mbH \& Co. KG

Waldseestraße 3-5 | 76530 Baden-Baden

Printed and bound in Germany.

ISBN (Print): 978-3-8487-5761-9

ISBN (ePDF): 978-3-8452-9937-2

DOI: https://doi.org/10.5771/9783845299372

\section{c) $(9) \Theta$}

This work is licensed under a Creative Commons Attribution

- Non Commercial - No Derivatives 4.0 International License. 


\section{Table of Contents}

$\begin{array}{ll}\text { Preface } & 9\end{array}$

$\begin{array}{ll}\text { Author's Note } & 11\end{array}$

1 Introduction 15

1.1 The Event of Political Violence 15

1.2 Status Quaestionis 20

1.3 The State Martyr Figure 26

1.4 Organization of the Investigation 33

2 A Discourse Analytical Approach to Political Violence 40

2.1 The Representation of Violence in the Context of Political Struggle 40

2.2 Narratives of Sovereignty and Rebellion 48

2.3 Hegemonic and Subversive Uses of the Martyr Figure 59

2.4 The Discourse Analytical Approach 64

2.5 Performativity of Discursive Practices 71

2.6 Unity of the Discursive Formation and Methodological Framework 82

3 Signatures of the Martyr Figure 90

3.1 The Martyr Figure as a Counterpart of the Sovereign 90

3.2 Sacrifice, Scapegoat, Martyrdom 99

3.3 Emergence of the Martyr Figure 109

3.4 Institutionalization, Militarization, and Nationalization of the Martyr Figure 
4 Cultural, Social and Political Context of the Event of Political Violence

4.1 The Rhetoric of Sacrifice During the Risorgimento and the Resistenza

4.2 1948-1978: Thirty Years of Italian Political History

4.3 Emancipation and Political Violence in the «Years of Lead»

4.4 The Moro Case: History and Conspiracy

5 Construction of a Willing Martyr

5.1 Opposing Narratives and Representations: Red Brigades Versus Italian State Versus Aldo Moro

5.2 The Image of Moro Before the Kidnapping

5.3 16 March 1978: First Reactions to the Kidnapping

5.4 Framing «the People» and «the Enemy»: Construction of National Identity

5.5 The Image of the Coming Martyr

6 Moro's Voice and its Annihilation

6.1 Sanctity of Human Life

6.2 Reduction to Bare Life

6.3 Grand Finale: Consolidation of the State Martyr

7 Memorialization Practices and Memory Struggle

7.1 Contested Memory and Practices of Memorialization in the Public Space

7.2 Literary Interventions

7.3 Moro's Image on Television and in Italian Cinema

7.4 Beatification Process

8 How to Narrate and Represent Political Violence 363

8.1 Discourse and Cultural Analysis 364

8.2 Performativity and Signatures of the Martyr Figure 365

8.3 The Moro Case 
8.4 Towards an Aesthetics of Resistance

List of Figures

Bibliography

385

Filmography

409

Register

411 


\section{Preface}

Since the terrorist attacks on the Twin Towers in New York on September 11, 2001, terrorism and, more generally, political violence have become central topics in media representations as well as in academic debates and studies. The recent spread of allegedly religiously motivated suicide bombings and other kinds of attacks involving the deaths of both attackers and victims has caused an attendant surge of interest in the relationship between events of political violence and the martyr figure. Many contemporary studies seek to understand martyrological representations and narratives as forms of propaganda for a particular cause and aim, in order to highlight the mechanisms and procedures by which martyr figures are constructed and contested. This investigation is a contribution to the debate concerning the relationship between martyrdom and political violence. It places emphasis on historical, social and cultural phenomena, which so far have been largely neglected, namely the emergence, aesthetics and performativity of the state martyr figure. Because of the actuality of so-called «Islamicist terrorism", many researchers have focused on the role of the martyr figure in the Islamic religious and cultural tradition, often comparing it in particular with Christian and Jewish concepts of martyrdom. Researchers often highlight the overlap between terrorism and martyrdom by identifying commonalities and differences in the use and function of martyrological representations in different historical and social contexts of struggle. Great attention has been directed towards the propagandistic use of martyrological representation for the legitimization of violence and for the promotion of an ideology aimed at destroying «Western» culture, society, and institutions. Far from denying or criticizing these interpretations, this research study focuses on a structurally related but different phenomenon: the representation of victims of political violence as state martyrs who died for the salvation of the democratic social and political order and state institutions. While I focus on the martyrological representations of a specific case of political violence-the kidnapping, imprisonment and assassination of the Italian Christian Democrat politician Aldo Moro in 1978 by the Red Brigades - this work is not a case study in the strictest sense. The «Moro case» serves as a point of departure for developing critical reflection on the emergence, use and function of state martyrology and mythology in the modern and contemporary world. 
I began my PhD studies in 2013, as a joint doctoral degree between the Universität Zürich and the Università degli Studi di Macerata under the supervision of Daria Pezzoli-Olgiati and Carla Danani. In 2016, I matriculated at the Ludwig-Maximilians-Universität München, which took over the cooperation agreement for the implementation of joint doctoral supervision with the Università degli Studi di Macerata. This $\mathrm{PhD}$ thesis won the 2018 award of the Münchener Universitätsgesellschaft. My research has been supported by two grants from the Universität Zürich (Forschungskredit Candoc) and from the Divisione della cultura e degli studi unversitari (DECS) of the Republic and Canton Ticino, to whom I owe much thanks. I would also like to thank the Swiss National Science Foundation (SNSF) for taking on the costs of printing and Open Access publication, as well as the employees of Nomos publishing house for their excellent cooperation. Moreover, I would also like to express my gratitude to my tutors Daria Pezzoli-Olgiati and Carla Danani for their support, without which this study would have never existed. Many thanks also go to the members of the research group Media and Religion-especially AnnaKatharina Höpflinger, Dolores Zoé Bertschinger, Marie-Therese Mäder, Michael Ulrich, Natalie Fritz, Roger Meier, Paola von Wyss-Giacosa and Stefanie Knauss - who have always helped, advised and encouraged me in my work. I'm also grateful to Richard Amesbury, Robert Yelle, Michael Braunschweig, Giulia Giubergia, Sidsel Undseth Bakke, William Arfam and Franc Wagner for the fruitful discussions and their inputs, as well as Annamarie Benson, Joyce Fegan and Martin Ford for proofreading this $\mathrm{PhD}$ thesis. Finally, my special thanks go to my father Raffaele, my brother Jacopo and my sisters Luna and Eleonora for their boundless support. 


\section{Author's Note}

All translations, Italian and German, are my own unless indicated otherwise in the footnotes. 
Es gibt keine Herrscher mehr, keine Könige, die die Masse, die die Meute noch im Zaume halten können; es gibt nur noch das Bild des Märtyrers.

Jacob Taubes, Die politische Theologie des Paulus

No martyr is among ye now

Whom you can call your own.

Dylan, Bob, I Dreamed I Saw St. Augustine, from the album John Wesley Harding

È incredibile fino a che punto sia giunta la totale confusione delle lingue.

Aldo Moro, Lettera alla moglie Eleonora 


\section{Introduction}

This study inquires into the emergence and performativity of the state martyr figure from the perspective of a discourse and cultural analysis-oriented study of religion. It locates itself in the wake of investigations into the performative force of religious language, rhetorical patterns and narrative models in modern and contemporary political discourses. It specifically addresses the strategies by which social actors have tried to frame, give meaning to and relate a whole series of circumstances, facts, actions and reactions to each other, surrounding the kidnapping and assassination of Italian politician Aldo Moro in 1978. Focusing on practices of representation and memorialization of Moro's death as a sacrifice and martyrdom, this investigation aims to develop historical-philosophical reflection on the relationship between language and discourse, procedures of legitimization of political authority, the construction of political community and events of political violence. More generally, it aims to make a contribution to the debate about the relationship between religion, politics and violence.

The investigation is situated at the intersection of the disciplines of the study of religion and political philosophy. This transdisciplinarity requires the distinction of two different research levels. As an enquiry into the study of religion, it is especially interested in the individuation and analysis of religious significance within political discourse. More precisely, it aims to grasp the significance of the martyr figure within discursive practices surrounding and referring to the historical, cultural and political circumstances of Aldo Moro's death. As an enquiry into political philosophy, it aims, on the one hand, to focus on and criticize the political, ideological and instrumental use of the state martyr figure within a hegemonic discursive formation and, on the other, to explore the possibility of resistance through to the use of alternative, subversive forms of representation and memorialization.

\subsection{The Event of Political Violence}

The point of departure for this investigation is a series of events that began on March 16, 1978, with an attack by the Red Brigades (BR), in which the terrorist organization kidnapped Aldo Moro, and ended on May 9, 1978 
with his murder and the discovery of his body. On the morning of March 16, 1978, the Christian Democrat politician was ambushed together with his security guards in via Fani, Rome. Four officers were killed in the ambush; a fifth officer died a few hours later in hospital. The politician was on his way to parliament to begin debates aimed at ratifying a new government. It was to be the first implementation of the political vision as defined by the compromesso storico («Historic Compromise»), a historical political alliance and accommodation between the Christian Democracy (DC) and the Italian Communist Party (PCI). This strategy originated from within the PCI, but Moro had promoted it within his own party and was considered the architect of the new government headed by Giulio Andreotti, who assumed the office of Prime Minster on the same day as the kidnapping. For the first time in Italian history, the PCI, despite not being part of the government, would surrender its oppositional role by agreeing not to contest the executive. After the ambush, Moro was abducted and held in captivity in via Montalcini, Rome.

During the 55 days in which Moro was held captive, the BR published nine communiqués through the press, which on the one hand attacked and accused what they called the «Imperialist State of the Multinationals» (SIM), and on the other hand addressed the Italian "proletariat», promising the imminent beginning of the revolution. Moreover, they did not only send their communiqués to the media, but also some of the letters that Moro wrote during his captivity. From within the so-called «people's prison» Moro wrote several letters, among others to co-workers at the university, cabinet ministers, colleagues from the DC, members of other parties, the Secretary General of the United Nations, his family, friends, and Pope Paul VI. ${ }^{1}$ In these letters, Moro tried to convince the government, his own party, the Catholic Church and civil society of the moral imperative

1 Most of Moro's letters were not delivered and appeared in three separate historical moments. Twenty-six autographs - the letters written by Moro's hand that were known to have been delivered and were recovered from their addressees-appeared during the period of time in which Moro was held prisoner. A second set of the letters became public in October 1978. Twenty-eight letters were found in a BR hideout, an apartment in via Montenevoso in Milan, by the Italian anti-terrorist unit headed by Carabinieri general, Carlo Alberto dalla Chiesa. The Carabineri found the set, which consisted of photocopies of typed, unsigned letters. In addition, a part of the so-called Memoriale, Moro's responses to BR interrogations, was found alongside the photocopies. The last collection of letters became public in June 1990, when a second cache of letters was found in the same apartment in via Montenevoso, behind a plasterboard discovered (at least according to the official version) by workers during some renovation works. It consisted of 419 handwritten 
and political utility of negotiations for his release. In one of their eight communiqués, the BR proposed exchanging Moro's life for the freedom of thirteen prisoners. The choice to make some of Moro's letters public, especially those in which he asked the representatives of his own party and of the government to open negotiations for his liberation, was part of their communications strategy. They «used» the media, propagandistically, for the diffusion of their political convictions and to accuse their enemies and, strategically, to force, through the dissemination of some of Moro's letters, political parties to choose the path of negotiations. This strategy soon proved to be a complete failure.

The new «government of national solidarity»—-formed a few hours after the abduction with the votes of the major parties-decided straightway, even before some explicit requests could be made, to adopt the so-called linea della fermezza («line of firmness»), a political strategy which consisted of the categorical refusal to negotiate with the terrorists for Moro's liberation. The leaders of both the DC and the PCI as well as most of the media considered it unacceptable to negotiate with the terrorist organization. Indeed, the latter claimed that any negotiation would legitimize the position of the terrorists and probably open the path for other acts of politically motivated violence. The DC was divided into two factions: a minority of Moro's friends and allies argued in favor of negotiations, while most party representatives were worried, for similar reasons to those of the Communists, but mostly because they feared the possible political consequences of leaving the PCI as the only opposition to negotiations with the terrorists. ${ }^{2}$

Threatened by the rejection and radical critique of the «line of firmness» expressed by Moro in his letters, politicians began to say, and most parts of the media repeated this, that Moro was no longer himself. The Interior Minister Francesco Cossiga established a so-called comitato degli esperti, consisting of well-known linguists and graphologists as well as the American adviser and expert on international terrorism Steve Pieczenik, which concluded that the letters were the product of an alienated mind. This allowed the Prime Minister Giulio Andreotti to inform the Chamber of Deputies that «a careful and competent evaluation of the text of the letter addressed

and two typed pages, which reproduced most of the letters and the Memoriale. Miguel Gotor, who has edited the letters, trying to order them chronologically, dedicated an extensive study to them and to the history of their appearance and estimates that forty-eight of Moro's letters were not delivered during the time he was kidnapped. See Gotor 2008, 223-235.

2 See Glynn/Lombardi 2012, 2. 


\section{Introduction}

to Mr. Cossiga led experts to believe that the letter was actually written by Aldo Moro, but it is not morally attributable to him.»3 On April 25 the Christian Democrats in their Roman headquarters, distributed to reporters a document signed by fifty people, who declared themselves «old friends» of Moro, stating that «[h]e is not the man we know, who with his spiritual political and legal vision, has contributed to the drafting of the Republican Constitution.» ${ }^{4}$ The operation of delegitimizing Aldo Moro's letters also played out massively in the press. Several hypotheses were made in different newspapers, for example, that he was writing under duress or was suffering from the psychological effects of the Stockholm syndrome.

On May 9, Aldo Moro was assassinated. His body was found in via Caetani in Rome, halfway between the headquarters of the DC and the PCI, in the trunk of a red Renault 4. In the final days of his life, Moro seems to have realized that he would soon be killed. On April 24, in a letter to the secretary of the DC Benigno Zaccagnini, which was published on the same day as the BR's eighth communiqué, Aldo Moro once more vehemently criticized his party's categorical refusal to negotiate, asking that «neither an authority of the State nor a party man attend my funeral» and «to be followed by the few who truly loved me and so are worthy of accompanying me with their prayers and their love.»5 Moro's family took his request seriously and, following the recovery of his body, issued a statement requesting «that the will of Aldo Moro be fully respected by the State and party authorities"6 and organized a private funeral that was held on May 10, in Torrita Tiberina, a small town near Rome where Moro spent his summers. Three days latter, in the absence of Moro's body, a state funeral was held in the Archbasilica of St. John Lateran in the presence of the majority of the representatives of the political establishment and Pope Paul VI. The funeral was televised and followed throughout Italy.

3 See Bianconi 2001, 174; it.: «Una attenta e competente valutazione del testo della lettera indirizzata all'onorevole Cossiga ha indotto gli esperti a ritenere che la lettera è stata materialmente scritta da Aldo Moro, ma non è moralmente a lui ascrivibile.».

4 Quoted in Sciascia 1978, 102; it.: «Non è l'uomo che conosciamo, con la sua visione spirituale, politica e giuridica che ha ispirato il contributo alla stesura della stessa Costituzione repubblicana.».

5 Moro 2008j, 100; it.: «[...] chiedo che ai miei funerali non partecipino né Autorità dello Stato né uomini di partito. Chiedo di essere seguito dai pochi che mi hanno veramente voluto bene e sono degni perciò di accompagnarmi con la loro preghiera e con il loro amore.».

6 Quoted in Glynn/Lombardi 2012, 4; it.: «[...] che sia pienamente rispettata dalle autorità dello stato e del partito la precisa volontà di Aldo Moro.». 
During his 55 days of captivity, the media strongly influenced the way in which Moro's kidnapping and imprisonment were handled by the institutions and presented to the public. Newspapers, radios and televisions provided daily reports on the status of the investigation and on the debates about the political strategy to be adopted by the government and political parties. But the majority of the media did not limit themselves to providing information on the investigation and on the decisions (or lack of decisions) of political parties and institutions. In fact, they largely served as a platform for the justification of the «line of firmness» adopted by the government and most of the parliamentary parties. Not only journalists, but also writers, artists, politicians, representatives of the clergy and academicians intervened in the press, expressing moral and political judgments about what was happening, accusing some and absolving others, offering possible interpretations and proposing plans and strategies of action. The media were a stage for political, philosophical and ethical statements as well as for the rhetorical celebration or demonization of certain individuals, social groups or political parties by other individuals, social groups and political parties.

Despite Moro having categorically denounced «the sacrifice of innocents in the name of an abstract principle of legality» ${ }^{7}$ as morally unjust and politically unsustainable, most of the political and civil society and the media represented his death as a sacrifice for the state and as martyrdom for the salvation of the Italian Republic and its citizens. Indeed, since the day of the kidnapping in via Fani, Aldo Moro was glorified as a great statesman, thus beginning what Alessandro Silj has pointedly defined as a «beatification process.» ${ }^{8}$ The construction of a state martyr is definitely a key element within this process of beatification. This beatification process and the politico-ideological strategic instrumentalization of this event of political violence have never ceased and continue to persist into the present. State apparatuses, representatives of the government, political parties and the established media represented and still represent Moro as a martyr. In fact, in September 2012 the Diocesan Tribunal of Rome gave the green light for an investigation into the potential beatification and canonization of Aldo Moro. The main argument of the promoters of the beatification is that Moro's death is a martyrium in odium fidei, namely martyrdom that occurred because of the executioners' aversion to Christian faith. Although

7 Moro 2008b, 8; it.: «[...] il sacrificio degli innocenti in nome di un astratto principio di legalità.».

8 Silj 1978, 185. 


\section{Introduction}

the process began in recent times, this model of an explicitly Christian representation of the event has been present from the beginning, as this research will demonstrate.

\subsection{Status Quaestionis}

The circumstances of Moro's kidnapping, detention and assassination were the subject of an enormous amount of discursive practices and were debated in many lengthy institutional procedures. They have been the subject of five trials and three debates in parliamentary commissions of enquiry, one of which is still active. They were recounted and presented using many perspectives adopted by different social actors within different media. These include movies, novels, journalistic investigations, monuments, interviews, documentaries, theatrical plays, songs, as well as essays in criminology, history, law, and psychology. Despite this plurality of voices, narrative forms, mediums and perspectives, there is a theme or a recurring motif in the discourse on the Moro case: his death was and is still represented as a martyrdom and a sacrifice for the sake of national security and unity.

Both the renewal of terrorist actions in Italy - the assassination of Massimo D'Antona in 1999 and of Marco Biagi in 2002 by the self-declared «New Red Brigades»—at the turn of the century and the importance of the global security agenda nowadays are surely among the basic causes behind the increasing interest in the dissemination and implementation of the culture of violence that characterized the seventies and the first half of the eighties in Italy. ${ }^{9}$ Although the BR were only one of many terrorist groups and despite the fact that between 1974 and 1988 they claimed to have committed 86 murders, the killing of Aldo Moro was an act of political violence that dominated public debates and the collective memory the most. ${ }^{10}$ It is undoubtedly the most significant act of political violence in Italian history from the World War II onwards and one of the most serious cases of political assassination worldwide, only comparable with the assassination of Mahatma Gandhi, John Kennedy and Yitzhak Rabin. ${ }^{11}$ Never before had an event of political violence in Italy been addressed this significantly through novels, journalistic investigations, interviews, movies, documentaries and theatrical plays.

9 See Antonello/O'Leary 2009, 1.

10 See Zavoli 1994, 467.

11 See Formigoni 2016, 378. 
Despite the BR having already carried out a number of kidnaps and murders, the kidnapping and assassination of Aldo Moro in 1978 was undoubtedly their most striking act. It is not surprising, therefore, that there is an enormous number of publications of different kinds on the Moro case. These publications can be divided into two broad categories. The first category includes all research exploring the factual and historical circumstances of the kidnapping, imprisonment and assassination of Aldo Moro. They aim to answer the following questions: Who did what, when, where, how and why? The studies in the first category can be divided into two sub-categories. Many of these studies have the characteristics and style of investigative journalism and apply the methods and instruments of forensics and criminal investigation. This interest in the crime's factual circumstances predominates them, as does the goal of clarifying who did what, when, how and where. The second sub-category of studies is interested in clarifying the historical setting, processes and responsibilities that led to the event of political violence. In these studies the prevailing question remains: why could these events occur? However, the boundary between forensic investigations and historical research is often fluid and blurred. Moreover, public interest in general focuses on the particular factual circumstances of spectacular events, such as the bombings in piazza Fontana and piazza della Loggia, and on the attack in via Fani-just to name a few -rather than on the causes and contexts of these events of political violence. ${ }^{12}$ This is also the case in a wide range of publications addressing the Moro case, which focus more on the allegedly inexplicable elements of the circumstances of Moro's kidnapping and assassination, rather than on the political, social and cultural context in which they occurred.

The second category of studies addresses the way in which this event of political violence has been narrated and represented in different kinds of media. These studies seek to describe, analyze and interpret the impact, the importance and role of the event in literature, journalism, cinema, art and, in more general terms, in the Italian cultural and social imaginary. These studies - their ways of approaching the event, their interests and questions, their methods and analytical tools-generally belong to or are influenced by academic fields dealing with semiotics, media representation and procedures of cultural production, regulation and reception. This research is clearly located in this second category of studies, retaining and elaborating their results and their general hermeneutic horizons. In a recent publication on the rhetoric and representation of political violence in Italy from

12 See Antonello/O'Leary 2009, 7. 


\section{Introduction}

1969 to 2009, Pierpaolo Antonello and Alan O'Leary identify and isolate three key narrative modalities that were used to account for events of political violence in these intervening years: the oedipal, the conspiracy and the sacrificial models. As they point out, all three can be considered «forms of textualization of the events which perform both an interpretative and representational function.» ${ }^{13}$

These three narrative models were generally used to frame and to give meaning to a wide range of events of political violence that happened in the whole period of the so-called «years of lead» (anni di piombo), somehow attempting to give a generalized explanation of the conflicts depicted. Within the first narrative modality, the escalation of political violence between 1968 and 1982 has been interpreted and represented as the outcome of a generational conflict, in which militant and utopian sons and daughters were revolting against fathers and mothers considered to have been responsible for fascism or, at least, to have betrayed the revolutionary values and principles of the Resistenza. Significantly, this kind of narrative and representation can be found in many books and interviews with former members of the BR, which understood Aldo Moro as the paternal figure and symbol of the nation and bourgeois authority, which they rejected. ${ }^{14}$ Similarly, the second narrative has been and is still used to represent and to interpret the anni di piombo, especially the circumstances of Moro's kidnapping and assassination. The so-called dietrologia - the production of conspiracy theories - is characterized by the attempt to find a fil rouge, a plot that would connect all the events of political violence that occurred in Italy in the anni di piombo. As Antonello and O'Leary observe, conspiracy theories were employed in particular by the Italian left, which was averse to recognizing the emergence of an ideology of violence within the working class and the student movement and its own inability to prevent it. Moreover, "conspiracy theory tends to confirm the extreme right's conception of a society ruled by violence, and implicitly validates the view that the effective exertion of authority and power is the only real question of importance.» ${ }^{15}$ The third narrative model is what interests this study, since it analyzes the ways in which the sacrificial narrative of the kidnapping, imprisonment and assassination of Aldo Moro has emerged and been consolidated, and the use, within that narrative, of semantic units, rhetorical patterns and images that make reference to and iterate elements of Chris-

13 Antonello/O'Leary 2009, 5.

14 See Tricomi 2009, 16-29.

15 Antonello/O'Leary 2009, 6. 
tian martyrology. The theme of this thesis can thus be conceptualized as the martyrological representation and narration of the kidnapping, imprisonment and assassination of Aldo Moro.

The presence of very divergent and conflicting representations and interpretations of the Moro affair is the sign of a very difficult relationship between narrative and history. There is long tradition of the questioning of this problem in Italian culture. ${ }^{16}$ In recent times, it has been interrogated in the writings of Carlo Ginzburg, who is interested in the rhetorical construction of historical events and their reference to "objective» reality. ${ }^{17}$ With regard to the anni di piombo and in particular to the events related to the kidnapping and murder of Aldo Moro, in Italy there is widespread dissatisfaction with judicial sentences as well as with «official» narratives, which is linked to a perceived need for supplementary justice. The diffusion of a wide range of narratives, hypotheses and interpretations in different media such as films, novels, essays, journal articles and TV documentaries, which are structured according to different «genres» and «modes», «has created the sense that history, above all in the Italian case, could and should also be written and interpreted outside the courtrooms or historical archives.» ${ }^{18}$ There are many artistic (at least in their intention and self-understanding), fictional representations of the Moro case, which try to fill an explanatory vacuum, that is, to give meaning to Aldo Moro's death, to explain not only what happened, but why it happened. As Antonello and O'Leary observe, «fiction has become the pre-eminent means to account for $[\ldots .$.$] missing pieces of our recent history and to keep the memory of$ certain events alive among non-experts. Fiction, and artistic representation more broadly, persistently supplement history, and function as an instrument that the tradition of Manzoni or Sciascia may contribute to challenging the verosimile of official history, to uncovering the vero of reality, to constructing a collective experience of justice.» ${ }^{19}$

Perhaps it is precisely because of this proliferation of divergent narratives and memorialization practices that, instead of producing a consensual collective memory, which reproduces and reflects social and political divisions, in recent years there has been a rapid increase in studies on representations of political violence in Italy. Interestingly, most of the scientific studies that focus on cultural productions related to the Moro case were

16 See Antonello/O’Leary 2009, 10.

17 See Ginzburg 1991.

18 Antonello/O'Leary 2009, 10.

19 Antonello/O’Leary 2009, 10. 


\section{Introduction}

conducted in the Anglophone academic world. ${ }^{20}$ Robin Erica Wagner-Pacifici's The Moro Morality Play is the first academic study that explicitly addresses the representations and narratives of the Moro case and focuses on the «dramatic/narrative [...] modes of structure», namely the ways in which the kidnapping and the murder of the Italian politicians were framed as «social drama.» ${ }^{21}$ This is undoubtedly a very important and pioneering investigation. The theoretical framework of Wagner-Pacifici's study is based on Victor Turner's social drama theory. Referring to the famous cultural anthropologist, the author addresses historical events as intrinsically representational, as they are interpreted through certain given models of narrative emplotment. Wagner-Pacifici also refers to Paul Ricoeur's reflections on the relationship between history and interpretation, according to which an event becomes «historical» only if there is an interpreter who organizes the facts of the event according to a narrative structure. ${ }^{22}$ The choice of using Turner's theory as a heuristic tool of analysis is due to the fact that it does not only «assert and employ a posteriori the narrative analysis of events but also regards the social actors themselves as proceeding through and attempting to direct certain events with, among other kinds of consciousness and motives (e.g., political, moral, economic), a theatrical selfconsciousness.» ${ }^{23}$ The theatrical self-consciousness of social actors is the main topic of the last chapter of Wagner-Pacifici's investigation. The researcher defines her own methodological approach as «ethnography of the social text» and the object of the analysis as the «intertextuality of the written, spoken, and gestured world.» ${ }^{24}$ She analyzes a broader body of sources $^{25}$ and distinguishes between three levels of analysis: a) modes of address, b) stylistic variations and c) different codes and channels. In a second

20 See Glynn/Lombardi 2012, 11-12.

21 Wagner-Pacifici 1986, 5-7.

22 See Wagner-Pacifici 1986, 6.

23 Wagner-Pacifici 1986, 7.

24 Wagner-Pacifici 1986, 15.

25 Radio news program transcripts (firsts and second national RAI, independent left-wing Radio Onda Rossa and Radio Città Futura); television news program transcripts (first and second national RAI channels); newspaper articles, editorials, letters to the editor and photographs (in L'Unità, Il Popolo, Il Messaggero, Corriere della Sera, La Repubblica, Lotta Continua, Il Manifesto, Il Giornale, Il Tempo); all publicly available letters by Aldo Moro; the nine communiqués of the BR (and the false seventh communiqué); the texts of speeches delivered during this period by Prime Minister Andreotti, Pope Paul VI and former Secretary General of the United Nations Kurt Waldheim; the places established as the spatial frames of the event (via Fani and via Caetani). See Wagner-Pacifici 1986, 16-17. 
analytical step, she analyzes the totality constituted by this heterogeneous pool of «texts» as «social drama.»

Other scholars focus on the emergence, strategies and goals of left-wing terrorism in Italy. Political scientists David Moss and historian Richard Drake analyzed the documentation produced during the legal proceedings against the BR and the first Parliamentary Commission of Enquiry and interpreted the significance of the event in the light of those documents. ${ }^{26}$ In two articles, David Moss also analyzes the terrorist operations of the BR as a sequence of symbolic actions and communicative acts. ${ }^{27}$ Drake also deepens the theme of Italian terrorism in a series of articles, in which he examines the cultural, political and social contexts of both right-wing and leftwing terrorism and further analyzes the way in which the Moro case was politically and legally handled. ${ }^{28}$ In recent years there has been an increasing interest in the media's representation of the Moro case in different academic fields. Several recent publications focus their attention on the investigation of cinematic representations. This is the case in the survey conducted by Alan O'Leary, who analyzes the representation of terrorism in Italian cinema and dedicates one chapter to the representation of the Moro case in different movies. ${ }^{29}$ The same author has edited, along with Ruth Glynn and Giancarlo Lombardi, an anthology on the subject of terrorism in the cinema. ${ }^{30}$ The films that deal with the Moro case were analyzed and compared in a number of other academic articles. ${ }^{31}$ One of the cinematic productions dealing with the kidnapping and killing of Aldo Moro that has been analyzed and discussed the most is Marco Bellocchio's BuonGIORNO, NOTTE (Italy, 2003). ${ }^{32}$ Other scholars address the representation of the kidnapping and murder of the Italian politician in theater, television and literature. With regard to the theater, special attention was paid to the theatrical piece by Marco Baliani Corpo di Stato. Il delitto Moro: una generazione divisa, which was broadcast live on the RAI network in $1998 .{ }^{33}$ Isabella Pezzini has analyzed the debate and the representation of the Moro affair in documentaries and television services, in particular in Sergio Za-

26 See Moss 1989; Drake 1995.

27 See Moss 1981; Moss 1983.

28 See Drake 1984; Drake 1999; Drake 2001; Drake 2008.

29 See O'Leary 2011.

30 See Glynn/Lombardi/O’Leary 2012.

31 See Testa 2007; O’Leary 2009; O'Leary 2012; Lombardi 2009.

32 See Lombardi 2007; Glynn 2009; Mancino 2014.

33 See Marini-Maio/Nerenberg 2012; Marini-Maio 2012. 
voli's La notte della Repubblica. ${ }^{34}$ Last but not least, several authors have examined the representation of the events of spring 1978 in literature. ${ }^{35}$

\subsection{The State Martyr Figure}

Given this extensive bibliography, one cannot but pose the legitimate question: is further research on the representation and rhetoric of the Moro case really necessary? Is there still something of importance left to investigate? The answer is of course: yes, there is. There are still many issues and problems that, through a thorough analysis of the representations and narratives with which different social actors framed what happened over the last four decades, have to be brought to light. However, this research would not have been possible if a considerable number of studies had not already identified key issues, important questions, and drawn attention to a number of cultural practices and media representations linked to the case. These studies will be a constant reference point within this investigation, providing interesting impetus for reflection and discussion. This study is a contribution to the series of research studies that have tried to understand and to explain how a single event of political violence could impact upon Italian culture so deeply, affecting language, media communication, categories of historical understanding, artistic representation, practices of representation and memorialization. Moreover, despite Wagner-Pacifici and other scholars having already drawn attention to sacrificial narratives of the event of political violence in specific media, a systematic analysis of the use and function of sacrificial and martyrological representations and narratives is lacking. This study makes up for this by analyzing and placing representations and narratives that have emerged in different media in a time frame that spans almost four decades in relation to each other. Furthermore, this investigation addresses the allocation of the martyr role and the representation of the event of political violence as a sacrifice and martyrdom from the point of view of discourse and cultural analysis and focuses on the questions of how, through such allocation and representation, a political community is constructed and political authority is legitimized.

The thematic fulcrum on which this investigation turns is the performativity of martyrological representations and of the sacrificial narrative that has been and is still used to account for the event of political violence. As

34 See Pezzini 2009; Pezzini 2012.

35 See Testa 2007; Mecchia 2012. 
has been mentioned above, the sacrificial narrative has been identified as one of three key modes of representing political violence in Italy. In Narratives of Sacrifice: Pasolini and Moro, Pierpaolo Antonello adopts the Girardian theory of the scapegoat mechanism to explain how, within the sacrificial narrative mode, Moro's assassination assumes the significance of sacrifice for the sake of the political community: «a man's death is exploited by political power to repair the worn-out fibers of its authority, to reaffirm the ragioni dello Statos, to «mythicallys rebuild the Republic anew.» ${ }^{36}$ Following an interpretative path already traced by Leonardo Sciascia and addressed by Wagner-Pacifici, the author highlights how, during the 55 days of captivity, the «rhetoric of the State and of the mass media forced Moro's image to make the $[\ldots]$ symbolic trajectory: from «uomo solo, and «creatura to spersonaggio, to a fictional character, a character that was politically and mythically exploited by the sacrificers, by the spurgers', who toyed with the idea that Moro was morally subjugated by the BR, deprived of his

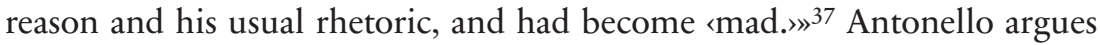
that this negation of the human traits of the victim was functional in justifying the sacrificial act as a way of excluding Moro from the political community. Moreover, he highlights the presence in Aldo Moro's letters of a sort of Christological counter-narrative. Shifting from the perspective of the «sacrificers» to that of the "victim», he argues, the mythological scapegoat assumes the connotation of the Christian martyr: «Moro cannot interpret his fate according to the logic of this political «myth», but through the figural ur-example of the victim who was unjustly scapegoated: Christ.» ${ }^{38}$ The argument goes further saying that the «martyr» Moro used his body as testimonial evidence, since the language of the body was the only thing that was left to him; he is the «anti-hero that refused to be part of the collective ritual in which his body would be exhibited and sanctified by the same authorities that contributed to his death. ${ }^{39}$ Antonello mentions four examples of anti-sacrificial cultural productions, namely Leonardo Sciascia's L'affaire Moro, an article by Italo Calvino which appeared on May 18, 1978 , in the newspaper Corriere della Sera, Marco Baliani's theatrical performance Corpo di Stato, and Marco Bellocchio's Buongronno, notTe. In the latter especially he sees the "plenitude of the figura Christi» realized and he interprets its final scene as a «symbolic and Christological resurrection», as

36 Antonello 2009, 38.

37 Antonello 2009, 40.

38 Antonello 2009, 40.

39 Antonello 2009, 41. 


\section{Introduction}

an «attempt to reconcile ourselves to the trauma of that event, with the collective responsibility for that murder, to undo (were it only possible) the tragic trajectory taken by events, asking for a redemptive, symbolic form of collective forgiveness. ${ }^{40}$

Antonello's article indicates the general coordinates of a possible analysis of the sacrificial narrative model and undoubtedly offers an interesting point of view, which this investigation will further develop and discuss. The author adopts a bipolar scheme of interpretation. This scheme postulates the presence of two opposing models, two ways of narrating violence: on the one hand mythological-sacrificial narrative, which represents Moro's death as necessary for the salvation of society; on the other hand there is the Christological-martyrological narrative, which instead unmasks and brings out the immorality and iniquity of the scapegoat mechanism. Despite this interpretative scheme, which allows the identification and exposure of two different ways of narrating and representing political violence and to rightly point out the subversive nature of a certain kind of martyrological representation, it tacitly obscures the fact that the figure of the martyr has played and still plays a very important role within those representations, through which state mythology is constructed and sustained. This study will demonstrate that the martyr figure is not an exclusive character of the Christological narrative or, more precisely, that in many representations Christological and mythological narratives overlap to the point of becoming, in certain cases, indiscernible. The interpretative scheme adopted by Antonello cannot explain this phenomenon-it was not the goal nor the issue in his article-because it implicitly relies on the Girardian anthropological presupposition that sacrifice is a ritual form that «restrains» violence understood as something rooted in human nature. According to René Girard, violence is an inevitable expression of mimetic desire, which he considers a universal human trait. ${ }^{41}$ For Girard there are two ways to restrain violence from its socially destructive excesses: on the one hand there is the sacrifice of the scapegoat, which is expressed and elaborated linguistically in the myths of non-Christian societies, and on the other hand there is the Christian martyr, who is represented in the Christological narrative. Girard, in other words, hypostatizes the relationship between ritual and narration, between event and representation, in the belief that there are two spheres of meaning, two essentially distinct and separate ways to attribute meaning. This interpretative scheme, which in my view is already

40 Antonello 2009, 43.

41 See Girard 1979. 
questionable when used to explain phenomena of violence in pre-modern societies, is even more problematic when it comes to explaining phenomena of violence and the way in which meaning is attributed to them in modern and contemporary society. Because of its universalistic anthropological approach, the scapegoat theory does not pay enough attention to the historically changing relationship between language and violence, discursive and non-discursive events, or to the way in which violence is represented differently in different pragmatic and hermeneutic contexts.

This is the reason why this study approaches political violence and martyrological representations from the perspective of discourse analysis. One of the central goals of this study is to demonstrate that the figure of the martyr does not have an essential and unchanging meaning and function, but rather that it has undergone a series of signatures, through which it has become part of a mythological narrative that, instead of exposing, conceals the political use of violent events. Instead of considering the martyr figure to be fundamentally and essentially external and «oppositional» to the political myth justifying the «reason of state», this study wants to show how it became part of this myth, becoming even one of its central and most important figures. The first novel element of this study can therefore be formulated in the following way: instead of assuming two distinct strategies of representation which always recur as two essentially distinct semiotic spheres, it assumes that to grasp the meaning and function of martyrological representations of Moro's death, one must first carefully analyze the pragmatic and hermeneutic context in which they appear. In other words: instead of assuming a fixed, universal function of the martyr figure, this study aims to analyze it in a context of appearance and figure out, from time to time, the different functions it assumes. Only through this approach, this study claims, can one get to the bottom of the strange phenomenon of the emergence of the state martyr figure.

The second novel element is deeply connected to the first. Since the goal is to analyze the martyr figure in its various media and contexts of appearance, it is necessary to examine a large body of the media. In this respect, the approach is similar to that of Wagner-Pacifici, but differs from it in three respects. First, this study also examines media and representations missing in her research, which examines almost only representations produced during or shortly after the 55 days of Moro's imprisonment; I analyze representations that were produced over a period of almost 40 years. Secondly, the focus of this study is neither the dramatic construction of the event nor the dramatic self-awareness of the social actors, but the performativity of the martyrological representation of the event. In other words, 
this study is not so much interested in the intentions of the acting subjects, but rather on the efficacy of the discursive practices themselves. Thirdly, this study approaches the representations according to the theoretical and methodological framework of discourse analysis and not that of the «ethnography of the social text.» The focus lies not in the intertextuality that gives shape to a social drama, but in the identification of regularities and exceptions within a discursive formation. Moreover, it focuses on the hegemonic, doxological practices of representation as well as on the attempt to subvert them.

The third novel element of this study lies in its genealogical analysis of the martyr figure. As Wagner-Pacifici observes, social actors reacted to the kidnapping and murder of Aldo Moro through the recurrence of «their culture's stock of sedimented symbols, archetypal characters, and rhetorical appeals.» ${ }^{42}$ The question of imitation or iteration of historically «sedimented» forms of representation is the "center of gravity» of this investigation. The central questions are: What exactly happens during the process of the iteration and dislocation of the martyr figure from its «original» context of appearance, which as we will see is that of the early Christian communities, to the modern and contemporary context which is at issue here? How was it possible for the martyr figure to be transformed into the figure of the state martyr? This study considers martyrological representations as discursive practices with a performative force, as they are able to appeal to individuals, affect their feelings and determine the way they perceive, understand and relate to the political community and to authority. Obviously, the martyr figure could not exercise such a performative force without appearing with certain regularity. In other words, the more frequent its materialization and media manifestations in the public space, the higher its efficacy and ability to appeal to people. The spatial, temporal, and multimedia diffusion of the martyr figure can thus be regarded as a condition of possibility for the figure's own success and efficacy.

But the diffusion of the martyr figure alone does not explain its success; on the contrary: this quantitatively successful dissemination must be qualitatively justified. This study argues that this success depends on the aesthetic potential of secularized Christian language: «Christianity produced language. It has been and still is a potentiated linguistic genius [Sprachgeist $].{ }^{43}$ The figure of the martyr has played a fundamental role in this «linguistic genius» since the beginning. Despite, as I argue in the third

42 Wagner-Pacifici 1986, 7.

43 Schleiermacher 2012, 17. 
chapter, the signification of martyrdom as a bodily act witnessing the truth of the soteriological power of Christ's death and resurrection emerged in the second century AD (and not already in the New Testament), the interpretation of the Passion of Christ as a form of martyrdom soon became a central and generally accepted topos of Christian theology. The death of the Messiah on the cross was soon framed as a sort of martyrdom prefiguring and empowering all other coming forms of martyrdom. Within Christianity, it represents to some extent the act of witnessing absolute truth par excellence. In Catholic theology, martyrdom is today still conceptualized not only as the imitation of Christ, the most radical and powerful act of witnessing the absolute truthfulness of Christian religion, but also as a practice that in itself has a soteriological power. ${ }^{44}$ As we will see, the martyr figure is intrinsically connected to an eschatological understanding of history: in its original context of appearance, a Christian martyr was both someone who witnesses the soteriological power of Christ, the truthfulness of the fi-

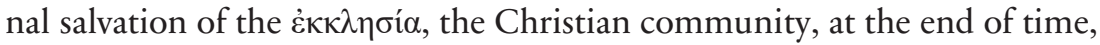
and someone who accuses the profane political authority as based on the mythological glorification of power and on the exercise of violence. Now this study argues that despite or, more precisely, because of the process of secularization, the idea of martyrdom as an act of witnessing an absolute truth could be successfully transposed and reutilized in modern and contemporary representations of events of political violence. The martyr figure that was originally part of a narrative of rebellion, which radically rejected any kind of exercise of violence, became part of a narrative in which the exercise of violence by the sovereign is basically represented as a legitimate means in the fight against the enemies of society. In the context of modernity, with the emergence of nation-states, martyrdom assumed the meaning of an act that witnesses the necessity of the state as this absolute entity, which saves the secular political community called the «nation-state» from its destruction. Moreover, the mystical relationship between the Christian martyrs' bodies and the body of the Christian community reappears in state mythology as a mystical relationship between state martyrs' bodies and national communities.

This is the perspective with which this study addresses the martyrological representation of Aldo Moro. In the last four decades, Moro's death has been repeatedly represented as a form of martyrdom necessary for the salvation of the Italian Republic and for the sake of national unity. Through the allocation of the martyr status, Moro's death has come to assume the

44 See Rahner 1937. 


\section{Introduction}

meaning of a (voluntary) witness to the absolute and transcendent truth of human rights guaranteed by the Italian Constitution, as well as the necessity of the Italian State to guarantee these rights. This study argues that the martyrological representations of Aldo Moro's death serve to mythologize and de-historicize the event of political violence, that is, to make it appear as the necessary and unavoidable outcome of a cosmic conflict between good and evil forces. Within this mythological framing, the state assumes the connotation of the absolute sovereign, who is necessary to restrain and contain the forces of absolute evil that seek to destroy order and society. Following the research path outlined by Walter Benjamin, Carl Schmitt, Jacob Taubes and Giorgio Agamben, this study addresses state mythology as a secularized theological-political narrative in which the state assumes the meaning of the «katechontic» restrainer that impedes the "war of all against all.» While, in their original context of appearance, martyrological representations were part of a narrative of rebellion that opposed and subverted hegemonic narrative glorifying sovereign authority by revealing its power-preserving function, state martyrology has the opposite function of sustaining and concealing the mechanism of the glorification and legitimization of power. Moreover, by mythologizing violence as the unavoidable outcome of a perennial fight between good and evil, state mythology and martyrology conceal the intrinsic relationship between state and nonstate violence, that is, between the sovereign exercise of power and terrorism. In other words, they serve to obscure the utility of terrorism for the subsistence of established power relations.

A central reference point in this study is in particular Giorgio Agamben's homo sacer theory. ${ }^{45}$ Far from wanting to demonstrate the universal validity of this theory, this study uses it as an heuristic tool to grasp the complicated relationship between sovereign power over bare life, practices of sacralization and events of political violence. Rather than understanding the sacralization of a political community as the result of a ritual act of (self-)sacrifice, this study understands sacralization as the result of the exclusion of Aldo Moro from the profane and political sphere during his captivity by the means of discursive practices, which made him appear as someone who already appertained to the sacral sphere and thus could no longer participate in political debate. This reduction to bare life was, from this point of view, the outcome of a strategy necessary to silence Moro's voice, who from the «people's prison» tried to subvert the rhetoric of the «reason of state.» When he was actually murdered, the government, major

See Agamben 1998. 
political parties and most of the established media were able to retrospectively represent him as the sovereign-martyr who died for the sake of national security and unity. From this point of view, reduction to bare life and the allocation of the martyr role are two sides of the same coin or, more precisely, two moments within the same process of sacralization.

To sum up, this study argues that the effectiveness of martyrological representations depends on a) the historically stratified meaning and aesthetic potential of the martyr figure, $b$ ) their repetitive materialization and media manifestations in the public space, c) their ability to appeal to the audience, that is to say, to appeal to the «consumers» of the discursive practices through which Aldo Moro is represented as a state martyr. Discursive practices produce an emotional and ideological response in the public that is capable of putting mechanisms of identification with a constructed political collectivity into motion, delimitating it from other (existing or possible) forms of collectivity. The construction of the symbolic unit of the community itself can be seen as a result of discursive practices. Moreover, through his serial representation as a martyr, Aldo Moro acquires a sacred status and his death, the connotation of being a witness to the meta-historical or absolute truth of civil and human rights and, more importantly, of the necessity of sovereign political authority for the defense of citizens. By virtue of this sacralization, the martyr serves as a symbolic body of national community, which is experienced as sacred.

\subsection{Organization of the Investigation}

Political violence is first of all a real, non-discursive phenomenon, the result of a clash between material bodies and things, but like every phenomenon it needs to be narrated and represented, in order to become meaningful; only in language and through language can it acquire a certain meaning. The next chapter outlines the basic hermeneutic horizon and the conceptual, theoretical and methodological framework of this study. Moreover, it presents and in particular distinguishes between two different and opposite models of representing and narrating events of political violence. This distinction is fundamental to this study, since it serves as the starting point for the development of its path of investigation. Starting from the assumption that those acts of violence that occur in the context of a struggle between at least two groups of individuals are political, the chapter describes two oppositional discourses within which such acts of violence are represented and narrated as acts of resistance or of terrorism. Referring to 


\section{Introduction}

Michel Foucault, this study defines these discourses respectively as the discourse of rebellion and as the discourse of sovereignty. I argue that the martyr figure, in its «original» context of appearance, was a central figure within the discourse of rebellion, which had the function of delegitimizing a given political authority. The chapter continues by addressing the problem of the emergence of state martyrologies, arguing that the martyr figure has undergone a long process of re-signification, at the end of which it became part of the narrative of sovereignty, thus begging to serve as a figure for the legitimization of state authority. The conceptual and methodological apparatus of discourse analysis will be set out in the last three sections of this chapter. The establishment of this apparatus has a strategic and tactical function. The goal is to put a coherent system of heuristic tools in place as well as lay the interpretative path that shall allow me to face and to analyze the discursive practices related to the aforementioned event of political violence. Section 2.4 presents the characteristics and specificity of the discourse analytical approach to the martyrological representation of the kidnapping and assassination of Aldo Moro. Section 2.5 discusses the performativity of martyrological representation as discursive practices, which have the power to appeal to individuals and groups and to construct and sustain national political identities. Finally, the last section presents the organization of my corpus of sources and the methodological framework of the study.

The third chapter discusses the relationship between sacrifice, martyrdom and political violence from a theoretical point of view and reconstructs the history of the martyr's figure signatures. First, it summarizes and discusses the state of research into the martyr figure in various academic disciplines and exposes this study's approach, which is concerned with two aspects: on the one hand, the focus on the emergence of the state martyr figure, which has so far been largely ignored, and on the other hand, the transition from an approach that addresses martyrdom as a ritual practice to an analysis in which the martyr figure is considered a product of discursive practices. The thesis can be summarized as follows: the performative force of the martyr figure-understood as the ability to appeal to individuals and to produce collective identification with social and political order through the sacralization of the same-is not necessarily the result of a ritual act of self-sacrifice performed by a voluntary subject, but rather the product of the allocation of the martyr role through discursive practices. Secondly, the chapter exposes the advantages of choosing to use the homo sacer theory to analyze how Aldo Moro has been represented and memorialized over the last four decades. Thirdly, the chapter deals with the geneal- 
ogy of the figure of the Christian martyr, drawing attention to the specificity of the use of the term $\mu$ óptus in the social and political context of the first Christian communities, and showing how the term no longer referred to the linguistic act of witnessing in a trial, but to the act of self-sacrifice as a witness to Christian faith. The last part of the chapter describes the signatures of the martyr figure over the centuries, that is, the most significant pragmatic and hermeneutic dislocations that preceded and determined the emergence of the state martyr figure in modernity. It shows how, with the institutionalization of Christianity, the figure of the martyr takes on a new meaning and a new function. The figure of the soldier martyr, who dies in battle in defense of the Christian faith and is functional for the legitimation of «holy wars», emerged. It also describes the development of the martyrs' cult and especially of the martyria, that is, places of worship around which a ritual for the glorification and sacralization of power and political authority took place. Finally, it shows how with the birth of the nation states the figure of the state martyr emerged and how, at the least from the French Revolution on, it became part of a mythological narrative of the state.

The fourth chapter describes the pragmatic and hermeneutic context in which martyrological representations of Aldo Moro emerged and were consolidated. The first part of the chapter discusses the ideological and cultural heritage of the Resistenza and of the Risorgimento. Its focus is mainly on the rise of national martyr figures in Italy from the nineteenth century onwards and the importance of this in the formation of national identity. The second part of the chapter describes the sociopolitical and cultural context in Italy after the World War II, illustrating the political history of the first three decades of the First Republic, namely from the Italian Constitution's entry into force in 1948 to the killing of Aldo Moro in 1978. It reconstructs the history of the two major parties, the DC and the PCI, and their relationship with the forces of the two blocs (especially the Soviet Union and the United States) during the Cold War. Particular attention is also given to the figure of Aldo Moro, his political career, his ethical, legal and political conception of the state, and the difficult and controversial role he played in the DC. Finally, it addresses the role played by the secretary of the PCI Enrico Berlinguer and of the Christian Democrat Aldo Moro in drawing up the strategia dell'attenzione and the compromesso storico to counter the danger of an authoritarian drift and possible coup d'etat in Italy (which found articulation in the so-called strategia della tensione). The third part faces the political conflicts and struggles that began with the movement of 1968 and in particular in the period of the autunno caldo (1969), as 


\section{Introduction}

well as the emergence and evolution of Fascist terrorist groups on the one hand, Anarchist and Marxist-Leninist groups on the other. Particular attention is paid to the birth of the BR, their relationship with the worker and student movements, as well as the formation and development of the ideology of the «armed struggle.» Finally, the last part of the chapter briefly summarizes the facts and gray areas of the Moro case and the various theories concerning the possible involvement of state apparatuses (Italian or foreign), secret services and occult groups in the events that led to death of the Christian Democrat. The purpose is not to strive for one or another interpretation, but rather to draw a clear line of demarcation between what is established as a fact, what is just hypothetical, and what is clearly the product of a simplistic reading of events and untenable conspiracy theories. It also aims to provide the readers with information to enable them to understand the reasons why, almost four decades since the murder of Aldo Moro, there is still no shared and accepted representation and memory of what happened in the spring of 1978.

The fifth and sixth chapters examine the media's representation of the Moro case in the time period from the day of the kidnapping (March 16) to the day on which the state funeral was held in the Archbasilica of St. John Lateran in the presence of Pope Paul VI (May 13). The first part of the fifth chapter identifies and describes three distinct models of representation used by different social actors during and after Moro's abduction and imprisonment. First of all, there is the model of representation used by the BR in their communiqués, in which the killing of Moro's escort is framed as a revolutionary guerrilla act and the captivity of Moro as a proletarian trial against the DC. Then, there is the model of representation adopted by both the DC and the PCI, as well as by most of the established media, which firstly represents Aldo Moro as a great statesman willing to sacrifice himself (before the publication of his first letter), then as a man robbed of all political dignity and reduced to a mere instrument in the hands of the BR (after the publication of his first letter), and finally as a state martyr (after his death). Finally, there is the model adopted by Moro and by very few other social actors, aiming to oppose and to highlight the ideological character of the other two representative models. The second part illustrates the public image of Moro before the abduction, in order to make clear the radical change that it underwent in a very short time. This part specifically addresses a famous newspaper article by Pier Paolo Pasolini, in which Aldo Moro is represented as a man of power, but also as «the least involved of 
them all.» ${ }^{46}$ The allegations directed at the DC in early 1978 concerning the Lockheed scandal are also mentioned. This part also discusses a speech held by Moro in defense of the Christian Democrats Luigi Gui and Mario Tanassi, who were likewise accused of being involved in the system of corruption that emerged with the Lockheed scandal, in which the then party president clearly expresses his aversion to any attempt «to offer $[\ldots]$ a victim to the reason of state. ${ }^{47}$ The fourth part examines in the first place the rhetoric of national unity in the press, the symbolism of the flags, the different ways of constructing and representing the attack in via Fani as an attack on the whole community, and secondly, the representation of the BR as an external entity that is not attributable to Italian society. In particular, it highlights a tendency by the media and representatives of the major parties to use semantic units and rhetorical forms aimed at representing the conflict of the BR versus the Italian State in terms of a struggle between the forces of good and the forces of evil. Finally, the last part focuses on the representation of Aldo Moro as a "great statesman» willing to sacrifice himself in order to save the Italian Republic and its society, and of the BR as «monsters» or «beasts», whose only aim was the destruction of social order and of the well-being of citizens. Particular attention is paid to the reproduction and description in the media of the first photograph of Moro delivered to the press by the BR. Finally, the chapter concludes by showing how on Easter Day (March 26, 1978) the rhetoric used in several newspaper articles tended to represent Moro's imprisonment as a form of «Calvary» analogous to that of Christ, that is, how the Passion of Christ has been rhetorically used as a prefiguration of the passion of Moro.

The sixth chapter resumes the analysis of the media's representation from March 30, 1978 onwards, the day when Moro's first letter addressed to the then Interior Minister Francesco Cossiga was published by different newspapers. The first part describes Moro's and very few other social actors' attempts to let the argument of the «the sanctity of human life» of every single citizen prevail over the argument that negotiations for the prisoner's liberation would betray the «reason of state» and undermine the legitimacy of state institutions and apparatuses. The chapter goes on to show how some few intellectuals and journalists as well as Aldo Moro himself, in the letters he wrote during his imprisonment, tried to resist the widespread hegemonic representation of the events in the media, offering

46 Pasolini, Pier Paolo, «Il vuoto del potere», Corriere della Sera, 2.2.1975, 1; it.: «[...] il meno implicato di tutti [...].»

47 Moro 1979, 353; it.: «[...] offrire [...] una vittima alla ragione di Stato.» 


\section{Introduction}

an alternative reading of what was happening. It also describes the formation of the so-called "party of the negotiation" and analyzes, in particular, the position paper in favor of negotiation published by the radical-left newspaper Lotta Continua. The first part of the chapter highlights how Moro, aware of the media operation to deny the authenticity of his letters, began to distance himself from his own party ( $\mathrm{I}$ do not want, I repeat, the men of power around me») $)^{48}$ and finally accepted his imminent death, understanding and expressing it in Christological terms ( I have only understood in these days what it means to be necessary to add our own suffering to the suffering of Jesus Christ for the salvation of the world»). ${ }^{49}$ The second part of the chapter reconstructs the way in which, at first, the established media denied the authenticity of Moro's letters or disbelieved the psychological and physical integrity of the prisoner, but then went on to represent Aldo Moro as a man denuded of all political dignity and concerned only with his individual salvation. This strategy is interpreted in light of the homo sacer theory as a hegemonic practice functional to the exclusion of Moro from the political sphere. It also shows how this operation is related to the rhetoric of the "reason of state.» The last part of the chapter finally analyzes the consolidation of the representation of Moro as a state martyr after the finding of his corpse on May 9, 1978. It shows how Moro is re-sacralized as a great statesman, a sovereign-martyr who died for the salvation of the Italian Republic.

The seventh chapter focuses on different practices of memorialization and commemoration of Aldo Moro, on the way in which the Moro case has been represented in literature and cinema, and finally discusses briefly the reason and arguments behind the launch of an initiative promoting the beginning of a process for the beatification and canonization of Aldo Moro by the Catholic Church. The aim of the chapter is to describe the attempt to construct an official memory, as well as to draw attention to the forms and practices of subversive and alternative representation that challenge official memorialization practices. The first part of the chapter examines memorialization practices which attempt to construct an official memory of the events of spring 1978. It focuses on monuments erected in memory of Aldo Moro and on the ritual practices of commemoration

48 Moro 2008k, 143; it.: «Io non desidero attorno a me, lo ripeto, gli uomini del potere.»

49 Moro 2008f, 60; it.: «Ho solo capito in questi giorni che vuol dire che bisogna aggiungere la pripria sofferenza alalsofferenza di Gesù Cristo per la salvezza del mondo.» 
which happen on the occasion of the anniversaries of the attack in via Fani (March 16) and the discovery of Moro's body (May 9). The chapter continues with an analysis of critical interventions by three important Italian intellectuals and writers: Umberto Eco, Italo Calvino, and Leonardo Sciascia. This part, in particular, brings to light the way in which Sciascia and Eco deconstruct both the rhetoric of the BR as well as the dominant representation of Moro's abduction and death in the media. It further shows how Calvino, despite being aware of the instrumental dimension of the hegemonic discourse on the abduction and killing of Moro, basically reproduces a sacrificial and mythological conception of political violence. The third part deals with the representation and memorialization of the events of 1978 in television and cinema. Since there are many television and film productions which deal with these events, documentaries and films in which the use or criticism of martyrological representations play a leading role have been chosen. The last part of the chapter addresses the initiative launched in 2012 by the Federazione dei Centri studi Aldo Moro e Renato dell'Andro to obtain the beatification and canonization of Aldo Moro by the Catholic Church. This final part reconstructs the procedural steps of the first phase of the process of beatification and canonization; secondly, it analyzes the arguments for the recognition of Moro's death as a form of martyrium in odium fidei expressed by two of the promoters of the case, Luigi Ferlicchia and Monsignor Andrea Venezia, and by Postulator Nicola Gianpaolo.

The final chapter summarizes the results of the study and draws attention to aspects and questions that still have to be explored. In particular, it develops reflections on the actuality of the issue of the performative force of the martyr figure and, more generally, of the iteration of language units, rhetorical forms, and narrative models which belong to one or more religious traditions, when it comes to framing or giving meaning to events of political violence. The study ends with some reflections concerning the problem-which is difficult because of its ethical, political, and even esthetical implications: What kind of representations and narrations of events of political violence could continue to deploy performative force, appealing to people to reject all kinds of implementations of violence, both by state and non-state organizations, without falling into the trap of mythicization? 


\section{A Discourse Analytical Approach to Political Violence}

\subsection{The Representation of Violence in the Context of Political Struggle}

The term violence can be used in many ways. In common language we refer to natural phenomena, such as earthquakes or tornados, as violent. We may also generalize violence, referring to all forms of behavior or forms of life involving physical force intended to hurt, damage, or kill other forms of life. We may also speak metaphorically of the violence of feelings, of violent speaking or writing, of certain forms of representation-the violence of a song, a novel or a poem-, of political systems, of the law, and so on. The term violence is used to refer to a wide range of phenomena with various connotations, which is why it is important to clarify what form of violence is at stake in this investigation. First of all, it is necessary to focus on the relation between violence as a term and real phenomena. For this reason, I operate with two levels of delimitation. The first realm of delimitation concerns the phenomena referred to, namely the denotation of the term, while the second concerns the meaning of the term, that is, the connotation it assumes through different uses.

The term violence refers to historical events where human beings act with their bodies to damage other bodies. Bodies are the means through which acting individuals exert physical force on other individuals. Violence happens in a specific historical moment and involves human beings acting with their bodies to change the status, or the integrity, of other bodies. Starting from this formulation, we can make two general phenomenological delimitations. The first is obvious: only human beings commit the form of violence examined in this investigation. Secondly, we are not dealing with phenomena that are violent in a metaphorical way, nor is the violence referenced here exercised by means of language. It is also not the violence of perceptions or feelings focused on subjective experience. The focus of this study is the phenomenon of action which has material and bodily consequences and happens at a certain, specific moment.

In the history of humankind, this form of violence was and is inflicted daily on a large number of men and women. Most violent acts that occur on a daily basis, today and throughout history, do not become objects of discourse; on the contrary, most accounts are never told, never represented, and fade into oblivion. It can be assumed that in any historical period, rep- 
resentations of acts of violence in public spaces are a minority among many acts of violence. Obviously, this cannot be empirically proven, because historical events that were never told, that were not represented and/or recorded, are not observable for future generations and thus limit our historical knowledge. While this is true, it is self-evident that only a tiny part of the violent acts that actually happened in history have been narrated, documented and represented, and have thus become part of our historical and collective memory. Moreover, it can be assumed that acts of violence occurring in what is generally called the "private sphere of life» are documented to a lesser extent than those occurring within a public context. Acts of violence exercised in places far from an observing audience (for example, a barn, house, convent, or workroom), are less represented and narrated than those that occur in a space frequented by a multitude of people. In other words, the larger the audience, the greater the chance of acts of violence being represented and narrated. Perhaps this is the reason (or at least one of the reasons) why our libraries and museums are filled with representations of wars, battles, executions, public tortures and killings of all kinds. Conversely, acts of domestic violence are less frequently documented. This, then, allows me to make another phenomenological distinction between different types of violence. The acts of violence at stake here are those that occur in front of an audience and of which there is at least one documented representation that is embodied in a material medium.

Representations of violence vary; for example, murder can be represented as a result of God's plan, as necessary for the salvation of a community, as an act of pure evil, or as a psychopathological outcome. Thus, if it is true that the term violence, as we define it, always denotes the typology of phenomena described above, it is also true that there is always a connotation. The connotation of the term depends on the way the term is used within discourse or, more precisely, within a discursive practice. The term always assumes a certain meaning within a certain pragmatic and hermeneutical context. This means that the same act of violence can assume different connotations, depending on how, by whom, when and where it is represented. At this point, we can approach the second kind of delimitation. This investigation addresses a real phenomenon, a historical event, which is largely and regularly represented as an act of political violence.

In modernity, there are two terms generally used, depending on the context, to define acts of violence within the context of a struggle against an existing political authority: resistance or terrorism. The first term normally carries a positive connotation and represents violence as a legitimate means 
in the fight against a political authority that is considered illegitimate. One example of this is the struggle against the Italian Fascist regime under Mussolini. The concept of martyrdom, which in its «original» context of apparition indicated a passive act of resistance against violence perpetuated by the political authority, is also used to represent people who actively acted violently against totalitarian and despotic states. In Italy, the cult of the «martyrs of the Resistance» against Fascism is widespread, evidenced by the many plaques erected to partisans in the squares and streets of many Italian cities; but the allocation of the martyr role also affects people who actively fought violently against democratic political systems. In fact, even the men responsible for the September 11 attacks, to name only the most striking example from this century, are considered martyrs among certain groups and communities. In short, individuals considered to be «terrorists» by some people can be considered «martyrs» by others.

Terrorism is a term that was and is still used to describe violence perceived as illegitimate. One contemporary example of this is the violence perpetuated in the name of the so-called Islamic State or DAESH. Obviously, the perception of a certain act of violence as legitimate or illegitimate is a question of perspective, inasmuch as some individuals and groups regard a political authority as legitimate, while others do not. The Red Brigades saw themselves as inheritors of the Resistenza against the Italian Fascist regime during World War II and as legitimate revolutionary fighters against the Stato Imperialista delle Multinazionali. This, to them, was the historical continuation of the Fascist regime responsible for imperialism and the economic exploitation of workers by the bourgeois class. Most Italian citizens disagreed with this view (although, as we shall see, the project of lotta armata was, for a time, partially supported by the student movement). Instead, to most citizens the Red Brigades were nothing but terrorists and brutish murderers, who indiscriminately killed people.

At first glance, it thus seems that the terms «martyrdom» and «terrorist attack» can be used to represent the same identical act of political violence, depending on the perspective and ideological setting of both the producers and consumers of discursive practices. This is also the thesis of Karin Fierke, who, as we will see in detail in the next chapter, distinguishes between two different, competing language games: the language game of those who resist state violence, which represents a person who died in passive or active resistance as a martyr; and the language game that «expresses the meaning structure employed by state authorities, which depoliticizes, by identifying the actor as a criminal or terrorist, whose death may be at- 
tributed to ssuicide.»» ${ }^{1}$ What I take care to emphasize is that, despite their antithetical meanings, the two words «martyr» and «terrorist» both refer to people that died within the context of a struggle against existing state apparatuses.

If we look at the history of the term «terrorist», we realize that the origin of the word has a completely different meaning from its current application. In fact,

the term was coined to refer to an allegedly illegitimate use of violence by the revolutionary government of France against its own people in the period of the sterror (1793-94). By the early twentieth century the word had shifted to refer to the illegitimate use of violence against the state, which could be seen as, in some sense, operating within the nation. $^{2}$

The term «terrorism» is thus no longer used to represent the use of violence by a political authority as illegitimate, but is rather used to make the repressive state apparatuses appear absolutely necessary for the defense of citizens and society. The term «martyr» also underwent a transformation, but one far more complex than that of the term «terrorist» and with much more ancient historical roots. In fact, as we will explore in the next chapter, the term underwent a series of shifts in a long process of re-signification, by which it was transposed from a discourse of rebellion to a discourse of sovereignty.

In the lectures at the College de France, particularly the lectures in the years 1975-1976, which were published with the title Society Must Be Defended, Michel Foucault argues that war and violence are central to understanding power as a «relationship of force» and as «something that is exercised and exists only in action.» Inverting Clausewitz's famous proposition, he proposes approaching power as «the continuation of war by other means.» ${ }^{3}$ Furthermore, he analyzes the «how» of power, namely the way in which discourses of power generate powerful effects. He is interested in the «multiple relations of power» that «traverse, characterize, and constitute the social body.» Foucault also stresses the fact that power relations «are indissociable from a discourse of truth» and that they «can neither be established nor function unless a true discourse is produced, accumulated,

1 Fierke 2013, 48.

2 Janes/Houen 2014, 1.

3 Foucault 2003, 14-15. 
put into circulation and set to work.» ${ }^{4}$ Foucault's analytical approach is characterized by a focus on the effective practices, the networks, the dispositives, and the micro-mechanisms through which discourses of power and subjectivity are produced.

Starting from this conceptualization of war and power, Foucault addresses the emergence and political function of the two aforementioned discourses. His main thesis can be summarized as follows: until the end of the Middle Ages, the discourse of sovereignty had the main function of enforcing, glorifying and legitimating power relations. Foucault underlines the continuity between the discourse of sovereignty in the Middle Ages and the "politico-legendary history of the Romans.» ${ }^{5} \mathrm{He}$ argues that the way in which the discourse of sovereignty represents power corresponds very closely to the Indo-European and especially Roman representations of power. Implicitly referring to Georges Dumezil, he indicates the two main functions of this system of representation: on the one hand, the power to subjugate and to bind through the use of obligations, oaths, commitments and the law and, on the other hand, the power to fascinate and terrorize through the use of rituals and discursive practices of glorification. ${ }^{6}$ In other words, the discourse of sovereignty was at once «juridical and magical.» ${ }^{7}$

On the threshold of modernity, especially with the constitution of modern nation-states, the concentration of power, and the monopolization of war and violence, a new discourse appeared. Foucault characterizes it as a «counter-historical» discourse, which "was no longer a discourse of sovereignty, of even race, but a discourse about races, about a confrontation between races, about the race struggle that goes on within nations and within laws. ${ }^{8}$ Just as he emphasizes the analogy between the discourse of sovereignty and the Roman way of representing power, he also identifies the presence and operativeness of «a certain number of epic, religious or mythical forms which, rather than telling of the untarnished and uneclipsed glory of the sovereign, endeavor to formulate the misfortune of ancestors, exiles, and servitude» within this new discourse. ${ }^{9}$ These new forms of representation and narration of war and violence, Foucault ar-

4 Foucault 2003, 24.

5 Foucault 2003, 71.

6 See Foucault 2003, 68.

7 Foucault 2003, 73.

8 Foucault 2003, 69.

9 Foucault 2003, 71. 
gues, «are much more closer to the mythico-religious discourse of the Jews than to the politico-legendary history of the Romans»; in fact,

at least from the second half of the Middle Ages onward, the Bible was the great form for the articulation of religious, moral and political protests against the power of kings and the despotism of the church [...]. In the Middle Ages, Jerusalem was always a protest against all the Babylons that had come back to life; it was a protest against eternal Rome, against the Rome of the Caesars, against the Rome that shed the blood of the innocent in the circus. The Bible was the weapon of poverty and insurrection; it was the word that made men rise up against the law and against glory, against the unjust laws of kings and the beautiful glory of the Church. To that extent, it is not surprising that we see, at the end of the Middle Ages, in the sixteenth century, in the period of the Reformation, and at the time of the English Revolution, the appearance of a form of history that is a direct challenge to the history of sovereignty and kings - to Roman history — and that we see a new history that is articulated around the great biblical form of prophecy and promise. $^{10}$

This new «discourse of rebellion and of prophecy, of knowledge and of the call for the violent overthrow of the order of things» challenges the discourse of sovereignty, because, by iterating biblical motifs, figures and narratives, it uncovers what the discourse of sovereignty deliberately and strategically concealed: that power, rulers, kings, and laws are the result of the triumph of some through the submission of others. ${ }^{11}$ According to Foucault, the discourse of rebellion relates to a new kind of historical memorialization:

In Roman-style history, the function of memory was essentially to ensure that nothing was forgotten-or in other words, to preserve the law and perpetually to enhance the luster of power for so long as it endured. The new history that now emerges, in contrast, has to disinter something that has been hidden, and which has been hidden not only because it has been neglected, but because it has been carefully, deliberately, and wickedly misrepresented. Basically, what the new history is trying to show is that power, the mighty, the kings, and the laws have concealed the fact that they were born of the contingency and injustice

10 Foucault 2003, 71 (emphasis added).

11 Foucault 2003, 74. 
of battles. [...] Unlike the historical discourse of Indo-European societies, this new discourse is no longer bound with a ternary order, but with a binary perception and division of society and men; them and us, the unjust and the just, the masters and those who must obey them, the rich and the poor, the mighty and those who have to work in order to live, those who invade lands and those who tremble before them, the despots and the groaning people, the man of today's law and those of the homeland of the future. ${ }^{12}$

This new kind of memorialization is explicitly eschatological, inasmuch as it unmasks "Rome as a new Babylon» and demands «the lost rights of Jerusalem.» ${ }^{13}$ As Foucault highlights, in the Middle Ages, Rome "functioned as a sort of permanent and contemporary historical presence», inasmuch as «all the nations of Europe claimed to have been born of the fall of Troy»; this is the reason why «all the nations, all the States, and all the monarchies of Europe could claim to be Rome's sisters.» ${ }^{14}$ By iterating and referring to biblical motifs, figures and narratives, the discourse of rebellion reproduces and recontextualizes an eschatological understanding of history. The European Nations are represented as oppressive powers that, like those of Babylon and Rome, will be defeated by an approaching new and definitive political order. However, as Foucault explains, it would be a mistake to regard the discourse of rebellion as belonging only to the oppressed and the enslaved:

It is true that we see it taking shape, at least initially perhaps, in the eschatological themes or myths that developed together with the popular movements of the second half of the Middle Ages. But it has to be noted that we very quickly-immediately-find it in the form of historical scholarship, popular fiction, and cosmo-biological speculations. For a long time it was an oppositional discourse; circulating very quickly from one oppositional group to another, it was a critical instrument to be used in the struggle against a form of power, but it was shared by different enemies or different forms of opposition to that power. We see it being used, in various forms, by radical English thought at the time of the seventeenth century revolution. A few years later, we see the French aristocratic reaction using it against the power of Louis XIV, and it has scarcely been transformed at all. In the early

12 Foucault 2003, 72-74.

13 Foucault 2003, 74.

14 Foucault 2003, 75. 
nineteenth century, it was obviously bound up with the post-revolutionary project of at last writing a history whose real subject is the people. But a few years later, we can see it being used to disqualify colonized subraces. This is, then, a mobile discourse, a polyvalent discourse. Although its origins lie in the Middle Ages, it is not so marked by them that it can have only one political meaning. ${ }^{15}$

Foucault defines the new discourse as a discourse about race and not about class struggle, precisely because it was soon used to qualify and legitimize the political interests of different political groups in the struggle against each other. This is why the term «race» should not be understood as «pinned to a stable biological meaning», but rather as a word that «designates a certain historico-political divide.» ${ }^{16}$ In other words, the discourse of rebellion is a discourse about race struggle as it represents history as the conflict between at least two major "groups which, although they coexist, have not become mixed because of the differences, dissymmetries, and barriers created by privileges, customs and rights, the distribution of wealth, or the way in which power is exercised.» ${ }^{17}$ However, Foucault clearly says that the history of revolutionary projects and practices is intrinsically bound to the emergence of counter-historical discourse. ${ }^{18}$

According to Foucault, the counter-historical discourse of rebellion did not replace the discourse of sovereignty. Rather, both continue to operate throughout modernity and into postmodernity in a struggle characterized by perpetual interaction between each other, producing fields of knowledge and knowledge-contents. More precisely, at a certain historical moment, the discourse of sovereignty intruded upon and took possession of the discourse of rebellion, inverting its functionality. The glorification of power relations, then, is realized through the representation of the state as the bastion of the defense of society and the social heritage of one race, that is: the nation-state as a unified social body that must be defended from inside and outside. As Foucault puts it:

Whereas the discourse of races, of the struggle between races, was a weapon to be used against the historico-political discourse of Roman sovereignty, the discourse of race (in the singular) was a way of turning that weapon against those who had forged it, of using it to preserve the

15 Foucault 2003, 76-77.

16 Foucault 2003, 77.

17 Foucault 2003, 77.

18 See Foucault 2003, 79. 
sovereignty of the State [...]. Thanks to the shift from law to norm, from races in the plural to race in the singular, from the emancipatory project to a concern with purity, sovereignty was able to invest or take over the discourse of race struggle and reutilize it for its own strategy. State sovereignty thus becomes the imperative to protect the race. It becomes both an alternative to and a way of blocking the call for revolution that derived from the old discourse of struggles, interpretations, demands, and promises. ${ }^{19}$

Fundamental to this study, this passage allows us to understand and analyze the emergence of the state martyr figure. Foucault delineates the historical process through which the discourse of sovereignty took possession of the biblical figures and narratives that previously belonged to the discourse of rebellion. The martyr figure is precisely one of these appropriated biblical figures, just as martyrology is one of these narratives. In fact, when Foucault writes that «Jerusalem was always a protest against [...] eternal Rome, against the Rome of the Caesars, against the Rome that shed the blood of the innocent in the circus", he implicitly refers to the martyr figure, inasmuch as among the people who died in the circus of the imperial cities disseminated in the Roman Empire, there were many who in the counternarrative of Christian martyrology are represented as martyrs. As we will see, just as the sovereign figure is essential to the discourse of sovereigntywhose function ultimately is nothing more than to make the power and monopoly of violence appear absolutely necessary for the protection of race (or, more precisely, of society within the boundaries of the nationstate) -, the martyr figure is indispensable to the discourse of rebellion. Therefore, to understand the nature, structure and development of the discourse of rebellion, as well as to understand how the discourse of sovereignty took possession of certain elements that originally belonged to the «mythico-religious discourse of the Jews», we have to analyze the emergence and shifts of the martyr figure.

\subsection{Narratives of Sovereignty and Rebellion}

Before I focus on the process that led to the emergence of the state martyr figure, it is necessary to delineate in more detail the modes of emplotment of both discourses of sovereignty and rebellion as well as to describe how

19 Foucault 2003, 81-82. 
they function, or the source of their performative efficacy. The concept of emplotment was coined by Paul Ricoeur and defines the arrangements of events into an ordered narrative whole. ${ }^{20}$ Since the goal here is not to describe the two discourses in terms of their historical emergence and positivity, but rather to identify their two general structures, two modes of narrating and representing events of violence that can be found in different pragmatic-hermeneutic contexts, I will no longer talk of discourses, as discourses are always unrepeatable singularities appearing positively in specific historical contexts, but of narratives. The narrative of sovereignty and the narrative of rebellion are not to be considered to be two historical manifestations, that is, two narratives recounted and invented by specific authors in places and times that could be clearly localized in history, but rather as the historical a prioris or conditions of possibility for the emergence of positive and very concrete discourses of sovereignty and rebellion. ${ }^{21}$ They are, in other words, not things locatable in a chronology, but rather operative forces within history. ${ }^{22}$

The narrative of sovereignty refers to war and violence as fundamental presences in the history of mankind and as permanent threats that can destroy society at any moment. Within this narrative, violence is represented as something inherent in human beings, as if humans had some sort of natural predisposition to violence that permanently threatens the social order. The sovereign seeks to neutralize or at least to minimize the potential for violence inherent in every society and every historical period. To prevent the emergence of primitive, anarchic and savage violence, the sovereign must take possession of violence and monopolize it. In other words, it must be so powerful that it can impose peace by the means of violence. The narrative of rebellion instead refers to war and violence as a confrontation between two groups, as a hostile encounter between the oppressed and their oppressors, and always emerges as the negation of the narrative of sovereignty inasmuch as it challenges its way of representing history, specifically historical events of violence. Instead of enforcing and legitimizing the power of the sovereign as necessary for the defense of society, the narrative of rebellion seeks to reveal the iniquity of sovereign power and unmask its contingency and injustice. The narratives of sovereignty and of rebellion can be understood as antithetical ways of referring to and giving meaning to political violence. The first represents violence as a per-

20 See Ricoeur 1991, 138-139.

21 See Foucault 1972, 126-131.

22 See Agamben 2009, 110. 
manent threat to society, which must be controlled and held off by the political authority, while the other represents violence as an instrument of oppression used by a certain group to rule and control another. Thus, these narratives hold two opposite political functions. The narrative of sovereignty legitimizes the use of violence by a political authority as necessary to prevent the use of violence by the enemies of society. In contrast, the discourse of rebellion does not legitimize any kind of violence, but rather unmasks it as a simple and pure instrument of the fight and struggle for power. Within the discourse of rebellion, violence is neither legitimate nor illegitimate, but merely a means to the attainment of power.

At the base of modern hegemonic political thought, with the idea of sovereign power at its ideological core, is the anthropological Hobbesian premise: in the "state of nature» men are homo homini lupus. This anthropology postulates a state of nature, in which human beings live in a permanent «war of all against all» while life is «solitary, poor, nasty, brutish and short», due to man's passion and to the "perpetual and restelesse desire of Power. ${ }^{23}$ To avoid the infinite perpetuation of war, individuals must relinquish a degree of individual sovereignty to an authority that, in return, provides protection. In order for man to recognize the authority of the sovereign, a permanent fear of punishment is necessary. To counter the «state of nature», Hobbes conceives the state as a machina machinorum, which holds a monopoly on violence to ensure peace.

The mechanism that legitimates holding a monopoly on violence within modern hegemonic political thought follows a mythical narrative structure. The «mythical symbol of the Leviathan» does not simply function as an illustration of political theory, but is rather a symbol that recalls and highlights the mythical substrate that accompanies hegemonic modern political thought. ${ }^{24}$ According to Hans Blumenberg, myth is one of the original structures of human thought: because «fear $[$ Angst $]$ must be rationalized to fear [Furcht] again", and man invents «artifices such as the supposition of the familiar for the unfamiliar, the explanations for the unexplainable, the names for the unnamable.» The myth, in other words, is an «absolutism of reality.» ${ }^{25}$ Thus, on one hand, the Leviathan is the explanation of the inexplicability of chaos and, on the other, puts order into reality. Chaos is the situation of war of all against all. This chaos is generated from below, by the masses in revolt, by the mob. The mob is Behemoth, the monster

23 Hobbes 2003, 79 (EW III 85).

24 See Taubes 1983, 9-15.

25 Blumenberg 2014a, 10-11. 
that lives in the shadows and in the mud (Job 40: 19-24), and the Leviathan is its corrective: an awesome power that keeps the chaos in check. Consequently, the function of the Leviathan's symbol is to keep the mythical fear of chaos alive. Without the Leviathan, the mechanism that legitimizes violence perpetuated by the state loses its symbolic power, and therefore, the sovereign remains a sterile figure, without body and without authority.

In the 20th century, the narrative of sovereignty found its greatest representative in the jurist Carl Schmitt. Schmitt brought Hobbes' reasoning to its most extreme consequences. In Schmitt's thought, the sovereign is defined as one who decides on the state of exception:

$\mathrm{He}$ [the sovereign] decides whether there is an extreme emergency as well as what must be done to eliminate it. Although he stands outside the normally valid legal system, he nevertheless belongs to it, for it is he who must decide whether the constitution needs to be suspended in its entirety [...]. There exists no norm that is applicable to chaos. For a legal order to make sense, a normal situation must exist, and he is sovereign who definitely decides whether this normal situation actually exists. All law is situational law». The sovereign produces and guarantees the situation in its totality. He has the monopoly over this last decision. Therein resides the essence of the state's sovereignty, which must be juristically defined correctly, not as the monopoly to coerce or to rule, but as the monopoly to decide. The exception reveals most clearly the essence of the state authority. The decision parts here from the legal norm, and (to formulate it paradoxically) authority proves that to produce law it need not be based on law. ${ }^{26}$

The power to decide on the state of exception is the missing piece in Hobbes' theory. It is the piece that manifests the sovereign as legitimate only within a framework of mythical thought. The sovereign is only absolutely necessary to the preservation of order when confronted with advancing chaos. This is the strategic core of Schmitt's political theology: he conceives the state as a katechon, an arresting power whose raison d'etre is to stop the anarchic, chaotic and demonic forces that perpetually threaten the social order. ${ }^{27}$ This also reveals that the representation of violence and war as a potentially omnipresent threat plays a central and strategic role in the discourse of sovereignty.

26 Schmitt 1985, 7, 13.

27 See Schmitt 1988, 59-62; Schmitt 1996. 
In the contemporary world, the mythic structure of violence legitimization manifests itself in the language and rhetoric adopted by many purported democratic and liberal governments. A paradigmatic example of this rhetoric comes from US President George W. Bush's administration in its justification of the US' military intervention in Iraq. The Bush administration represented enemies of the United States not simply as political opponents tied to specific interests-economic, national, cultural etc.-but as the acolytes of absolute evil. By placing the concept of the «terrorist» at the center of foreign policy, the Bush administration managed to universalize the enemy. The figure of the terrorist is the main character of a mythical narrative. In the rhetoric of the «war on terror», the «terrorist» is not a specific enemy within a specific cultural context linked to its own historicity, but rather a variable without determinations; it could be anyone and be anywhere. The enemy embodies the Otherness in body politics: an outsider that is at the same time an insider. Fear of foreigners and complete difference on the one hand, and fear of chaos caused by the masses, or the social body itself, on the other are constitutive for the acceptance of violence perpetuated by the state. What sustains this narrative is not a structure of logical and rational thought, but rather a mythical one. The mythical narrative of the sovereign is based on the idea of permanent violence and war, in which the enemy can be anyone. It is this mythical universal enemy that allows states to declare a permanent state of exception, in which the use of violence always seems necessary, inevitable, and therefore, legitimate.

According to Jacob Taubes, the narrative of sovereignty finds its opposite in Walter Benjamin's idea of the messianic revolution. In his eight theses on the philosophy of history, Benjamin takes the fundamental concepts of Schmitt's thought and overturns their meaning: the state of exception, which in the writings of Carl Schmitt is dictatorially imposed or dictated from above, becomes the starting point for a messianic revolution from the bottom. ${ }^{28}$ To understand the meaning of this reversal, it is necessary to take into account the distinction made by Benjamin between mythical and divine violence:

Far from inaugurating a purer sphere, the mythical manifestation of immediate violence shows itself fundamentally identical with all legal violence, and turns suspicion concerning the latter into certainty of the perniciousness of its historical function, the destruction of which

28 See Taubes 1987, 28. 
thus becomes obligatory. This very task of destruction poses again, in the last resort, the question of a pure immediate violence that might be able to call a halt to mythical violence. Just as in all spheres God opposes myth, mythical violence is confronted by the divine. And the latter constitutes its antithesis in all respects. If mythical violence is lawmaking, divine violence is law destroying; if the former sets boundaries, the latter boundlessly destroys them; if mythical violence brings at once guilt and retribution, divine power only expiates; if the former threatens, the latter strikes; if the former is bloody, the latter is lethal without spilling blood.

When Benjamin speaks of mythical violence, which founds the law, he clearly has in mind the violence perpetuated by the state, specifically the kind of violence that legitimizes itself through recourse to fear of chaos. In this sense, violence is lawmaking: it constitutes the established order, which contains the chaos that arises from the masses, from the mob. Law does not possess the power to legitimize violence perpetuated by the state -it has only the function of making it legal. Furthermore, law is a result of mythical violence, and violence is the means to deploy the power over mere life. The concept of mere life is a boundary concept since it marks the intersection of mythical and divine violence. Within the narrative of sovereignty (and therefore within the logic of mythical violence), a human being can be reduced to mere life- to a body that a political authority may freely dispose of -where authority may find legitimacy in destroying it for the sake of maintaining peace. In a sort of dialectic inversion, mere life is also the condition of possibility for the redemption of the oppressed; it is a specific form of life, from which it is possible to destroy the law and delegitimize violence perpetuated by the state. What Benjamin calls divine violence is precisely that form of power that manifests itself and becomes possible in the condition of mere life:

[...] with mere life the rule of law over the living ceases. Mythical violence is bloody power over mere life for its own sake, divine violence pure power over all life for the sake of the living. The first demands sacrifice, the second accepts it. ${ }^{29}$

What is this violence that «accepts sacrifice», that «is lethal without spilling blood»? Is it not a contradiction to speak of violence that accepts sacrifice? I propose to elucidate this distinction by resorting to the distinction be-

29 Benjamin 1995, 297. 
tween active and passive violence. An example of passive violence, for Benjamin, is a general strike, which aims at suspending sovereign power over mere life and annihilating the rule of law. ${ }^{30} \mathrm{~A}$ strike is violent because it opposes the violence of the state, and it is passive because it opposes violence without spilling blood. Accepting sacrifice means accepting the possibility of giving up one's own life for a cause larger than life itself. In the context of oppression, sacrifice is a "form of life» through which a single subject, passively resisting the violence perpetuated by the state, highlights the injustice suffered by a group of individuals. The kind of violence that resides in the act of sacrifice is no longer a means, as it is in the case of violence that founds the law and maintains order, but pure manifestation. ${ }^{31}$ In this sense, sacrifice is an «act of speech» in which the suffering body manifests the injustice experienced by a group to a larger audience. The injured or dying body becomes the medium that bears witness to the condition of an oppressed group. The transformative power of self-sacrifice lies precisely in the reconstitution of the boundaries surrounding the individual body that is sacrificed and the larger body politic. Double performativity of the act of sacrifice therefore exists: the act not only witnesses injustice, but also shapes the body politic, making possible a common identity between people who may never meet but who are still united by a common experience. Therefore, the divine violence mentioned by Benjamin can be understood as the symbolic power that flows from the suffering or dying body. Perhaps, then, this is the meaning behind the concept of mere life. With mere life the rule of law, (a system of rules that legalizes violence perpetuated by the state), ceases, because its deep iniquity is «materialized» in the body of the one who sacrifices himself or herself.

Why does Benjamin define the violence related to the act of sacrifice as «divine»? Once again, we can find the coordinates to answer this question in Jacob Taubes' writings. In his interpretation of the Pauline letters, Taubes clarifies Benjamin's messianism. His argument begins as such: the Messiah is a martyr, meaning the one whom with his own sacrifice bears witness to injustice. In the tradition of Western thought, the best-known example of such a sacrifice is the sacrifice of Christ on the cross. Christ is the one who, with his sacrifice, undermines the authority of the Roman Empire and the authority of the Jewish theocracy, testifying with his own body the injustices perpetuated by the established power. For Taubes, in the Pauline letters, Christ is conceived as the one who, with his own sacri-

30 See Benjamin 1995, 291-292.

31 See Agamben 2005a, 62. 
fice, constitutes a universal social body. In the community of Christ there is no difference between Greeks, Jews and Romans, between fathers and sons, between slaves and masters. On the contrary, the battered body of the Christ is the symbol of the universal community of the oppressed..$^{32}$ Indeed, the identification of the individual with the community no longer takes place in terms of ethnicity, as in the case of the Jewish law of the Old Testament, and even in terms of belonging to a specific realm such as the law of the Empire, but rather in terms of belonging to a community of universal subjects. ${ }^{33}$

For Taubes, the martyrdom of Christ is the paradigmatic example of an act that delegitimizes the established order and simultaneously constructs and legitimizes a new community. This legitimation of the oppressed community is expressed in the idea of resurrection. The resurrection of Christ promises the resurrection of all, at the end of time, in a new body politic. ${ }^{34}$ The dialectic of martyrdom and resurrection, of a past and future event, constitutes what both Taubes and Benjamin call a «messianic time» or «now-time».35 This time is characterized by a conception of history in which the established order is already perceived as illegitimate, but is not yet a new order. The eschatological tension between the act of martyrdom (a past event) and the resurrection of all in a new body politic (a future event) constitutes the «now-time». This allows us to clarify Benjamin's concept of divine violence. The violence inherent in sacrifice is «divine» because it breaks the mechanism of mythical thought, in which history is conceived as circular. In fact, the circular concept of time, which is the basis of mythic thought, follows the logic of the eternal return: every time the world is threatened by chaos, mythical violence falls upon it to restore order. Divine violence departs from this concept of repetition, which implicitly legitimizes and justifies the maintenance of the status quo, and creates the possibility of a radical change.

In summary, mythical and divine violence are two different ways of conceiving the body politic and historical time. On the one hand, active violence founds the state and the dictatorship of the law, using the perpetual fear of the onset of chaos. Mythical violence always needs an enemy that signifies chaos and evil. From this point of view, the body politic of the sovereign state must always exclude someone who, as potentially danger-

32 See Taubes 2003, 164.

33 See Taubes 2003, 146.

34 See Taubes 2003, 71-72.

35 See Taubes 1987, 21-24; Benjamin 1968, 261. 
ous, does not have the same rights as citizens of the state. What makes this mechanism of inclusion/exclusion very effective is that, since anyone is potentially dangerous, anyone can be represented and perceived as the enemy. The perpetuation of this omnipresent enemy is guaranteed only within a circular conception of history. Indeed, the need for maintenance of order is provided only if the danger of chaos is perceived as always latent.

Acts of passive violence, which undermine the legitimacy of the state through witnessing evil uses of violence, are the radical antitheses of active violence. Violence perpetuated by the state loses its legitimacy when what was previously represented as an enemy, or force of chaos, is displayed in all its weakness: a weak body, or mere life. The act of passive resistance reveals the structure of the mythical narrative, showing the absurdity of the fear of chaos, and reveals the ultimate function of such a prominent narrative, which is the maintenance of power over mere life. The body of the oppressed becomes the signifier of an entire community of oppressed people, now a political body that is no longer based on a mechanism of exclusion, but on a universal conception of the human being. In this respect, the martyr figure is the antithesis of the Leviathan. ${ }^{36}$ If the Leviathan is the mythical symbol of the authoritarian sovereign, a monster that embodies the citizen and protects the citizens from external enemies and from themselves, the martyr figure is the divine symbol of the community of the oppressed. This undermines the illegitimacy of state violence, showing its deep iniquity, and lays the basis for forming a universal political body.

From this point of view, the martyr figure becomes the model for the development of an aesthetic of resistance. In fact, the purpose of my argument is not to make a pamphlet on martyrdom, but to highlight the aesthetic dimension of political practices, especially within practices where the staging and representation of the body holds a central role. In order to highlight what is at stake here, I propose to compare the act of martyrdom with a less radical form of resistance than self-sacrifice, which, following a suggestion made by Giles Deleuze and Giorgio Agamben in two different essays, ${ }^{37}$ is exemplified in Herman Melville's novel Bartleby, the Scrivener: A Story of Wall Street. Melville describes a less radical form of resistance than self-sacrifice that is still quite powerful. Bartleby is always the one who says «no, I prefer not», when his boss asks him to do something. This is an example of a speech act, in which a lack of action forces the authority of the master into a state of crisis. When Bartleby denies the will of his master,

36 See Weigel 2007b, 15; Fierke 2013, 53.

37 See Agamben/Deleuze 2012. 
the hierarchical structure of the relationship between the two characters is completely thrown into crisis. This occurs in such a way that the authority of the employer loses all meaning. The fundamental difference between the act of Bartleby and the radical act of martyrdom is obvious: Bartleby does not have to sacrifice his body or his own life to undermine the authority of the powers in charge, because Bartleby does not fight against state institutions. Instead, he fights against a particular model of work organization personified by his employer.

What is interesting, however, is not the difference between the two acts, but their similarities. In both cases, we find an act that rebels against the expectations of those who operate within dominant discourses. Just as Bartleby shatters his employer every time with every negative response, state institutions are completely unable to grasp the meaning of this kind of martyrdom. Indeed, within the narrative of sovereignty, a healthy individual never sacrifices his own life, and from the point of view of a sovereign power the act of martyrdom is a meaningless action. The reason for this is that, as suggested by the above analysis of the anthropological implications of Hobbes' thought, the narrative of sovereignty always begins with the premise that man is a selfish animal, only interested in the preservation of his own life. The power of martyrdom lies precisely in this: that the power over mere life and death ceases to exist when an individual accepts the possibility of sacrificing life itself. When faced with sacrifice, the expectation of the sovereign, (that is, that every man will do anything to save himself), collapses like a house of cards. From this perspective, it appears that the core of Benjamin's divine violence is not so much a willingness to sacrifice one's own life for a cause, but rather the ability to override the rules of the dominant narrative. The performativity of resistance lies not only in the fact that the act makes manifest the iniquity of mythical violence, but also that the act goes against all expectations. This reformulation of the passive act of resistance drives the development of a less radical concept of mere life, one in which mere life possesses power beyond sacrifice.

We may reinterpret the concept of mere life not as a reduction of the human being into a body, or living flesh, but as the condition of possibility to develop a performative language that starts from the body. As previously explored, for Benjamin, the reduction of man to a mere life occurs under the dictatorship of the law; it is a product of the practices of government in which the idea of defending sovereignty, and the need to contain chaos, justifies the use of violence. Yet, for Benjamin, if this reduction is a product of mythical violence, it is also the condition of possibility of divine vio- 
lence. To determine the relationship between these two types of violence, Benjamin uses the Hegelian concept of «antithesis» to show that it is mythical violence itself that produces its own negation. The overcoming of a thesis and its antithesis lies in the production of heterogeneous forms of life, which become possible with the condition of mere life. The reduction of a subject to a mere life undermines all signifiers of social life: confronted with mythical violence, the subject ceases to identify with a particular ethnicity, gender, or social status and experiences itself as equal to all other beings. Starting from this universal «zero point», the subject develops subversive forms of life, which, against all the expectations of the dominant narrative, override its rules and undermine its structure.

In Gender Trouble, Judith Butler explains the performativity of such a subversive act in the following way: «If subversion is possible, it will be a subversion from within the terms of the law, through the possibilities that emerge when the law turns against itself and spawns unexpected permutations itself. The cultural constructed body will then be liberated, neither to its «natural past, nor to its original pleasures, but to an open future of cultural possibilities. ${ }^{38}$ Here, subversion is understood particularly as a subversion of gender categories. The mechanism by which the subversion becomes possible, however, is applicable to other forms of categorizationsuch as those of ethnicity or social status-produced by the dominant narrative. But what mechanism is it? For Butler, the practices of drag and cross-dressing are examples of a subversive act against the categories of gender. These practices are parodies of categories constructed by the dominant discourse. By parodying the identifications of gender, these practices highlight their own contingency and gender's constructed nature. Their performativity lies in advertising the fact that any form of identification is constructed within a discourse. In fact, «performative suggests a dramatic and contingent construction of meaning.. ${ }^{39}$ This performativity is only possible because the body presents itself as a «signifying lack.» ${ }^{40}$ What allows a person to become aware that every identity is constructed? It seems to me that, according to Butler, it is precisely through subversive acts that it is possible to undermine the categorizations of the dominant discourse, and therefore to make visible their constructed nature. Mere life is exactly this «zero point» from which the constructed nature of all social determinations emerges and becomes manifest. The reduction to mere life is what re-

38 Butler 1990, 93.

39 Butler 1990, 139.

40 Butler 1990, 135. 
veals to us the signifying lack of the body, opening the possibility for the creation of alternative forms of life, no longer determined by the dominant narrative.

But what kind of political practices might subvert the logic of mythical thinking? As I argue above, such a thought is kept alive by the conception of man as a selfish animal, interested only in preserving its own life and increasing its own power. Therefore, one must try to think and give a shape to forms of life through bodily and/or language performances, which destabilize this conception of human beings. Martyrdom, understood as self-sacrifice for a higher cause over mere individual survival, is one of these forms; perhaps even the most paradigmatic form. But there are many other, less radical ways to subversively use language and body. Contestations enacted by public assemblies, strikes, vigils, and the occupation of the public space are, for example, important forms of embodied action with which dominant expectations and categorizations can be subverted, especially when they bring together individuals «belonging» to social strata, ethnicities, nationalities, genders, etc. in defense of the rights and dignity of social minorities. ${ }^{41}$ The subversive power of these practices lies in something very simple: all these practices show that human beings are capable of acting in solidarity and fighting for others, and thus have the power to make manifest the deep iniquity of the entire narrative of sovereignty. They not only show that human beings are much more than homo homini lupus, but also show that behind the excuse of defending national security and order lies an inhuman logic, one that is, in its nature, mythical.

\subsection{Hegemonic and Subversive Uses of the Martyr Figure}

If the martyr figure is antithetical to that of the sovereign, and the performative force of martyrdom lies in its ability to reveal the iniquity of state violence and to unmask the legitimizing mechanism of the mythical narrative of the sovereign, how can we explain the emergence of the state martyr figuration? How is it possible, with regard to the case at the center of this study, that Aldo Moro was represented as a martyr of the Italian Republic, who died for the defense of the state? The state martyr figure seems to function conversely to the statement above: rather than delegitimizing the political authority, and serving as a symbolic body of oppressed communi-

41 See Butler 2015. 
ties, the state martyr seems to legitimize and support the discourse of sovereignty, serving as a symbol of the national community. In other words, the central figure of the discourse seems, in this case, to become part of the discourse of sovereignty.

The two archetypical narratives outlined in the previous section introduce at least three major problems. First, by referring explicitly to the martyrdom of Christ as a model of non-violent resistance, in the previous section I deliberately omitted reflection on the presence of martyrologies within concrete and positive discourses in which violently acting individuals are also represented as martyrs. In fact, the martyr figure also played and still plays an important role in narratives that can hardly be regarded as an expression of the suffering of oppressed communities. There are thus martyrological representations in which the situation is at least partially reversed compared to what has been outlined above. In these situations the victims are not represented as martyrs who died by the hands of state apparatuses but, on the contrary, are depicted as martyrs who sacrificed themselves in defense of the nation-state, its principles and its laws.

The second problem is directly connected with the first: since the aim of the previous section was to outline the two archetypes of sovereignty and rebellion narratives, I did not problematize the different roles martyrological representations play in positive historical discourses. By focusing on «self-sacrifice» as a bodily performance, I omitted any discussion of the role of language, rhetoric and media within both mechanisms of legitimization/delegitimization, political authority and subjectification/communization. In fact, as we develop later, an act of «self-sacrifice» deploys performative power only if it is represented, recognized and accepted as such by social actors. The specific case of martyr figuration examined in this study should be considered a borderline-case, inasmuch as it is highly problematic to talk about self-sacrifice, because Aldo Moro categorically refused to assume the role of a martyr. Since Aldo Moro did everything in his power to avoid being killed, it is necessary to change our approach and focalize on the performativity of discursive practices that represent and construct his death as martyrdom.

A third, more general problem concerns violence perpetuated not by members of the state apparatuses (primarily police and military forces), but by those who use active violence as a means of political struggle against established forms of political authority. We must, then, consider the reality of non-state violence, namely those forms of violence that function and perpetuate the narrative of sovereignty by maintaining and spreading the fear of an omnipresent internal and/or external enemy. What happens if 
the martyr figure becomes part of a narrative that represents victims of non-state violent acts as «martyrs»? In other words: what happens if terrorism becomes the point of reference for the production of state martyrologies?

The task of solving these problems is reserved for the next chapter, which describes the historical process that led to the incorporation of the martyr figure within the narrative of sovereignty. The process of dislocation from its original context of apparition suspended the fundamental opposition of the figure of the martyr to the sovereign, resulting in the annihilation of the narrative of rebellion. Potential discursive re-enactment of the narrative dropped drastically, since its central figure was incorporated within the narrative of sovereignty. The concepts of martyrdom and sovereignty coincide and overlap in a sphere of indiscernibility, from which emerged the state martyr figure.

The martyrological representation of Aldo Moro is located at the end of a long process of displacement and relocation of the martyr figure. What makes the Moro case special, taking on almost a character of exemplarity, is not merely the serial, repetitive and massive presence of representations of Moro as a state martyr, but rather that these representations were contested even before the actual event of violence, to which the representations relate, happened. Several other social actors besides Aldo Moro objected and attempted to give, both during the 55 days in which Moro was held prisoner and after, an alternative representation of the violent event. The Moro case is therefore an excellent starting point not only for analyzing the functioning and performativity of the figure of the state martyr and understanding how such a figure could become part of a discourse of sovereignty, but also for identifying and discussing alternative forms and models of representation of events of political violence, which have, at least potentially, the power to subvert hegemonic discourses. In fact, what makes this case so interesting is that the figure of the martyr was and still is used in both dominant and subversive forms of representation and narration. In other words, in the pragmatic and hermeneutic context of the case study, the subversive use of the martyr figure survived, thus revealing that, at least potentially, it still plays a role in discourses of rebellion to the mythical narrative of the nation-state.

If the martyr figure can be used in both narratives of sovereignty and rebellion in the same historical context, then the martyr's performativity cannot be understood by hypostatizing its meaning and function, but by accounting for its different uses and discursive manifestations. Martyrological representations exercise a performative force inasmuch as they strongly 
influence and canalize the interpretation and perception of historical events of political violence. Within the dominant and hegemonic discourse, representations of Aldo Moro as a state martyr serve to conceal political power structures and legitimize established forms of political authority. As I will try to demonstrate in the fifth and sixth chapters, through the use of martyrological representations and the allocation of the state martyr role, different social actors tried to attribute the meaning of a voluntary act of self-sacrifice in defense of the nation-state and for the sake of the Italian citizens' well-being to Moro's death. Martyrological representations are discursive practices that deploy a performative force inasmuch as they are able to signify Aldo Moro as a sacral victim, a martyr who witnesses the truthfulness of citizen rights and the necessity of the nation state as the supreme guarantor of these rights. Here, he becomes the central figure of a narrative in which sovereign state authority is experienced and perceived as absolutely imperative. Moro's violent death in itself acquires the meaning of an absolute and meta-historical event, namely of an event that could not be avoided as it was necessary for the preservation and the defense of the Italian Republic and the laws and values at the base of a liberal, democratic political order.

Through this absolutization of a specific historical event of violence, the social struggle of the seventies in Italy assumes the connotation of a conflict between good and evil forces, order and chaos, and the preservation and destruction of life. The effectiveness of this absolutization is threefold. First, it legitimates state authority and its monopoly on violence, presenting it as necessary for the defense of society and the preservation of the rights and lives of citizens. Second, it justifies the decisions (and non-decisions) made by the Italian government during the Moro affair, in particular the decision not to negotiate for Moro's release. Third, it causes «consumers» (as well as "producers») of hegemonic representations to identify with the national community, inasmuch as Moro's body becomes the symbolical body of the national community and thus serves as a symbol of collective identification. Aldo Moro becomes the symbol of a political community who suffered and risked destruction yet found renewed strength, inner solidarity and vitality.

Now, what distinguishes the subversive use from the hegemonic use of the martyr figure? For the purpose of this study, I propose to distinguish between instrumental and poetic uses of language. According to Agamben,

Language $[\ldots]$ appears for each speaker as what is the most intimate and proper; and yet, speaking of an «ownership» and of an intimacy> of 
language is certainly misleading, since language happens to the human being from the outside, through a process of transmission and learning that can be arduous and painful and is imposed on the infant rather than being willed by it. And while the body seems particular to each individual, language is by definition shared by others and as such an object of common use. ${ }^{42}$

Each use of language units-signs, words, and constellations of words (sentences) - is an iterative use. Discursive practices take up something that is always already given, a positivity present in history, placing them in a new hermeneutic and pragmatic context. The unique character of discursive practices depends on historical location, through which the same sign, word or sentence not only takes on a special and different meaning from time to time, but also does something different each time. The effectiveness of language is determined not only by semantic elements themselves, but also by the signatures to which they are subjected as well as by the context in which they appear. As will be discussed in detail in the next chapter, Foucault and Agamben define the iteration and dislocation of language units as a signature.

The concealment of iteration and dislocation characterizes the instrumental use of language. Discursive practices are instrumental when they use semantic elements as tools for the objectification and absolutization of reality or to hide their historicity and contingency. This concealment leads to the hypostatization of words and things, acts or events. In other words, the instrumental use of language completely hides the externality of language, the external imposition to which we are exposed every time we make use of language itself. In this way, not only is historicity concealed, but so is the historical development of the language; in addition, its performative force is masked and silenced. As Agamben notes, today we live in an age that has perfected and taken to extremes this instrumental use of language:

What has changed $[\ldots]$ is that language no longer functions as a historical a priori, which while remaining unthought, determines and conditions the historical possibilities of speaking human beings. In being totally identified with being, it is now put forward as a neutral ahistorical or post-historical effectuality, which no longer conditions any recognizable sense of historical becoming or any epochal articulation of time. This means that we live in a time that is not-or at least pretends

42 Agamben 2015b, 86. 
not to be-determined by any historical a priori, which is to say, a posthistorical time (or rather, a time determined by the absence or impossibility of such an a priori). ${ }^{43}$

The ethical and political value of poetry and, more generally, art, lies in its ability to use semantic elements without hiding its signatures, but rather by making them manifest. Discursive practices that make poetic use of language reveal and unmask the exteriority of language:

[Poets] must [...] abandon conventions and common use and, so to speak, render foreign the language that they must dominate, inscribing it in a system of rules as arbitrary as they are inexorable [...] The appropriation of language that they pursue, that is to say, is to the same extent an expropriation, in such a way that the poetic act appears as a bipolar gesture, which each time renders external what it must unfailingly appropriate. ${ }^{44}$

In order to be able to distinguish between instrumental and poetic, subversive uses of the martyr figuration, this investigation has to reconstruct its historical signatures and metamorphoses. In the seventh chapter, I will discuss examples of alternative usages of the martyr figuration that operate poetically, at least in the sense of the definition presented above, since they make explicit and highlight its radical historicity, versatility and ambiguity. A large majority of martyrological representations of Aldo Moro operate according to instrumental language usage, since they hide the martyr figure's stratifications of meaning and metamorphoses. They disguise in particular the strong subversive potential it had in its «original» context of appearance, that is, within a discourse of rebellion.

\subsection{The Discourse Analytical Approach}

Discourse theory has already been incorporated into the study of religion for some time. Fundamental reflections on the fertility of the «discursive study of religion» were first formulated in the eighties. ${ }^{45}$ Hans Kippenberg proposed an interpretative model, which refers to the theory of speech acts and rejects an essentialist separation of action and language by understand-

43 Agamben 2015b, 114.

44 Agamben 2015b, 86.

45 See Kippenberg 1983; Lincoln 1989. 
ing linguistic expressions as acts. This creates the possibility of examining religious expressions as discursive practices that significantly determine the construction of reality. Kocku von Stuckrad in particular argues for the discursive study of religion. ${ }^{46}$ More specifically, he argues for the inclusion of both sociological discourse analysis as well as historical discourse analysis in the theoretical framework of the study of religion. Sociological discourse analysis assumes that everything perceived, experienced and felt is structurally intertwined with the socially constructed forms of preserved, recognized and objectified knowledge. ${ }^{47}$ On the other hand, historical discourse analysis examines the discursive genealogy of meaning or realitygenerating processes of communication in history. ${ }^{48}$ According to von Stuckrad, the combination of these two approaches opens up a new perspective on the research subject of the study of religion. From the perspective of discourse theory, religion loses the status of a phenomenon sui generis and therefore can be studied as an empty signifier, which constantly receives new meaning within different discursive practices and is constituted by them. The subjects of a discourse analysis-oriented study of religion are, accordingly, discourses on religion. These discourses produce meaning and orders of knowledge materialized in certain concrete practices and institutions.

This investigation is in line with von Stuckrad's proposal of a discursive study of religion. However, since the discursive practices investigated in this investigation cannot all be explicitly considered elements of a discourse about religion, the selection criteria of what is a legitimate research subject within the study of religion must be extended. I am of the opinion that the discipline is not limited to discourses on religion, but also extends to discourses in which linguistic and visual elements occur, which iterate semiotic, narrative and rhetoric models that «belong» to historically preserved religious systems of knowledge and representation. This extension allows the examination of the role and function of «religious signs» within discourses, which are difficult to identify as explicitly «religious». The focus of this investigation resides, on the one hand, in those representations and narratives that recall and iterate elements of language linked to the figure of the martyr, and on the other, in the political use and function of those elements of language.

46 See von Stuckrad 2003; von Stuckrad 2010; von Stuckrad 2013.

47 See Keller 2008.

48 See Landwehr 2008, 92. 
Following Foucault's understanding of the goal and analytical strategy of «historical-philosophical research», rather than conceptualizing and isolating putative transhistorical universals, I want to establish a conceptual framework that allows for the exploration of an event of political violence and its representation in discursive practices as singularities. Foucault calls this interpretative path an examination of «eventualisation» (événementialisation)..$^{49}$ Using a topological terminology, the aim of this investigation can be described as an attempt to map the history of the event. The positivity of the historical event is the focal point on the basis of which it becomes possible to analyze the organization, function, and the interconnection of the discursive practices referring to the event. The unit of these discursive practices is what from now on I will call discursive formation. The goal of historical-philosophical research is to «record the singularity of events outside of any monotonous finality», to «reject the meta-historical deployment of ideal signification and indefinite teleologies»" ${ }^{50}$ and to analyze "groups of elements where, in a totally empirical and temporary way, connections between mechanism of coercion and contents of knowledge can be identified. ${ }^{51} \mathrm{~A}$ central question concerning historical-philosophical research into discursive formations is: «How is it that a particular statement appeared rather than another?» 52 If we apply this principle to this study, further questions are raised: how and why is a concrete historical event of political violence repetitively and regularly represented in different media with the martyr as a central figure? Which interplaying mechanisms of coercion determine the acceptance and diffusion of martyrological representations? Which mechanisms of coercion organize, select and canalize the modes and contents of the representations of the event in a certain direction rather than another? What effects of power are linked to the martyrological representation of the event?

The state martyr figure cannot deploy effects of power without a certain diffusion and regularity of manifestation in the public space and materialization in different media. It would be hard to sustain the thesis presented above if there were only one or few martyrological representations. If the first task of this investigation is the individuation of martyr figuration signatures, its second task is to analyze its diffusion and regularity within the discursive formation referring to the Moro case and to describe how, when

49 Foucault 2007, 59.

50 Foucault 1977, 139-140.

51 Foucault 2007, 59.

52 Foucault 1972, 27. 
and where this figure emerged. In other terms, it has to analyze the general organization of the discursive formation referring to Moro's death to prove that the martyr figure has effectively a prominent presence within it. To master this task, I will use some of the instruments found in Foucault's different «toolboxes», as the French historian and philosopher once defined his books. ${ }^{53}$ One toolbox in particular will serve as a central point of reference: the work Archeology of Knowledge. In the center of this book stands the effort to relate the description and individuation of statements in their singularity of appearance with the broader task of analyzing discursive formations. The starting point is the demarcation or distanciation of archeology from traditional scientific procedures and the epistemological premises of what is generally known as the «history of ideas». This critique concerns a range of categories, such as «tradition», «science», «literature», «politics», «book», «authorship», etc., whose functions are to synthetize a «population of dispersed events», to set and define unities of knowledge and to link those unities with the ideas of a genuine source or origin, continuity and collective consciousness. ${ }^{54}$ Foucault proposes to deconstruct this principle of ordering so as to identify and describe other unities, or other «discursive formations». He also criticizes what we could call an essentialism of meaning, namely the idea that historical statements, events and objects are always to be considered and analyzed as «documents", or signs of something else, searching for their hidden meaning and essential truth. ${ }^{55} \mathrm{He}$ opposes this with his conception of enunciations as unrepeatable events, which must be described as «monuments», i.e. to describe the historical, discursive, institutional and material conditions for their appearance.

The position of Archeology of Knowledge within Foucault's thought is controversial. There have been many attempts to distinguish Foucault's works according to phases, ${ }^{56}$ wherein some researchers understand the Archeology as part of a first group of discourse analytical works, opposed to and viewed as outdated after a second phase of analysis of power. ${ }^{57}$ Others consider this work quite relevant and not obsolete in relation to Foucault's theory of power. ${ }^{58}$ Although preferring the latter reading, this study does not defend a certain model of systematization of Foucault's works, but

53 Foucault 2002, 887.

54 Foucault 1972, 22; See Kammler 2014b, 54.

55 See Foucault 1972, 138-139.

56 See Kammler 2014a, 11.

57 See Davidson 2003, 192; Gehering 2004, 10.

58 See Dreyfus/Rabinow 1983, 79-100. 
rather takes seriously his exhortation to use his books as research tools. From this point of view, I follow the line traced by British cultural studies, especially by Stuart Hall, and seek to address discursive practices as «signifying practices» that have an intrinsically performative force, i.e. the power to exert effects. Hall addresses discourse as a «system of representations», i.e. «a group of statements which provide a language for talking about-a way of representing the knowledge about-a particular topic at a particular historical moment.» ${ }^{59}$ Here, the effectiveness of the relation power/ knowledge is at stake, namely the way in which the discourses assume the authority of the truth and the power of discursive formations to produce and sustain regimes of truth. ${ }^{60}$ It is not the content but the effects of the truth of discursive practices that are at stake here.

Stuart Hall defines representation as «the production of the meaning of the concepts in our minds through language», arguing that «it is the link between concepts and language which enables us to refer to either the sreal> world of objects, people or events, or indeed to imaginary world of fictional objects, people and events.» ${ }^{61}$ The representations that are at stake here are of the first kind, since they refer to a real event-the assassination of Aldo Moro-and a real individual, which is at the same time a material object-Moro's dead body. This is obvious: the statements «Aldo Moro is dead» or "Aldo Moro has been killed» refer to something real and not imaginary. The language elements within these statements are signs-written or spoken words - that carry and express meaning. The kind of meaning they carry is understandable to all, because we all agree on the meaning of «is dead» or «has been killed». There is a general consensus that guarantees that all who use, read or listen to these words correlate them with shared conceptions of what it means to be «dead» or to be «killed» (which obviously is not the same). The same can be said for the proper noun «Aldo Moro", which refers to a certain person and not another, and all will agree without discussion-no work of interpretation is needed-which individual is intended. This representation is denotative inasmuch as the consensus is wide and all people agree on the meaning of the sentences and to what the individual words refer.

This first level of meaning does not seem to pose problems of any kind. The allocation of meaning and communication work smoothly. But if we say, write, listen or read «Aldo Moro died so that the Republic can live» or

59 Hall 1993, 291.

60 See Hall 2013b, 33-34.

61 Hall 2013b, 3. 
«Aldo Moro has been killed by beasts», the work of representation is not the same. Here we are faced with a second level of signification referred to as connotative. Here, the signifiers used connect with broader themes and meanings, linking them with what Hall calls «the wider semantic fields of our culture» and the "wider realms of social ideology». 62 In fact, a meaningful use and understanding of these statements presuppose that we have an idea of the «life of the Republic» or an idea of «bestiality». In the first statement, the word «life» is used metaphorically, as it refers to something (the Italian Republic) that does not have a life in the common sense of the word. The same can be said of the attribution of bestiality to the BR, which for all we know had no animals in their ranks. The Republic is not a living organism or, more precisely, can be considered a living organism only in a broader, metaphorical sense. The BR were not beasts but, as we will see, for many social actors they acted, thought and felt $a s$ beasts. Both statements thus require an active process of interpretation.

The first statement has meaning only for those who are familiar with political language-a second kind of shared code, which presupposes, but is not identical with, the basic code of language. Only if we know the code of political language can we interpret the statement and create meaning for ourselves. The statement presupposes, for example, that we have an idea of a republic as a form of government, or a sovereign state, that may cease to exist (for example, because of a coup, a war-civil or with other nations-, a revolution, etc.). Furthermore, it presupposes pre-existent knowledge of the idea that the government «represents the body of citizens» (another political metaphor), and that if the government ceases to exist, the body of citizens symbolically «dies» due to the loss of its representation. The specific use of these words is ideological, which is demonstrated by the fact that the concept of a republic, can be contested as evidenced by Marxist-Leninists, as the BR identified themselves, or by anarchists. The implication of the republic as a good and right form of government proves the use of these words is ideological as well. To summarize, we can say that at this second level of signification, the understanding of the performance requires the knowledge of a given code of political language, and that even if individuals have this knowledge, we cannot necessarily presuppose they accept this knowledge as true.

The use of the word «beasts» in the second statement requires interpretation, because we must know the meaning of this attribution of «bestiality» to a group of individuals. As we will see, within the specific cultural con-

62 Hall 2013b, 23-24. 
text of this statement, bestiality implies ferocious animal behavior and the non-reflected use of violence. To say that the BR are beasts implies that they acted, or killed, like beasts - that is, without a clear political purpose. The very act of killing assumes the meaning of an act that is not political but ferocious and tied to the most bestial human passions: an ancestral and primitive death wish. As we shall see, the denial of the political nature of the act strategically denies the responsibility of government policies, political parties, and in general, all those involved in the affair. With beasts, in fact, it is not possible to negotiate. Thus, this second level of signification is linked to wider realms of ideology. It does not only imply the knowledge of the conventional use of «beasts» as a metaphor in reference to individuals acting violently, but also a certain interpretation of the causes of the violent act. The event is inscribed in a meaningful system of causes and effects. The representation should therefore be considered part of a narration, a way of telling what happened, which of course can be (and has been) contested.

Let us return one more time to the first statement. Here, we are faced with a more complex, meaningful construction of a causal relationship through the use of the word «for», by which the perpetuation of the Republic is represented as an effect of Aldo Moro's death. Death is not represented as a simple fact, but as an event with a political reason and meaning. Now, taken in its singularity and without knowing the context in which the statement was written or spoken, it is impossible to exactly identify its meaning. We understand that the statement constructs a causal relationship, but we are not able to say how to interpret it. Why is the death of a single man, who as president of the Christian Democratic Party played an important political role even without acting as a government representative, important for the subsistence of the Italian Republic? It is only by taking into account the general pragmatic, discursive and hermeneutic context in which the statement was made that we can grasp its meaning. For example, we have to know that the Italian government refused to negotiate with the terrorists (even before the terrorists proposed negotiations) for the liberation of Aldo Moro and argued that such a deal would be equal to political legitimation of the terrorists and undermine the values and principles at the base of a democratic political order. We have to know that this statement was the title of the first page of the newspaper Corriere della Sera the day after Moro's body was found, and that during the entire period of the kidnapping this newspaper supported the government's «line of firmness». We also have to know that Moro's death was represented, even before its occurrence, as inevitable according to the following scheme 
of logic: If Moro lives, then the Republic will die; if the Republic lives, Moro will die.

All this will be discussed in detail afterwards. Here, I want to call attention to the fact that the meaning of single signs and statements often depends «on larger units of analysis-narratives, statements, groups of images, whole discourses which operate across a variety of texts, areas of knowledge about a subject which have acquired widespread authority.» ${ }^{63}$ This is why to analyze the production of meaning through representation, we must switch from a genuine semiotic to a discursive approach, and thus not study language, but discourse as a system of representation. Representation itself is not analyzed as a way to produce meaning, but as a source of the production of social knowledge connected to social practices and micromechanisms of power. This switch from the semiotic to the discursive approach directly leads into the orbit of Michel Foucault's thought, whose studies were focused primarily on the analysis of rules and practices linked to the production of knowledge. Especially in his later work, he was concerned with the implementation of knowledge through discursive practices in specific institutional settings to regulate the conduct of people. By focusing on the link between knowledge and power, he drew attention to the effectiveness of discursive practices, their ability to not only produce meaning, but also to signify in one way rather than in another and thus to profoundly affect the way we perceive the world, others and ourselves. This also affects our way of being in the world, to act (or not act). In other words, he highlighted the performativity of discursive practices.

\subsection{Performativity of Discursive Practices}

The first researcher who drew attention to the performativity of language is John Langshaw Austin through his general theory of speech acts. According to this American philosopher, speech acts are not simply a way to communicate something, but a way to do something. They actively deploy effects on reality and factuality. Austin identifies «three groups of things» that are done by saying something. He calls the first one a locutionary act, "which is roughly equivalent to uttering a certain sentence with a certain sense and reference, which again is roughly equivalent to <meaning> in the traditional sense.» ${ }^{64} \mathrm{He}$ opposes traditional ways of conceiving the use of

63 Hall 2013b, 27.

64 Austin 1962, 108. 
language with two others, which he calls the performances of illocution and perlocution. What distinguishes these two different dimensions of the use of language from the former is that they produce effects or consequences, that is, they have a force. By focusing on the force of discursive practices, Austin introduces a completely new way of analyzing the use of language. The interest is no longer directed (only) to the truth or falsity of linguistic units, to their referential relation to the world and their function as «bearers» of meaning, but rather to the conditions in which a speech act is successful or unsuccessful or, in Austin's terminology, «happy or unhappy», in deploying some effects. ${ }^{65}$

One of the most typical examples of illocutionary force is a judge delivering a sentence, through which a man is condemned. The act of formulating the sentence corresponds to the act of condemning. The effect here is somehow internal to the performance itself, because the latter deploys its power at the same moment the formulation is expressed. The judge has this power because of conventions, the institutionalized rules that determine him as actually holding this power. It is therefore a preexisting system of conventions that stabilizes the authority of the agent and thus guarantees the success of the speech act. The perlocutionary force is instead defined by Austin as the effect speech acts have on the audience, such as the ability to persuade, to convince, to scare and so on. The force of a perlocutionary act is external to the performance itself because it is related to the reactions of the audience of the speech act. One of the most important differences between illocutionary and perlocutionary acts is that the former are «bound up with effects», while the latter produce consequences «in the sense of bringing out states of affairs in the normal> way, i.e. changes in the natural course of events.» ${ }^{66}$ The point here is that Austin's illocutionary acts (as well as locutionary acts) always follow conventions, while perlocutionary acts «may always achieve their response or sequel by non-conventional means.» ${ }^{67}$ In other words, the force of perlocutionary acts lies in their ability to break with expectations, to be an exception to rules and conventions. Another important difference between the two uses of language stressed by Austin is that the effects of illocutionary acts are always intentional, while perlocutionary acts may be unintentional. ${ }^{68}$ In fact, as Austin argues, one or more intended effects can be achieved only when

65 Austin 1962, 132.

66 Austin 1962, 116-117.

67 Austin 1962, 118.

68 See Austin 1962, 106. 
there are conventions that guarantee the speech act has certain effects and not others. This does not apply to perlocutionary acts, as we have seen: we do not follow the tracks established by and through conventions.

Austin's How to Do Things with Words was an influential work that deployed itself with strong performative power. Jacques Derrida gave one of the first direct critical responses to Austin's theory of performativity in his essay Signature Event Context, written in 1971. In this essay, Derrida counters Austin's understanding of conventionality and intentionality on which the distinction of perlocutionary and illocutionary acts is based. According to the French philosopher, the root of the theory's problem is that Austin does not take into account the structure of locution before any illocutory or perlocutory determination. ${ }^{69}$ For Austin the intentionality of the speaker is central to the accomplishment of the performative. This leads Austin to focus on illocutionary acts, looking for what he calls «the pure performative», namely a speech act that is realized by and through the presence of an intentional agent. ${ }^{70}$ The presupposition is that «there is always someone who is delegated to speak or that performative discourse has to take the form of discrete verbal enunciation.» ${ }^{71}$ The consequence of this is the failure to recognize (or at least the underestimation of) the performative power of language even in the absence of a speaking subject.

The second problem with Austin's theory, which is intrinsically tied to the first one, is his conception of conventionality. As Derrida observes, the success of performative utterances does not depend only on the conventionality constituting the pragmatic circumstances in which they occur, but also in «a certain conventionality intrinsic to what constitutes the speech act itself.» ${ }^{72}$ In fact, the condition for the function of such acts is a certain «self-identity» of the language elements or units within them..$^{73}$ Only if this self-identity is guaranteed, are the speech acts recognizable; only if the statement «I condemn you» makes sense for the speaker and the listener, is it able to deploy an illocutionary force. Derrida's argument that a certain stability in the identity of language unities is a precondition of performativity because it allows recognition and identification should not be confused with the idea that speech acts with identical language units are in turn also identical. In fact, all concrete manifestations of language should

69 See Derrida 1988, 14.

70 Derrida 1988, 81 (see also 83-93).

71 Butler 2010, 150.

72 Derrida 1988, 15.

73 Derrida 1988, 10. 
be considered unique and unrepeatable events, even when they have the same signs in the same sequential order. In order to explain this central point, Derrida introduces the concepts of iterability or citationality:

We should first be clear on what constitutes the status of <occurrence or the eventhood of an event that entails in its allegedly present and singular emergence the intervention of an utterance [énoncé] that in itself can be repetitive or citational in its structure, or rather $[\ldots]$ : iterable. [...] Could a performative utterance succeed if its formulation did not repeat a «coded or iterable utterance, or in other words, if the formula I pronounce in order to open a meeting, launch a ship or a marriage were not identifiable in some way as a «citation〉? [...] there is a relative specificity, as Austin says, a relative spurity> of performatives. But this relative purity does not emerge in opposition to citationality or iterability, but in opposition to other kinds of iteration within a general iterability. ${ }^{74}$

The introduction of the notion of iterability in the theory of performativity has two main consequences. First, it allows us to redefine conventionality as a condition for the success of speech acts, insofar as it now indicates not only the pragmatic, extra-linguistic conventions surrounding speech acts, but also the conventionality of language itself. In other words, a speech act can be performative and exert effects only if it iterates pre-existent language units that guarantee its recognizability. As Judith Butler observes, recalling the example of the judge: «the judge learns what to say, and must speak in codified ways, which means that the codification and ritualization of that discourse precedes and makes possible the subject who speaks.» ${ }^{75}$ This brings me directly to the second consequence: the de-potentiation and relativization of the role of a conscious and intentional speaker as a precondition for the functioning of a performative utterance. If successful speech acts always iterate pre-existent language unities, pre-established formulations, then we can imagine situations - and in this investigation we will face many of them-in which language exerts a force without the immanent presence of an intentional speaker. To understand this, two operations are necessary: we must replace the concept of speech acts with discursive practices, and we must highlight the mediality and materiality of those practices. In other words, we must turn our attention to Michel Foucault's theory of discourse.

74 Derrida 1988, 17-18.

75 Butler 2010, 148. 
In Archeology of Knwoledge, written two years before Derrida's aforementioned essay, Foucault discusses (although he does not explicitly mention the American philosopher) Austin's theory of performativity, in particular its concept of the illocutionary act. He argues that

the speech act is not what took place just prior to the moment when the statement was made (in the author's thought or intentions); it is not what might have happened, after the event itself, in its wake, and the consequences that it gave rise to; it is what occurred by the very fact that a statement was made, - and precisely this statement (and not other) in specific circumstances. Presumably, therefore, one individualization of statements refers to the same criteria as the location of acts of formulation: each act is embodied in a statement and each statement contains one of those acts. They exist through one another in an exact reciprocal relationship. ${ }^{76}$

The main innovation compared to Austin's lies in a focus on embodiment, i.e. on the mediality and materiality of discursive practices. In fact, it is exactly because of this shift from verbal enunciation in particular to all forms of embodiment of language in general that I propose a strategic switch from the concept of speech acts to that of discursive practices. The concept of discursive practices does not only avoid the postulate of an intentional speaking subject, implicit in the notion of speech, but also opens this research field to an analysis of correlations between singular manifestations of language: in other words, analyzing discursive practices as elements of a discursive formation. This theoretical switch changes the way we conceive and analyze performativity, since the effects of discursive practices cannot be identified without taking into consideration their medial and material manifestation: "Could one speak of a statement if a voice had not articulated it, if a surface did not bear its signs, if it had not become embodied in a sense-perceptible element, and if it had not left some trace-if only for an instant-in someone's memory or in some space?» 77 Materiality and mediality are constitutive for the functioning of discursive practices because they «must have a substance, a support, a place, and a date. And when the requisites change, it too changes identity. ${ }^{78}$ Thus, it is always in and because of a concrete, unique context of appearance that practices have a performative force, that is, they are able to exert effects of power.

76 Foucault 1972, 83.

77 Foucault 1972, 100.

78 Foucault 1972, 101. 
Each practice should therefore be considered a unique, unrepeatable and singular event. But if this is correct, we must solve an important problem: how is it possible to analyze, as this investigation wants to, the efficacy of martyrological representations in their different contexts of appearances? In fact, if it is true that each discursive practice is unique and exerts a performative force precisely because of its uniqueness, then it does not seem possible to compare different martyrological representations in order to individuate a common function or an identical force. As we have seen, Derrida argues that what can be iterated are not concrete performances, the absolute singularities of language events, but rather language unities (signs, statements, etc.). Following this line of reasoning, he argues that it is the iterability of language units that guarantees that language performances, in their uniqueness and non-repeatability, have a performative force. Does that mean that different discursive practices using identical language units necessarily produce the same effects? Again, to solve this problem we must turn to Foucault, who argues that the task is not to find a common identity of different discursive practices but rather to identify certain regularities within and between them, which can then be compared with other regularities. ${ }^{79}$ Foucault distinguishes between the uniqueness of enunciations and the repeatability of statements. It is worth quoting the central passages on this topic:

The enunciation is an unrepeatable event; it has a situated and dated uniqueness that is irreducible. Yet this uniqueness allows a number of constants—grammatical, semantic, logical—by which one can, by neutralizing the moment of enunciation and the coordinates that individualize it, recognize the general form of a sentence, a meaning, a proposition. The time and place of the enunciation, and the material support that it uses, then become, very largely at least, indifferent: and what stands out is a form that is endlessly repeatable, and which may give rise to the most dispersed enunciations. But the statement itself cannot be reduced to this pure event of enunciation [...] For a statement may be the same, whether written on a sheet of paper or published in a book; it may be the same spoken, printed on a poster, or reproduced on a tape-recorder; on the other hand, when a novelist speaks a sentence in daily life, then reproduces the same sentence in a manuscript that he is writing, attributing it to one of his characters, or even allowing it to be spoken by that anonymous voice that passes for that of the 
author, one cannot say that it is the statement in each case. The rule of materiality that statements necessarily obey is therefore of the order of institution rather than of spatio-temporal localization; it defines possibilities of reinscription and transcription (but also thresholds and limits), rather than limited and perishable individualities. [...] Whereas an enunciation may be begun again or re-evoked, and a (linguistic or logical) form may be reactualized, the statement may be repeated-but always in strict conditions. ${ }^{80}$

Following Foucault's argumentation, we can say that a statement-for example «Aldo Moro is a martyr»—can of course be repeated, but performativity depends on the mediality of signs or, in other words, the material embodiment of language. ${ }^{81}$ There is a substantial difference between whether the statement «Aldo Moro is a martyr» is pronounced by a government minister, a bishop, a journalist or a Fiat worker; and it is equally different if this statement is expressed during dinner with friends, said by a character in a movie, delivered during a commemoration broadcast on television, written in a newspaper or painted on the walls of a train station. The meaning of the statement may remain the same (as we will see, this is also not always the case) but its performative force depends on the context of apparition. The task of discourse analysis is, then, on the one hand, to analyze discursive practices in their different context of medial and material manifestation, and on the other, to compare them in order to find regularities and variations.

Foucault uses a series of terms to address the issue of repeatable materiality: re-inscription, re-evocation, re-actualization, repetition. What is at stake here can be circumscribed with this question: What are the conditions of possibility of the transfer of signs from one context to another? Or, to reformulate the question from the point of view of semio-pragmatics: What are the characteristics that a sign should have in order to have more success to be repeated, and relocated in a new pragmatic and hermeneutic context? The question of repeatable materiality is related to the discussion of iteration in Derrida's writings as well as Charles Sanders Pierce's type-token distinction. ${ }^{82}$ Both Foucault's and Derrida's discussion of the problem of repetition/iteration is only understandable if one is willing to reject the idea of the existence of an original type, from which all tokens would be de-

80 Foucault 1972, 101-105.

81 See Wirth 2002, 44.

82 See Wirth 2002, 47. 
rived. ${ }^{83}$ Both philosophers argue, though with different terminology, that there is not something like an absent original sign, statement, representation or idea, which could be iterated and thus presented through discursive practices and in different material and medial manifestations. Rather, discursive practices always iterate already existing signs and statements, that is, signs and concepts that were embedded in previous historical discursive practices. The basic thesis is that there is no transcendental source or origin of language, but that any use of linguistic forms always refers to forms previously used (some of which are archived or memorialized in various types of media). If one accepts the fundamental conception of the nature of language, then it becomes possible to grasp the function of iteration through and within discursive practices. The thesis is as follows: It is the customcreating iteration which increases the potential for further repetitions. The more widespread the signs, statements, and representations, both syncretically and diachronically, the higher their chances of being reiterated in further discursive practices increases. The analysis of martyrological representations as discursive practices that exert effects of power thus takes into account their materiality, exteriority and seriality (repetition). The success of martyrological representations depends on their repetitive materialization and medial manifestation in different discursive practices. Only in the massive spread of the martyr figure in public spaces can a stable and lasting «system of knowledge» emerge, through which the efficacy of the discursive practices is guaranteed. ${ }^{84}$

As previously mentioned, Foucault characterizes the effectiveness of discursive practices with reference to the correlation between knowledge and power. Discourse analysis must detect the «connection between mechanisms of coercion and contents of knowledge» ${ }^{85}$ in order to understand what allows contents of knowledge to constitute themselves as elements of truth and thus deploy effects of power. For Foucault, this allows us to understand the conditions of acceptability of a system of knowledge. Discursive practices exert effects on their recipients as well as on the acting subjects themselves. They can have the power to influence the way we perceive and experience others, things and events in the world as well as ourselves. When social actors speak, write, photograph, perform (here in the sense of bodily action) or film something-in short, when they make use of repre-

83 See Derrida 1988, 7.

84 Foucault 2007, 59.

85 Foucault 2007, 59. 
sentational systems ${ }^{86}$ - they do not simply report on or describe things as they are, but instead represent them in one way rather than another. In this way, they are not only able to affect how we perceive and experience reality, but also influence our imagination, our normative view of the world and, subsequently, our actions. Referring to Louis Althusser, we can call this the power of interpellation, namely, the ability to appeal to the receivers, consumers and re-producers of discursive practices and demand from them subjective positioning. Through the process of interpellation, individuals are «recruited» and «transformed» into subjects. ${ }^{87}$ We can also define this process as subjectification, referring to the process of constructing individual identity. This is not necessarily forced from outside, (it does not need to be an instrument of power used consciously by others), but it is often the result of self-allocation. The individual is able, through discursive practices, to incite its own subjectification and build its own identity. Interpellations are not able to produce only subjects, but collective identities as well. In fact, the subjectification process is almost always based on the distinction of belonging/not belonging to a certain collectivity. The distinction can be based on a differentiation in gender, race, nationality, political conviction and so on. Discursive practices then produce, in their receivers as well as in their producers, an ideological response, which launches mechanisms of subjective identification with a certain collectivity and delimitation from other forms of (existing or potential) collectivity. The construction of subjectivities and collectivities can be considered a result of discursive performances.

Judith Butler powerfully draws attention to the importance of performativity of discursive practices and, more generally, to the «reiterative power of discourse to produce the phenomena that it regulates and constrains.» ${ }^{88}$ Butler's research is important for this study because she links, adopting Foucault's thesis that the subject is always discursively constructed, the question of the performativity of discursive practices with the question of identification. By analyzing the process of «assuming a sex», she shows that «sexed identifications» are constructed through the means of discursive

86 See Hall 2013a, xvii.

87 See Althusser 2014, 188-194. In line with Foucault's thought, we can understand the interpellation by discursive practices not as an instrument of power used exclusively by the state apparatuses or the ruling class (as theorized by Althusser), but rather as a form of micro-physics of power, through which «docile subjectivities» are routinely produced. For more details in this regard, see Hanssen 2000, 97-157.

88 Butler 1993, 2. 
practices, which are regulated by the heterosexual imperative. Through the iteration of pre-existent and regulated discursive practices, individuals assume a specific identity over another. Stuart Hall argues that this concerns not only «sexed identifications», but all forms of social and political identification, and stresses the role played by the exclusion of what we could call counter-identities, which within discourses are represented as abnormal or abject: «all identities operate through exclusion, through the discursive construction of a constitutive outside and the production of abjected and marginalized subjects.» ${ }^{89}$ Furthermore, Hall highlights the intrinsic link between identificatory practices and the double-sided character of discursive subjection/subjectification. Discourse does not only construct certain subjectivities, (figures that are always specific to a specific discursive regime and a specific historical time), but also provides subject positions for identification. Individuals, as they cannot live and act outside certain given discursive formations, cannot assume an identity until they identify with those positions or figures constructed and sustained by means of discursive practices.

I argue that martyrological representations of Aldo Moro have the power to appeal to people and to produce identification with the republican nation-state. Through the consumption (and reproduction) of martyrological representations, individuals experience themselves as part of a political collective, which is (constantly) threatened by those who are outside, who are external to it. The state martyr figure is part of an ideological structure, whose main function is to construct a "good, normal and sane» inside and a «bad, abnormal and dangerous» outside. A fundamental point is that this twofold mechanism of identification is connected with the construction of a regime of truth. The political community and its dangerous outside are experienced as absolute, ahistorical entities. The assassination of Aldo Moro becomes a sort of hypostatized event that symbolizes a cosmic war between good and evil forces, between the nation state and its enemies.

This last point cannot be fully understood without taking into account what I call a mythical narrative of the nation state, where «myth» indicates an «absolutism of reality» (Absolutismus der Wirklichkeit)..$^{90}$ As a form of absolutism, the myth is a narrative that conceals precisely that it is a narrative, namely that it is only one way, among many ways, to represent and cognitively organize reality. One of the tasks of this investigation is to deconstruct this narrative, focusing peculiarly on its effects of power. Fou-

89 Hall 1996, 15.

90 Blumenberg 2014a, 10. 
cault stresses the intrinsic relationship between power and concealment strategies, arguing that "power is tolerable only on the condition that it masks a substantial part of itself. Its success is proportional to its ability to hide its own mechanisms. Would power be accepted if it were entirely cynical? For it, secrecy is not in the nature of an abuse; it is indispensable to its operation.»91 The task is then to unmask the instrumental, and consequently ideological dimension of the martyrological representation of Aldo Moro, along with its central role in the construction, acceptability and maintenance of nation state mythology, which functions to legitimate established power structures. In short, I consider the martyr to be the fundamental rhetorical figure in the modern mythical narrative of the nation state.

To summarize thus far, the discourse analytical approach to the martyrological representations of Aldo Moro and their performativity takes into account the following different aspects. Firstly, the martyr figure could not be performative and deploy effects of power if people did not recognize it, that is, if the martyrological representation of Aldo Moro had not preceded historically by other martyrological representations. It is because martyrological representations iterate and implicitly refer to previous historical, successful figurations - that the figure can successfully operate in its new pragmatic and hermeneutic context of appearance. The consideration of this aspect falls under the domain of the analysis of the martyr figure's signatures. Its task is to detect the «secret index» and the historical stratifications of the figure, as well as to «attempt to restore the conditions for the appearance of a singularity born out of multiple determining elements of which it is not the product, but rather the effect.» ${ }^{92}$ Secondly, discourse analysis describes the new pragmatic and hermeneutic context in which the martyr figure appears. Only by considering the particular social, cultural, mediatic, political and economic context of the event and its representations is it possible to identify and understand the peculiarity and uniqueness of the connotative and symbolical significance that the figure of the martyr takes on. Thirdly, the discourse analytical approach scrutinizes each martyrological representation in its temporal, medial and material context of appearance. In a following step, all martyrological representations of Aldo Moro are compared and placed in relation to each other in order to show their seriality and diffusion in public spaces and within different me-

91 Foucault 1978, 86.

92 Foucault 2007, 64. 
dia. This allows regularities and exceptions in the discursive formation to emerge.

The consideration of these last two aspects falls under the domain of the archeology of discourse. Archeology analyzes the processes of the shortage, regrouping and unification of the discursive formation. It seeks to describe the rhetorical organization and distribution of discursive practices and then identify which rules, criteria of selection, control, organization and canalization regulate their appearance. Starting from the positivity of the concrete representations of the killing of Aldo Moro, archeological analysis individuates the system of acceptability that makes a certain way of representing the event more acceptable than others. The efficacy and acceptance of representations within a discursive formation is proportional to the amount of their serial iteration. The main questions here will be: How do representations interact; how do they appear in the public space; and what mechanisms of selection, control, organization and canalization regulate their appearance?

\subsection{Unity of the Discursive Formation and Methodological Framework}

What are the characteristics of the discursive formation that this study seeks to examine? What are the grouping and unification principles that enable us to describe and analyze this discursive formation? More concretely, how can we unify and define the discursive formation that refers to the events of political violence, which is the starting point of this study-the kidnapping and killing of Aldo Moro? According to Foucault, the term «discourse» indicates first of all the "totality of all effective statements»" namely all spoken and written discursive events. At this level, one can speak of discourse in the singular. The strategic function of this first definition is twofold. On the one hand, it makes explicit the difference between discourse analysis and the analysis of language. Language is a «system for possible statements $[\ldots]$ that authorizes an infinite number of performances», while the field of discursive events is a "grouping that is always finite and limited at any moment to the linguistic sequences that have been formulated.» ${ }^{94}$ On the other hand, it serves to distance itself from other forms of unification of knowledge (books, oeuvres, science, etc.) in order to make it possible to describe and analyze other unities.

93 Foucault 1972, 27.

94 Foucault 1972, 27. 
The positivity of all discursive practices forms what Foucault calls the archive, that is, the «system of formation and transformation of statements» or, recalling Hall's operationalization of Foucault's discourse theory for cultural studies, the system of formation and transformation of representations. This archive is not simply, at least not only, a collection of all that has been said, written, or, more generally, represented in a certain culture or society, but also what «defines at the outset the system of [...] enunciability» as well as the «system of $[\ldots]$ functioning» or «mode of occurrence» of representations. ${ }^{95}$ In other words, the archive is not only an ensemble of memories, and past discursive and cultural practices, but also determines the horizons of what and how something can be represented, as well as the modes in which representations can occur in the public space. The archive thus not only contains all the discursive practices that can be iterated and recontextualized, but also determines the rules and modes of iteration and recontextualization themselves.

As Foucault highlights, «it is obvious that the archive of society, a culture, or a civilization cannot be described exhaustively; or even, no doubt, the archive of a whole period.» ${ }^{96}$ For this reason each archeological analysis has to identify and determine how to group discursive practices within a certain discursive formation. Since Foucault wrote Archeology of Knowledge, many different proposals on how to group discursive practices within a single discursive formation have emerged in scholarship. ${ }^{97}$ Foucault himself indicates four systems of formation, which concern a) the objects, b) the enunciative modalities, c) the concepts and d) the strategies of discursive formation. These systems of formations, Foucault argues,

must not be taken as blocks of immobility, static forms that are imposed on discourse from the outside [...]. By system of formation [...] I mean a complex group of relations that function as a rule: it lays down what must be related, in a particular discursive practice, for such and such an enunciation to be made, for such and such a concept to be used, for such and such a strategy to be organized. To define a system of formation in its specific individuality is therefore to characterize a discourse or a group of statements by the regularity of a practice. ${ }^{98}$

95 Foucault 1972, 129-130.

96 Foucault 1972, 130.

97 See Diaz-Bone 1999; Keller 2011; Jäger 2004; Hjelm 2011; Landwehr 2008.

98 Foucault 1972, 73-74. 
This means that every discourse analytical study must be designed individually, because each field of discursive practices has its own rules of formation. Within this study, the virtual corpus of sources of this search includes the totality of all the discursive practices in which, in one way or another, the kidnapping, imprisonment, and assassination of Aldo Moro are represented. From this point of view, violence itself is considered the extra-discursive object/event, or the referent of the group of discursive practices that this study wants to analyze. I call this a virtual corpus, because the amount of media referring to the kidnapping and assassination of Aldo Moro is enormous and it is therefore practically impossible to analyze them all in a single inquiry. For this reason, we need principles of selection that allow us to establish and define a concrete corpus. ${ }^{99}$ In an enquiry that examines historical discursive formations, it is important that the selected media and representations are numerous and distributed over a sufficiently long period of time. In this study, the time frame is almost four decades: from 1978 to the present.

The first principle of selection concerns the enunciative modalities of discursive formation. The focus lies here on all the discursive practices in which the events of violence are inscribed in a narrative, that is, the event is emplotted. In other words, this study addresses discursive and cultural practices configuring events, agents and objects as part of a larger whole, in which each part takes a place in the network that constitutes the narrative response to why, how, who, where, and when. The main features of the enunciation modes in which I am interested are: the presence of a teleological representation of the event indicating the causes, reasons, motives and goals that have determined what happened; the presence of opinions and moral judgments about the main perpetrators (the «guilty people») and the main victims (the «innocent people»); and the frequent use of rhetorical patterns and figures. The second principle of selection concerns the language forms used in the discursive practices. The focus here is on the use of language units (blood, martyr, witness, sacrifice, innocence, torture, accusation, guilt, etc.) and rhetorical patterns («He died so that the Republic lives»; «Moro's Passion view from the Pope»; etc.) which implicitly or explicitly recall and refer to the figure of the martyr. These language units and rhetorical patterns are found mainly in sources in which a historical, moral and/or political judgment of the events is inscribed into a narrative plot. The third principle of selection concerns the strategies within discursive formation. I understand «strategy» as a threshold concept that allows 
the correlation of Foucault's project of an archeological and genealogical analysis with his works on the constellation power/knowledge. In fact, in a famous lecture entitled Qu'est ce que la critique?, held in 1978 at the Sorbonne for the Société Française de Philosophie, Foucault prescribed three sets of methodological tools required to master the task of investigating the "conditions of acceptability» that produced power/knowledge «events»: the already known archeology and genealogy, to which he added the analysis of strategies. ${ }^{100}$ Archeology is described here as an analytical procedure that focalizes on the system of acceptability, while genealogy serves to discard the conventional monocausal model of derivation in favor of multiple «descendants» and investigate «conditions of apparition» that allow multiply determined historical singularities to be consolidated. Then he added a third tool, the analysis of strategies, which surveys the plurality of effects produced by a perpetually mobile, contentious agonistic field of struggles. In this and other lectures, ${ }^{101}$ Foucault redefined discourse, that is, discursive formations, as strategic force fields of ever-contending discursive acts. ${ }^{102}$

Given this redefinition, this study takes into account sources in which there are discursive practices in competition with other discursive practices. The dimension of struggle between different representations of the event of violence is both a selection and an analytical criterion. By focusing on the agonistic element within discursive practices, it becomes possible to analyze and compare their effects on the whole discursive formation. The central task of analyzing strategies is to show that in the struggle between discursive practices, between ways of representing the event of violence, some have more success than others, thus becoming the models for further representations. This therefore serves to bring out a regularity that produces a hegemonic model of representation, as well as to individuate alternative, anti-hegemonic representations.

The concrete corpus of sources analyzed in this investigation includes a wide range of media and modes of representation. The examination of different media and modes is a methodological challenge: different semiotic forms characterize the modes, while media have their own mechanisms of production and specific strategies of mediation. ${ }^{103}$ Discourse analysis is a

100 See Foucault 2007, 41-81.

101 See especially Discourse on Language and the lectures held at the College de France in 1975-1976: Foucault 1972, 215-238; Foucault 2003.

102 See Hanssen 2000, 97.

103 See Kress/van Leeuwen 2001, 24-44. 
theoretical and methodological framework, which makes it possible for us to compare different modes of representation with regard to their appearance and interaction in the public space. Different media «employ» discursive practices, and at the same time are also elements of the infrastructure that organizes, controls and selects discursive practices into an ordered system of knowledge and representation.

The primary sources analyzed in this study are articles published in seven Italian newspapers: Corriere della Sera, La Repubblica, La Stampa, L'Unità, Il Popolo, Avanti! and Lotta Continua. The first three were and still are the newspapers with the highest national circulation (except for the sports information newspaper Gazzetta dello Sport, which today is ranked third, followed in fourth place by La Stampa). ${ }^{104}$ Since this study aims to analyze the use and performativity of martyrological rhetoric on a national scale, these newspapers are of great interest. L'Unità, Il Popolo and Avanti! were official organs of the three major parliamentary parties-the Italian Communist Party (PCI), the Christian Democracy (DC) and the Italian Socialist Party (PSI) - during the Moro affair and until the beginning of the nineties, while Lotta Continua was the newspaper of far left extra-parliamentary organization of the same name. These last four newspapers are an important source for understanding the relationship between ideologies and political positions, discursive strategies and the representation of the events. Although I examined the articles published in these newspapers throughout the year 1978, I place my focus on newspaper articles published in the period ranging from March 16, the day of the kidnapping, to May 14, the day after Aldo Moro's public funeral. The results of my analysis of the newspapers published in this time frame are presented in the fifth and sixth chapters. The seventh chapter addresses and analyses different media productions in a much broader time frame, namely from 1979 to 2016. Here the focus lies on the different practices of memorialization within different media. As mentioned in the introduction, here the analysis focuses on memorialization and commemoration of Aldo Moro, the representation of the events of political violence in literature and cinema, and finally on the debate emerging in the Italian press in response to the launch of an initiative promoting the beginning of a process for the beatification and canonization of Aldo Moro by the Catholic Church.

The sources have different semiotic modes (images, written and spoken words, images-in-motion, etc.) within different media (newspapers, maga-

104 See http://www.adsnotizie.it/dati_ante98.asp (accessed May 6, 2016); http://ww w.adsnotizie.it/_dati_DMS.asp (accessed May 6, 2016). 
zines, television, movies, books, records, etc.). My discourse analysis must simultaneously take into account the specificity of individual sources and create an interpretive space in which these can be compared and placed in relation to each other. In view of this dual task, my methodological process is divided into four steps: context analysis (contextual framework), macroanalysis, micro-analysis, and analysis of the discursive formation. This approach combines the methodological tools of historical discourse analysis $^{105}$, critical discourse analysis ${ }^{106}$ and multimodal discourse analysis ${ }^{107}$.

Context analysis distinguishes between four levels: each discursive practice-each representation-stands in a situational, medial, institutional and historical context. ${ }^{108}$ Firstly, on the level of contextual analysis, this investigation must clarify the position (the situation) in which the particular discursive practice occurs, that is, who does what at what time? Furthermore, the occasion on which the discursive practice occurs (Easter Day, the funeral of Aldo Moro, the annual anniversary of the event, among others) must not be neglected. The same applies to the media (party newspapers, monuments, etc.) and the type of document in which the discursive practice occurs (editorial, novel, documentary, etc.). The institutional context must consider the institutional setting under which the document emerged. This is particularly important with regard to the citation or publication of government documents or procedural acts, press releases, party statements, etc. Finally, the entire historical context must be considered, that is, the overall political, social, economic and cultural situation.

Macro-analysis examines the general structure and surface of media representation. As regards textual sources, in this study the following aspects will be taken into consideration: material texture, formal/graphic design (photos, drawings, headings, inscriptions, etc.), the disposition in individual sections, emplotment, the way the author/speaker may stand in the document, the principles of representation or mediation strategies, and the presence of key topics and subtopics. As regards audiovisual sources, macro-analysis follows the methodology of cinematic diegesis and must consider the following aspects: figures and characters (types, roles, situations, conflicts, action structures), spaces (the function of space within the narrative, connections/breaks between space and action) and the narrative

105 See Landwehr 2008.

106 See Jäger 2004.

107 See Kress/van Leeuwen 2001.

108 See Landwehr 2008, 107; Jäger 2004, 176. 
perspective (the relation between characters, space, time, audience position, connections/breaks between different narrative perspectives). ${ }^{109}$

The micro-analysis of textual sources focuses on argumentation, rhetoric and style, which is found on the text level, sentence level, and word level. ${ }^{110}$ On the text level special consideration is given to patterns of argumentation, rhetoric structure and the acting causalities, hierarchies and categorizations. The analysis of the sentence level is concerned with the arrangement of main and subordinate clauses, the sentence types and the rhetorical figures (metaphors, prefigurations, etc.) that are used. On the word level, the denotative or connotative uses of words are determined. The micro-analysis of audiovisual media examines the «aesthetic of the surface», which encompasses the following aspects: image composition/design (framing, image composition, camera setting, camera perspective, light, color), montage (cutting style, rhythm), and the auditory level (origin of sounds, noise, music, language). ${ }^{111}$

The method of analyzing the audiovisual sources adopted here also uses the categories of socio-semiotic multimodal discourse analysis. These categories are not limited to linguistic texts, but are applicable to all semiotic systems, and are therefore pan-semiotic. Language and visual communication realize the same far-reaching and comprehensive systems of meaning, but have their own means, forms and restrictions in expressing them independently. From the basic assumption of the multimodality of communication results the concept of multimodal texts. These texts consist of different semiotic modes, such as music, speech, intonation, image, physical expression, etc. This study considers its audiovisual sources to be multimodal texts.

The three methodological steps just presented relate to the analysis of different media - the discursive practices embodied in the media-in their singularity. The fourth methodological step focalizes on regularities and exceptions within the whole discursive formation. It strives to identify recurrent and deviating words, motifs, rhetorical figures, images, themes, etc. as well as the central and most influential social actors. The aim here is primarily a matter of reconstructing and describing the complex interrelations between structure and action, and between discursive formation and discursive practices. Ultimately, in the analysis of practices as well as of the

109 See Bienk 2008.

110 See Landwehr 2008, 118-134.

111 See Bienk 2008. 
entire discursive formation, the main question relates to the «establishment of a legitimate worldview.»112

112 See Landwehr 2008, 128. 


\section{Signatures of the Martyr Figure}

\subsection{The Martyr Figure as a Counterpart of the Sovereign}

The figure of the martyr has been investigated from many points of view through different theoretical and methodological models. In recent years, it has been the subject of research in various academic disciplines. Since the attack on the Twin Towers on September 11, 2001, greater attention has been paid especially to the ideologies of martyrdom in Islamic culture and society. ${ }^{1}$ Beyond terrorist attacks, other contemporary social phenomena also contributed to the proliferation of studies and research on the topic, such as self-immolation and other forms of physical destruction or injury during the Arab Spring and the Arab-Israeli conflict. ${ }^{2}$ All these events have re-drawn attention to the phenomena and contexts of political violence.

Studies on martyrdom are heterogeneous. ${ }^{3}$ Both general and specific historical studies exist: for example, Paul Middleton describes the general development of martyrdom, as a concept and as a social phenomenon in Christianity, Islam and Judaism, while other studies focalize on the role and function of the martyr figure in specific historical contexts. ${ }^{4}$ Moreover, in recent years many anthologies were published which examine martyrdom as a cultural phenomenon in relation to, among others, visual art, film, theater, poetry and prose. ${ }^{5}$ Other researchers specifically focus on the issue of martyrdom as a «religious-political challenge». 6

Although a plurality of interests, questions, and hypotheses exists, one can distinguish between essentialist and constructivist approaches to the martyr figure. The essentialist position attempts to define the «being and essence of the martyr», which is obviously highly problematic, since, by distinguishing true (and good) martyrs from false (and bad) martyrs, it can

1 See Gambetta 2005; Pedazhur 2006; Kepel 2015; Ali/Post 2008; Juergensmeyer 2008.

2 See Khalili 2007; Allen 2006; Allen 2009; Fierke 2013.

3 Key works on martyrdom include Bowersock 2002; Boyarin 1999; Castelli 2004; Wicker 2006; Cook 2007; Middleton 2011; Mitchell 2013.

4 See Middleton 2011; Hung 2008; McWilliam 1995; Spiegeleer 2014.

5 See Krass 2008; Horsch 2011; Pannewick 2004; Weigel 2007a.

6 Niewiadomski 2011. 
and often is used by certain individuals or social groups to deny the martyr role and status to other individuals or social groups. Those who want to prevent the martyr figure from being «exploited» by others, always advocate the essentialist and normative approach. Those who choose the essentialist perspective often decide on the basis of ethical, religious and/or political convictions. The essentialist approach has its historical roots in Christian theology, which since its beginnings has sought to establish criteria in order to determine the essence of martyrdom. ${ }^{7}$ But the essentialist perspective does not only belong to the Christian theologies of past ages. The essentialist definition can also be found in contemporary debates and writings about phenomena of political violence. As Sigrid Weigel notes,

the discrepancy between the European conceptions of martyrs, which have their origin in Christian history, and television pictures from the international battlefields, with scenarios of Shi'ite or Sunni worshiping martyrs, often triggers a discussion as to whether the suicide bombers [...] are strue martyrs . [...] The criteria for who is recognized as a martyr are always formulated from the perspective of a certain confession. ${ }^{8}$

Today, this approach is often criticized in academic writings as a form of dangerous cultural essentialism. ${ }^{9}$ In fact, one of the main characteristics of the new academic orientation in dealing with the topic of political violence and the figure of the martyr is the transition from an essentialist to a constructivist approach. Where the essentialist approach tends to involve a fixed definition of martyrdom-based on the definition, an event is then determined to be an act of martyrdom or not-, the constructivist approach instead analyzes the social and cultural production of the figure of the martyr and the self-allocation of the martyr role. The fundamental question asked in current research on martyrdom is therefore: How and for what purpose are martyrs «made»? However, despite the criticism of essentialist approaches and although the issue is discussed in different ways and from different perspectives, many researchers support the thesis that the emergence of martyr figures and the allocation of martyr roles have a polit-

7 Clement of Alexandria, who condemns «voluntary martyrdom» as a form of «selfkilling», was the first to distinguish between «true» and "false» martyrdom; in this regard see Middleton 2014, 123.

8 Weigel 2007, 16.

9 See Weigel 2007b, 16-19; Krass/Frank 2008, 8; Middleton 2011, 1-30. 
ical function. ${ }^{10}$ What does this political function consist of? Why does the figure of the martyr always, or at least so often, emerge in relation to contexts of political struggle?

In the second edition of the Encyclopedia of Religion, Samuel Klausner defines martyrdom as an act of self-sacrifice, which «imbues economic and political conflict with sacred meaning " and «aims to reduce political authority to ineffectiveness by challenging the sacred basis of the legitimacy of the adversary's authority. [...] The martyr [...] is a sacred symbol of an authority around which the society rallies.» ${ }^{11}$ Although Klausner does not express it explicitly, at the roots of this view there is undoubtedly the idea, exposed by Hubert and Mauss, that sacrifice is a sacrum facere, a ritual practice that consecrates the sacrificial victim. ${ }^{12}$ Through sacrifice, the victim passes from the realm of the profane to the realm of the sacred (in Durkheim's sense of the terms). Martyrdom, as an act of self-sacrifice, consecrates both the victim and the political authority of the social group to which the victim belongs. The self-sacrifice of the victims of political violence legitimizes a new political order.

Another important issue in current research on the martyr figure is the distinction, which plays a decisive role in the mimetic theory of René Girard, between the sacrifice of the scapegoat and the self-sacrifice of the martyr. According to Girard, at the core of sacrifice there is substitution, that is, fury felt toward one party is redirected toward a surrogate scapegoat, who was chosen only because of his or her vulnerability and dispensability. ${ }^{13}$ The sacrificial object is thus an innocent who pays the debt of a guilty party. From this point of view, sacrifice is a ritual practice through which a community is reconciled to itself by the extermination of a victim. By contrast, Girard describes (Christian) martyrdom as the annulment of the «violent sacred», because of its recognition of the victim's innocence. ${ }^{14}$ Maria Grazia Recupero dedicates an extensive anthropological-philosophical work to martyrdom, in which the Girardian conceptualization of martyrdom is well summarized. The general thesis is that in the historical transition from archaic myths to the mythical-ritual structure of Christianity, disclosure of the sacrificial mechanism occurred, through which sacrifice assumed a political function. The strength of the archaic myth-in which

10 See Weigel 2007b, 13-15; Fierke 2013; Krass/Frank 2008, 7-21; Recupero 2011.

11 Klausner 2005, 5738.

12 See Hubert/Mauss 1964.

13 See Girard 1979.

14 See Kirwan 2009, 921. 
the sacrifice of the scapegoat is able to end a social crisis - is its ability to «hide» the victim. Martyrdom, in contrast, showcases the innocence of the victim and thus the arbitrariness of sacrifice. In other words, the archaic sacrifice legitimates the status quo, whereas the Christian anti-sacrifice constitutes and legitimates the future community. ${ }^{15}$

Karin Fierke, a researcher in international relations, also supports the argument that the martyr figure delegitimizes the status quo and legitimates new forms of political community. She describes sacrifice as a «form of life» or a practice which is visible across cultures yet is embedded in different systems of meaning. ${ }^{16}$ Unlike Girard and Recupero, she argues that self-sacrifice, rather than being a substitution, «is an act of speech in which the suffering body communicates the injustice experienced by a community to a larger audience.» ${ }^{17}$ Since the sacrifice of the material body is an act that communicates without words, it must be understood as an inversion of the speech act, that is, the illocutionary act, which has a certain force in the act of saying. By contrast, she considers self-sacrifice as a perlocutionary act because it produces effects in the feelings, thoughts or actions of the audience. She criticizes Girard's argument because it is based on the distinction between pre-modern practices of sacrifice and their elimination in modernity, while contemporary self-sacrifice is a political weapon, which crosses the boundaries between the two:

On the one hand, the frameworks for attributing meaning to the act are $[\ldots]$ at least in part religious, but also refer to international laws relating to human rights. On the other hand, the use of self-sacrifice as a political weapon has been facilitated by the development of a global, and particularly a visual, media. [...] In this respect, acts of political self-sacrifice are situated across three different ways of organizing life: the pre-modem religious; the rationalized modern state, which is part of the international system; and the globalizing postmodern culture of the media. Against this background, political self-sacrifice may play a role in bringing alternative forms of community into being. ${ }^{18}$

From this point of view, she argues that political self-sacrifice in modernity does not involve the substitution of a marginalized victim, by which existing power structures are reinforced and legitimized, but rather communi-

15 See Recupero 2010, 20.

16 Fierke 2013, 33.

17 Fierke 2013, 37.

18 Fierke 2013, 38. 
cates a political message on behalf of a marginalized community, potentially contributing to its regeneration. ${ }^{19}$ On the basis of four examples from the period after World War II, she argues that an injured or dead body can function as a medium of an experienced injustice. ${ }^{20}$ Fierke compares the functioning of the act of self-sacrifice within modern and contemporary societies with «traditional» ritual action, which transforms the profane into the sacred. ${ }^{21}$ She indicates formality, traditionalism, invariance, and shared features with theatrical performance as main characteristics of successful ritual actions. ${ }^{22}$ She quotes Chaterine Bell, who states that «ritualization is the way to construct power relations when the power is claimed to be from God, not from military might or economic superiority.» ${ }^{23}$ Self-sacrifice, she argues, is a sacralizing act that transfers the divine qualities of the sacrificed victim to the marginalized community. According to this view, the martyr is the person who, sacrificing himself for the sake of an oppressed community, makes the injustice and arbitrariness of violence exercised by those who hold political authority visible on his or her body and, at the same time, sacralizes the marginalized community. Fierke refers explicitly to Giorgio Agamben's conceptualization of «bare life»:

The visualization of bare lifes in images of the body is a central element of the emotional impact [...]. The observer is faced with bare life, stripped of its social meaning, standing alone and facing his or her own mortality [...] The sight of the suffering body represents a confrontation with bare lifes that is followed by a struggle to inscribe it with meaning, which is spectacularized by the visual nature of the performance. ${ }^{24}$

Thus, the visualization of bare life not only delegitimizes dominant power structures, but also potentially legitimizes alternative forms of community. According to Fierke, the transformative power of self-sacrifice lies in the reconstitution of the boundaries surrounding the individual body that is sacrificed and a larger «body politic»:

19 Fierke 2013, 54.

20 The hunger strikes of 1980-1981 in Northern Ireland; the martyrdom of the Polish Roman Catholic priest Popieluszko in 1984; the self-immolation of Buddhist monks in Vietnam in the early sixties; self-sacrifice in the Middle East.

21 Fierke 2013, 44.

22 Fierke 2013, 40-44.

23 Bell 2009, 116.

24 Fierke 2013, 79, 101-102. 
The agent of political self-sacrifice, often referred to as a martyr, becomes the embodiment of the suffering nation. If Hobbes' Leviathan $[\ldots]$ is the symbol of the authoritarian sovereign, who embodies the people, the martyr is the embodiment of the nation, which seeks to transcend its humiliation through a restoration of dignity and sovereignty. The two images, Leviathan and the martyr, are not mutually exclusive in a situation of this kind but are, rather, the site of contestation and a struggle for recognition..$^{25}$

In fact, the main goal of her study is to contrast the image of the Leviathan, in which the body of the biblical monster contains the peoples of the state, with the image of the martyr as the symbol of resisting people when the state violates its commitment to protect. Finally, she argues, «selfsacrifice is a performance of speech in a context in which speech has been silenced. It expresses a desire to have a voice.» ${ }^{26}$

Interestingly, we find a very similar theoretical model in Sigrid Weigel's studies on the martyr figure. ${ }^{27}$ She assumes that in the violent death of the martyr, life is reduced to its purely fleshly dimension (unsurprisingly, she too refers to the concept of «bare life»), and that precisely this reduction leads to the sacralization of the dead body. Death acquires a metaphysical sense and gains the status of a profession of faith. The body itself becomes a witness of truth. The martyr is the paradigmatic figure of one who, even in death, remains steadfast in his or her faith. In reference to Carl Schmitt, Weigel sees the martyr as a dialectical negation of the sovereign. For those who are brutalized by the sovereign power and who live in submission, opting for martyrdom represents the ability to act "sovereignly». If the sovereign is defined as the one who decides on the state of exception, who has power over «bare life», the martyr is the one who decides in the state of exception. ${ }^{28}$ Weigel also observes a return of the figure of the martyr in secularized societies and considers it an ideal medium for ritual reproduction. Through photography, film and the Internet the reproducibility of martyrological representation has increased exponentially. ${ }^{29}$ Weigel describes martyrs as «media of ritual reproducibility»: images, narratives and rituals contribute to the spread of the martyr figure, which serves as a model for imitation. The perfect interplay between the martyr figure and the most

25 Fierke 2013, 53.

26 Fierke 2013, 247.

27 See Weigel 2006; Weigel 2007b.

28 See Weigel 2007b, 12.

29 See Weigel 2007b, 21. 
advanced media technology, she argues, can only be understood by analyzing the structure of the martyr's "performative, ritual reproducibility». ${ }^{30}$ Furthermore, the compatibility of global media technology with religious symbols and cults is guaranteed by images: in the era of the digital reproducibility of images, the dynamics of ritually re-produced martyr figures are accelerated and amplified. ${ }^{31}$

This means that to fully understand the performativity of the martyr figure, it is not enough to analyze martyrdom as a performance of the body, in the sense of self-sacrifice as an act of speech, but also the performativity of discursive practices and the manifestation and materialization of these practices in the public space. Here too, Weigel and Fierke seem to follow a similar interpretive path. In fact, the latter explicitly states that the sacrificial act alone is not sufficient to produce the delegitimization of the political authority in charge. The act itself can be described and represented not only as a form of martyrdom, but also as a suicide (or murder-suicide in the case of suicide bombings). This depends on the attribution of meaning, that is, how the act is represented. Based on her empirical study, Fierke identifies a formal constant in the dynamics between the act and its linguistic representation. In all four cases she analyzes, the community to which the agent of self-sacrifice belongs, tends to politicize and sacralize the act by representing it martyrologically. Conversely, the social actors who recognize the sovereign power in force tend to depoliticize the act by representing it as a suicide or murder-suicide. Referring to Wittgenstein, Fierke proposes a distinction between two language games:

The first language game of martyrdom provides a structure of rules within which the resistance gives meanings to acts of political self-sacrifice. The martyr is a witness to injustice, which refers to the humiliation of a population vis-à-vis what is defined as an occupying power, as distinguished from the historical but oppressed community that the resistance seeks to restore. This draws on a larger international discourse on human rights, which prohibits humiliation and highlights the dignity of all people. [...] The second language game expresses the meaning structure employed by state authorities, which depoliticizes, by identifying the actor as a criminal or terrorist, whose death may be attributed to ssuicides. The naming of the criminal or terrorist is part of a securitizing move that identifies an existential threat to the state,

30 Weigel 2007b, 20.

31 See Weigel 2007b, 21. 
which links to a larger international discourse of sovereignty and justifies the punishment or elimination of this extremist element. ${ }^{32}$

According to Fierke, there are thus two different language games that operate on the basis of two competing discourses - the discourse of sovereignty and the discourse on human rights-which refer to the same event. The act of political self-sacrifice is, from this point of view, the site of a discursive contestation.

We have thus reached the heart of this study: the role of language and discourse in the construction and contestation of martyr figures. Let us attempt to summarize the aforementioned considerations. Firstly, as pointed out by Fierke, the act of self-sacrifice alone is not enough to make a martyr. A martyr must be represented and then become socially recognized as a martyr. In other words, in order for someone to be able to emerge as a martyr figure, it is not sufficient for an audience to witness the martyr's violent death; someone must represent the event of violence as a form of martyrdom. From this point of view, we can define martyrological representations as perlocutionary discursive practices through which the victim referred to is sacralized and its sacredness transferred to the oppressed community. Second, as suggested by Weigel, the consolidation and diffusion of martyr figures is directly proportional to the amount and serial production of martyrological representations. The reproduction of the figure in the media increases its performativity. This means that to understand martyrdom it is not enough to analyze it as an act of bodily self-sacrifice; it is also necessary to analyze the serial representation of an event of violence as an act of martyrdom. The focus thus moves from the attitudes and subjective intentions of social actors to the mechanisms of production and reproduction of martyr figurations.

But there is an element that Fierke's and Weigel's theoretical models seem unable to integrate and explain: the emergence of the state martyr figure. Both understand the martyr figure as a counterpart of the sovereign, since they focus on martyrs from communities without political legitimation or, more precisely, communities whose legitimacy is questioned by so-called sovereign states. The case of the martyrological representation of Aldo Moro reveals a completely different situation, a kind of exception, which is difficult to explain with these two theoretical frameworks. First, Aldo Moro wrote on several occasions that he had no intention of sacrificing himself for the national community and thus refused the

32 Fierke 2013, 48. 
allocation of the state martyr role. Fierke's model of explanation does not seem to be adequate in analyzing the martyrological representation of Aldo Moro for the simple reason that her study focuses on willing martyrs. Second, Weigel and Fierke do not seem to consider the possibility that acts of violence perpetrated by non-state organizations may be directed against representatives of the sovereign power and that the consecutive death of a holder of political authority may be represented as a form of martyrdom. Third, there is a problem concerning Fierke's distinction between two different and separate language games, according to which martyrdom is always somehow an appeal to human rights, while established political authorities always refer to the discourse of national security. In fact, as we will see, the Italian government, major political parties and the established media argued that Aldo Moro had to sacrifice himself and accept his role as a state martyr in order to save the Italian State and its institutions. Conversely, Aldo Moro argued that it was iniquitous to sacrifice him with the argument of national security, because the state had the duty to preserve every single human life. We are therefore faced with a very strange situation: Moro was represented as a state martyr, whose death was necessary to safeguard national security. The situation is even more complicated, because the choice of not dealing with the Red Brigades to obtain the release of Moro was justified with the argument that the Italian State could not deal with terrorists, because they endangered the safety of the citizens. In other words, Moro had to sacrifice himself to ensure that the state could continue to defend human rights. Fourth, in the case of Aldo Moro, the figure of the martyr operates both as a political body of the community-the people of the Italian Republic_-as well as a legitimizing figure of dominant power structures and relations.

In a recent publication, Paul Middleton presents some general reflections on martyrdom, which can help shed some light on the phenomenon of state martyrology. He perfectly sums up the role of political purposes in the cultural processes of the «creation» of martyrs as well as their contestation:

Religious, political, and even academic theological accounts of martyrdom today function primarily as identity markers which reinforce religious, cultural, national and even trans-national group boundaries. The distinction between a «martyr $>$ and a «terrorist is the difference between two stories; [...] Martyrologies still function as a means of creating group identity, through sympathy or rejection of particular martyrs; martyrology demands people take sides. [...] Martyrs can be appropriated or even «created in order to legitimate religious or political 
causes [...] Significantly, this can be the case whether or not the «martyr intended to die for that cause, or even counted themselves among the movement which goes on to celebrate their martyr status. [...] Martyrologies can be created independently of the particular convictions of the martyr . [...] In the end, martyrdom cannot be defined; martyrdom is what martyrdom does; a narrative that creates or maintains group identity, by holding up an ideal representative of the community, who chose to or is made to die for its values. ${ }^{33}$

Thus, according to Middleton, martyrs can even be created when there is no intentionality of self-sacrifice. This means that, in some cases, martyr figures can be constructed only through the serial and repetitive representation of events of violence as martyrdoms, which is exactly what happened with Aldo Moro. In the case of the Christian Democrat politician, it makes no sense to speak of an act of self-sacrifice, since we know that Moro rejected self-sacrifice «in the name of an abstract principle of legality.» ${ }^{34}$ It is thus only and exclusively through language and discourse that the victim was sacralized and through which its sacredness was transferred to the national community.

\subsection{Sacrifice, Scapegoat, Martyrdom}

Sacrifice, from the Latin sacrificium (sacer, «holy»; facere, «to make»), carries the connotation of a religious act that sanctifies or consecrates an object. Offering is often used as a synonym (or as a more inclusive category in which sacrifice is a subdivision) and means the presentation of a gift (Latin offerre, «to offer, present»). Romance languages contain words derived from both Latin words. The German Opfer is generally understood as a word deriving from offerre, but some derive it from the Latin operari («to perform, accomplish»). Some scholars have tried to distinguish between offering and sacrifice, such as for example the cultural anthropologist Jan van Baal, who defines offering as «every act of presenting something to a supernatural being» and sacrifice as «an offering accompanied by the ritual killing of the object of the offering.. ${ }^{35}$ This definition can be criticized as too narrow, however, «since killing» is applied only to living beings, human or an-

33 Middleton 2014, 128-130.

34 Moro 2008b, 8; it.: «[...] in nome di un astratto principio di legalità.».

35 van Baal 1976, 161. 
imal, and thus does not cover the whole range of objects used in sacrifice as attested by the history of religions. ${ }^{36}$ Nevertheless, The Encyclopedia of Religion indicates three essential elements of sacrifice, which are somehow present in van Baal's definition: sacrifice as a gift or a payment to some supernatural or transcendent entities; destruction, which can be applied both to unanimated objects and to living beings; the removing of something from a human's disposal, which is transferred to the supernatural or transcendent recipient. In a general morphology or topology of sacrifice, the Encyclopedia distinguishes between the sacrificer (or offerer), the sacrificed material, the praxis or rite of sacrifice, the place and time of sacrifice, the recipient of sacrifice and the intention of sacrifice.

For a long time, scholars have tried to develop theories on the origin of sacrifice. In Primitive Culture: Research Into the Development of Mythology, Philosophy, Religion, Art, and Custom, published in 1871, Edward Burnett Taylor argues that sacrifice was originally a simple business transaction of do ut des («I give so that you will give in return»). The English anthropologist supposes that «higher» forms of religion, including monotheism, gradually developed out of animism as the «earliest» form. According to Taylor, sacrifice as abnegation or renunciation developed only gradually from the practices of making gifts to spirits resident in nature, gifts through which the spirits could be bribed; but even when it was developed, Taylor argues, the do ut des idea continued to be operative for a long time in the later stages of religion.

18 years later, William Robertson Smith developed a theory of sacrifice for the Semitic world, which he regarded as universally applicable, in his masterpiece Lectures On the Religion Of the Semites. Here, he criticizes Taylor's theory for not paying sufficient attention to the function of sacrificial practices, which according to him was the establishment or maintenance of social community. Assuming that the shared core of the earliest forms of religion (among the Semites and elsewhere) was the belief in a theriomorphic tribal divinity with which the tribe had a blood relationship, Smith defines sacrifice as a ritual communal meal in which a totemic animal (which under ordinary circumstances was not to be killed) was slain and eaten in order to renew the community. According to Smith, in this ritual the recipient, offerers and victims were all of the same nature; therefore, sacrifice was originally a meal in which the offerers entered into communion with the totem. 
In their famous Essai sur la nature et la fonction du sacrifice, published in 1898, Henri Hubert and Marcel Mauss reject both Taylor's and Smith's attempts to develop a theory of sacrifice, arguing that their mistake was the attempt to identify the essence of sacrifice by searching for its origin in ancient and primitive cultures. The problem with Taylor's theory is that «this theory described accurately the phases of the moral development of the phenomenon» but «it did not account for its mechanism», while «the great flaw in [Smith's] system is that it seeks to bring the multiplicity of sacrificial forms within the unity of an arbitrarily chosen principle. ${ }^{37}$ According to Hubert and Mauss, Smith's theory arbitrarily chooses totemism as a universally applicable point of departure and reconstructs the development of the forms of sacrifice solely by analogy and without adequate historical basis. In particular, Hubert and Mauss criticize Smith for claiming to establish a historical sequence and a logical derivation between the communion sacrifice and other kinds of sacrifice. Instead of deriving all forms of sacrifice from one soriginal communion sacrifice, they want to demonstrate that «the expulsion of a sacred spirit, whether pure or impure, is a primordial component of sacrifice, as primordial and irreducible as communion. ${ }^{38}$ Hubert and Mauss summarize their thesis with the famous formula, according to which

Sacrifice is a religious act which, through the consecration of a victim, modifies the condition of the moral person who accomplishes it or that of a certain object with which he is concerned. ${ }^{39}$

The victim is not holy by nature, as it is in Smith's theory. Rather, the consecration is effected by destruction, and the connection with the sacral world is completed by a sacred meal. Implied here is the view (which returns to Émile Durkheim) of the French sociological school that the sacral world is simply a projection of society. Ultimately, Hubert and Mauss consider the recipient of sacrifice to be simply a hypostatization of society itself.

The idea that the consecration of the sacrificial object is obtained by its destruction deeply influenced theories of martyrdom. This is true not only for Samuel Klausner's definition of martyrdom, but also for Fierke's conceptualization of martyrdom as an act of self-sacrifice-that is, the destruction of one's own body-, through which the sacrificed self becomes sa-

37 Hubert/Mauss 1964, 2, 5.

38 Hubert/Mauss 1964, 6.

39 Hubert/Mauss 1964, 13. 
cred and with him the community to which the martyr belongs. The same can be said of Weigel's understanding of martyrdom, who, referring explicitly to Hubert and Mauss, argues:

If, in the case of the archaic or pagan sacrifice, in whose ritual the gift to the gods is sanctified, the moral change of the sacrificer [des Opfern$d e n]$ goes hand in hand with the transformation of the sacrificed [des Opfers/Geopferten] into something sacred, a radical change comes into play with the martyr. For here, it is one and the same person who is killed or kills himself, and who, at the same time, becomes sacred and undergoes the moral transformation that predisposes this person to become a saint. ${ }^{40}$

I believe that this way of conceiving either the sacrificial ritual, in which a sacrificer destroys an object other than himself or herself, or martyrdom, in which the agent of sacrifice and the person sacrificed are the same, is highly problematic because it is based on the silent premise that sacralization or consecration is primarily the result of ritual practice. Though Fierke and Weigel recognize the fundamental role of language, rhetoric and discourse in the construction (and contestation) of martyr figurations, they still think of the function and performativity of martyrdom in ritualistic terms. But, as the case of Aldo Moro perfectly exemplifies, there can be situations in which sacralization is achieved only by means of discursive practices - that is, when an event of violence is represented linguistically, rhetorically and narratively as a ritual, a sacrifice, a form of martyrdom. I do not want to say that ritual practices do not have a sacralizing functionthe history of religion is full of such rituals. What I am saying is, in fact, very simple: no sacrifice or martyrdom has performative efficacy unless it is supported by a mythical narrative and that, in the absence of a ritual, it is possible to sacralize a person, to produce the sacred, with only the aid of what we can define as discursively constructed mythology.

There is a second reason why I am very skeptical of the attempt to conceive sacralization or consecration as the outcome of a ritual act, in which an object or a person must be sacrificed. I suspect that behind this theorization lies a universalistic conception, according to which human social life is governed by man's natural disposition toward aggressiveness, which results in a certain cyclical, eternal return to violence. The idea of an intrinsic and therefore universal relationship between sacrifice, sacralization and violence, which, in my opinion, implicitly operates in the theory of $\mathrm{Hu}$ - 
bert and Mauss, is the core of René Girard's thought. In fact, for Girard, who tries to combine Hegel's analysis of the dialectic struggle for recognition and Nietzsche's notion of ressentiment, each human being is driven by desire for what others have or want. He calls this «mimetic desire». ${ }^{41}$ This causes a triangulation of desire and results in conflict between the desiring parties. This mimetic contagion increases to a point where society is at risk, and it is at this point that the scapegoat mechanism is triggered. This is the point where one person is singled out as the cause of the trouble and therefore expelled or killed by the group. Social order is restored in people's contentment that they have eliminated the cause of their problems by removing the scapegoated individual; and then the cycle begins again.

Despite Girard criticizes «the formalistic tradition of Hubert and Mauss", arguing that their problem is in the belief that "sacrificial rites have no basis in reality», his scapegoat theory reproduces their idea of sacralization as the outcome of ritualized destruction, that is, violence. ${ }^{42}$ The main problem here is not the definition of sacrificial practices as a ritualized form of violence-a definition that, when the sacrificial object is a living being, can hardly can be denied — but in the idea that this ritualized violence is necessary for the establishment and perpetuation of social order. This idea is also at the basis of the Girardian conception of martyrdom. In fact, the French Catholic scholar understands myth and gospel as two rival descriptions of the social process of violent persecution. In the Gospels and Christian martyrologies, he argues, the perspective that prevails is not that of the community, but that of the oppressed victim. This allows him to expose his specific secularized Christian conception of history: «throughout occidental history persecutory representations (myths) have lost their effectiveness. For Girard, our contemporary recognition of the victim's innocence $[\ldots]$ is ultimately a radicalized intensification of our solidarity with the martyrs - which in turn derives from our immersion in the story of Christ's Passion.» ${ }^{43}$ This conception of martyrdom as a radical rejection of violence history is only apparently similar to that of Walter Benjamin and Jacob Taubes, which I discussed in the previous chapter. Indeed, starting from the premise that violence is a natural disposition of man, Girard comes to regard state repressive apparatuses as necessary tools for the containment of violence:

41 See Girard 1979, 143-168.

42 Girard 1979, 6-7.

43 Kirwan 2009, 920. 
The elimination of sacrificial violence is not just $\operatorname{good}$ > or 〈bad ; it is an ambivalent and ambiguous progress in the fight against violence, which may include regressive moments when humans, who in the past were being held back by this violence, become more violent. The peace we have enjoyed until recently is often based on sacrificial violence, which is obviously no longer present in the form of blood sacrifice, but which exists in institutions such as the police, the army, the dominance of American power, which still instills respect around the world. ${ }^{44}$

Ultimately, Girard has a political-theological understanding of history similar to that of Thomas Hobbes and Carl Schmitt. Since, in the state of nature, human beings live in a permanent "war of all against all», the monopoly of violence by the state assumes the connotation of something absolutely necessary to restrain the omnipresent threat of the apocalypse. In such a world, the sacrifice of innocents is, however tragic, inevitable. In Girard's thinking, the martyrdoms of those who imitate Jesus Christ are human attempts to imitate the divine, that is, something that is radically metaphysical and metahistorical:

What Jesus calls us to imitate is his desire, it is the momentum that directs him toward the goal he has set: to be more like the Father. [...] His only purpose is to become the perfect image of God. Christ therefore commits with the utmost zeal to imitating this God who is his Father. Inviting us to imitate him, he invites us to imitate his own imitation. ${ }^{45}$

The crucial point is that, for Girard, martyrdom is the imitation of something that is not human, since humans are predisposed by nature to mimetic desire. In this way, martyrdom assumes a metaphysical connotation, where both violence and non-violence are depoliticized, because the first is placed in the sphere of nature while the second is located in the domain of the divine sphere; the human being is therefore imprisoned between these two poles. Despite saying the opposite, Girard ultimately does not consider martyrological representations to be instruments of political struggle against sovereign power, but to be human attempts to overcome «natural» guilt: the guilt of being an animal who desires mimetically.

44 Girard 2011, 24.

45 Girard 2001, 27. 
To counteract these two theoretical problems-the conception that sacralization is primarily the result of ritual destruction and the anthropological premises underlying it-I propose to take inspiration from Giorgio Agamben's theory of the homo sacer. According to the Italian philosopher, the sacralization or consecration of human beings is the result of the praxis of excluding them from the community, a ban through which life is depoliticized and reduced to «bare life». Marcel Mauss drew attention to the homo sacer figure in his first study of sociology of religion, published in 1896. ${ }^{46}$ In this text, he points out that, in ancient Rome, not only was what belonged to the gods of the city sacred, but so was what the individual granted to the gods. In other words, everything withdrawn from common usage was sacred. The main distinction here between res sacra and res communes is that what belonged to the gods could not belong to men, and vice versa. Thus, if something was consecrated to the gods, it belonged definitively to the sphere of the sacred. This could also affect people. In fact, the Roman penal code prescribed that the chief priest could consecrate a criminal to the gods before the altar and in the presence of the people. The consecreatio capitis et bonorum, Mauss claims, was both a religious and legal practice, and only later, through the historical development of criminal law, did the distinction between public law and religious law emerge. In an important passage, Mauss writes that «l'homme devenu sacer était voué à la mort. Tout citoyen avait le droit de le tuer, de détruire sa propriété, son troupeau» [«the man who had become sacer was doomed to death. Every citizen had the right to kill him, to destroy his property, his flock»]. ${ }^{47}$ Agamben, although he does not explicitly mention Mauss' essay, resumes the argument traced by the French anthropologist and proposes «to interpret sacratio as an autonomous figure», which «may allow us to uncover an originary political structure that is located in a zone prior to the distinction between sacred and profane, religious and juridical.» ${ }^{48}$ This originary structure is that of the sovereign exception, namely what allows the sovereign to suspend the law in the state of exception and to ban a person from the political community by consecrating that person to the gods. To consecrate someone means nothing more than to permit someone to be killed without such killing being considered a murder, that is to say, without the killing being prosecuted and punished by law:

46 See Mauss 1896a; Mauss 1896b.

47 Mauss 1896b, 59.

48 Agamben 1998, 74. 
The sovereign sphere is the sphere in which it is permitted to kill without committing homicide and without celebrating a sacrifice, and sacred life - that is, life that may be killed but not sacrificed-is the life that has been captured in this sphere. ${ }^{49}$

According to Agamben, this practice of consecration-the sovereign decision through which an individual is deprived of his or her social and political life and reduced to «bare life»-«is the originary activity of sovereignty.» ${ }^{50}$

Unlike Hubert and Mauss (in the Essai sur la nature et la fonction du sacrifice there is no reference to the figure of the homo sacer, which is why we are led to believe that Mauss had dropped the intuition he had had two years before), Agamben conceives consecration not exclusively as the result of religious ritual performances, but of practices of exclusion, which are both juridical-political and religious. Furthermore, this consecration is achieved not only by means of ritualized practices of exclusion, but also and especially through discursive practices of declaring that someone is already sacred and thus killable without punishment. Thus, it is not only through ritual acts performed with the body, but also through discursive practices performed by iterating language units, rhetoric patterns and narrative models, that consecration is produced. In other words, the success of consecration is related to the ritualization of both corporal and discursive practices - that is, the repetition of actions and representations that were established and promoted over time.

It is clear that Agamben's homo sacer theory does not have the universal claim of explaining the function of all kinds of sacrificial practices in any historical and pragmatic hermeneutic context, but rather considers the role of consecration within and in reference to what Foucault, as we have seen, defines as the discourse of sovereignty or the «politico-legendary history of the Romans». It is therefore in the context of Greek-Roman culture that consecration intended as a form of exclusion from the profane community of the living, that is, from the political and juridical spheres, must be placed. Thus, the homo sacer theory allows us to better understand and explain the intrinsic relationship between sovereignty and violence, between sovereign exception and the reduction of a human to bare life in the context of «Western» history, culture and society. ${ }^{51}$

49 Agamben 1998, 83.

50 Agamben 1998, 83.

51 As William Cavanaugh rightly observes, «the West is a construct, a contested project, not a simple description of a monolithic entity.» Here I use the term 
At this point, the task is to understand the relationship between the homo sacer figure and the martyr figure, to thus analyze the encounter, confrontation and mutual influence between the consecration of bare life through the sovereign practice of exclusion and sacralization through martyrological representations. In the next chapters, I will expose the heuristic value of the homo sacer theory for my analysis of the martyrological representation of Aldo Moro and, in broader terms, for understanding the state martyr figure's performativity. But before that it is necessary to first reconstruct the history of the signatures of the concept of martyrdom in order to understand how the martyr figure emerged in the encounter between the discourses of sovereignty and rebellion, between the "politico-legendary history of the Romans» and the «mythico-religious discourse of the Jews».

Signature is a terminus technicus of discourse analysis. ${ }^{52}$ It broadens the interpretative horizon that makes it possible to observe how signs and concepts change meaning over time. In this sense, it marks a breaking point between semiology and hermeneutics. Semiology is what allows the identification of signs, while hermeneutics discovers their meaning in a particular historical, political, social and cultural context. A central task of this study is to reconstruct the history of the martyr's signatures and in particular to demonstrate that, on the threshold between the Middle Ages and modernity and with the emergence and constitution of modern national states, the martyr figure underwent a signature through which it was transposed from the pragmatic and hermeneutic context of Christian religion (and theology) to a secular (and political) one.

From this point of view, the emergence of the figure of the state martyr is a product or result of secularization. In fact, in line with Agamben, secularization can be regarded as a process of dislocation of signs and concepts from the sacred to the profane sphere of meaning. Signatures play an important strategic role: they direct the interpretation of signs in a certain direction. The central idea is that some religious language forms, which in modernity and post-modernity are used in profane and secular contexts and discourses, have a secret index: they recall previous religious meanings without making them explicit. ${ }^{53}$ Among these secularized religious lan-

«Western» in the same way as Cavanaugh uses it, namely as an ideological construct which is both made and shaped by certain narratives and forms of representation. Just like the "myth of religious violence» analyzed by Cavanaugh, state martyrology should be understood as «an ideological accompaniment to shifts in Western configurations of power.» See Cavanaugh 2009, 7, 12.

52 See Foucault 1966, 44; Agamben 2009, 33-80.

53 See Agamben 2011, 3-4. 
guage forms there is the figure of the martyr or, more precisely, there are the signs, images, and the rhetorical and narrative structures through which the figure of the martyr takes shape and manifests itself in a new semiotic, pragmatic and hermeneutic context.

The phenomenon of the formation of analogies, the transfer, resetting or reversal of religious language into new contexts, can also be conceptualized, in line with Hans Blumenberg, as a prefiguration. ${ }^{54}$ According to the German philosopher, prefiguration is an anthropologically derivable process that consists in reducing the complexity of reality by iterating past forms of representation, narrative models, and rhetorical patterns in order to reduce contingency and create meaningfulness (Bedeutsamkeit). Prefigurations are "acts of repetition» (Akte der Wiederholung), by which actions or events are made plausible and significant by relating them to the characteristics, power and meaning attributed to historical or mythical actions or events. ${ }^{55}$ The success of such meaningful analogies is de facto determined by both the conciseness and the contextual applicability of the reference figures. Prefiguration «does» something only through its concrete appearance in a particular pragmatic and hermeneutic context. It is a practice which iterates a certain past event or action and transposes the meaning or efficacy attributed to it in its «original» context to another event or action.

The performativity of the martyr figure is strongly linked to what Hans Blumenberg calls the «aesthetic potential of secularized [religious] language». ${ }^{56}$ In The Legitimacy of the Modern Age, the German philosopher quotes Friedrich Schleiermacher's aphorism, according to which «Christianity produced language. It has been and still is a potentiated linguistic genius [Sprachgeist $]$ from the beginning $[\ldots]^{.{ }^{57}}$ Referring to this aphorism, Blumenberg argues that «the phenomena of secularization derives to a large extent from this linguistic genius, from the familiarities that it produced, the transferable materials that it left behind it, and the residual needs that are associated with its materials.» ${ }^{58}$ There are certain signs, concepts and statements that deploy a specific form of performativity with a specific power of persuasion by referring to a religious «linguistic genius», to residues of religious signification. According to Blumenberg, secularized religious language has a «rhetorical function», which is that «of

54 See Blumenberg 2014b.

55 Blumenberg 2014b, 9.

56 Blumenberg 1985, 108.

57 Schleiermacher 2012, 17.

58 Blumenberg 1985, 114. 
evoking effects along the spectrum between provocation and familiarity by means of an emphatic display of the terminology's marks of derivation».59

In line with the arguments of both Agamben and Blumenberg, this investigation is based on the assumption that a critical analysis of the figure of the martyr and its performativity cannot help but consider its historical roots and transformations. What is the «original» meaning of the figure of the martyr, and what is its secret index? In order to avoid any misunderstanding, I wish to underline that I am not arguing that there is a genuine, true meaning of martyrdom, which has remained unchanged for centuries. That would mean a return to a dangerous form of essentialism. My goal is not to detect an inexistent essential meaning, but to trace the «cultural and medial metamorphosis» of the martyr figure in history. ${ }^{60}$

\subsection{Emergence of the Martyr Figure}

In what social, political and cultural context did the martyr figure emerge for the first time in history? The question of the origin of martyrdom has been a controversial research topic for a long time and even today the debate seems to be far from coming to an end. There are two basic approaches to the question. On the one hand, there are researchers who are interested in determining the origin of the idea of martyrdom, namely in understanding in what social, political and cultural contexts the $i d e a$ of a voluntary form of martyrdom, considered positive, desirable or «noble», could be developed. On the other hand, there are researchers for whom martyrdom begins at the moment when ancient Christians started using the term martyrdom to describe a person who chooses to suffer death rather than renounce faith in Christ or obedience to his teachings. ${ }^{61}$

We find this last kind of approach both in Norbert Brox's classic study Zeuge und Märtyrer and in the more recent study Martyrdom and Rome by Glen Bowersock. Both trace the evolution of the term from its pre-Christian use in courtrooms to its titular use in Christianity. Originally, the

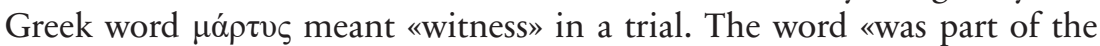
forensic and legal language of Greek court», but it could also be used metaphorically for all kinds of observations and attestations. It thus never

59 See Blumenberg 1985, 104-105.

60 Weigel 2007b, 16.

61 See Moss 2012, 2. 
designated «dying for a cause» until the mid-second century AD. ${ }^{62}$ Resuming a thesis already present in Brox's study, Bowersock argues that the concept of martyrdom was alien to the ancient world and criticizes those researchers who consider, for example, the death of Socrates, the three Jews in the fiery furnace of Nebuchadnezzar, or the Maccabees, earlier forms of martyrdom. ${ }^{63}$ According to Bowersock, «martyrdom, as we understand it, was conceived and devised in response to complex social, religious and political pressures», which took place from the second century onwards. ${ }^{64}$

Many scholars criticize this kind of approach and instead point to ancient Jewish «antecedents» of Christian martyrdom. William Hugh Clifford Friend calls attention to forms of martyrdom found in Daniel and in the second and fourth books of the Maccabees, claiming that «without Maccabees and without Daniel, a Christian theology of martyrdom would scarcely have been possible.» ${ }^{65}$ The «martyrdoms» of Eleazar (2 Maccabees 6-7), who is killed for refusing to eat pork, and of the seven brothers tortured and killed when each refused to abandon the ancestral laws, are often addressed as pre-Christian examples. In his study of the Maccabean martyrs, Jan Willem van Henten argues that the deaths of Jewish heroes for the salvation of their people formed the notion of martyrdom in the early Church. ${ }^{66}$ Also, Middleton argues that the epattern of refusal to compromise religious belief in the face of an edict and then torture is common to both Jewish and Christian martyr acts», which is why «the novelty of the

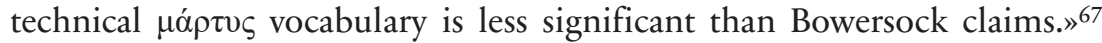
The tradition of «noble-death» in Greco-Roman literature and culture is also often addressed as an antecedent of Christian martyrology. Scholars highlight that, in fact, early Christian writers praised pagan suicides as forerunners of martyrdom. ${ }^{68}$ Candida R. Moss shows, on the basis of many examples of «noble deaths» (Homeric heroes, Antigone, Lucrezia, Socrates, etc.), how the memory of pre-Christian heroic suicides acts as a reference for the creation of martyr figures in the second and third centuries, stressing that, «when interpreting their own experiences and their own concept

62 Moss 2012, 4.

63 See Baumeister 1980; Musurillo 1954.

64 Bowersock 2002, 5.

65 Frend 1965, 65.

66 See van Henten 1997.

67 Middleton 2014, 121.

68 See Weigel 2007b, 22-24, Middleton 2014, 121; van Henten/Avemarie 2002, 1-8. 
of martyrdom, early Christians, transformed, shaped, and subverted existing cultural tropes.» ${ }^{69}$

Although there are undoubtedly Greek-Roman and ancient Jewish influences, I agree with Brox's and Bowersock's thesis, according to which the martyr figure emerged for the first time in the second century. In fact, there are substantial differences between the martyr figure and the tradition of death for faith in the Jewish context or of the noble death in the Greco-Roman context. In both traditions, death was a sign of virtue: «the willingness to die proved the purity of one's intentions and served as a guarantor of the veracity of one's claims.» ${ }^{70}$ Undoubtedly, in the Jewish context, death also had the connotation of «dying for God»; $;{ }^{71}$ but the act of dying was not conceived and represented as an act of witnessing faith before the mid-second century AD. Bowersock points out that, even in the New

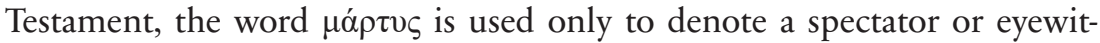
ness, one who testifies to what he has seen. ${ }^{72}$ However, there is no doubt that within the New Testament the act of witnessing assumes a different connotation. The word continues to denote the act of witnessing something verbally (or the person who is a witness to something), but what is being witnessed now has a transcendent and metaphysical value. In the

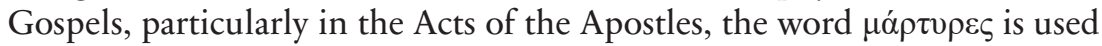
to designate those who witnessed Jesus' suffering and especially those who witnessed his resurrection (see, for example, Luke 24:48 and Acts 1:22, $2: 32,3: 15)$. What is witnessed is thus no longer the truth of a historical fact, as in the case of something witnessed before a trial, but of an absolute truth. The earliest appearance of these words, referring to death at the hands of a hostile authority, is in the Martyrium polycarpi, which describes the events connected with the execution of the elderly bishop of Smyrna, a town in western Asia Minor, around the year 150.

This new meaning of the term «martyrdom», namely «to die for a cause», is therefore a product of late antiquity. It gradually took shape in the second century and «had been an essentially urban manifestation of Christian zeal»; in fact, «martyrdom in a city provided the greatest possible visibility for the cause of the nascent Church, and it simultaneously exposed the Ro-

69 Moss 2012, 47.

70 Moss 2012, 47.

71 Weigel 2007b, 24.

72 According to Bowersock, the only passage in the entire New Testament «that might have effectively encouraged the sense of martyrdom as it was to develop» is Acts 22:20, where Paul refers to the stoning of Stephen with the words: «when the blood of your martyr Stephen was shed». See Bowersock 2002, 15. 
man administrative machinery to the greatest possible embarrassment.» ${ }^{73}$ What happened in the second century was not a simple renomination of a social phenomenon that did not change over time. In the Greek cities of Asia Minor, Bowersock identified the necessary context for the genesis of the phenomenon of Christian martyrdom. Martyrdom could occur only if a Roman magistrate chose to impose the death penalty on a confessing Christian. From this point of view, the apparatus of Roman court procedures, along with their technical language, was a conditio sine qua non for the emergence of martyr figurations. This is why the first martyrological narratives had a common narrative structure that reproduced the fundamental steps of Roman court procedure. ${ }^{74}$ For the whole durance of the martyr's trial large parts of the population were present:

The whole drama unfolded in the conspicuous places of a city. The martyr was moved from prison to tribunal, usually in the agora and close by the temple at which sacrifice to the emperor would be enjoined. The final scene was normally set in the amphitheater [...]. Martyrdom served as a catalyst of the intellectual and social rituals of the city by holding a mirror to the traditional functions of the agora and the amphitheater as well as to the urban environment to which they belonged-prison, temple, and brothel. Furthermore, crowds were an essential part of the martyrdoms, and these could only be mustered in sufficient numbers in the big cities. ${ }^{75}$

It is in this context (and under the influence of the ethics of suicide modeled on the paradigm of Greek-Roman tradition) that «an ideology of death to promote a cause» was born. ${ }^{76}$ Of course, voluntary death, understood as suicide, was soon harshly criticized by Church fathers (particularly by Clement of Alexandria and Origin), and the concept of martyrdom again assumed, in its theological interpretation, the meaning of «bearing witness", in the sense of a confession of faith in God: to die as a martyr means, then, to witness the truth of Christ's death and resurrection-martyrdom as imitatio Christi. Despite this reinterpretation or re-signification, the idea of martyrdom as a sort of «bodily performance» remained. During the second century, the public death of members of the Christian sect became the act of witnessing the transcendent and absolute truth embodied

73 Bowersock 2002, 42.

74 See Lanata 1973.

75 Bowersock 2002, 52, 55.

76 Bowersock 2002, 74. 
by Christ. Through the signature of the word «martyrdom»-that is, the transposition of the term from a legal and forensic context into a religious one-public events of violence acquired a new, metaphysical meaning. This signature strongly determined attribution of meaning to events of political violence in which someone was tortured or killed. Dying (in certain circumstances) became an act of witnessing the truth of the Christian faith, or, more specifically, the truth of Christ's death and resurrection.

Candida R. Moss, despite assuming a less radical position, underlines the importance of this re-signification:

Even if the shift in the term's meaning does not mark the beginning of martyrdom itself, the refinement of language and the application of titles as identity markers are important historical developments. These moments of transition reveal changes in the structures of ancient social and conceptual hierarchies. ${ }^{77}$

One of the most important changes lies in the fact that, through the representation of violent death in the public space as «martyrdom», an ideology was promoted which was strongly subversive. In classical Rome, sacrificing one's life for one's family or community was considered honorable, but, as Carlin Barton notes, «Romans rarely identified with or wanted to be seen as victims $[\ldots]$. Their stories of the vindication of honor are designed not to elicit pity, not to reveal a victim, but to reveal an unconquered will.»78 Early Christians were undoubtedly influenced by these attitudes, but they understood themselves as part of a community of believers. If, within Roman culture, spectacles of death were intended to deprive criminals of their honor through stripping them of agency, Christians appeared to have chosen to die and their deaths were represented as acts of witnessing the truth of Christ's revelation. Martyrs assumed the meaning of fully active citizens of the city of God. Furthermore, the Acta martyrum «ensured that these performances were not only remembered but individualized as acts of personal self-expression. Martyrdom was, in these accounts, an act [...] legitimized by the example of the Passion of Christ.» ${ }^{79}$ In the same way that, according to Pauline theology, Christ was considered the symbolic body of the Church (and vice versa), the martyrs, as imitators of Christ in death, were experienced as being the same symbolic body. The martyr, we can say, assumed the meaning of one who re-actualized the mystical bond

77 Moss 2012, 6.

78 Barton 2002, 27.

79 Janes/Houen 2014, 5. 
between Christ and the community. ${ }^{80}$ In eschatological terms, it can be said that the figure of the martyr also had a legitimizing function. The Christian martyr figure, by witnessing the death of Christ with his own death, also bore witness to the future establishment of the city of God. In this way, it delegitimized the authority of the Roman Empire. ${ }^{81}$

The martyr figure, in the first context in which it appeared, was part of what in the second chapter I define as a narrative of rebellion. Moreover, the opposition proposed by Foucault between the «mythical-religious discourse of the Jews» and the "politico-legendary history of the Romans» here becomes clearer and more intelligible. In fact, what Middleton calls the «radical martyrdom» of early Christianity seems to be the encounter/ clash of these two discourses. ${ }^{82}$ The martyr figure maintained subversive potential as long as it was inscribed within an eschatological and messianic narrative structure. This structure emerged historically for the first time in apocalyptic literature and was consolidated in the messianic narrative of Christianity. Apocalyptic and messianic thought developed in the historical context of conflicts between conquerors and the conquered, first under the Macedonian Empire of Alexander the Great, and then under the Roman Empire, and strongly influenced the cultural, religious and political history of late ancient world.

The novelty of the Christian messianic narrative lies not in the vision of a coming Kingdom of God, which already existed in the apocalyptic and eschatological narratives that preceded it, but in the idea that the Kingdom will soon be realized or even that it has already been realized. In the Gospels, the apostles are the martyrs, namely those who witnessed the life and death of Christ (the Messiah) as the revelation/realization of God's Kingdom. In further development of the narrative, the Messiah himself became the martyr, the witness, who by dying revealed/realized the Kingdom and the accuser, who delegitimates not only the authority of the Roman emperors, but all forms of earthly authority. In the second century, martyr-

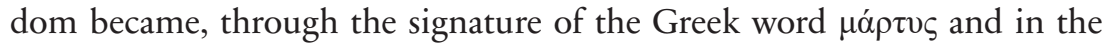
context of struggle between Christian communities and the Roman Empire, an act of witnessing through death, which unmasked and exposed the iniquity of the violence perpetuated by the political authority. Christ was

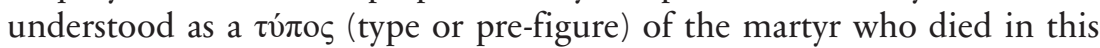
struggle. It is a typological analogy, similar to the analogy used by Paul

80 See Rahner 1958, 91.

81 See Recupero 2010, 24.

82 Middleton 2006. 


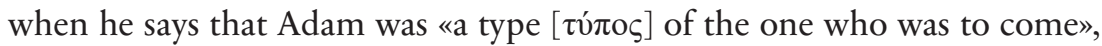
that is, of Christ. The Christ-martyr thus assumed the connotation of the archetypal martyr, to which every form of Christian martyrology refers. ${ }^{83}$

The eschatological and messianic narrative radically challenged the Greco-Roman way of conceiving and narrating politics and of glorifying power. The Romans saw a threat to the stability and social peace of the Empire in the behavior of Christians, because it undermined the very essence on which the acknowledgment and legitimization of political authority was based. Religion has always played an important role in the mechanisms of legitimization of the social and political structures of the ancient Roman civilization. Religion was closely associated with socio-political reality, for which a distinction between inner (religious) and public (political) spheres was inconceivable. Especially with the expansion of the Empire, when it was no longer possible to govern the masses through the institutions of the polis, the princeps as a leader had to monopolize all power. In this way, the auctoritas passed to the princeps and the religious worshiping of the gods of the state culminated in the imperial cult. As Erik Peterson notes, the cult of the «old» state divinities could be tolerant, but the new imperial cult was necessarily intolerant, since the divine was now embodied by the figure of the emperor and demanded its own recognition as a numen praesens. ${ }^{84}$ To refuse to worship the Roman deity or the divinities of the Empire and oppose the adoration of the emperor's image meant, for the authority and for Roman citizens, a lack of loyalty and a public demonstration of disavowal of the constituted power. That is why the main accusation of Christians was atheism, blasphemy, impiety, crimen religionis, crimen majestatis, which, though with different shades, indicated the same political problem: opposition to the official religion and therefore the rejection of established power structures and political authority. ${ }^{85}$

The rejection of the "politico-legendary history of the Romans» by the early Christian communities was a radical act of political subversion and revolt. Hannah Arendt is right when she writes that «Christian morality $[\ldots]$ has always insisted that everybody should mind his own business and that political responsibility constituted first of all a burden, undertaken exclusively for the sake of the well-being and salvation of those it freed from worry about public affairs.» ${ }^{86}$ However, this radical rejection of vita activa

83 See Recupero 2010, 22.

84 See Peterson 1937, 82.

85 See Noce 1987, 26.

86 Arendt 1998, 60. 
—understood as the participation in public and political life - was in itself actually quite political. In fact, within the messianic and eschatological narrative, the distinction between private life and political life, between

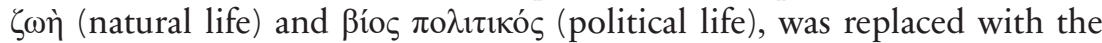

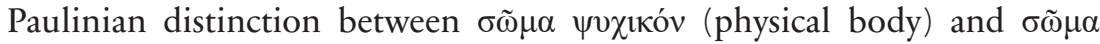
$\pi v \varepsilon v \mu \alpha \tau$ cóv (spiritual body). The physical body is the one humanity shares with Adam, a body of the dust of the earth, while the spiritual body is what Christ acquired in his resurrection and that all those who belong to him will have in their future resurrection in heaven (1 Cor 15:47-48). Thus, the radical difference between the Greco-Roman and the JewishChristian ways of understanding man, society and the world cannot be emphasized enough. As Arendt argues,

the Christian sglad tidings of the immortality of individual human life had reversed the ancient relationship between man and world and promoted the most mortal thing, human life, to the position of immortality, which up to then the cosmos had held. [...] It is precisely individual life which now came to occupy the position once held by the life of the body politic, and Paul's statement that «death is the wages of sin', since life is meant to last forever, echoes Cicero's statement that death is the reward of sins committed by political communities which were built to last for eternity. It is as though the early Christians-at least Paul, who after all was a Roman citizen-consciously shaped their concept of immortality after the Roman model, substituting individual life for the political life of the body politic. ${ }^{87}$

The messianic and eschatological narrative desacralized the cosmos and sacralized individual life. According to Arendt, the Greco-Roman understanding of natural, private life, whose center was the home and family, was based on the idea that borders, the boundaries between one estate and another, were sacred. The sacrality of the household, which «was born of necessity», was radically different from «the realm of the polls», of political life, which "was the sphere of freedom». Freedom was thus located exclusively in the political and profane realm, while necessity was "primarily a prepolitical phenomenon», in which «force and violence are justified [...] because they are the only means to master necessity-for instance, by ruling over slaves—and to become free.» ${ }^{88}$ Here, the status of the homo sacer becomes perhaps clearer: Within ancient Roman culture and society, sacer

87 Arendt 1998, 314.

88 Arendt 1998, 30-31. 
was the human being that belonged to the gods, that is: someone who cannot act freely in the public and political sphere. The Christian messianic and eschatological narrative radically subverted this understanding of the relation of household to city, of freedom to necessity, by declaring that every individual life was free thanks to the resurrection of Christ, a prefiguration of the resurrection of all believers at the end of time. In Greco-Roman culture, a sacred individual was not free, inasmuch as his or her life belonged to the gods and thus was no longer subjected to the rules of the city; for early Christians, a sacred individual became free through his or her faith in the saving power of Christ' death and resurrection.

Now, we should be able to better understand the singularity of the situation in which the first martyrological narratives emerged. By refusing to recognize the official religion of the Empire, the first Christian communities endangered the entire conceptual and knowledge system, the hegemonic discourse on which imperial power was based. The martyrological representation of violent death at the hands of Roman magistrates was based on a mechanism of subversion of language, through which the term «martyrdom» assumed the meaning of a performance of the body with which an individual witnessed the truth of the revelation of a new, universal community in which every human being is free. From the point of view of a messianic and eschatological understanding of history, without which the martyr figure could never have emerged, the distinction between a legitimate and illegitimate use of violence itself made no sense, because there was no legitimate power in the world despite that of God.

\subsection{Institutionalization, Militarization, and Nationalization of the Martyr Figure}

Early Christian communities took possession of elements of Greco-Roman language and rhetoric, subverting their significance. The signature of the term martyrdom is a paradigmatic example of this very effective re-signification of language, through which the «original» meaning of terms did not disappear but rather assumed a different connotation, permitting a different usage. This subversive re-signification did not had a long life, inasmuch as the subversive potential of the martyr figure was soon disempowered by a further re-signification that occurred during the historical process that led to the institutionalization of the Christian religion. After Constantine, the institutions of the Empire and the Christian Church were increasingly intertwined. The Christian Church mirrored the centralized imperial bu- 
reaucracy when it stabilized its structure and hierarchy. The imperial and Christian administrative structures coincided, and soon religious leaders also adopted civilian roles. In this changed cultural, social and institutional context, a cult of martyrs developed whose main function was to legitimize the new political and administrative structure of the Empire. The center of worship of the martyrs was the (real or fictional) places of their burials. In these places, monuments of different types, from simple memorial stones up to sumptuous sanctuaries, were erected. ${ }^{89}$

The term $\mu \alpha \rho \tau$ ṕpiov thus underwent further re-signification. It was then used to indicate sanctuaries and reliquaries built on the remains of martyrs. These $\mu \alpha \rho \tau u ́ p i \alpha$ increasingly functioned as symbols of God's victory over the enemy, the moment of the heavenly triumph. As Maria Grazia Recupero observes, these places served as spatial markers that legitimized the hierarchy of urban administration: «The increasingly decisive role of bishops - the main holders of public functions in the city of the 4th centurymerges with the progressive organization, institutionalization, and administration of the cult of martyrs.» ${ }^{90}$ Martyrs were considered mediators between the community and the sacred, between the inside and the outside, that is, as intercessors between earthly and divine power. Around the martyrs' sanctuaries, a new form of political legitimization developed based on the glorification and acclamation of a political power and hierarchy that participated in the martyrs' sacredness. The figure of the martyr thus became the point of reference, the fulcrum on which practices of acclamation and the glorification of power revolved, practices which, as we have seen, were typical of imperial society and culture.

Martyrological language was then used to describe a life of spiritual discipline and asceticism: «martyrdom could become democratized, everyone could participate. [...] Just as martyrdom had produced heroes of who had displayed acts of extreme courage and endurance, so asceticism could be taken to an extraordinary level.» ${ }^{91}$ The martyr figure also served, after a long process of consolidation of the of martyr cult, to legitimate the concept of Christian Holy War. As observed by Adolf von Harnack in his famous study Militia Christi, from the beginning Christianity appropriated a military lexicon ${ }^{92}$, while systematic militarization of the martyrs occurred around the $10^{\text {th }}$ and $11^{\text {th }}$ centuries by aligning the exaltation of Christian

89 Pricoco 2007, 67.

90 Recupero 2010, 180.

91 Middleton 2011, 84.

92 See von Harnack 1905. 
spirituality with military glory. ${ }^{93}$ Within the Christian tradition, Augustine established rules that defined when it was justified to start a war (jus ad bellum) as well as what were legitimate and illegitimate forms of violence within war (jus in bello). According to him, war was legitimate when it was waged to obey divine command. ${ }^{94}$ A number of Christian Holy Wars were waged against pagans between the seventh and ninth centuries by figures such as Charlemagne and the English kings St. Oswald and St. Edmund; both kings were venerated as martyrs. As Paul Middleton highlights, «once killing in battle was theologically justified as participation in Christian Holy War, it was only a small step before the dead in such conflicts were viewed as martyrs. ${ }^{95}$ Soldiers who fought in wars blessed by Pope Gregory VII were considered militia Christi insofar as they were seen as imitating the sacrifice of Christ.

The first Christians understood martyrdom as a spiritual conflict against Satan, who wanted to remove them from their confession through the instruments of torture inflicted by the Romans. Satan was considered the power behind every evil in the world, the one who with his continuous action was responsible for the emperor's idolatry and the violent and immoral bloody spectacles of the Romans. In particular, persecution was considered work carried out by emperors under the influence of Satan. In the context of Christian Holy Wars the understanding of Satan changed, since the martyr-warrior figure was understood as someone fighting against infidels. Satan was now understood not only as a force operating in the souls of all humans, but also as an entity that, through pagans and infidels, intended to destroy Christian society and kingdoms. The second Crusade preacher Bernard of Clairvaux assured crusaders that both killing and dying for God was not a sin, but something wanted by God: «The knights of Christ may safely do battle [...] as death for Christ, inflicted and endured, bears no taint of sin, but deserves abundant glory.» ${ }^{96} \mathrm{~A}$ martyr was no longer someone who died by the hand of an illegitimate political authority, but a warrior who killed infidels and was willing to die in doing so.

Paul Middleton highlights the role of martyr figures in the context of the struggle between the Catholic Church and the Reformation movement. The same event of violence was interpreted and represented in opposite ways: some viewed it as the legitimate execution of a heretic, while oth-

93 See Recupero 2010, 13.

94 See Janes/Houen 2014, 9-10.

95 Middleton 2011, 86.

96 Quoted in Middleton 2011, 89. 
ers represented it as the death of a martyr, as an act of bearing witness to the true doctrine and an accusation of the false church that fell into sin. Jan Hus, who was influenced by the teachings of John Wycliffe and whose work would influence Martin Luther, gave a «mass for martyrs», specifically for three men who were beheaded after a mob burned a papal bull in July $1402 .{ }^{97}$ For Luther, the martyrdoms of those who were killed or injured due to their criticism of the Catholic Church were signs that the true Church was reborn. When two Augustinian friars were burned in Brussels in 1523, the Reformation movement gained its first martyrs. Through the production of martyrological representations, the Reformers could claim continuity with the past.

However, Luther himself criticized the Anabaptist movement and its own martyrological representations. While the two kingdoms doctrine of Lutherans and Calvinists de facto legitimized political authority as the necessary sword to restrain evil, according to Anabaptist theology there was no kingdom other than that of God. In 1525, the radical preacher Thomas Müntzer, who was foremost amongst those reformers criticizing Luther's compromises with feudal authority, was executed in the German Peasants' Revolt. When Luther was confronted with the deaths of Müntzer and other Anabaptists, he resorted to Augustine's adage: non poena sed causa facit martyrem. The deaths of Anabaptists were recalled in pamphlets and songs. From the mid-sixteenth century these martyrologies, such as the Swiss Brethren Hymnal (1564) and the famous Menonnite Martyrs' Mirror (1660), were collected, edited and printed. Although both Catholics and Protestants were impressed by the manner of death assumed by Anabaptists, ultimately they justified their execution as a legitimate means in the fight against heresy. ${ }^{98}$

Unlike Anabaptism, Protestantism spread quickly and quickly gained the support of princes; in many areas, civil authorities supported the new version of the faith. In the military, political and civil clashes that followed the confessional split of the Protestant from the English Reformations, the temporal and ecclesiastical political institutions lined the opposing fields of Protestantism and Catholicism, not only in terms of religious convictions but to also consolidate their political power and authority. In the context of the European wars of religion, thousands of Protestants were tried for heresy and burned at the stake, particularly in Germany, France, the Low Countries, and Switzerland. As Middleton highlights,

97 See Middleton 2011, 91.

98 See Middleton 2011, 96. 
For the first time heretics were not isolated individuals, but comprised a mass movement of mutual support and encouragement, aided in no small measure by the printing press. Soon after the burning of the Augustinian monks in 1523, no fewer than sixteen editions of a martyrological pamphlet were in circulation, expressly calling the friars both saints and martyrs. Stories of martyrs, letters of exhortation, and sermons created a theology for a new age of martyrdom. Luther and Calvin both wrote to those in prison urging them to remain steadfast to the true faith, and follow the example laid down by the martyrs before them. ${ }^{99}$

In these letters, the Passion of Christ, as well as the violent deaths of the early Christians, were represented as models to inspire acts of courage and self-sacrifice, while those that persecuted the Protestants were represented as demonic forces and compared to Roman emperors, such as Nero and Diocletian, and Satan.

According to Middleton, the most enduring martyrology of this time was John Foxe's Book of Martyrs. This book, published originally in 1563, was a direct response to the persecution of Protestants under Mary Tudor, who wanted to return England to Roman Catholicism. In the short reign of «Bloody Mary», more than 300 Protestants were executed. In the Book of Martyrs, Foxe represents Protestants as the true Church, the Roman Catholics as heirs of the ancient persecutors, and the Pope as a contemporary manifestation of evil analogous to the evil of Roman Emperors. When Mary Tudor died in 1558 and was replaced by Elisabeth I, English Protestants interpreted this as the work of God's hand: «The martyrs were vindicated. History repeated itself. As the persecuted Church became the religion of the Roman Empire, so with the dawning of a new age of security, Elizabeth was portrayed by Foxe as the new Constantine.»100

During the period of the European wars of religion, martyrologies functioned to categorize Christians into martyrs, persecutors and heretics; ultimately, each religious denomination tried to connect its own beliefs and practices with the early Church. Each narrative reinforced the religious convictions of a martyr's group and served to accentuate the boundaries between competing movements. While the narratives of reformists' movements, such as the Anabaptists, iterated elements of the messianic and eschatological narratives of the first Christian communities, inasmuch as

99 Middleton 2011, 96-97.

100 Middleton 2011, 103. 
they rejected recognizing and thus legitimizing any earthly political authority, most martyrologies were used to legitimize different political authorities and construct different collective identities. As Middleton points out, martyrologies have continued to serve as identity markers and as narratives of legitimization in the context of political struggle until the present day:

It is my contention that insights from the history of martyrology fatally undermine contemporary attempts to distinguish between (true) and 'false > martyrs. Those religious, political, and even academic theological accounts of martyrdom today function primarily as identity markers that reinforce religious, cultural, national and even trans-national group boundaries. The distinction between «martyr» and «terrorist $>$ is the difference between two stories. ${ }^{101}$

A good example of national martyrology is that which emerged in the context of the rebellion of the Scottish covenanters against the English monarchy. As Middleton argues,

the covenant was $[\ldots]$ a contract between the Scottish nation and God, over and against the claims of Charles I to be God's prince. [...] At the height of the covenanting uprisings, the king instituted a policy of extra-judicial killing. Once again, where a British monarch saw dangerous sedition, the covenanters saw martyrs. However, the covenanters were not only martyrs for God, the National Covenant made them martyrs for Scotland. [...] Just as the martyr Jan Hus became an important marker of Czech nationalism, so the covenanting martyrs reinforced a distinctively Scottish sense of religious identity. [...] Although the covenanters were driven by a religious cause, they were part of a much more significant political shaping of the nation. ${ }^{102}$

This was, if not the first, one of the first examples of explicitly national martyrology. However, this was not a nation-state martyrology in modern terms, since it was still based on the medieval conception of the relationship between secular political authority and divine sovereignty. The concept of sovereignty, in other words, was not yet secularized. Interestingly, the modern concept of state sovereignty, which is the basic principle underlying the dominant Westphalian model of state foundation, emerged in the context of the European wars of religion. Jean Bodin, though he did

101 Middleton 2014, 128.

102 Middleton 2011, 114-115. 
not invent sovereignty, was certainly the first who conceptualized it in a systematic manner. In his masterwork Les Six Livres de la République, published in 1576, Bodin sought to find a way to end chaos and war, which he perceived to be the natural result of the feudal order, in which principalities, guilds, cities, and trading unions were formally united under the Church and Emperor, but which did not have the power to subdue the others in a time of crisis. According to the French jurist and philosopher, the sovereign must be both able to create laws ex nibilo (the «positive law») and free to break them at his own discretion, otherwise he is bound to the laws he creates and therefore can no longer be the sovereign. ${ }^{103}$ After experiencing religious wars himself, Bodin's goal was «to make civil law the will of the sovereign» in order «to undermine some of the impact of customary and natural law. Effective law becomes the command of the sovereign.»104 Thus, he conceives sovereignty as absolutely independent from the subjects, inasmuch as the sovereign becomes the source of his own legitimacy responsible only to God.

Despite Bodin's unquestionable importance for the development of state theory, the "father» of the modern narrative of sovereignty is Thomas Hobbes. Like Bodin's most famous work, the Leviathan was also a political answer to the historical context of religious wars. Thomas Hobbes published the Leviathan in 1651, three years after the end of the Thirty Years War. The anthropological assumptions on which the theory is founded reflect the experience of violence and terror. As we saw in chapter two, according to Hobbes, people, by entering into society, agree to give up their «natural» sovereign rights in order to avoid constant civil wars and anarchy, to which humans are prone due to their «evil» human nature. Since the sovereign is not bound by this original contract, there are no limits to his authority. While Bodin bases the legitimacy of the sovereign on the divine sanction, Hobbes builds his own on the social contract between «naturally free and equal» individuals. Hobbes is thus the first thinker who really secularized the concept of sovereignty; but the «secret index» of the theological understanding of sovereignty continues to operate implicitly in Hobbes' conceptualization. The idea of an absolute enemy, which can potentially destroy society from the inside or outside, is in fact itself the product of a signature from the pragmatic hermeneutical context of Christian religion and theology to a secular one. An eschatological conception of history deprived of the idea of a messianic salvation is the basis of a mythical

103 See Fuller 1966, 19.

104 Vincent 1987, 54. 
narrative in which the state monopoly of violence becomes an undisputed dogma.

It is in this historical, pragmatic and hermeneutic context that the state martyr figure was able to emerge. The statalization and nationalization of the martyr is the product of the mutual relationship of influence between the modern discourse of sovereignty and what Foucault calls discourse about race struggle. The secularizations of an eschatological understanding of history-history which is now understood as the battlefield in which society within national borders is permanently threatened by internal and external enemies-, sovereignty and the martyr figure are constitutive moments in the development of a modern political religion. Marcela Cristi proposes a definition of political religion that resumes, criticizes and develops Robert N. Bellah's concept of civil religion, which I consider useful for the purposes of this study. Bellah defines civil religion in America «as a genuine vehicle of national religious self-understanding», which provides a «transcendental goal for the political process» and contributes to the unity and collective identity of Americans. ${ }^{105}$ More than three decades after Bellah's publication, Cristi adopts some central aspects of this definition, but makes remarkable changes:

Civil religion is concerned with both the social and the political order. Civil religion tends to sacralize certain aspects of civic life by means of public rituals and collective ceremonies. [...] Civil religion may be considered a belief system or, a surrogate religion that expresses the self-identity of a collectivity. Yet, like secular ideologies of different kinds, civil religion may also attempt to force group identity and to legitimize an existing political order by injecting a transcendental dimension or by putting a religious gloss on the justification. This latter manifestation I call political religion. ${ }^{106}$

According to this definition, political religion has one modus operandi and two functions. The term «sacred» indicates the modus operandi. Civil religion operates through practices of sacralization, which are identified with rituals and ceremonies. Those practices are anchored in a system of beliefs, which seems to be both the fundament and the product of sacralization practices. Their functions concern two areas of human life: social and political organization. First, sacralization causes identification of the individual with collectivity and, second, there is a legitimization of the political or- 
der. Although not explicitly stated, the difference between political religion and other kinds of ideologies, which Cristi terms «secular», is that the former gives political and social order a transcendent dimension. It is necessary to postulate this distinction, otherwise the concept of political religion would lose all heuristic value.

Cristi stresses the political and ideological implications of political religion. According to Cristi, Bellah was strongly influenced by Durkheim, who «conceives religion as essentially a spontaneous phenomenon.» ${ }^{107}$ Due to this adoption of Durkheim's «consensual tradition», Bellah's notion of civil religion is not useful in studying those cases in which political religion is used as a tool to further national policies or programs. Cristi proposes combining the theoretical model of Durkheim with that of JeanJacques Rousseau, that is, conceptualizing political religion on the basis of its dual manifestation: as a culture and an ideology. Durkheim's notion allows one to take into account elements of spontaneity within political religion. By contrast, the Rousseauian model allows one to consider the possibility of the imposition of political religion.

Indeed, Rousseau-despite calling it «civil religion»—conceptualizes a political religion that is designed and controlled by the state. He hypothesizes that this form of religion is necessary for the proper functioning of a good republican political order. The main function of political religion is to ensure the loyalty of citizens to the social contract, the law and the nation. He considers Christianity (and all forms of positive religion) inadequate to fulfill this task; there must be a «purely civil profession of faith, the articles of which it is the business of the sovereign to determine.» ${ }^{108}$ The articles are the following: there is a benevolent god; there will be life after death; the just will be rewarded and the wicked punished; the social contract and the laws are sacred; sectarian intolerance is prohibited. ${ }^{109}$

Rousseau, like most Enlightenment thinkers, believed that Christian religion was destined to disappear with the collapse of the old regime; but he also believed in its indispensability as a source of transcendental morality for the legitimization of the state. This is why his philosophical project called for the creation of a new religious belief. This is the meaning of the adverb "purely» in the citation above: Rousseau considers a form of faith purged of the language and the mythologies of positive religions, primarily Christianity. Rousseau leaves no doubt that political religion must be im-

107 Cristi 2001, 7.

108 Rousseau 1994, 166.

109 See Bertham 2004, 185. 
posed. The state must fix its own cult, its dogmas and its language forms. But is it possible to shape an ideology that is not articulated by the semantics, narratives, and rituals from earlier traditions of thought and action? To rephrase the question: is it possible to create a new religious language and way of social acting from nothing?

There are two passages in Rousseau's oeuvre that I consider important to highlight why the idea of a «pure» civil religion should be considered abstract and ahistorical. Those passages also help to establish a connection between the issue of political religion and that of martyrdom and, in particular, the emergence of national martyrs. The first passage is situated at the end of his Social Contract and clarifies the way in which the state should impose civil religion. Rousseau writes that «it does concern the state that each citizen should have a religion which makes him cherish his duties» and that if a citizen is «incapable of cherishing the laws and justice sincerely, or of sacrificing, when necessary, his life for his duty", he or she should be banished from the state by the sovereign. ${ }^{110}$ The second passage is situated in his Discourse on Political Economy:

If it were to be said that it is well for one to die for the sake of all, I should admire the saying in the mouth of a virtuous and worthy patriot who voluntarily goes to his death out of duty, for the good of his country; but if the meaning is that a government is permitted to sacrifice an innocent person for the good of the mass, I hold this maxim to be one of the most execrable that tyranny has ever invented. ${ }^{111}$

For Rousseau, a state that sacrifices its citizens is tyrannical, but a citizen who is not willing to sacrifice himself or herself does not have the right to participate in the rights and civil liberties guaranteed by the state and should be banished. If the state cannot force citizens, the only option that remains is to convince them that it is right to sacrifice themselves for the state. This is where the ideological dimension of civil religion becomes visible: «Good citizenship [...] has to be imposed and enforced through what Willaime has called L'Etat éducateur.» ${ }^{112}$ However, what means does the state have at its disposal to convince people of the necessity of the state itself to the point that they are willing to sacrifice their lives for it?

During and after the French Revolution, many people died due to their belief in the values and principles of the Republic. Many of these devout

110 Rousseau 1994, 166.

111 Rousseau 1994, 19.

112 Cristi 2001, 29. 
citizens were at the center of a new, specifically republican, form of devotion. As indicated by historian Albert Soboul, particularly with the increasing importance of the sans-culottes in political life, popular worship developed around the «martyrs of freedom», which goes hand in hand with the processes of dechristianization. ${ }^{113}$ The most famous martyr of the French Revolution was certainly the deputy and journalist Jean-Paul Marat. ${ }^{114}$ «In memory of Marat», wrote Soboul, «sans-culottes saw an affirmation of their republican principles, a form of popular communion, an exaltation of their revolutionary faith.»15

Political rhetoric played a significant role in the formation of this new form of worship. On 1 Brumaire an II (1793), citizen Pannequin delivered an Eloge de Marat before the societé populaire of the Section de Picques. In this speech, Marat, who was killed in June of that year, was honored as «'apôtre et le martyr de la liberté». ${ }^{116}$ As noted by Joseph Clark:

from the opening assertion that Marat had sanim[é] le néant, recré[é] la nature to the conclusion that the immortel ami du people» was «le ministre envoyé de la part du Dieu de la nature, pour porter la parole de vie parmi les peuples qui marchaient dans les ombres de la mort>, Pannequin's Eloge was saturated with biblical allusions and messianic motifs. ${ }^{117}$

The birth of this republican martyrology shows why Rousseau's «purely civil profession of faith» is a problematic concept. It does not consider that faith in and commitment to any kind of values or principles cannot be born or develop in a vacuum, but are instead born of necessity and always articulated by adopting practices and language forms which are socially, culturally, and linguistically predetermined. The idea of the heroic sacrifice in the popular imagination turns into a cult of the martyrs. The cult of the «martyrs of freedom» resumes and iterates semantics, narrations and rituals that were developed and established within the Christian tradition. ${ }^{118}$

113 Soboul 1966, 332.

114 See Soboul 1966, 331-337; Schechter 2014, 161.

115 Soboul, 1966, 335.

116 Quoted in Clarke 2007, 171.

117 Clarke 2007, 171.

118 It is not irrelevant to note that the French Revolution also produced martyr figures on the opposite political front, namely the Catholics and counter-revolutionaries. A famous example is that of the martyrs of Compiègne. It is even more significant that the murderer of Marat Charlotte Corday acquired the status of a martyr of the counter-revolution. This means that there were two com- 
From this point of view, republican martyrology can actually be considered a narrative that functions analogously to political religion as defined by Cristi. Firstly, martyrs were figures with which citizens who were loyal to the revolutionary project and the Republic could identify. Their representation and adoration as martyrs make them excellent symbols of the "political body». At the same time, the cult of the martyrs certainly functioned to legitimize the new political order and delegitimize the ancient régime. Their death was a sort of manifestation of the truth of republican principles, since they demonstrated the will of the sovereign citizens to die for the sovereign state.

Unlike the thoughts and hopes of Rousseau, the civil religion of the First Republic was articulated by taking up and reframing forms of representation that belonged to the semantic and symbolic system of the Christian tradition. Does this mean that we must deny the secular nature of the revolution and, with it, the modern sovereign state? Not at all. Both are results of the secularization process. I argue that it is precisely due to the process of secularization that the state martyr figure was able to emerge and quickly spread. On the threshold between the Middle Ages and modernity and with the emergence of nation-states, the martyr figure underwent a macrosignature through which it was transposed from the pragmatic and hermeneutic context of Christian religion (and theology) to a secular (and political) one. This transfer was possible because the figure of the martyr soon proved to be useful for the construction of the mythical narrative of the nation-state and able to appeal to the people by making them feel part of a new form of political community called the Republic. The birth of the modern narrative of the nation-state and the secular signature of martyrdom are closely linked historical phenomena.

Here it is important to draw attention to the close link between the secular use of the rhetoric of martyrdom, the birth of the nation-state and human rights discourse. As Agamben noted,

in the system of the nation-state, the so-called sacred and inalienable rights of man show themselves to lack every protection and reality at the moment in which they can no longer take the form of rights belonging to citizens of a state. [...] This is in fact implicit in the ambiguity of the very title of the French Declaration of the Rights of Man and

peting martyrologies: one revolutionary, secular, and republican; the other counter-revolutionary, religious, and Catholic. They were narratives in competition, but they referred to the same language and rhetoric. 
Citizen, of 1789. In the phrase La déclaration des droits de l'homme et du citoyen, it is not clear whether the two terms homme and citoyen name two autonomous beings or instead form a unitary system. ${ }^{119}$

This ambiguity is also present in the state martyr figure, which functions as a witness to the truth of universal principles, yet simultaneously serves as a symbolic political body for the citizens of a particular nation. As Hannah Arendt argues,

The reason why life asserted itself as the ultimate point of reference in the modern age and has remained the highest good of modern society is that the modern reversal operated within the fabric of a Christian society whose fundamental belief in the sacredness of life has survived, and has even remained completely unshaken by, secularization and the general decline of the Christian faith. [...] No matter how articulate and how conscious the thinkers of modernity were in their attacks on tradition, the priority of life over everything else had acquired for them the status of a sself-evident truth».120

Just as modern political thought regards the sacredness of the life of the individual as a sacred truth encoded in the various declarations of human rights and constitutions of nation-states, it considers that the sovereign state must hold the monopoly on violence to be equally true and that, in exceptional situations, political authority has the right, if not the duty, to suspend human rights, that is, to reduce individuals or groups to mere life. This is undoubtedly one of the constitutive paradoxes of modern political thought: it tries to unify two ways of conceiving the sacredness of life, which, in reality, are diametrically opposed. On the one hand, there is the idea that life is sacred as part of the universal community of humanity; on the other hand, life is sacred in the sense that it can always potentially be killed (or left to die) in order to save and defend particular communities within the borders of nation-states.

Modern state martyrologies should be regarded ultimately as nothing more than very effective narratives concealing this paradox and ambiguity. The state martyr is one who, by dying, witnesses the necessity of the sovereign state as a guarantor of human and citizens' rights and national security. It is therefore no longer a testimony to the truth of the founding events of Christian religion - the liberation and salvation of the righteous

119 Agamben 1998, 126.

120 Arendt 1998, 314, 319. 
through the death and resurrection of Christ, which prefigure the death and resurrection of all the righteous in the future universal communityand an accusation of a political authority that decides over life and death. On the contrary, the state martyr figure is an instrument for the concealment of the real functioning of sovereign power, part of a complex mechanism, which, ultimately, has only one function: the maintenance and constant revival of modern state mythology. 


\section{Cultural, Social and Political Context of the Event of Political Violence}

\subsection{The Rhetoric of Sacrifice During the Risorgimento and the Resistenza}

The previous chapter demonstrated that the rise of both the ideology of nationalism and of modern nation-states is intrinsically linked with the emergence of the state martyr figure and the rhetoric of sacrifice for the nation. The chapter exposed the long process of re-signification by which the martyr figure ceased to be part of a discourse of rebellion that delegitimizes any kind of established political authority and became part of the modern discourse of sovereignty. Now I will turn to the specific case of political violence on which this study focuses: the kidnapping, imprisonment and murder of Aldo Moro. This chapter will first describe the presence and function of the rhetoric of sacrifice and the martyr figure in two key moments of Italy's modern political history: Italian unification or the Risorgimento, namely the political and social movement that consolidated the different states on the Italian peninsula into the single State of the Kingdom of Italy in the nineteenth century; and the Resistenza against Fascism before and during World War II. Understanding the consolidation of the idea of sacrifice and of the state martyr figure within these two key moments of Italy's modern history is fundamental, since the memory of both-but especially of the Resistenza,-profoundly determined the Italian political imaginary and the identity of the Italian people after World War II. Moreover, the Resistenza, both as a myth and as a historical movement, is ubiquitous in the discursive and cultural practices that refer to the kidnapping, imprisonment and assassination of Aldo Moro.

Nationalism profoundly shaped the actions of peoples and states in the nineteenth century. As Hans Kohn points out in his book The Idea of $\mathrm{Na}$ tionalism, nationalism encompasses the oldest feelings of man, such as the predisposition to love one's place of birth or childhood, the predilection for one's mother tongue and domestic customs, and, finally, the tendency to be proud of one's own way of life and to look down on other ways of life or face them with mistrust. ${ }^{1}$ It was only at the turn of the nineteenth

1 See Kohn 1944. 
century, however, that politicization of broader sections of the population within individual states was so advanced that the national feeling, which heretofore was rather spontaneous, became ideologically substantiated.

The age of absolutism had a great significance for the formation of nationalism, because during this period the princes created the modern state, and thus the vessel of modern nationalism was prepared. Without the concentration of power in the hands of the sovereign, and without the leveling of older social structures as a result, the essential prerequisites for the enforcement of nationalism would have been lacking. The centralization of political power in the state, both internally and externally, had already been accompanied by nationalist sentiments in the seventeenth century, particularly in the confrontation of Europe with Louis XIV. The decisive intellectual work for the formation of national understanding was conducted in the second half of the eighteenth century, especially by the East Prussian Johann Gottfried Herder (1744-1803). Herder thought he could recognize the character of peoples in folk songs; they appeared to him as an expression of their heart and soul. He claimed that all manifestations of life of a people were emanations of their specific life principles. For Herder, the peoples were unities who developed organically, and were thus creatures of God, which differed from other unities in their own destiny and tasks.

Modern nationalism fully developed with the French Revolution. The conception of the Third Estate as a nation was conceived above all as a weapon against antiquated social stratification, but was also quickly used against external «enemies». During the external struggles of the revolutionary period, the loyalty of the French strongly focused on their nation. It was not just a question of defending the rights of the nation against the resistance of European monarchies, but it was argued that, through its recent history, France had enacted a world-historical event and thus had the right to claim leadership in Europe.

One of the most influential thinkers of Italian nationalism and republicanism was Giuseppe Mazzini (1805-1872). In his publications and correspondence, he repeatedly argued that Italy played a world-historical role. Just as Italy had already strongly influenced the culture and institutions of Europe in antiquity and again in the Renaissance, its task now was to open up the age of nations through their rebirth and thereby take over spiritual leadership. Mazzini was convinced that only democracy could lift the peoples. His belief that freedom, equality, and fraternity were only guaranteed in the Republic defined him as a Republican. He idolized the people in a similar way to romantic French nationalism. Mazzini was, with Giuseppe 
Garibaldi, one of the most prominent Carbonari revolutionaries because of his actions during the unification of Italy or Risorgimento and his spearheading of the Italian revolutionary movement. ${ }^{2}$

Another leading exponent of the Risorgimento was the Italian clergyman, philosopher and first President of the Chamber of Deputies of the Kingdom of Sardinia, Vincenzo Gioberti (1801-1852). In one of his most important writings, Del primato morale e civile degli Italiani, he maintained that the Italians always exceeded all nations in art and science; they were the most «universal» of all nations and the center of Christianity. According to Gioberti, Italy sunk from its greatness by turning away from Catholicism to political thought, similarly to France. For this reason, he encouraged a return and renewal of Catholic thought. Catholicism and the papacy thus gained high importance. Gioberti did not regard the papacy as an obstacle, but rather as conducive to Italian unification. ${ }^{3}$

According to Maurizio Viroli, republican political writers of the eighteenth and nineteenth centuries wanted to resurrect a religion that he describes as «civic Christianity», which appealed to Italian people in defending republican liberty and serving the common good. ${ }^{4}$ Viroli distinguishes between three different ways of appealing for the «resurrection of religion»: some writers wanted to renew the Christian religion and make it compatible with liberal values; others, though with less success, tried to model civic religion on Rousseau's religion civile; and others wanted to develop a religion of duty and liberty compatible with, but not identical to, Christian religion. All of them, however, were united by the conviction that religious sentiment was necessary to unite the Italian people. ${ }^{5}$

As Viroli highlights, in the discursive practices of the Risorgimento, cultural studies identify the conception of the nation understood as a

community of combatants united in a sacred commitment to uphold the quasi-metaphysical entity of the patria/nazione (fatherland/nation), whose distinctive features are kinship (parentela), love/honor/virtue (amore/onore/virtü), and sacrifice (sacrificio), with its grim complements of pain, death, and mourning. [...] The nation was imagined as a «community of progeny> (comunità di discendenza) that reaches back to great figures of the past who belong by natures to the community they have illuminated with their deeds. [...] The biological nexus between gener-

2 See Fenske 2003, 476-477.

3 See Fenske 2003, 476-477.

4 Viroli 2012, xv.

5 See Viroli 2012, xv. 
ations and individuals, summarized in the word blood, was regarded as a fundamental feature of the nation. In addition, the religious connotation of the Risorgimento's nationalism clearly emerges from the relentless use of religious words like «regeneration', sapostolate), faith, 〈resurrection〉, holy war», and «crusade〉. ${ }^{6}$

The protagonists of the Risorgimento, Viroli claims, «drove action, to the point of self-sacrifice.» ${ }^{7} \mathrm{He}$ offers the example of Luigi Settembrini, who «embodied a model of religiosity that inspired generous actions for one's country» and promoted «a religion of virtue and liberty that his father taught him, with reference to classical and Christian examples.» ${ }^{8}$ Settembrini, who was affected by the wave of liberalism that spread throughout Italy at that time, and who soon after his marriage began to conspire against the Bourbon government, was arrested in 1839, imprisoned in Naples, and liberated three years later. After being arrested, Settembrini awaited the court's verdict and, fearing a death sentence, wrote to his wife declaring his willingness to accept martyrdom:

If I am sentenced to death, I can promise on our love, and on the love we have for our children, that your Luigi will not betray his principles; I will die with the certainty that my blood will bear good to my country; I will die with the serene courage of the martyrs. ${ }^{9}$

The willingness to become a martyr during the Risorgimento is also exemplified, Viroli claims, by the "martyrs of Belfiore», who were put to death by the Austrian government between 1851 and 1855 . The priest and organizer of the anti-Austrian insurrection plan, Enrico Tazzoli, stressed the duty of Catholic priests-three of the sentenced were clergymen - to be willing to engage in self-sacrifice for the fatherland. Similarly, Father Luigi Martini exalted the Christian faith of the sentenced, arguing that their love of the fatherland coincided with the Christian message. Martini glorified Tito Spoeri, the most famous among the pro-independence fighters sentenced to death in the valley of Belfiore, as someone who approached capital punishment in the spirit of a Christian martyr. He wrote that Spoeri found great consolation in reading the Gospel, strived to conciliate God and the people and both religion and the fatherland, and maintained that

6 Viroli 2012, xvi-xvii; see also Mario Banti/Ginsborg 2007; Mario Banti 2000.

7 Viroli 2012, 140.

8 Viroli 2012, 141.

9 Settembrini 1934, 239 (trans. Viroli 2012, 141). 
only the religious spirit could afford the nation's Risorgimento with the necessary strength.

According to Viroli, this and other examples «illustrate the difference between the new religion of liberty and Rousseau's old idea that liberty requires the repudiation of Christianity.» ${ }^{10}$ The Italian Risorgimento, he argues,

was an experience of political emancipation made possible by a twofold process: a departure from the republican religion introduced by the Jacobins, and the rediscovery, in the great riverbed of Christianity, of a religious conception that pointed to moral and political liberty as the supreme duty, and therefore openly opposed the doctrine and practice of the church-although the Catholics who became witnesses and apostles of the new faith were neither few nor unimportant. ${ }^{11}$

I am quite skeptical about the heuristic value of this distinction between the French republican religion and an Italian "new religion of liberty», since, as we have seen in the previous chapter, Christian language and narratives were secularized, iterated and used in the context of the French Revolution and during the formation of the French First Republic, though in a less explicit way than in Italy. Finally, martyrological representations had, from a strictly political point of view, the same function in both countries, namely to frame national identity and to construct a mythology of the republican state. However, Viroli's excellent and inspiring study demonstrates how the figure of the republican martyr, also a state martyr figure, in the Italian pragmatic and hermeneutic context of the nineteenth century was able to emerge and be consolidated in a more effective, explicit and lasting way than in France. This is most likely due to the fact, as Jenny Ponzo observes, «that Italian «civil religion» tends to manifest itself in-and to identify itself with - a syncretic set of practices combining institutional, ideological, Catholic, and sub-Christian elements.» ${ }^{12}$

Also in the context of the Resistenza against Fascism, the rhetoric and language of martyrdom was diffuse. As Viroli points out, the stories of two radical liberal intellectuals, journalist Piero Gobetti (1901-1926) and politician Giovanni Amendola (1882-1926), «two of the most prominent early martyrs of antifascism», reveal the great importance of religious sentiment

10 Viroli 2012, 144.

11 Viroli 2012, 153.

12 Ponzo 2017, 142. 
and language in the early Resistance. ${ }^{13}$ The former advocated «a more spiritual religiosity, a heroic morality that guides the life and action of man and peoples», ${ }^{14}$ while the latter approached the Gospel «with a soul free from apostolic ends, and only yearning after reproaching the pure expression of humanity.» ${ }^{15}$ Although the Vatican had an ambiguous relationship with Fascism, opposing it with little or no resistance and often even openly helping the regime, there were undoubtedly many Catholics who opposed the regime. Many leftist Catholics in particular understood and described resistance to Fascism as a Christian duty. Priest Giovanni Minzoni, killed by Fascists on August 23, 1923, wrote in the same year:

Today I realize that a much harsher battle is waiting for me. We are tenaciously preparing for the fight, and with weapons that for us are sacred and divine, those of the first Christians: prayer and goodness. Retreating would entail renouncing a sacred mission. With an open heart, and the prayer for my persecutors that I hope will never die from my lips, I am waiting for the storm, persecution, and perhaps death for the triumph of the cause of Christ. ${ }^{16}$

Similarly, Catholic journalist and politician Igino Giordani (1894-1980), in Rivolta Cattolica, published in 1925, openly exhorted Catholics to revolt in the name of their faith and insisted on the anti-Christian and antiCatholic character of nationalism. Don Luigi Sturzo was of the same opinion, arguing that Fascism erected a Leviathan «that absorbs every force and becomes the expression of an impending political pantheism»; ${ }^{17}$ according to him, Fascism, like all forms of totalitarianism, had a deeply anti-Christian character, since «idolatry $[\ldots]$ is the totem of primitive societies, the symbol of the clan, the tribe, the race, the nation.» ${ }^{18}$ Another Catholic, the editor of the party newspaper Il Popolo Giuseppe Donati (1889-1931), highlighted the importance of religious values in the commitment to democracy by referring to Mazzini:

All politics is inspired by spiritual principles and is oriented to spiritual purposes [...]. This is why we call ourselves, besides democrats, Christian as well. The movement of the Christian Democrats is con-

13 Viroli 2012, 185.

14 Gobetti 1969, 75 (trans. Viroli 2012, 181).

15 Amendola 1953, 143 (trans. Viroli 2012, 183).

16 Quoted in Palumbi 2003, 24 (trans. Viroli 2012, 187).

17 Sturzo 1965, 258 (trans. Viroli 2012, 189).

18 Sturzo 1967, 286 (trans. Viroli 2012, 190.). 
nected with the purest traditions of our Risorgimento. Mazzini said that either democracy will be religious, or it will not exist». And for us, as for Giuseppe Mazzini, religiosity is nothing other than the spirit of duty that drives us to sacrifice and complete commitment to the triumph of an ideal. These spiritual values are expressed in the purest form of Christianity, which is a law of love, freedom, justice and charity especially for our fellow human beings. ${ }^{19}$

In some cases, the Catholic opposition to Fascism was expressed by referring explicitly to Christian eschatological language. This is the case of philosopher Piero Martinetti (1872-1943), who in Gesù Cristo e il cristianesimo, published in 1934, argued that the official Catholic Church was too distant from the Church of Christ, which was «a persecuted sect of the poor and the humble». He also affirmed that, though the Kingdom of God could never be realized in history,

no obstacle whatsoever can obstruct the renewal of that pure Christian tradition that rises above the history of the churches like the celestial Jerusalem, which in the Apocalypse rises from the ruins of heaven and earth. In all times, there have been men who, inspired by the sacred traditions of the gospel of Jesus Christ, have raised themselves to the eternal gospel written in the depth of the human spirit; they have not built kingdoms, nor have they founded churches, but have conserved among men the tradition of truth. ${ }^{20}$

Martinetti's language and eschatological narrative were not related to the concepts of nation and fatherland. He iterated and recontextualized the radical rejection of violence against and exploitation of the "poor and humble» by political authorities, which he found originally expressed in the Gospel and especially in Paul's letters. He, in other words, recalled the narrative of rebellion against established political power without mixing and linking it with the narrative of sovereignty, which, as we saw, in modernity is always related to the mythicization of the nation-state.

The situation is different with regard to historian Adolfo Omodeo (1889-1946), who cultivated the idea of bringing together the traditions of the Risorgimento and ancient Christianity. His political ideas are a perfect example of the interaction between the discourse of rebellion and the discourse of sovereignty identified by Foucault. For Omedeo, the man of the

19 Donati 1971, 139-140 (trans. Viroli 2012, 190-191).

20 Marinetti 1923, 170 (trans. Viroli 2012, 202). 
Risorgimento «lived a new faith» and embodied the nation «just as the seven thousand Israelites who at the time of Elija had knelt down before Baal embodied the true Israel», ${ }^{21}$ because «they were aware that they were working and suffering for Italy and a universally human ideal, which pertained to all men.» ${ }^{22}$ Through the mechanism of prefiguration, Omodeo represents Italy here as the Promised Land. As Viroli points out, he understood the resurrection of Italy as the revelation of divine assistance to the people. However, confronted with the «fanatical fury of nationalism and iron dictatorship», a sort of Christian cosmopolitism matured in him. Recalling the spiritual condition that oriented his studies, in 1946 he wrote that

without repudiating my country, I felt a broader fatherland was arising, which comprises everything that all the peoples have acquired (also within the worship of their own countries) according to universal values. $^{23}$

This reproduces the same kind of ambiguity that, as we saw in the previous chapter, characterizes the French Declaration of the Rights of Man and Citizen, and which creates a constitutive paradox of modern political thought: the contemporaneity of particularism and universalism, a universalistic idea of ethics and a particularistic conception of the mission and tasks of a nation or, as Omodeo expresses it by referring to Mazzini, of a civilization:

The whole history of mankind is the gradual revelation of divine providence. [...] Once the task of Christianity has been resolved in the new religion of progress, and once an era has ended rather than begun with the French Revolution, one must usher in a new era that is at once social and religious. To Italy, which should rise again as if it had to show the miracle of the forces that can restore faith, falls sthe initiatives that will give to the world a third Italian civilization, and not with the force of arms, or with a theocratic dominion, but with the association of free peoples, who have to proceed together toward the divine end. [...] This faith endowed many with the courage to take action and, instead of dismaying them in the objective calculation of the facts, exalted them to the point of martyrdom. ${ }^{24}$

21 Omodeo 1951, 444-445 (trans. Viroli 2012, 203).

22 Omodeo 1946, xviii (trans. Viroli 2012, 206).

23 Omodeo 1970, 5 (trans. Viroli 2012, 209).

24 Omodeo 1946, 304, 308 (trans. Viroli 2012, 207). 
Now, these examples demonstrate that both in the context of Italian unification and in the context of resistance against Fascism, the discourse of rebellion expressed through the rhetoric and language of sacrifice and martyrdom was diffuse, helping to invite people to resist and fight against established political authority. In the context of the Risorgimento, the idea of martyrdom was intrinsically bound with national identity, the willingness to sacrifice oneself for the fatherland. During the Resistenza, the discourse of rebellion could be articulated, in some cases, without reference to the nation. Nonetheless, many promoters and fighters of the Resistance used patriotic and national rhetoric to frame and give meaning to their actions. The myths of the nation and the fatherland, inherited from the eighteenth and nineteenth centuries, were simply too widely disseminated and embedded in culture and political consciousness.

According to Viroli, it is a mistake to confuse the «universalistic ideal of the patria» with the "particularistic idea of nation», since, «in the first case, we have a civil religion centered on the political and moral value of liberty, which sustains liberal and republican institutions» while, in the second case, «we find a political religion centered on the principles of cultural and or ethnic homogeneity and uniqueness, designed to uphold domestic political and social discrimination or aggressive foreign policy.» ${ }^{25}$ Here I disagree with Viroli for the simple reason that «patria» and «universality» are two mutually exclusive concepts or ideas. Since the term "patria» (the Latin term for «fatherland») frames peoples metaphorically as families, the attribution of «universality» to it makes sense only on the condition of describing humanity as a family and earth as the «fatherland» of humanity.

However, it is important to emphasize that within the discourses and narratives produced in the context of the Resistenza, the rhetoric and language of sacrifice and martyrdom were not only used to appeal to a patriotic defense of the nation and to frame national identity. The line of continuity traced by Viroli between Risorgimento and Resistenza, and the attribution of a new «religion of liberty» to men and women who fought in both contexts of struggle, is questionable. In fact, as Norberto Bobbio and Claudio Pavone indicate, the Resistance, unlike the Risorgimento, was characterized by the overlapping of three wars: patriotic war, civil war, and class war. ${ }^{26}$ In other words, the Resistenza was not a «second Risorgimento», as argued by a certain Italian historiography for some time. ${ }^{27}$

25 Viroli 2012, xvii.

26 See Bobbio 2015; Pavone 2006.

27 See Bidussa 2015, ix. 
Like in other European countries occupied by the German army, the Resistance was a national liberation struggle against the imposition of the Nazi regime. As such, the idea of the patria played a fundamental role. But on a second level, it was not only a movement seeking to liberate the nation from foreigners, but also from a regime that had established a regime of dictatorship and abolished all constitutional liberties. Most resistance movements in other countries were exclusively patriotic warfare movements, while in Italy the Resistance was both a patriotic and an antifascist movement against the external and the internal enemy. Thus, the Resistance held the dual significance of a national (against Germans) and political liberation struggle (against Fascist dictatorship) for the regaining of national independence and political and civil freedom. Finally, as Bobbio argues, it was «a movement of social emancipation [...], the only great popular movement in the history of modern Italy.» ${ }^{28}$ Therefore, «there were those who fought the Resistance exclusively as patriotic warfare; those who fought it also and above all as an antifascist war; finally those who adhered to it with the impetus and hopes of social renewal.» ${ }^{29}$

The rhetoric and language of sacrifice and martyrdom were implemented by all political fronts in this three-sided war. In fact, Fascist propaganda had its own martyrological representations and rhetoric of self-sacrifice for the fatherland's glory. The philosopher Giovanni Gentile, one of the most famous ideologues of the regime, wrote for example that «Fascism is a religion, political and civil, because it has its own conception of the state and an original way of conceiving life. [...] Christian martyrs and the young heroes of the Fascist revolution have confirmed, through the ages, a bright reality: only a religion can negate and undo the attachment to mundane life.» ${ }^{30}$ As there was widespread use of the rhetoric of sacrifice and martyrdom on the popular Catholic front faced with Italian Fascism, there was also a use of such rhetoric, though to a lesser extent, by Communist and Socialist partisans. ${ }^{31}$ In general, the importance of the figure of the martyr during the Resistenza, and even more in its memorialization after the end of the war, is demonstrated by the name given to so many antifascist brigades, such as the Brigata Martiri della Grappa, Brigata Garibaldi Martiri di Lovere, Brigata Martiri della Val Leogra, Brigata Garibaldi Martiri di Alessandria, to name a few. The same can be said about the toponymy of

28 Bobbio 2015, 7.

29 Bobbio 2015, 8.

30 Quoted in Gentile 1993, 117.

31 See Perona 2000; Spriano 1975. 
public places: piazza Martiri della libertà, piazza Tre Martiri, Cava dei Martiri, Casa del Martirio, and so on. ${ }^{32}$

In conclusion, the figure of the martyr and the rhetoric of sacrifice were used on all fronts of the patriotic, civil and class wars. As Pavone observes, in the civil war between Fascists and antifascists, the two sides contended for the recent past of the nation, especially the Risorgimento; while the Fascists' appeal to the Risorgimento was primarily national and patriotic, antifascists appealed to the Risorgimento as a historical affirmation of the general principles of freedom, justice and brotherhood. ${ }^{33}$ Both fronts resumed and iterated the sacrificial and martyrological language and rhetoric that, as we have seen, were extensively diffused in the discursive practices of the Risorgimento. For the Fascists, death in battle was equivalent to martyrdom for the glory of the nation, understood as the unity of the Italian race. On the opposite front, martyrdom and self-sacrifice could take on different meanings. Some understood and represented it as martyrdom for the establishment of a democratic and liberal Republic, while others saw sacrifice as the price in the fight for social justice, the victory of the proletariat and the formation of a socialist society without class differences.

Post-war Italians were the «children of the Resistenza», which was at the same time a war against foreign invaders, internal Fascism and for the radical transformation of society. ${ }^{34}$ After the end of the conflict, Italian people generally agreed that both foreign invaders and Fascists were defeated. On these first two levels, the Resistenza was regarded as successful, but those who held out revolutionary hope in the liberation war claimed that the Resistance had failed and that the dead had died in vain. On the opposite side, there were those who represented the Resistance as a second Risorgimento, as if a new Italy had been born; but, as Bobbio says, «truth, as always, lies in the middle: the Resistance was a rescue, not a revolution; a wake from a bad sleep filled with nightmares, not a complete metamorphosis.»35

32 See Collotti/Sandri/Sessi 2001.

33 See Pavone 2015, 35.

34 Bobbio 2015, 15.

35 Bobbio 2015, 12. 


\subsection{8-1978: Thirty Years of Italian Political History}

The great achievement of the antifascist Resistenza was the drafting of the Constitution, which came into force on 1 January, 1948, and was written by a ruling class formed by the elites of antifascist parties present in the National Liberation Committee. The Constitution resulted from a compromise achieved democratically between the two new political forces born or reborn after the collapse of Fascism: the worker movement, divided between the Italian Communist Party (PCI) and the Italian Socialist Party (PSI), which in the first elections of 1946 obtained together about 40 percent of the vote, and the Catholic movement, whose party, the Christian Democracy (DC), had solely 35 percent of the vote in the same elections. ${ }^{36}$ In the struggle against the regime, they had developed a common language and progressively created a project that excluded both the pure and simple restoration of pre-emptive liberalism and the revolutionary programs of Jacobinism or Bolshevism. Among the results obtained with the Constitution, the following should be remembered: Republic instead of monarchy; a second house, the Senate of the Republic, also democratically elected and no longer appointed from above; suffrage extended to women; recognition of political parties; the assertion of broader social rights alongside the reaffirmation of traditional rights of liberty; the establishment of a Constitutional Court called to safeguard the constitutional rights of citizens, even against Parliament. ${ }^{37}$

There are two major problems that the political elite was unable to resolve. On the one hand, democratic culture did not penetrate the whole country and antifascism found great resistance in vast territorial spheres and in large social strata. In fact, vast social strata, which were refractory and essentially indifferent to democracy, did not intimately accept the Constitution and in 1946 massively voted in favor of the monarchy. Francesco Biscione defines this set of substantially anti-democratic forces as the "submerged of the Republic», which influenced (and still influences) the political, civil and institutional life of the country. ${ }^{38}$ These submerged, anti-democratic forces with authoritarian tendencies determined the evolution of the Italian political landscape by inducing Alcide De Gasperi, leader of the DC, to change strongly, between 1946 and 1947, the face and attitude of his party, which in 1947 excluded Socialists and Com-

36 See Ginsborg 1990, 98-112.

37 See Bobbio 2015, 13.

38 See Biscione 2003; Biscione 2012, 35-40. 
munists from the cabinet. However, the exclusion of the PCI and PSI from the cabinet in 1947 must also be understood as directly connected with the incipient Cold War and De Gasperi's ambition to place Italy on the path delineated by the Truman doctrine, which would soon lead to the Marshall Plan.

The second problem in the Italian political landscape lay precisely in the failure to recognize the full political legitimacy of the leftist parties and, in particular, of what would soon be the largest Communist party in the Western bloc. The exclusion of leftist parties from the government converged with the formation of the Western bloc and corresponded to the US' political needs and goals. The PCI, which became the second Italian party after it had split from the PSI in 1947, placed the DC within the impossibility of acknowledging the Communists' legitimacy; the PCI was a democratically legitimized national force, yet ideologically and politically bound with the Soviet Union and the nascent Communist bloc. The DC thus assumed political and electoral primacy, which lasted for over forty years. It remained antifascist, especially at the summit, yet also represented anti-democratic and authoritarian social forces.

The DC was founded in 1943 as the successor to the Italian People's Party. After the war, the DC, with major US backing, was able to gain power by demonizing socialist or communist inspired revolutions. The DC was a mass party with a heterogeneous but predominantly bourgeoisie mass base, which appealed to people by focusing on the rhetoric of national security. Internationally, the DC gained the support of the US and NATO. Moreover, a NATO stay-behind organization called Gladio was established during the Cold War in Italy with the purpose of counteracting a possible attack on the Warsaw Pact's forces in Western European countries and combating communism with forms of psychological warfare and the use of false flag techniques. ${ }^{39}$ Antisocialist and anticommunist propaganda was also strongly supported by the Catholic Church. The institutional church repeatedly expressed itself with antisocialist and anticommunist vehemence in papal encyclicals and other pronouncements, as in a famous 1949 decree: the faithful who professed the doctrine of materialist and anti-Christian communism «will be treated as apostates to the Catholic faith,

39 Haberman, Clyde, «Evolution in Europe; Italy Discloses Its Web Of Cold War Guerrillas", New York Times, 16.11.1990, http://www.nytimes.com/1990/11/16/wor ld/evolution-in-europe-italy-discloses-its-web-of-cold-war-guerrillas.html (accessed August 22, 2017). 
in the excommunication procedure especially reserved to the Holy See.» ${ }^{40}$ After World War II, papal diplomacy had emerged as a key player in shaping the post-fascist future of Italy:

Following the abolition of the monarchy by popular referendum in June 1946, and given the effective absence of the organized anti-fascist parties and trade unions during the twentieth century, the Roman Catholic Church with its network of 24,000 parishes throughout the peninsula was now the major surviving National Italian institution. It is therefore not surprising that Catholicism, in various institutional forms, played a powerful and central role in the post-war reconstruction of Italy, social, economic, political and international. ${ }^{41}$

In Italy, as in most of Western Europe, there was a resurgence of Christian sentiment due to the fact that the Church as an organization had overcome the war as well as because of the need for a vision of the world that was not compromised by Fascism. Moreover, after the fall of Fascism people still wanted a political ideology that incorporated all aspects of life as Fascism had done. ${ }^{42}$ There was still a demand for political activity that could be integrated with life, and the DC, with the support of the Catholic Church, made this identification possible by offering a holistic view of life. In Italy, the decisive influence came from a school developed in France that renewed Christian thought. The DC found its ideal of Christian society, the idea that Christian virtues should be used for the construction of society, in the writings of Emmanuel Mounier and Jacques Maritain. By combining the old liberal ideas of representative government and political and economic freedom with the Christian personalism and humanism theorized by Mounier and Maritain, an ideology that allowed the transition from Fascism to a democratic society with a parliamentary regime was developed, keeping intact, at least initially, the possibility of integrating politics into everyday life. Many Christian Democrats believed Italian democracy could be expanded under their continued leadership. This belief, embodied by Alcide De Gasperi and later carried on by Aldo Moro, shaped the very strategy of the DC, which aimed to be a centrist party che guarda a sinstra-which looked to the left.

40 Decretum, 1.7.1949, Actae Apostolicae Sedis, 1949 (quoted in Pombeni 1977, 300); see also Drake 2008, 450-451.

41 Pollard 2008, 109.

42 See Mosse 2015, 5-13. 
Ever since January 21, 1927, when Amedeo Bordiga, together with fifteen other ex-Socialist party members (including Antonio Gramsci) founded the PCI, Communists have had a significant political presence in Italy. During World War II, many Communist and Socialist partisans believed the Resistance could and would have a revolutionary outcome and that they would be able to sweep away not only the residues of fascism but also the capitalist bourgeois state, an expectation encouraged by the success of Tito in Yugoslavia and the continuing Communist struggle in the Greek Civil War. When the Communist leader Palmiro Togliatti returned to Italy in 1944, he sought to dispel the idea of revolution by explaining to his comrades that, as Stalin had decided, revolution could not occur in Italy since it had fallen into the Western sphere of influence according to the terms of the Yalta agreement. Nevertheless, some Communists did not abandon their revolutionary dreams or hand over their arms to the Allied forces in May 1945: many simply buried them in their backyards to keep their hopes of a real proletarian revolution in Italy alive.

Although Communists had actively participated in the drafting of the Constitution, after May 1947 the PCI was excluded from all governing coalitions up to $1976 .{ }^{43}$ After the elections of 1946, the PCl's legitimacy and effectiveness was nearly decimated by the results of the 1948 national elections. As Wagner-Pacifici observes, «these elections, distinguished from the 1946 elections by the serious anti-Communist campaign of the DC, overtly and adamantly guided by Washington, effectively denied the PCI any formal participation in any national government, at least for the foreseeable future.» ${ }^{44}$ The election played a decisive role in changing the party's ideology and strategy, which gradually distanced itself from the Soviet bloc and the idea of a proletarian revolution by means of political violence. During the Resistance, Italian Communists-especially thanks to the patient political work of Palmiro Togliatti as well as to Antonio Gramsci's writings - had already become internationally known for their efforts to develop a specific Italian form of communism. Togliatti pursued a parliamentary route to socialism committed to working with the other "popular» and "progressive» forces in a government of Resistance Unity. This

43 Despite not being represented in the executive, the PCI constructed an entrenched and powerful political organization, which represented the interests and aspirations of several sectors of Italian society and was thus able to govern regions like the Red Belt of Emilia-Romagna, Tuscany, the Marches, and Umbria, and several important cities, such as Bologna and Florence, as well as Rome and Turin from 1975 to 1985.

44 Wagner-Pacifici 1986, 25. 
form of communism, which was known as la terza via (the third way), asserted a commitment to democracy and a gradually increasing refusal of the Soviet model. Togliatti strived to convince his comrades that Fascism was not essentially an elite regime, but rather a reactionary regime with mass characteristics and that, given the ability of reactionary parties to attract a heterogeneous mass of voters, the PCI had to appeal to people beyond traditional working-class voters, to the middle classes, in order to avoid the re-emergence of a reactionary movement. ${ }^{45}$

The PCI's break with the Soviet Union gradually unfolded. In 1956, following the invasion of Hungary by Soviet troops, there was enough dissent within the PCI to justify a break with the Communist Party of the Soviet Union (CPSU). The overthrow of Nikita Khrushchev in 1964 was another step in the direction of a definitive rupture. The definitive break took place after the invasion of Czechoslovakia by the Warsaw Pact countries. In 1969, Enrico Berlinguer, participated in the international conference of Communist parties in Moscow, where he challenged the CPSU's leadership and told Leonid Brezhnev that the invasion of Czechoslovakia clarified the insurmountable differences within the Communist movement on questions concerning national sovereignty, socialist democracy and the freedom of culture. One of the most important aspects of this rupturing process concerned the rhetoric of violent revolution. The majority of the PCI's leadership as well as its party newspaper L'Unità represented violence as a political instrument used by reactionary forces and was thus illegitimate in the fight for social justice and emancipation. Despite the Resistenza being remembered as a legitimate armed fight against Fascism, the party leadership began to say that the Resistance had not been a revolutionary movement. ${ }^{46}$

In 1973, Berlinguer wrote an article in the PCI weekly magazine $L a R i$ nascita, entitled Riflessioni sull'Italia dopo $i$ fatti del Cile ( Reflections On Italy After the Facts Of Chile»), in which he launched the project of a compromesso storico («Historic Compromise»), namely the project of a political alliance and accommodation between the DC and the PCI. According to Berlinguer, who explicitly referred to the «ever-impending menaces of reactionary adventures», the overthrow of the democratically elected Allende Government in Chile by General Augusto Pinochet with the help of the US administration of President Richard Nixon proved that the left could not aspire to govern in democratic countries without establishing compro-

45 See Wagner-Pacifici 1986, 26.

46 See Wagner-Pacifici 1986, 26. 
mises with moderate forces ${ }^{47}$ Berlinguer's fears about the possibility of a coup d'état in Italy were not completely unfounded. In fact, an envisaged plot-the so-called Piano Solo-for an Italian coup had been requested by the then President of the Italian Republic, Antonio Segni, and was prepared by the commander of the Carabinieri Giovanni de Lorenzo in 1964. Neo-fascist groups allegedly planned another failed coup d'état, which was named after Junio Valerio Borghese, an Italian World War II Fascist commander, in 1970. Berlinguer's most important ally in attempting to create an alliance between the DC and PCI was Aldo Moro. Aldo Moro was the central figure in Italian politics in the sixties and seventies. He was the most important DC strategist and the greatest interpreter of the role of the Catholic party in Italian society as an element of stability and progress. ${ }^{48}$

Born on September 23, 1926, in Maglie, Moro grew up in a middle-class home. At the age of twenty-one, Moro pursued a degree in law at the University of Bari and subsequently obtained an assistant professorship in the Philosophy of Law, History, and Politics. Moro arrived at the University of Bari with a deep attachment to the Church and a predisposition toward progressive Catholic thought. In 1939, he was elected president of the Federazione Universitaria Cattolica Italiana (FUCI). The traditions of reactionary Catholicism never tempted Moro, who early on became convinced that the crisis of modern culture could only be overcome by a new understanding of Christianity, not by a return to the outmoded and discredited past. From 1946 to 1948, Moro edited one of the most prestigious Catholic periodicals, Studium, an important vehicle for progressive Catholic thought: «In passionate and eloquent editorials inspired by the Church's tradition of social justice, from Rerum nouerum to Pius XII's wartime appeals for Christian mercy, Moro called upon the Italians to be tolerant, loving, and charitable. [...] Moro's Studium editorials chronicled his performance as a Christian Democratic delegate to the Constituent Assembly of the Republic, where he actively defended the cause of a strongly antifascist pluralist state. Working on the Commission of Seventy-Five, which helped to prepare the agenda for the plenary assembly, Moro expressed his concern for social issues. He called for an interventionist state, one that would actively fight poverty and injustice, and not simply create ideal conditions for the enrichment of some millionaires.»49

47 See Berlinguer, 1975.

48 See Biscione 2012, 14.

49 Drake 1995, 6-7. 
Actively pursuing his academic career at the University of Bari, Moro published his first book in 1939, and in the decade that followed became a heavily published legal scholar. Moro's first important work was Lezioni di filosofia del diritto, a compilation of lectures he gave for two courses at the University of Bari on the law (1944-1945) and on the state (1946-1947). Moro's humanistic moral premise was founded on the idea that life is guided not only by mechanical laws, but moves toward spiritual goals of selfrealization through the agency of love: «He defined love as the fully conscious energy of God creating man, and of man seeking God. Love in this most exalted sense is the real motor of history. From that moral premise, Moro drew the principles of his Catholic activist political philosophy. $\mathrm{He}$ identified himself unreservedly with the fundamental revolution articulated by Christ: all human beings, regardless of background or circumstances, are perfectly equal in the sight of God. Moro held that this was the single most revolutionary assertion in history. For two thousand years the world had struggled in vain to understand it. All other revolutionary programs, he believed, were of trifling significance.» ${ }^{50}$ Moro criticized both liberalism and socialism as

two unilateral opposing and false theses of a liberally oriented State, where liberty does not correspond to ethical freedom but to selfish caprice, and of a State oriented in a social sense, where society is not yet equal to ethical society, where people live together free and in loving solidarity, but to a hard and objective quid, which, despite being made up of men, has no human substance since their true humanity has been denied. ${ }^{51}$

Moro argued that individual liberty and social welfare were entirely dependent upon each other: «an ideal completely coherent to its nature belongs to the State, which is liberal and social at the same time and is precisely liberal because it is social and is social because it is liberal.» ${ }^{52}$ According to

50 Drake $1995,8-9$.

51 Moro 2006, 129; it.: «[...] due opposte tesi unilaterali e false di uno Stato orientato in senso liberale, dove libertà non è uguale a libertà etica, ma a capriccio egoistico, e di uno Stato orientato in senso sociale dove ancora società non è uguale a società etica, come libera e amorosa solidarietà delle persone, ma a un quid duro e oggettivo, che, costituito di uomini, non abbia tuttavia, per essere stati questi negati nella loro vera umanità, sostanza umana.»

52 Moro 2006, 128; it.: «[...] appartiene allo Stato una idealità del tutto coerente alla sua natura, che è liberale e sociale ad un tempo e precisamente liberale perché sociale e sociale perché liberale.» 
him, the state must promote the ethically inspired liberty of all, not liberty in the materialistic sense of simply creating a zone of free movement for acquisitive egotists. Moreover, he stressed that man does not exist solely for social ends, which is one of the reasons why limits had to be imposed on the state's power to control the individual. According to Moro, the state exists exclusively as a tool of man, to help him realize his full humanity.

Moro was also a fervid proponent of an ethical understanding of the law, according to which positive law is lawful until it responds to the profound demands of justice for which the legal order is destined:

Natural law cannot but be positive in some measure; it resolves itself, far from abstraction, in the very concrete actions that take place in a certain social experience, inspired by the universal and irreducible demands of human consciousness. ${ }^{53}$

As Norberto Bobbio rightly points out, once natural law is recognized as a condition of the validity of positive law, the violent rupture of the constituted order-that is, revolution-becomes legitimate in cases in which there is an unbearable gap between natural law and the law in force. ${ }^{54} \mathrm{In}$ other words, from the point of view of natural law or, more precisely, of the natural law in force assumed by Moro, revolution is undoubtedly a right in the full sense of the term. Without entering into the debate on the legitimacy or illegitimacy of the revolution in post-war Italy, it should be emphasized here that for Moro the ultimate foundation of legal systems had to be Christian ethics, in particular the Christian understanding of individual human life as something absolute, sacred, and thus inviolable. According to Moro, if a given law proves to be, in its concrete application, contrary to that value, it is the duty of each individual to oppose it.

Aldo Moro implicitly opposed the concept of the «ethical state», which became, through Giovanni Gentile, the official formula for defining the fascist state. In The Value of the State, the contrast between the conception of the «ethical state of absolute idealism»-developed by the Right Hegelians and appropriated by the fascist regime-and what Bobbio defines as Moro's «spiritual conception» of the state is clearly stated:

53 Moro 2006, 298-299; it.: «Il diritto naturale non può non essere in qualche misura positivo; esso si risolve infatti, ben lungi dal perdersi in una astrazione, nelle concretissime azioni che si svolgono in una determinata esperienza sociale, ispirate alle esigenze universali ed irriducibili della coscienza umana.»

54 Bobbio 1980, 13. 
We are now able to evaluate the meaning and intrinsic validity of recurring expressions in doctrines that qualify the State as the universal, the God on earth, the absolute value, completely ethical. [...] In these terms, there is, in our view, both a profound insight into the truth and a serious misunderstanding. [...] The possible misunderstanding that leads to considering the State $[\ldots]$ as an autonomous reality, the only reality in which human values can be said to be realized, must be fractured. This position swings between considering the totalitarian experience of the State as the only valid form of ethical experience and the rejection of the same human content of the State, which leads to conceiving the value of [the State] as a different and autonomous criterion of ethics and religiosity. Instead, it must be reaffirmed that if the State is, of course, ethical, it is because it welcomes and compoundes in harmony the values developed by individuals and by the smaller social aggregates of which it is composed and without which it would not be. So it is clear that no myth can substitute for the only ethic that has meaning in human life and thus no religiousness other than that of men. The State does not have its own autonomous religious experience, although it is ethical and religious in the sense that we have specified. ${ }^{55}$

Moro was not the only progressive Catholic intellectual and politician «looking to the left». He aimed to interpret Catholicism in the most progressive way possible, but there was nothing unprecedented about that. In fact, similar efforts throughout Italy, especially in the north, characterized the culture of Italian Catholicism after World War II. Another important

55 Moro 2006, 126.; it.: «Siamo in grado ormai di valutare il significato e la intrinseca validità delle espressioni ricorrenti nelle dottrine che lo Stato qualificano come l'universale, il Dio in terra, l'assoluto valore, in tutto etico. [...] In tali espressioni c'è, a nostro avviso, una profonda intuizione della verità e insieme un equivoco grave. [...] Va fugato il possibile equivoco che induca a vedere lo Stato [...] come un'autonoma realtà, nella quale soltanto possa dirsi realizzato il valore umano. Posizione la quale oscilla tra l'intendere la totalitaria esperienza dello Stato come la sola valida forma di esperienza etica e il rigettare lo stesso umano contenuto dello Stato, fino a concepire il valore di questo alla stregua di un diverso ed autonomo criterio di eticità e di religiosità. Ed invece bisogna riaffermare che, se lo Stato è, com'è certamente, etico, lo è in quanto in sé accoglie e compone in armonia i valori sviluppati dai singoli e dagli aggregati sociali minori dei quali si compone e senza dei quali non sarebbe. Dunque è chiaro che nessun mito può sostituirsi all'unica eticità, che abbia significato nella vita umana e così nessuna religiosità diversa da quella degli uomini. Lo Stato non ha una sua autonoma esperienza religiosa, anche se è etico e religioso nel senso che abbiamo precisato.» 
exponent of leftist Catholicism was jurist and politician Giuseppe Dossetti, who became Vice Secretary of the DC in 1946. Like Moro, he was influenced by Jacques Maritain's Humanisme integral (1936). Maritain, though regretting Marx's atheism and acceptance of violence as a legitimate means in the proletarian struggle, professed there was a large element of sincerity in Marxism and socialism in general. He shared the Marxist aversion to the destructive capitalist cult of individual enrichment, which he denounced as the ineluctable consequence of the anthropocentric humanism that he wanted to replace with integral or theocentric humanism. Maritain's ideas were useful to the Catholic left in Italy as a point of departure in the search for an exit from Fascism. The Dossettiani, including Giuseppe Lazzati, Giorgio La Pira and Amintore Fanfani, stood in the vanguard of these searchers. As Richard Drake indicates, «when Moro joined forces with the group, he seconded strongly Maritain's ideas about the necessary connection between political and social democracy and about the fundamental importance of tolerance in political dealings with all adversaries. At the same time, by stressing the necessarily laic nature of politics in a pluralistic democracy, Moro distanced himself from some of the more exalted interpretations of Maritain, particularly that of Dossetti.» ${ }^{56}$

However, Moro's encounter with Dossetti reinforced many of his own independently formulated ideas about politics and morality. Moro joined Civitas Humana, a Catholic association of intellectuals. In Cronache sociali, first published in May 1947 and which eventually became the journal of this group, the Dossettiani criticized the centrist liberalism of De Gasperi, arguing that under his leadership the DC became more than an anticommunist force representing US policy interests in Italy: «De Gasperi became a problem [for the Dossettiani] primarily because the party secretary and government leader did not envisage fundamental changes in Italy's internal power relations; he sought to improve existing capitalist structures not to replace them with anything more ethically advanced.» ${ }^{57}$

At the end of the forties, Dossetti abandoned politics to campaign for the cultural change that would prepare Italy to accept a Christian political program. By this time, Moro had joined the Iniziativa Democratica, a progressive political group within the DC that many former Dossettiani also joined. Amintore Fanfani, who profited from the party crisis of 1953, was the leader of this group. In 1947, De Gasperi made him minister of labor. Fanfani remained a steadfast ally of Dossetti during the Constituent As-

56 Drake 1995, 11.

57 Drake 1995, 14. 
sembly, but after 1947 he rapidly assumed a moderate position on many fundamental issues of foreign policy and reforms, and soon it became difficult to distinguish his stance from that of De Gasperi. After becoming party secretary in 1954, Fanfani controlled the party until 1959, continuing to praise idealism while accomplishing few of the agricultural, fiscal and bureaucratic reforms he had intended. During Fanfani's years as party secretary, political instability worsened: from 1953 to 1958 six governments fell. By attempting to emulate his predecessor by centralizing party power under his control, Fanfani antagonized a coalition of Christian Democrats called the Dorotei (because they plotted against him at the convent of the Sisters of Santa Dorotea in Rome). In 1959 he was deposed and Aldo Moro became the new party secretary. Before entering into this office, it had already held the posts of minister of justice (1955) and minister of education (1957). Moro was chosen by DC hierarchs because of his «unthreatening presence, his image as a reverse Fanfani [...]. They assumed that in this position Moro, unlike his predecessor, would defer to them.» ${ }^{58}$

At the beginning of his secretarial office, Moro could not disappoint the expectations of the party hierarchy. Moro experienced the breakdown of Fanfani's position as secretary and took no initiative that might disturb the status quo. He moved from the left to the center in an attempt to mediate the disputes between the party's progressive and conservative factions; in fact, it was the center-right Christian Democrats who had supported him against Fanfani. However, Moro began to develop a more courageous political program, which aimed to realize the «opening to the left» and the alliance with the Socialists that was much desired by the Dossettiani. The socalled third generation of Christian Democratic leaders formed a new left within the DC and began to pressure the party leadership for a political understanding with Socialists. Giovanni Galloni, who in 1953 formed the Sinistre di Base, emerged as an important political force after the elections on 7 June of that year; but what pushed Moro to become the most important interpreter of the political project first developed by the Dossettiani and then relaunched by Sinistre di Base, was the ongoing social revolution in Italy. The Marshall Plan had made an economic miracle possible, which in less than a generation had transformed the largely agricultural Italy of 1945 into an industrial society. The industrial cities of the north underwent violent expansion as millions of peasants left the land in the north and south. ${ }^{59}$ This process led to what poet and filmmaker Pier Paolo Pa-

58 Drake 1995, 18.

59 See Zampagni 2000. 
solini described as an «anthropological mutation» of the Italian people. ${ }^{60}$ More than nine million Italians migrated between regions from 1955 to 1977, but the period of greatest movement overall came in the years 1958 to 1963 , precisely when Moro became party secretary. Paul Ginsborg describes these years as «the beginning of a social revolution» during which «Italy ceased to be a peasant country and became one of the major industrial nations of the West.» ${ }^{61}$ During this period, labor disturbances in the industrial triangle of Milan, Turin and Genoa grew more numerous and violent. At the DC's Eighth Congress in 1962, Moro spoke for six hours on the theme of Italy's need for a "cautious union» between the PSI and the DC. ${ }^{62}$ His language and rhetoric were all but simple, but his main argument was clear: the only alternative to an alliance with Socialists was an alliance with the historically discredited right, but, he argued, a frightened form of conservatism would have been the worst possible choice for the Christian Democrats. The Tambroni government had tried this strategy in 1959 with disastrous outcomes, including violent demonstrations and strikes all over Italy that left ten people dead and dozens injured.

In 1963, Moro assumed the Prime Minister's office for the first time-he would become Prime Minister four more times: 1964, 1966, 1974, 1976-, while Mariano Rumor became the DC's secretary. In the elections of the same year, Communists gained votes while the DC lost votes; for more than a decade conservatives blamed Moro for the growing «Communist threat». Moro was not only confronted with the growth of the PCI, which was still considered an illegitimate party, and with criticism within his party, but was also particularly worried about the close ties between the far right and military circles. He knew about the Piano Solo scheme of General Giovanni de Lorenzo and other reactionaries, and their attempted coup of 1964. As Drake observes, «after becoming aware of De Lorenzo's scheme, Moro always had a weather eye out for right-wing plotters; they, in his judgment, posed the greatest danger of all to the ship of state, precisely because they were on board and in charge of its security and navigation.» ${ }^{63}$

From here on, Moro became extremely cautious. He became famous for his legendary stalling tactics and obfuscating rhetoric, becoming the undisputed master of the so-called strategia di logoramento, the DC's notorious ability to prolong debate and hold off legislative action for which he be-

60 See Battista 1999.

61 Ginsborg 1990, 212.

62 See Drake 1995, 21.

63 Drake 1995, 22. 
came a sort of archetype. Meanwhile, Communists continued to make steady gains at the polls. After the elections of 1968 , from which the Socialists emerged as the principal losers, Moro's government fell from power. What Paul Ginsborg calls the «Era of Collective Action» began: «From 1968 onwards paralysis of above gave way to movement of below. There followed a most extraordinary period of social ferment, the high season of collective action in the history of the Republic.» ${ }^{64}$ In November 1967, large student strikes and occupations had already erupted at Milan's Catholic University, and for months afterwards similar developments became regular occurrences in different parts of Italy. By the autunno caldo («hot autumn») of 1969, student leaders had joined forces with militant factory workers, emulating the French experience of the March 1968 protests in Paris. ${ }^{65}$ Confronted with the country's labor unrest, student protests and political violence, Moro decided to adopt and promote the so-called strategia dell'attenzione («strategy of attention»). On June 29, 1969, he spoke before the Eleventh Congress of the DC arguing that it had become necessary to legitimize the PCI as an integral part of Italy's democracy. Moro understood the inclusion of the PCI in the majority as the only way to eliminate the "anomaly» in Italian democracy (with respect to the other European democracies), which was the lack of alternation between different blocs in the government. ${ }^{66}$

On December 12, 1969, there was also the Piazza Fontana bombing, which was initially attributed to anarchists but, as was fully ascertained by the courts, was the work of the right-wing group Ordine Nuovo and is considered by many as the starting point of the anni di piombo ("years of lead») and the strategia della tensione («strategy of tension»). It has largely been proven that there were acts of obstruction implemented by state apparatuses aiming to hide the real perpetrators and probably the true masterminds of the terrorist attack. ${ }^{67}$ In the draft report by the Commissione parlamentare d'inchiesta sul terrorismo in Italia e sulle cause della mancata individuazione dei responsabili delle stragi, published in 2000, US intelligence was accused of being responsible for inspiring the «strategy of tension» in which the indiscriminate bombing of the public and the threat of a right-wing coup were used to stabilize center-right political control of the country:

64 Ginsborg 1990, 298.

65 See Drake 1999, 71.

66 See Wagner-Pacifici 1986, 37.

67 See Bull Cento/Cooke 2013; Galli 2004, 7; Ginsborg 1990, 333-335; Formigoni 2016, 252. 
«those massacres, those bombs, those military actions had been organized or promoted or supported by men inside Italian state institutions and, as has been discovered, by men linked to the structures of United States intelligence.» ${ }^{68}$ As Biscione observes, «the strategy of tension appears as the result of different strategies and components [...]; there are several forces that interact with each other [...] with a common goal: to contrast the PCI strategy.» ${ }^{69}$ As Aldo Moro himself wrote during the 55 days he was held prisoner by the Red Brigades (BR): «With regard to the strategy of tension, which for years caused bloodshed in Italy, even without achieving its political goals, one cannot but point out that, alongside responsibilities that lie outside Italy, there were indulgences and connivances by organs of the state and by some sectors of the Christian Democracy.» ${ }^{70}$

The historical periodization of the anni di piombo-the formulation derives from the Italian title given to Margarethe von Trotta's movie Die BLEIERNe Zeit (Germany, 1981)—spans approximately from 1968 to 1983, which has been described as the "crucible» of many of the political, social, ideological and cultural problems accumulated in Italy since the end of the World War II. ${ }^{71}$ Scholars generally indicate the bombing of a bank in Piazza Fontana in Milan as the beginning of this period. This event was the beginning of a long cycle of political violence: between 1969 and 1983 there were more than 14,000 incidents of politically motivated violence, resulting in 374 deaths and more than 1170 injuries. ${ }^{72}$ In the 1970s, no fewer than 597 terrorist groups (of both the left and right) were counted in Italy. ${ }^{73}$ Between 1969 and 1975, mainly right-wing groups committed assassinations and political acts of violence (95 percent of the assassinations between 1969 and 1973, 85 percent in 1974 and 78 percent in 1975). ${ }^{74}$ The extreme left intensified its terrorist activities only later: almost 80 percent of the deadly assassinations that occurred in the period between 1978 and

68 Quoted in Willan, Philip, «US «supported by anti-left terror in Italy». Reports Claim Washington Used a Strategy of Tension in the Cold War to Stabilize the Centre-Right», The Guardian, 24.7.2000, 19.

69 Biscione 2012, 137.

70 Moro 1997a, 227; it.: «Per quanto riguarda la strategia della tensione, che per anni ha insanguinato l'Italia, pur senza conseguire i suoi obiettivi politici, non possono non rilevarsi, accanto a responsabilità che si collocano fuori dell'Italia, indulgenze e connivenze di organi dello Stato e della Democrazia Cristiana in alcuni suoi settori.»

71 Antonello/O'Leary, 2009, 1.

72 See Jamieson 1989, 19-21.

73 See Townshend 2002, 68.

74 See Della Porta/Rossi, 1984, 25. 
1982 were attributed to the extreme left or the extreme left claimed responsibility for them. ${ }^{75}$ As has been rightly observed, this period had an enormous impact «upon so many aspects of Italian cultural life, tinting everyday language, media communication, categories of historical understanding and artistic representations of all kind.»76

Moro took the problem of terrorism with the utmost seriousness, since he largely shared the left's increasing concern about the danger posed by neo-fascist intriguers. He tried to oppose both the right-wing and left-wing terrorism of the seventies by working to deprive them of support in society. The extremists frightened Moro so much that he vigorously renewed his opening to Berlinguer, who, as we saw, was concerned about growing signs of mass support for the far right as well as by the violent overthrow of Salvador Allende's left-wing government in Chile. Moreover, popular support for the PCI was growing: it won 25.3 percent of the vote in 1963, 26.9 percent in 1968, 27.2 percent in 1972, 33 percent in the 1975 regional and local elections and 34.4 percent in $1976 .{ }^{77}$ While Moro's strategy was initially criticized by many leaders of the DC, as well as by the United States and other NATO member countries, after the 1975 and 1976 elections, with the PCI on the verge of becoming the leading party in the land, many other of his party colleagues began to agree with him. Joined by Fanfani and Andreotti, Moro implemented the 1976 historic compromise with Enrico Berlinguer from the PCI.

In an attempt to realize the historic compromise, Moro and Berlinguer faced a number of obstacles. Many continued to oppose his political strategy both in Italy and abroad. The United States in particular implacably opposed Moro's strategy: «Even during the Jimmy Carter years the answer was still «no〉 to the idea of compromising with the Communists. Democratic president or Republican, a most rigid orthodoxy prevailed in Washington on the subject of Italy's Communist party.» ${ }^{78}$ In Italy, there were those associated with the right wing of the DC who called Moro a «Marxist» and accused him of wanting to give the country to the Communists. ${ }^{79}$ In reality, Moro certainly was not auguring real structural change in Italian politics, since he was, after all, a Christian Democrat. The DC had been involved in every one of Italy's major scandals since the end of the war-the

75 See Rossi 1993, 96.

76 Antonello/O'Leary 2009, 1.

77 See Ginsborg 1990.

78 Drake 1995, 30.

79 See Wagner-Pacifici 1986, 37. 
Fiumicino Airport scandal, the Lockheed scandal, the Petrolio scandal, the Propaganda 2 (P2) secret Masonic lodge scandal—and Moro always stoutly defended his party against the charge that it was nothing but an engine of corruption in Italian life.

On August 11, 1976, a new government under the leadership of Giulio Andreotti gained the approval of the Chamber of Deputies. This government was called governo di non-sfiducia (not no-confidence), because it was based on the abstention of the opposition parties. The Communists and Socialists were not part of the government, but they agreed not to cause its downfall. In turn, the DC consulted them fully on its political program. Andreotti's government survived in this fashion until January 1978. Andreotti was certainly not the kind of politician that Berlinguer and more generally the PCI appreciated. He was a conservative Catholic and a pupil of De Gasperi, who since the birth of the First Republic had held practically every ministerial post. As Ginsborg highlights, Andreotti «had been Minister of Defense for many years, at a time when the secret services were being infiltrated by the extreme right wing. [...] Well-liked in the Vatican, Andreotti was subtle and cynical; for the DC he was the ideal man for a slow 〈logoramento (wearing down $>$ ) of the Communists.» ${ }^{80}$

In contrast to Andreotti-who in the last four decades has been accused, among other things, of being the éminence grise behind the P2 Masonic lodge, and was tried (and absolved) for mafia association and for complicity in the assassination of journalist Mino Pecorelli-Moro truly believed in the feasibility and necessity of the Historic Compromise. The grande tessitore (master weaver), as Italian political commentators often called him, believed it possible to gradually perform the same operation on the PCI that he had performed on the PSI in the sixties: he hoped to eventually bring the Communists into the government without challenging the DC's state system. He knew that his policy involved some risks, but an even greater risk would result from a do-nothing strategy. On February 28, 1978, Moro addressed the Assembly of the Christian Democratic Senators and Deputies, where he spoke about the party's need for an understanding with the PCI that would respond to a real social, economic and political emergency. ${ }^{81}$

On March 16, 1978, just as he was going to the Chamber of Deputies to discuss the confidence of the new government of Andreotti with the PCI in the majority, Aldo Moro was kidnapped by the BR. Fifty-five days later

80 Ginsborg 1990, 378.

81 See Moro 1979, 374-391. 
he was found dead in the trunk of a car in the center of Rome. It is hard to say if Moro's political project would have had a certain success; what one can say for sure is that with the death of Moro the entire Italian political landscape underwent a radical transformation. Above all, for those who had seen with their own eyes the advent and fall of Fascism, Moro's assassination marked the end of an era of hope. As the liberal historian Arturo Carlo Jemolo comments: «When I recall the many who shared with me the great hopes of 1945 and the following years, I think that those who closed their eyes in time to not see Italy in 1978 have been loved by God.» ${ }^{82}$

\subsection{Emancipation and Political Violence in the "Years of Lead»}

In 1969, publisher Giangiacomo Feltrinelli published a pamphlet entitled Estate 1969, which can be considered the first enunciation of the inevitability of the armed struggle for the «socialist revolution» in the post-war Italian context. ${ }^{83}$ This prophecy was implemented by the myth of the Resistenza tradita («betrayed Resistance»), the revival of the Gruppi di azione partigiana («partisan action groups») and the experiences of Vietnam, Cuba and other minor guerrillas. The massacre at Piazza Fontana, interpreted by Feltrinelli in another essay as the confirmation that Persiste la minaccia di un colpo di stato in Italia! («The Threat Of a Coup In Italy Persists!»), strongly influenced the idea that in Italy there was a need for a return to arms to form a more just and egalitarian society and to contrast capitalism and imperialism. ${ }^{84}$

The 1950s in Italy were characterized by economic development, patronage and anti-communism. The "patronization» of the state economy led to the appointment of Christian Democrats to key positions in the growing number of organizations entrusted with industrial and commercial development, including state banks, welfare agencies, holding companies-such as the Istituto per la Ricostruzione Industriale (IRI) and the Ente Nazionale Idrocarburi (ENI) - and economic reform agencies. Where the Christian Democrats were unable to use the patronage system to obtain support, particularly in northern urban areas, repression was employed to limit the extent of political opposition. This was particularly visible in their harassment of the working-class movement. Although the ban on free trade

82 Jemolo 1978, 301.

83 See Galli 2004, 8.

84 Feltrinelli, 2012. 
unions had ended after the end of Fascism, the government continued to restrain their activities, which were seen as obstructive to economic progress. As has rightly been noted, this repressive policy was part of a «broader anti-Left strategy affecting the rights and livelihood of whole sectors of the population within the exercise of an informal dictatorship». This was in part a consequence of Italy's strategic position as a member country of the North Atlantic Treaty Organization (NATO) bordering along the Soviet bloc.» ${ }^{85}$ As I already mentioned, the Catholic Church also played a significant role in limiting the influence of the left in Italian society in return for the state's support of its moral positions.

In spite of this repressive policy, the quality of life for most Italians improved markedly during the post-war years. The number of occupied houses increased by 50 percent between 1951 and 1971. At the start of the fifties less than 8 percent of houses contained electricity, running water and washing facilities; this nearly quadrupled to 30 percent a decade later. ${ }^{86}$ Many Italians were able to buy such household appliances as washing machines and fridges; cars became affordable mass commodities. Undoubtedly, the arrival of modern goods reflected the ability of many Italians to live comfortably for the first time, but the initial beneficiaries were the middle classes, while many working-class families did not benefit from modernization until the sixties. The radical change in daily life in Italy was also determined by the great migration from the countryside to Italian cities. Many immigrants, especially from the south, experienced a sense of alienation as they abandoned their home communities and were forced to live in far from ideal conditions. Even within the family, women continued to maintain a subordinate position, although, to some extent, the restrictions on the lives of women continued to be eroded by the spread of mass education and increasing literacy. Moreover, a higher number of Italians than ever before were able to enjoy various forms of cultural entertainment (including theatrical and cinema performances, concerts and spectator sports).

The arrival of modern forms of cultural consumption revealed serious tensions within Italian society between tradition and innovation. The ruling classes and ecclesiastical hierarchy, while supportive of economic progress, were fearful of the emancipating effects of the social and cultural transformation that accompanied the boom. As Dunnage highlights, «during the fifties Fascist legislation continued to be used to censor cinema

85 Dunnage 2002, 157.

86 See Dunnage 2002, 158. 
films, theatrical productions and newspaper publications. The state also attempted to enforce rigid moral standards by prohibiting kissing in public and waging war on the bikini. Likewise, the Christian Democrats saw the new medium of television as a means of enforcing traditional mores and anti-Communism, as the RAI (Radio Audizioni Italia) state broadcasting company was regulated with a powerful system of internal censorship. The Catholic Church backed the government in its cultural policy, capitalizing on television for the purpose of transmitting religious programs, though this was not without serious contradictions. ${ }^{87}$

Following the repression of the fifties, there was greater institutional tolerance of civil rights and modern social and cultural practices in the early sixties. There are several reasons for this evolution. First, the modernizing reform from within the Catholic Church after the death of Pope Pius XII moved in the direction of ending its interference in people's electoral preferences. Moreover, not only did important Catholic intellectuals begin to publicly criticize the free play of market forces in society and to call for greater social justice, but so did representatives of the Vatican's hierarchy. Second, the formation of a center left government, accommodating the PSI, in 1963 facilitated the introduction of some social reforms including, among other things, the introduction of a national social insurance and health system, regional devolution and greater state economic planning in order to overcome the north-south divide.

This change at the institutional level was also a response to pressure from below, in particular to a growing sense of public intolerance towards a corrupt government and repression. The press strongly contributed to the development and diffusion of a critical attitude towards the political class and it began to publish important investigations into political corruption as well as to address the negative social phenomena produced by the economic boom. A growing movement toward change, which culminated in the mass civil rights and union action towards the end of the sixties, began as a reaction to Fernando Tambroni's formation of a Christian Democrat government with the support of the neo-fascist Italian Social Movement (MSI) and the Monarchists in the spring of 1960. The movement was formed not only by those of the older generation defending the memory of the Resistance but also by a large number of young people. Despite the demand for greater political and social emancipation during the early sixties, tension remained. The institutions were unable to follow the pace of economic development and social transformation to which much of Italian 
society aspired. Furthermore, the center left governing coalition failed to implement most of the reforms it set out to achieve. This is in part attributable to the attitude of the PSI, which failed to stand up to the Christian Democrats and began to imitate the clientelistic strategies of its main coalition partner.

The educational reforms of the sixties strongly contributed to the explosion of protests in Italian universities. Although it allowed hundreds of thousands of children of the middle and working classes to have access to education, it had grave inadequacies, in particular its failure to create social equality. Access to upper secondary and higher education was facilitated as a result of the reforms, but working-class students remained disadvantaged. Many poor students were forced to work rather than attend university classes due to limited financial assistance. Furthermore, the universities failed to move away from their traditional elitism and were not restructured in order to handle higher numbers of staff members and the greater demand for teaching space. ${ }^{88}$ Police brutality in suppressing riots and student demonstrations also contributed to increasing tensions. Although protest policing was generally less repressive in the sixties than in previous decades, the number of deaths and injuries from police charges, bullets and tear gas during student demonstrations, industrial strikes and land occupations escalated from the end of $1968 .{ }^{89}$

As already mentioned, in 1969 an alliance between students and workers came into being. The industrial action of 1968 and 1969 was marked by an increase in the number of participants. The scale and success of the industrial strikes can be attributed to several factors: the worsening of working conditions in the factories; the availability of cheap labor supplies, which dried up in the mid-sixties with full employment, giving the working-class greater leverage in its confrontation with the bosses than before; greater educational opportunities which led to a more literate working-class; and the negative social effects of urbanization and mass migration. ${ }^{90}$ Although the mass of new workers had little experience with union action, the impetus for revolt initially coming from highly politicized skilled workers quickly spread to unskilled non-union sectors of labor. The protests demanded better pay, greater democracy within factories, the organization of work and the reduction of health hazards and better social conditions. During the early seventies the union battles spread beyond the initial sec-

88 See Ginsborg 1990, 298-304.

89 See Dunnage 2002, 173.

90 See Dunnage 2002, 175. 
tors of conflict, involving an increasing number of Catholic workers as their union, the Confederazione Italiana Sindacati Lavoratori (CISL), began to accept the new confrontational model of industrial relations.

The improvement of the working conditions in the factories and the recognition of certain workers' rights were undoubtedly the direct result of the industrial action of the late sixties and early seventies: «In addition to improvements in wages and work conditions and some protection against arbitrary authority, the workers had reasserted the right to organize themselves as a collective body.» ${ }^{91}$ Legislation ratified Article 39 of the Constitution, which guaranteed workers the right to form trade unions and enter into collective labor contracts. Moreover, the Statuto dei Lavoratori (Workers' Rights Statute) of 1970 secured a union presence at the company level and allowed unions to take employers to court. However, the "hot autumn» did not benefit all workers, since the smaller factories and companies were largely unaffected, and their employees were not covered by the Statuto, and neither were large numbers of women homeworkers. After the international oil crisis of 1974, which set off severe inflation, the protest movements began to concentrate on broader social concerns, transposing the direct action strategies to the community at large (including the organization of squatting to overcome housing problems and forms of autoriduzione to overcome rising prices, such as the non-payment of bus tickets and electricity bills). ${ }^{92}$

In the second half of the seventies, the initiatives of the social movements were gradually absorbed by the official left and taken up at higher levels of union representation as part of the overall strategy of the institutionalization of protest. During the years of the compromesso storico, the union confederations supported a policy of wage restraint and fiscal austerity in respect of Berlinguer's belief that in return for its «sacrifices» the working-class would achieve hegemony in Italian society. As Dunnage notes, «though the unions gained institutional status as a result of this, the grass roots clearly lost out as a result of the government's failure to prevent redundancies and control inflation.» ${ }^{93}$

A direct consequence of the demands of the worker and student movements was the reformation of the cultural and media landscape. The years of the «economic miracle» saw the nationalization of mass culture, particularly with the advent of state-controlled national television. In the climate

91 Barkan 1984, 76.

92 Dunnage 2002, 178.

93 Dunnage 2002, 179. 
of the seventies, the state monopoly over the media was brought into question and an anti-authoritarian shift allowed greater freedom of expression. In 1975, a new regulatory law reduced government control over RAI. The influence of the DC was not totally removed but rather shared out first with the PSI, which assumed control over the second state channel (RAI 2), and then with the PCI, which was granted control over RAI 3 when it was introduced in 1979.

Specific issues that engendered the student movement were subsumed in a general critique of the capitalist order. The cultural climate of the Chinese and Cuban revolutions, as well as of the peace movement founded in Italy in 1967 in protest against the Vietnam War, influenced many young Italians. Students expressed a desire for an alternative lifestyle, which they tried to put into practice by occupying universities and turning them into revolutionary communes. Extra-parliamentary left weekly newspapers such as Lotta Continua and Il Manifesto, both founded in 1969, began to challenge the national press over their representation of worldwide events. Not only did Marxists play a central role in the movement, but so did radical left-wing Catholics. In 1968, the extra-parliamentary intellectual journal Nuovo Impegno noted that even the Catholic segment of the student movement had become identified with illegal methods of opposing the academic status quo, accepting «the forms of struggle that the university Marxist left had proposed.» ${ }^{94}$ While many members of the Roman Catholic lay association Azione Cattolica deserted to the youth movements, several dissident Catholic organizations denounced the Church as an ally of the rich and privileged. The radical priest Don Lorenzo Milani, who soon became a reference figure of the movement of 1968 , began to comment publicly on the anti-Christian character of the socioeconomic system that exploited the poor. As Drake observes, «his radical ideas did not originate in Marxist theory, but from the message of the Gospel about the evil consequences for mankind of cupidity.»95

Many of the so-called ultra-left groups grew largely in the northern industrial cities of Torino, Milano and Genova. These groups did not feel represented by the PCI, which they considered merely a reformist party that, seeking alliance with the DC, had betrayed the revolutionary cause. Their early activities consisted of school occupations, the promotion of political strikes, the occupation of vacant houses and the purveyance of controinformazione (counter-information). Groups like Lotta Continua and Au-

94 Quoted in Drake 2008, 454.

95 Drake 2008, 456. 
tonomia Operaia wanted to provide an alternative and subversive view of factories, schools, the police, facts and events of international politics, and of the worker and student movements provided by the established mass media: «they sought to renovate political discourse by rejecting the bureaucratic jargon of the established media presentation of politics.» ${ }^{96}$

In the mid-seventies, violent action escalated as demonstrations ultimately developed into armed combat with police. The question of violence was also prominently debated in books, magazines, pamphlets and newspapers. As we saw, some parts of state apparatuses and right-wing groups promoted a strategy in order to create a tense climate. Thus, the question of violence was already present in the Italian political consciousness and imaginary, which is why «the ultraleft cannot be blamed for having introduced violence into Italian society.» ${ }^{97}$ Moreover, it is highly probable that one of the main goals of the «strategy of tension» was precisely to produce a violent reaction within the worker and student movements for the purpose of promoting public demand for law and order. For this reason, one of the central questions that ultra-left groups debated in their ranks and in their publications was: how could and should we oppose the violence primarily used as a political instrument by right-wing groups and state apparatuses?

As Wagner-Pacifici indicates, discussions on violence followed two distinct and opposed lines of reasoning. The first declared that violence produces irretrievable destruction and never social emancipation, brotherhood, justice and equality. Nevertheless, a distinction was made between legitimate and illegitimate violence in relation to the antifascist struggle. For example, Lidia Menapace, in a preface to a collection titled On Violence. Politics and Terrorism: A Debate Within the Left, argued that while Fascist violence was deliberately used as a means of exercising power and glorified by Fascist propaganda, Resistance violence was the expression of a situation of necessity, a means to survive and to oppose the regime. ${ }^{98}$ The historian Claudio Pavone makes a similar distinction by saying that Resistance fighters did not give «violence a value, especially to bloody violence, a liberating value as such», did not have «the aesthetic pleasure of killing»,

96 Wagner-Pacifici 1986, 44.

97 Wagner-Pacifici 1986, 45.

98 See Wagner-Pacifici 1986, 46. 
but acted out of necessity, responding to a moral duty. ${ }^{99}$ Moreover, writing about the killing of Aldo Moro, Pavone claims that the BR were related to a culture of violence as a value and identity- «I shoot therefore I am»which recalled the Fascist culture of death opposed by the Resistance. ${ }^{100}$

The second line of reasoning saw violence as an appropriate method of struggle only if it was an expression of the will of the masses. Criticizing the anti-violence front of the PCI-DC alliance, one Lotta Continua group from Torino wrote in 1977:

It is necessary to specify that this «anti-violence front has, as its primary goal, the political expropriation of the masses and is, from this perspective, allied to the class enemy who proposes the same object. We, instead, must be ready to develop the capacity of the movement to strike the enemy even with avant-garde action when these actions have a real mass reference. And it is on the mass representativeness, on the capacity and opportunity to develop politically and to develop the revolutionary process that we judge violence and the determinate use of offensive weapons. ${ }^{101}$

As Drake points out, this discursive legitimization of violence refers both to Catholic and Marxist traditions. The already mentioned journal Nuovo Impegno, for example, represented the Colombian priest and predecessor of liberation theology Camilo Torres, who was killed in 1966 in a guerrilla attack, as the «incarnation [...] of the revolutionary priest/martyr who had given soaring expression to the cause of uniting Catholicism and Marxism against the capitalist oppressor of mankind.» ${ }^{102}$ The history of Lotta Continua reveals that there was a mutual influence between leftist Catholicism and Marxism on both a theoretical and a practical level. A large component of Catholics, with long experience as leaders in the student movement, joined the leader Adriano Sofri in launching the autonomist movement.

The real dilemma for ultra-left groups was how to evaluate the violence of the BR. In the early seventies, various groups showed sympathy and expressed support for the BR and their actions. In defending the BR's kid-

99 Pavone, Claudio, La Resistenza, 28.4.1980, paper delivered in the first cycle of the seminar Etica e Politica of the Centro Studi Piero Gobetti, typewritten script, 7; quoted in Bidussa 2015, xviii.

100 See Pavone, Claudio, «Sparo, dunque sono. Il nodo della violenza», Il Manifesto, 6.5.1982, 7.

101 Quoted in Wagner-Pacifici 1986, 46.

102 Drake 2008, 463. 
napping of business executive Idalgo Macchiarini on March 3, 1972, Lotta Continua declared: "We hold that this action belongs properly to the generalized desire of the masses to conduct the class struggle on the terrain of violence and illegality.» ${ }^{103}$ However, Lotta Continua would thereafter oppose most Red Brigades actions and, gradually abandoning the discourse of legitimization of proletarian violence, focalized on the social questions of the day: divorce, abortion, homosexual rights, school reform and aid for the south.

The widespread justification of «revolutionary» violence by ultra-left groups during the autunno caldo undoubtedly provided a framework within which terrorism could develop. However, it must be highlighted that the «strategy of tension» and right-wing terrorism played a key role in radicalizing the conflict and in provoking a violent reaction by the worker and student movements. Between 1969 and 1980, extreme right-wing groups were responsible for the majority of deaths and injuries caused by terrorist attacks. Besides the Piazza Fontana massacre of December 1969, the rightwing terrorist campaign included numerous train bombings, the most serious of which happened in 1974 and 1984 on the Bologna-Florence railway line, and the bombing in August 1980 of Bologna station, which caused the deaths of 85 people. Moreover, there are fundamental differences between the broad movement and the terrorist bands: «For all their faults, the revolutionary groups realized that any transformation of Italian society had to derive from action in civil society, from the building of a mass movement, of changing popular consciousness. Success or failure was to be measured in these terms alone. The terrorists, by contrast, by choosing to work clandestinely and to use exemplary violent action, cut themselves off from reality and put in its place their own invented world. Their arid communiqués were the supreme example of abstract ideology replacing social analysis.»104 The idea of a nascent revolution put forward by these movements was thus extremely simplified and mythicized by the terrorists. The terrorist groups developed, in line with structural changes within the social movements, an intensification of violence among a minority of actors only: «the fundamentally open-minded and pluralistic nature of the protest movements was replaced by an anti-democratic and totalitarian vision of how to solve problems.» ${ }^{105}$ The increasing violence that characterized BR

103 Lotta Continua, «Comunicato di Lotta Continua: Il sequestro di Macchiarini, dirigente alla Sit Siemens», 9.5.1972.

104 Ginsborg 1990, 362.

105 Dunnage 2002, 188. 
actions from the mid-seventies onwards, as well as their decision to go underground, isolated the terrorists from working-class members of society, though the attitude of the latter towards terrorism remained ambivalent.

The BR were undoubtedly the most active left-wing terrorist group in Italy from the beginning of the seventies. Though representing only a minority of protest activists, the founder members of the BR played an important role in the mobilizations of 1968 and 1969 and began to organize the lotta armata, the armed fight, between 1969 and 1970. The founders of the BR came from diverse social and ideological backgrounds: Renato Curcio and his wife Margherita Cagol were students at Trento university and members of Maoist groups, while Alberto Franceschini was active in the FGCI (the Communist youth movement) in Reggio Emilia. Many of the first members had a strong Catholic background in common and were from working-class or lower-middle-class families. Franceschini's father was a worker and antifascist, who was deported to Auschwitz, and his grandmother was a leader of the peasant leagues. ${ }^{106}$

The first leaflet of the BR signed in the singular (Brigata Rossa) appeared in Milan in April 1970. In October of the same year, the journal Sinistra Operaia announced the creation of the BR as the avant-garde of the proletarian struggle against capitalism. The early actions of the BR, from 1972 onwards, were no more than armed propaganda concentrated in Milan and then Turin. In their first actions, BR members «only» beat and humiliated rightwing trade unionists, managers and foremen, principally in the two Milanese factories of Pirelli and Sit Siemens; sometimes, they set their cars on fire. In March 1972 they kidnapped, though only for 20 minutes, the manager of Sit Siemens Idalgo Macchiarini. In early 1974, they announced an attack on «the heart of the state» for the first time. ${ }^{107}$ On 18 April they kidnapped the judge Mario Sossi, whom they viewed as a fanatical persecutor of the working-class and student movement, and held him prisoner for 35 days. Submitted to a «trial», Sossi was sentenced to death. The BR, however, offered the state an option, that is, they demanded the release of members of the organization XXII Ottobre, who would have obtained a safe conduct in Cuba, North Korea or Algeria, in exchange for his release. Paolo Emilio Taviani, Minister of the Interior, rejected the blackmail; the court of Genoa offered to review the position of the detainees, exploiting the possibilities offered by procedural rules, but prosecutor Francesco Coco reiterated his «no» to any form of blackmail. The BR de-

106 See Franceschini/Buffa/Giustolisi 1988.

107 See Galli 2004, 61. 
cided to release Sossi without receiving anything in return. The magistrate was released in Milan on May 23, 1974. Although they did not get what they demanded, the action enabled the BR to achieve national notoriety.

Until the Sossi kidnapping, the BR had not killed anyone yet. The first two murders claimed by the BR were committed on June 17, 1974, when two members of the Italian Social Movement (MSI), Giuseppe Mazzola and Graziano Giralucci, were killed during a raid on the MSI headquarters in Padua. In October of the same year, one of the members of the BR group who had attacked the MSI headquarters in Padua, Roberto Ognibene, killed Marshal Felice Maritano while trying to escape from the Carabinieri. When, in June 1975, Margherita Cagol was killed in a skirmish with the police, the number of violent activities increased. This also marked the moment of the dissolution of the first BR generation and the formation of the second. As Wagner-Pacifici observes, «while the first generation had begun with pamphleting, burning cars, kneecapping that resulted in the eventual return of the hostage and only toward the end became involved in violent police skirmishes that resulted in deaths, the second wave of BR members often shot to kill. Thus one of the first noted differences was an increased level of violence and a military efficiency to go with it.» ${ }^{108}$

Under the leadership of Mario Moretti, though he was a member of the first generation, the BR started killing their targets and legitimized their actions by representing their victims as absolute enemies of the workingclass. In June 1976, the BR killed the general public prosecutor of Genoa, Francesco Coco, and two of his bodyguards in order to prevent the trial of the founders of the organization, who had been arrested. The intensification of violence coincided with declining levels of protest within society at large, which enhanced a loss of faith in legal forms of collective behavior. This led to the increasing bureaucratization and militarization of the BR, which then began to assume the characteristics of a clandestine group: «The organization is puritanical and sacrificial and the BR of Moretti tend to regard clandestinity as a form of religious, ascetic practice. [...] A monastic organization is being recreated in paramilitary teams, obeying the need $[\ldots]$ to sacralize death and blood, not the death of the believer but of the militant.» ${ }^{109}$

108 Wagner-Pacifici, Robin Erica, The Moro Morality Play: Terrorism as Social Drama (Chicago/London: The University of Chicago Press, 1986), 52.

109 Bocca 1985, 138, 181; it.: «L'organizzazione è puritana e sacrificale e il brigatista morettiano tende a considerare la clandestinità come una forma di vita religiosa, 
Towards the end of the decade, the BR reached their most violent phase. They first understood themselves as the vanguard of the worker movement, then turned to believing that, in the context of the Historic Compromise, the «bourgeois» state had assigned the task of controlling the working-class to the trade unions. Trade union leaders promoting the Historic Compromise strategy within both the PCI and the DC became their main targets. After the assassination of Aldo Moro, the actions of the BR continued with regularity until February 1982 . The killing continued and increased throughout 1979 and 1980. However, they became more and more isolated, and defections from their ranks grew. Moreover, General Carlo Alberto dalla Chiesa-who was assassinated by the mafia in Palermo in 1982 under circumstances not yet fully clarified-was at last appointed to coordinate the anti-terrorist offensive. In fewer than three years, the group was detected and dispersed by Italian investigators with the aid of several leaders under arrest, who decided to collaborate with the judicial system. After the mass arrests, which took place in the late eighties, the group faded into insignificance. ${ }^{110}$

In its final years, the BR became increasingly isolated from the rest of society. In fact, the killing of Aldo Moro can be seen as the action by which the BR marked their own end, or more generally, the decline of terrorism in Italy. As we saw in the first chapter and will deepen in the next two, the BR, after Moro's abduction, demanded the liberation of imprisoned terrorists in exchange for the liberation of the Christian Democrat politician; but the government, the PCI and the DC, as well as most of the established media, immediately assumed an intransigent position. Ginsborg-whose negative opinion about Moro becomes manifest when he writes that he «wrote a series of anguished letters [...], begging them to try to secure his release»-supports the decision of no negotiation: «had Moro not been killed but exchanged for one or more imprisoned terrorist, the BR would have appeared both invulnerable and willing to compromise, with the result that their appeal would almost certainly have widened.»111

This statement by Ginsborg, who is undoubtedly one of the major and more qualified scholars of modern and contemporary Italy, is to be rejected for at least two reasons. First, the argument that the liberation of Moro

ascetica. [...] Si ricrea una organizzazione monastica nelle squadre paramilitari obbendendo al bisogno di $[\ldots]$ sacralizzare la morte e il sangue, non più la morte del credente ma del militante.»

110 See Galli 2004.

111 Ginsborg 1990, 385 (emphasis added). 
would have had the negative effect of legitimizing terrorism cannot be verified as it moves in the sphere of hypothetical history. Secondly, if one really wants to reason in hypothetical terms, it would seem correct to argue that the liberation of Moro could also have had the positive effect not only of de-mythologizing and de-escalating the social conflict and political struggle, but also of allowing the emergence of a different image, a different conception of state apparatuses and their functions. In fact, hypothetical engagement for the liberation of Moro could also have been perceived through a certain media representation strategy as the demonstration that the state and the major political parties were committed to the ultimate goal of safeguarding individual human life. Assuming a position of intransigence, the state, major political parties and the established media reproduced a certain image of the state and its functions, according to which in exceptional situations a single life can be sacrificed for the security of society. The position taken by Ginsborg, which at first sight might appear to be a sort of ethical utilitarianism according to which Moro's life had to be sacrificed in order to save the lives of other citizens from future terrorist attacks, is based on the assumption that the exchange of prisoners would have necessarily endangered the safety of many Italians. The fact is that many citizens were killed in spite of the government's and the parties' decision not to negotiate; we will never know what would have happened if history had gone differently. However, what we can say with certainty is that the thesis according to which negotiations for Moro's liberation would inevitably have had negative repercussions on Italian society and its institutions is highly questionable.

There is a third reason for rejecting Ginsborg's statement, which regards the negative effects of Moro's death. Aldo Moro's assassination determined not only the end of the popular support on which the BR and the project of violent revolution still counted, but also the annihilation of the emancipatory movement with strong political participation that had developed since the 1960s. The idea of an egalitarian and just society seemed contaminated, definitively delegitimized by the actions of groups such as the BR. In the end, the process that led to the atomization of Italian society, senseless consumerism and growing individualism and the fetishization of commodities - a process that began with the economic boom-was able to continue without obstacles. Moreover, Moro's death marked the end of that policy of solidarity inaugurated by the Christian politician. It does not seem exaggerated to say that without Moro-and without Berlinguer, who died in 1984-the concrete possibility of achieving the so-called third way to form a democratic political model not subject to the unique thought of 
capitalism had become impossible. In the second half of the eighties, the ideology called Craxism - from the name of Bettino Craxi, leader of the PSI from 1976 to 1993 and Prime Minister from 1983 to 1987-was established and supported privatization and liberalization, moving the PSI from left-wing to center-left. Under Craxi, the PSI formed a coalition with the DC and other moderate parties called Pentapartito, which for a while ensured them a stable majority with which to govern. When, after nationwide judicial investigations, the deep system of corruption at the base of this coalition emerged, there was nothing left to stop the rise of Silvio Berlusconi to power.

\subsection{The Moro Case: History and Conspiracy}

Almost four decades after the attack in via Fani on March 16, 1978, where the BR killed the five bodyguards of Aldo Moro and then the Christian Democrat politician 55 days later, there is not yet a definitive version, or a generally recognized interpretation of what «really» happened. As written by political scientist Giorgio Galli,

the kidnapping [of Aldo Moro] is a unique case not only in their [of the BR] history, but in the entire history of guerrilla warfare in the West $[\ldots]$. Interpretations of what happened include a wide range that goes from everything is clarified [...], with the BR as sole protagonists, to the idea of a conspiracy hatched by the CIA and managed by the Italian P2, through to the appeal on the front page of the <Corriere della Sera, in which Franceschini argues that Moretti is in fact an undercover CIA agent. ${ }^{112}$

It is practically impossible to mention, and even less so to summarize all the inquiries on the circumstances of the kidnapping and murder of the Christian Democrat politician. There is a permanently growing number of different interpretations of documents and testimonies collected in the five trials that were held at the Corte d'Assise of Rome, in the parliamentary committees of inquiry that dealt with the affair and of other testimonies and documents that have not been collected (and verified) in the trials or commissions. The amount of evidence, testimonies, police reports, com-

112 Galli 2004, 106; Franceschini was one the historical leaders and founders of the $\mathrm{BR}$; Moretti was one of the BR leaders in the late 70s and one of the kidnappers of Aldo Moro; P2 was a clandestine (after 1976) Masonic lodge. 
mission reports, photographs and ballistic analyses produced, collected, cataloged and interpreted in four decades is enormous. In the court proceedings alone more or less 460,000 pages were produced. ${ }^{113}$ Even larger is the amount of documents in the archive of the second parliamentary commission of inquiry - the Commissione parlamentare d'inchiesta sul terrorismo in Italia e sulle cause della mancata individuazione dei responsabili delle stragi, established in 1988 and worked on until 2001-which amounts to a total of about 1,500,000 pages. In addition to this mass of documents, there is a comprehensive collection of 130 volumes of documents attached to the final reports of the first commission-the Commissione parlamentare d'inchiesta sulla strage di via Fani, sul sequestro e l'assassinio di Aldo Moro e sul terrorismo in Italia -, which was established in 1979 and concluded its work in 1983. ${ }^{114}$ It can be assumed that the third commission, which is called Commissione parlamentare di inchiesta sul rapimento e sulla morte di Aldo Moro and officially began to work in May 2014, will also produce a considerable amount of documents.

The reconstruction of the circumstances of Moro's kidnapping, imprisonment and assassination emerged in the five court proceedings, according to which the Operazione Fritz-as the BR called the kidnapping-was conceived, executed and completed only by the BR, is rejected by many journalists, historians and politicians. The theses and hypotheses expressed by the various authors dealing with the Moro case are located between two opposing poles: while some believe that there was a conspiracy hatched by state institutions, organizations such as the Masonic lodge P2 and/or secret services (either Italian or from other countries), others are convinced that the BR acted without outside interference and without taking orders from anyone. Over the years, an extensive number of hypotheses-more or less plausible, imaginative and creative-emerged. A wide range of individuals and groups has, from time to time, been accused of involvement in the kidnapping, imprisonment and assassination. ${ }^{115}$

113 See Lofoco 2015, 9.

114 See Satta 2003, xix.

115 Various entities were accused of having helped-materially, logistically-or even of being the real masterminds and instigators of the BR in the preparation and execution of the operation: the Masonic lodge «Propaganda 2» (P2); the Italian intelligence services Military Intelligence and Security Service (SISMI), Intelligence and Democratic Security Service (SISDE), Executive Committee for Intelligence and Security Services (CESIS); the Italian clandestine NATO «Stay Behind» organization called "Gladio»; the United States of America and specifically the Central Intelligence Agency (CIA); the USSR and specifically the Russian 
Hypotheses about an international conspiracy were already formulated in 1978. In a parliamentary debate about the kidnapping and murder of Aldo Moro, which took place on May 19, 1978, the Communist deputy Ugo Spagnoli raised the question of a possible conspiracy. Christian Democrat Vittorio Cervone repeated Spagnoli's claim in another debate on the Moro kidnapping four days later in the Italian Senate. ${ }^{116}$ In October 1978, Leonardo Sciascia, who at that time was member of the Parliament for the Radical Party, published a book entitled L'affaire Moro, in which he questions the official version. However, as we will see in chapter seven, he does not argue that there was an international conspiracy to prevent Moro from continuing his political project. Rather, he argues that part of the ruling class and the state apparatuses took the opportunity to dismiss Moro. In other words: he argues that there were no masterminds who directed the BR, who instead acted according to their own will, but once they had kidnapped Moro, several social actors worked to ensure that he would never come out alive from the "people's prison». Ultimately, Sciascia was first to take the accusations Moro put forward in his letters seriously and assigned the ultimate responsibility for Moro's death to the government and the major political parties. However, many of Sciascia's fellow party members, such as Emma Bonino, took a more radical position, underlining the thesis of the Sicilian intellectual and accusing the United States, the CIA or other NATO members of masterminding the kidnapping. ${ }^{117}$ There is, however, a big difference between saying that national or international actors ordered the kidnapping and assassination of Moro and saying that certain social actors acted, when Moro had already been kidnapped, in order to prevent his possible release.

The first publication in the English language-Robert Katz's Days of Wrath (1980)-despite being characterized by an analytical accuracy absent in Italian publications until then, replicated the investigative attempts al-

Committee for State Security (KGB); the German Red Army Faction (RAF); the State of Israel and specifically its Institute for Intelligence and Special Operations (Mossad), and the criminal syndicate called 'Ndràngheta that was based in Calabria. Very often, the conspiracy theories also point to a Machiavellian mind, to a grande vecchio, which would have masterminded everything; among the most often nominated individuals we find: the former US Secretary of State Herny Kissinger; the former Interior Minister Francesco Cossiga, the former president of the Council of Ministers Giulio Andreotti; and the former Venerable Master of the clandestine lodge P2 Licio Gelli. See Hof 2013.

116 See Hof 2013, 238.

117 See Hof 2013, 238. 
ready widespread in Italy at that time to reconstruct the chronology of and identify the main protagonists (and their responsibilities) in the Moro affair. Katz excludes the possibility that there were foreign powers interfering in the political management of the Moro case and claims that all decisions «were made exclusively in Rome, determined rather less by the spirit of democracy than the passing exigencies of domestic power politics». He also adds that «interests of powers far bigger than Italy was hot breath on Rome's neck. At no time were the men in the via delle Botteghe Oscure [the site of the headquarters of the PCI] unaware that Eurocommunism was on trial both in Moscow and Washington, and not for a moment did Christian Democracy forget the United States and Germany.» ${ }^{118}$

Politician and member of the first parliamentary commission of inquiry Sergio Flamigni, who also dedicated many studies to the topic, vehemently argued that Aldo Moro was killed because of his policy of openness towards the PCI, since it was strenuously opposed by the US' administration, the Soviet nomenclature, NATO, the German, French and Israeli governments, and in Italy by the Masonic lodge P2 and the right wing of the DC. ${ }^{119}$ In his first book, published in 1988, he advocates that Moro was betrayed by his former colleagues and by state officials. Also, as a member of the Commissione parlamentare d'inchiesta sulla strage di via Fani, sul sequestro e l'assassinio di Aldo Moro e sul terrorismo in Italia, he was one of the most prominent people who suspected that the «mistakes» in the search for Moro did not occur accidentally. ${ }^{120}$ In his latest book, Flamigni writes about a patto di omertà (pact of silence) made by terrorists with areas of apparatuses of the Italian State and members of the right wing of the DC aimed at covering the accomplices in and the instigators of the crime. ${ }^{121}$

The former magistrate, and Moro's brother Alfredo Carlo Moro, is skeptical of the thesis that the BR planned, organized and executed Moro's abduction without help and indicates more than twenty issues that remain unexplained. Ultimately, he concludes that the BR were given direct or indirect help at many stages and that the full range of motives and responsibilities has yet to be determined. ${ }^{122}$ In 1998, then President of the Republic, Luigi Scalfaro, supported this view, expressing his doubts in Parliament that the real masterminds of the kidnapping had all been identified. In

118 Katz 1980, 315.

119 See Flamigni 1998, 178.

120 See Flamigni 1988.

121 See Flamigni 2015.

122 See Moro 1998. 
1998, historian Francesco Biscione proposed an interpretive scheme of the Moro crime based on the hypothesis of the «double crime», according to which the murder of the politicians was the result of a convergence of heterogeneous forces and that both international and national right-wing groups, which wanted to defeat Moro's political project, had contributed to the elimination of the hostage. ${ }^{123}$

In 2000, Giovanni Pellegrino, who presided over the Commissione parlamentare d'inchiesta sul terrorismo in Italia e sulle cause della mancata individuazione dei responsabili delle stragi from 1994 to 2001, published a book in cooperation with journalists Giovanni Fasanella and Claudio Sestieri, which focuses on the thesis of the «double hostage». According to him, several Italian and foreign secret services contacted the BR to obtain from the terrorists all the secrets Moro had supposedly told his kidnappers. ${ }^{124}$ There was not a double crime, Pellegrino argued, but rather a double hostage inasmuch as the BR had not one but two sources of blackmail: the prisoner's life and his writings.

Ferdinando Imposimato who, as public prosecutor, investigated the Moro case, argues that Moro «had to die» because of his policy of openness towards the PCI. In accordance with Cold War logic, Moro was a persona non grata in the Italian political class and had to be eliminated in order to preserve Italy's position within NATO. In his latest book, Imposimato even claims that the then Prime Minister Giulio Andreotti and Interior Minister Francesco Cossiga knew where Aldo Moro was imprisoned-via Montalci$\mathrm{ni}$ in Rome-from the first days after the kidnapping. This thesis is based largely on statements made by Giovanni Ladu, a Sardinian officer of the Guardia di Finanza, who in 2009 said to Imposimato that he was a member of a group of soldiers that oversaw the prison of via Montalcini from April 24,1978 , onwards. In 2012, another «witness» wrote a series of emails to Imposimato maintaining that he was also a part of the soldier's group that controlled the prison. However, there are many inconsistencies in Ladu's statements and good reasons to believe that the one who wrote the emails to Imposimato in 2012 was none other than Ladu himself, pretending to be another person. In November 2013, the prosecutor Luca Palamara began to investigate Giovanni Ladu, accusing him of slander. ${ }^{125}$

Other authors are critical of these theses, arguing that the kidnapping and killing of Aldo Moro is only and exclusively attributable to the BR.

123 Biscione 1998, 125-139.

124 Fasanella/Sestieri/Pellegrino 2000.

125 See Lofoco 2015, 139-142. 
Unlike those who are convinced of the existence of a conspiracy, a secret international network or a «grand old man» who pulls the strings of history, this second category of authors works in a less speculative and hypothetical way, basing their theories on documents and testimonies whose reliability is examined on the basis of factual evidence. Vladimiro Satta, the archivist of the second Parliamentary Commission of Enquiry, is convinced that there are no bigger mysteries to unravel concerning the Moro affair. ${ }^{126}$ In his dense and meticulous analysis of documents and records in the archive of the Commission, he identifies only four minor questions that remain unanswered; questions, however, which according to him cannot overturn the verdict reached by the five trials dedicated to the events.

Similarly, the already mentioned Giorgio Galli argues that there was not a conspiracy and that the BR operated without the help of anyone. However, Galli also identifies five «dark spots never clarified». ${ }^{127} \mathrm{He}$ supports the thesis that the Italian intelligence services infiltrated the BR and monitored their activities, but categorically denies that they were aware or even the masterminds of the «Fritz operation». According to Galli, the reasons for the kidnapping and killing of Moro cannot be found in international political interests linked to the Cold War, but in the interests of the BR, who kidnapped Moro in order to obtain political recognition. The BR were not directed or helped by anyone, but rather acted according to their own revolutionary plan, believing that kidnapping Aldo Moro was equivalent to an attack on the "heart of the state», as they wrote in their Risoluzione della Direzione Strategica delle Brigate Rosse, a sort of programmatic manifest written and distributed in February 1978. In this document, the BR identified the SIM-Stato Imperialista delle Multinazionalias the common enemy of the proletarian class, which can only be destroyed by the means of revolutionary violence:

In this historical phase, at this point in the crisis, the practice of revolutionary violence is the only policy which has a real opportunity to address and resolve the antagonist contradiction that opposes the metropolitan proletariat to the imperialist bourgeoisie. At this stage, the class struggle takes on, on the initiative of the revolutionary vanguard, the shape of war. ${ }^{128}$

126 See Satta, 2003.

127 Galli 2004, 107.

128 Brigate Rosse, 1878f, 66; it.: «In questa fase storica, a questo punto della crisi, la pratica della violenza rivoluzionaria è l'unica politica che abbia una possibilità reale di affrontare e risolvere la contraddizione antagonista che oppone prole- 
All BR members who directly or indirectly participated in the action and who talked about the goals pursued by Moro's abduction in the proceedings have repeatedly reiterated this position: Moro was merely a symbol of Democratic Christian power, an exponent, among others, of the so-called «Imperialist State of the Multinationals» and was among the most vulnerable. According to their declarations, Moro was chosen after a series of assignments and checks that led to the discarding of other targets.

However, as historian Guido Formigoni observes, the hypothesis of more sophisticated political intent behind the decision to abduct Moro and not, for example, Francesco Cossiga or Giulio Andreotti, cannot be discarded. In symbolic terms, the abduction was linked to the political process of convergence between the DC and PCI: «Moro was the weaver of a political operation which, paving the way for the dialogue between the DC and the major component of the Italian left, aimed at stabilizing politics. [...] Moro was basically among the very few Christian Democrats [...] (and perhaps the only one) capable of deeply linking strategy and tactics, national and international dimension.» ${ }^{129}$ The BR's goal was therefore not only to block and contain the convergence process between the DC and the PCI, but also to prevent its realization. According to Formigoni, they believed that raising the level of the conflict in military terms would have led the system to collapse from the inside, thus favoring a revolutionary situation with the idea of driving the proletarian masses to support the armed struggle.

Moreover, Moro certainly had many enemies within his own party, state apparatuses and international circles. In fact, «many of the secret service leaders entrusted with the task of coordinating Moro's rescue operation were members of $\mathrm{P} 2$, which has been associated with the overall terrorist sstrategy of tension> characterizing the seventies and eighties.» ${ }^{130}$ As also Formigoni argues, the doubt remains that terrorist environments may not be so isolated and autonomous in their determination: "Somehow their choice and their behavior might have also been moved by some external influence or force.» ${ }^{131}$ Formigoni also highlights that the parliamentary commissions of inquiry and the trials of the BR have brought to light a series of conspicuous omissions, incomprehensible acts, inefficiencies, actual

tariato metropolitano e borghesia imperialistica. In questa fase la lotta di classe assume, per iniziativa delle avanguardie rivoluzionarie, la forma della guerra.»

129 Formigoni 2016, 339.

130 Dunnage 2002, 189.

131 Formigoni 2016, 339. 
deviations in the investigation and strange coincidences, which definitely helped the terrorists and prevented police forces from finding out where Moro was imprisoned. The historian argues that a definitive judgment cannot be given because of a lack of evidence, but that undoubtedly the Italian State did not do everything it could to save Moro through the collaborative work of the police, military and intelligence services. ${ }^{132}$

Other «mysteries» in the Moro case concern texts written by Aldo Moro during his 55 days of captivity. In a recent study, Miguel Gotor examines the letters of Aldo Moro using a sophisticated historical, philological and cultural approach. Gotor criticizes the «interpretive shortcuts» taken by most of the authors who have dealt with the Moro case. According to him, it is simplistic to believe that Moro's death was solely due to the actions of a gang of criminals; but it is equally reductive to consider the kidnapping and murder of the politician as the result of the actions of secret services or occult power groups that operated according to a logic linked to the geopolitical period of the Cold War. Gotor believes that, in order to understand «why Italy was the only country in the world in which the student movement of 1968 [...] was gradually transformed into a violent conflict with armed vanguards right and left», one has to insert the «Moro affair» into the political, social and cultural context of post-war Italy. ${ }^{133}$ Gotor's enquiry tries to reconstruct this context and understand how the BR, the government, Moro's family and the collaborators acted by analyzing the documents they produced.

The historian, who is also a member of the Commissione parlamentare di inchiesta sul rapimento e sulla morte di Aldo Moro and a Senator of the Democratic Party (PD), follows the same analytical process in the study $I l$ memoriale della Repubblica, which examines a series of texts Aldo Moro wrote during his kidnapping to answer the interrogations of the BR. ${ }^{134}$ While the first study sought to reconstruct the strategies, intentions and actions of the main protagonists of the 1978 events, the writings of Moro in this publication are the reference point for a broader historical reconstruction that aims to shed light on the power struggles, interests and policy choices that determined the "crisis of the seventies». ${ }^{135}$ In particular, the goal of this second study is to reconstruct the complicated and strange history of the discovery of Moro's writings. In the so-called «people's prison",

132 See Formigoni 2016, 345.

133 Gotor, 2008a, xvi.

134 Gotor 2011.

135 Gotor 2011, 548. 
the politician not only wrote many letters, a part of which became public during his imprisonment, but also a large series of texts and notes generally referred to as Moro's Memoriale. He almost certainly wrote a part of these texts in response to the BR's interrogation, while another part seems to be the fruit of free autobiographical reflections or descriptions of his own vision of recent Italian political history. It is not entirely clear why the BR-the leader of the BR group that kidnapped and assassinated Moro, Mario Moretti, claims that none of them realized the possible «political» use of Moro's papers ${ }^{136}$ _ did not disclose these materials during or in the immediate aftermath of the sequestration, since they contain critical judgments on the DC's connection with the «strategy of tension». Moreover, in these texts, Moro also illustrated quite clearly the goals and methods of this strategy, mentioned implicitly the activity of the NATO stay-behind organization Gladio, and addressed the relations between international politicalmilitary environments and internal political problems in Italy.

Gotor's reconstruction also clearly demonstrates the existence of two secret negotiations during Moro's captivity. On the one hand, there was an attempt by the Vatican, among whose protagonists were the priests Cesare Curioni, Pasquale Macchi and Antonello Mennini, to negotiate with the BR. On the other hand, there was an attempted negotiation involving the Socialists Bettino Craxi, Claudio Signorile and Antonio Landolfi, the member of Autonomia Operaia Franco Piperno, the journalist Lanfranco Pace, and two members of the BR, Valerio Morucci and Adriana Faranda. ${ }^{137}$ Gotor believes that the actual holders of political authority during Moro's imprisonment-that is, Prime Minister Giulio Andreotti and Interior Minister Francesco Cossiga-were most likely aware of the two secret negotiations. Moreover, Gotor feels Pellegrino's hypothesis is plausible, according to which the Italian government was betrayed at the last moment by an «unfaithful agent», the one who was entrusted with the task of recovering Moro's papers in a dual secret negotiation also involving the release of the prisoner:

In that circumstance, the intermediary may have not acted according to Italy's national interests [...] but to a supranational dimension linked to the «Cold War?, to a different level of loyalty imposed by the logic of the opposing blocs. [...] A logic that heavily influenced not only the relations between the Soviet and Atlantic bloc, but also those

136 See Moretti 2000, 158-159.

137 See Gotor 2008, 260-273. 
between the north and south of the Mediterranean basin where Italy was a hinge between two worlds, but also [...] a giant geographic, political, military, commercial, and espionage pier, and a transit passage for so much legal and illegal traffic that linked the Middle East's troubles to the geometries of Atlantic Europe.

However, Gotor believes that the thesis of a «dual state»-that is, the idea of a parallel state that would have plotted to kill Moro-is not sustainable since in Italy state authority was always weak, stratified and polycentric, and thus unable to organize a secret complot. In fact, he adds,

public firmness and secret negotiation are the only possible condition of the exercise of power in an emergency situation when the central authority is fragile, without mutual trust and the place of an endemic struggle between factions. ${ }^{138}$

As evidenced by this incomplete list of hypotheses and interpretations of what happened in the spring of 1978, the Moro case remains the subject of debate and its clarification is far from over. It is not possible and not even the task of this study to defend a certain hypothesis or model of interpretation, since this would require a specific investigation of all the evidence, clues and testimonies that have emerged in the last four decades. However, one cannot but notice that there are studies of undoubted seriousness and scientific rigor, such as those of Galli and Gotor, only to mention two, which highlight a series of unclear points, omissions and deliberately planted false leads which, for good reason, have led to the belief that even today there are facts and information that are not in the public domain. It is equally clear that the various assumptions of conspiracy or of dark or missing elements were often used for certain political purposes and to legitimize or delegitimize, and to accuse or to absolve institutions, political groups, parties and individuals. ${ }^{139}$ That being said, it cannot be excluded that members of state apparatuses, foreign and national intelligence services and, more generally, social actors who did not belong to the BR, pursued their goals, acting in a planned manner to determine the outcome of the Moro case. The problem is that as long as no unmistakable evidence emerges - if such evidence really exists—all that remains very hypothetical.

However, as I will show in the next two chapters, there is at least something that is not hypothetical and which can be demonstrated: during the

138 Gotor 2008, 273.

139 See Hof 2013, 232-256. 
55 days of Moro's imprisonment, different social actors acted in concert, giving shape to political and media campaigns in which the choice of not negotiating with the BR to obtain Moro's release was represented as necessary for national security and, more generally, for the salvation of the state. Moreover, I will prove that, although Moro categorically criticized the «line of firmness» in his letters and refused to assume the role of a state martyr, he was repeatedly represented as such. Further, in the next chapters I will argue that the rhetoric of public firmness and the martyrological representation of Aldo Moro were related to a state mythology in which the conflict between state and terrorism assumed the connotation of a metaphysical fight between good and evil. If Moro, as I believe, was not killed with the direct-logistical, material - help or complicity of state apparatuses, the intelligence services or occult political groups, it is certain that during his imprisonment most representatives of the government, major parties and the established media produced a hegemonic discourse and worked according to a strategy of representation, whose function was to make Aldo Moro's death morally and politically acceptable for public opinion. 


\section{Construction of a Willing Martyr}

\subsection{Opposing Narratives and Representations: Red Brigades Versus Italian State Versus Aldo Moro}

Virtually every one of the first Christian martyrologies reaches its climax in the public arena of the games. These games had the function not only of entertaining, but also of holding together a complex network of political, religious, and social elements of the empire. As Paul Middleton observes, «in the stadium, the power, justice, and glory of the empire were celebrated amid the spectacle of gladiator duels, wild beasts, and the execution of criminals.» ${ }^{1}$ The games were thus a form of representation, glorification and celebration of both the political power and the legal system, of both the executive and legal authority. The trials, the fights with beasts, the executions, the tortures inflicted upon the members of the Christian communities can be considered, from this point of view, to be part of this system of practices, which enforced and glorified political authority and the exercise of violence, which were experienced as both legal and legitimate.

Martyrological representations produced by the first Christian communities radically opposed these practices of the glorification and representation of power. The first Christian martyrologies did not refer to a system of rules created and enforced through social or governmental institutions, but to certain ethical norms and values, which were experienced and represented as not identical to the law in force. Since there was no organized and legitimized institution to guarantee these norms and values and the members of the Christian communities radically rejected the legislation and the legitimacy of the authority that enforced and applied the law, one can say that martyrological representations were initially anti-legal. However, what they implicitly or explicitly criticized was often not the legal system as such, but the extra-legal effect of legitimization, challenging the fundamental moral norms and values to which the legal system referred.

Describing the context in which Christian martyrologies emerged in formal terms, we can distinguish between two opposite ways of representing and narrating actions and events related to trials and their punitive, often violent effects. The condition for the emergence of such different represen-

1 Middleton 2011, 58. 
tations is the presence of at least two large conflicting groups, one of which controls political and juridical institutions and state apparatuses, while the other does not. The situation can also be described in the following way: there is a context of political struggle between two groups-between individuals who identify themselves with two symbolically and discursively constructed forms of social and/or political community-in which the judicial authority enforced by one group brings to trial one or more of the other group's members. Both groups produce different narratives referring to the actions and events related to the trial. The first narrative has the function of legitimizing the decisions of the juridical authority by referring to law and ethics, while the second one attempts to delegitimize these decisions by highlighting its oppressive and unethical character.

Also in the socio-political context in which the kidnapping, imprisonment, and assassination of Aldo Moro occurred, two fronts were «contending» for legitimacy, which produced and implemented two opposing narratives: on the one hand, in their communiqués the Red Brigades (BR) represented Aldo Moro as the accused in a trial against the «Imperialist State of the Multinationals» (SIM); on the other hand, representatives of the Italian government, of political parties and most parts of the media represented Aldo Moro first as a great statesman who embodied the best virtues and characteristics of a brave and committed politician, then as a hostage at the mercy of his kidnappers, and finally as a martyr who died for the salvation of the Italian Republic. But here the situation is, in a sense, completely overturned, insofar as here was a group, without political legitimacy and which did not refer to an institutionalized legal system, implementing the trial's narrative. Conversely, representatives and supporters of the generally recognized political authority and political groups produced martyrological representations.

The implementation of the trial's narrative by the BR was a result of their self-understanding as the true avant-garde of proletarian revolution as well as part of their propaganda strategy. They understood and represented their actions as part of a legitimate trial, in which not only the behavior of Aldo Moro, but of the representatives of the whole political system was indicted. It is worth mentioning some of the answers given to journalist Giorgio Bocca by those members of the BR who participated in the Fritz operation. The journalist asked them why they decided to kidnap Moro and what were the goals of the operation. Lauro Azzolini suggested one reason-hate for the Christian Democracy (DC)—and three goals: to convince the proletariat, through a demonstration of military power and effi- 
ciency, that revolution by means of violence was feasible; to understand, through the interrogation of Moro, the structures of power; and to obtain the recognition of political prisoners. ${ }^{2}$ In other words, for Azzolini the operation was, at the same time, a performance with an appellative function, a means of acquiring otherwise inaccessible knowledge, and a political instrument to force the state to no longer deal with the BR as if they were a group of criminals, but as a legitimate political group.

Other members of the terrorist organization summarized the operation's goal a little differently. The operation's chief, Mario Moretti, emphasized the appellative function of the operation, but minimized the intention of discovering hidden truths or becoming aware of secret information:

Why Moro? Because he was, for almost two decades, the supreme executor of power in Italy, because he was the demiurge of Bourgeois power, present in mediations and in decisive choices. [...] Someone has tried to attribute to us interests and methods of interrogation that we never had. The interrogations were secondary to the action. The important thing for us was not what Moro would have said, but what the imprisonment would have moved, unleashed in the revolutionary area. Do you really believe that we organized an operation of that kind, in which we played our entire organization, to uncover the scandals of the Christian Democracy? They were not really there to be uncovered; all of Italy knew and is aware of them; they are, so to speak, routine, normality. ${ }^{3}$

Another member of the operation, Valerio Morucci, stressed in particular the objective of obtaining political recognition:

The ideological apparatus of the BR [...] is reduced essentially into two parts, rather a corollary, the SIM and the Second Republic. The SIM or Imperialist State of the Multinationals or global capitalist super-gov-

2 See Bocca 1985, 205-206.

3 Bocca 1985, 206-207; it.: «Perché Moro? Ma perché sua era, da almeno vent'anni, la suprema gestione del potere in Italia, perché era il demiurgo del potere Borghese, presente nelle mediazioni e nelle scelte decisive. [...] Qualcuno ha voluto attribuirci interessi e metodi inquisitori che non abbiamo mai avuto. Gli interrogatori sarebbero stati secondari all'azione. L'importante per noi non era ciò che Moro avrebbe detto, ma ciò che il sequestro avrebbe smosso, scatenato nell'area rivoluzionaria. Le pare che avremmo organizzato una operazione di quel tipo, in cui giocavamo tutta la nostra organizzazione, per scoprire gli scandali democristiani? Ma quelli non erano proprio da scoprire, l'Italia intera conosceva e li conosce, sono, per così dire, routine, normalità.» 
ernment, which Moro is the representative of in Italy as a leader of the DC [Christian Democracy]. [...] Starting from the false but dogmatic premise that there is a SIM, everything must follow: Moro is the irreplaceable pivot of the imperialist project, the DC cannot do without him, the other parties cannot do without the DC; so the game is won at the start, the state will be forced to deal, to pay a very high price. The justicialist goal does not exist, the BR do not care to be told off by Moro about the misdeeds of the DC [...]. Moro was not doomed from the start, but the price for his life was the political recognition of the BR by the DC, from the DC in the first place as a guarantor of the SIM and the other parties. [...] What else would the exchange between the political prisoner Moro and some of the political prisoners of the revolutionary area have been if not a political recognition? Not their mere release. That's why the executive rejected the proposals of the Socialists who wanted the release, but reaffirmed the absence of recognition. [...] Pope Paul VI, UN Secretary Waldheim, and Arafat made recognitions of that type, but the BR wanted the recognition of the DC. ${ }^{4}$

It is interesting to note that both Morucci and Moretti excluded a «justicialist» intention, arguing that the goal was not to try Aldo Moro in order to bring out the «misdeeds of the DC». But if this is true, why, in the first communiqué issued by the BR on March 18, 1978, two days after the attack in via Fani, did they explicitly write about a trial against Moro and the DC?

4 Bocca 1985, 206, 220; it.: «L'apparato ideologico delle BR [...] si reduce in sostanza a due punti, anzi a un corollario, il SIM e la Seconda repubblica. Il SIM o stato imperialista delle multinazionali o supergoverno capitalistico mondiale, di cui Moro è il rappresentante in Italia come leader della DC [...]. Partendo dalla premessa falsa ma dogmatica che esiste il SIM, tutto ne deriva: Moro è il perno insostituibile del progetto imperialistico, la DC non può fare a meno di lui, gli altri partiti non possono fare a meno della DC; dunque la partita è vinta in partenza, lo stato sarà costretto a trattare, a pagare un prezzo altissimo. L'obbiettivo giustizialista non esiste, alle BR non interessa farsi raccontare da Moro le malefatte della DC. [...] Moro non era condannato in partenza, ma il prezzo della sua vita era il riconoscimento politico delle BR da parte della DC, da lei in primis come garante del SIM e degli altri partiti. [...] Che altro se non il riconoscimento politico era lo scambio fra il prigioniero politico Moro e alcuni prigionieri politici dell'area rivoluzionaria? Non la loro semplice scarcerazione. Ecco perché l'esecutivo respinse le proposte dei socialisti che volevano la scarcerazione, mentre riaffermavano il no al riconoscimento. [...] Riconoscimenti di quel tipo di furono da parte del papa, paolo VI, dal segretario dell'ONU, Waldheim, da Arafat, ma le BR volevano quello della DC.» 
It is necessary to extend and further deepen the trial against the regime [...]. This is one of the directives by which the Movement of the proletariat Offensive Resistance marches. [...] Let it be clear then that with the capture of Aldo Moro, and the trial in which he will be submitted to a People's Court, we do not intend to end the match, nor much less to show off a ssymbol, but to develop a password by which the entire Movement of Offensive Resistance is already measuring itself, to make it stronger, more mature, more incisive and organized. We intend to mobilize the vastest and most unified armed initiative toward the ultimate development of the class war for communism; to carry the fight to the Imperialist State of the Multinationals; to disarticulate the structures, the projects of the imperialist bourgeoisie by attacking the political-economic-military personnel who are its expression. ${ }^{5}$

What does organizing a trial in order «to develop a password» mean? Behind this militaristic rhetoric lurks the idea of providing an example that the «proletariat» or, more generally, the «people» could imitate. The BR understood themselves as fighting in an avant-garde way, as a sort of proletarian military elite who were "performing» a ritual trial whose main function was to appeal to the people to reinforce and reproduce the same ritual structure of accusation, judgment and execution. They used judicial rhetoric in the (perhaps unconscious) belief that it served to legitimize the use of violence by making it appear as part of the truthful and meaningful revolutionary process of liberation. The paradox of all this is that, to achieve this effect, the BR sought the recognition of the DC, which for them was equivalent to the so-called SIM; they wanted to be recognized as a legitimate, although hostile, political force. In other words, they seemed to believe that only through recognition of their political identity by the state could the performance succeed, appealing to the people, who would finally begin the «ultimate revolution».

5 Brigate Rosse 1978a, 35; it.: «Bisogna estendere e approfondire il processo al regime [...]. È questa una delle direttrici su cui è possibile far marciare il Movimento di Resistenza Proletario Offensivo. [...] Sia chiaro quindi che con la cattura di Aldo Moro, il processo al quale verrà sottoposto da un Tribunale del Popolo, non intendiamo «chiudere la partita né tanto meno sbandierare un «simbolo», ma sviluppare una parola d'ordine su cui tutto il Movimento di Resistenza Offensivo si sta già misurando, rendendolo più forte, più maturo, più incisivo e più organizzato. Intendiamo mobilitare la più vasta e unitaria iniziativa armata per l'ulteriore crescita della guerra di classe per il comunismo. Portare l'attacco allo Stato Imperialista delle Multinazionali. Disarticolare le strutture, i progetti della borghesia imperialista attaccando il personale politico-economico-militare che ne è l'espressione.» 
The BR, by staging a trial and using legal-procedural language in their communiqués, tried to present themselves as a legitimate alternative to state institutions. It was an attempt to reinforce a set of organized and regularized expressions, figures and activities related to official trials, namely one of the central instruments for controlling and punishing an individual's behavior, as a procedure of prefiguration, that is: as an attempt to copy established rhetorical forms and narrative patterns, which historically have proved performatively effective. Although it may seem illogical, the BR tried to replace the state apparatuses by copying and replicating their structures, practices, and semiotic and rhetorical forms. What is significant here is a postscript at the end of the aforementioned first communiqué:

In relation to the trial in Turin, we have already said that the trial, through which a Special Court wants to quash the Communist Revolution, is nothing but a farce. Another trial is taking place in the country, in which the struggles of the proletariat against its imperialist enemy can be seen, which in the development of the Civil War for the construction of a Communist Society, charges and tries the bourgeoisie and its servants. [...] We also consider all the imprisoned communist fighters hostages in the hands of the enemy and we will treat any retaliation or reprisal as what they are: war crimes. ${ }^{6}$

The rhetorical strategy adopted here operates with the distinction falsity/ authenticity: the trial in Turin, in which the historical BR leaders were accused, is represented as a «farce», an illegitimate political mise-en-scène, and is contrasted to the «real» trial, in which the proletariat accuses and tries the bourgeoisie. The attribution of truthfulness, which was exemplary of their own «trial», is undoubtedly an attempt to increase their performative efficacy through language and rhetoric.

The BR understood the trial against Aldo Moro and the DC as part of a guerrilla strategy pursuing multiple goals. As a general purpose, they wanted to light the spark of the revolution. More concretely, they wanted to interrupt the «long Communist march into the institutions» to affirm the

6 Brigate Rosse 1978a, 36; it.: «Sul processo di Torino. Abbiamo già detto che il processo attraverso il quale un Tribunale Speciale vorrebbe liquidare la Rivoluzione Comunista, non può che essere una farsa. Ben altro processo è in atto nel paese, è quello che vive nelle lotte del proletariato contro il nemico imperialista, che nello svilupparsi della Guerra Civile per la costruzione di una Società Comunista, mette sotto accusa la borghesia e i suoi servi. [...] Riteniamo inoltre tutti i combattenti comunisti imprigionati, ostaggi nelle mani del nemico e sapremo trattare eventuali ritorsioni o rappresaglie per quello che sono: crimini di guerra.» 
prospect of the revolutionary fight and lay the groundwork for their own hegemony within the left. Moreover, they wanted to create contradictions within the political forces. The fate of the hostage, Moretti said, depended on the contradictions that would emerge in the political forces, and «the execution of the prisoner was an eventuality that we could not discard» if such contradictions did not emerge, as actually happened in the 55 days of Moro's imprisonment. ${ }^{7}$ According to Barbara Balzerani, another member of the organization, for the BR there was a «war between two opposing armies, that of the state that does not hesitate to kill to maintain the established order and that of the revolutionary avant-gardes that has decided to respond to the level imposed by power.» ${ }^{8}$ After carrying out many attacks in the previous year, in early 1978, terrorists tried to provoke neo-fascist environments with the murder of two members of the Italian Social Movement (MSI). The violent reaction that ensued seemed to set up a situation of civil war. In a similar way, with the abduction of Moro, they wanted to spread the feeling that Italy was a country in disorder and without a government capable of governing, forcing the DC and other parties to reveal their impotence or to react with authoritarian and anti-democratic measures. ${ }^{9}$

The BR's trial rhetoric was thus inseparably tied to war rhetoric. The trial of Moro and the DC took on the connotation of a war crimes trial. The BR also justified the killing of Moro's five bodyguards with war rhetoric. In various testimonies released later on in prison, they spoke of their concern to avoid killing innocent victims, such as locals, workers or bystanders, but for the bodyguards the discourse was different: «One could object that the life of a policeman is not less worthy than that of a child, but that is another discourse. At that moment, we are at war with the state: the clash is between Moro's bodyguards and us. It is either us or them. If we fail, our comrades die.» ${ }^{10}$ De facto, the killing of the bodyguards was

7 Moretti 2000, 117; it.: «L'esecuzione dell'ostaggio era una eventualità che non potevamo scartare.»

8 Balzerani 1998, 74-75; it.: «[...] guerra tra due eserciti contrapposti, quello dello Stato che non esita ad uccidere per mantenere l'ordine costituito e quello dell' 〈avanguardia rivoluzionaria che ha deciso di rispondere sul terreno imposto dal potere.»

9 See Giovagnoli 2009, 45.

10 Moretti 2000, 121-122; it.: «Si può obbiettare che la vita di un poliziotto non vale meno di quella di un bambino, ma questo è un altro discorso. In quel momento noi con lo stato siamo in guerra: lo scontro è tra noi e la scorta di Moro. O noi o loro. Se sbagliamo muoiono dei compagni.» 
not accepted by most of those who, within the worker and student movements and in general within the extra-parliamentary left, had so far sympathized with the BR. As theater director and actor Marco Baliani observed, the 55 days of Moro's captivity were like a «watershed for an entire generation, my generation. It was as though in those days there came to maturity a deep laceration that may have already existed, but only fully manifested itself, became visible, in that moment.» ${ }^{11}$ This change within the worker and student movements has been well recorded, albeit with a certain amount of rhetoric, by L'Unità, who two days after the attack wrote that «people hear that; they know that the assassinated carabinieri and agents are their brothers; they are workers like us. The pain for this scattered blood is deep and authentic among the people.»12

Most of the representatives of the state apparatuses and of the government as well as of the majority of the press reacted to the BR's trial narrative by adopting and reinforcing the rhetoric and emplotment strategies which, as we have seen, came to establish themselves as an alternative and opposing way of representing and narrating a trial as early as from the first century AD. We are here faced with a reversal of roles and language games: Aldo Moro became the symbol of the body politic of the wounded nation, the class and the political system on trial, the martyr who suffered and died for the welfare and safety of the Italian Republic. In this martyrological narrative, the BR are portrayed as an evil force, infernal beasts craving only destruction and death.

Both trial and martyrological narratives had different strategies of appellation and of construction of a political community. In fact, the struggle between the two narratives is not only a struggle for the establishment and propagation of a certain image of Moro-martyr vs. politician co-responsible for all the evil that happened in Italy after World War II-but also for the hegemony over the concept of «people» and in general over the idea of the body politic. The discursive effort to establish who the people are and who is the legitimate representative of the people is based on what Chantal Mouffe and Ernesto Laclau describe as «constitutive exclusion», by which all particular notions of inclusion are established. ${ }^{13}$ All forms of representa-

11 Baliani 2011, 27.

12 Spriano, Paolo, «La piazza e lo Stato», in: L'Unità, 18.3.1978, 1; it.: «La gente lo sente, lo sa che i carabinieri e gli agenti assassinati sono suoi fratelli, sono lavoratori come noi. Il dolore per questo sangue sparso è profondo, autentico in mezzo al popolo.»

13 See Mouffe/Laclau 1986. 
tion of political community are based on implicit or explicit lines of demarcation between an inside and an outside. So, when the BR, the political parties, the media, the representatives of government and state institutions make assertions about who the people are, there is always someone who is excluded from this collective identity. As Judith Butler observes,

when the struggle over deciding who belongs to the people gets intense, one group opposes its own version of the people to those who are outside, those considered to threaten the peoples, or to oppose the proposed version of the peoples. As a result, we have (a) those who seek to define the people (a group much smaller than the people they seek to define), (b) the people defined (and demarcated) in the course of that discursive wager, (c) the people who are not the peoples, and (d) those who are trying to establish that last group as part of the people. ${ }^{14}$

This is exactly what happened within the discursive struggle for the hegemony over the representation of the events of spring 1978. The BR tried to define «the people» as the Italian proletariat and themselves as the legitimate revolutionary avant-garde who acted and spoke for this people, by excluding the representatives of the political parties in Parliament, judges, police officers and other employees of the state apparatuses, and in general all members of the so-called bourgeoisie. They did that through performative acts of delimitation, which took the forms of both linguistic and bodily performativity. In fact, the killings of Moro's five bodyguards on March 16 and of Aldo Moro himself on May 9, like so many other political assassinations and bombings, were not (only) military operations, but (especially) performances with which the BR wanted to demarcate themselves from other groups of the parliamentary as well as extra-parliamentary left. Their message was: we are the only true revolutionary vanguard, because we not only talk but are willing to and also capable of killing the enemies of the people. And, as we have just seen, they also regarded their actions as examples to be given to the people, that is, as performances with which they appealed to the people to imitate them. From this point of view, the ultimate line of demarcation that defined the BR's idea of who is part of the people and who is excluded, was not primarily the distinction between the working-class and bourgeoisie, but the distinction between those who had the will to act violently and those who did not. But since each performance can be interpreted by the public, other than as intended by the agents of

14 Butler 2015, 4. 
the performance itself, the BR issued their communiqués, that is, linguistic performances, through which they tried to represent their actions not as assassinations but as legitimate executions.

On the other side, the government and most of the media operated by defining the BR as an actual and concrete emanation of a permanent and omnipresent danger, a will of violence that threatened the political body of the nation and that could potentially break out at any moment. Within the mythical narrative of the nation-state, Aldo Moro assumed the role of the martyr that is willing to sacrifice himself for the sake of the threatened «people». To be willing to use violence to achieve its own ends, the state must assume the monopoly on violence and even be willing to sacrifice its own citizens; the individual body is an expendable commodity for the wellbeing of the political body. Not only were the BR discursively excluded from the body politic, but so was anyone who challenged the hegemonic narrative, even Aldo Moro himself. From the moment he began to write in his letters that the state had to deal with the terrorists, he challenged and criticized a series of ethical and political premises on which nationstate mythology is based. Representatives of the government and institutions as well as the majority of the media responded to this criticism with discursive practices intended to deconstruct and cancel out Moro's political identity, in order to make him appear as an individual reduced to mere life, de facto excluding him from the body politic. This argument will be deepened further.

During the 55 days of Moro's captivity, there were some attempts to represent and narrate what was happening in an alternative and subversive way, challenging both the trial and martyrological narratives. In fact, not all the social actors who were involved in this mammoth media spectacularization of the kidnapping, imprisonment and assassination of Aldo Moro aligned themselves with either the rhetoric and emplotment strategies of the BR on the one hand, or those of the political parties, the government and most of the media on the other. What makes the case so interesting is in fact that Aldo Moro himself tried to resist. Leonardo Sciascia wrote that Aldo Moro, before being kidnapped and during his entire political career, used language as a weapon because he was aware of «the Italian and Catholic secret of how to disperse the new into the old, to use every new tool to serve the ancient rules and, mainly, to produce negative knowl- 
edge of human nature, in negativity.» ${ }^{15}$ Well, after his abduction, stripped of power, Aldo Moro tried to use the old to say something new or at least to subvert what the ruling parties, the government and most of the media were saying. From a formal point of view, Moro's attitude resembles that of Bartleby in Melville's story, which, as we saw in chapter two, is summed up in the formula I would prefer not to. ${ }^{16}$ In his letters, the Christian Democrat politician used language units and rhetorical forms linked to martyrological and trial narratives in a subversive way, trying to give a different connotation to words like «people», «state», «guilt», «accusation», «judgment», «salvation», and so on. He reinforced semantic and rhetorical elements used in both trial and martyrological narratives, but in a completely different way. $\mathrm{He}$, in some ways, assumed the role of a martyr but held it against those who did not want, or at least did nothing, to save him.

Moro opposed the vision of man and politics that was operative in the national state mythology. He inverted the logic of the «reason of state», arguing that the state and its apparatuses lose all sense, all reason for being, if their actions are not based on the ethical principle of the sanctity of human life. As we saw, he actually supported this conception of the state and of human life in some of his academic writings and political speeches. In the letters he wrote from the "people's prison", he reaffirmed his conviction, attempting not only to save himself, but to subvert and withstand a dangerous ideology, which considers men to be means for political purposes and mere life to be expendable, instead of looking at human life, speaking in Kantian terms, as an end in itself. The words and sentences written by Moro in captivity are like a crack in the wall of the hegemonic representations and narratives of what happened in the spring of 1978; they have operated and still operate as examples and points of departure for a variety of other representations and narratives that seek to react to, criticize and deconstruct the dominant political ideology, the state mythology and doxology.

I identified three different ways of representing and narrating the events of 1978, three different uses of language units and rhetorical forms. All three referred to the same events and emerged within the same general social, cultural and political context, but with different objectives and strategies. All three revolve around the figure of Aldo Moro: Moro as a defen-

15 Sciascia 1978, 34; it.: «Il segreto italiano e cattolico di disperdere il nuovo nel vecchio, di usare ogni nuovo strumento per servire regole antiche e principalmente, di una conoscenza tutta in negativo, in negatività, della natura umana.»

16 See Agamben/Deleuze 2012; Whyte 2009. 
dant accused of being the person most responsible for all the evils caused by the capitalist and imperialist bourgeoisie in Italy; Moro as a martyr, to be sacrificed for the safety of the Republic; and finally, Moro as a human being to be saved. The first two of these narratives operate according to mythological narrative mechanisms. They reduce the complexity of reality, they divide humanity by resorting to the dichotomy of good versus evil, they represent history as an eternal fight between state and mankind, between Leviathan and Behemoth. They are similar since they are based on the same ideological paradigms, and they need each other to survive and reproduce. The pseudo-messianic narrative of the BR does nothing more than reverse and reinforce the interpretative and representative patterns of the nation-state mythology, because it absolutizes and substantializes good and evil, conceives violence as the engine of history and the only tool to change it and, above all, understands the human being as an expendable commodity. The BR regarded themselves as the inheritors of the Resistance, as the fighters on the side of the oppressed, but instead they acted, spoke, and wrote reproducing practices and narratives of oppression. Only the third strategy of representation and narration breaks down and completely distances itself from the ideological paradigms and the oppressive practices of nation-state mythology. It is able to offer resistance to the instrumental use of the martyr figure, to the legitimization of violence (both that practiced by the state and by terrorist organizations), and to the absolutization of good and evil because it uses language and rhetorical forms poetically (see chapter two). By defining these linguistic and discursive performances as "poetic», I will argue that not only can art and poetry resist hegemonic narratives, but rather that acratic and para-doxological discursive practices, to be effective, must act as poetry and thus, in line with the definition given by Agamben, bring to light the historicity of linguistic forms that they use. Aldo Moro's letters, as well as other media and social actors who have been inspired by these letters, operate exactly in this way: they expose and unmask the instrumental use of language, the rhetorical mechanism through which signs and words are hypostatized so that representations of non-discursive facts, events, and actions appear to be absolutely correspond to reality. In other words, they oppose and radically reject hegemonic political discourse through the disempowerment of its rhetorical and linguistic tools and the deconstruction of its paradigms. ${ }^{17}$

17 I already mentioned in chapter two that the martyrological narrative pattern was not the only one used to approach and give certain moral, historical and political significance to the events of the spring of 1978. The interpretative model that 


\subsection{The Image of Moro Before the Kidnapping}

Aldo Moro was known, before the BR kidnapped him, especially for his difficult language, which was often incomprehensible to those who were not deep connoisseurs of the jargon used by the political and cultural elite of the country. He was famous for his ability to defend the DC from corruption charges and scandals with very long and exhausting speeches in Parliament. Since the end of the war, the DC leaders and parliamentarians were perpetually involved in scandals. ${ }^{18}$ Further, the party was notorious for the so-called strategy of logoramento (dragging-out), which consisted in the endless prolongation of parliamentary debates and for holding off legislative action. In 30 years of political supremacy (from the election of the First Republican Parliament in 1948 to 1978) very few significant laws were passed; for the most part, the laws that were successfully passed in Parliament were known as leggine (little laws). ${ }^{19}$ Moro was one of the most enduring leaders of the DC from the beginning of its supremacy. He was Prime Minister five times (three times from 1964 to 1968 and twice from 1974 to 1976 ) and held many diverse political positions. ${ }^{20}$ In this long political career, he constantly played the role of the «defender to the bitter end» of the DC. As observed by Wagner-Pacifici, "where Aldo Moro was an archetypical Christian Democrat though was his natural proclivity toward logoramento. Moro's mode of logoramento was linguistic.» ${ }^{21}$

The writer, poet and filmmaker Pier Paolo Pasolini was probably one of the first Italian intellectuals to criticize the instrumental use of language by the DC and in particular by Aldo Moro. In an article published in the Corriere della Sera in February 1975, which became popular as the «Article of the Fireflies», he diagnosed the transition from a totally repressive political regime founded on Fascists values - «the continuity between Fascist Fas-

shaped the Moro affair as a conflict between generations, as well as the narrative modality of conspiracy based on the idea that the BR were puppets controlled by obscure international political right-wing forces or a «grand old man», also played a central role.

18 See Wagner-Pacifici 1986, 32.

19 One important reason, among others, for the failure of successful parliamentary legislation was the different interpretation that the two major parties, the PCI and DC, had of the Constitution. See Wagner-Pacifici 1986, 33.

20 National Secretary of the Christian Democracy (1959-1964); Minister of Justice (1955-1957); Minister of Public Education (1957-1959); Minister of Foreign Affairs (1964-1974); President of the National Council of the Christian Democracy (1976-1978).

21 Wagner-Pacifici 1986, 34. 
cism and Christian Democratic Fascism is complete and absolute»-to a uniquely and completely capitalist regime. Pasolini argued that the DC had obtained an absolute majority in the 1948 elections through the votes of the peasantry, managed by the Vatican, propagating the same values on which the Fascist regime was already based: «the Church, Fatherland, family, obedience, discipline, order, savings, and morality». ${ }^{22}$ These values were «real» as they were rooted in the «agricultural and paleo-industrial» Italian culture. This reality, he argued, got lost the moment when these values were transformed into «national values», becoming a form of «atrocious, stupid, and repressive state conformity: the conformity of Fascist power and Christian Democratic power.» ${ }^{23}$ Through the industrial homologation, Italians suffered a «mutation» that turned them into «degenerate, ridiculous, monstrous, criminal people». The engine of this mutation is, according to Pasolini, «the power of compulsive consumer behavior». ${ }^{24}$

The radical criticism that Pasolini moved through the political class is that politicians had not noticed this mutation. It is at this point in his argumentation that the author addressed the «completely new language» used by Moro:

The men of power of the Christian Democracy [...] have not noticed that it [the power] was «different: incommensurable not only to them, but to all forms of civilization. As always (see Gramsci), one could only notice the symptoms within language. In the phase of transitionnamely dduring the disappearance of fireflies - the men of power in the Christian Democracy quite abruptly changed their way of expressing themselves, adopting a completely new language (which is after all as incomprehensible as Latin), especially Aldo Moro, who (for an enigmatic correlation) appears as the least implicated of them all in the

22 Pasolini, Pier Paolo, «Il vuoto del potere», Corriere della Sera, 2.2.1975, 1; it.: «[...] la Chiesa, la Patria, la famiglia, l'obbedienza, la disciplina, l'ordine, il risparmio, la moralità.»

23 Pasolini, Pier Paolo, «Il vuoto del potere», Corriere della Sera, 2.2.1975, 1: it.: «Nel momento in cui venivano assunti a <valori nazionali non potevano che perdere ogni realtà, e divenire atroce, stupido, repressivo conformismo di Stato: il conformismo del potere fascista e democristiano.»

24 Pasolini, Pier Paolo, «Il vuoto del potere», Corriere della Sera, 2.2.1975, 1; it.: «[...] un popolo degenerato, ridicolo, mostruoso, criminale. [...] il comportamento coato del potere dei consumi.» 
horrible things that have been organized since '69 to the present day, in an attempt, so far formally successful, to still retain power. ${ }^{25}$

There are at least three important things to highlight. In the first place, Pasolini referred to 1969, the year of the Piazza Fontana bombing, and more or less explicitly suggested that according to him the leaders of the DC were implicated in it. In doing so, he seemed at least to partially consider the possibility of a political conspiracy, aimed at increasing the tension in Italy to ensure the maintenance of power by the ruling class. Pasolini's thesis falls partially into what I have previously called the narrative of conspiracy. ${ }^{26}$ The hypothesis that some members of the ruling class were implicated in some of the massacres that happened in Italy during the so-called «years of lead» plays a central role in Italy's cultural imaginary. The possible involvement of representatives of political parties, the government, the military, etc. in the Moro case is still the subject of debate in the media and in the new Parliamentary Commission of Inquiry. The Piazza Fontana bombing and the role played during the event by the secret services, the military apparatus and some representatives of the political class-last but

25 Pasolini, Pier Paolo, «Il vuoto del potere», Corriere della Sera, 2.2.1975, 1; it.: «Gli uomini del potere democristiani [...] non si sono accorti che esso era <altro»: incommensurabile non solo a loro ma a tutta una forma di civiltà. Come sempre (cfr. Gramsci) solo nella lingua si sono avuti dei sintomi. Nella fase di transizione - ossia «durante> la scomparsa delle lucciole - gli uomini di potere democristiani hanno quasi bruscamente cambiato il loro modo di esprimersi, adottando un linguaggio completamente nuovo (del resto incomprensibile come il latino): specialmente Aldo Moro: cioè (per una enigmatica correlazione) colui che appare come il meno implicato di tutti nelle cose orribili che sono state organizzate dal ' 69 ad oggi, nel tentativo, finora formalmente riuscito, di conservare comunque il potere."

26 It should be said, however, that until now what happened in that period still remains unclear and that, in some cases, the involvement of politicians and representatives of the state apparatuses has been proven not only by historians, but also by magistrates. As Anna Cento Bull and Philip Cooke pointedly observe, «there exists very substantial circumstantial evidence pointing in the direction of their [of part of the state apparatuses, especially secret service and parts of the armed forces] involvement in neo-fascist terrorism, at least in the sense of aiding and abetting their subversive activities and/or protecting them from persecution. Another suspicion is that the State did not do everything it could to fight left-wing terrorism, allowing it some space to develop in order to keep the Communist Party at bay, since the latter's gradual path to power was jeopardized by the emergence of revolutionary groups to its left. [...] In short, there are sufficient elements to argue that the behavior of the Italian State in fighting armed terrorism has been relatively opaque and twisted» (Bull/Cooke 2013, xii). 
not least by Aldo Moro - are the subject of the Film Romanzo DI UNA strage (Marco Tullio Giordana, IT 2012). As I will highlight and discuss in the seventh chapter, this film traces a fil rouge, suggesting a secret, obscure but meaningful interconnection between the bombing of 1969 in Milan and the killing of Aldo Moro in 1978.

Second, Pasolini draws attention to one of the basic premises of this investigation: the importance of the study of language in identifying and understanding historical, social, cultural and ideological transformations. His reference to Gramsci is significant. As the founding member of the Italian Communist Party (PCI), he considers language an ideological battleground. Through a detailed analysis of the use of language, one can understand the functioning of power mechanisms better: «For a literate and not ideological bourgeois, it is important to remember again, with Gramsci, that if the new Italian reality produces a new language, national Italian, the only way to possess it and to make it your own is to know with absolute clarity the national reality that produces it.» ${ }^{27}$ Pasolini had already analyzed Moro's language in another article, commenting on a speech made by him for the opening of a highway-the Autostrada del Sole-that took place in February 1964. He argued that Moro «has instrumentalized the highway's inauguration to make a political appeal to Italians, telling them something politically very sensitive: to cooperate in overcoming the economic situation and work together in theory and in practice, that is, to be willing to accept personal sacrifices.» ${ }^{28}$ Moro's speech was, in the analysis and critique of Pasolini, the paradigm of an instrumental and «technological» use of language. For the Italian poet and filmmaker, Moro's speech exemplified, within the language of official politicians, a loss of the prevailing reference to Latin and emphatic classicism, which was replaced with a reference to the efficiency of communicative language and technology. Not without a certain amount of irony, in the «Article of the Fireflies» Pasolini pointed out that this new language remained as «incomprehensible» as

27 Pasolini 1991, 23-24; it.: Per un letterato non ideologicamente borghese si tratta di ricordare ancora una volta, con Gramsci, che se la nuova realtà italiana produce una nuova lingua, l'italiano nazionale, l'unico modo per impossessarsene e farlo proprio, è conoscere con assoluta chiarezza quale è e cos'è quella realtà nazionale che lo produce.»

28 Pasolini 1991, 17; it.: «Moro strumentalizza l'inaugurazione dell'autostrada per fare un appello politico agli italiani, raccontando loro un fatto politicamente assai delicato: quello di cooperare al superamento della congiuntura: cooperare idealmente e praticamente, di essere, cioè, disposti ad affrontare dei sacrifici personali.» 
Latin. In other words, it was a new national, technical and instrumental language that hid its own ideological function.

The third interesting point is that Pasolini seems to accuse but at the same time also to absolve Aldo Moro, claiming that a) he, more than others, was the demiurge of the new, incomprehensible political language and that b) he was the least implicated among all of the DC leaders in the massacres and cases of corruption that took place in Italy in those years. $\mathrm{He}$ seems to be saying that Aldo Moro was the proponent of a language that has the function of concealing the misdeeds of the DC, but that he was not responsible (or at least less so than others) for the misdeeds themselves. This passage assumed an unsuspected significance after the kidnapping and murder of Aldo Moro, being quoted and discussed in many articles and other media referring to the Moro case. It has often been quoted by those who advocate the theory of a conspiracy on a national or international scale as well as by those who interpret it as a sort of Pasolinian prophecy.

In L'affaire Moro, Leonardo Sciascia called attention to the prophetic character of this article (which is today still the subject of academic studies and debates). ${ }^{29}$ The Sicilian writer was particularly concerned by the use of the formulation - placed between brackets by Pasolini-«for an enigmatic correlation». According to Sciascia, in this short parenthesis «there is something like the premonition, like the prefiguration of the Moro affaire.» ${ }^{30}$ The thesis, or rather Sciascia's impression, that the Moro case «had already been written", and how that impression is connected to the idea of a prefiguration in Pasolini's article, will be discussed in the seventh chapter. ${ }^{31}$ For the moment, I want to point out how the image of Moro depicted by Pasolini before the kidnapping has affected the perception and representation of Moro after the kidnapping. Sciascia maintained that it is precisely the fact that Moro, especially in the eyes of critics and enemies of the DC, was «the least involved of all» which gave him «the incontestable and actually alleviating authority to speak on behalf of everyone: power along with sacrifice. ${ }^{32}$ He suggested that, precisely because Moro was after all an hon-

29 See Didi-Hubermann 2006.

30 Sciascia 1978, 16; it.: «[...] c'è come il presentimento, come la prefigurazione dell'affaire Moro.»

31 Sciascia 1978, 24-25; it.: "Questo racconto [...] [s]i adeguava all'invincibile impressione che l'affaire Moro fosse già stato scritto, che fosse già compiuta opera letteratia, che vivesse ormai in una sua intoccabile perfezione.»

32 Sciascia 1978, 36; it.: «Ma proprio l'essere meno implicato gli dava, su tutti nella Democrazia Cristiana, l'incontrastabile e anzi alleviante autorità di parlare in nome di tutti, potere e insieme sacrificio.» 
est politician and not interested in increasing his own personal power, he could be the perfect apologist and defender of the DC's policy. The writer also seemed to suggest that he was kidnapped precisely for this reason. To be the voice of the DC and as such the embodiment of its power made him the natural and perfect target for the terrorist organization.

The importance of Moro as a defender of the DC is clearly visible if one looks at the last speech that he delivered in Parliament. In this speech, he defended two former ministers of the DC, Luigi Gui and Mario Tanassi, from the accusation of being the recipients of bribes linked to the Lockheed scandal. The Lockheed scandal concerned serious cases of corruption that took place in various countries in the 1970s, and in particular the Netherlands, West Germany, Japan and Italy. Between 1975 and 1976, the US Senate Church Committee (which investigated abuses in governmental operations with respect to intelligence activities) discovered a widespread, consolidated system of corruption practices in the export and sale of weapons by the Lockheed Corporation. In Italy, the scandal involved the delivery of Hercules C-130 aircraft, which had been received by the Air Force since 1972. In 1976, many politicians involved in the negotiations were accused of accepting bribes of billions of lire to promote the purchase of the aircrafts. In fact, a 1969 letter by Lockheed's lawyer was discovered in February of the same year, in which he reported that two Italian ministers and a certain «Antelope Cobbler» had requested and received bribes. Rome's prosecutor opened a judicial inquiry when the scandal broke in the Italian press; in March Antonio Lefebvre, an Italian agent for Lockheed, and General Duilio Fanali, the head of the Air Force, were arrested. Some prominent politicians were also implicated in the charges, including the former ministers Luigi Gui and Mario Tanassi.

As President of the DC, Moro spoke in Parliament to defend Gui and Tanassi on March 9, 1977, thus exactly a year before the kidnapping. I want to quote here the most significant passages of this speech, in order to enable the reader to get an idea of Moro's language as well as of his role as defender of the DC:

Prejudicial attitudes, rigid accusatory positions and the unavailability of reflection unfortunately characterized, and it hurts to have to recognize that, this debate. [...] In these oratories the prosecution's framework has not occasionally, but intentionally expanded, reaching, beyond the men, the Party who led Italy for thirty years and is still today, albeit its movements toward the left, in a dominant position and with great responsibility. Its power is not an expression of a regime; it comes not from coercion, but by consensus, by the strong awareness in public 
opinion of the importance of ensuring values and ways of life and of the unacceptability of certain global alternative proposals. [...] We are accused of creating a square around Mr. Gui [...]. This is not pure opportunity; it is not a calculation, a preliminary closure before a purifying truth is accepted, which is suited to a democracy that needs to have the courage to identify and to correct any deviation. We are instead faced with a procedural step, which requires a yes or no from us to an accusation. [...] We should say that Gui is guilty [...] and similarly we should think about Mr. Tanassi. But we cannot come to recognize this, neither implicitly nor explicitly, because of reasons of conscience. Conscience, I say, and not utility-indeed, the political reason may suggest a dilatory attitude. [...] Even some of us have looked at this liberating perspective. But we have thought a lot about it. It would be like offering, for our party utility, for a Party alibi, a victim to the reason of State. Thinking more deeply, we have given up [this possibility] and we did, as they say, create a square around Gui, because our conviction is [his] innocence, because we only see suspicions and artifices aimed at contesting a life of dignity, which before was never questioned, a life dedicated not to power games, not to party intrigues, but to the cause of democracy and to the State. [...] We find, in this position, the Christian Democracy united and with it we intend to defend the Christian Democracy as a whole. [...] To anyone who wants to globally overwhelm our experience; to anyone who wants to carry out a trial, moral and political, to be celebrated in the squares, as has been said cynically, we respond with the strongest reaction and with an appeal to public opinion that has not recognized in us a historical guilt and has not wanted our strength decreased. We do not accept being considered corrupt, because it is not true. [...] Dear colleagues, you have announced to us the process in the squares, we tell you that we do not will accept being put before trial. If you have minimum wisdom, $[\ldots]$ we firmly say to you to not underestimate the great force of public opinion, which, for more than three decades, found its expression and its defense in the Christian Democracy. 33

33 Moro 1979, 350-354; it.: "Atteggiamenti pregiudiziali, rigide posizioni accusatorie, indisponibilità alla riflessione hanno caratterizzato purtroppo, duole doverlo riconoscere, questo dibattito. [...] In questi oratori poi il quadro dell'accusa si è, non occasionalmente, ma intenzionalmente dilatato, fino a toccare, al di là degli uomini, il Partito che ha guidato per trent'anni l'Italia ed è ancora oggi, pur negli spostamenti di forza verso sinistra, in una posizione dominante e di alta responsabilità. Il suo potere non è un'espressione di regime; non nasce dalla coercizione, 
This speech illustrates well the political climate in Italy prior to the Moro kidnapping. In the previous chapter, we saw that Moro-the grande tessitore, as Italian political commentators often called him-wanted to bring the PCI into the government without challenging the DC's state system. The intransigent defense of the DC in his last speech in Parliament unequivocally expresses this position and political strategy. Moro made it explicitly clear to the opposition parties, in particular the PCI, that there would be no self-critical attitude among the DC, that no one could threaten the unity of the party and challenge its dominance in Italian politics. Only under these conditions would the alliance with the PCI be possible. ${ }^{34}$ Moreover, with this speech Moro definitely acquired the DC's internal legitimacy as the party's lawyer. ${ }^{35}$

ma dal consenso, dalla profonda consapevolezza, nell'opinione pubblica, di importanti valori e modi di vita da garantire e dell'inaccettabilità di talune globali proposte alternative. [...] [C] i si accusa di fare quadrato intorno all'on. Gui [...]. Non si tratta di pura opportunità; non si tratta di un calcolo, di una chiusura pregiudiziale di fronte alla verità da accettare, una verità purificatrice e quindi consona ad una democrazia che deve avere il coraggio di identificare e di correggere ogni deviazione. Noi siamo invece di fronte ad una fase della procedura che richiede da noi un sì od un no ad una accusa. [...] Di coscienza, dico, e non già di utilità, ché anzi forse la ragione politica potrebbe suggerirci un atteggiamento dilatorio. [...] Anche qualcuno di noi avrà guardato a questa prospettiva liberatoria. Ma si è pensato molto. Sarebbe stato come offrire, per la nostra utilità di Partito, per un alibi di Partito, una vittima alla ragione di Stato. Pensandoci appunto più a fondo, vi abbiamo rinunciato ed abbiamo fatto, come si dice, quadrato intorno a Gui, perché la nostra convinzione è l'innocenza, perché vediamo solo sospetti ed artifici rivolti a contestare una vita di mai smentita dignità, una vita dedicata non a giochi di potere, non ad intrighi di partito, ma alla causa della democrazia ed al servizio dello Stato. [...] In questa posizione troviamo unita la Democrazia cristiana ed intendiamo con essa difendere la Democrazia cristiana nel suo insieme. [...] A chiunque voglia travolgere globalmente la nostra esperienza; a chiunque voglia fare un processo, morale e politico, da celebrare, come si è detto cinicamente, nelle piazze, noi rispondiamo con la più ferma reazione e con l'appello all'opinione pubblica che non ha riconosciuto in noi una colpa storica e non ha voluto che la nostra forza fosse diminuita. Non accettiamo di essere considerati dei corrotti, perché non è vero. [...] Onorevoli colleghi, che ci avete preannunciato il processo sulle piazze, vi diciamo che noi non ci faremo processare. Se avete un minimo di saggezza, $[\ldots]$ vi diciamo fermamente di non sottovalutare la grande forza dell'opinione pubblica che, da più di tre decenni, trova nella Democrazia cristiana la sua espressione e la sua difesa.»

34 See Ginsborg 1990, 379.

35 See Formigoni 2016, 320. Interestingly, a year later, in the «Memorial» written in the «people's prison», Moro criticized the position he took in this speech, admit- 
This speech also clearly shows how much political language was imbued with trial rhetoric. The body of judgment to which Moro made several references is "public opinion». This expression is used in a similar way to that of "people», but with the difference that it particularly highlights the public dimension of the "people»: public opinion is the expression of the people as the only entity that has the right to observe, evaluate and judge the political parties. The logic underlying the speech is also interesting. As pointed out by Sciascia, Moro's speech contains at least two syllogisms: «the freedom and integrity of the country are intangible; Christian Democracy represents the freedom and integrity of the country; Christian Democracy is intangible» and "the unchanged electoral support shows that the Christian Democrats are not guilty; Mr. Gui is a Christian Democrat; Mr. Gui is not guilty.» ${ }^{36}$ The real core of the speech is not, however, the innocence of Mr. Gui, but the innocence of the Christian Democrats as a party that represents and defends «public opinion».

The passage in which Moro said that the DC was not willing to offer «a victim to the reason of State» is particularly relevant for this investigation, because it clearly presents elements of (anti-)sacrificial language and rhetoric. In fact, there is considerable similarity between this sentence and another present in Moro's letter to Zaccagnini, written during his imprisonment and published in newspapers on April 25, where he argued that «with its inaction, $[\ldots]$ in the name of reason of State, the state organization condemns [me] to death and without too much thinking about it.» ${ }^{37}$ In both cases, Aldo Moro asserts individual rights (in the case of Gui, the right to be presumed innocent until proven otherwise; in its own case, the right to life) over alleged national interests.

ting he underestimated «the expectation for justice of large parts of the country» (Moro 1997d, 273).

36 Sciascia 1978, 36; it.: «[...] la libertà e l'integrità del paese sono intangibili; la Democrazia Cristiana rappresenta la libertà e l'integrità del paese; la Democrazia Cristiana è intangibile. Sillogismo da cui rampolla quest'altro: l'immutato consenso elettorale dimostra che la Democrazia Cristiana non ha colpa; l'onorevole Gui è democtistiano; l'onorevole Gui non ha colpa.»

37 Moro 2008j, 100; it.: "Con la sua inerzia, [...] in nome della ragion di Stato, l'organizzazione statale condanna a morte e senza troppo pensarci su.» 


\subsection{March 1978: First Reactions to the Kidnapping}

On the morning of March 16, Aldo Moro came out of his apartment in via del Forte Trionfale in Rome to go to the Chamber of Deputies, where the ratification debate on the fourth Andreotti government was due to begin. As was his custom, he planned to stop along the way at the Church of Santa Chiara where he prayed every morning before going to Parliament. Wagner-Pacifici observes that «in this daily personal voyage between the institutions of the Church and the State, Moro, representing well his own personal and public history of institutional involvement, embodies the combination that his party claimed to represent on a grander scale.» ${ }^{38}$ Thus not only did the language he spoke contribute to cementing his image as the symbolic embodiment of the DC, but so did his daily habits.

After the kidnapping and even more so after his death these images changed. Moro's usual route itself acquired a new meaning. If before it exemplified the close relationship between the Church and the Italian State that, since the end of World War II, had always characterized the DC's government policy, from March 16, onwards it could be understood and represented as Moro's path to martyrdom. There is a sort of topological symbolism-the fact that every day Aldo Moro followed a path that started from home (natural family) and, passing by the Church (Christian family), took him to Parliament (political family) - that predisposes Aldo Moro as an ideal subject to be portrayed as a martyr of both the Church and the Italian State.

At about 9 a.m. in via Fani the two cars of Aldo Moro and of his escorts were blocked by a group of terrorists who immediately opened fire, killed the five bodyguards in a few seconds and kidnapped Moro (see figure 1). ${ }^{39}$ At 9.25 a.m. the second radio network interrupted its programs and aired the first newscast on the attack:

We interrupt broadcasting for dramatic news that sounds incredible and that, although it has not yet officially been confirmed, unfortunately seems to be true. The President of the Christian Democrats, Mr.

38 Wagner-Pacifici 1986, 62.

39 The precise mode of the attack, the operational details, the circumstances of previous and subsequent attacks, the responsibilities, the components of the terrorist fire group, the possible presence of other components extraneous to the BR, and the possibility of collusion and external aid are all aspects of the story debated during the trials, in the parliamentary committees and in journalism, and are still today the subject of great discussion and doubts. 
Aldo Moro, was kidnapped a short time ago in Rome by a terrorist group. ${ }^{40}$

The rhetoric of «drama» became a leitmotif of the media's representation of political violence from the very beginning. At 10.10 a.m. a call came to the news agency Agenzia Nazionale Stampa Associata (ANSA) in Rome, claiming the attack was carried out by the BR. «We have kidnapped the president of the DC Aldo Moro and eliminated his bodyguards, Cossiga's leather heads. Signed BR.» ${ }^{41}$ Other newsrooms in Turin and Milan received phone calls in which the BR claimed responsibility for the attack and nothing more. As Wagner-Pacifici has observed, the «unqualified nature of this acknowledgment» was dramaturgically very effective, because it left room for interpretation about the intentions of the terrorist group..$^{42}$ This undoubtedly facilitated the emergence of the conspiracy narrative.

40 Quoted in Selva/Marcucci 2003, 8-9; it.: «Interrompiamo le trasmissioni per una drammatica notizia che ha dell'incredibile e che, anche se non ha avuto finora una conferma ufficiale, purtroppo sembra sia vera. Il Presidente della Democrazia Cristiana, l'onorevole Aldo Moro, è stato rapito poco fa a Roma da un commando di terroristi.»

41 Quoted in Imperi 2016, 46; it.: «Abbiamo rapito il presidente della DC Aldo Moro ed eliminato la sua guardia del corpo, teste di cuoio di Cossiga. Firmato, Brigate rosse.»

42 Wagner-Pacifici 1986, 63. 


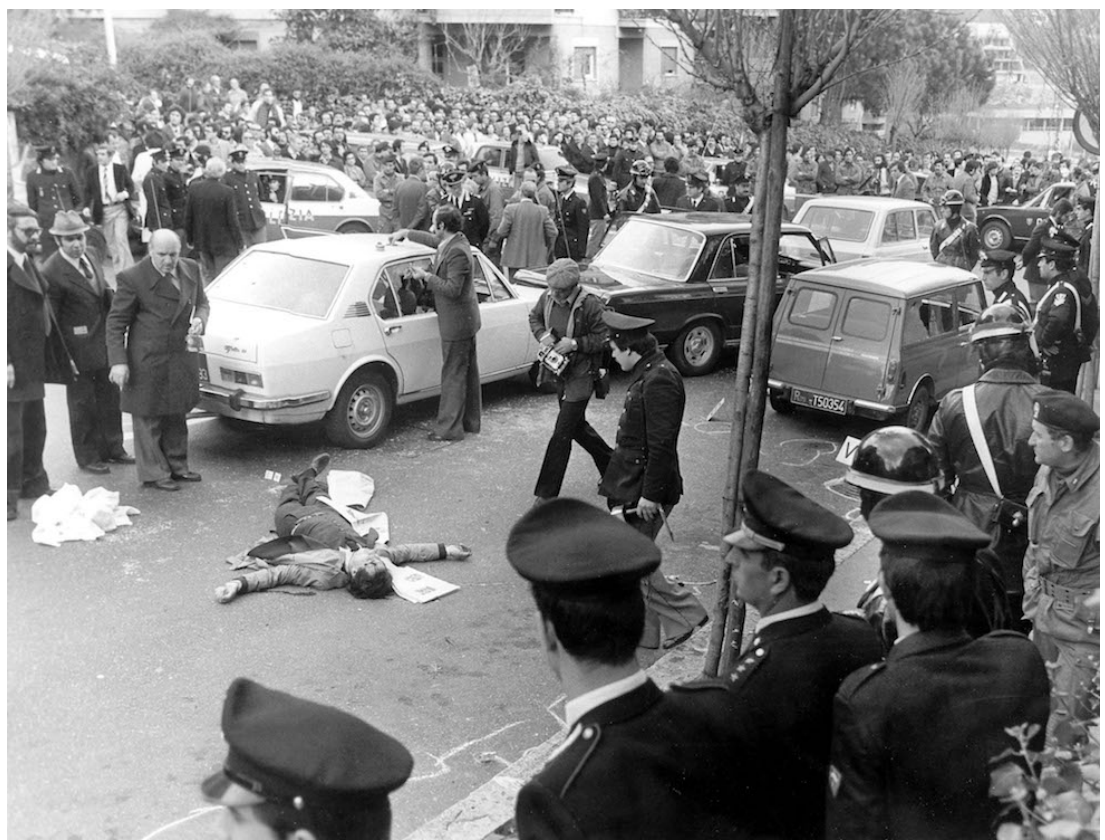

PICTURE 1: The attack in via Mario Fani, Rome, March 16, 1978. The picture show the body of one of Aldo Moro's five guards, Raffaele Iozzino, lying on the ground.

In a special edition of the second television network's news program (TG2) at 10.01 a.m., the journalist Giancarlo Cercano informed viewers that in Milan and Turin there were rumors, according to which, the fugitive Mario Moretti, then head of the BR, was connected with foreign intelligence agencies. In the same extraordinary edition, the television presenter Giancarlo Santalmassi reported the hypothesis that there could be links between the BR and the German Red Army Faction (RAF). The next edition of TG2's news broadcast reported that there were suspicions that some members of the RAF may have been active in Italy. In the extraordinary edition of the first television network's news program (TG1), journalist Bruno Vespa noted that «according to preliminary reports, the terrorists used the same technique that was used in Germany against German indus- 
trial President, Schleyer.» ${ }^{43}$ This shows that the hypothesis of an international conspiracy by foreign intelligence services, as well as the possibility of international collaboration between different terrorist groups, spread quickly from the very beginning of the affair. The aforementioned special edition of the TG1 also aired the TV report by journalist Paolo Frajese filmed in via Fani shortly after the ambush. This service, in which the viewer is confronted with the dead bodies of Moro's bodyguards and the cars riddled with bullets, has been shown in almost all the documentaries about the Moro case and has strongly affected the way in which the event has been memorialized visually.

At 10.20 a.m., in an emergency summit the parties of the parliamentary majority agreed to reduce the parliamentary debate times to vote on the fourth Andreotti government. Shortly after, the Unitary Trade Union Federation declared a nationwide general strike to be held in the afternoon in piazza San Giovanni in Rome to publicly express the workers' support for the institutions and the Italian State. An extraordinary council of ministers chaired by Prime Minister Giulio Andreotti established the first steps toward the coordination of all police forces and the army, as well as to convene the Inter-Ministerial Committee for Security (Comitato interministeriale per la sicurezza). Meanwhile, Interior Minister Francesco Cossiga established a Technical-Operational Political Committee (Comitato politico tecnico-operativo), also called Crisis Management Committee (Comitato di gestione crisi), which had the task to arrange an operational plan and to coordinate investigations in the search for the terrorists and the hostage. During the 55 days, each transaction and any information had to come from the Interior Ministry, including communications and outgoing news about the developments in the investigation. The outgoing news, however, was quite sparse and covered by strict secrecy. ${ }^{44}$

Moreover, Cossiga established two other committees: the Committee of Information (Comitato informazione) and the Committee of Experts (Comitato degli esperti). The first was composed of members of the secret service, police and army and had the task of gathering and coordinating relevant information to identify the kidnappers and to discover where Aldo Moro was being held. The second was a smaller group composed of psychiatrist Franco Ferracuti, psycho-graphologist Giulia Conte Micheli, military

43 Quoted in Imperi 2016, 47; it.: «Secondo le prime ricostruzioni, i terroristi hanno usato la stessa tecnica che è stata usata in Germania contro il presidente industriale tedesco, Schleyer.»

44 See Imperi 2016, 56-57. 
strategist Stefano Silvestri and the American adviser and expert on international terrorism Steve Pieczenik. The existence of the Expert Committee only became public in 1981, after the revelations made by Interior Minister Cossiga to the Parliamentary Commission of Inquiry. ${ }^{45}$ The committee had the task of trying to influence the press to minimize the effect of the BR's propaganda campaign and, above all, to de-enhance Moro's image. ${ }^{46}$ In a recent publication, Steve Pieczenik said his role in the Committee of Experts was to convince the Italian government to let Moro die, considering it the only way to defeat the BR. ${ }^{47}$

The special editions of the afternoon news broadcast live images of the union demonstration in piazza San Giovanni and the interventions of general secretaries Luciano Lama (Confederazione Generale Italiana del Lavoro CGIL), Luigi Macario (Confederazione Italiana Sindacati Lavoratori - CISL) and Giorgio Benvenuto (Unione Italiana del Lavoro - UIL). They all strongly condemned the bombing, lined up alongside the institutions and condemned the attack, saying that the BR were «against the people». At the same time, however, they expressed their opposition to any attempt to establish a special and exceptional law and a "police state». 48 They therefore reacted to some authoritarian ideas shared by conservative circles in Italian politics. In fact, the leader of the Republican Party Ugo La Malfa, speaking the same afternoon in the House of Representatives (Camera dei Deputati), represented the situation as a «state of war» and demanded the establishment of «exceptional measures of war». Giorgio Almirante, secretary of the Italian Social Movement (MSI), went so far as to require the replacement of Interior Minister Cossiga with a military official, the promulgation of exceptional laws and the restoration of the death penalty. ${ }^{49}$ The government, however, rejected these proposals. At the Chamber of Deputies, Prime Minister Andreotti stated that the laws that were in force were sufficient and that he was against the introduction of exceptional or extraordinary laws. The proclamation of the state of emergency and the introduction of the death penalty were rejected. It was a conviction shared by most representatives of the political forces that generalized repressive action, the restriction of democratic freedoms, and the suspension of certain rights

45 See Flamigni 1988, 127-156.

46 See Formigoni 2016, 357-358.

47 See Amara 2009.

48 Special edition of the TG2, 17.03 p.m.

49 See Giovagnoli 2009, 46. 
would have widened sympathies with the BR, facilitating the civil war they wanted to provoke. ${ }^{50}$

Despite major forces, the government decided not to introduce exceptional laws or to declare a state of emergency or of war; four days after the kidnapping a series of measures hitherto blocked by many opponents were adopted. The Parliament gave the police some of the powers that had been taken away in previous years. ${ }^{51}$ In response to these measures, there was a strong fear that citizens' rights would be eroded and lead to a partial suspension of democracy. The Corriere della Sera, though accepting the measures, expressed «bitterness» at the measures taken, and the famous constitutionalist Stefano Rodotà criticized them harshly, defining them as «exceptional measures»: «We are scraping the bottom of the barrel [...], we are now moving on the very subtle ridge that divides constitutional legality from the pure and simple use of authoritarian tools.» ${ }^{52}$ The jurist basically argued that the measures decided by the Parliament and which were declared to be not exceptional de jure were exceptional de facto. Beyond this consideration, it should be pointed out that, from an operational point of view, these measures did not help the police and magistrates to find out where Aldo Moro was being detained or to capture members of the BR at all. Only very slowly was more coordination between the police, Carabinieri and financial guard established. Investigators found it difficult to organize their work, and the newspapers recorded daily examples of errors and delays in the management of investigations. The impression that the investigations did not lead to any concrete results was very widespread. ${ }^{53}$

Although the terrorists had not yet made any specific request, politicians and journalists had already begun, on March 16, to discuss the hypothesis,

50 See Giovagnoli 2009, 49.

51 The main measures adopted were the following: the provisional arrest of crime suspects for 24 hours; the immediate interrogation of the arrested without the presence of a lawyer if done within one hour; phone interceptions decided by the police without the permission of magistrates for an indefinite time; the abolition of the investigative secret of magistrates and at the request of the Interior Minister; increased penalties for attacks on public facilities; the strengthening of the great judicial sites. See La Stampa, «Le misure urgenti decise dal governo entreranno in vigore da mezzanotte», 21.3.1978, 2.

52 Rodotà, Stefano, «Misure eccezionali», La Repubblica, 23.3.1978, 1-2; it.: «Si sta raschiando il fondo del barile [...], ci muoviamo ormai sul crinale sottilissimo che divide la legalità costituzionale dal puro e semplice impego di strumenti autoritari.»

53 See Carbone, Fabrizio, «Prevenire subito», La Stampa, 21.3.1978, 1-2; Carraciolo, Lucio, Un'inchiesta che sembra nata morta, La Repubblica, 25.3.1978, 4. 
which was considered very likely, that the BR would make a request to exchange Moro for some prisoners. During these days, the trial against Renato Curcio, Alberto Franceschini and other members of the first generation of the BR in Turin was proceeding. In the press and in the various parties, the conviction that the BR would ask for the release of their comrades immediately spread quickly. Their first communiqué, which was made public on March 18, would deny these suspicions, but for two days that opportunity was the focus of many discussions. Immediately, the voices opposed to any negotiations prevailed and soon the government, most of the political parties and the established media settled on what was to be called the «line of firmness». We will address the issue of the debate on firmness vs. negotiation in more detail later on. For now, I want to draw attention to the fact that this rhetoric was intrinsically connected to a certain kind of representation of the relationship between the political body, nation-state and democratic government. This connection already emerges in an exemplary manner in a speech given by the Prime Minister on the evening of March, 16. At 8 p.m., live from the seat of the government, television news aired Andreotti's «speech to the country»; I quote here the most significant passages:

The response that has occurred in Parliament [...], but also in the statements of all political groups and the response that has occurred all over the country with massive demonstrations condemning the violence by men from all classes, who left factories, schools, offices, and homes, constitutes a response of solidarity to a concept of republican legality that is not rhetoric. [...] But they must live somewhere, these young people and these men and these women, who, unfortunately, are allowing themselves to be mobilized for criminal acts of this kind. There must be families that, in a not yet irreparable moment, can say a word to them, to make them rethink the sad aggregation which they are engaging in. I think $[\ldots]$ that no one should lose sight of a goal which does not conflict at all with what is called the firmness of the State, which is nothing reactionary, nothing repressive, which is the affirmation of calm ordered life within Italian cities, especially the most troubled. I think we should [...] make a great appeal to the conscience of non-violence. I think that is the worthiest way $[\ldots]$ to respond to 
this terrible act, and it is certainly what, many years ago, Aldo Moro taught us and for which he has always fought. ${ }^{54}$

This speech anticipated a discursive strategy that was reproduced and repeated continuously during the 55 days of Moro's imprisonment, and even afterwards. Besides that, it already contained some elements that predispose and facilitate the emergence of the martyrological and sacrificial representations of the political violence of the event, which were soon to emerge and quickly spread in the Italian public space. There are at least two aspects within the rhetorical structure of this speech that well illustrate the way in which the government and most of the media reacted to the kidnapping of Aldo Moro.

First, Andreotti's speech referred to the response of the Parliament, of all political groups and of the demonstrations of March, 16 in order to represent Italy as a reunited country. In the Italian State, political parties and ordinary people are represented as a single voice, a single body that gives a response of solidarity. Not only do the divisions between the parties disappear, but so do those between political representatives and represented citizens. Moreover, the reference to men of all classes has, in particular, the function of making class distinctions-a basic distinction in the rhetoric used by the PC, left-wing media, by extra-parliamentary left-wing political groups as well as by the BR and other terrorist organizations-secondary and irrelevant, since people were faced with «this terrible act». The difference between workers («who had left factories»), housewives, children, pensioners and the unemployed («homes»), students («schools») and workers of the

54 It.: «La riposta che vi è stata in Parlamento [...], ma anche nelle precise affermazioni di tutti i gruppi politici e la risposta che vi è stata in tutto il paese con manifestazioni imponenti di condanna della violenza da parte degli uomini appartenenti a tutte le classi che avevano lascito le fabbriche, le scuole, gli uffici, le case, costituisce una riposta di solidarietà ad un concetto di legalità repubblicana che non è retorico. [...] Ma vivranno in qualche parte questi giovani o questi uomini o queste donne, purtroppo, che si lasciano mobilitare per azioni criminose di questo genere. Vi saranno delle famiglie che possono in un momento ancora non irreparabile dir loro una parola perché ripensino alla triste aggregazione nella quale si vanno coinvolgendo. Penso [...] che nessuno debba perdere di vista un obbiettivo, che non contrasta minimamente con quella che si chiama fermezza dello Stato, la quale non ha niente di reazionario, niente di repressivo, che è l'affermazione della tranquillità di vita nelle città italiane specie quelle più turbate. Io penso che noi dobbiamo [...] fare un grande appello alla coscienza della non violenza. Credo che sia questo il modo più degno [...] di rispondere $[\ldots]$ a questo atto terribile, e certamente è questo che, in anni lontani, Aldo Moro ci ha insegnato ed è questo per il quale si è sempre battuto.» 
middle class («office») is cancelled out rhetorically by Andreotti making reference to the response given by «the people» demonstrating in the squares. Such units of identification are replaced immediately with the usual «identity marker» within the DC's rhetoric: the family. In Andreotti's speech, the «great appeal» to the people is, first of all, an appeal to families; there are no more differences between exploiters and the exploited, between the working-class and bourgeoisie, but only families equal to each other.

Secondly, one cannot but note the rhetorical sophistication with which the «firmness of the State» is connected with the aim of ensuring «tranquility in the Italian cities» and the "great appeal to non-violence». The firmness of the state is thus represented as a necessary condition for the safety of Italian society. But the most significant phrase, which reveals great familiarity with a strategic use of language, is the one where the principles of firmness, republican legality and non-violence are represented as something that «Aldo Moro taught» to the Italian people. In relatively few sentences, the Prime Minister, succeeded in creating a link between the policy of firmness (which closed the door to any political negotiations even before the BR made a concrete request), the people's will and Aldo Moro's will. In other words: Aldo Moro was called into action to defend the same policy of firmness that, a little less than two weeks later, he was to criticize in the first of his letters published by newspapers. The most rhetorical and, in terms of performative efficiency, less successful part of the whole speech, however, is another; namely when Andreotti argued that, «the response of solidarity to a concept of republican legality $[\ldots]$ is not rhetoric». Here the Prime Minister took on an almost defensive position, as he foresaw criticism of him being too rhetorical. A strategist of concealment should not explain what he wants to hide: it is as if a thief, whose theft has not yet discovered, was to go to the police saying, «I have not stolen». However, the Prime Minister's speech did two things: it constructed discursively a certain identity for «the people» and attributed a certain willingness to Aldo Moro. The effectiveness of his speech became evident the following day, when most of the newspapers employed analogous strategies of representation.

\subsection{Framing «the People» and «the Enemy»: Construction of National Identity}

Andreotti's rhetoric was used in many articles that appeared in different newspapers in the first days after the kidnapping. The topic that dominat- 
ed the newspapers on March 17 is obviously the ambush in via Fani, which has been addressed in a range of subtopics: the dynamics of the abduction; the killing of Moro's five bodyguards; the debate in Parliament; the quick passing of the new government; the reactions and stances of political parties and of the newly elected government; the supposed intentions, strategy and goals of the BR; the reactions of governments and newspapers from other countries; and the emergency planning of the government. But by far, the most foregrounded subtopic was the half-day national strike held in several Italian cities; in particular, the rhetoric of the «response of the country» dominated the headlines of the front pages:

L'Unità: Instant Response to the Kidnapping of Moro and to the Barbaric Massacre of Five Bodyguards [subheadline]; Extraordinary Democratic Shout-The Italians Stand by in Defense of the Republic-The New Majority Has Been Formed in Parliament [title]; In Many Cities, the Workers Leave the Factories Even Before the Proclamation of the General Strike-Huge Crowds at Demonstrations-Intense Hunting in the Capital for the Terrorist Group (Composed by Many People) Who Attacked the Cars of the President of the DC and of His Bodyguards with Gunfire-One of the Killers Was Speaking German?-A Meticulously Prepared Plan-The Debate in the House-Confidence in the New Government Was Voted on Urgently [headline]. ${ }^{55}$

Il Popolo: After the Infamous Assassination of the Bodyguards [subheadline]; Anguish for Moro [title]; Silence From the BR After the First Statement in Which They Claimed Responsibility for the Kidnapping and Murder-Unanimous Sorrow for the Victims of the Ferocious Ambush-The Direction of the DC Reunited Permanently-The Country Reacts As One to This New Serious Challenge to Democratic Institu-

55 L'Unità, 17.3.1978, 1; it.: «Immediata risposta al rapimento di Moro e al barbaro eccidio di 5 agenti» [subheadline]. Straordinario sussulto democratico - Gli italiani si stringono a difesa della Repubblica - Si è formata in Parlamento la nuova maggioranza [title]. In molte città gli operai abbandonano le fabbriche prima ancora della proclamazione dello sciopero generale - Immense folle alle manifestazioni - Serrata caccia nella capitale al commando (composto da molte persone) che ha assalito a raffiche di mitra le auto del presidente della DC e della scorta Uno dei killer parlava Tedesco? - Un piano minuziosamente preparato - Il dibattito a Montecitorio - Votata con urgenza la fiducia al nuovo governo [headline].» 
tions: General Strike and Large Demonstrations and Marches Throughout Italy-Touching Messages of Solidarity to the Party [headline]. ${ }^{56}$

Avanti!: Instant Popular Reaction to the Kidnapping of Moro and the Killing of his Bodyguards [subheadline]; The Country Mobilized Against Sedition [title]. Parliament Reacted by Voting for Confidence in the Government-Millions of Workers Across Italy Demonstrate the Firm Will to Defend the Republic-The Commitment of the Socialist Party-Emotion and Outrage Around the World [headline]; Attack Against Democracy [editorial]. ${ }^{57}$

La Stampa: Grave Hours of the Republic for the Bloody Enterprise of the BR [subheadline]; After the Massacre, No Trace of Moro-The Country Has Stood Still: It Says No to Terrorism [title]; The Ambush of the President of the Christian Democrats, Yesterday Morning Shortly After 9 A.M., Committed by a Militarily-Trained Unit-Moro Had Just Left Home in Monte Mario-The Terrorist Group Consisted of 12 People-The Killers Fired More Than 80 Shots at the Bodyguards and Then Dragged the Leader to a Fiat 128 [headline]; There Can Be No Negotiations with Terrorists [editorial]. 58

56 Il Popolo, 17.3.1978, 1, it.: «Dopo l'ignobile assassino degli uomini della scorta [subheadline]. Angoscia per Moro [title]. Silenzio delle Brigate Rosse dopo il primo comunicato nel quale rivendicavano le responsabilità del rapimento e della strage - Unanime cordoglio per le vittime del feroce agguato - La direzione della DC riunita in permanenza - Il Paese reagisce compatto a questa nuova gravissima sfida alle istituzioni democratiche: sciopero generale e grandi manifestazioni e cortei in tutta Italia - Commosse testimonianze di solidarietà al Partito [headline].»

57 Avanti!, 17.3.1978, 1; it.: «Immediata reazione popolare al rapimento di Moro e all'uccisione degli agenti [subheadline]. Mobilitato il paese contro ogni eversione [title]. Il Parlamento reagisce votando la fiducia al governo - Milioni di lavoratori in tutta Italia manifestano la ferma volontà di difendere la Repubblica - L'impegno del Partito Socialista - Emozione e sdegno in tutto il mondo [headline]. Attentato alla democrazia [editorial].»

58 La Stampa, 17.03.978, 1; it.: «Ore gravi della Repubblica per la sanguinosa impresa delle Brigate rosse [subheadline]. Dopo il massacro, nessuna traccia di Moro il Paese si è fermato: dice no al terrorismo [title]. L'agguato al presidente della Dc, ieri mattina poco dopo le 9, compiuto da un reparto addestrato militarmente Moro era appena uscito di casa a Monte Mario - Il commando era di 12 persone - I killers hanno sparato oltre 80 colpi sulla scorta e poi hanno trascinato il leader su una 〈128〉 [headline]. Con i terroristi non si tratta [editorial].» 
La Repubblica: No News on the DC Leader After the Massacre of His Bodyguards [subheadline]. The Abduction of Moro-Italy ReactedGeneral Strike, Confidence in the Government [title]. They Have Struck the Heart of the State [editorial].59

Corriere della Sera: The Most Serious Political Crime of the Last Thirty Years While the Crisis Was Finishing [subheadline]. Moro Kidnapped, Five Bodyguards Massacred-The Country Rejects the Blackmail of the 〈BR> [title]. React with Strength [editorial]. ${ }^{60}$

The language and rhetoric used here reveal an incredible similarity and monotony of the reactions of the mass media. All six newspapers put emphasis on the fact that the country, Italy, Italians have reacted spontaneously, succinctly, and unanimously. The spectacle of demonstrations received much more attention than the attack in via Fani. As Wagner-Pacifici highlights, «the demonstrations were as (if not more) symbolically rich in their presentation as was the kidnapping itself»; the performativity of the concerted bodies and flags in the strikes and demonstrations was used «to attend to the rhetoric and symbolism of solidarity and success.» ${ }^{61}$

The newspaper that gave more coverage to the representation of the demonstrations held in Rome, Milan, Turin and Bologna was the official organ of the PCI. In a front-page article in L'Unità — accompanied by a photograph shot straight down of the demonstration in Rome-the description of the masses reached an almost epic timbre:

The image that Italy, the working-class, the grand masses of workers, the young people, the students and all the people offered yesterday is -we say it without rhetoric - an image that can be compared only to other grave hours in our recent history, hours in which the popular consciousness knew spontaneously how to respond to the reactionary challenge, even before the trade unions and political parties' appeals

59 La Repubblica, 17.3.1978, 1; it.: «Nessuna notizia del leader dc dopo la strage della sua scorta [subheadline]. Il rapimento di Moro - L'Italia ha reagito - sciopero generale, fiducia al governo [title]. Hanno colpito il cuore dello Stato [editorial].»

60 Corriere della Sera, 17.3.1978, 1; it.: «Il più grave crimine politico degli ultimi trent'anni mentre si chiudeva la crisi [subheadline]. Moro rapito, cinque uomini della scorta massacrati - Il Paese rifiuta il ricatto delle «Brigate Rosse` [title]. Reagire con forza [editorial].»

61 Wagner-Pacifici 1986, 104-105. 
had reached them. There was something that was reminiscent of July 14, 1948, the attempted assassination of Togliatti. ${ }^{62}$

There is an astonishing similarity between the rhetoric of this article and that in the Prime Minister's speech. Also here, the article (which is unsigned) asserted its own non-rhetoricity. Moreover, several units of identity are listed in a growing climax that begins with the category of the "working-class» and ends with the category of the "people». But in contrast to Andreotti's speech, here the central identity of unity (as pointed out by the repetition) is that of «workers», which appear as the authentic expression of the «people». There is also no reference to employees, to those who work in offices (the bourgeois or middle class). This kind of representation functions according to a slightly different mechanism than that operating in the speech by Andreotti and more generally in the language and rhetoric of the DC. While the family category is formally applicable to each individual - because each one is or was a member of a family - and therefore includes any individual (within the country), the category of worker, at least in Communist jargon, is applicable only to those who work in factories or in the fields. The sum of the families is quantitatively the people, while the working-class exemplifies the category of people; at the climax of the cited article, the worker becomes the paradigm of the people: «A paradigm entails a movement that goes from singularity to singularity and, without leaving singularity, transforms every singular case into an exemplar of a general rule. [...] The paradigmatic case [here: the worker] becomes such by suspending and, at the same time, exposing its belonging to a group [here: the people].» ${ }^{63}$

What is also interesting in the article cited last is the reference to the failed attack on the historic leader and founding member of the PCI, Palmiro Togliatti. The same comparison between the assassination attempt of 1948 and the via Fani attack is proposed in an article on the second page

62 L'Unità, «Straordinario sussulto democratico», 17.3.1978, 1; it.: «L'immagine che L'Italia, la classe operaia, le grandi masse lavoratrici, i giovani, gli studenti, e tutto il popolo hanno offerto nella giornata di ieri, è - lo diciamo senza retorica - una immagine che trova riscontri soltanto nelle ore gravi della nostra storia recente, quelle nelle quali la coscienza popolare ha saputo reagire alle sfide reazionarie spontaneamente, d'istinto, prima ancora che le giungesse l'appello dei sindacati e dei partiti. C'era qualcosa che ricordava il 14 luglio del 1948, l'attentato a Togliatti.»

63 Agamben 2009, 22, 31. 
in the Corriere della Sera; here, the journalist Giulio Nascimbeni argued that

[a]lso yesterday, like three decades ago, a shudder traveled through Italy and for a few hours old spirits, old shadows, invaded people's thoughts. [...] [W] ho remembers the events of July 1948, feels the same bewilderment, as if the kidnapping of Moro and the killing of his five bodyguards repurposed the image of an exasperated country that can run all risks and yield to every temptation. ${ }^{64}$

Here again we are facing a prefiguration: a past event is called upon to represent and to make sense of another more recent event. But while in Nascimbeni's article the prefiguration is used to give a kind of tragic representation of the Italian situation, bringing attention to the exasperation of the country and the ever-present danger of «falling into temptation», in the article in L'Unità it is used to demonstrate and authenticate the epic ability of the Italian people to respond with courage, instinctively and organically to events of political violence.

Another common element in many articles is the reference to flags in the demonstrations. ${ }^{65}$ Journalist Giancarlo Fossi, in an article on the third page of La Stampa, after the usual reference to «workers, employees, women, young people, pensioners, all visibly moved", drew attention to the country's unity, as exemplified by the proximity of the PCI's «flags with sickle and hammer» and DC's «white flags with the crossed shield». ${ }^{66}$ The same reference to «red flags and white banners with the crossed shield» can

64 Nascimbeni, Giulio, «Quando Pallante sparò a Togliatti», Corriere della Sera, 17.3.1978, 3; it.: "Anche ieri, come trent'anni fa, un brivido ha percorso l'Italia e per qualche ora vecchi spiriti, vecchie ombre, si sono insinuati ne pensieri della gente. [...] Chi ricorda il luglio del '48 avverte lo stesso smarrimento, come se il rapimento di Moro e l'uccisione dei cinque uomini della sua scorta riproponessero l'immagine di un Paese esasperato che può correre ogni rischio, cedere a ogni tentazione.»

65 See Silj 1978, 20.

66 Fossi, «Giancarlo, Roma: duecentomila lavoratori in piazza - Chiusi negozi e cinema, scioperi revocati», La Stampa, 17.3.1978, 3; it: «Non solo la piazza era completamente gremita, anche le strade di accesso, per centinaia di metri, erano stipate di operai, impiegati, donne, giovani, pensionati, tutti visibilmente commossi, ma esasperati per il susseguirsi di atti criminosi, sempre più gravi, contro la liberta personale e le istituzioni. Molte bandiere rosse con falce e martello, molte le bandiere bianche con lo scudo crociato [...].» 
be found in an article in the Corriere della Sera ${ }^{67}$ Also, the organ of the PCI praised the intermingling of red and white flags («Red and white flags are waving in the cold wind on a livid day in March»). ${ }^{68}$ The PCI was in the position of having to point out that its electorate had no connection with nor sympathy for the ideology of the BR and that not only Communist leaders such as secretary Enrico Berlinguer, but also the workers publicly condemned the actions of the terrorist group. With the daily references to student demonstrations against violence throughout the early months of 1978, which continued on into the months of Moro's abduction, L'Unità attempted to discard any proximity of the student movement to the BR. Interestingly, on the fifth page of Il Popolo the photographs of the crowded piazza San Giovanni in Rome only showed white Christian Democrat flags. Also, the headline "The Civil Protest Of the People With the DC» does not highlight the workers' participation.

All these modalities of representation had a precise function: the relegitimization of the political forces. It has been noted that they also had the function of uniting the political forces and, more generally, of presenting the unity and solidarity between the generations, social strata and classes. ${ }^{69}$ Although this is correct, it should also be noted that the two party newspapers L'Unità and Il Popolo especially worked with different strategies to legitimize their own party, above all through different ways of referring to and framing «the people». Both parties responded to two different crises of legitimacy: on the one hand, the PCI had to defend itself from the accusation that the BR were nothing but the children of the PCI; on the other, the DC had to divert attention from the Lockheed scandal and present itself as the true target of the attack in via Fani.

Not all newspapers took part in this chorus of glorification of the "country's response». The conservative newspaper Il Giornale wrote that the demonstration in Rome was not a "politically unitary manifestation».70 Also, the journalist Giorgio Bocca, in an article on La Repubblica argued that the demonstration in Milan expressed «a general rejection [...] of terrorism $[\ldots]$ and a still strong difficulty in overcoming or settling deep po-

67 Corriere della Sera, «All'appello dei sindacati rispondono quindici milioni di Italiani», 17.3.1978, 1; it.: «Bandiere rosse e vessilli bianchi con lo scudocrociato sventolano sopra la marea di teste.»

68 L'Unità, «Straordinario sussulto democratico», 17.3.1978, 1; it.: «Sventolano al freddo vento di una livida giornata di marzo bandiere bianche e rosse.»

69 See Wagner-Pacifici 1986, 107.

70 Quoted in Silj 1978, 21. 
litical differences in the name of a uunion sacrée of antiterrorism.» ${ }^{71}$ Bocca's observation is very interesting and also relevant from a theoretical point of view, inasmuch as it draws attention to the fact that the rituality of concerted bodies in the public space was not sufficient to «consecrate» national unification. It is only at the level of linguistic performance, of discursive representation of the demonstrations in the mass media, that this sacralization was successful. ${ }^{72}$ Several intellectuals and journalists harshly criticized the way the media reacted to the kidnapping. Giovanni Testori denounced «the wave of rhetoric that has invaded television and newspapers $»^{73}$ and Franco Fortini declared that $«[t]$ he eight to nine pages that the newspapers devoted to the event» worried him «more than the abduction itself.» ${ }^{74}$ Journalist Enzo Forcella also acknowledged the problem, but felt the rhetoric necessary in order to «give back to the national community a minimum level of unity and identity, that is, to reconstruct consensus around some common values starting with the fundamental ones of survival and civil coexistence.» ${ }^{75}$

I already highlighted that each discursive construction of collective identity is based on the mechanism of constitutive exclusion. Sometimes this exclusion is implicit and only emerges through analytical work, while other times it is explicitly expressed in discursive practices. This is the case with most of the representations of «the people» that appeared in the media in the days following the kidnapping of Moro. Those who were excluded from the national collective identity were obviously the BR. Wagner-Pacifici has observed that the BR were represented along three sets of markers, «three separate, but interacting, oppositional pairs: indigenous versus for-

71 Bocca, Giorgio, «A Milano gli operai tornano in prima fila», La Repubblica, 17.3.1978, 9; it.: «[...] un rifiuto generale $[\ldots]$ del terrorismo $[\ldots]$ e una difficoltà per ora forte a superare o a comporre le profonde differenze politiche nel nome dell'‘union sacrée> antiterroristica.»

72 Wagner-Pacifici expresses this idea by referring to Victor Turner's theory and terminology: «[...] the predominant framing of the demonstrations was theatrical and not ritual» (Wagner-Pacifici 1986, 111).

73 Quoted in Giovagnoli 2009, 103; it.: «[...] l'ondata di retorica che ha invaso la televisione e i giornali.»

74 Quoted in Giovagnoli 2009, 104; it.: «Le otto-nove pagine che i quotidiani hanno dedicato all'episodio mi preoccupano più del rapimento stesso.»

75 Forcella, Enzo, «Bandiere Rosse, Bandiere Bianche», La Repubblica, 24.3.1978, 6; it.: «[...] ridare alla comunità nazionale un minimo di compattezza e d'identità, cioè per ricostruire il consenso attorno ad alcuni valori comuni a cominciare da quelli fondamentali della sopravvivenza e della convivenza civile.» 
eign, common criminal versus political criminal, left versus right.» ${ }^{76}$ As I will now demonstrate, the first two of these strategies of representation aimed to exclude the BR from the collective identity of the «Italian people», while the latter aimed to link the BR and their ideology with the political adversary in order to delegitimize it.

In the front-page headline of March 17, L'Unità wondered if «One of the Killers Was Speaking German?», implicitly suggesting the possible connection between the BR and the RAF. The hypothesis on foreign interference -namely that the BR had been helped or directed by foreign forces in planning and/or carrying out the attack-made its way especially into the milieu and the press of the radical and extra-parliamentary left. On March 17, the front page of Il Manifesto headlined:

The bloody kidnapping of Aldo Moro is the last act of a decade of massacres covered up by the state. Italy has been reduced to a frontier country, a battlefield for secret services and shady interests. Workers who take to the streets want to know where the roots of this degeneration are. But today confidence was given to a government that is the continuity of a past of silence and omertà [a code of silence]. ${ }^{77}$

Also, Lotta Continua claimed that the attack was the result of «an internal logic of international relations between states» ${ }^{78}$ and that there was $«$ direct interdependence between BR and maneuvers with an international character». ${ }^{79}$ According to the student and worker movements' newspaper, the kidnapping had the function of strengthening the opposite political front, further compacting it with inevitable authoritarian outcomes, justified by a pressing «reason of state». For this reason, arguing that they would never «choose between a murderous State and an identical form of

76 Wagner-Pacifici 1986, 72.

77 Il Manifesto, «Il sequestro sanguinoso di Aldo Moro», 17.3.1978, 1; it.: «Il sequestro sanguinoso di Aldo Moro è l'ultimo atto di un decennio di stragi coperte dallo stato. L'Italia è ridotta a paese di frontiera, campo di avventura di servizi segreti e loschi interessi. Gli operai che scendono in piazza vogliono sapere dove sono le radici di questa degenerazione. Invece oggi si è data la fiducia a un governo che è la continuità di un passato di silenzio e omertà.»

78 Lotta Continua, «Rapito Moro, il gioco più pesante e sporco che sia mai stato provato sulla testa dei proletari italiani», 17.3.1978, 1; it.: «[...] una logica tutta interna ai rapporti internazionali tra stati.»

79 Lotta Continua, «Lo Stato continua», 18.3.1978, 1; it.: «[...] una diretta interdipendenza tra BR e manovre a carattere internazionale.» 
terrorism ${ }^{80}$, the newspaper demanded the opening of negotiations for the liberation of Moro as early as in the first days of the kidnapping. There were also those who understood the actions of the BR as inscribed in the logic of the Cold War conflict. For example, a March 16 editorial by the radio station Radio Città Futura, operated by the Movimento, affirmed that

Italy has become a country in which maneuvers are being conducted by American and Soviet secret services, and those secret services of dependent countries, Czechoslovakia, Poland, Hungary and then, naturally, the Germans and Israelis and Arabs. That is, Italy has essentially become a battlefield in which the secret services are operating with their different interests. ${ }^{81}$

It was not only the media of the extra-parliamentary left that made a hypothesis about possible foreign interference. One of the «evidences» used to support or at least make the hypothesis appear plausible was the «efficiency» of the BR in carrying out the attack in via Fani. Several journalists found it suspicious that the BR had fired several shots without hurting Aldo Moro, or that they not only got away with the hostage but had also cut many telephones lines in the area in order to prevent the rapid arrival of the police. In almost all the newspapers' March 17 editions, there was an article that underlined the precision with which the attack was carried out and/or highlighted the similarities with the Schleyer case: «Analogies with the Schleyer Case Pose Troubling Questions»; «Bonn-Overlooking the Hypothesis That German Terrorists Have Also Acted in Rome»; «BonnKidnapped Like Schleyer»; "An Act Recalling the German Schleyer»; «Twelve Killers for a Scientific Massacre»; «The Lightning Ambush».82 This and other articles described a number of similarities with the Schleyer case (the technique used in the kidnapping, namely the blocking of the first car with another car; the fact that members of both terrorist organizations were in prison at the time of the attack, etc.) as evidence of the possibility

80 Lotta Continua, «Non sarà un nuovo Stammheim», 17.3.1978, 10; it.: «Non saremo costretti a scegliere fra uno Stato omicida e un terrorismo a lui identico.»

81 Quoted in Wagner-Pacifici 1986, 74.

82 Avanti!, "Le analogie con il caso Schleyer pongono inquietanti interrogativi», 17.3.1978, 10; Corriere della Sera, «Bonn - Si affaccia l'ipotesi che a Roma abbiano agito anche i terroristi tedeschi», 17.3.1978, 7; Sansa, Tito, «Bonn - Rapito come Schleyer», La Stampa, 17.3.1978, 4; Cianciullo, Antonio, «Un'azione alla tedesca che ricorda Schleyer», La Repubblica, 17.3.1978, 5; Mafai, Miriam, «Dodici killer per un massacro scientifico», La Repubblica, 17.3.1978, 1; Spigarelli, Piero, «Il fulmineo aguato», Il Popolo, 17.3.1978, 1-2. 
of the participation of German terrorists or at least of outside help in the attack (for example, in the form of military preparation in a training camp).

Why were so many journalists not able to imagine that an Italian terrorist organization could organize and execute such an attack? The great connoisseur of Italian culture Leonardo Sciascia gave the best answer to this question: "Of an institute that does not function, of a hospital in which patients are mistreated or in which there is no room, of a late train, of an airplane that does not take off, of a letter never arriving, of a party that fails, the motto is always the exclamation: our things! [...] The BR functions perfectly: but (and the but is necessary), they are Italians. They are our thing, whatever the relations they may have with revolutionary sects or foreign secret services.» ${ }^{83}$ The logic underlying the articles mentioned above is as follows: the via Fani attack was executed with great efficiency; Italian things are inefficient; so the attack must have been organized and carried out under the direction or with the help of foreigners. Oreste Scalzone, a leader of the radical left group Potere Operaio, gave the following explanation on this strategy of exclusion, a strategy that has continued to this day: «The only constant is this obstinate will to find some explanation that proves that the BR are exogenous to this society, to the Italian situation of class contradictions. The very power that terrorism reveals on this type of society-one thinks on its use of information channels-becomes the very source of the argument used to negate its independent, endogenous character.» 84

The declaration of the exogenous character of the BR was not the only strategy implemented in order to exclude the BR from the collective identity of the «Italian people». The second way of framing the terrorist organization was to declare them «common criminals» or «fanatics». In the aforementioned speech by the Prime Minster Andreotti, the BR are already depicted as «common criminals». The day after, Il Popolo described the attack in via Fani as a «ferocious assassination» and «a regurgitation of barbarism, or the face of a new and ancient evil that has been afflicting the country

83 Sciascia 1978, 127-128; it.: «Di un istituto che non funziona, in cui si è maltrattati o in cui non c'è posto, di un treno che ritarda, di un aereo che non parte, di una lettera che non arriva, di una festa che non riesce, il suggello è sempre l'esclamazione: «cose nostre! [...] Le Brigate rosse funzionano perfettamente: ma (e il $m a$ ci vuole) sono italiane. Sono una cosa nostra, quali che siano gli addentellati che possono avere con sette rivoluzionarie o servizi segreti di altri paesi.»

84 Deaglio/Menapace/Scalzone 1978, xxiii. 
for centuries: the hate, the perfidy, a cruel and criminal fanaticism.» ${ }^{85}$ The newspaper dedicated the whole fourth page, entitled «Democracy Does Not Give Up» (Non cede la democrazia), to the representation of the BR. One of the articles on this page represented the terrorists as «lunatics», «ferocious», "crazy madmen», «murderers», whose actions were nothing more than a "cynical struggle, which is arrogant, inhuman in its ruthlessness, and nourished by deep contempt for human values and life.» ${ }^{86}$ The newspaper also quoted the telegram written by the Pope to Cardinal Poletti, Vicar of Rome, in which Paul VI described the attack as an act of «inhuman ferocity that has affected people generously committed to the fulfillment of their duty, bleeding once again the streets of this city, once a master of civilization, now a helpless witness to barbaric rejuvenation.» ${ }^{87} \mathrm{An}$ analogous rhetoric had also already been used on March 17 by L'Unità, Corriere della Sera and La Stampa, in which the BR are regularly described as criminals.

As Alessandro Silj has pointedly noted, this kind of representation was part of a strategy of depoliticization of the BR and the mythicization of the event of political violence:

For years, the problem of the BR had been removed, relegating it to the category of common criminality, madness, or at best, of textures essentially extraneous to the Italian social fabric because they were maneuvered by occult foreign powers. Now Aldo Moro was kidnapped. Referring to the victim, one could not speak only of a political leader, because that would be the equivalent of recognizing the BR's action as a political action, carried out by a political organization [...]. So it becomes a necessity, since the BR are the (monster), to sublimate the figure of Moro and to transform him into a 〈Hero〉 and a 〈Saint $\rangle$. Only in this way can these latest events be brought back to the scenario of ever,

85 Gilmozzi, Marcello, «Una guerra disperata», Il Popolo, 17.3.1978, 1; it.: «[...] feroce assassinio, $[\ldots]$ un rigurgito di barbarie, o il volto di un male nuovo ed antico che da secoli travaglia il paese: l'odio, la perfidia, un fanatismo crudele e criminale.»

86 Cavedon, Remigo, «La 〈svolta〉 terroristica è nella logica delle BR», Il Popolo, 17.3.1978, 4; it.: «[...] squilibrati [...] pazzi furiosi $[\ldots]$ assassini $[\ldots]$ feroci $[\ldots]$. [...] una lotta cinica, spavalda, inumana nella sua spietatezza, nutrita di profondo disprezzo per i valori umani e la vita.»

87 Il Popolo, «Paolo VI: sprofondo è il nostro dolore», 17.3.1978, 1; it.: «[...] disumana ferocia, che ha colpito persone generosamente impegnate nell'adempimento del proprio dovere, insanguinando ancora una volta le strade di questa città un tempo maestra di civiltà, ora testimone impotente di rinata barbarie.» 
which is not political, but mythological, where there is no space for the chiaroscuro and only those who choose a side in the battlefield can have citizenship rights. [This is] [t]he great battle between good and evil. ${ }^{88}$

The process of mythicization thus already began from the beginning of the Moro case. Silj highlights that the public assessment of the BR was dialectically bound up with an assessment of the identity of Moro. The performativity of this mythicization is twofold: on the one hand, it allowed, as we will deepen further, the justification of the «line of firmness», inasmuch as it was impossible to negotiate with monsters and madmen; on the other hand, it reinforced and sustained the myth of a society and a nation in perpetual danger and battling with an absolute enemy, an enemy that has no real political ends, but is just bent on chaos and destruction. Moreover, Silj points out that Moro could not be identified only as a political leader, because then the conflict between the Italian State and the BR would have appeared only as a political conflict (and therefore as historical and not metaphysical). For this reason, Moro had to be transformed into a hero and a saint. As I will show later, the sacralization and representation of Moro (more than as a saint and a hero) as a martyr was preceded by a procedure of depoliticization, through which he was excluded from the political sphere, deprived of political identity and his life reduced to mere life.

Not all social actors deployed a strategy aimed at excluding the BR from the political body in order to stress an alleged national unity. For the right of the political spectrum, the BR were nothing but the children of the PCI. Ultraconservative parties referred to the BR as «Communist terrorists». 89 Similarly, the Minster of Public Education Giovanni Galloni, a member of

88 Silj 1978, 29; it.: «Per anni il problema delle BR era stato rimosso, relegandolo nel novero della criminalità comune, della follia, o nella migliore delle ipotesi di trame essenzialmente estranee al tessuto sociale italiano perché manovrate da occulte centrali straniere. Ora Aldo Moro è stato rapito. Riferendosi alla vittima, non si può parlare soltanto di leader politico, perché ciò equivarrebbe a riconoscere l'azione delle BR come un'azione politica, eseguita da un'organizzazione politica [...]. Ecco dunque la necessità, se le BR sono il «mostro», di sublimare la figura di Moro per farne l'‘Eroe` e il «Santo». Soltanto in questo modo è possibile ricondurre gli ultimi avvenimenti nello scenario di sempre, che non è politico, bensì mitologico, in cui non c'è spazio per i chiaroscuri ma può avere diritto di cittadinanza soltanto chi non rifiuta la scelta di campo. La grande tenzone fra il bene e il male.»

89 See Morcellini/Avallone 1978, 445. 
the DC, raised the issue of the «Stalinism» of the BR. ${ }^{90}$ The attitude of the Communists and the left in general was obviously different. The PCI as well as many people and groups of the extra-parliamentary left claimed that the leftist, international, pro-proletarian position taken by the BR was «nothing but rhetoric». The historian and journalist Leo Valiani, a former Communist, wrote that the problem with these young fanatics was their «lack of political and economic culture» and that «never before has the validity of the historical opposition of the true Marxists and, of course, of Liberal Democrats and Christian Democrats to terrorism been so clearly confirmed.» ${ }^{91}$ Valiani thus did not deny the «Italianness» of the BR, nor did he represent them as beasts or crazy people, but considered them to be just too stupid to understand and participate in political life. The exclusion of them from political life goes hand-in-hand with the inclusion of the PCI, the DC and other parties like the Italian Republican Party or the Radical Party within the spectrum of legitimate political actors.

Another very widespread form of representation, especially within the media of the left, was the accusation of Fascism: «the accusation of ¿Catholic messianism, which had been at the center of the PCI's former critique of the BR, now receded as the Fascism> of the BR was «discovered in the mid and late seventies.» ${ }^{22}$ This kind of representation also appeared during the 55 days of Moro's imprisonment, as is perfectly exemplified by the headline of an article in L'Unità: «The Language of Freda [a Fascist terrorist] and That of the BR.» ${ }^{93}$ In short, a part of the right represented the BR as Communists, while a part of the left represented them as Fascists (or, in the case of Valiani, as too stupid for politics). As Wagner-Pacifici observes, each one "chose its line of attack on the basis of its own particular sense of the best strategy to use to assert its own legitimacy.» ${ }^{94}$ This type of representation, however, remained minor to those who glorified the unity of the country and represented the BR as entities outside of the national political body.

90 See Roggi, Enzo, «La segreteria DC conferma la linea dell'intesa democratica», L'Unità, 30.3.1978, 8.

91 Valiani, Leo, «La democrazia ha altre armi per difendersi», Corriere della Sera, 20.3.1978, 1; it.: «[...] mancanza di cultura politica ed economica [...]. Mai come in questo caso si conferma la validità dell'opposizione storica degli autentici marxisti e, naturalmente, democratici liberali e dei democratici cristiani al terrorismo.»

92 Wagner-Pacifici 1986, 84.

93 L'Unità, «Il linguaggio di Freda e quello delle BR», 27.4.1978, 1.

94 Wagner-Pacifici 1986, 86. 
Sociologist and journalist Francesco Alberoni gave perhaps the most interesting representation of the $\mathrm{BR}$, describing them as a sort of sect of fanatics, which combined Marxist ideology with the religious topos of the apocalypse:

There is a revolutionary Marxist nucleus in the country [...]. They dream of a revolutionary apocalypse, from which a proletarian revolution will emerge. It is a theological-religious conception of politics present in Russia before the Revolution, in Spain, in South America, but also in the farthest past. In Italy, this idea has been adopted by some student groups disappointed by the fact that 1968 had no revolutionary outlet, $[\ldots]$ disappointed by the success of a moderate party such as the PCI, [...] by all that has not led to what their ultimate desire is: the bloodbath, the apocalypse from which a new wonderful world should emerge. The BR are the organized point of this army of the apocalypse. The mindset of the terrorists is that of the soldier of an army that fights against all that is earthly. Because for them the world is absolute evil and must be annihilated by the purifying fire of a revolution..$^{95}$

Alberoni excludes the BR from political life by underlining their religious fanaticism. Unlike Valiani, he does not believe that it is their stupidity that prevents them from legitimately participating in political life, but their specific eschatological conception of history. They do not believe in progress and democratic debate, but in the mythical struggle between good and evil that will only be brought to an end in the final battle. If Alberoni is right, we could say that there were two conflicting but only apparently antithetical mythologies, inasmuch as they converge at least on

95 Alberoni, Francesco, «L'esercito dell'apocalisse», Corriere della Sera, 19.3.1978, 3; it.: «Esiste nel paese un nucleo marxista rivoluzionario [...]. Essi sognano un'apocalisse rivoluzionaria da cui emergerà poi una rivoluzione proletaria. Ė una concezione teologico-religiosa della politica presente in Russia prima della Rivoluzione, in Spagna, in Sudamerica, ma che ritroviamo anche nel più lontano passato. Da noi in Italia si è fatta strada in alcuni gruppi studenteschi delusi dal fatto che il 1968 non ha avuto uno sbocco rivoluzionario, [...] delusi dal successo di un partito gradualista come il PCI, [...] da tutto ciò che non ha portato a quello che è il loro ultimo desiderio: il bagno di sangue, l'apocalisse da cui dovrebbe emergere un nuovo mondo meraviglioso. Le Brigate Rosse sono la punta organizzata di questo esercito dell'apocalisse. [...] La mentalità dei terroristi è quella del soldato di un esercito che combatte contro tutto ciò che è terreno. Perché per loro il mondo è il male assoluto e deve essere annientato dal fuoco purificatore della rivoluzione.» 
one point: the representation of the conflict as an absolute struggle between good and evil. Just as the death of Aldo Moro was sacralized as a sacrifice for the salvation of the state, violence was sacralized and legitimized by the BR because it was motivated by a political cause that we could call metaphysical, a cause that they experienced as transcending history. The $\mathrm{BR}$ «adorned themselves with the sacred vestments of the Resistance fighters $[\ldots]$ as missionaries following their own sacred tradition. ${ }^{96}$ Once again, we are faced with a prefiguration, namely the legitimization of actions by reference to past actions that have been memorialized and legitimized by history and enjoy general political recognition. Just as violence in the Resistance was legitimated by the necessity of defeating Fascism, revolutionary violence is experienced as legitimated by the necessity of defeating capitalism.

Finally, there is a fourth mode of representation of the BR that cannot be put on the same level as the three previous modes, as it does not follow the mechanism of discursive inclusion/exclusion aimed at creating a national collective identity, but rather wants to draw attention to the problem of identity itself. This is the representation that frames the political conflict as a conflict between generations. The journalist and co-founder of Il Manifesto Rossana Rossanda was probably the social actor who most vehemently called attention to the fact that the BR were not at all out of Italian reality. Rossanda used the image, which became famous, of the «family album». ${ }^{97}$ The journalist pointed out that the language and rhetoric of the BR had much in common with those used in the past by PCI militants, particularly during the period of resistance to Fascism. The $\mathrm{BR}$, in fact, used the Resistance's terminology to describe and justify their actions.

Wagner-Pacifici describes the Resistance as a root paradigm, which stood for courage undeterred by an invasion, sacrifice, necessary and legitimate violence, and antifascism. ${ }^{98}$ During the 55 days and also after, references to the Resistance were continually made by the PCI, such as for example by Enrico Berlinguer, who the day before Moro's body was found in via

96 Pacifici refers here to Denis Donoghue, who has noted that the Irish Republican Army, in a very similar way to the BR, tried to sacralize their own actions by taking «possession of the entire Republican tradition from the Rising of 1798 to the Fenians and the Man of Easter Week in 1916» (Donoghue, Denis, «The Hunger Strikes», The New York Review of Books, 22.10.1981, 29, quoted in Wagner-Pacifici 1986, 158).

97 Rossanda, Rossana, «L'album di famiglia», Il Manifesto, 2.04.1978, 1.

98 Wagner-Pacifici 1986, 169-175. 
Catani wrote that «the road of unity is the only just road, the only one capable of strengthening democracy, of rendering invincible the Republic born out of the Resistance.»99 The BR challenged exactly this kind of representation, in which the democratic and republican state appears the true goal of the Resistance. According to them, the PCI had betrayed the revolutionary spirit of the Resistance by coming to terms with the enemy. They understood themselves as the true heirs of the Resistance, as the brigades of a new resistance. Even the mass movement that they dreamed of was called, in the "Resolution of the Strategic Directorate of the BR» that accompanied the fourth communiqué, the «Proletarian Offensive Movement of Resistance». ${ }^{100}$

When Rossanda noticed the similarity between the BR's language and Communist language during and after the war, her goal was not to denounce an alleged link between the PCI and the BR, but rather to put into perspective the political vacuum left by Gramsci's and Togliatti's party, who, after having fought the Christian Democracy as an expression of capitalism for decades, now «no longer knows how to define [it], whether as a friend or an enemy.» ${ }^{101}$ In other words, the problem at stake was the collective identity not of the nation, but of the left, and more precisely of those who still felt attached to the cause of the struggle against capitalism. The young leftists felt betrayed by the generation of their fathers and mothers, as they idealized the generation of their grandparents and grandmothers, who had fought in the Resistance. ${ }^{102}$ To weaken the BR's appellative potential and that of other terrorist organizations, Rossanda argued, the PCI and extra-parliamentary left had to distance themselves from the DC and return to «traditional» values of the anti-capitalist struggle.

The problem of the left's identity crisis found expression in the slogan «neither with the State nor with the BR», which spontaneously emerged on the morning of March 16 at a student meeting at the Faculty of Political Science in Rome, where Aldo Moro was holder of the Chair of Institutions

99 Berlinguer, Enrico, «Berlinguer al popolo e agli elettori», L'Unità, 8.05.1978, 1; it.: «[...] la via dell'unità è l'unica giusta, l'unica che può rendere forte la democrazia, invincibile la Repubblica nata dalla Resistenza.»

100 Brigate Rosse 1978f, 95.

101 Rossanda, Rossana, «Lalbum di famiglia», Il Manifesto, 2.03.1978, 1; it.: «[...] non si sa più bene come definire, se avversario o amico.»

102 The theme of the generational conflict had already been introduced by Pasolini in 1973, when the journal Nuovi Argomenti described Left Extremism as a rebellion of children against fathers, who rewrote the romance of their grandfathers engaged in Resistance; see Pasolini 1973. 
of Law and Criminal Procedure. With this slogan, the students expressed their opposition to the violent methods used by the BR, but at the same time they signaled that they did not want to take the side of the DC, as the PCI did. As Lotta Continua wrote in an article entitled «It Will Not Be a New Stammhein» (in reference to the prison where some terrorists of the German Rote Armee Fraktion died in 1977), a part of the left did not want «to be forced to choose between a homicidal state and a form of terrorism identical to it.» ${ }^{103}$ In that sense, the students' slogan meant refusal of both terrorist and institutional violence. From this line, the support for the negotiations for the exchange of prisoners and the salvation of Moro would then be developed.

\subsection{The Image of the Coming Martyr}

Immediately after the attack in via Fani, the image of Moro underwent a transformation. Aldo Moro was no longer represented primarily as one of the most important leaders of the DC, but became the people's leader, the symbol of a wounded nation, attacked by a band of barbarous, ferocious and crazy assassins. He thus ceased to be only a collective figure and became the embodiment of the collective itself.

According to Wagner-Pacifici, in Italy there is nothing like a national collective identity but rather «several different collectivities»; this is the reason why «the «target» [of the attack] was alternately identified as the heart of the State, the Historic Compromise, Democracy, the Christian Democratic Party, the Communist Party, the Republic, the Institutions of the State, and $[\ldots]$ the Mass Media.» ${ }^{104}$ Too many divisions along political, religious, cultural, geographical and institutional boundaries, whose roots partly extend deep into history, hinder the formation of a stable national collective identity. Thus, from the beginning, different social actors considered the kidnapping of Aldo Moro an attempt to challenge the different collectives to which they belonged or, more precisely, with which they identified. Many Catholics saw it as a criminal act against the values represented by the DC; others, especially many non-parliamentary radical leftists, saw it as an attempt to delegitimize the student and worker movements. The Communists privately understood the primary target of the BR

103 Lotta Continua, «Non sarà un nuovo Stammhein», 17.3.1978, 14; it.: «Non saremo costretti a scegliere tra uno Stato omicida e un terrorismo a lui identico.»

104 Wagner-Pacifici 1986, 89. 
to be their delegitimization, while Christian Democrats were convinced that the real target was the DC. But despite these different understandings of the concrete target, both parties publicly presented the attack as an attempt to destroy Italian collectivity. Both party newspapers and independent newspapers, as we have seen, described the target with terms which, in different ways and combinations and with different nuances, all refer to an alleged national collective identity: Italy, country, state, republic, democratic institutions, republican institutions, etc. For a relatively short period of time, namely for the duration of Moro's imprisonment and a little further, different social actors and political groups seemed to put aside ideological conflicts and different visions of politics and society to join in a rhetoric of national unity. Nevertheless, the perception that a certain particular collective, and not the whole nation, had been attacked never completely vanished. This tension between particular collectivities and the concerted construction of national identity, as well as the related forms of representation, determined the way in which the media represented Aldo Moro during his 55-day imprisonment.

The construction of this national identity is intrinsically linked to the transformation of Moro's image into a symbol, the embodiment of collectivity. After March 16, Moro's incomprehensible speeches were reinterpreted as demonstrations of his cultivated and sophisticated legislative work. His strategy of exhausting opponents was transformed into humble patience: «Moro: His Style Is Tolerance» is the title of an article by journalist Enzo Biagi in the March 17 edition of the Corriere della Sera. ${ }^{105}$ Among the most commonly used adjectives to describe the politician, we find words such as melancholic, stationary, hieratic, honest, thoughtful, mild, lucid, solitary, persuasive, serene, sad, cautious, slow, reticent, contradictory, pessimistic, optimistic, Christian, proud, elusive, tolerant, patient, spiritual. Between March 17 and 21, Italian journalists resorted to almost all of the resources of Italian vocabulary.

The title of the fifth page of the March 17 edition of La Stampa, described Moro as «One of the Most Prestigious and Human Figures» ${ }^{106}$; on the same page, Stefano Reggiani wrote that

$[\ldots]$ his figure is like his character, an evanescent moment (his closed eyes, his slow pronouncement, which was affected by his disease, as one could see in one of his last appearances on TV); a moment later

105 Biagi, Enzo, «Moro: Il suo stile è la tolleranza», Corriere della Sera, 17.3.1978, 3.

106 La Stampa, «È una delle figure più prestigiose ed umane», 17.3.1978, 5. 
the figure is firm, characterized by the meticulous oratory of the congresses and by the white stain of his hair, as if it would be a predetermined originality. ${ }^{107}$

In an article entitled «Aldo Moro Is the (Weaver of the New Italian Reality» published the next day, the leader of the Italian Republican Party Giovanni Spadolini described Moro as «the most foreign to slogans, to the suggestions of myths or contingent infatuations, among the Christian Democrats.» ${ }^{108}$ On March 19, in an editorial entitled «The Assassins Like Judges», the newspaper defined Moro as «one of the great statesman of our time» and expressed the trust that «by the strength of his spirit and the height of his civil and religious faith, he will overcome [the ordeal], even in the fragility of his health and of all that is human, while remaining himself.»109

La Repubblica gave a lot of coverage to the reactions of Moro's family and of Christian-Democrats, with often dramatic titles like "A Family in Anguish but «with Aldo's Reserve» or «It Is as If They Kidnapped Our $\mathrm{Dad}$, and in the DC in Milan Anger Explodes». ${ }^{110}$ In an editorial in the March 17 edition, the image of Aldo Moro was not yet transformed. In fact, he was described as a man who

for twenty years represented the DC's democratic continuity. With all his sluggishness, his delays, his mistakes, he is the man who transformed the party from centrism to the alliance with Socialists before,

107 Reggiani, Stefano, «Aldo Moro, lo statista degli equilibri difficili», La Stampa, 17.3.1978, 5; it.: «[...] la sua figura è come il suo carattere, un momento evanescente (gli occhi socchiusi, la pronuncia lenta e impacciata dalla malattia come si vide in una delle sue ultime apparizioni in tv, un attimo dopo ferma, inchiodata all'oratoria puntigliosa dei congressi e alla macchia bianca dei capelli, come a una prestabilita originalità.»

108 Spadolini, Giovanni, "Aldo Moro è il «tessitore» della nuova realtà italiana», $L a$ Stampa, 18.3.1978, 3; it.: «[...] uno dei democristiani più estranei alle parole d'ordine, alle suggestioni dei miti o delle infatuazioni contingenti.»

109 La Stampa, «Gli assassini come giudici», 19.3.1978, 1; it.: «È toccata ad Aldo Moro, uno dei grandi statisti del nostro tempo, una prova tremenda, ma alla quale confidiamo che egli, per la forza del suo spirito e per l'altezza della sua fede civile e religiosa, possa sovrastare [una prova tremenda], pur nella fragilità della sua salute e di tutto quanto è umano, rimanendo ogni attimo sé stesso.»

110 Mori, Anna Maria, "Una famiglia nell'angoscia però «col riserbo di Aldo», La Repubblica, 17.3.1978, 6; Pansa, Gianpaolo, «È come se avessero rapito nostro padre e nella DC di Milano esplode la rabbia», La Repubblica, 17.3.1978, 7. 
and to the parliamentary majority with the PCI today [...]. He is today the hub of a complex yet still uncertain situation, still fluid [...]. ${ }^{111}$

Despite Aldo Moro being identified as a DC man, the editorial is entitled «They Have Struck the Heart of the State». Here the tension between Moro as a party representative and as a representative of the whole political body is particularly manifest. The newspaper was able to represent him simultaneously as a symbol of the DC and of the state because, on the one hand, he is identified as the real weaver of the Historic Compromise and, on the other, because since 1948 the DC had ruled interruptedly: Aldo Moro was the DC and the DC was the Italian State.

The Communist hagiography is also very interesting. As Alessandro Silj pointedly notes, Aldo Moro was transformed into «an archangel of democracy whose virtues far surpass the rare mistakes.» ${ }^{112}$ Although the Communist newspaper did not represent Moro as the embodiment of the nation, it began a campaign of glorification of the politician's virtues. The journalist Mario Meloni, better known under the pseudonym Fortebraccio, in reference to an episode of $1954^{113}$, wrote on the first page of the March 17 edition of L'Unità:

We, despite rejecting his invitation, cannot forget, nor have we ever forgotten, with how much delicacy, and with how much regard and even respect, he was able to address us with his authoritative exhortation. And there was, in his words, a profound melancholy and a sort of secret solidarity: we felt that we were in front of a man who understood and in whose mind there was no intent to overpower others. ${ }^{114}$

111 La Repubblica, «Hanno colpito il cuore dello Stato», 17.3.1978, 1; it.: «Aldo Moro rappresenta da vent'anni la continuità democratica della DC. Con tutte le sue lentezze, i suoi ritardi, i suoi errori, è l'uomo che ha trasferito il partito dal centrismo all'alleanza coi socialisti prima, e alla maggioranza parlamentare col PCI oggi [...]. È oggi il punto di cerniera di una situazione complessa ancora incerta, ancora fluida [...].»

112 Silj 1978, 31.

113 In 1954, Moro attempted to dissuade the author of the article, who was then his party colleague, from making a hostile statement about the signing of the Treaty of the European Union.

114 Fortebraccio, «Uno che ha capito», L'Unità, 17.3.1978, 1; it: «Noi, che pure respingemmo il suo invito, non possiamo dimenticare, né mai abbiamo dimenticato, con quanta delicatezza, e con quanto riguardo e addirittura rispetto seppe rivolgerci la sua pur autorevole esortazione. E c'era, nelle sue parole, anche una malinconia profonda e una sorta di segreta solidarietà: sentimmo che avevamo 
The same March 17 edition also published the speech held the day before in Parliament by the secretary of the PCI Enrico Berlinguer, in which he spoke of an «attack carried out with calculated determination against one of the most eminent personalities of Italian politics, against a statesman profoundly committed to the democratic cause.»115 Two days later, in an editorial Berlinguer identified the target of the attack in via Fani to be democracy, rather than the state:

It has been stated that Aldo Moro was abducted to attack a symbol, among the most powerful, of this efforts aimed at preventing political and institutional detachment. But beyond Moro as a person [...] they wanted to attack the whole Italian democracy. [...] It is the greatest conquest of the people that is threatened. [...] The democratic regime and the Italian Constitution are decisive and inalienable achievements of the popular movement. ${ }^{116}$

Here, the attack on Aldo Moro becomes an attack on the people, on the popular movement that gave birth to democracy. But Berlinguer did not go so far as to identify, as other newspapers did, Aldo Moro with democracy or the Italian State (or both). Moro is represented as being a representative of democracy, not the embodiment of democracy. Evidently, the PCI secretary tried to get rid of those who recognized Moro's status as a symbol of the whole of democracy, to avoid making the DC appear as the political target of the BR. For Berlinguer, the DC was not the true defender of democracy; it was the popular movement.

For the DC's Il Popolo, after the kidnap Aldo Moro became the true soul (and mind) of the party as well as the embodiment of the country. Alfredo Vinciguerra described Moro as the «DC's most prestigious leader» and as «the man of State: the political point of reference for the large majority of

di fronte un uomo che capiva e nell'animo del quale non trovava posto alcun sentimento di sopraffazione.»

115 L'Unità, «Berlinguer: Assicuriamo al Paese l'impegno unitario e tenace del PCI», 17.3.1978, 1.

116 Berlinguer, «Enrico, Unità e rigore», L'Unità, 17.3.1978, 1; it.: «Si è affermato che Aldo Moro è stato rapito proprio per colpire un simbolo, tra i più significativi, di questo sforzo teso a impedire lo scollamento politico e istituzionale. ma al di là della persona di Moro [...] si è voluto colpire l'insieme della democrazia italiana. [...] È la conquista più grande del popolo che viene minacciata. [...] Il regime democratico e la Costituzione italiana sono conquiste decisive e irrinunciabili del movimento popolare.» 
Italians.» ${ }^{117}$ On the same page, another article commented on an article that Moro published in 1977 and in which he wrote about terrorism and violence. The journalist argued that in this article

the portrait of a man, as well as of a politician and a statist, emerges, who, with his own life, has committed himself to the peace and the common good of all citizens, whom he understood not as abstract entities but, in his Christian sensibility, as brothers. ${ }^{118}$

Two things have to be emphasized about this article. First, it characterizes Moro as someone who devoted his whole life to his political commitment. Moro is represented not simply as a politician that does politics like a job, but someone for whom politics is a vocation. The martyrological representation of his death is somehow anticipated here: precisely because Moro had devoted his life to the common good, he would accept sacrificing himself for the defense of the citizens, the Republic and its democratic institutions. Secondly, the relationship between Moro and the Italian citizens is described in terms of a familial communion. The political body comes to assume an explicit Christian connotation here, since the relationship between the citizens and the politician Aldo Moro is represented as a community of brothers; the Italian State is metaphorically signified as a family.

The media construction of a certain image of Aldo Moro the day after his abduction is entirely centered on his habits, character traits, rhetoric, and political strategy, as well as on his role and function within the DC. They are all constructions of an image in the absence of a real image of Aldo Moro's body. The aesthetic dimension, the corporality of Moro, did not play a decisive role yet. This changed starting from March 18 when television and special newspaper editions published the BR's first communiqué (after the kidnapping), accompanied by a photograph of Moro portrayed in the "people's prison» (see figure 2). The seizure of the Christian Democrat politician and its possible consequences thus became an unequivocal reality. As we saw, the communiqué declared the beginning of the trial of Aldo Moro in front of a "people's court». The photograph of Aldo Moro

117 Vinciguerra, Alfredo, «Come salvare il paese», Il Popolo, 17.3.1978, 3; it.: «[...] leader più prestigioso della DC $[\ldots]$. [...] uomo di Stato: il punto di riferimento politico per la stragrande maggioranza degli italiani.»

118 Giuntella, Paolo, «Così disse condannando la violenza», Il Popolo, 17.3.1978, 3; it.: «Ne emerge un ritratto d'uomo, oltre che di politico e di statista, impegnato con la propria vita per la pace e il bene comune di tutti i cittadini, sentiti non come una entità astratta, ma nella sua sensibilità cristiana, come fratelli.» 
gave credibility to the communiqué as it proved that Aldo Moro was alive and actually a prisoner of the BR.

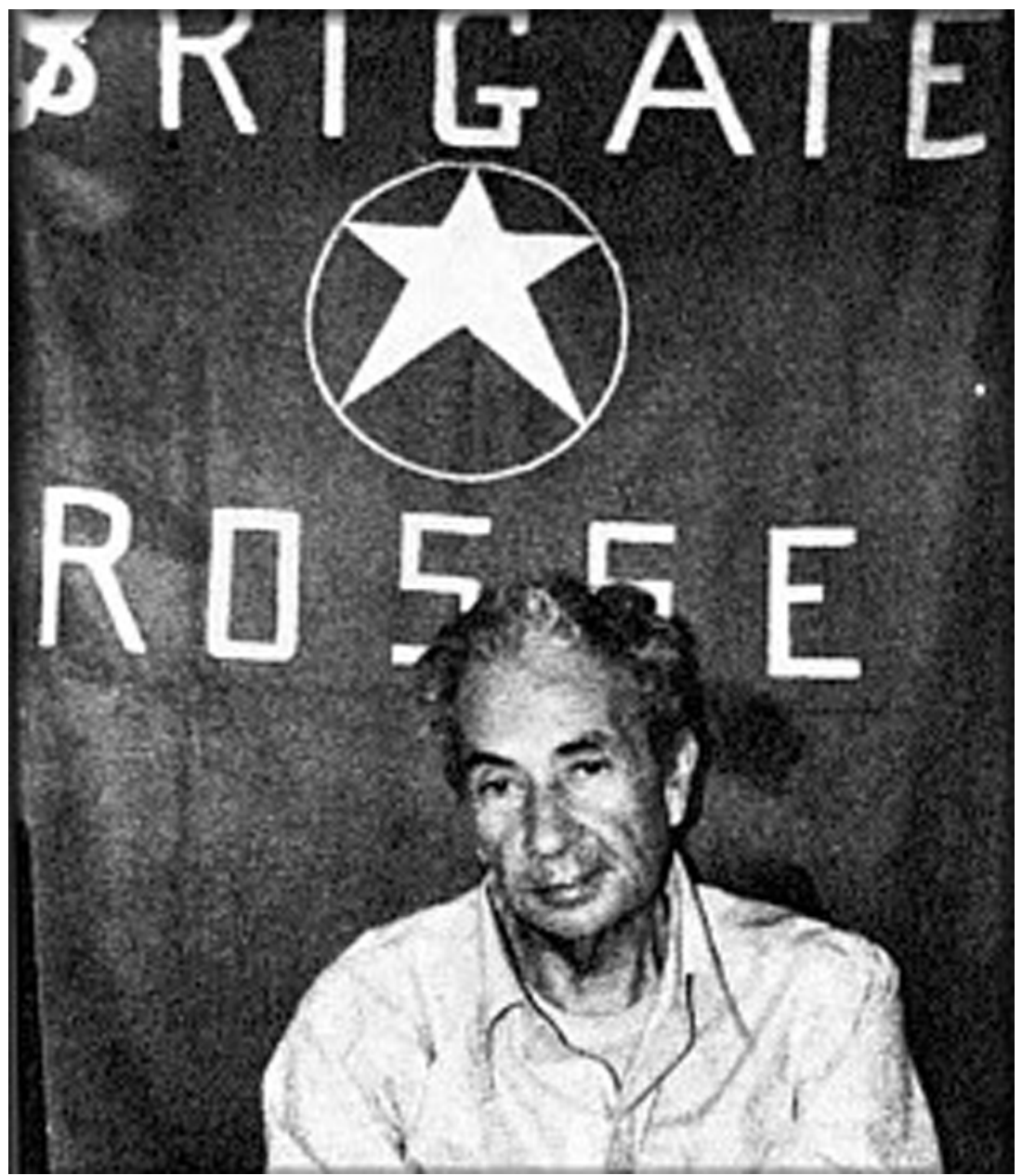

PICTURE 2: Aldo Moro in the first Polaroid issued by the Red Brigades.

On March 19, the six papers examined here all dedicated their front-page titles to the news of the diffusion of the photograph. The only exception was the Communist newspaper, which focused on the «emotion» of the citizens during the funeral of the five dead bodyguards held the day before. Only in the sub-headline is it reported that «Criminals Make Contact by 
Sending the Photo of Moro». ${ }^{119}$ It is also the only newspaper that did not mention the trial in its headline. All six newspapers reproduced the picture, albeit in different sizes: L'Unità only reserved $2.8 \%$ of the front-page surface for the photograph, while the Corriere della Sera reserved 14.1\% for it (see figure 3). ${ }^{120}$ In L'Unità Moro's picture appeared under the title «A Tortured Man» and the text at the side emphasized that the newspaper had been "forced to reproduce it [...] out of a chronicle duty», but that it was doing so «with the reproach of someone touching a document handled by professional assassins. These are beasts, who are even hard to compare with Fascists.» ${ }^{121}$ The image of Moro was then commented on as follows:

Look at this photo. It is the image of a man whose kidnappers promise to martyrize him in one of those tragic farces which they call trials in order to prolong the challenge to Italian democracy and the honor of this Republic. ${ }^{122}$

The term «martyr» here makes its first explicit appearance. Not surprisingly, after this mention of the coming martyrdom of the Christian Democrat politician, the newspaper explained to the reader who «the people» were:

They dare even, these beasts, to write in their messages the word speople». What have they got to do with the people? The people are good, they are human, they are right. The people gathered yesterday around the coffins of the assassinated policemen and Carabinieri. They ask to be released from terrorist gangs. They want to live and progress in peace. ${ }^{123}$

119 L'Unità, «Commossi funerali dei cinque assassinati - I criminali si fanno vivi inviando la foto di Moro», 19.3.1978, 1.

120 See Silj 1978, 12.

121 L'Unità, «Un uomo torturato», 19.3.1978, 1; it.: «L'animo con cui siamo costretti a riprodurre - per un dovere di cronaca - la foto di Aldo Moro nelle mani dei suoi carcerieri e molto triste. Lo facciamo con il ribrezzo di chi tocca un documento maneggiato da assassini di mestiere. Queste sono belve che è perfino difficile paragonare ai fascisti.»

122 L'Unità, «Un uomo torturato», 19.3.1978, 1; it.: «Guardate questa foto. È l'immagine di un uomo che i suoi rapitori si ripromettono di martirizzare, in una di quelle tragiche farse cui danno il nome di processi; e ciò per fare durare più a lungo la sfida alla democrazia italiana e all'onore di questa repubblica.»

123 L'Unità, «Un uomo torturato», 19.3.1978, 1; it.: «Osano persino, queste belve, scrivere nei messaggi la parola ‘popolo». Che cosa c'entrano essi con il popolo? Il popolo è buono, è umano, è giusto. Il popolo si è raccolto ieri intorno alle bare degli agenti e dei carabinieri assassinati. Chiede di essere liberato dalle bande terroristiche. Vuole vivere e progredire in pace.» 


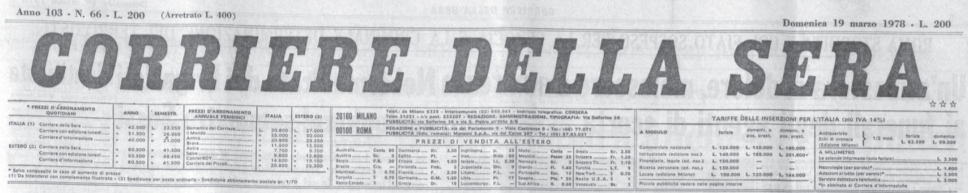

UNA FOTO E UN FARNETICANTE MESSAGGIO HANNO ROTTO IL SILENZIO SUL RAPIMENTO DEL PRESIDENTE DC

\section{Le Brigate rosse annunciano il processo a Moro Anche reparti dell'Esercito nella caccia ai terroristi}

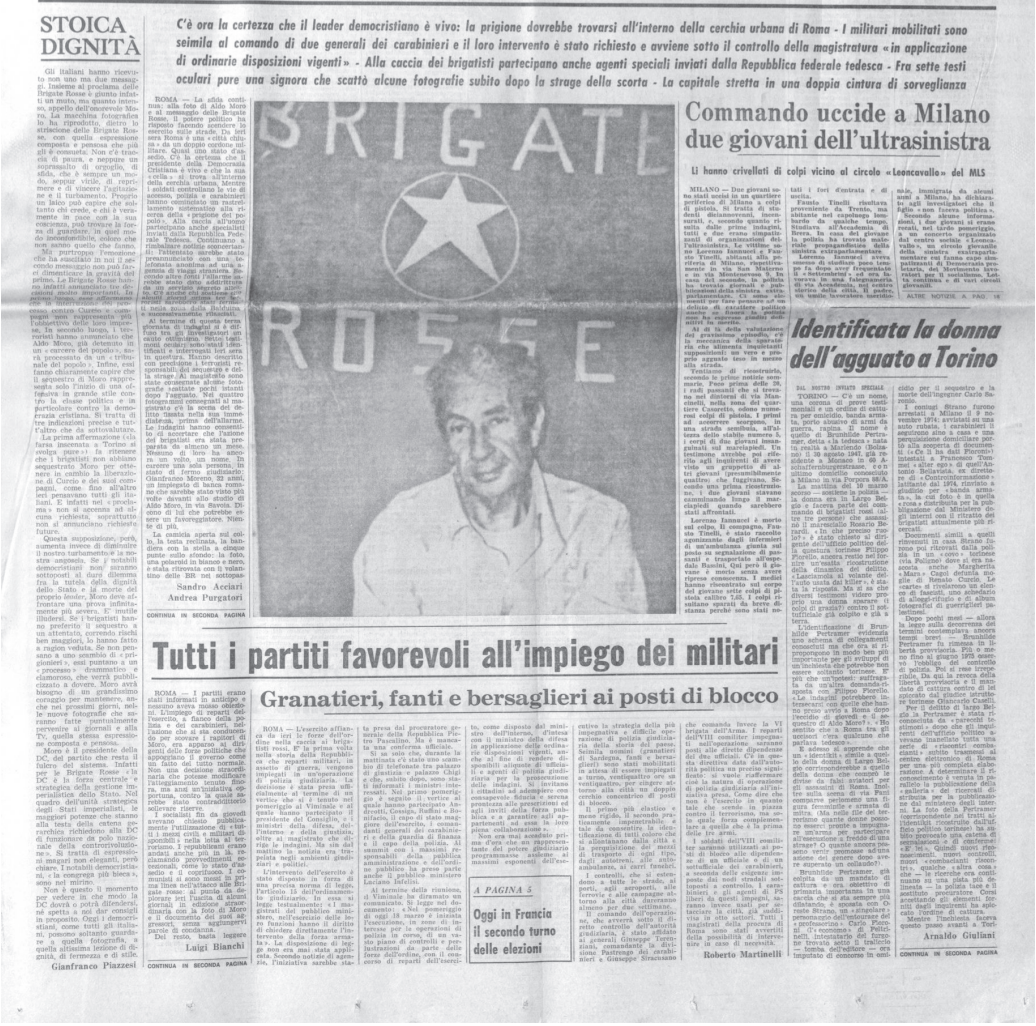

PICTURE 3: Front page of the Corriere della Sera, March 19, 1978.

On pages 1, 2, 4, 10 and 11 of L'Unita, the «unity of the people» is further underlined with the reproduction of photographs showing the masses that appeared at the funeral or in the vigils held in several Italian cities. The sacrifice of Moro's escort, as well as his coming martyrdom, are, in the 
rhetoric adopted by the Communist newspaper, the events around which a united Italy would be reborn. In the Corriere della Sera editorial, the martyrological representation is subtler and less obvious, but perhaps for this reason more effective. In fact, the editorialist uses the instrument of prefiguration in such a way that Aldo Moro appears as a modern-day Jesus Christ and his imprisonment as a modern passion:

The camera has reproduced him, in front of the banner of the BR, with that composed and thoughtful expression for which he is known. There is no trace of fear, nor even a burst of pride, of challenge, which is always a way, albeit virile, to suppress and overcome agitation and turmoil. Even a layman can understand that only someone who believes, and who is truly at peace with its conscience, may find the strength to look in such an unmistakable way at those who do not know what they are doing. [...] Moro will need a great deal of courage to maintain, in the coming days, in his photos that will be duly sent to newspapers and television companies, that composite and thoughtful expression. [...] Today the Christian Democrats, like all Italians, can only look at this photo, this highest lesson in dignity, firmness and style. ${ }^{124}$

This article is particularly interesting for three reasons. First, it contains a direct quotation from the Bible through which an analogy between the suffering of Jesus a few moments before dying on the cross and the suffering of Aldo Moro is constructed. Just as Jesus, in Luke's gospel (Luke 23, 34), asks the Father to forgive the Roman soldiers because they do not know what they do, in the photograph's interpretation by editorialist Gianfranco Piazzesi, Aldo Moro seems to ask forgiveness (to whom?) for the BR's actions only through his look and expression. The crucial point of this prefiguration, its strategic function, lies in the fact that everyone

124 Piazzesi, Gianfranco, «Stoica dignità», Corriere della Sera, 19.3.1978; 1; it.: «La macchina lo ha riprodotto, dietro lo striscione delle BR, con quella espressione composta e pensosa che più gli è consueta. Non c'è traccia di paura, e neppure un soprassalto di orgoglio, di sfida, che è sempre un modo, seppur virile, di reprimere e di vincere l'agitazione e il turbamento. Proprio un laico può capire che soltanto chi crede, e chi è veramente in pace con la sua coscienza, può trovare la forza di guardare, in quel modo inconfondibile, coloro che non sanno quello che fanno. [...] Moro avrà bisogno di un grandissimo coraggio per mantenere, anche nei prossimi giorni, nelle sue fotografie che saranno fatte puntualmente pervenire ai giornali e alla $\mathrm{Tv}$, quella espressione composta e pensosa. [...] Oggi i democristiani, come tutti gli italiani, possono soltanto guardare a quella fotografia, a quella altissima lezione di dignità, di fermezza e di stile.» 
knows the bloody end of Jesus in the Gospel's narrative. With this analogy, Aldo Moro's death is not only anticipated, but is loaded with metaphysical meaning, appearing as something that has already been written and cannot be avoided. In fact-here we come to the second point-for Piazzesi the hostage is able to look at his kidnappers in that way, in the way Jesus looked at his torturers, only because he is a man of faith who is at peace with his conscience and his destiny. The man of faith can look at them this way because he does not fear what he knows will happen. In this representation, Moro seems to commit his spirit to the hands of the Father, as Jesus does in Luke's narrative; here he becomes the true heir of the Christian martyrs. Finally, Piazzesi, by referring to Moro's expression in the photo as the highest lesson in dignity, implicitly appeals to the reader to learn from the martyr, to take him as an example to imitate. The editorial thus reproduces and applies the mechanism of interpellation, which in the third chapter we identified as a central performative force of martyrological narratives: Just as martyrs, through their own death, imitate the Passion of Christ, viewers of martyrdom are called to imitate the martyr, to live and die with the same courage and dignity. We find an analogous representation of Moro as an example to imitate in the pages of Il Popolo, where Ruggero Orfei, an important representative of the Christian Associations of Italian Workers (ACLI), writes that «the suffering of Aldo Moro is a collective and national witness, a lesson that no one can evade.»125

The representatives of the DC also praised the exemplarity of Moro as a prisoner figure. As La Stampa reported, the party vice-secretary Giovanni Galloni said that «it really impressed us to see him with a serene and melancholy look in such difficult circumstances. The impression that we Christian Democrats had [looking at the photograph] is of serenity and greatness of mind.» The image is even interpreted as an appeal to «keep our strength in mind and to be worthy of the firmness and serenity shown by Aldo Moro.» ${ }^{126}$ In other words, for Galloni the image is an appeal to remain firm in the strategy of non-negotiation. The performative force of the image was also stressed by senator Adolfo Sarti, who said that, «if the BR

125 Orfei, Ruggero, «La sofferenza di Aldo Moro è collettiva e una testimonianza nazionale alla cui lezione nessuno deve sottrarsi», Il Popolo, 19.3.1978, 4.

126 La Stampa, «Emozione, speranza alla sede della DC. Zaccagnini: Moro ne esce esaltato", 19.3.1978, 3; it.: «[...] ci ha veramente impressionato il vederlo con lo sguardo sereno e malinconico in una circostanza tanto difficile. L'impressione che noi democristiani ne abbiamo ricavato, è di serenità e grandezza d'animo. [...] Dobbiamo mantenere la nostra forza d'animo e per essere degni della fermezza e della serenità dimostrata da Aldo Moro.» 
were susceptible subjects, they would be annihilated by this image of nobility, by his malicious irony, by his unobtrusive and extraordinary intelligence.» ${ }^{127}$ Finally, the party secretary Benigno Zaccagnini described the photo as «an exaltation of the DC, its function, and an exaltation of Moro's political and moral figure», transforming it into a party icon. ${ }^{128}$

In an article by Lietta Tornabuoni in the Corriere della Sera, the photograph is interpreted as a sort of violation of the secrecy and sacredness of the body. In fact, the journalist stresses that Moro «has a very strong sense of privacy. He never took off his jacket in public: the picture that shows him in a shirt already seems a sort of violation, the only pictures of him in a bathrobe, swimsuit or sweater are those of holidays stolen with a long lens; clothes are his natural way of presenting himself.» ${ }^{129}$ The photograph is portrayed as profanation of the political figure of Moro, of his public image, through which he is exposed in his nakedness. Nevertheless, Tornabuoni expresses optimism when she writes that «in prison, if he is left in mental and physical integrity, he can hardly suffer self-deception. In addition to the aid that can give him his religious faith, it is more likely that his powerful Superego will be even strengthened and stimulated by his consciousness of being in an extraordinary situation, by the conviction of the importance that his behavior can have for Christian Democracy and for the Country, by the proud challenge of living up to his self-vision, facing the toughest ordeal.» ${ }^{130}$ Moro's psyche and body, his religious faith and his condition in captivity, his inner convictions and the exceptionality of

127 La Stampa, «Emozione, speranza alla sede della DC. Zaccagnini: Moro ne esce esaltato», 19.3.1978, 3; it.: «Se le Brigate rosse fossero soggetti ragionevoli sarebbero annientate da questa immagine, dalla nobiltà di chi vi è ritratto, dalla sua malinconica ironia, dalla sua non occultabile e straordinaria intelligenza.»

128 La Stampa, «Emozione, speranza alla sede della DC. Zaccagnini: Moro ne esce esaltato», 19.3.1978, 3; «Mi pare che sia una esaltazione della DC, della sua funzione, e un esaltazione della figura politica e morale di Moro.»

129 Tornabuoni, Lietta, «Nelle mani delle BR un prigioniero fragile e fortissimo», Corriere della Sera, 24.3.1978, 1; it.: «[...] ha un senso molto forte della riservatezza. Non si è mai tolto la giacca in pubblico: la fotografia che lo mostra in camicia è già sembrata una sorta di violazione, le sue uniche immagini in accappatoio, in costume da bagno o in maglione sono quelle delle vacanze rubate con il teleobbiettivo; i vestiti sono il suo naturale modo di presentarsi.»

130 Tornabuoni, Lietta, «Nelle mani delle BR un prigioniero fragile e fortissimo», Corriere della Sera, 24.3.1978, 1; it.: «Nella prigionia, se gli è lasciata la padronanza mentale e integrità fisica, difficilmente Moro può soffrire di smarrimento di sé. Oltre all'aiuto che può dargli la sua fede religiosa, è più probabile che il suo fortissimo Superego risulti ancora rafforzato e stimolato dalla coscienza di trovarsi in una situazione straordinaria, dalla convinzione dell'importanza che il 
being reduced to a mere bodily presence will thus allow him to resist for the good of the country. Though not explicitly mentioned, the rhetoric used leaves little doubt as to what the «toughest ordeal» is: Aldo Moro will have to live up to the figure from which his party takes its name: as Christ on the cross, he will have to face the ordeal of death. Tornabuoni implicitly says what Gustavo Selva and Eugenio Marcucci, in a chronicle of Moro's 55-day imprisonment published in May 1978, explicitly say in the section on Easter Day:

It is a bitter Easter: the tragedy of Moro [...] is a symbolic expression of the condition in which we find our country. After the sacrifice of five servants of the State $[\ldots]$ the most prestigious and best-known political leader of Italy is spending Easter in a sprison of the people> [...]. Aldo Moro will be able to revive with his religious faith the meaning of the Resurrection, a symbol of peace and real liberation even in this terrible ordeal. ${ }^{131}$

The newspaper that made the most use of the prefiguration of Christology to represent and narrate the captivity of Moro was Il Popolo. On March 21, on page five the newspaper published several interventions by Catholic intellectuals under the overall title «The Courage to Say «No to ViolenceThe Strength of Reason». In an article accompanying these interventions, journalist Alfredo Vinciguerra argued that «the wave of violence» in Italy was caused by nihilism, the Feuerbachian conception of mankind, the logic and anthropology of Darwinism and Marxism. To "save the country», the author continued, a secular «sense of duty» would not be enough, since a «new religious sense of life» was needed; indeed, «only a sense of moral order based on the religious, sacred meaning of things and life excludes opportunities for dealing with the cancerous reasons for violence.» ${ }^{132}$ The interventions by Catholic intellectuals echoed the article and described

suo comportamento può avere per la Democrazia cristiana e per il Paese, dalla sfida orgogliosa di mostrarsi all'altezza della propria idea di sé nell'affrontare la prova più difficile.»

131 Selva/Marcucci 1978, 33; it.: «È una pasqua amara: la tragedia di Moro [...] è un'espressione emblematica della condizione in cui si trova il nostro paese. Dopo il sacrificio di cinque servitori dello Stato $[\ldots]$ il leader politico più prestigioso e più noto d'Italia trascorre la pasqua in una sprigione del popolo [...]. Aldo Moro saprà rivivere con la sua fede religiosa il significato della Resurrezione, simbolo di pace e di reale liberazione anche in questa terribile prova.»

132 Vinciguerra, Alfredo, «Le mani armate di cuori disarmati», Il Popolo, 21.3.1978, 5 ; it.: "C’è da chiedersi [...] se possa bastare <un nuovo senso del dovere» a salvare questo Paese $[\ldots]$, o se non sia necessario soprattutto un nuovo senso religioso 
Moro as the spiritual leader of this religious conception of life and the world. Leone Piccioni, professor of contemporary literature at the University of Rome, wrote that «the serene and firm face of Moro is the symbol of the truth of the Christian message and the freedom that he witnesses», while Romolo Pietrobelli, then National President of Azione Cattolica, argued for the necessity of being «able to re-emerge with force and sacrifice for a reconstruction [of the values that are at the bottom of civil consciousness], which are increasingly needed: the civil values of freedom, democracy, consistency, tolerance, discretion, that in Aldo Moro, as they are in a few believing politicians, are accompanied by a deep Christian inspiration.» But the most interesting intervention was that of Francesco Grisi, President of the Italian Writers Free Trade Union, who wrote that

[...] our choice is that the State cannot negotiate with the BR. The painful eventual death of Moro, killed by the BR, signifies the everlasting quality of his testimony in the golden dawn of liberty. Often, immolation precedes the resurrection of the truth. [...] Maybe for Moro there is, yes, the problem of the Communist Party but, above all, there is the problem of the communion of the saints. The discourse is metaphysical, theological, even if it is apparently political and constitutional. In this sense, Moro is a Pascalian intellectual in the line of an outdatedness [inattualità] of history. It seems strange that the man who is most involved in our history in Italy is actually the most disengaged . $^{133}$

In this article, Moro is already operating in a metaphysical and metahistorcial sphere: his anticipated death is transcended into a vague absolute truth and functions as a sort of rite of passage from the early world to the commu-

della vita [...]. Solo un ordine morale fondato sul senso religioso, sacrale, delle cose e della vita esclude ogni possibilità di appiglio alle cancerose ragioni della violenza.»

133 Grisi, Francesco, «La figura di Moro va al di là del rapporto con la cronaca: il suo discorso è metafisico e teologico», Il Popolo, 21.3.1978, 5; it.: «[...] la nostra scelta è che lo Stato non può trattare con i brigatisti rossi. La dolorosa eventuale morte di Moro ucciso dai brigatisti significa la sua perennità di testimonianza nell'albo d'oro della libertà. Spesso la immolazione precede la risurrezione nella verità. [...] Forse per Moro c'è si il problema del partito comunista ma c'è il problema, soprattutto della comunione dei santi. Il discorso è metafisico, teologico, anche se apparentemente sembra politico e costituzionale. In questo senso, Moro è un intellettuale pascaliano nella linea di una inattualità della storia. Sembra strano che l'uomo che è più impegnato nella nostra storia in Italia sia l'uomo più «disimpegnato’.» 
nity of the saints in paradise. Here Moro is, therefore, already represented as a homo sacer, as someone who, despite still living, is excluded from the sphere of human life and has already begun to participate in the sacred sphere of the community of saints. Moro is already a martyr: the only thing missing to make his martyrdom definitive is the «immolation» that precedes the «resurrection of the truth». Moro is symbolically already in the sacred sphere, but his body is materially still present in the physical, profane world. In order to complete the process from the profane to the sacred, only one thing is missing: he must be killed.

The event's prefiguration as a passion reached its peak on Easter Day. On page four, the Corriere della Sera summed up the period of time that had elapsed since the day of the kidnapping in an article titled «Ten Historical Days of Passion». ${ }^{134}$ In this article, it is not so much the terminology nor the rhetorical formulas (except for the title), but rather its structuration in ten sections, summarizing the ten days since the attack in via Fani, which seems to tacitly evoke the idea of a sort of Via Crucis of Moro. However, rhetorical excess is achieved in another article by the writer, playwright and art critic Giovanni Testori, which was published on the first page of the same newspaper. Although there is no explicit reference to the abduction of Aldo Moro, the event is clearly the hidden fulcrum on which each phrase and word rotates:

These are the dull, scorching days of hatred; days without visions and without light in the darkness; they are also the days of indifference, which fill the most arid and most disgraceful filth with hatred and darkness. [...] The more the dark [buio] and darkness [tenebra] increase, the more a society blinded by the chains of profit and, together, by the chains of the private matter of God increase and multiply the impetus towards that indifference; as if profit and material, capitalist secularism and Marxist secularism could not offer to the dark [buio] and darkness [tenebra] an answer other than their total elusion. [...] What I am trying to say is certainly against the possibility that we will find the strength to pronounce the word we need most. [...] When will we decide to break the chains and to lift the slab of the tomb where we persist in being closed? Hope: this is [...] the word that weeps most under our elusions and our abdications. [...] The difficulty lies in accepting it, in taking it, in bringing it to light, in letting it in-

134 Martinelli, Sergio, «Dieci storici giorni di passione», Corriere della Sera, 26.3.1978, 4. 
vade us all and entirely. Then from its derelict and moaning tremor, like that of someone who has been forgotten for a long time, [hope] will increase, grow in us and with us, and it will be like the banner that one day rose from the grave where the crucified Son of Man was closed. [...] At a certain point in history, Calvary is no longer negotiable; $[\ldots]$ to ascend it with the hope and love is necessary so that peace and justice will be revealed in the end [...], it is necessary to not abdicate, but to put our life in relation to the supreme Otherness that we have wrecked, insulted and on which we have spat, and that, despite everything and [passing] through the pain, still dare to call us with the words, tears and moanings of betrayed and forgotten righteousness, hope and love. ${ }^{135}$

More than an article from an independent newspaper in 1978, this text appears at times to be an apocryphal of the New Testament. The use of oppositional metaphors such as light and darkness recalls to mind some passages of the First Epistle of John, the fourth of the Catholic epistles, in which the author reminded his addressees that Jesus Christ «is the atoning sacrifice for our sins» (1 John 2:2), that «whoever claims to live in him

135 Testori, Giovanni, «Il bisogno della speranza», Corriere della Sera, 26.3.1978, 1-2; it.: «Sono i giorni cupi e roventi dell'odio; i giorni senza sguardi e senza luce nelle tenebre; sono altresì i giorni dell'indifferenza che, dell'odio e delle tenebre, risulta la filiazione più arida e più turpe. [...] Più il buio e le tenebre aumentano, più una società accecata dalle catene del profitto e, insieme, dalle catene della materia privata di Dio accresce e moltiplica le spinte verso quella indifferenza; come se profitto e materia, laicità capitalista e laicità marxista non sapessero offrire al buio e alle tenebre altra risposta che la loro totale elusione. [...] Quello che sto cercando di dire va certo contro la possibilità che si trovi la forza di pronunciare la parola di cui abbiamo più bisogno. [...] Fino a quando non ci decideremo anche noi a rompere le catene e a sollevare la lastra del sepolcro in cui ci ostiniamo a star chiusi? La speranza; è questa $[. .$.$] la parola che più$ piange sotto le nostre elusioni e le nostre abdicazioni. [...] La difficoltà sta nell'accettarla, nell'assumerla, nel portarla alla luce, nel lasciarsene investire tutti e interi. Allora dal suo tremito belante e derelitto, come di chi è stato troppo a lungo dimenticato, essa balzerà, crescerà in noi e con noi e sarà come lo stendardo che, un giorno, s'è alzato dalla tomba dove era stato chiuso il figlio crocefisso dell'Uomo. [...] A un certo punto della storia, il calvario non è più rinviabile; [...] per salirlo con la speranza e l'amore necessari affinché alla sua fine s'apra quella pace e quella giustizia [...], bisogna non abdicare, ma porre la nostra vita in relazione a quella suprema Alterità che abbiamo sconciato, sputato e bestemmiato e che, malgrado tutto, proprio attraverso il dolore, osa ancora chiamarci con le parole, le lacrime e i belati della giustizia, della speranza e dell'amore traditi e dimenticati.» 
must live as Jesus did» (1 John 2:6), that «darkness is passing and the true light is already shining» and that «anyone who claims to be in the light but hates a brother or sister is still in the darkness» (1 John 2:9). The text also reminded readers that the apocalyptical time had already begun: «this is the last hour, and as you have heard that the antichrist is coming, even now many antichrists have come. This is how we know that it is the last hour» (1 John 2:18). Christians know that they live in the last hour, because many antichrists are there, that is, those who deny that «Jesus is the Messiah», that deny «the Father and the Son» (1 John 2:22). The text exhorted to «not love the world» (1 John 2:15) with earthly motives but to love the Father and stresses that «anyone who loves God must also love their brother and sister» (1 John 4:21). Similarly, Testori stressed that the days of 1978 were «days of hatred». Testori's antichrists are the liars who, because of their «Marxist» or "capitalist secularism», are concerned only with «profit» and «matter» and deny the «light» that comes from the crucified «Son of Man» (the expression appears 81 times in the Koine Greek of the four Gospels). Days of hatred will come to an end, according to Testori, only when people accept the necessity to live «in relation to the supreme Otherness» and that "Calvary is no longer negotiable». One can hardly not see here a tacit reference to the situation of Moro, who is exhorted to accept the Calvary that will open the doors to the realization of justice and peace. Testori seems to implicitly say that in order to overcome the days of hatred, one must not only live as Jesus, but also be willing to die like Jesus.

In an article published in Il Popolo, the Jesuit theologian and political scientist Bartolomeo Sorge wrote explicitly what Testori had only alluded to. In fact, the exhortation to accept martyrdom could hardly be more obvious:

The liberation and salvation of man are realized [...] according to the shocking logic of the Easter event. Christians of all ages bear witness to it. Also today. [...] Like Christ, they are destined to revive the world of the mystery of a death that paradoxically leads to life [...] of a self-sacrifice that even when it is the fruit of obstinate hate becomes a supreme demonstration of love. [...] It is necessary that the Christ bear these sufferings to enter into his glory> (Luke 24:26). So even today, in the light of Easter, Christians learn what their destiny is. [...] At this Easter of 1978, we need to deepen this meaning of the death and resurrection of Christ. [...] One cannot help but suffer with those who weep for the loss of five innocent lives, heroic victims of duty and of absurd barbarism. [...] One cannot help but be worried about the fate of he who is in the hands of unconscionable people, only craving, in the delirium 
of lucid madness, to trample and to deconsecrate the values of civic coexistence, to humiliate the dignity of man, to dishearten the State. This Easter reminds us that hatred is defeated at the start, because the Beast> has already been won by the One who is «the Strongest> (Luke 11:21). [...] By virtue of the spower of resurrection', suffering results in an indomitable moral force [...]. From proof comes the unity of consciousness around the values that must be firmly defended-with life, if necessary-so that the new world that has already begun grows in justice and peace. ${ }^{136}$

Unlike the text by Testori, here the reference to the attack in via Fani and Moro's captivity is explicit. On the Easter Day of 1878, the author reminds Christians that they are called to «bear witness» to "the death that paradoxically leads to life». One can be worried about the situation of Moro but, after all, in the light of Easter Day Christians should know «what their destiny is». So should Moro who, as a Christian, do nothing but accept that his destiny is to sacrifice his life for the defense of «the new world that has already begun». It is the world in which the state guarantees and enables civic coexistence and the "dignity of man». But, as the author argues, Christians should not fear this destiny, because they know that «the Beast» has already been defeated. The text does not specify who is «the Beast» and who is «the Strongest», but given the analogical construction, it seems clear

136 Sorge S.J., Bartolomeo, «Potenza della Risurrezione», Il Popolo, 26.3.1978, 1; it.: «La liberazione e la salvezza dell'uomo si realizzano [...] secondo la logica sconvolgente dell'evento pasquale. I cristiani di ogni tempo ne rendono testimonianza. Anche oggi. [...] Come Cristo, essi sono destinati a far rivivere dinanzi al mondo il mistero di una morte che paradossalmente porta alla vita, [...] d'un sacrificio di sé che anche quando è frutto d'un odio lucido e ostinato si trasforma in una prova suprema d'amore. [...] «Bisogna che il Cristo sopportasse queste sofferenze per entrare nella sua gloria (Lc 24.26). Così, anche ai giorni nostri, nella luce di Pasqua il cristiano apprende qual è il suo destino. [...] In questa Pasqua 1978 abbiamo particolare bisogno di approfondire questo significato della morte e della resurrezione di Cristo. [...] Non si può non soffrire con chi piange cinque vite innocenti, vittime eroiche del dovere e d'una barbarie assurda. [...] Non si può non trepidare per la sorte di chi è in mano di gente senza coscienza, bramosa soltanto, nel delirio d'una lucida pazzia, di calpestare e di dissacrare i valori d'ogni convivenza civile, di umiliare la dignità dell'uomo, di avvilire lo Stato. Il ritorno di Pasqua ci ricorda [...] che l'odio è sconfitto in partenza, perché 〈la Bestia è già stata vinta da Colui che è il 〈Più-Forte〉 (cfr. Lc $11,21) .[\ldots]$ In virtù della spotenza della risurreziones, la sofferenza si traduce in forza morale indomabile [...]. Dalla prova nasce l'unità delle coscienze rette intorno ai valori che è necessario difendere con fermezza - con la vita, se occorre affinché il nuovo mondo, che è già iniziato, cresca nella giustizia e nella pace.» 
who assumes these roles in 1978: the BR are «the Beast», while the Italian State is «the Strongest». The author therefore proposes a sort of theological-political reading of the events through which the BR/Italian State conflict assumes a metaphysical connotation. In the thinking of Carl Schmitt, the Leviathan-state is understood as an absolutely necessary entity to counter the Behemoth-Beast, a satanic and demonic force whose purpose is to destroy society and civil coexistence, to annihilate human dignity and to realize a state of perpetual civil war, of war of all against all. ${ }^{137}$ Only within this mythological and theological-political framework can the death of Aldo Moro appear as absolutely necessary, since his salvation, which could only be achieved by negotiation with «the Beast», would amount to a defeat for the Italian State and a victory for anarchic chaos. Through the use of martyrological prefiguration, the author makes such death appear to be bearable, if not desirable, even for the one who has to die because it is death that paradoxically leads to life.

We have seen so far how, even in the first 10 days after his abduction, a transformation of Moro's image began, through which he was more and more removed from the profane sphere of life and history. Aldo Moro was stylized as the symbol of a nation wounded and threatened by a gang of crazy assassins, beasts and/or fanatics. The conflict between the BR and the Italian State was represented as a perpetual war between good and evil. His imprisonment was prefigured as a passion, which would lead to the salvation of the Italian State and with it of the Italian society. Such representations, as I will discuss in the next chapter, were intrinsically linked to the attempt to justify the line of firmness. The argument that negotiations with the BR would endanger the institutions and national security alone would not have been enough to make Moro's death acceptable. It was necessary to make Moro's sacrifice appear not only as inevitable and necessary, as an event that was part of the divine plan, but as a voluntary decision by Moro himself. But at the end of March 1978, something happened that seriously questioned this kind of representation: the BR issued Aldo Moro's first letter, in which the Christian Democrat politician expressed his preference for negotiation and rejected the «line of firmness». The anti-martyr's

137 See Schmitt 1996, 21-22: «According to Hobbes, the quintessential nature of the state of nature, or the behemoth, is none other than civil war, which can only be prevented by the overarching might of the state, or the leviathan. It follows that one of the monsters, the leviathan sstates, continuously holds down the other monster, the behemoth «revolutionary peoples. [...] the leviathan is sthe only correctives for the behemoth. The absolutism of the state is, accordingly, the oppressor of irrepressible chaos inherent in man.» 
voice went against all expectations, requiring a new rhetorical and discursive approach, a new strategy of representation. 


\section{Moro's Voice and its Annihilation}

\subsection{Sanctity of Human Life}

On March 16, several social actors had already taken a stand against the possibility of undertaking negotiations for the release of Moro, thus forming what was called the "party of firmness». Their refusal was immediate, despite the absence of any mention of negotiations in the communiqué of the Red Brigades (BR) in which they claimed responsibility for the attack. On March 17, the director of the Italian second national radio station Gustavo Selva reported that «Carlo Donat-Cattin [then vice-secretary of the Christian Democracy (DC)] [...] has justly said that no blackmail could or would be accepted from the BR.» ${ }^{1}$ The following day, in a meeting of the leadership of the DC, the position of the party in case of a negotiation request was discussed. The nearly unanimous decision of the party was negative. Interviewed by the Corriere della Sera, the Christian Democrat Luigi Granelli said that «it is clear that there are fundamental values on which we can only be inflexible. And there is, on the other hand, the salvation of a human life that is always unrenounceable. How to reconcile these two requirements depends on the circumstances in which this eventuality should be configured.» ${ }^{2}$ Thus, as early as in the immediate aftermath of the via Fani attack, the situation is described in terms of a moral dilemma, in which the state has to decide between fundamental values and the salvation of human life. Although Granelli seemed to be considering it possible to find a line of action that could reconcile the defense of both values (the values of the state and the value of human life), the party majority had already decided that the «sense of the state» had to prevail. The Italian Communist Party (PCI) also immediately took on an uncompromising position, as is exemplified by all the editorials of L'Unità published from March 27 onwards during the duration of Moro's imprisonment. The

1 Quoted in Wagner-Pacifici 1986, 129.

2 Russo, Giovanna, «La direzione Dc discute la linea da tenere nel caso di un ricatto», Corriere della Sera, 18.3.1978, 2; it.: «È chiaro che ci sono valori fondamentali su cui non si può che essere inflessibili e c'è, dall'altra parte, la salvezza di una vita umana che è sempre un dovere irrinunciabile. Come conciliare queste due esigenze dipende dalle circostanze in cui questa eventuale ipotesi dovesse configurarsi.» 
Communists, who for the first time after thirty years felt part of the government and not the opposition, all wanted to prove that they could be a legitimate government party and willing to defend the state from its enemies. They also felt compelled to distance themselves from the BR to avoid being accused of being too indulgent with those who referred to the same or similar cultural and ideological backgrounds. ${ }^{3}$

In the first communiqué issued on March 18 and published by newspapers the day after, the BR made no reference to the possibility of an exchange of prisoners and wrote that their goal was to «unify the revolutionary movement» and to try Aldo Moro, «the political godfather and the most faithful performer of the directives imparted by imperialist powers. ${ }^{4}$ The absence of a request for the exchange of prisoners resulted, halting for a short period of time the debate on the question of firmness and negotiation. On the day of the communiqué's publication, Gianfranco Piazzesi wrote that «the Christian Democrats will not be subjected to the harsh dilemma between the protection of the dignity of the State and the death of its leader. ${ }^{5}$ In the following days, the media debate focused mainly on the question of what the BR wanted to achieve with the so-called "people's trial». One of the founders of the organization, Renato Curcio, in the courtroom of the Torino trial said that «the trial will be held, and very seriously, somewhere else. [...] We will try the entire DC. Moro is in the hands of the proletariat.» ${ }^{6}$ Curcio summarized what the members of the strategic direction of the BR wrote in the first communiqué: since the bourgeois state was illegitimate, the Torino trial was a farce; the real trial would be held in the "people's prison». The response of political parties and of the established media was to immediately discredit this trial as a farce too. Almost all newspapers printed the word «trial» in quotation marks every time they referred to the trial in the "people's prison». As Wagner-Pacifici notes, «the Torino trial and Moro's speople's prison» trial confronted each other as mirror images. [...] By reciprocally denying reality to each other, these protagonists were asserting their claim to be the only legitimate authority. $[\ldots]$ The simultaneity of these two major trials was noted and ex-

3 See Wagner-Pacifici 1986, 132-133; Giovagnoli 2009, 87-88.

4 Brigate Rosse 1978a, 34-35; it.: «[...] unificare il movimento rivoluzionario [...]. [...] il padrino politico e l'esecutore più fedele delle direttive impartite dalle centrali imperialiste.»

5 Piazzesi, Gianfranco, «Stoica dignità», Corriere della Sera, 19.3.1978. 1; it.: «[...] i notabili democristiani non saranno sottoposti al duro dilemma fra la tutela della dignità dello Stato e la morte del proprio leader.»

6 Quoted in Wagner-Pacifici 1986, 242. 
ploited by the press as the constant comparative assessments bolstered the no-negotiators case». ${ }^{7}$

The problem of the exchange of prisoners and with it of the declared incompatibility of the «reason of state» with the possibility of negotiating for the salvation of Aldo Moro began to be discussed again in the media in the final days of March, when the BR began to deliver letters written by Aldo Moro. During his kidnapping, Moro wrote at least 97 messages in letters, last wills and notes. As reconstructed by historian Miguel Gotor, these texts became public at three different moments, within 12 years. The first part of the letters became public during his 55 days of imprisonment; ${ }^{8} \mathrm{a}$ second part was discovered in a BR hideout on October 1, 1978, in via Monte Nevoso in Milan by the special antiterrorist nucleus led by General Carlo Alberto dalla Chiesa; finally a third part was casually discovered on October 9, 1990, behind a panel of chalk by a worker during some of the renovations of the house in the same apartment where the previous finding had taken place. ${ }^{9}$ In the hideout in via Monte Nevoso, a set of texts and notes written by Moro containing the answers to the interrogation to which he was subjected by the kidnappers, as well as a series of reflections on the last thirty years of Italian history was also found. Researchers and journalists refer to such writings with the programmatic name «Memorial». Several studies have been carried out on the texts written by Moro during his imprisonment, and many perplexities have been expressed, though

7 Wagner-Pacifici 1986, 240.

8 Twenty-six letters were definitely delivered by the BR during Moro's 55 days of imprisonment. Sixteen were addressed to political and institutional personalities. One letter was addressed collectively to the DC. The Democratic Christian politician also wrote a letter to Paul VI, which was delivered to the Vatican on April 20, 1978, and made public by Giulio Andreotti on May 23, 1980. Aldo Moro also sent eight letters to his wife Eleonora, which were published for the first time in 1979 in the book L'intelligenza e gli avvenimenti by the Aldo Moro Foundation, and one to Nicola Rana, Moro's university assistant and collaborator from 1955 on. According to Gotor, two other letters, of which the originals are still missing, were certainly delivered because Moro's wife recalls having them in her hands: these are the letters to Luigi Cottafavi, head of the UN's representation for Europe in Geneva and UN Deputy Secretary-General, and that to UN Secretary-General Kurt Waldheim. Thus, according to Miguel Gotor, the letters delivered by the brigades rise to twenty-eight. There are also at least eight letters, which Gotor believes were successfully delivered, despite the fact that recipients have always denied it. See Gotor 2008b, 223-235.

9 See Gotor 2008a, xix-xx. 
not yet fully clarified, on the circumstances in which they were discovered. ${ }^{10}$ In this study, I do not treat the issue of the discovery of the letters and the so-called «Memorial»; instead, I focus specifically on the eight letters published during Moro's imprisonment. ${ }^{11}$

The first of Moro's letters, addressed to Interior Minister Cossiga, became public on March 30, 14 days after the attack in via Fani. The letter was accompanied by the third communiqué, in which the BR wrote that «the practice of revolutionary violence is the only policy that has the real chance to challenge and resolve the antagonistic contradiction that oppos-

10 See Arlati/Magosso 2003; Barbagallo 2008; Bocca 1978; Flamigni 1997; Gotor 2008b; Gotor 2011; Di Sivo 2013.

11 The letters published during the 55 days of Moro's sequestration are the following. The first letter was delivered to the addressee Francesco Cossiga, Interior Minister, on March 29 and published on March 30. The BR submitted the photocopy of the manuscript to the following newspapers: Il Messaggiero, Radio Onda Rossa, Corriere della Sera, Secolo XIX, and Gazzetta del Popolo. The second letter, addressed to Benigno Zaccagnini, Secretary of the DC, was delivered to Nicola Rana (a colleague of Aldo Moro) on April 4 and published on April 5. The BR submitted the photocopy of the manuscript, along with their fourth communiqué and the "Risoluzione della Direzione Strategica delle Brigate Rosse», to the Italian news Agency ANSA and to the newspapers La Repubblica, Secolo XIX, Il Lavoro, Il Messaggero, La Stampa and Gazzetta del Popolo. The third letter was delivered on April 10 and published on April 11. It addressed Paolo Emilio Taviani; however, the Christian Democrat Senator was not really the recipient of the letter but the person to whom the considerations made by Moro in the interrogation are addressed. This is a sort of report given by the prisoner during the interrogations, the only part of the so-called «Memorial» that the BR divulged during and after the capture of Moro. The terrorists provided a photocopy of the manuscript attached to their fifth communiqué to the newspapers La Repubblica, Il Messagero and La Stampa. The fourth letter was delivered to the addressee Benigno Zaccagnini on April 19 and published April 22 in La Repubblica. The fifth letter was found, following an anonymous call, by the editor of the afternoon newspaper Vita sera, together with a copy of the eighth communiqué, on April 24 and published on April 25. The sixth letter was delivered in April to Corrado Guerzoni and Nicola Rana, who handed over a photocopy of the manuscript to Fabio Isman, a journalist from Il Messaggero, who published it on April 29. This letter does not address a specific recipient, but the DC as a whole. The seventh letter was delivered to the addressee Bettino Craxi, Secretary of the Italian Socialist Party, on April 29 and published in the Corriere della Sera by the will of the recipient on May 1. The eighth and last letter that was published during Moro's captivity was delivered to the President of the Italian Republic Giovanni Leone on April 29 and published on May 4 in the main Italian newspapers. See Moro 2008a; Bocca 1978. 
es the metropolitan proletariat and the imperialist bourgeoisie.» ${ }^{12}$ The BR showed little interest in establishing a relationship with the institutions or parties and argued that «the interrogation $[\ldots]$ continues with the full cooperation of the prisoner». Although, as they themselves wrote, the prisoner had asked them if he could «write a secret letter», and they decided to publish it, «since nothing is hidden from the people». ${ }^{13}$ Already in this letter, Moro harshly criticized the line of firmness adopted by the ruling parties, particularly by the DC, and proposed an alternative interpretationcompared to what the newspapers wrote and what the BR probably allowed him to read-of the «reason of state»:

It is out of the question-I was told with great clarity-that I am considered a political prisoner, subjected, as President of the Christian Democracy, to a trial to ascertain my thirty-year responsibility [...]. I have to think that the serious charge that is being made against me is addressed to me as a qualified exponent of Christian Democracy as a whole, in the management of its political line. All of us in the leading group are involved in this and it is our collective action that is under charge and for which I have to answer. In the circumstances described above, beyond any humanitarian considerations, which also cannot be ignored, the reason of State comes into play. Above all, this reason of State in my case means [...] that I am under a full and uncontrolled domain, subjected to a popular trial $[\ldots]$, that I am in this position having all the knowledge and sensibilities that derive from long experience, with the risk of being called or induced to speak in a way that may be unpleasant and dangerous in certain situations. Furthermore, the doctrine that kidnapping must not profit [the kidnappers], [...] does not stand up in the political circumstances, where it causes incalculable and certain damage not only to the person but to the State. The sacrifice of innocents in the name of an abstract principle of legality, while an undeniable state of necessity mandates saving them, is unacceptable. [...] Let God enlighten you for the better, avoiding you get-

12 Brigate Rosse 1978b, 43; it.: «[...] la pratica della violenza rivoluzionaria è l'unica politica che abbia la possibilità reale di affrontare e risolvere la contraddizione antagonistica che oppone proletariato metropolitano e borghesia imperialista.»

13 Brigate Rosse 1978b, 42-43; it.: «[...] l'interrogatorio [...] prosegue con la completa collaborazione del prigioniero. [...] [Il prigioniero] ha chiesto di scrivere una lettera segreta [...]. Gli è stato concesso, ma siccome niente deve essere nascosto al popolo ed è questo il nostro costume, la rendiamo pubblica.» 
ting bogged down in a painful episode, upon which many things could depend. ${ }^{14}$

Moro's message to Interior Minister Cossiga and to the government in general is clear: if you do not work for my release, I may be forced to say things, which could be dangerous for the state and its institutions. ${ }^{15}$ The politician stressed that the trial did not concern his person in particular, but the DC in general. Since the trial was about thirty years of government with his own party in power, the «reason of state» came into play. According to Moro, it was in the interest of the state to work for his release, re-

14 Moro 2008b, 7-8; it.: «È fuori discussione - mi è stato detto con tutta chiarezza che sono considerato un prigioniero politico, sottoposto, come Presidente della D.C., ad un processo diretto ad accertare le mie trentennali responsabilità [...]. Devo pensare che il grave addebito che mi viene fatto, si rivolge a me in quanto esponente qualificato della D.C. nel suo insieme nella gestione della sua linea politica. In verità siamo tutti noi del gruppo dirigente che siamo chiamati in causa ed è il nostro operato collettivo che è sotto accusa e di cui devo rispondere. Nelle circostanze sopra descritte entra in gioco, al di là di ogni considerazione umanitaria che pure non si può ignorare, la ragione di Stato. Soprattutto questa ragione di Stato nel caso mio significa [...] che io mi trovo sotto un dominio pieno ed incontrollato, sottoposto ad un processo popolare [...], che sono in questo stato avendo tutte le conoscenze e sensibilità che derivano dalla lunga esperienza, con il rischio di essere chiamato o indotto a parlare in maniera che potrebbe essere sgradevole e pericolosa in determinate situazioni. Inoltre la dottrina per la quale il rapimento non deve recare vantaggi, discutibile già nei casi comuni, dove il danno del rapito è estremamente probabile, non regge in circostanze politiche, dove si provocano danni sicuri e incalcolabili non solo alla persona, ma allo Stato. Il sacrificio degli innocenti in nome di un astratto principio di legalità, mentre un indiscutibile stato di necessità dovrebbe indurre a salvarli, è inammissibile. [...] Che Iddio vi illumini per il meglio, evitando che siate impantanati in un doloroso episodio, dal quale potrebbero dipendere molte cose.».

15 There was much discussion about what Moro could have revealed to his prisoners, especially concerning NATO-related secrets, and it has been hypothesized that the interrogation of the prisoner aroused many concerns in the political class about the military «secrets» that Moro could reveal. In fact, in the so-called «Memorial» found in via Monte Nevoso, there is a note that could refer to Gladio, the Stay-behind NATO operation in Italy, which in 1978 was still secret and whose existence became public only in 1990, when, just a few weeks after, the second discovery of parts of the «Memorial» was revealed by Prime Minister Giulio Andreotti (see Moro, 1997e). The BR, however, did not use Moro's revelations and said, posteriorly, that they were not able to appreciate the reference to this topic. (see Moretti 2000, 159; Braghetti/Tavella 1998, 109). Their interests, however, were different and the main purpose of the interrogation seemed to be to confirm the relationship between the so-called «Imperialist State of the Multinationals» and the DC (see Giovagnoli 2009, 115-116). 
gardless of humanitarian considerations, that is, regardless of the value of its personal life, because what he might say to the BR would seriously jeopardize the DC and the Italian State. Here Moro's argumentative strategy is totally in line with his speech held in March 1977 in defense of Gui and Tannassi: He appealed to interior minister Cossiga and other party representatives to prevent his trial going ahead before the so-called people's court, in the same way as he had firmly opposed the trial in the squares of the two former ministers. The Moro who wrote this letter was still the party's and state's man, for which the trial of his person was equivalent to a trial of his own party, which in turn was equivalent to a trial of the state. It is significant that Moro, as he had said that Gui did not have to be a victim to immolate himself for the welfare of the party, warned the government and his party not to sacrifice him in the name of an abstract principle of legality. ${ }^{16}$ In other words, Moro drew attention to the scapegoat mechanism-the sacrifice of a single victim acting as a substitute for the (alleged) guilt of a collective-and pointed to two reasons, one politico-juridical, the other politico-ethical, for not allowing the mechanism to be realized: first, because the reason of state required negotiations for the liberation of the prisoner, since his revelations in an interrogation could have had negative consequences for the party and the state and, secondly, because the state would fail to fulfill its mandate to guarantee the life and wellbeing of a citizen, especially if it was an innocent citizen. In this first letter, negotiations for

16 Legal arguments against the possibility of the exchange of prisoners had triggered the debate on the question of firmness and negotiations since the first day of the kidnapping. As early as on March 16, Interior Minister Francesco Cossiga and Minister of Justice Francesco Paolo Bonifacio immediately excluded the possibility of an exchange. The press stressed that the existing legislative system did not leave any discretion to the executive in granting bail to prisoners awaiting trial, such as Curcio and other members of the BR under trial in Turin (see Conso, Giovanni, «Scambio Moro-BR nonsenso giuridico», La Stampa, 20.3.1978, 2). In addition, the judgment of the Court of Cassation in relation to the Sossi case (the magistrate Mario Sossi was kidnapped and then released by the BR in 1974; on this occasion, the terrorists had requested, without success, the exchange of prisoners) and the Legge reale of 1975 also precluded the judiciary from granting provisional freedom in cases of serious crimes. The Minister of Justice had the power to suspend the execution of the sentence, but only if the sentence was already definitive and only under precise conditions provided for by law. In short, it was almost impossible to legally accept an exchange request without a specific legislative intervention to change standards. It is likely that Aldo Moro came to know or imagined that this kind of argument would have been brought in favor of the line of firmness, and for this reason he warned Cossiga not to insist on «abstract principles of legality» (see Giovagnoli 2009, 88). 
Moro's liberation are described as the only way to guarantee the wellbeing of both the collective and the individual.

The argumentative strategy remained largely the same in the second letter that became public, on April 5, which was addressed to Benigno $\mathrm{Za}$ ccagnini. Here Moro warned the Secretary of the DC to «assume the responsibilities that are both individual and collective», reinforced his status as a "political prisoner» and urged the party not to discuss in terms of «abstract law (though there are norms about the state of necessity) but on a level of human and political openness, if it is not possible with realism to give the only possible positive solution to my situation, proposing the liberation of prisoners on both sides, attenuating to the attention in the context of a political phenomenon.» ${ }^{17}$ Otherwise, he added, «the inevitable consequences will fall on the Party and the people.» ${ }^{18}$ The prisoner stressed once more that he was being charged for responsibilities that should be shared collectively by the whole party. He again emphasized the necessity of a buman and political solution and drew attention to the state of necessity, provided for by the Italian criminal code Art. 54, according to which a person should not be held liable for his or her actions, in relation to a crime that was committed to save himself or herself or others from actual danger of serious injury. ${ }^{19}$

The first two letters undoubtedly had some content written on the indications of the terrorists, and revealed a situation of partial and distorted information about what was happening outside the prison, a situation in which Moro depended on how much the BR wanted to communicate with him. They cannot be considered devoid of his specific intentions. As the historian Guido Formigoni writes, Moro was convinced that «his abduction had drastically crushed the state's order and that only his release could have healed the wound, while a rigid refusal of contacts would simply rep-

17 Moro 2008c, 13-14; it.: «[...] assumere le responsabilità che sono ad un tempo individuali e collettive [...]. Sono un prigioniero politico. [...] Si discute qui, non in astratto diritto (benché vi siano le norme sullo stato di necessità), ma sul piano dell'opportunità umana e politica, se non sia possibile dare con realismo alla mia questione l'unica soluzione positiva possibile, prospettando la liberazione di prigionieri di ambo le parti attenuando l'attenzione nel contesto proprio di un fenomeno politico.»

18 Moro 2008c, 14; it.: «[...] le inevitabili conseguenze ricadranno sul Partito e sulle persone.»

19 Article 54 of the Italian Criminal Code states: «Non è punibile chi ha commesso il fatto per esservi stato costretto dalla necessità di salvare sé o altri dal pericolo attuale di un danno grave alla persona, pericolo da lui non volontariamente causato, né altrimenti evitabile, sempre che il fatto sia proporzionato al pericolo.» 
resent a formal defense of a fake order already failed. [...] Certainly, the idea that he syielded to the jailers in a human and anti-heroic attempt to save his own life must be discarded [...]. Simply, once again he [...] tried to conduct politics in the name of his ideals and his vision of things. ${ }^{20}$ When Moro wrote these letters, he could not have known that the BR would have made them public and certainly could not have imagined with how much monotony, unity and repetition most parts of the media, political parties and various public personalities would react to his letters. From March 30 onwards, the process of depoliticizing Aldo Moro-the operation «Moro is not Moro»-began.

On April 10, the BR published the fifth communique and the third «letter» by Moro, which is actually to be considered a part of the «Memorial», in which the prisoner harshly criticized the Christian Democrat politician and Senator Paolo Emilio Taviani. In fact, he had written a very angry passage about the former minister, who a few days earlier had publicly denied that Moro himself, at the time of the kidnapping of the magistrate Mario Sossi, had spoken against the refusal to engage in negotiations (in the letter to Zaccagnini published on April 5, Moro had written that he had always been in favor of negotiations and that he had said this to Taviani and Gui during Sossi's captivity). We thus know that, from a given moment on, Moro was aware that some of his letters had become public. The BR wanted to demonstrate that the interrogation was proceeding and that the prisoner was making revelations and expressing judgments that could put the government and the DC in serious difficulty. ${ }^{21}$ From this moment on, the general perception was that Moro's writings (the writings of the prisoner during the trial and perhaps even any documents he had kept in the bags which he had with him on the day of the kidnapping) could play an important role. These materials had become part of a complex form of management of the hostage: Moro and his writings became a «double hostage».22 In the passage on Taviani, Moro again referred to both political

20 Formigoni 2016, 354.

21 See Formigoni 2016, 356.

22 According to Senator Giovanni Pellegrino, Chairman of the Commissione parlamentare d'inchiesta sul terrorismo in Italia e sulle cause della mancata individuazione dei responsabili delle stragi from 1996 to 2001, after the publication of the text on Taviani «the institutional apparatuses, not only Italian, but also [of other] western and eastern [countries], began to perceive that Moro was saying or could say things of great interest to the BR. That is to say, when they understood that the Red Brigades had a «double hostage in their hands: Moro and the secrets he knew» (Fasanella/Sestieri/Pellegrino 2000, 165; see also Gotor 2008b, 272). 
and humanitarian reasons for negotiations, and recalled that other countries had shown more «reasonable flexibility» in managing similar situations. Moro was questioning the reasons for Taviani's denial and for such inflexibility on the part of the government and the political parties, and wondered if there was maybe foreign «influence»: «Is there an American and German influence, perhaps, in keeping firm against me?» ${ }^{23}$

On April 15, the BR announced that the trial was over and that the prisoner had been sentenced to death. In the sixth communiqué, they declared that Moro had said nothing that the "proletarians» did not already know. This statement was probably only formal and aimed at causing a reaction in the parties and among public opinion. However, the decision was probably communicated to the prisoner. During this time, he wrote a series of letters, which were not published during his imprisonment, that were very affectionate and addressed to family and friends. He instructed his wife, Eleonora, to freely decide on the funeral honors and added: «Take care of yourself and try to be as calm as you can. We will meet again. We will be together again. We will be together in love again.» ${ }^{24}$

On April 17, Amnesty International issued a press release, reporting that people close to Aldo Moro and his family had contacted the organization and that it was willing to try to get in touch with the kidnappers to pave the way for negotiations. Amnesty International reinforced its opposition to the death penalty, arguing that executions for political coercion, both by governments and by anyone else, are equally unacceptable. ${ }^{25}$ The Secretariat of the DC defined Amnesty International's position very positively, stating that it had responded to the wish expressed by the party in the days before. Caritas Internationalis also took a similar position, saying it was available to intervene with its own humanitarian methods.

On April 18, a false communiqué announced the death of the DC leader by «suicide», indicating the Lago della Duchessa (the Duchess Lake), in the mountains of the province of Rieti, as the place where the body of Moro could be found. Security forces made this false communiqué with the help of a forger; it was a mise-en-scène constructed, according to some, to force the $\mathrm{BR}$ to prove that the hostage was alive and, according to others, to test

23 Moro 2008e, 43; it.: «Vi è forse, nel tenere duro contro di me, un'indicazione americana e tedesca?»

24 Moro 2008g, 63; it.: «Tu curati e cerca di essere più tranquilla che puoi. Ci rivedremo. Ci ritroveremo. Ci riameremo.»

25 See Imperi 2016, 92. 
the reactions that Moro's death would produce among the public. ${ }^{26}$ Moro himself, in a note in the "Memorial», described the fake communiqué and the reaction of the media as a «big macabre edition on my execution.» ${ }^{27}$ On April 20, the BR published the seventh, and real, communiqué, in which they accused «Andreotti and his accomplices» of the «macabre miseen-scène. ${ }^{28}$ The communiqué was accompanied by the second Polaroid photo, where Moro was pictured with a copy of the April 19 edition of $L a$ Repubblica (see figure 4). In this communiqué, the kidnappers openly took positions for the «liberation of Communist prisoners» for the first time, presenting it as the only chance for Moro's salvation, while also calling an ultimatum of 48 hours. $^{29}$

26 See Lofoco 2015, 99-102; Flamigni 1997, 38, 335; Manca 2008, 117; Biscione 2012, 59-60.

27 Moro 1997b, 319; it.: «[...] macabra grande edizione della mia esecuzione.» It is interesting to note that in this brief text Moro criticized the Italian press and journalism in general, observing that the country was dominated by five or six newspapers, which in the days of his captivity again demonstrated «how easy it is to monopolize the market of opinions» [it: «[...] come sia facile chiudere il mercato delle opinoni»].

28 Brigate Rosse 1978c, 126; it.: «[...] Andreotti e i suoi complici [...] macabra messa in scena.»

29 Brigate Rosse 1978c; it.: «[...] liberazione di prigionieri comunisti.» 


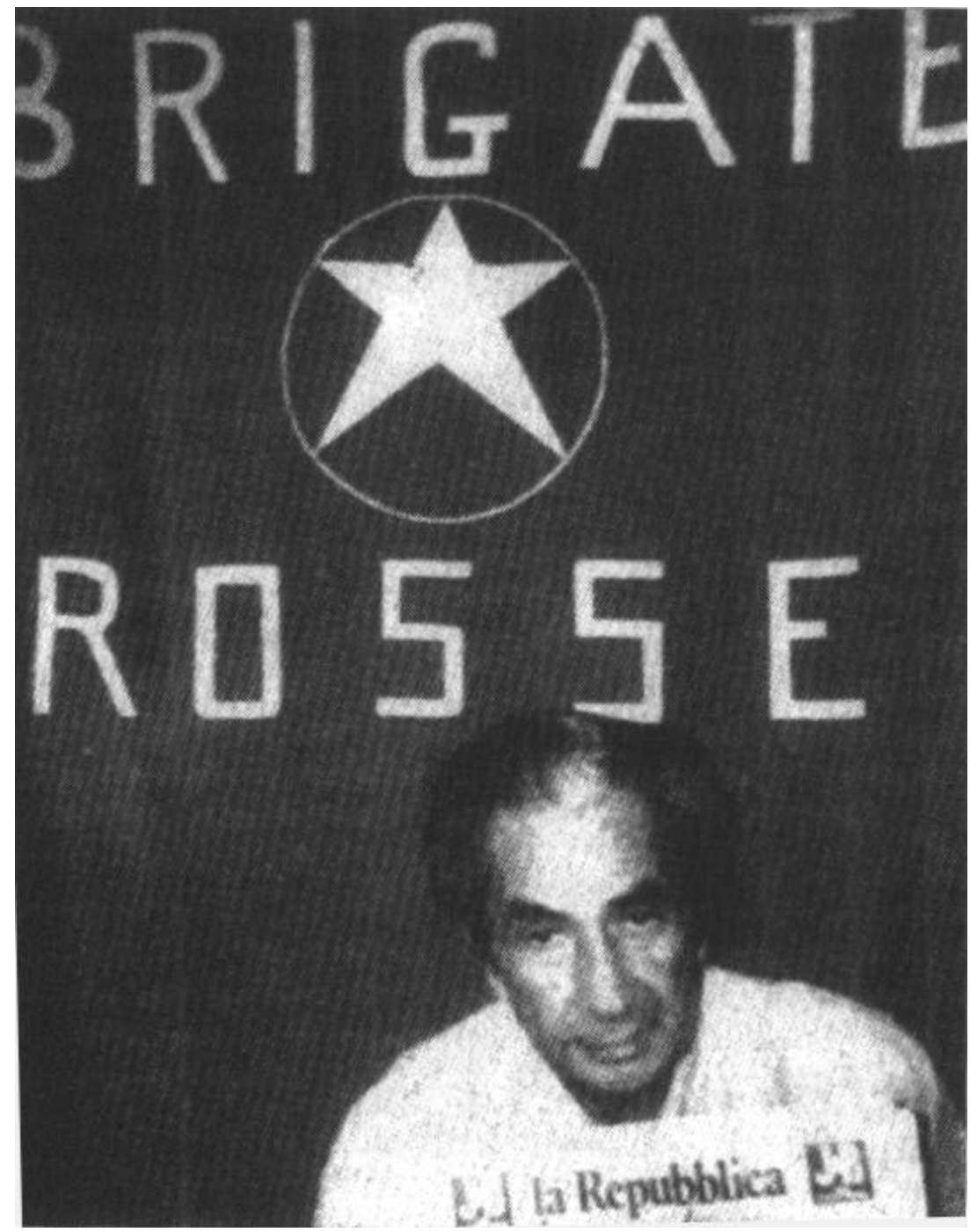

PICTURE 4: The Polaroid attached to the seventh communique of the Red

Brigades showing Aldo Moro with a copy of the newspaper La Repubblica of April 19, 1978.

After the diffusion of the seventh communiqué, the debate on firmness vs. negotiation flared up again, and a minority "party for negotiation» began to oppose the "party of firmness». As early as on April 19, a group of peo- 
ple «close to the family» had written an appeal published in Lotta Contin$u a$, claiming that «every man has the right to life» and asking «a non-fideist and fetishist defense of the $[\ldots]$ prerogatives and functions» of the state. ${ }^{30}$ Among the many signatories there were leaders of Azione Cattolica, the Associazioni Cristiane Lavoratori Italiani (ACLI) and the Federazione Universitaria Cattolica Italiana (FUCI), unionists, priests, some bishops, some leftists, Italian intellectuals such as Norberto Bobbio, foreign intellectuals such as Heinrich Böll and Pauolo Freire, and theologians such as MarieDominique Chenu and Jürgen Moltmann. ${ }^{31}$ On April 20, the Secretary of the PSI spoke in favor of the negotiations. Moro himself considered the position very important and wrote to Craxi and several other people in the following days. ${ }^{32} \mathrm{He}$ also wrote a second letter to the Pope (the first one was written around April 8; though scholars believe it was delivered, it was not disclosed during Moro's captivity), asking him again to adopt a position in favor of negotiations. This letter was not made public during Moro's captivity. ${ }^{33}$

During those days, there were at least two attempts, which were however destined to fail, to open negotiations with the BR. Paul VI initiated the first attempt and, through his secretary Monsignor Pasquale Macchi, mobilized all of the responsible prison chaplains to try and enter into contact with the BR. The hypothesis was to offer a large sum of money, maybe 10 billion lire. ${ }^{34}$ Apparently, the government tolerated the initiative, since all party leaders gave the green light to Andreotti. ${ }^{35}$ At some point, linking this agreement with the possibility of exile for a member of the BR not yet imprisoned was even hypothesized. However, the initiative failed because of internal divisions in the Roman Curia and above all the inability to build an effective channel of communication with the kidnappers. ${ }^{36}$ On the morning of April 22, Radio Vaticana interrupted the programs to read Paul VI's appeal to the "men of the BR». A special edition of L'Osservatore Romano published the passage of the appeal, in which the Pope asked the BR to release Moro «simply, without conditions». ${ }^{37}$ According to some in-

30 Lotta Continua, «Un appello», 19.4.1978, 1; it.: «[...] per ogni uomo il diritto alla vita $[\ldots]$ una difesa non fideistica e feticista delle [...] prerogative e funzioni.»

31 See Lotta Continua, «Le adesioni all'appello», 20.4.1978, 1.

32 See Formigoni 2016, 364-365.

33 See Moro 2008h, 68-69.

34 See Formigoni 2016, 364-365.

35 See Giovagnoli 2009, 137.

36 Forlani 2014.

37 Quoted in Imperi 2016, 108. 
terpretations, this formulation was added to the message, which the Pope wrote straight off during the night, on the advice of the government and especially of Andreotti. That Moro was aware of the Pope's message is demonstrated by a letter to his wife, delivered on May 5, in which he wrote, in the certainty that he would soon die: «The Pope did ever so little; perhaps he will feel guilty.» ${ }^{38}$ The second attempt to open negotiations was initiated by some exponents of the Socialist Party along with the leaders of Autonomia Operaia. The hypothesis was to make a «humanitarian act» of state clemency for a detainee to pressurize the kidnappers into liberating Moro. But this initiative was severely criticized by the press and representatives of both the PCI and the DC. ${ }^{39}$

On the same day as the BR published their seventh communiqué, they delivered three of Moro's letters to Moro's wife: one, already mentioned, was adressed to the Pope, one to his wife and one to Zaccagnini. In the latter, which was published in the newspaper La Repubblica on April 22 as requested by Moro, the prisoner radicalized his appeal:

Is it possible that you all agree on wanting my death for an alleged reason of State as some lividly suggest, almost as a solution to all the problems of the country? [...] If this crime would come to pass, it would open up a terrible spiral that you could not face. You would be overwhelmed. It would open a rift with the humanitarian forces that still exist in this Country. It would open, unmistakably, despite first appearances, a fracture in the party that you could not contain. [...] I tell you clearly: for my part, I will not absolve and I will not justify anyone. [...] I remind you, and I remind all the political forces, that the Republican Constitution, as the first sign of novelty, has abolished the death penalty. With your own inertia, insensitivity and blind respect for the reason of State, by doing nothing to prevent [the death penalty], you would reintroduce it, as a matter of fact, into our legislative system. Here, in the democratic Italy of 1978, in Beccaria's Italy, as in past centuries, I am condemned to death. That the sentence is executed depends on you. [...] If you do not do something, it will be written as a dreadful page in the history of Italy. My blood would fall on you, on the party, the Country. [...] May God enlighten you, dear Zaccagnini, and enlighten the friends to whom I address a message of despair. Do not think of the few cases in which it [the State] has done right [fol-

38 Moro 2008m, 178; it.: «Il Papa ha fatto pochino. Forse ne avrà scrupolo.»

39 See Formigoni 2016, 365; Silj 1978, 129-158. 
lowing the rules of law], but of the many resolved according to the rules of humanity [...]. If pity prevails, the Country is not finished. ${ }^{40}$

The crucial point in these statements is not so much the explicit and radical rejection of the line of firmness, but rather the fact that Moro himself used an anti-sacrificial rhetoric, which was a sort of counterpart to the one that emerged after his death. In his representation of the event-moreover, of an event that had yet to happen!- - the state was identified as the agent of the sacrificial action. Moro here took the roles of a judge and of an accuser. This line of conduct by the government and the ruling parties was judged incompatible with the rules of humanity. The core of these values was, for Moro, piety. Thus, in his letters a distinction and a rupture emerged between the legal, abstract principles of the state and another kind of higher values. Only if the state gave up the former and accepted the latter would the country be safe. According to the Christian Democrat politician, the law could not be the foundation of the legitimacy of the Italian State, but only the extra-legal, universal value of the sanctity of human life. Using the formula «my blood shall be upon you», an evident allusion to the BibleLeviticus 20-Moro cursed all those who continued to support the line of firmness. The sacrifice wanted by the government here becomes sacrilege, an act that desacralizes and delegitimizes its political authority.

40 Moro 2008i, 72; it.: «È possibile che siate tutti d'accordo nel volere la mia morte per una presunta ragion di Stato che qualcuno lividamente vi suggerisce, quasi a soluzione di tutti i problemi del paese? [...] Se questo crimine fosse perpetrato, si aprirebbe una spirale terribile che voi non potreste fronteggiare. Ne sareste travolti. Si aprirebbe una spaccatura con le forze umanitarie che ancora esistono in questo Paese. Si aprirebbe, insanabile, malgrado le prime apparenze, una frattura nel partito che non potreste dominare. [...] Io lo dico chiaro: per parte mia non assolverò e non giustificherò nessuno. [...] Ricordate, e lo ricordino tutte le forze politiche, che la Costituzione Repubblicana, come primo segno di novità, ha cancellato la pena di morte. Così, cari amici, la si verrebbe a reintrodurre, non facendo nulla per impedirla, facendo con la propria inerzia, insensibilità e rispetto cieco della ragion di Stato che essa sia di nuovo, di fatto, nel nostro ordinamento. Ecco, nell'Italia democratica del 1978, nell'Italia del Beccaria, come in secoli passati, io sono condannato a morte. Che la condanna sia eseguita, dipende da voi. [...] Se voi non intervenite, sarebbe scritta una pagina agghiacciante nella storia d'Italia. Il mio sangue ricadrebbe su voi, sul partito, sul Paese. [...] Che Dio ti illumini, caro Zaccagnini, ed illumini gli amici ai quali rivolgo un disperato messaggio. Non pensare ai pochi casi nei quali si è andati avanti diritti, ma ai molti risolti secondo le regole dell'umanità e perciò, pur nelle difficoltà della situazione, in modo costruttivo. Se la pietà prevale, il Paese non è finito.» 
Moro was not the only one to refer to the sanctity of human life. In fact, this «root paradigm» was also handpicked by the Socialist Party and the various groups on the Italian radical left. ${ }^{41}$ Communists and Christian Democrats also alluded to this value, when they gave their verbal approval to actions they ambiguously referred to as «humanitarian initiatives» taken to save Moro. But this approval was always followed by the specification that nothing, not even the intrinsic value of Moro's life, could cause the government to give in to the request for negotiations. On the contrary, the advocates of negotiations emphasized the relevance of the sanctity of human life by claiming that they were against any form of the death penalty. Two days after the publication of the appeal for the liberation of Moro, Lotta Continua reaffirmed its opposition to the line of firmness arguing that

the killing of Aldo Moro is against all the reasons for the struggle in which we are engaged. Because we are opposed to the death penalty, wherever it is applied and however it is justified [...]. Because we are radically and irreducibly averse to this state, which in death, in war and in fear seeks to force what it does not have, the authority it does not have, the legitimacy that it does not have. [...] Why has no newspaper published the text of the appeal [...]? [...] Here is the paradox of a state that, while delegating humanitarianism to the 〈operating institutions〉 such as the Red Cross or Amnesty International, has no other concern than that $[. .$.$] to hold the family of Aldo Moro hostage, to impose on$ individual exponents the role of Abraham sacrificing Isaac. ${ }^{42}$

Like Moro, Lotta Continua described the line of firmness as a death sentence, which transforms the people involved into sacrificers. The comparison with the sacrifice of Isaac has the function of highlighting the sacrilegious nature of the line of firmness. The state and the parliamentary par-

41 See Wagner-Pacifici 1986, 182.

42 Manetti, Clemente, «Scandalo e silenzi», Lotta Continua, 20.4.1978, 1; it.: «L'uccisione di Aldo Moro è contro tutte le ragioni della lotta in cui siamo impegnati. Perché siamo contro la pena di morte. Dovunque sia applicata e comunque venga giustificata. [...] Perché siamo radicalmente e irriducibilmente e avversi a questo stato, che nella morte, nella guerra e nella paura cerca la forza che non ha, l'autorità che non ha, la legittimazione che non ha. [...] Perché nessun giornale, nessuno, ha pubblicato il testo dell'appello [...]? [...] Qui sta il paradosso di uno stato che, mentre delega l'umanitarismo alle istituzioni addette come la Croce Rossa o Amnesty International, altra preoccupazione non ha se non quella [...] di tenere in ostaggio la famiglia di Aldo Moro, di imporre ai singoli esponenti il ruolo di Abramo che sacrifica Isacco.» 
ties are considered illegitimate, because they did not act according to the moral imperative that no life should be spent. The state, unlike God, is willing to sacrifice one of its own children. Interestingly, one of the journalists from Lotta Continua demonstrated that he had perfectly understood the mechanism of martyrological representation when he wrote that «in Christian Democracy, a corpse is being sought to be martyred - the first martyr of the party», adding further: «The BR [...] should realize that [if they kill Moro] they would only repeat an April 18, 1948.»43 The journalist referred here to the elections of April 1948, when the DC gained extraordinary electoral success. In other words, the journalist predicted that the possible killing of Moro would have had the effect of reinforcing the DCwhat actually happened in the administrative elections of May 14 and 15, 1978, less than a week after Moro's death (by the way, we are again facing a prefiguration, which in this case is twofold: on the one hand, there is the analogy between Moro and Isaac and, on the other hand, between the political situation of April 18, 1948 and that of April 18, 1978). However, the lucid analysis by the Lotta Continua journalist did not prevent Lucio Lombardo Radice from declaring in L'Unità just three days later that since

Christian martyrs refused to save their lives by [refusing] to burn incense in offering to divinized emperors; [similarly], citizens of the Free Italian Republic [...] cannot recognize the dignity and equality of interlocutors to the enemies of their democratic institutions, in order to avoid the Republic's ruin. ${ }^{44}$

There is something bitterly ironic about a Communist declaring in a Communist newspaper that the citizens of the Republic have to act similarly to Christian martyrs, in order to defend the Republic. Especially when one considers that Moro was transformed into a martyr of both the DC and the Italian State and, above all, given that the one who was about to die, refused to assume the role of a martyr. It is total confusion of languages.

On April 24 the BR issued their eighth communiqué in which they demanded the release of 13 detainees, including members of the terrorist

43 Lotta Continua, «In cerca di un martire», 18.4.1978, 1; it.: «Nella DC si cerca un cadavere da rendere martire - il primo martire del partito", «Le BR [...] si rendano conto che non farebbero altro che ripetere un 18 aprile 1948.»

44 L'Unità, «Una dichiarazione di Lucio Lombardo Radice», 21.4.1978, 3; it.: «I martiri cristiani rifiutavano di salvare la loro vita bruciando incensi agli imperatori divinizzati; I cittadini della libera Repubblica italiana [...] non possono riconoscere dignità e parità di interlocutori ai nemici delle loro istituzioni democratiche, proprio per non pagare il prezzo della rovina della Repubblica.» 
group XXII Ottobre, the founders of the BR and other members of the organization recently arrested and on trial in Turin. The communiqué clearly stated that only the exchange of "political prisoners", «only an immediate and positive response by the DC and its government, unequivocally given and concretely implemented, will allow the release of Aldo Moro». It also stressed that «humanitarian appeals» as well as the government's attempt to involve Caritas in possible mediation were useless. ${ }^{45}$ In short, what they wanted was not money, not secret negotiations: what they sought most of all was official recognition as a political organization with a legitimate cause, and they understood the exchange of prisoners as a way of obtaining this recognition: «the paradoxical situation of the BR was precisely what they were depending upon, they were rejecting the illegitimate to bring about their own legitimation.» ${ }^{46}$ When captured by the police, the BR members always declared themselves political prisoners, as if they expected that the relevant Geneva Conventions would apply to their cases. They knew that in cases of a state negotiating with enemies the contending parties usually appealed to the generally recognized laws of war, as provided by the combined declarations of the various Geneva Conventions. ${ }^{47}$ The paradox of the BR's strategy thus resided in the fact that they wanted to gain political recognition on the basis of international conventions signed by states, which they considered illegitimate. They wanted the state to recognize the state of war and to treat the detained members of their organization as prisoners of war.

Along with the eighth communiqué, the BR issued a letter by Moro, again addressed to Zaccagnini, which was published in many newspapers on April 25. In this letter, Moro wrote that initiatives of «generic humanitarian character» served no purpose and that "politically the theme is not that of human piety, but of the exchange of some prisoners of war (war or guerrilla warfare, as you want), [...] as highly civilized countries (almost universally) do, where exchange is practiced not only for objective humanitarian reasons, but for the salvation of innocent human life. ${ }^{48}$ For Moro, therefore, the salvation of the individual was not a humanitarian issue

45 Brigate Rosse 1978d, 132; it.: «[...] prigionieri politici [...] solo una risposta immediata e positiva della DC e del suo Governo, andata senza equivoci, e concretamente attuata potrà consentire il rilascio di Aldo Moro.»

46 Wagner-Pacifici 1986, 154.

47 See Wagner-Pacifici 1986, 155-175.

48 Moro 2008j, 99; it.: «[...] generico carattere umanitario [...] politicamente il tema non è quello della pietà umana, pur così suggestiva, ma dello scambio di alcuni prigionieri di guerra (guerra o guerriglia come si vuole), come si pratica in paesi 
(therefore, purely moral), but a political choice. The move touched on a topic of important political philosophy, as he argued, the state had the task of safeguarding an individual's life. He thus tried to re-politicize his own «bare life», to reintroduce it into the profane sphere of politics. We will come back to this point later. As in the previous letter, Moro again assumed the role of the judge, especially accusing, not to say cursing, the DC:

I repeat: I will not absolve nor justify anyone. No political or moral reason can push me to do so. [...] Christian Democracy should not believe that its problem finishes with the elimination of Moro. I will still be here as an irreducible point of contention and alternative, to prevent others doing with Christian Democracy what is being done today. For this reason, for an obvious incompatibility, I ask that neither State authority nor party men participate in my funeral. ${ }^{49}$

These are the words of a man who had already come to know he would be dead soon. Saying «I will still be here», Moro presented himself as a political and moral authority who would survive his own death, an authority that would be the reference point for generations to come. But it is not the authority of a martyr who wants to be imitated; on the contrary, it is the authority of someone who opposed a certain kind of hegemonic discourse, of someone who has attempted to subvert a certain kind of representation of the event and tried to offer an alternative kind of representation.

On April 29, Il Messaggero exclusively published a letter from Moro, this time addressed to the DC as a whole. Here Moro seems to have already accepted that he will die. The text has the character of a testament:

[...] even with my many faults, I think I have lived with hidden generosity and fragile intentions. I die, if my party decides so, in the fullness of my Christian faith and in the immense love for an exemplary family that I love and hope to watch from heaven. [...] But this bloodbath will not be good for Zaccagnini, nor for Andreotti, neither for

altamente civili (quasi la universalità), dove si scambia non solo per obbiettive ragioni umanitarie, ma per la salvezza della vita umana innocente.»

49 Moro 2008j, 100; it.: «Ripeto: non assolverò e non giustificherò nessuno. Nessuna ragione politica e morale mi potranno spingere a farlo. [...] Non creda la D.C. di avere chiuso il suo problema, liquidando Moro. Io ci sarò ancora come un punto irriducibile di contestazione e di alternativa, per impedire che della D.C. si faccia quello che se ne fa oggi. Per questa ragione, per una evidente incompatibilità, chiedo che ai miei funerali né autorità di Stato né uomini di partito.» 
the DC nor for the Country: each one will bear their own responsibility. I do not want around me, I repeat, the men of power. I want close to me those who really loved me and will continue to love me and pray for me. If all this is decided, God's will will be done. But no one responsible can hide behind the fulfillment of an alleged duty. Things will be clear, will all be clear soon. ${ }^{50}$

Here it is no longer the politician Aldo Moro who speaks, but the man and the Christian Aldo Moro. He expresses his hope of getting to heaven and repeats his last will with regard to his funeral. Power and love are the two opposing metaphysical forces the prisoner seems to see at work in the world: only one of them, he declares, has the right to participate in the rite he hopes will lead him to the other world. In a letter that was not published and was found only as a copy of a manuscript in October 1990, Moro wrote to his wife:

Dearest, I would like to have the faith that you and Grandma have, to imagine the choirs of angels that will lead me from earth to heaven. But I'm a lot cruder. I have only understood in these recent days what it means to add our own suffering to the suffering of Jesus Christ for the salvation of the world. And now, my sweetest bride, I embrace you with all my heart and hold on to you with our beloved sons and daughters, hoping to stay with you forever. A tender kiss, Aldo. ${ }^{51}$

This is the only explicit reference to the Passion of Christ that we can find in the letters by Moro though, in another letter to his wife, Aldo Moro had

50 Moro 2008k, 143-144; it.: «[...] pur con le mie tante colpe, credo di avere vissuto con generosità nascoste e delicate intenzioni. Muoio, se cosi decide il mio partito, nella pienezza della mia fede cristiana e dell'amore immenso per una famiglia esemplare che io adoro e spero di vigilare dall'alto dei cieli. Ma questo bagno di sangue non andrà bene né per Zaccagnini, né per Andreotti, né per la DC, né per il Paese: ciascuno porterà la sua responsabilità. Io non desidero intorno a me, lo ripeto, gli uomini del potere. Voglio vicino a me coloro che mi hanno amato davvero e continueranno ad amarmi e pregare per me. Se tutto questo è deciso, sia fatta la volontà di Dio. Ma nessun responsabile si nascondi dietro l'adempimento di un presunto dovere. Le cose saranno chiare, saranno chiare presto.»

51 Moro 2008f, 60; it.: "Carissima, vorrei avere la fede che avete tu e la Nonna, per immaginare i cori degli angeli che mi conducano dalla terra al cielo. Ma io sono molto più rozzo. Ho solo capito in questi giorni che vuol dire che bisogna aggiungere la propria sofferenza alla sofferenza di Gesù Cristo per la salvezza del mondo. [...] Ed ora dolcissima sposa, ti abbraccio forte con tutto il cuore e stringo con te i nostri figli e i nipoti amatissimi, sperando di restare con voi cosi per sempre. Un tenerissimo bacio, Aldo.» 
already used the term «Calvary». ${ }^{52}$ Faced with an awareness of death, Aldo Moro tried to make sense of the events through the prefiguration of the Passion. Thus, even Moro was convinced, at some point, that it is necessary to add our own suffering to the suffering of Jesus Christ. Does this imply that in the end Aldo Moro agreed to assume the role of a martyr? Only if we could ask him, could we give a definitive answer to that question. But one thing is certain: if this is really a case of acceptance of martyrdom, it is certainly not martyrdom for the state. In fact, Moro did not write that it is necessary to suffer for the salvation of the Italian State, or of the Italian Republic, but for the salvation of the world. If the concept of martyrdom here plays some role then it is a concept that rejects any kind of theological-political instrumentalization.

\subsection{Reduction to Bare Life}

We have so far seen that Aldo Moro refused to adopt the role of state martyr. The Italian public became aware of that on March 30, when Moro's first letter was published, though he did not know it. As Wagner-Pacifici notes, «many of the protagonists, including the Communists, the Christian Democrats, the established mass media, and the Catholic church hierarchy, would have preferred an eventual self-sacrifice on the part of Aldo Moro. In this version, Moro would have recognized his symbolic destiny and willingly have donned the martyr's mantle.. ${ }^{53}$ This is exactly what many social players wrote and hoped for before the publication of the first letter. But from March 30 onwards, Moro's voice from the «people's prison» hindered the martyrological representation and narrative, which until then had been forming and consolidating itself smoothly. As we have seen, Moro had already been discursively excluded from the profane sphere of political life, and his transition to the community of saints was considered only a matter of time. Moro had already been consecrated, had already become homo sac$e r$, and as such he could not return to life in the profane sphere of public and political life. But the voice that rose from the «people's prison» contrasted with this kind of representation, showing that Moro was not only alive but still intent on participating in political life. At this point, it became necessary to develop strategies that could undo that voice. Thus be-

52 Moro 2008d, 31.

53 Wagner-Pacifici 1986, 218. 
gan the process of removing the public and political character of Aldo Moro.

On March 30, the newspapers seemed to all agree: the letter to Cossiga was written under conditions of torture, under the effect of drugs, or both. L'Unità wrote that the letter «comes from the bottom of a den, from the darkness of a cell where a man with no chance of defense, isolated from any contact that is not that of the kidnappers, in their complete mercy, has been suffering a physical and psychological inhumane siege for days.» ${ }^{54}$ The following day, in the editorial of the same newspaper one could read that

No one had any doubts. The letter by Moro [...] was written in a state of moral and physical constraint that removes any authenticity and hence every meaning and value to things that are said [inside]. And that is not the case only for yesterday's correspondence [...], it is also true for other documents compiled with the same calligraphy that, unfortunately, we still have to expect from the kidnappers. ${ }^{55}$

The editorial of the Corriere della Sera argued similarly, asking rhetorically:

Who wrote this letter? Did Aldo Moro, president of the Christian Democracy, statesman, the largest mediator and inspiration for Italian politics, cautious strategist, write it? Or did Aldo Moro write it, but was reduced to impotence by cruel imprisonment, isolated, perhaps stunned in his own psychic control by drugs or something else?56

Newspapers began to distinguish between Moro the politician and Moro the prisoner, as if they were not the same person. The Moro that wrote this

54 Gambescia, Paolo, «Una tragica lettera di Moro», L'Unità, 30.3.1978, 1; it.: «[...] arriva dal fondo di un covo, dal buio di una cella dove un uomo senza possibilità di difesa, isolato da qualsiasi contatto che non sia dei rapitori, in loro completa balia, subisce ormai da giorni un assedio fisico e psicologico inumano.».

55 L'Unità, «Fermezza», 31.3.1978, 1; it.: «Nessuno ha avuto dubbi. La lettera di Moro $[\ldots]$ è stata scritta in uno stato di costrizione morale e fisica tale da togliere ogni autenticità e quindi ogni significato e valore alle cose che vi si dicono all'interno. E ciò non vale solo per il messaggio di ieri [...], vale anche per altri documenti compilati con la stessa calligrafia che, purtroppo, dobbiamo ancora aspettarci dai rapitori.»

56 Corriere della Sera, «Ma la Repubblica non sarà mai loro prigioniera», 30.3.1978, 1; it.: "Chi a scritto questa lettera? L'ha scritta Aldo Moro, presidente della DC, statista, massimo mediatore e ispiratore della politica italiana, cauto stratega? $\mathrm{O}$ l'ha scritta ancora Aldo Moro, ma ridotto all'impotenza da una crudele prigionia, isolato, forse stordito da droghe o altro nel suo stesso controllo psichico?» 
letter could not have been the one that they all knew and, above all, he could not be the political figure that in the days before most newspapers had praised as the best or the most important Italian statesman. Moro's letter was even compared to political suicide: «In short, Moro, in exchange for his physical salvation, would subscribe, with an unacceptable distinction between people kidnapped by common criminals and people kidnapped by political criminals, his political suicide. And that is exactly what prevents us from accepting or even believing [what is written in the letters].» ${ }^{57}$

Also, the issue of calligraphy-friends, family, and acquaintances as well as experts had confirmed immediately that it was actually that of Morowas debated over and over in articles. The most interesting thing for this study (and which seems to come from a grotesque novel) is an article on the front page of the Corriere, in which an «expert graphologist» interprets the letter to Cossiga as follows: «In writing the word legality, Moro flipped the pen up as if the term had been imposed on him. So I deduce that, instead, he intends to sacrifice himself and that he rejects the exchange.. ${ }^{58}$ While the front page assumed that Moro was sending encrypted messages and that he was still psychologically unbroken, the third page already reported Moro's annihilation with the headline «Isolation, Drugs, Extended Wake. This Is How Personality Is Annihilated.» ${ }^{59}$ The thesis that Moro wrote under torture or under the influence of drugs was also backed up in articles published in La Repubblica, La Stampa, Avanti! and L'Unità. ${ }^{60}$ La Repubblica published an interview with magistrate Mario Sossi titled:

57 La Repubblica, «Quelle parole non sono le sue», 30.3.1978, 1; it.: «Moro, insom$\mathrm{ma}$, in cambio della sua salvezza fisica, sottoscriverebbe, con una inaccettabile distinzione tra rapiti della criminalità comune e rapiti della criminalità politica, il proprio suicidio politico e di statista. Ed è proprio questo che ci ripugna di accettare o anche solo ritenere verosimile.»

58 Munzi, Ulderico, «Nascosti due messaggi fra le righe delle pagine scritte dal prigioniero", Corriere della Sera, 31.3.1978, 1; it.: «Nello scrivere la parola <legalità Moro ha fatto volare la penna verso l'alto come se il termine gli fosse stato imposto. Quindi io deduco che, invece, intende sacrificarsi e che nel suo intimo rifiuta lo scambio."

59 Chierici, Maurizio, «Isolamento, droga, veglia prolungata. Ecco come si annienta la personalità, Corriere della Sera, 31.3.1978, 3.

60 See De Luca, Fausto, «Parole scritte sotto tortura», La Repubblica, 30.3.1978, 1; Pace, Giovanni Maria, «Tortura dura e raffinata ma senza l'uso di droga», La Repubblica, 31.3.1978, 5; Avanti!, «Forse Moro è stato drogato», 31.3.1978, 14; Rizzo, Aldo, «Una linea ferma», La Stampa, 31.3.1978, 1; La Stampa, «Quali farmaci possono usare le BR su Moro», 31.3.1978, 2; L'Unità, «Moro poteva essere sotto l'effetto di un ipnotico», 31.3.1978, 2. 
«In the People's Prison Psychological Violence Causes Death to Be Desired.» ${ }^{61}$ The only ones who, in the two days of March 30 and 31, are unwilling to make the assumption that Moro is plagued or delusional is that of the Socialists, which is interesting because it was the only parliamentary party that in the coming days officially argued for negotiations. Interviewed at the party congress in Turin, the Socialist deputy Enrico Manca expressed, like so many others, doubt that Moro's letter was entirely spontaneous, but added: «However, it seems to me that the questions that he poses, the choices he asks for are real. And they have to be evaluated with a lot of political sensibility.» ${ }^{62}$

Except for a few very rare voices, the reaction of the media and of the political parties to the first letter was to represent Moro as plagued by the $\mathrm{BR}$, which is why the arguments for negotiations were not taken seriously. One of these rare voices was that of journalist Carmine Pecorelli, founder and director of the press agency and magazine Osservatore Politico, who was killed in Rome a year after Moro's kidnapping. Pecorelli was one of the first to explicitly claim that Moro's kidnapping had been organized by a «lucid superpower» with «the primary goal [...] of moving the Communist Party out of the area of power [...] since it is the common interest of the two world superpowers to mortify the rise of the PCI, that is, of the leader of Eurocommunism, of Communism aspiring to become democratic and democratically guide an industrial country." ${ }^{63}$ In an article of April 4, 1978, Pecorelli criticized the line of firmness and described it as dictated by those who wanted to «sacrifice» Moro:

Aldo Moro will be sacrificed on the altar of the reason of State. Of which State? Unable to administer justice, unable to defend its citizens,

61 Saba, Antonio, «Nel carcere del popolo la violenza psicologica fa desiderare la morte», La Repubblica, 31.3.1978, 4.

62 Bocca, Giorgio, «Al centro del dibattito c’è quel sprigioniero»", La Repubblica, 31.3.1978, 2; it.: «Mi pare però che le domande che pone, le scelte che chiede siano reali. E andranno valutate con molta ponderatezza politica.»

63 Pecorelli, Carmine, «Il Paese si può e si deve salvare», Osservatore Politico, 2.5.1978, reprinted in: Flamigni 2006, 290-291; it.: «L'agguato di via Fani porta il segno di un lucido superpotere. La cattura di Moro rappresenta una delle più grosse operazioni politiche compiute negli ultimi decenni in un Paese industriale, integrato nel sistema occidentale. L'obiettivo primario è senz'altro quello di allontanare il Partito comunista dall'area del potere nel momento in cui si accinge, all'ultimo balzo, alla diretta partecipazione al governo del Paese. È un fatto che si vuole che ciò non accada. Perché è comune interesse delle due superpotenze mondiali mortificare l'ascesa del Pci, cioè del leader dell'eurocomunismo, del comunismo che aspira a diventare democratico e democraticamente guidare un Paese industriale.» 
incapable of punishing the dishonest and speculative, unable to offer prospects to the Country, lacking command and moral authority, this State is only standing today by renewing the macabre ritual of human sacrifice. The very ones who today have refused to save Moro's life are the same ones that yesterday denigrated Germany and Israel for refusing to engage in negotiations with Palestinian terrorists; they are the same ones who applauded the German CDU, who were willing to negotiate for [the liberation of] Lorenz. So why not negotiate for [the liberation of] Moro? Who benefits from [the line of] no negotiation? ${ }^{64}$

Pecorelli, who took Moro's first letter seriously because he believed the politician was warning his party and the government that he could reveal information about secret international operations against the Communist threat, thus represented Moro as a scapegoat, chosen to renew the state.

When the second letter became public, the strategy adopted by the established media to depoliticize Moro, went a step further. In an intervention at the Chamber of Deputies, Prime Minster Andreotti said that Moro's letter "was materially written by Aldo Moro but is not morally accountable to him.» ${ }^{65}$ The speech was reproduced in full by Il Popolo and quoted widely by L'Unità. The editorial in La Repubblica described Moro as a puppet, pointing out that «it is not through having a puppet that [the BR] can talk to a nation.» ${ }^{66}$ In the same newspaper, journalist Sandro Viola wrote that «in the gloomy atmosphere of the people's prison, the statesman, the political leader, no longer exists. [...] That impression of mastery —of the self and of the situation-still emerging in the letter to Cossiga a

64 Pecorelli, Carmine, «Alla riscoperta dello Stato», Osservatore Politico, 4.4.1978, reprinted in: Flamigni, 2006, 265; it.: «Aldo Moro sarà sacrificato sull'altare della ragion di Stato. Di quale Stato? Incapace di amministrare la giustizia, incapace di difendere i cittadini, incapace di punire disonesti e speculatori, incapace di offrire prospettive al Paese, privo di autorità di ordine e di morale, questo Stato oggi si tiene in piedi solo rinnovando il macabro rituale del sacrificio umano. Quelli stessi che oggi hanno rifiutato di salvare la vita a Moro, sono gli stessi che ieri inveivano contro la Germania e contro Israele rei di non voler trattare con i terroristi palestinesi; sono gli stessi che hanno plaudito alla DC tedesca disposta a trattare per Lorenz. Perché allora non trattare per Moro? A chi giova non trattare?»

65 Manfalotto, Rosario, «Andreotti alla Camera: «Non si può patteggiare con gente che ha le mani grondanti di sangue», Corriere della Sera, 5.3.1978, 2; "La lettera a Cossiga è stata materialmente scritta da Aldo Moro ma non è moralmente a lui ascrivibile.»

66 La Repubblica, «quelle parole non sono credibili», 5.4.1978, 1; it.: «Non è attraverso ha un fantoccio che [le Brigate Rosse] possono parlare con una nazione.» 
week ago, has disappeared»; the title of the article did not leave room for interpretations: «In 20 Days They Killed a Leader». ${ }^{67}$

The day that the note from the «Memorial» in which Moro criticized Paolo Emilio Taviani was published, the reaction of the press was practically unanimous. In La Repubblica Sandro Viola, in an article titled «A Distorted Voice from the «People's Prison», wrote that «what stands out $[\ldots]$ is the fall of Moro, the weakening of his every capacity to maintain the role that the long political career, the many duties of the State had been conferred upon him in those decades.» ${ }^{68}$ Along the same lines, La Stampa described Moro as «a man who is psychologically destroyed, abandoned, available to compromises dictated by isolation and fear, [...] a prostrate person, fallen into a state of psycho-physical dissipation.» ${ }^{69}$ Another article in the same newspaper argued that Moro had been «reduced to an object.» ${ }^{70}$ The Corriere della Sera, in turn, wrote that Moro's words «sound like a denial of the best part of his political personality» and on the second page a headline declared: «Here Is the Text of the Note on Taviani. Friends: An Unrecognizable Moro».71

In Corriere della Sera, Gianfranco Piazzesi adopted another kind of representation, which could be described as an attempt to «infantilize» the hostage..$^{72} \mathrm{He}$ quoted a study by the US think tank Rand Corporation and compared Moro's situation with that of a helpless child (after first comparing it with the situation of partisans during the Resistance against Fascism):

67 Viola, Sandro, «In 20 giorni hanno ucciso un leader», La Repubblica, 5.4.1978, 1; it.: «Nella cupa atmosfera del carcere del popolo, lo statista, il leader politico non esistono quasi più. [...] Quell'impressione di padronanza - die sé e della situazione - che ancora emergeva nella lettera a Cossiga d'una settimana fa, è scomparsa.»

68 Viola, Sandro, «Una voce stravolta dal carcere», La Repubblica, 11.4.1978, 1; it.: "Quel che risalta [...] è la caduta dell'uomo Moro, l'indebolimento di ogni capacità di mantenere il ruolo che la lunga carriera politica, le tante cariche dello Stato gli avevano conferito in quei decenni.»

69 Carbone, Fabrizio/Mazzocchi, Silvana, «Doppio ricatto, contro lo Stato e la famiglia», La Stampa, 11.4.1978, 1; it.: «[...] un uomo psicologicamente distrutto, abbandonato, disponibile a compromessi dettati dall'isolamento e dalla paura, [...] una persona prostrata, caduta in uno stato di sfacelo psico-fisico.»

70 La Stampa, «Una cieca violenza», 11.4.1978, 1; it.: «[...] ridotto a oggetto.»

71 Valiani, Leo, «Noi, nelle carceri del fascismo», Corriere della Sera, 11.4.1978, 1; it.: «[...] suonano come una la negazione della parte migliore della sua personalità politica»; Corriere della Sera, «Ecco il testo dello scritto su Taviani. Gli amici: 〈Un Moro irriconoscibile»", 11.4.1978, 2.

72 See Silj 1978, 171. 
During the Resistance, many Italians subjected to psychological stress at least equal [to that of Moro], and even to physical torture, were able to cope without fear of their abusers. [...] The total physical dependence of the hostage on the kidnappers often brings him to a state of total psychological introjection. In other words, he finds himself in the same situation as that of a baby who needs help and who, given this fact, identifies with his parents. Like a baby, the hostage ends up identifying with his kidnappers. ${ }^{73}$

Alessandro Silj rightly noted that this infantilization of the hostage was the logical counterpart of the bestialization of the BR: «Animals and babies, as is known, don't engage in politics. Rather they are only capable of inspiring horror or pity.» ${ }^{74}$ With regard to the first part of the quoted article, it is important to notice that the comparison with Resistance partisans was often used during the 55 days of Moro's captivity: before the publication of the first letter, in positive terms to make Moro look like a sort of modern partisan, and after, in negative terms to basically represent him as a coward. Through the comparison between the letters by Moro and those of a man of the Resistance who was condemned to death, the Catholic Moro was accused «of not having accepted dying, of having failed to perform a beautiful death', of not being able to drink the Socratic-partisan hemlock, of not having accepted martyrdom.» ${ }^{75}$

A few days after, Piazzesi-who on March 13, a few days before Moro's abduction, still described Moro as «our most authoritative and profound statesman» and the «supreme mediator of all Italian parties» ${ }^{76}$ — continued his own campaign of delegitimizing the politician by writing that:

In no case, however, will he [Moro] still be the Christian Democrat leader of greater authority and prestige, nor the sure point of reference for all other parties, starting with the Italian Communist Party. [...]

73 Piazzesi, Gianfranco, «La forza della dignità», Corriere della Sera, 7.4.1978, 1; it.: «Durante la Resistenza molti italiani sottoposti a uno stress psicologico almeno pari [a quello di Moro], e anche a torture fisiche, seppero fronteggiare in maniera impavida il loro aguzzini.» The day before, also in La Repubblica Moro's writing was described as «infantile, elementary», see Carraciolo, Lucio, «ll giorno più lungo", La Repubblica, 6.4.1978, 2.

74 Silj 1978, 162.

75 Gotor 2008b, 191.

76 Piazzesi, Gianfranco, "Aldo Moro: il suo ritratto è nei promessi sposi», Corriere della Sera, 13.3.1978, 3; it.: «[...] il nostro più autorevole e profondo statista. [...] il supremo mediatore di tutti i partiti italiani.». 
Saying this, we do not intend to make any judgment on the way the president of the Christian Democracy is enduring the trial to which he has been subjected. We only find, with realism equal to bitterness, that certain wounds inflicted by the kidnappers and the prisoners will never be completely remedied. ${ }^{77}$

Fortebraccio expressed his disappointment with Piazzesi's article in L'Unità, defining it as «absolute foolishness and ruthless cruelty» and asserting that the journalist from the Corriere wanted to «anticipate [...] a sentence that the jailers themselves have not yet pronounced.» ${ }^{78}$ But confronted with Moro's letter to Zaccagnini, published on April 22, Fortebraccio also changed his mind and described the prisoner as «a man morally and psychologically destroyed, [...] a Moro diametrically opposite to what we have always known.» ${ }^{79}$ Even more explicit was Indro Montanelli, who in the April 12 edition of Il Giornale wrote that Moro, «as a political man, disappeared on March $16 .{ }^{80}$

The process of de-politicizing Moro continued after the publication of two letters addressed to Zaccagnini on April 22 and 25. The leader of the Republican Party Giovanni Spadolini, who, in an article titled «I Defend the Image of Moro", argued that

it was necessary to oppose from the beginning and with firmness the attempt to interpret in any sense the letters extorted to Moro in the hell of the prison. [...] [For the BR] the moral demolition of Moro's character $[\ldots]$ is even more important than his physical elimination. ${ }^{81}$

77 Piazzesi, Gianfranco, «La tregua», Corriere della Sera, 14.4.1978, 1; it.: «In nessun caso, però, egli sarà ancora il leader democristiano di maggiore autorità e prestigio, né tantomeno un sicuro punto di riferimento per tutti gli altri partiti, a cominciare dal PCI $[. .$.$] dicendo questo non intendiamo avanzare un giudizio qualsi-$ asi sul modo in cui il presidente della Dc sta superando la prova a cui è stato sottoposto. Ci limitiamo a constatare, con un realismo uguale soltanto all'amarezza, che certe ferite inflitte dai rapitori e dai carcerieri non potranno mai essere del tutto rimarginate.»

78 Fortebraccio, "Ci vada piano», L'Unità, 15.4.1978, 1; it.: «[...] una assoluta insensatezza e di una spietata crudeltà» «[...] anticipare [...] una sentenza che $\mathrm{i}$ carcerieri stessi non hanno ancora pronunciato.»

79 Fortebraccio, «Quello vero», L'Unità, 23.4.1978, 1; it.: «[...] un uomo moralmente e psicologicamente distrutto, [...] un Moro diametralmente opposto a quello che abbiamo sempre conosciuto.»

80 Quoted in Silj 1978, 179; it.: «[...] come uomo politico, è scomparso il 16 marzo.»

81 Spadolini, Giovanni, «Difendo l'immagine di Moro», La Stampa, 27.04,1978, 1; it.: «Bisognava opporsi fin dall'inizio, e con decisione, al tentativo di «interpretare» in qualunque senso le lettere estorte a Moro nell'inferno del carcere. [...] 
The image Spadolini claimed to defend was that of Moro as a political figure, that is, before he was abducted on March 16. According to the Republican politician, it was wrong to even try to understand the Moro of the letters, because he was no longer the same person. As reported by La Repubblica, the DC was of the same opinion; in fact, within the party it became normal to distinguish between

a Moro-Dr. Jeckill, that is, the leader that we all know, and Mr. Hyde, that is, the man who has fallen sunder the full and uncontrolled domination> of his jailors, a different and opposite human being, a man of revenge and death in contrast to the demiurge capable of broader and bold political openings, in the most difficult of situations. ${ }^{82}$

To explain Moro's dual nature, on the same day, the Corriere della Sera interviewed a psychologist who explained that «social deprivation, that is, isolation from one's own kind, can cause a personality split.» ${ }^{83}$ On April 25 , the day on which Italy celebrates its liberation from Fascism, a document was signed by more or less fifty personalities from within the Catholic world, claiming that the letters were not authentic. Il Popolo published this document the following day, indicating that it had been signed by «old friends of Aldo Moro», which affirmed that

1) The Aldo Moro we know, who with his spiritual, political, and juridical vision contributed to the drafting of the Republican Constitution, is not present in the letters addressed to Zaccagnini, which were published as [if they were] his: they constitute an attempt to destroy Moro's physiognomy [...].

2) The irreparable guilt for an eventual, absurd murder falls only on the perpetrators of the murder: the BR cannot pretend to blame

La demolizione morale del personaggio Moro [...] è perfino più importante della sua eliminazione fisica.»

82 De Luca, Fausto, «Ma chi scrive quelle lettere?», La Repubblica, 26.4.1978, 1-2; it.: «[...] un Moro-dottor Jeckill, insomma il leader da tutti conosciuto, e mister Hyde, cioè l'uomo caduto ssotto il pieno e incontrollato dominio dei suoi carcerieri, umo diverso e opposto, uomo della vendetta e della morte contrapposto al demiurgo capace delle più ampie e audaci aperture politiche, nelle situazioni più difficili.»

83 Medail, Cesare, «Non scrive così per paura», Corriere della Sera, 26.4.1978, 1; it.: «[...] è la deprivazione sociale, cioè l'isolamento dai propri simili, che può determinare uno sdoppiamento di personalità.» 
others for the death sentence, which the Italian State does not recognize as applicable in any case, on others. ${ }^{84}$

In the already quoted letter addressed to the DC, published on March 29, Moro expressed his disappointment at this document, as drawn up by his self-declared «friends»:

It is true: I am a prisoner and I am not in a happy state of mind. But I have not undergone any coercion nor am I drugged, I write in my own style, I have my usual handwriting. But I am, they say, someone else and I do not deserve to be taken seriously. Therefore, in response to my arguments they do not even answer. [...] And I must say that I was deeply saddened (I would not have believed it possible) by the fact that some friends, such as Bishop Zama, the lawyer Veronese, G.B. Scaglia and others, without knowing or imagining my suffering, which is not disconnected from lucidity and freedom of spirit, have doubted the authenticity of what I was upholding, as if I were writing under the duress of the BR. How can one explain this endorsement of the claim of my non-authenticity? 85

It may be that Moro posed the right question because, in the reactions to the latter letter, the conviction that the letters by Moro were not authentic

84 Il Popolo, «Vogliono distruggere la figura di Moro», 26.4.1978, 3; it.: «1) L'Aldo Moro che conosciamo, con la sua visione spirituale, politica e giuridica che ne ha ispirato il contributo alla stesura della stessa Costituzione repubblicana, non è presente nelle lettere dirette a Zaccagnini, pubblicate come sue: esse costituiscono un tentativo di distruggere la fisionomia di Moro [...]. 2) L'irrimediabile colpa per un eventuale, assurdo omicidio ricade soltanto sugli esecutori materiali e gli organizzatori dello stesso: le Brigate Rosse non possono illudersi di scaricare su altri il peso della condanna a morte che lo Stato italiano non riconosce applicabile in nessun caso.»

85 Moro 20081, 140-141; it.: «È vero: io sono prigioniero e non sono in uno stato d'animo lieto. Ma non ho subito nessuna coercizione, non sono drogato, scrivo con il mio stile per brutto che sia, ho la mia solita calligrafia. Ma sono, si dice, un altro e non merito di essere preso sul serio. Allora ai miei argomenti neppure si risponde. [...] E devo dire che mi ha profondamente rattristato (non lo avrei creduto possibile), il fatto che alcuni amici, da Mons. Zama, all'avv. Veronese, a G. B. Scaglia ed altri, senza né conoscere né immaginare la mia sofferenza, non disgiunta da lucidità e libertà cli spirito, abbiano dubitato dell'autenticità di quello che andavo sostenendo, come se io scrivessi su dettatura delle Brigate Rosse. Perché questo avallo alla pretesa mia non autenticità?» 
began to waver, though the support for the line of firmness remained practically unanimous. The Corriere della Sera argued that

It is pointless to try to determine if Moro really wants the things he writes. The important thing is that the BR want them, otherwise they would not deliver their letters. [...] [I]t is undeniable that the messages signed by Aldo Moro contradict all the values for which he had fought until March 16: How can the jealous guardian of Christian Democracy's pride $[\ldots]$ rage at his party to the point of endangering his survival? [...] There is, on the one side, a man who desperately and humanly invokes salvation, while out there are men who must seek the salvation of a whole national community. ${ }^{86}$

La Stampa said practically the same thing, arguing that

Whatever the genesis of the writings may be-free, forced, drugged, negotiated between those who dictate and who write- $[\ldots]$ they are certainly responsive and functional to the strategy and tactics of the BR. If Moro is the author, the BR are the de facto editors. ${ }^{87}$

L'Unita, on the other hand, did not change its strategy of representation, continuing to argue that the person who wrote the letters was no longer Aldo Moro:

We are facing another testimony of depersonalization of a man by his captors. [...]. That's why this letter does not come from Moro, but from its perpetrators. [...] [It] would be really too offensive to judge a man who is no longer master of himself. [...] What is, in fact, the essence of the request formulated in the letter? [...] It is the recogni-

86 Scardocchia, Gaetano, «Si intravvede fra le righe un'inquietante domanda», Corriere della Sera, 30.4.1978, 2; it.: «È inutile cercare di stabilire se Moro vuole davvero le cose che scrive. L'importante è che le vogliano le BR, altrimenti non recapiterebbero le sue lettere. [...] [È] innegabile che i messaggi firmati da Aldo Moro contraddicono tutti i valori per i quali egli si era battuto fino al 16 marzo: $[\ldots]$ Come può il geloso tutore dell'orgoglio DC [...] infierire sul suo partito fino al punto da metterne a repentaglio la stessa sopravvivenza? [...] C'è da una parte un uomo che disperatamente e umanamente invoca la salvezza, mentre fuori ci sono uomini che devono cercare anche la salvezza di tutta una comunità nazionale.»

87 Zucconi, Vittorio, «Le lettere: Strategia BR e resistenze di Moro», La Stampa, 30.4.1978, 2; it.: "Quale che sia la genesi degli scritti - libera, coatta, drogata, negoziata fra chi detta e chi scrive - [...] essi sono certamente rispondenti e funzionali alla strategia e alla tattica delle brigate rosse. Se Moro ne è l'autore, comunque le BR ne sono gli editori.» 
tion of their status as combatants, it is the capitulation of the democratic State, the leak, through which all the disruptive drives can come out, until reaching chaos. ${ }^{88}$

In short, after a long process in which Moro was represented as tortured, drugged, freakish, infantile, depersonalized, weak, morally and psychologically dead, with a double personality and much more, on April 30, what had so far been submerged under a tide of rhetoric, finally began to become explicit: regardless of the authenticity or inauthenticity of the letters by Moro, he had to be sacrificed for the salvation of the democratic state, the Italian Republic and national unity. As we have seen, almost all parliamentary parties, with the participation of almost all of the media, had already decided from the beginning that there would be no negotiations to save Moro. From this point of view, Moro's letters were only obstacles to overcome. Despite the use of different rhetorical and representative strategies, they all sought to ban and remove Moro, the Moro of the letters, from the public and political space.

The obstacles were overcome through the distinction between a public Moro, a symbol of both the party and the Italian State, and a private Moro, the person kidnapped by the BR and robbed of the ability to communicate and to act in the public space. Evidently, the BR were primarily responsible for the annihilation of Moro's right to act and to express himself. It would be very naive to think that Moro, inside the "people's prison", could have said and written what he wanted. There are also factual findings which prove that the BR censored him, deciding which letters to publish and which to not, probably also forcing Moro to rewrite and reformulate determinative sentences and passages. ${ }^{89}$ We also know that, at least initially, they made him believe that his letters would not become public and thus he could write confidentially to politicians, friends and family. But parliamentary political parties, primarily the DC and the PCI, and most of the established media were equally responsible for having delegitimized and de-

88 L'Unità, «Il Loro disegno», 30.4.1978, 1; it.: «Siamo di fronte a un'altra testimonianza di spersonalizzazione di un uomo da parte dei suoi carcerieri. [...] Ecco perché questa lettera non viene da Moro, ma dai suoi aguzzini. [...] sarebbe veramente troppo offensivo voler far carico di certi giudizi a un uomo non più padrone di sé, e pensare di fare dei suoi scritti un qualsiasi uso politico. [...] Qual è, infatti, in sostanza, la richiesta che si formula nella lettera? [...] È il riconoscimento ad essi dello status di combattenti, è la resa, quindi, dello Stato democratico, la falla attraverso la quale possano rovesciarsi tutte le spinte disgreganti, fino al caos.»

89 See Gotor 2008b, 185-389. 
politicized first the letters, declaring them as inauthentic, and then the prisoner himself, representing him as a weak man, interested only in his own salvation.

Resuming Giorgio Agamben's reflections on the concept of «bare life», we can define the reduction of Moro to a purely private character, with no longer any right to speak, such as the annihilation of the faculty of having «the logos by conserving [the living being's] own voice in [the polis]». If the «politicization of bare life» is «the metaphysical task par excellence» by which «the humanity of living man is decided», then we can define the rhetorical, narrative and discursive strategy adopted by the media and political parties during the Moro case as the de-politicization of bare life, by which the humanity of the living is denied. ${ }^{90}$ Agamen's homo sacer theory allows us to shed light on the rhetorical, narrative and discursive process through which Aldo Moro was excluded from the political community. This theory predisposes the conceptual apparatus through which it is possible to understand and to explain the functioning, the performativity and effectiveness of the discursive practices, the representative forms by which the Moro case was framed during and after the 55 days of his imprisonment. Aldo Moro was consecrated to the sacred sphere as early as his abduction, when the government decided not to undertake the path of negotiation. As we have seen, in the first two weeks of his imprisonment, that is, before the first letter was published, Aldo Moro had already been raised to the status of a mythical figure, a paladin of democracy and a collective symbol of national unity. On Easter Sunday, through the employment of the rhetorical tool of prefiguration, his sacrifice for the state was placed in relation to the sacrifice of Jesus Christ, thus constructing a meaningful analogy between the salvation of the state and the salvation of the world. Conversely, the BR were represented as a demonic force devoted only to the achievement of chaos and the destruction of society. The BR thus took on the role, in what actually appears to be a Schmittian theological-political narrative, of the Behemoth-beast that the Leviathan-state must stop at all costs, while Aldo Moro became the voluntary martyr willing to die for the salvation of the state. Another thesis by Agamben seems to find confirmation here, namely that «what are secularized, today, are essentially eschatological concepts. ${ }^{91}$

Moro thus already belonged to the sacred sphere, and the only thing left of him in the profane world was a mere body without a voice, flesh that

90 Agamben 1998, 8.

91 Agamben 2015a, 67. 
simply had to cease to live. But then something unexpected happened: Moro made use of his voice in an attempt to re-politicize himself, to return to the public and political sphere. And it is here that what Alessandro Silj has defined «a massive operation of institutionalized falsification", whose only function was to silence Aldo Moro, becomes operative. ${ }^{92}$ It is important to be accurate: Agamben defines homo sacer as one who can be killed but not sacrificed. If, at first glance, this definition does not seem to match the Moro case, a closer look reveals the heuristic value of the homo sacer theory. In fact, what was the «line of firmness» adopted by the government and the political parties within it, as well as by the larger part of the media, if not a nibil opstat, a declaration that nothing hindered the killing of Moro, namely its exclusion from the sphere of the law? Article 2 of the Italian Constitution, where it is written that La Repubblica riconosce e garantisce $i$ diritti inviolabili dell'uomo, was declared invalid for Moro, the prisoner of the BR. What is at stake is obviously not the impunity of the BR, the perpetrators of the homicide, but of those who allowed, or at least who did nothing, to prevent the murder. If it is thus correct to say that the state of exception was not actually declared de jure-basically with the argument that this would have meant recognizing a war and the BR as a political foe-it was actually applied de facto. Although it was only for a single person, the rights guaranteed by the Italian Constitution were suspended.

As Paolo Heywood argues, the political strategy adopted during the Moro case proves that two apparently incompatible paradigms of governance, sovereignty and governmentality, can coexist. ${ }^{93}$ Governmentality involves those kinds of practices whose goal is the preservation of law through regularized and rational techniques of government, such as courts, prisons, and social services, whilst sovereignty involves practices, such as torture and capital punishment, which are always implemented for the preservation of the sovereign power itself, not of law. This distinction calls to mind the distinction made by Walter Benjamin between violence which is lawmaking and violence which is law-preserving. ${ }^{94}$ The lawmaking violence is that exercised, for example, during revolutions, through which a new form of political order and with it a new legislative system is established. But it is also the violence exercised to counter a revolution in order to preserve the state. This is the violence exercised by the sovereign in the state of exception, which «neither preserves nor simply posits law, but rather conserves it in

92 Silj 1978, 184.

93 See Heywood 2009.

94 See Benjamin 1995. 
suspending it and posits it in exempting itself from it.» ${ }^{95}$ Or, in Foucault's terms, it is the illegal violence that is legitimized with reference to the «reason of state»:

There will be times when raison d'Était will no longer make use of [...] laws due to a pressing and urgent event and must out of necessity free itself from them. In the name of what? In the name of the State's salvation. ${ }^{96}$

The particularity, the exemplarity of Moro's case lies in the fact that the state allowed others to kill Moro, thus allowing a group to exercise sovereign violence, a group that was convinced instead of exercising revolutionary violence to destroy the old political order and establish a new one. From this point of view, we can say that in this case, sovereignty resided in the hands of a non-state group, permitting those statesmen with the responsibility for the less problematic (as they are legal) techniques of discipline and law-preserving violence to "conceal [their] savage and sovereign violence» by projecting «themselves as mere maintainers of the law, as if the very invocation of legality, however perverted, can make them appear legitimate and respectable.» ${ }^{97}$

But how can one explain the second part of the definition, according to which the homo sacer cannot be sacrificed? Did the Italian press not repeatedly claim that Moro had to be sacrificed for the salvation of the Italian State? This is where the enormous potential for the ideological construction of the state martyr figure lies: the state cannot be the agent of the sacrifice, because by it being so, the dark bond between biopolitics and thanatopolitics, «the capacity [of supreme power] to constitute oneself and others as life that may be killed but not sacrificed» would become manifest. ${ }^{98}$ Here, the function of martyrological rhetoric is precisely to hide this dark bond, transforming the victim of violence into the voluntary agent of his or her own sacrifice. Since the sovereign power cannot sacrifice «bare life», the construction of the figure of the martyr becomes very useful. This kind of martyrology is none other than a state mythology, whose purpose is the concealment of sovereign power over «bare life». At this point, we can describe the practical and representational strategies adopted by the government, by major parliamentary parties and by the established press as

95 Agamben 1998, 64.

96 Foucault 2009, 262.

97 Hansen 2006, 282.

98 Agamben 1998, 101. 
a strategy of double concealment. Both the externalization of sovereign power and the sacralization of Aldo Moro are ways of concealing the power over «bare life». From this point of view, the figure of the martyr appears to be an indispensable tool, or at least a very useful one, for the legitimization of dominant power structures. In fact, as noted by Michel Foucault,

power is tolerable only on the condition that it masks a substantial part of itself. Its success is proportional to its ability to hide its own mechanisms. Would power be accepted if it were entirely cynical? For it, secrecy is not in the nature of an abuse; it is indispensable to its operation. ${ }^{99}$

The homo sacer theory allows us to further put into perspective a fundamental paradox within modern law and politics, a paradox that determined the political management and influenced the media representation of the Moro case. This paradox concerns the relation between the two dogmas of the "sanctity of human life» and the «reason of state». As we have seen, on April 19 Lotta Continua published an appeal for the release of Moro, which claimed the primacy of the right to life of every single individual. Indeed, practically all social actors publicly acknowledged the presence of this paradigm. In fact, the advocates of the line of firmness «generally introduced their positions by first rhetorically asking: what is more sacred than human life?» 100 One has only to read the editorials of the newspaper editions of April 21 to become aware of the rhetorical and argumentative monotony with which the line of firmness was defended without abandoning the proclamation of the right to life. The Corriere della Sera wrote that «every chance of saving a human life should be [...] explored rigorously» but at the same time that "one cannot give in to blackmail, this was and remains obvious to everyone.»101 La Repubblica posed the problem as a dilemma in which, however, the choice was clear: «It is about sacrificing a man's life or losing the Republic. Unfortunately, for democrats the choice does not allow any doubt.» ${ }^{102}$ Similarly, L'Unità asked rhetorically: «Who $[\ldots]$ can be so inhumane as to not want with all his or her strength, the life

99 Foucault 1978, 86.

100 Wagner-Pacifici 1986, 186.

101 Corriere della Sera, «La Repubblica non si baratta», 21.4.1978, 1: it.: « [...] ogni possibilità di salvare una vita umana va [...] esplorata fino in fondo [...]. Non si può cedere al ricatto, questo era e resta ovvio per tutti.»

102 La Repubblica, «Sacrificare un uomo o perdere lo Stato», 21.4.1978, 1; it.: «Si tratta di sacrificare la vita di un uomo o di perdere la Repubblica. Purtroppo, per i democratici la scelta non consente dubbi.» 
of the president of the DC to be saved? [...] Let us reflect well, [...] while maintaining the most intransigent rejection, what is defended is the very basis of freedom and democracy.» ${ }^{103}$ Even more explicit was La Stampa, which claimed that «nothing is more sacred than human life» but that «we are not so foolish as to ignore that the very strict defense of the law, which is decisive to its violation in any way, is the only true and valid defense of the life of all citizens.» ${ }^{104}$ The motivations given by the various editorialists were essentially all based on the same premise, namely that negotiations would affect national security: the state cannot negotiate with an organization that is not political, but criminal (Corriere della Sera); the notion of a «state of war» cannot be accepted because, among other things, it would simply give the state's repressive apparatuses the right to suspend constitutional guarantees against the BR (La Repubblica); if we accept negotiating today, we will be forced to make deals in future as well (L'Unità); if we surrender this time, we will open the way for new blackmail (La Stampa).

In the last days of April, the media also discussed the initiative of the Socialist Party a lot-which from the beginning was presented as «humanitarian»- and the appeals of the Secretary General of the United Nations, the Pope, and the Caritas; practically all agreed that a «humanitarian» attempt to save Moro was acceptable, but "political» negotiations were not. ${ }^{105} \mathrm{Ev}$ eryone knew, however, that the BR would not free Moro because of a few so-called «humanitarian appeals», as they explicitly wrote in the seventh communiqué. The distinction between humanitarianism and politics had no other function than to conceal the structure of the sovereign exception, namely that exactly because Moro's life was «sacred», it was excluded from the political sphere and it was no longer the task of the state to defend it. ${ }^{106}$ According to Agamben,

103 L'Unità, «Il prezzo vero», 21.4.1978, 1; it.: «Chi [...] può essere così disumano da non volere con tutte le sue forze che la vita del presidente della DC venga salvata? [...] Riflettiamoci bene, [...] mantenendo il più intransigente rifiuto, ciò che si difende sono le basi stesse della libertà e della democrazia.»

104 La Stampa, «Perché lo Stato non può piegarsi a degli assassini», 21.4.1978, 1; it.: «[...] nulla è più sacro della vita umana. [...] non siamo tanto sprovveduti da ignorare che appunto la difesa rigida della legge, un no deciso di violarla in alcun modo, rappresentano la sola difesa vera e valida della vita di tutti i cittadini.»

105 Wagner-Pacifici 1986, 186.

106 Very significant in this regard is the editorial, titled «God Forgives but Caesar Punishes», written by the editor and co-founder of La Repubblica Eugenio Scalfari after the above-mentioned appeal by the Pope. Here Scalfari said more or less explicitly that Moro's life was now in the hands of God because «Caesar 
the separation between humanitarianism and politics that we are experiencing today is the extreme phase of the separation of the right of man from the rights of the citizen. In the final analysis [...] humanitarian organizations $[\ldots]$ can only grasp human life in the figure of bare or sacred life, and therefore, despite themselves, maintain a secret solidarity with the very powers they ought to fight. ${ }^{107}$

The fundamental paradox of modern politics, and which is at the core of the distinction between humanitarianism and politics made during the Moro case, is that of a state that guarantees constitutionally-based human rights but at the same time acts as a sovereign nation-state with the declared task of guaranteeing national security. From this point of view, the dogma of the sacredness of life manifests itself in all its ambiguity. What in the contemporary world is declared «sacred» is the «bare life» excluded from the political sphere. As Walter Benjamin already wrote almost a century ago:

However sacred man is (or that life in him that is identically present in earthly life, death, and afterlife), there is no sacredness in his condition, in his bodily life vulnerable to injury by his fellow men. What, then, distinguishes it essentially from the life of animals and plants? [...] Finally, this idea of man's sacredness gives grounds for reflection that what is here pronounced sacred was according to ancient mythical thought the marked bearer of guilt: life itself. ${ }^{108}$

Moro's guilt was to still be alive and, while he had already been declared sacred, to have tried to return to the political sphere, to have said «no, I would prefer not to» to the demand of dying for the state.

must administer the law and God knows how to command with prayer. Neither Caesar nor God deal with sinners, because the first punishes them, the second forgives them and-if he can—saves them.» See Scalfari, Eugenio, «Dio perdona ma Cesare castiga», La Repubblica, 23.4.1978, 1-2; it.: "Cesare deve amministrare con la legge e Dio sa comandare con la preghiera. Né Cesare né Dio trattano con i peccatori, perché il primo li castiga, il secondo li perdona e-se può-li salva.»

107 Agamben 1998, 133.

108 Benjamin 1995, 299. 


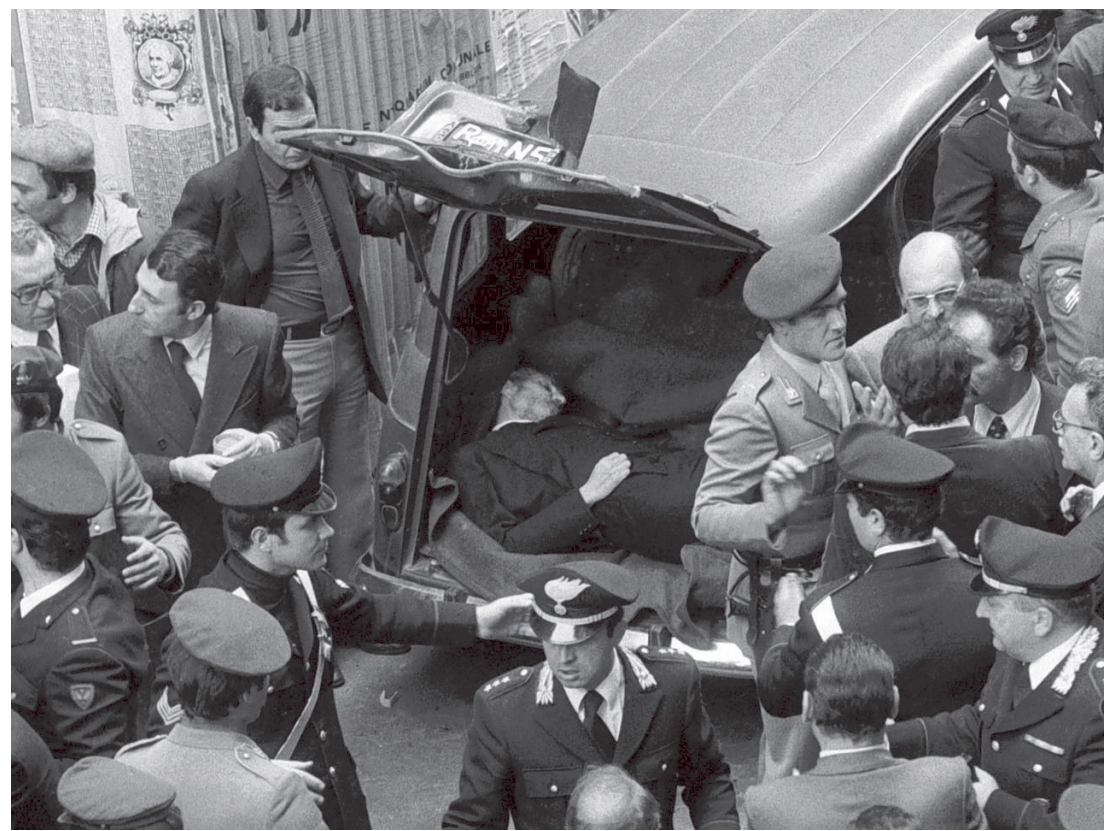

PICTURE 5: The finding of Aldo Moro's body in the trunk of a Renault 4 in via Catani, Rome, May 9, 1978.

\subsection{Grand Finale: Consolidation of the State Martyr}

On May 9, 1978, Aldo Moro was killed by the BR and abandoned in the hood of a car in via Caetani, in the center of Rome (see figure 5). As one of the members of the BR commando said, the choice to leave the corpse in via Caetani, halfway between the headquarters of the PCI and the DC, had a clear symbolic meaning: «the revolutionary front says no to the DC-PCI agreement.» 109 Four days earlier, they had spread their ninth and final communiqué, announcing the execution of the judgment:

Craxi's so-called 〈humanitarian proposals», whatever they are, since they exclude the release of the thirteen seized comrades, are only maneuvers for throwing dust into people's eyes, and are part of those power games, party or electoral interests, which do not concern us. The only clear thing is that, on the exchange of prisoners, the position

109 Bocca 1985, 230; it.: «[... ] il fronte rivoluzionario dice no all'accordo DC e PCI.» 
of the PSI is the same, full rejection, of the DC and its government, and that is enough for us. [...] Thus, we conclude the battle that began on March 16, by executing the sentence to which Aldo Moro was condemned. ${ }^{110}$

At 12.13 p.m. on May 9, a member of the BR telephoned Franco Tritto, one of Moro's assistants at the University in Rome, indicating the location where the police would find the body. RAI was not the first to arrive in via Caetani; it was a small private television broadcaster, the GBR, the only one filming the scene. The images taken by operator Valerio Leccese, as well as Gianni Giansanti's photo, showing the corpse lying in the Renault 4 trunk from above, are the only existing visual proof of the finding of Moro's body. ${ }^{111}$ The symbolic power of the image was immediately perceivable: it displayed Moro as the dead «body of the state», naked life surrounded by policemen and the Carabinieri, symbolically representing state apparatuses, and journalists, representing the media dispositive that shaped and framed the event. Those images «returned» Moro's body to the public space, the body that had been absent for 55 days. The public had only seen Moro in the two Polaroid photos distributed to the media by the BR, but both were used in order to perform an operation of degradation and delegitimization conducted on two fronts: on the one hand, the BR wanted to humiliate the politician as the symbol of the DC's power, while on the other hand, the government, major parties and established media used the photos to deprive Moro of his public image. The images of via Caetani have a different quality, because they no longer show bare life in its killability, but simply and brutally the dead body of a person. Artist Marco Baliani describes the impression he had when he saw the images of via Caetani as follows: «They fired machine guns, a burst as he stood there in pajamas and undershirt looking like he'd just woken up, like some old Roman retiree.»112 Baliani's words highlight the bizarre transformation that the politician's image underwent in the 55 days of his imprisonment: Mo-

110 Brigate Rosse 1978e, 144; it.: «Le cosiddette «proposte umanitarie〉 di Craxi, qualunque esse siano, dal momento che escludono la liberazione dei tredici compagni sequestrati, si qualificano come manovre per gettare fumo negli occhi, e che rientrano nei giochi di potere, negli interessi di partito od elettorali, che non ci riguardano. L'unica cosa chiara è che sullo scambio dei prigionieri la posizione del PSI è la stessa, di ottuso rifiuto, della DC e del suo governo, e questo ci basta. [...] Concludiamo quindi la battaglia iniziata il 16 marzo, eseguendo la sentenza a cui Aldo Moro è stato condannato.»

111 See Imperi 2016, 155.

112 Baliani 2011, 24. 
ro was kidnapped as a symbol, as a simulacrum of power, and was killed as a man, like any ordinary sixty-two-year-old man. On March 16, the BR kidnapped a man with a strong public image, a man considered by public opinion and by the BR themselves to be one of the highest representatives not only of the DC but of sovereign power. However, they involuntarily helped the government, established media and government parties to deprive Moro of his symbolic power and to reduce him to bare life. They did not realize that Moro's absence would not put the balance of power in trouble, but that on the contrary it favored Moro's political opponents, and that the same icon of power would be stripped of any authority, abandoned by the party, the government, and left at the mercy of terrorists, who, misjudging the successive evolutions of the struggle, killed a man who had become uncomfortable for the men of power. The BR's choice to leave the body inside a car trunk in the middle of Rome was not a casual one: they wanted to show that they were capable of striking at the «heart of the state». They thought that by killing Moro they could show that power can be defeated. They thought of killing the symbol, but paradoxically, by killing a man, they created a symbol. When they killed him, they unintentionally paved the way for the definitive establishment of Moro as a state martyr, the symbolic body of the nation. As Valeria Verdolini pointedly observes, «the symbol surpassed the body, the body assumed value and dignity only in the moment it moved toward the symbol.» ${ }^{113}$

Shortly before 6 p.m., Moro's family published a statement:

The family wants the precise will of Aldo Moro to be fully respected by state and party authorities. This means: no public event or ceremony or speech; no national mourning. Nor state funeral or memory medal. The family closes in silence and asks for silence. History will judge the life and death of Aldo Moro. ${ }^{114}$

Moro's last will was not respected. For more than a month Moro had been declared a coward, a weakling, a man reduced to an object, a man unworthy of the heritage of the Resistance, and now that Moro was finally dead, everything that had been written and said seemed to be erased from mem-

113 Verdolini 2006, 68.

114 Quoted in Imperi 2016, 145; it.: «La famiglia desidera che sia pienamente rispettata dalle autorità di stato e di partito la precisa volontà di Aldo Moro. Ciò vuol dire: nessuna manifestazione pubblica o cerimonia o discorso; nessun lutto nazionale. né funerali di stato o medaglia alla memoria. La famiglia si chiude nel silenzio e chiede silenzio. Sulla vita e sulla morte di Aldo Moro giudicherà la storia.» 
ory. In a moment, Moro assumed the state martyr role that the media and most parliamentary political parties had decided he had to assume from the beginning: «The beatification process, which began on March 16, declared invalid the doubts and reservations expressed in the previous few weeks and came, shortly after May 9, to its inevitable conclusion.»115 The first aspect of this beatification process to point out is the rhetoric of unification. As had already happened on March 17, all the newspapers praised the unity of the people. Here are the main headlines of the newspapers:

L'Unità: The Fierce Crime of the BR Wounds the Civil Consciousness of All Italians [subheadline]. The Assassination of Moro-Italy Has Stopped Suddenly Like on March 16-Millions of Men Mobilized Against Eversion [title]. ${ }^{116}$

Il Popolo: Pain and Anger Unify Italy [subheadline]. Aldo Moro Assassinated [title]. ${ }^{117}$

L'Avanti: The Italian People [Have to] React Firmly to the Brutal Assassination of Aldo Moro [subheadline]. Democrats All Unified-We Defend the Republic [title]. ${ }^{118}$

La Stampa: The BR Have Ended the Crime, Which Started in Via Fani With Barbaric Ferocity [subheadline]. Moro Murdered-Millions of Italians Take to the Streets [title]. ${ }^{119}$

La Repubblica: The Corpse Found in a Car a Few Meters From the DC and PCI Headquarters [subheadline]. The Assassination of Moro-The Country Reacts to the BR's Challenge [title]. ${ }^{120}$

115 Silj 1978, 185.

116 L'Unità, 10.5.1978, 1; it.: «L'efferato crimine delle BR ferisce la coscienza civile di tutti gli italiani [subheadline]. L'assassinio di Moro - L'Italia si è fermata di colpo come il 16 marzo - Milioni di uomini mobilitati contro l'eversione» [title].»

117 Il Popolo, 10.5.1978, 1; it.: «Dolore e sdegno uniscono l'Italia» [subheadline]. Aldo Moro assassinato [title].»

118 Avanti!, 10.5.1978, 1; it.: «Il popolo italiano reagisca con fermezza al brutale assassinio di Aldo Moro [subheadline]. Uniti tutti i democratici - Difendiamo la Repubblica [title].»

119 La Stampa, 10.5.1978, 1; it.: «Le BR hanno concluso con barbara ferocia il crimine iniziato in via Fani [subheadline]. Moro assassinato. Milioni di italiani scendono in piazza [title].»

120 La Repubblica, 10.5.1978, 1; it.: «Il cadavere ritrovato in un'auto a pochi metri dalle sedi della Dc e del Pci [subheadline]. Lassassinio di Moro - Il paese reagisce compatto alla sfida $\mathrm{BR}$ [title].» 
Corriere della Sera: Assassinated by the BR and Left in a Car in the Center of Rome [subheadline]. The Killing of Moro [title]. ${ }^{121}$

The Corriere della Sera was, therefore, the only newspaper to not place an emphasis on the unitarian response of the people in its main headline (see figure 6). This is probably because the newspaper was interested in putting all the focus on Aldo Moro's sacrifice as an appeal for the Italian Republic's rebirth, a sort of second Risorgimento. In the editorial entitled «He Died so That the Republic Lives», editor Franco Di Bella argued that:

For this Italian State, which has not succumbed to the blackmail of the negotiations, Moro sacrificed his life. Now the State, which has defended itself by not giving in, has a commitment to honor: to the martyr, to Italians and to itself. [...] The Republic must regain its strength and must restore, without emotional reactions, but with the firmness of the dark hours, the law of a civil society that mourns its own martyrs but also knows, dry-eyed, not to forgive: on behalf of those who for thirty years continued to work and sacrifice for a worthy and civilized country. ${ }^{122}$

121 Corriere della Sera, 10.5.1978, 1; it.: «Assassinato dalle Brigate Rosse e lasciato su un'auto nel centro di Roma [subheadline]. Il delitto Moro [title].»

122 Di Bella, Franco, «È morto perché questa Repubblica viva», Corriere della Sera, 10.5.1978, 1; it.: «Per questo Stato italiano, che non ha ceduto al ricatto delle trattative, Moro ha sacrificato la sua vita. Ora lo Stato che si è difeso non cedendo, ha un impegno da onorare: verso il martire, verso gli italiani e verso se stesso. [...] La Repubblica deve ritrovare la sua forza e deve ripristinare, senza reazioni emotive, ma con la fermezza delle ore buie, la legge di una società civile che piange i suoi martiri ma poi sa anche, a ciglio asciutto, non perdonare: in nome di chi per trent'anni ha continuato a lavorare e a sacrificarsi per un paese degno e civile.» 


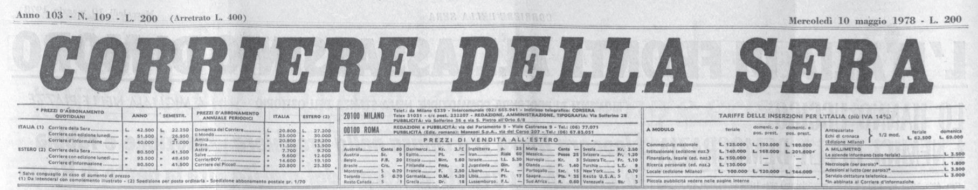

ASSASSINATO DALLE BRIGATE ROSSE E LASCIATO SU UN'AUTO NEL CENTRO DI ROMA

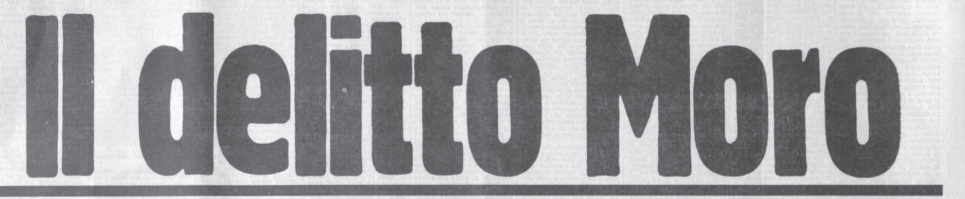

II cadavere ritrovato alle 13.30 di ieri nel bagagliaio di una Renault amaranto parcheggiata in via Caeteni, a metà strada tra la sede del PCl e quella della DC - Dove e quando

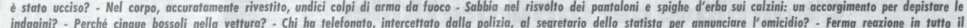
Paese con composte e commosse manilestarioni di popolo. Uno sciopero generale decretato dai sindacati . La famiglia non vuole funerali di Stato né medaglia alla memoria

È MORTO PERCHÉ

QUESTA REPUBBLICA VIVA

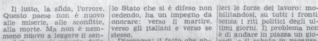

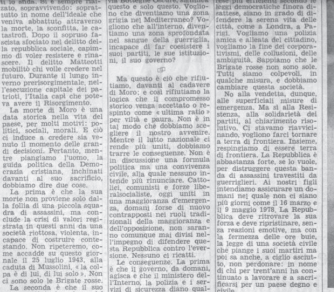

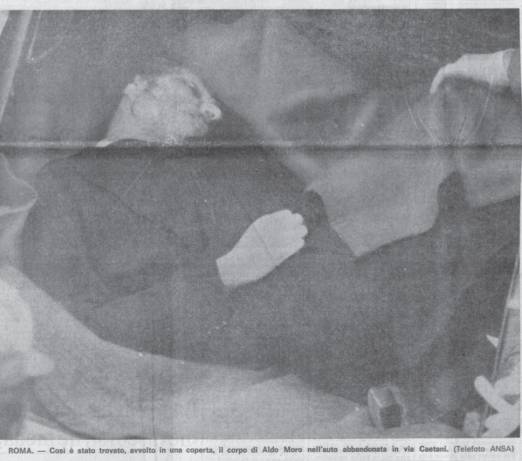

L'hanno trucidato con una raffica al cuore

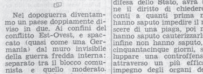

Ora scatfa un nuovo piano antiferrorismo

La volontà

popolare:

Prendetelis

\section{난}

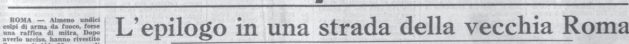

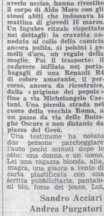

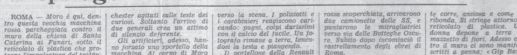

-
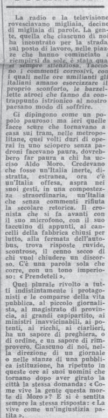

$=\frac{1}{m}=$

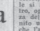

PICTURE 6: Front page of the Corriere della Sera of May 10, 1978.

Here Moro is explicitly represented as the agent of his own sacrifice and, therefore, as a voluntary martyr. The martyrdom of Moro assumes the connotation of a testimony and an appeal to future generations: you must be willing to die for the defense of the state. Like all of the other newspapers, 
the Corriere della Sera also recorded the reactions of the DC politicians, especially of Secretary Benigno Zaccagnini, who said: «I think of what Aldo Moro was for all of us, for Christian Democracy, his faith in freedom, illuminated by his extreme sacrifice.» ${ }^{123}$ Sacrifice for the state and sacrifice for the DC coincide with each other. Here the polyvalence and openness to resignification of the concept of sacrifice becomes manifest, inasmuch as it was used to indicate both Moro's sacrifice for the Republic and his sacrifice for the party on the same day and in the same newspaper. Furthermore, the newspaper reported different reactions coming from the Vatican media, for example that of Radio Vaticana, which asserted that it could not find the proper words to describe Moro's assassination, but that the wickedness of the criminals conferred an "almost sacrificial value» to the crime. ${ }^{124}$ The newspaper even reported the reaction of Swiss Confederation President Willi Ritschard, who said that «President Moro [...] has fallen [as a] martyr of democracy» ${ }^{125}$ and in an article with the headline «Today's History Has Roots in Far-off Crimes. That Day We Remembered How the Mateotti Martyrdom Began», the rhetorical instrument of prefiguration is once again used to include Moro's death in a sort mythical understanding of history as a universal struggle between good and evil forces, where violence happens in cyclical rhythms. ${ }^{126}$ The journalist Walter Tobagi reused the prefiguration the following day in an article called «From Matteotti to Moro: Two Crimes Against Democracy. A Martyr That Failed to Stop the Plots of Fascism». ${ }^{127}$

On page three, La Stampa published the reactions of several intellectuals and public personalities, including Cardinal Michele Pellegrino, Luigi Firpo, Arturo Carlo Jemolo, Norberto Bobbio, and Giovanni Conso. The

123 Padellaro, Antonio, «14,30: la disperazione entra nel palazzo di piazza del Gesù», Corriere della Sera, 10.5.1978, 4; it.: «Penso a quello che Aldo Moro è stato per tutti noi, per la democrazia cristiana, la sua fede nella libertà, illuminata dal suo estremo sacrificio.»

124 De Santis, Fabrizio, «Il dolore di Paolo VI dopo l'inutile appello - Il giornale vaticano: Dall'orrore alla speranza», Corriere della Sera, 10.5.1978, 5; it.: «un valore quasi sacrificale»

125 Barino, Mario, «Berna - Le BR hanno sbagliato i loro calcoli», Corriere della Sera, 10.5.1978, 10; it.: «Il presidente Moro [...] è caduto martire della democrazia.»

126 Tobagi, Walter, «Storia di oggi che ha radici in delitti lontani. Quel giorno ricordammo come ebbe inizio il martirio di Matteotti», Corriere della Sera, 10.5.1978, 8.

127 Tobagi, Walter, «Da Matteotti a Moro: due delitti contro la democrazia - Un martirio che non riuscì a fermare le trame del fascismo», Corriere della Sera, 10.5.1978, 6 . 
main headline on the page is «The Sacrifice That No One Will Forget». Cardinal Pellegrino-one of the signatories of the document who denied the authenticity of Moro's letters - wrote an article titled «The Death of the Innocent Mysterious Plan of God», saying that

Aldo Moro has disappeared before our eyes, but lives on in the grateful memory of the true Italians, of those who seek justice, freedom, and solidarity inspired by love. Aldo Moro taught us by word and example, to live and fight for these ideals, he teaches us, through his sacrifice, to remain steadfast in our faith, to hope against hope, even at this moment, one of the darkest and saddest, not only for his family and for his friends, but for Italy, for the big family of mankind. [...] God is our father and does not abandon us. It seemed that on the cross he had abandoned his Son, the innocent who expiated the sins of us all. But the sacrifice of Christ was our salvation. The sacrifice of those who suffer with Christ is, in the mysterious design of God, fruitful for our brothers. ${ }^{128}$

The sacrifice for the salvation of the world is here, once again, compared to the sacrifice for the salvation of the Italian collective. Moro is represented as a martyr that imitates Christ in his Passion, a Passion that must serve as an example for other martyrs to come. The Republican Luigi Firpo also represented Moro's death through recurring biblical images, referring to an Old Testament narrative:

Moro is ideally connected, with this heartbreaking outcome, to those, like him innocent, who fell at his side. [...] We have to proclaim loudly and clearly that their blood was not shed in vain. It cries revenge in the presence of God, awakens the dormant consciences, nourishes the firm

128 Pellegrino, Michele, «La morte dell'innocente disegno misterioso di Dio», La Stampa, 10.5.1978, 3: it.: «Aldo Moro è scomparso ai nostri occhi, ma vive nella memoria riconoscente dei veri italiani, di quanti cercano la giustizia, la libertà, la solidarietà animata dall'amore. Aldo Moro, che ci ha insegnato con la parola e con l'esempio, a vivere e a lottare per questo ideali, ci insegna, con il suo sacrificio, a mantenerci saldi nella fede, a sperare contro ogni speranza, anche in questo momento, uno dei più bui e più tristi, non solo per la sua famiglia e per i suoi amici, ma per l'Italia, per la grande famiglia degli uomini. [...] Dio è padre e non ci abbandona. Sembrava che sulla croce avesse abbandonato il suo Figlio, l'innocente che espiava per noi tutti colpevoli. Ma il sacrificio di Cristo fu la nostra salvezza. Il sacrificio di chi soffre con Cristo è, nel misterioso disegno di Dio, fecondo di bene per i nostri fratelli.» 
intentions, and marks both perpetrators and instigators with the mark of Cain. ${ }^{129}$

The rhetoric of blood and revenge, the mark of Cain: the conflict BR versus Italian State takes on a mythical connotation where the blood of innocents legitimizes the violence of the avenging and uncompromising state needed to defeat the wicked. In his article, Arturo Carlo Jemolo also recurred to the biblical archetype of the brother enemy, but in a slightly different way. He wrote that «there is nothing to be ashamed of [...]; I do not know of any people in history that were purely heroic [...]. In the face of such a perfect organization, I also think that special laws are useless; or they should be such $[\ldots]$ that my conscience says: no. It would be a propter in vitam, vivendim perdere causam. I prefer to die like Abel than live like Cain.» ${ }^{130}$ This passage is quite twisted because it begins by implicitly justifying Moro's letters, saying that not everyone can be brave, then continues by arguing that no special laws (the author means laws that are probably not in accordance with certain constitutional articles) should be made to facilitate the capture of the BR, because this would be inconsistent with democratic consciousness, and finally declares that it is better to die for a cause than to live as a traitor. In a few lines, the author thus succeeds in justifying the line of firmness and in representing Moro as a coward, who did not die with dignity for the cause of the state but who, through a violent death, turns into Abel, the innocent victim.

The philosopher, jurist and historian Norberto Bobbio, who had signed the appeal published in Lotta Continua, saw the assassination of the politician as an event in the face of which all citizens had the duty to identify with the Republic:

Now the dilemma either with the BR or with the States, which puts on the same level a gang of criminals and millions and millions of Ital-

129 Firpo, Luigi, «Feroci e senza un futuro», La Stampa, 10.5.1978, 3: it.: «Moro si ricongiunge idealmente, con questo esito straziante, a quelli, come lui innocenti, che caddero al suo fianco. [...] Si proclami alto e forte che il loro sangue non è versato invano. Esso grida vendetta al cospetto di Dio, risveglia le coscienze assopite, alimenta i fermi propositi, segna gli esecutori e i mandanti con il marchio di Caino.».

130 Jemolo, Arturo Carlo, "Adesso è indispensabile essere un popolo unito", $L a$ Stampa, 10.5.1978, 3: it.: «Non c’è [...] da vergognarsi [...]; non conosco nella storia alcun popolo composto tutto di eroi. [...] Di fronte a una organizzazione così perfetta penso io pure che leggi speciali siano inutili; o dovrebbero essere tali $[\ldots]$ che la mia coscienza dice: no. Sarebbe un propter vitam, vivendi perdere causam; preferisco Morire come Abele che vivere come Caino.». 
ians who recognize themselves, despite everything, in the State, is no longer tolerable [...]. Today, more than ever, we feel the need to be united around our Republic. ${ }^{131}$

The jurist and future minister Giovanni Conso wrote an article in which, by quoting and decontextualizing some passages of one of Moro's monographs on criminal law, tried to prove that Moro, at least the Moro before March 16, had always held the view that «The Interests of the State Must Always Have Priority Over Individual Ones»:

To disregard the subjective profiles of law means transforming human life into strange and tough social mechanics of actions and reactions where every light of humanity is gone, dazzled. The law and the State must ensure that, in the conflict of motives that pushes someone to act, every citizen gives prevalence to the motif corresponding to the objective voice of ethics, having social needs as a measure. All this does not detract from the fact that the interest protected by criminal laws always refers to the State, the sole and true passive subject of the crime. From this perspective, private individual interest remains devoid of direct protection. There is therefore no subjectification of the criminal form in favor of the individual, but a sublimation of the individual interest in the sphere of public interest. A sublimation that can lead to sacrifice. ${ }^{132}$

131 Bobbio, Norberto, «Per lo Stato democratico», La Stampa, 10.5.1978, 3: it.: «Ora non è più tollerabile il dilemma né con le Brigate rosse né con lo Stato, che pone sullo stesso piano una banda di criminali e milioni e milioni di italiani che si riconoscono nonostante tutto nello Stato [...]. Mai come oggi sentiamo il dovere di stringerci attorno alla nostra Repubblica.»

132 Conso, Giovanni, «Il giurista Aldo Moro: «Gli interessi dello Stato devono essere prioritari su quelli individuali»», La Stampa, 10.5.1978, 3: it.: «Prescindere dai profili soggettivi del diritto significa trasformare la vita umana in una strana e dura meccanica sociale di azioni e di reazioni, dove ogni luce di umanità è spenta, abbagliata. Diritto e Stato debbono far si che, nel conflitto dei motivi che spingono ad agire, ogni cittadino dia prevalenza al motivo corrispondente alla voce oggettiva della eticità avendo come metro le esigenze sociali. Tutto ciò non toglie che l'interesse tutelato dalle leggi penali faccia sempre capo allo Stato, unico e vero soggetto passivo del reato. In questa prospettiva l'interesse privato individuale resta privo di una tutela diretta. Non esiste, quindi, una soggettivazione della forma penale a favore del singolo, ma una sublimazione dell'interesse individuale nella sfera degli interessi pubblici. Una sublimazione che può portare fino al sacrificio.» [The passages in italics are quotations from Moro's book L'antigiuridicità penale (Palermo: Priulla, 1947)]. 
Conso thus distorted Moro's juridical studies to construct the jurist and politician as a voluntary martyr. Moro would never have said that the «objective voice of ethics», which for him was natural law understood from a Christian point of view, is equal to the positive law of the state. The second quotation is completely distorted, since Conso insinuated that Moro considered the interests of the state to be equivalent to public interest, which is simply not true. In fact, Moro had always had a pluralistic view of civil society and was convinced that «man is not only a singularity, not only an individual, but he or she is society in its various forms, a society that is not fulfilled by the state.» ${ }^{133} \mathrm{He}$ was firmly convinced that «the problem of law's sociality has to be resolved in a positive sense, and the rediscovered legal ethical essence of every ordinance, including that of the state, poses [...] delicate problems regarding the relationship between the various ordinances, which all implement, for the part that concerns them, all human ends in the light of one supreme ethical law.» ${ }^{134}$ Aldo Moro, in other words, supported the primacy of the dignity of the person as a social being, and placed emphasis on the irreducibility of the person to the political body. ${ }^{135}$ So Conso, by placing social interests and the interests of the state on the same level, not only distorted and overwhelmed Moro's juridicalethical thought, but also strategically avoided answering the simple question: how exactly would the exchange of prisoners endanger the social sphere? What he could not or did not want to say was that the power interests of parties, primarily of the DC, were in danger.

Meanwhile, Eugenio Scalfari replied to Socialist Giuseppe Saragat, who the previous day had said that «beside [Moro's] corpse there is the corpse of the First Republic, which has not been able to defend the life of the most generous political man in the country». The director of La Repubblica criticized this formulation by writing that the words of Saragat would «become

133 Moro said this during the session of the Commission for the Constitution (Commissione per la Costituzione) of March 24, 1947, which was in charge of elaborating and proposing the draft of the Constitution of the Italian Republic; quoted in Bobbio 1980, 25; it.: «L'uomo [...] non è soltanto singolo, non è soltanto individuo, ma è società nelle sue varie forme, società che non si esaurisce nello stato.»

134 Moro 2006, 149; it.: «Il problema della socialità del diritto ha da essere risoluto in senso positivo e la ritrovata essenza etico giuridica di ogni ordinamento ivi compreso quello statuale, mentre fa vedere in più concreta luce la società umana, pone [...] delicati problemi di rapporto fra i diversi ordinamenti, che attuano tutti, ciascuno per la parte che ad esso competa, tutti i fini umani nella luce di una sola suprema legge etica.»

135 See Bobbio 1980, 7-26. 
reality only if we all fail to face the work of re-establishing the first [Republic], the one that was born of anti-fascism, resistance and the union of democratic forces.» ${ }^{136}$ Here Moro's body becomes a metaphor of the political body, which according to Saragat died with Moro, but in Scafari's text it assumes the meaning of a starting point for a new beginning: the death of the individual, the resurrection of the political body. The newspaper also published the message of President of the Republic Giovanni Leone, who again explained to the public who the BR really were: «the beasts [...] did not even hear the cry that the whole of humanity called out, asking for the liberation of this man.»137 Like other newspapers, La Repubblica published some articles dedicated to the biography and personality of the assassinated politician. Reading the article by Corrado Augias, one almost has the impression it is a text of Christian hagiography:

The thinness exhausted physically, the difficulties of an almost indecipherable syntax, and the imprint on the face of mysterious suffering are the external data that $[. .$.$] had made of him an almost oracular$ stature. [...] His physiognomy, which in the past had characteristics of southern and small-bourgeois bonariety, was marked by age, with almost hieratic traits. He walked slowly, reclining his head slightly, talking without raising his voice, almost reluctantly. 138

L'Unità, besides focusing on the united reaction of «the people», emphasized the bestiality and inhumanity of the BR, which, «by using coercive

136 Scalfari, Eugenio, «Contro il terrore le leggi della Repubblica», La Repubblica, 10.5.1978, 1-2; it.: «Accanto al suo cadavere c’è anche il cadavere della prima Repubblica che non ha saputo difendere la vita del più generoso uomo politico del paese.> [...] Quello che Saragat teme e che taluno forse si augura, che cioè il 9 maggio le BR ci abbiano consegnato il cadavere della prima Repubblica, può diventare realtà solo se tutti insieme non affronteremo l'opera di rifondare la prima, quella nata dall'antifascismo, dalla Resistenza e dall'unione delle forze democratiche.»

137 La Repubblica, «Messaggio di Leone al paese», 10.5.1978, 2; it.: «Le belve [...] non hanno ascoltato neppure il grido che l'umanità intera ha lanciato perché quest'uomo fosse liberato.»

138 Augias, Corrado, "Quell'apparente paradosso della sua azione politica», $L a R e$ pubblica, 10.5.1978, 11-12; it.: «La magrezza estenuata del fisico, le difficoltà di una sintassi quasi indecifrabile, l'impronta sul volto di una sofferenza misteriosa, cono dati esteriori che $[. .$.$] avevano fatto raggiungere alla sua figura una$ statura quasi oracolare. [...] La sua fisionomia, che ebbe in anni lontani caratteristiche di bonarietà meridionale e piccolo-borghese, s'era andata segnano, con l'età, di tratti quasi ieratici. Camminava con lentezza, il capo leggermente reclino, parlava senza mai alzare la voce, quasi con riluttanza.» 
means that we are uninformed about, but which we can imagine, have martyred a man, devastated his mind, tried to use him cynically against his own ideas, against his dearest friends and the party.» ${ }^{139}$ The newspaper of the DC was instead completely focused on praising the political and human figure of Aldo Moro, who

is not dead and cannot die, because he has paid the highest price for his ideal of a democracy that is tolerant and open to novelty. [...] Aldo Moro has paid with his life [...] a huge tribute of pain and blood to a cause in which, today more than ever, all Italian people can and must recognize themselves. That is why we are certain that all Italian people will act $[\ldots]$ to eradicate the mortal cancer of terrorism from its body. ${ }^{140}$

Even more explicit was Alfredo Vinciguerra, who described Moro as the «master and martyr of liberty», who «is alive in the people's conscience.» ${ }^{141}$ Alongside Vinciguerra's article, was an article headlined «So the Pope Has Lived the «Passion> of Moro», which described the reactions of the Vatican. ${ }^{142}$ On May 11 Il Popolo, like La Stampa had already done the previous day, published the reactions of intellectuals and public figures under the main headline «Lections of Martyrdom». The most explicit martyrological representation was probably the one given by historian Gabriele De Rosa, who wrote that the BR «have not returned to the Country the dead body of Aldo Moro, but the living body of a martyr, the greatest martyr of the

139 Reichlin, Alfredo, «Perché l'hanno ucciso», L'Unità, 10.5.1978, 1; it.: «Usando mezzi coercitivi che non conosciamo, ma che possiamo bene immaginare, hanno martoriato un uomo, ne hanno devastato la mente, hanno cercato di usarlo cinicamente contro le sue stesse idee, contro i suoi amici più cari e il partito.»

140 Il Popolo, «Il prezzo più alto", 10.5.1978, 1; it.: " [...] non è morto e non può morire, proprio perché egli ha pagato il prezzo più alto a questo suo ideale di una democrazia insieme tollerante ed aperta fiduciosamente alle novità. [...] Aldo Moro ha pagato con la sua vita [...] un tributo enorme di dolore e di sangue ad una causa nella quale, mai come oggi tutto il popolo italiano può e deve riconoscersi. Per questo siamo certi che tutto il popolo italiano saprà reagire $[\ldots]$ per estirpare dal proprio corpo il cancro mortale del terrorismo.»

141 Vinciguerra, Alfredo, «Un paese folgorato», Il Popolo, 10.5.1978, 3; it.: «Maestro e martire della libertà [...] è vivo nella coscienza comune.»

142 Narducci, Mario, «Così il papa ha vissuto la passione di Moro», Il Popolo, 10.5.1978, 3 . 
modern history of the Italian and European democracy.» ${ }^{143}$ Here Aldo Moro assumed not only the role of a martyr of the Italian State, but of all the European states or, more precisely, of the European community itself. So wrote Sandro Caputo in an article headlined «The First Statesman Martyr of the Free European Community». ${ }^{144}$

We find this kind of representation in a speech given on the same day in Strasbourg by the President of the European Parliament, the Christian Democrat Emilio Colombo:

Dear colleagues, we now want to commemorate Aldo Moro, who was barbarously sacrificed. [...] The upper hand has retained an ice-cold, calculating, incomprehensible brutality, which has turned his captivity into sacrifice and martyrdom. [...] Moro was sacrificed for the very ideals for which he fought as a lecturer, as a politician, and as a statesman during his long, laborious, often controversial, but certainly fruitful years. [...] The Italian Constitution bears, especially in the section about the fundamental rights of man and of the citizen in a democratic society, the stamp of that Christian personalism, which influenced his conception of man, of society and of the state. ${ }^{145}$

Here, the victim is described as a defender of fundamental rights. Death itself takes on the meaning of a real witness to the moral truth of those rights. This death is the "price» that Moro (and with him the whole nation) «pays» for his commitment to fundamental rights. Moro is to some extent simultaneously a Christian martyr and a state martyr, inasmuch as the basic values of Christianity and those at the heart of the Italian Constitution are considered similar, if not identical. Moreover, there is another very significant aspect to highlight: in Colombo's speech, it is impossible to identify exactly who the intended agent of the sacrificial act is. There is a passage that, perhaps more than others, clarifies this lack of clarity. Colombo said that «incomprehensible brutality $[\ldots]$ has turned the captivity into sacrifice and martyrdom.» This formulation clearly has a strategic function, since it allows the speaker to make use of the rhetoric of martyrdom and

143 De Rosa, Gabriele, «Il suo nome è impresso a caratteri indelebili nella coscienza civile di tutti i popoli amanti della libertà»», Il Popolo, 11.5.1978, 5; it.: «Le Brigate rosse non hanno restituito al Paese il corpo morto di Aldo Moro, ma il corpo vivo di un martire, del più grande martire della storia moderna della democrazia Italiana e europea.»

144 Caputo, Sandro, «Il primo statista martire della libera Comunità europea», Il Popolo, 10.5.1978, 7.

145 Colombo 1978, 5-6. 
sacrifice without explicitly naming an agent. The BR are obviously the only agents of such brutality; however, in Colombo's speech they are not really addressed as the sacrificers of Moro. It is brutality, violence itself, which here qualifies the event as martyrdom. Detached from the intentionality of the subjects, the event of violence itself acquires a metaphysical connotation. It becomes a metaphysical force that acts in history, conferring a transcendental meaning to what has happened. An almost Manichean conception of history seems to be operative here, according to which a cosmic force-evil-operates in the world and determines the fate of a whole nation.

On May 11 two topics dominated media headlines: the commemoration in parliament and the private funeral in Torrita Tiberina. The newspapers described how the family buried Moro «silently» and «secretly» and reported that representatives of the DC and of the Church had unsuccessfully tried to persuade the family to allow a public funeral. ${ }^{146}$ Despite the family's statement, a public ceremony was held on May 13 in the Archbasilica of St. John Lateran in the absence of Moro's body. Zaccagnini, according to La Repubblica, justified the decision by saying that «the Moro family has to be understood. Moro, however, was one of the country's leaders, his public character belongs to the DC and the nation.» ${ }^{147}$ Similarly, the Communists' argument was that the family had to respect the needs of the collective and popular sentiment, because Moro belonged to Italy. ${ }^{148}$ As Wagner-Pacifici observes, "the representatives of the newly installed government, the major political parties, the established mass media, and the hierarchy of the Catholic Church enacted and attended public ceremonies of reconciliation. These ceremonies were to symbolize Italy's reunification, made possible by Moro's sacrifice.» ${ }^{149}$ All of the most important political personalities, delegates of a hundred countries, and the Pope participated in the funeral. Compared with what the newspapers wrote in the days leading up to it, the Pope's prayer at the end of the rite was not full of martyro-

146 Pansa, Gianpaolo, «Moro sepolto in silenzio», La Repubblica, 11.5.1978, 4; L'Unità, «La famiglia l'ha sepolto in silenzio nel paesino dove amava rifugiarsi», 11.5.1978, 2; Fedi, Giuseppe, «D’improvviso la famiglia lo ha seppellito in segreto", La Stampa, 11.5.1978, 1.

147 Pansa, Gianpaolo, «Moro sepolto in silenzio», La Repubblica, 11.5.1978, 4; it.: «La famiglia Moro va compresa. Moro, tuttavia, è stato uno dei leader del paese, il suo personaggio pubblico appartiene alla DC e alla nazione.»

148 See Katz 1980, 147.

149 Wagner-Pacifici 1986, 208. 
logical rhetoric but above all concerned the endurance of pain caused by death and the hope of eternal life:

Lord, listen to us! [...] You have not heard our supplication for the safety of Aldo Moro, for this good, gentle, wise, innocent man and friend; but You, Lord, did not abandon his immortal spirit, marked by faith in Christ, which is resurrection and life. For him, for him, Lord, listen to us. ${ }^{150}$

For La Stampa, that prayer had not only a religious but, above all a political significance, inasmuch as

for the men of the Italian government, rigid assertors of a democratic law that is the only defense for all citizens (even when the price is the life of a friend, brother, master), the comfort of the papal magisterium is extremely important, no less than the fraternal presence of the delegations of one hundred nations. ${ }^{151}$

Journalist Igor Man described the crowd and the flags outside of the Archbasilica in order to highlight, again, the people's and the parties' unity:

Outside the basilica, in the square [...] white, red, and green flags hoisted by young Republicans flutter in the wind. There are fifty thousand laymen and believers, mute and moved, standing or kneeling. There are some who are weeping but even some who are cursing the «executioners and assassins〉 [...]. Fifty thousand people: policemen, Carabinieri, soldiers, villagers, workers and the unemployed, people of ancient wards, women and children, young and old people, all together gathered to reflect, to pray, to curse. ${ }^{152}$

150 La Stampa, «Il discorso del Papa», 14.5.1978, 1; it.: «Signore, Ascoltaci! [...] Tu non hai esaudito la nostra supplica per la incolumità di Aldo Moro, di questo uomo buono, mite, saggio, innocente ed amico; ma Tu, o signore, non hai abbandonato il suo spirito immortale, segnato dalla fede nel Cristo, che è la risurrezione e la vita. Per lui, per lui, Signore, ascoltaci.»

151 La Stampa, «Solidarietà umana e politica», 14.5.1978, 1; it.: «Per gli uomini del governo italiano, rigidi assertori di una legge democratica che è la sola difesa per tutti i cittadini (anche quando il prezzo sia la vita di un amico, fratello, maestro), il conforto del magistero papale è di altissima importanza, non meno della presenza fraterna delle delegazioni di cento nazioni.»

152 Man, Igor, «Paolo VI e i delegati di cento paesi al solenne rito funebre in Laterano, La Stampa, 14.5.1978, 1; it.: «Fuori dalla basilica, nella piazza [...] garriscono il vento bandiere bianche bandiere rosse, e quelle verdi issate dai giovani repubblicani. Laici e credenti sono in cinquantamila, muti e commossi, che in piedi, chi in ginocchio. C’è chi piange man anche chi impreca contro $\mathrm{i}$ 〈boia assassini» 
In their commentary on the funeral, the editorialist of Il Popolo wanted to emphasize "which» Moro was commemorated on May 13: «In a recent speech, one of the last he made, Aldo Moro underlined the extreme passion> with which he has lived out his political commitment, which is the DC's commitment. [...] It is to this Moro that yesterday we said goodbye.» ${ }^{153}$ People must therefore forget the Moro of the letters: only the man who with «extreme passion» devoted himself to politics is worthy of being remembered. In the Corriere della Sera, journalist Fabrizio de Santis argued that the ceremony in the Archbasilica «is not the funeral of Aldo Moro, because the funeral was celebrated in silence last Wednesday [...], but the ceremonial tribute to the memory of a statesman who remained the victim of a national tragedy, the witness of faith overwhelmed by barbarism.» ${ }^{154}$ From outside the Archbasilica, another journalist reported that «when the Pope defines Moro as a (good, wise, gentle man, elderly ladies shout: 〈Holy, Holy! ' Then they receive the blessing.» ${ }^{155}$ The popular worshiping of Moro as a secular and religious martyr had definitely begun.

The state funeral for Aldo Moro seems to have the analogous function of the funeral per imaginem as described by Agamben, namely the rite in which a wax effigy or «colossus» takes the place of the missing corpse of the sovereign. Addressing the rite of the image in the Roman imperial apotheosis, Agamben argues that

the death of the emperor (despite the presence of the corpse, whose remains are ritually burned) frees a supplement of sacred life, as in the case of the man who survived consecration, must be neutralized by means of a colossus. Thus, it is as if the emperor had in himself not

[...]. Cinquantamila persone: poliziotti, carabinieri, soldati, borgatari, operai e disoccupati, popolino dei rioni antichi, donne e bambini, giovani e vecchi, tutti insieme raccolti a riflettere, a pregare, anche a maledire.»

153 Il Popolo, «L'ultimo addio per un 'giusto»", 14.5.1978, 1; it.: «In un recente discorso, uno degli ultimi discorsi da lui pronunciati, Aldo Moro sottolineava l'eestrema passiones con cui egli ha vissuto in ogni momento il suo impegno politico, che è l'impegno della DC. [...] È a questo Moro che ieri abbiamo detto addio.»

154 De Santis, Fabrizio, «Attorno al Papa si è trovato unito tutto il mondo politico italiano», Corriere della Sera, 14.5.1978, 2; it.: «Non è il funerale di Aldo Moro, perché il funerale fu celebrato in silenzio mercoledì scorso [...], ma il doveroso omaggio funebre alla memoria di un uomo di stato rimasto vittima di una tragedia nazionale, di un testimone della fede travolto dalla barbarie.»

155 Corriere della Sera, «Bandiere bianche, rosse, verdi», 14.5.1978, 1; it.: «Quando il pontefice definisce Moro come un uomo buono, saggio, giusto, le vecchiette gridano: 〈Santo! Santo!〉 Poi ricevono la benedizione.» 
two bodies but rather two lives inside one single body: a natural and a sacred life. The latter, regardless of the regular funeral rite, survives the former and can only ascend to the heavens and be deified after the funus imaginarium. [...] We find ourselves confronted with a bare life that has been separated from its context and that, so to speak surviving in death, is for this very reason incompatible with the human world. [...] For the emperor, the double funeral makes it possible to fasten onto the sacred life, which must be gathered and divinized in the apotheosis. [...] For the sovereign, death reveals the excess that seems to be as such inherent in supreme power, as if supreme power were, in the last analysis, nothing other than the capacity to constitute oneself and others as life that may be killed but not sacrificed. ${ }^{156}$

Despite Moro's body not being replaced by a colossus, the funeral in the absence of his mortal remains also had the function of neutralizing a supplement of sacred life. In fact, since Moro had previously been reduced to bare life by annihilating his public image, that is, his image as a sovereign statesman, it was necessary to reconsecrate him as the sovereign-martyr who had sacrificed his life for the salvation of the nation-state. Precisely because Moro was reduced to a bare life that can be killed but not sacrificed, it became necessary to perform a funeral that was a performance of consecration. ${ }^{157}$ Only after this performance could Moro definitely be worshipped as a sovereign-martyr. The BR only killed Aldo Moro; the Italian State had to consecrate him in order to let him ascend to the heaven of state mythology. The representatives of the constituted power could not afford to allow Moro, after all that he had written, to become the paladin of criticism of the function of power. From the naked life to which he was reduced, the natural life that was buried two days earlier in Torrita Tiberina, Moro had to reassume the role of the sovereign. The media campaign during his imprisonment had progressively separated Moro from his context, his public life form, thus transforming him into a homo sacer, that is, this strange life that lives outside both the sacral and profane spheres. The double funeral of Moro-public and private-seems to fulfill the need to «fasten onto the sacred life, which must be gathered and divinized». The state ritual turned Moro the homo sacer, the liminal figure of the political-juridical system, into Moro the sovereign, the nation's political body. The public funeral basically had the function of hiding the symmetry between the

156 Agamben 1998, 100-101.

157 See Heywood 2009. 
body of the homo sacer and the body of the sovereign, which, as Agamben argues, is at the very heart of modern political order: every life is dispensable, also and above all the life of someone who, for a certain amount of time, represented sovereign power.

Major political parties, representatives of the government and most parts of the established media thus tried to take possession of Aldo Moro and to establish his memorialization as the sovereign-martyr who sacrificed his life for the state's and society's salvation. However, not everyone accepted the hegemonic and doxological representation of the funeral. Despite the main headline on the first page of La Repubblica - «Moro's Funeral Closes the Most Dramatic Chapter of the Republic»-expressing the will to break with the past and look to the future, Scalfari's editorial gave a very different and less optimistic interpretation of the funeral, arguing that:

The country, in that immense and naked basilica, was not there. The people, with their passion and spontaneity, were absent, just as absent were the widow and the children of the deceased. The protagonist of that funeral was only the Institution, through its ancient and recent representatives, Catholics and secularists, Christian Democrats and Communists, who arrived together at this fatal destination. [...] It is difficult to understand what has gone on in the minds of those presidents, of those ministers, of those chamberlains of Catholic Power [...]. One thing is certain: between their past and their future there is a dead man, one of them, their guide. That dead man will weigh on everyone and it will not be easy to get rid of him. ${ }^{158}$

This article anticipated a sense of aversion to the ritual and discursive practices used to construct a state martyr figure, which would continue to persist and partly spread over the years to come. Scalfari's article represented Moro's death more as a sacrilege than a sacrifice, the funeral more as a profanation than a sacralization of the memory of the politician. In this ar-

158 Scalfari, Eugenio, «Lo sgomento dopo 30 anni di potere», La Repubblica, 14.5.1978, 1-2; it.: «Il paese, in quell'immensa e nuda basilica, non c'era. Il Popolo, con le sue passioni e la sua spontaneità, era assente, così come assenti erano la vedova e i figli dello scomparso. Protagonista di quella messa funebre era soltanto l'Istituzione, attraverso i suoi rappresentanti antichi e recenti, cattolici e laici, democristiani e comunisti, arrivati insieme a questo fatale appuntamento. [...] È difficile capire che cosa si è passato nell'animo di quei presidenti, di quei ministri, di quei ciambellani del Potere cattolico [...]. Una cosa è certa: tra il loro passato e il loro futuro c’è un morto, uno di loro, la loro guida. Quel morto pesa su tutti e non sarà facile liberarsene.» 
ticle, the impression of an unbridgeable distance between Moro's figure and the man of power begins to emerge. The Moro of the letters acts like a ghost that profanes the mechanism of the glorification of power, a voice that from the hereafter will continue to say: I do not belong to you. 


\section{Memorialization Practices and Memory Struggle}

\subsection{Contested Memory and Practices of Memorialization in the Public Space}

Collective memory, particularly what Aleida Assmann calls «political memory», is not simply the sum or condensate of a series of individual memories, but something which is made by institutions and larger social groups with the aid of memorial signs. Through memorial signs, such as monuments, museums, commemoration rites and ceremonies, groups and institutions are able to frame and reframe collective identities. According to Assmann, political constructions of memory consist of three main characteristics. First, they tend towards homogeneous unity and self-contained closure. Second, they are "emplotted» in a narrative that is emotionally charged and conveys a clear invigorating message. Third, they are anchored in material and visible signs as well as in performative actions, which periodically reactivate individual memories and enhance collective participation. ${ }^{1}$ As Biljana Menkovic argues, these materials and visible signs are manifestations of practices of the mythological narration of past events. ${ }^{2}$ Peter Reichel calls this the "politicization of memory", which began with the French Revolution, the emancipation of the bourgeoisie and the emergence of nation-states. ${ }^{3}$ War memorials are the most common public monuments. They are found in cities and villages, especially those commemorating the victims of the Second World War. It thus seems that there is a significant link between political violence and practices of memorialization. Reinhard Koselleck defines this memorialization of events of political violence as the new "political death cult of modernity", which serves for the legitimization of nation-states and the construction of national collective identities. ${ }^{4}$

In Italy, many memorials commemorate the two key moments of modern Italian history, the Risorgimento and the Resistenza. In the fourth chapter, we saw that in both historical contexts the rhetoric of sacrifice and martyrdom was quite diffuse. The use of such rhetoric is documented by

1 See Assmann 2010, 42-43.

2 See Menkovic 1999, 1-3.

3 See Reichel 1995, 21-27.

4 Koselleck 1999, 11. 
memorial signs that can be found in different Italian regions and places. It is useful to consider a few examples. In Mantova, via Chiassi, there is a plaque that commemorates the men condemned to death by hanging in the city between 1852 and 1855 by the general governor of LombardiaVeneto, Major General Josef Radetzky. The plaque states: «In this house, challenging the death, in the night of 2 August 1850, the martyrs of Belfiore and their comrades united to conspire against Austrian oppression». ${ }^{5}$ In Matelica, in the province of Macerata, there is a plaque that commemorates the partisans who died during the war in the town's territory as follows: «In the twentieth anniversary of the Resistance, the city of Matelica, remembering [this experience], immortalizes on this stone the martyrs of the partisan struggle». ${ }^{6}$ Similarly, in Ancona there is a large marble block located at one of the main and most visible access points to the city, in the port area, dedicated to «the fallen and the martyrs of the Resistance». ${ }^{7}$ In some cases, there is no need for the terms «martyr» or «martyrdom» to appear to perceive the presence of a martyrological or at least sacrificial conception of death. This is the case of a plaque located in the Cimitero monumentale della Certosa di Bologna, which states:

Partisan city faithful to ancient traditions did not want to be subjected to the arrogance of the German invader and with the pure blood of thousands of his youngest children, with its houses destroyed in epic diurnal fighting sustained with weapons taken from the enemy, was at the forefront of the unequal struggle and insurrection that in the radiant daybreak of April 1945 led the fatherland to the conquest of its freedom. ${ }^{8}$

Resistance here is clearly conceived as a patriotic struggle against invaders, where the «blood» of the «children» assumes the connotation of a material witness, which can be understood as an appeal to future generations for the defense of the freedom of the «fatherland». Some memorial signs trace

5 It.: «In questa casa sfidando la morte la note del 2 novembre 1850 si unirono a congiurare contro l'oppressione austriaca i martiri di Belfiore e i loro compagni.»

6 It.: «Nel ventennale della Resistenza la città di Matelica memore immortala sulla pietra i martiri della lotta partigiana.»

7 It.: "Ai caduti e ai martiri della Resistenza.»

8 It.: "Città partigiana fedele alle antiche tradizioni non volle soggiacere alla prepotenza del Tedesco invasore e col sangue purissimo di migliaia dei suoi figli minori con le sue case distrutte ed in epici diuturni combattimenti sostenuti con le armi sottratte al nemico fu all'avanguardia nell'impari lotta e nell'insurrezione che nell'alba radiosa dell'aprile 1945 portò la patria alla conquista della sua libertà.» 
a fil rouge between the struggle for Italian unification and the partisan Resistance, such as a plaque located on the old street walls of Frascati, in the province of Rome, which is dedicated «to the Resistance that heroically here marked the second Risorgimento on September 10, 1943».9 Another interesting plaque that is located in the village of Ceppo, in the province of Teramo, where in 1943 there was a battle between partisans and German soldiers, commemorates the fallen of the two nations as martyrs; the plaque states:

Here the battle faded; the prodigy was accomplished on September 25, 1943 in fraternity of arms with Yugoslav patriots and allied soldiers, artisans of Teramo, who were poor of means [but] not of courage, defeated powerful German forces. Established in the $39^{\text {th }}$ anniversary of the victorious day, this monument perpetuates the memory sanctified by the blood of martyrs and the fallen in the Resistance of Teramo. ${ }^{10}$

As shown in the previous chapters, sacrificial and martyrological representations were widely used during and immediately after the 55 days of Moro's imprisonment. It is not surprising, then, that some memorial signs commemorating Aldo Moro also reproduce such rhetoric and language. This is perfectly exemplified by a memorial dedicated to the «memory of Aldo Moro and the fallen soldiers of via Fani» situated in the Apulian city Brindisi and erected in June 1980. The monument was commissioned in 1979 by the municipal administration to artist Marcello Avenali and situated in the center of the roundabout at the north entrance of the city. The website brindisiweb.it provides the following description of the monument:

An anti-rhetorical sculpture, in balance with the chosen environment, set on the verticality of two adjacent bands of steel in modular slabs, both 12 meters high, which attract, reflect, move the light, and which diverge to the point where, perpendicularly, a group of stylized birds fly, as if it were pushed by a thin red line. The idea that life denied by violence nourishes the vitality of freethinking was a guide in the defi-

9 It.: «Alla Resistenza che eroicamente qui segnò il 10 settembre 1943 il secondo Risorgimento.»

10 It.: «Qui divampò la battaglia si compì il prodigio il 25 settembre 1943 in fraternità d'armi con patrioti Jugoslavi e soldati alleati artigiani di Teramo, poveri di mezzi non di valore volsero in fuga possenti forze germaniche eretto nel XXXIX anniversario della vittoriosa giornata questo monumento vuole perpetuarne il ricordo santificato dal sangue dei martiri e caduti della resistenza teramana.» 
nition of that twisted and broken tree, of that flight that quickly moves from red blood. ${ }^{11}$

This description uses a metaphorical reference to blood to signify Moro's death as a sort of sacrifice for the defense of freedom of thought. Similarly, another website refers to the red line as «the symbol of the victim's blood» and stylizes birds as a «symbol of the ideals that despite the violence and death fly high». ${ }^{12}$ Moreover, this rhetoric was also used in the plaque at the bottom of the monument:

Beyond the ephemeral time of the violent [people], Brindisi remembers Aldo Moro, gentle martyr-powerful mind-his blood spilled to forge future destinies for a free and worthy Italy. ${ }^{13}$

Less explicitly martyrological, but still interesting for the analytical purpose of this study, is the bust of the Christian Democrat statist that was erected in Bari in Piazza Aldo Moro. One of the streets facing the square was called via Martiri di via Fani, thus representing Moro's bodyguards as martyrs. The engraving on the stone that holds the bust reproduces a passage from a speech that Aldo Moro gave on March 20, 1976, during the $13^{\text {th }}$ Congress of the Christian Democracy (DC), in one of the most difficult moments of his political career. Here, he was confronted with a government crisis (the Italian Socialist Party had just moved away from the majority and had returned to the opposition), strong criticisms of the government and the party (the Lockheed scandal had just broken out), and in-

11 It.: «Una scultura anti-retorica, in equilibrio con l'ambiente prescelto, impostata sulla verticalità di due fasce affiancate di acciaio in lastre modulari, due superfici alte 12 metri, che attirano, riflettono, muovono la luce, divergono in alto nel punto in cui, perpendicolarmente, prende il volo un gruppo di stilizzati uccelli, come sospinto da una sottile linea rossa. L'idea che la vita negata dalla violenza alimenti la vitalità del pensiero libero fu di guida nella definizione di quell' albero contorto e squarciato, di quel volo che muove rapido dal rosso del sangue.» http://www.brindisiweb.it/monumenti/monumento_aldo_moro.asp (accessed August 20, 2017).

12 It.: "Il monumento è caratterizzato dal movimento sinuoso delle due parti di cui è composto, rappresentanti l'albero della vita squarciato e al suo interno una linea rossa, simbolo del sangue delle vittime e gli uccelli stilizzati simbolo degli ideali, che nonostante le violenze e la morte volano in alto.» http://www.brundarte.it/20 14/05/07/monumento-a-virgilio-e-uno-sguardo-al-patrimonio-monumentale-conte mporaneo/ (accessed August 20, 2017).

13 It.: «Sull'effimero tempo dei violenti, Brindisi leva in ricordo Aldo Moro, martire mite - mente potente - sangue sparso a forgiare destini futuri per un Italia libera e degna.» 
ternal party conflicts caused mainly by its policy of openness toward the Italian Communist Party (PCI). The plaque reproduces only a short passage of this speech, which, as with many of Moro's speeches, is quite long:

This country will not be saved, the great season of rights will be ephemeral, if a new sense of duty does not emerge in Italy. ${ }^{14}$

Extracted from the full text of the speech, this phrase completely loses the meaning it held in its original context, at least for those who did not hear or read the speech. Given that the appeal to duty during Moro's 55 days of prison was above all used by those who appealed to the raison d'État-the duty of not accepting negotiations with the BR-one cannot but notice that the sentence is implicitly used to make Moro's sacrifice appear as the ultimate fulfillment of his duty. There is no doubt that the sentence here assumes an instrumental and non-critical function. Moreover, on the side of Moro's bust, there is a second stone that reproduces the speech by the Pope from April 21, 1978, which, as we saw, implicitly endorsed the «line of firmness» adopted by the government. In Moro's speech, within the context in which it was originally held, the sentence was not an appeal to the «reason of state». On the contrary, Moro spoke of the «disruptive force of youth and the right of revolutionary succession» that initiated a "process of liberation", which "can be neither disputed nor circumvented with false promises». ${ }^{15}$ In other words, he called for the recognition of the demands of social justice-for example, the demand for full «recognition of women's value, $[\ldots]$ of their true independence and equality»—which for years had been expressed by young people, primarily by the student movement. ${ }^{16}$ Moreover, Moro requested the recognition of «the radically new weight that workers have in social organizations, their incomprehensible right to be not a mere tool.» Finally, he said without half measures that

Faced with this [social] blossoming, politics must be aware of its limits, ready to bend over this new reality, which takes away the rigidity of State reason, to give to [this new reality] the breath of man's reason.

14 Moro 1979, 337; it.: «Questo Paese non si salverà, la grande stagione dei diritti risulterà effimera, se non nascerà in Italia un nuovo senso del dovere.»

15 Moro 1979, 336; it.: «Chi può ignorare la forza dirompente della gioventù ed un diritto di successione rivoluzionaria che non può essere né contestata né aggirata con false promesse?»

16 Moro 1979, 336; it.: "Chi può negare che il riconoscimento del valore della donna, della sua originalità, della sua ricchezza, la sua reale indipendenza ed uguaglianza, siano un problema non eludibile a questo punto cruciale dello sviluppo storico?» 
[...] The law must be restored to its universal character, so that not only the law, but rights in their balance, together, prevail, as it is just, in social life. It is not about returning to the old and unbearable constraints, which sacrifice the person to a monstrous deity that does not deserve sacrifices. [...] A long-suffering historical experience brings to light the revolutionary claims of rights. But no society advances, no society achieves its goals, the most radical, of justice if the strict voice of consciousness and authentic sense of community do not place people in the right relationship of social solidarity. This country will not be saved, the great season of rights will be ephemeral if a new sense of duty does not emerge in Italy. ${ }^{17}$

Moro's speech therefore addressed the universality of rights and appealed for the recognition of the ethical primacy of human rights and justice over the «reason of state». That Moro explicitly appealed to his party to not sacrifice the person to the state, to that deity that Hobbes called Leviathan, is significant, since it demonstrates that he was well aware of the function of state mythology. There is no trace of this critique of the rhetoric of the «reason of state» left in the monument erected in Bari. Moro's words were extracted and decontextualized in such a way as to reverse, or at least to silence, its intended meaning.

Maybe the most important memorial sign is the one that was erected in via Caetani, the same place where Aldo Moro's body was found. On the first anniversary of the statesman's death, Moro was commemorated through the erection of a plaque that states:

On the morning of May 9, 1978, fifty days after his barbaric abduction, Aldo Moro's bullet riddled body was found in this place. [...] His sacrifice, coldly wanted with inhuman ferocity by those who tried in vain

17 Moro 1979, 336-337; it.: «Di fronte a questa fioritura la politica deve essere conscia del proprio limite, pronta a piegarsi su questa nuova realtà, che le toglie la rigidezza della ragione di Stato, per darle il respiro della ragione dell'uomo. [...] $\mathrm{Al}$ diritto va restituito il suo carattere universale, sicché non solo il diritto, ma i diritti nel loro equilibrato insieme prevalgano, com’è giusto, nella vita sociale. Non si tratta di tornare alla vecchia e insostenibile costrizione, che sacrifica la persona ad una mostruosa divinità che non merita sacrifici. [...] Una lunga sofferta esperienza storica porta alla luce le rivendicazioni rivoluzionarie dei diritti. Ma nessuna società avanza, nessuna raggiunge i suoi traguardi, i più radicali, di giustizia, se la voce rigorosa della coscienza ed un senso autentico della comunità non collochino le persone nel giusto rapporto di solidarietà sociale. Questo Paese non si salverà, la grande stagione dei diritti risulterà effimera, se non nascerà in Italia un nuovo senso del dovere.» 
to prevent the implementation of a brave and far-sighted program for the benefit of the entire Italian people, will remain as a warning and an instruction to all citizens for a commitment to national unity in justice, peace, in national progress. ${ }^{18}$

On the same day, another plaque was erected in via Fani, which commemorated the death of Moro's bodyguards as follows:

In this place $[\ldots]$ five men loyal [fedeli] to the State and democracy were killed with cold ferocity while fulfilling their duty. ${ }^{19}$

As Ruth Glynn and Giancarlo Lombardi observe, «although both plaques were dedicated on the same day, only in the case of via Caetani is the date of the plaque's erection the anniversary of the death that occurred there. Despite the fact that it was mounted on the anniversary of Moro's death, nothing in the wording of the via Fani plaque acknowledges the connection between the deaths it commemorates and that of the statesman abducted in the same location. In neither case is it acknowledged that those who died were victims of terrorism. In via Fani, the use of the passive voice constructs the deaths as resulting from the actions of unacknowledged forces. [...] Reference to the BR is equally absent from the plaque in via Caetani, where abstract wording dehistoricizes the death commemorated therein by depriving it of concrete agents.» ${ }^{20}$ According to Glynn and Lombardi, the phrase «by those who tried in vain to prevent the implementation of a brave and far-sighted program for the benefit of the entire Italian people» is intended to suggest that the BR were perhaps not the only ones responsible for Moro's death, but rather that some other «forces» were involved in the assassination. Furthermore, they argue that the memorial sign in via Caetani constructs the assassination as an assault on the Italian people as a whole. I agree with this interpretation and would add that this de-historicization serves not only to suggest the possible involvement and responsibility of obscure forces, but also contributes to the

18 It.: «Cinquantaquattro giorni dopo il suo barbaro rapimento, venne trovato in questo luogo, la mattina del 9 maggio 1978, il corpo crivellato di proiettili di Aldo Moro [...]. Il suo sacrificio freddamente voluto con disumana ferocia da chi tentava inutilmente d'impedire l'attuazione di un programma coraggioso e lungimirante $\mathrm{a}$ beneficio dell'intero popolo italiano resterà quale monito e insegnamento a tutti i cittadini per un impegno di unità nazionale nella giustizia, nella pace, nel progresso nazionale.»

19 It.: «In questo luogo [...] cinque uomini fedeli allo Stato e alla democrazia sono stati uccisi con fredda ferocia mentre adempivano il loro dovere.»

20 Glynn/Lombardi 2012, 6. 
mythicization of the event, which assumes the connotation of the outcome of a cosmic, metahistorical battle between good and evil. Reiterating a rhetorical strategy previously used during the 55 days of Moro's imprisonment, those who were responsible for his death are dehumanized: they craved death with «inhuman ferocity». Moreover, this also demonstrates that suggesting the possible involvement of forces and actors other than the BR - that is, the uncritical and superficial reference or implicit allusion to alleged conspiracies-only supports a mythical conception of violence and political conflicts.

Both via Fani and via Caetani serve as key places of annual commemorative practices on March 16 and May 9 (see figures 7 and 8). Glynn and Lombardi rightly point out that "over the years, the nature of commemoration has changed, with significant anniversaries and more recent years witnessing ever greater institutional representation» and that «the hierarchical importance of the via Caetani site has been maintained throughout.» Moreover, they draw attention to the fact that each place «has attested to deep divisions between institutions and the family members of the victims, who have tended to absent themselves from the official events.» ${ }^{21}$ In fact, Moro's family has always sustained, even in recent times, that the masterminds of the kidnapping were not all identified, accusing members of the DC and the government, particularly Francesco Cossiga and Giulio Andreotti, of being responsible for Moro's death. ${ }^{22}$ As previously mentioned in the fourth chapter, in 1998 Luigi Scalfaro, then President of Italy, endorsed the view of Moro's family as well as many historians, politicians and journalists, saying that the members of the BR were only the material performers of the attack, but that others were the real masterminds. Interestingly, after Scalfaro's intervention and during his presidency, the anniversaries of Moro's death became occasions for politicians to appeal to national reconciliation, which in 2008 culminated in the designation of 9 May as the «Memory Day for the Victims of Terrorism».23 David Moss rightly addresses the presence of conflicting practices of memorialization, observing that, «while Moro himself is now memorialized across Italy in annual commemorations, and in the large number of streets, schools and political cultural associations named after him, these external forms of re-

21 Glynn/Lombardi 2012, 6.

22 See Senzani, Fiorenza, «Per Moro non potevamo trattare.) Andreotti replica al figlio dello statista. Cossiga: non leggerò il suo libro», Corriere della Sera, 15.10.2007, 21.

23 See Glynn/Lombardi 2012, 8. 


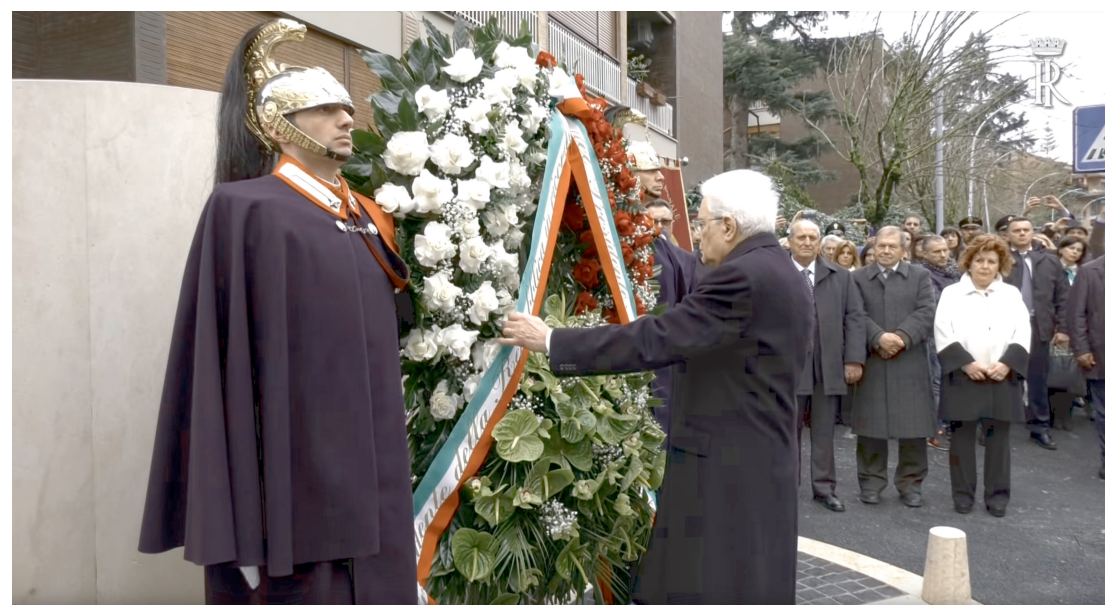

PICTURE 7: Sergio Matterella, 12th President of Italy, in via Fani, Rome, on the 40th anniversary of the kidnapping of Aldo Moro and the killing of his guards, March 16, 2018.

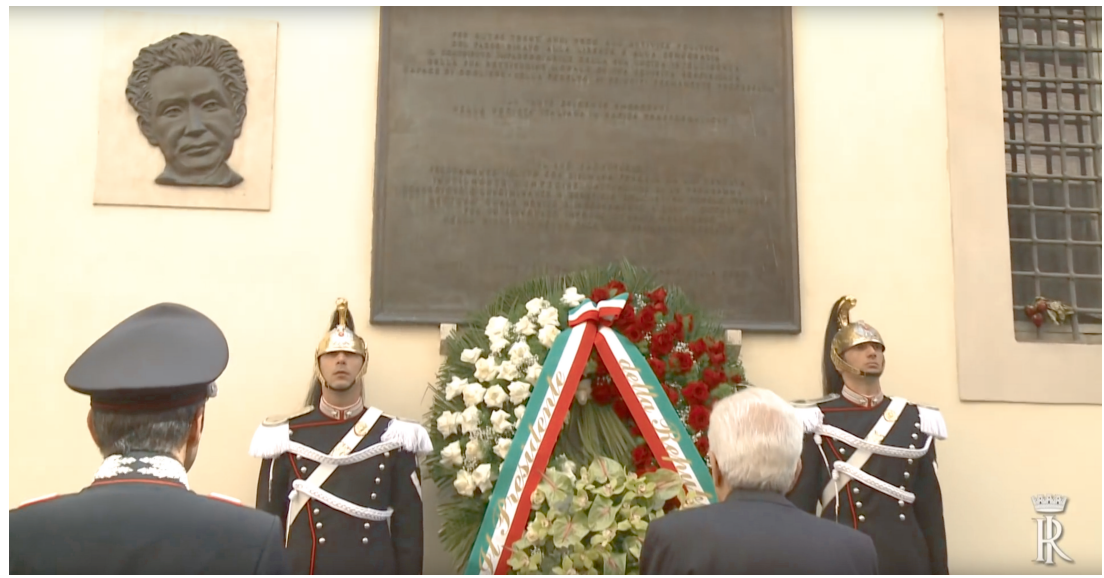

PICTURE 8 : Sergio Matterella, 12th President of Italy, in via Caetani, Rome, on the 37th anniversary of the assassination of Aldo, May 9, 2015.

membrance are not accompanied by a consensual collective memory of the significance of his life and death.» ${ }^{24}$ As an emblematic example of this ten-

24 Moss 2009, 168. 
sion between memorialization practices and unresolved collective memory, Moss points to a controversy that emerged in 1985 when a statue of Moro was erected in his birthplace, Maglie, representing him with a copy of L'Unità under his arm. Criticism of this statue, which is clearly intended to symbolize Moro's policy of openness toward the PCI, was also recently expressed. 25

At each anniversary of the kidnapping and assassination of Aldo Moro, the «Moro case» was and still is widely covered by the media. Despite newspapers focusing mainly on the trials, the work of parliamentary commissions, and the declarations and «revelations» of former members of the Red Brigades (BR), as well as on different conspiracy theories, sacrificial and martyrological language and rhetoric continue to reappear. The wording «the martyrdom of Aldo Moro» or «the sacrifice of Aldo Moro» reappears in many articles describing the commemorative rituals held in via Caetani or via Fani, but generally these articles do not express any judgment on the government's choice to adopt the «line of firmness». There are, however, some exceptions: to give just an example, in the editorial of the March 16, 1988, edition of La Repubblica, entitled «The Martyr Who Refused to Become a Symbol», the journalist Enzo Forcella argued that

[Moro's] sacrifice has served to overcome the abyss opened by terrorism, to restore a minimum of dignity to a shaky state and trust in the laws and moral values that must support any national community. It is a sacrifice, however, that the sacrificial lamb has refused. Until the last, as you know, Moro refused the role that destiny gave him, he did not accept becoming a symbol. The prisoner was right, as were those who did not accept yielding to terrorist blackmail, even at the cost of letting him die. There were, and are, two irreconcilable reasons. This is the topos of all the contradictions, the catastrophe that has transformed the slaughter of an eminent political man and his guards into a great tragedy, one of the rare, authentic tragedies of contemporary politics. ${ }^{26}$

25 See Mieli, Paolo, «Moro non voleva allearsi col PCI - Un compromesso (non) storico», Corriere della Sera, 13.11.2016, http://www.corriere.it/cultura/16_novemb re_13/moro-aldo-compromesso-storico-pci-dc-massimo-mastrogregori-salerno-co munisti-democristiani-ff773f9a-a9c7-11e6-9e75-99cc0b521152.shtml (accessed August 12, 2017).

26 Forcella, Enzo, «Il martire che rifiutò di divenire un simbolo», La Repubblica, 19.3.1988, 1; it.: "Il suo sacrificio è servito a superare il baratro aperto del terrorismo, a restituire un minimo di dignità a uno Stato traballante e di fiducia nelle leggi e nei valori morali che devono sostenere qualsiasi collettività nazionale. È un sacrificio, però, che l'agnello sacrificale ha rifiutato. Sino all'ultimo, come si 
Forcella iterates here the tragic representation of the event already widespread in 1978, by which Moro's death is represented as an inevitable event, something dictated by destiny. Within this tragic narrative, the figure of the scapegoat and the figure of the martyr can coexist, because the will of the martyr, otherwise a condition sine qua non for the allocation of the martyr role, does not matter, since destiny determines historical events.

Four decades after the events of 1978, this kind of uncritical justification of the line of firmness «had come to be questioned by almost all Italians, in the context of a generalized change of attitude towards 'reason of state' on the one hand and the 'right to existence' on the other.» ${ }^{27}$ As Piero Fassino, the former leader of the Democratic Left political party, expressly stated in 2007 after Italian journalist Daniele Mastrogiacomo was kidnapped in Afghanistan: «Moro's story has admonished us to consider that there is no reason of State that justifies the sacrifice of life. Perhaps we had to negotiate even then. Moro's life was just as important as that of Mastrogiacomo.» ${ }^{28}$ The process that led to this change was long and largely promoted by «mediatic reworking of the statesman image»; as Pezzini demonstrates in her important essay, the "recuperation» of Moro's image was traced on television by Sergio Zavoli's Notte della Repubblica (IT, Rai 2, 1990), while his «symbolic resurrection» was epitomized in Marco Bellocchio's film Buongionno, NOTTE (IT, 2003). ${ }^{29}$ However, before we turn our attention to cultural productions that specifically work with images or, more precisely, with moving images, it is necessary to analyze the literary interventions of three important Italian writers, which, in different ways, challenge and overcome hegemonic representations and institutional practices of memorialization, and that anticipate the reworking of Moro's image by television and cinema.

sa, Moro ha rifiutato il ruolo che gli assegnava il destino, non ha accettato di trasformarsi in simbolo. Aveva ragione il prigioniero, avevano ragione coloro che non hanno accettato, pur di salvarlo, di cedere al ricatto terrorista. Erano, e restano, due ragioni inconciliabili. Questo è il topos di tutte le contraddizioni, il punto di catastrofe che ha trasformato l'eccidio di un eminente uomo politico e della sua scorta in una grande tragedia, una delle rare, autentiche tragedie della politica contemporanea.»

27 Pezzini, 2012, 139-140.

28 Mazzocchi, Silvana, "Impossibile trattare per Moro, nel mirino c'era anche il PCI», La Repubblica, 31.3.2007, 15; it.: «La vicenda di Moro ci ha ammonito ha considerare che non c'è ragione di Stato che giustifichi il sacrificio di una vita. Forse bisognava trattare anche allora. La vita di Moro era importante come quella di Mastrogiacomo.»

29 Pezzini 2012, 136. 


\subsection{Literary Interventions}

Critiques of the hegemonic and doxological representation of Moro's death were expressed even before his death. Claudio Martelli, referring to those who denied the authenticity of Moro's letters, observed just over a week before the politician's assassination that «they seem to be more concerned with Moro's «memorys than with his life and discuss the interpretation of a style and a life that has not yet been lost.» ${ }^{30}$ Moreover, a few days after his death, the author of A Clockwork Orange Anthony Burgess observed that the process aiming at constructing the official memory of Moro's kidnapping and assassination had already begun and warned the Italian people «not to transform Moro into a saint». He also mentioned the interesting example of Charles I of England, who, after being executed by Oliver Cromwell, was canonized by the Anglican Church. This was a big mistake, Burgess argued, since through his glorification as a martyr the English conservative party became a theocracy. He expressed the hope, though a bit sarcastically, that this would not happen in Italy: «Christian Democrats in Italy will certainly not want to allow themselves to earn the collective aura of their boss' martyrdom!» ${ }^{31}$

Italo Calvino also intervened in an article published in the Corriere della Sera a week after the discovery of Aldo Moro's corpse in via Caetani. Here, the famous writer basically supported the line of firmness put forward by the government, major political parties and the established media, since

If Moro was kidnapped in order to upset the institutions of the Republic, the action, whoever contributed to inspiring it, could only have been solved in the way it was solved. They wanted to eliminate Moro as the man of the difficult balance between the DC and the PCI. But [they wanted] not to kill him immediately to prevent his last political operation from being consecrated by his martyrdom. Then begins the

30 Martelli, Claudio, «Perché non credere a quelle lettere?», Corriere della Sera, 1.5.1978, 3; it.: «Costoro sembrano più preoccupati della «memoria〉 di Moro che non della sua vita, e si disputano l'interpretazione di uno stile e di una vita che non è ancora perduta.»

31 Quoted in Silj 1978, 187; it.: «Dobbiamo badare bene a non fare di Moro un santo. [...] I democratici cristiani dell'Italia non vorranno certamente consentire a sé stessi di guadagnarsi l'alone collettivo del martirio del loro capo!» 
most perverse phase of the jailers' work: to use Moro against himself, against his party, against the line pursued up to that point. ${ }^{32}$

Calvino directly addressed the topic of martyrology, but seems to exclude the possibility that Moro, as actually happened, could be represented as a state martyr despite the content of his letters. He also believed that Moro would have died anyway regardless of the policy adopted by the government and parties. Moreover, he did not see any metamorphosis in the letters, or any change of perspective between the Moro before and the Moro after March 16, 1978. In fact, he argued, «what Moro wanted or had to write in the sense of taking distance from the men of his party seems to be studied so as not to harm anything or anyone, which is why it can be said that Moro basically remained a party man until the end.»33 However, he stated, «it was clear that Moro renounced his public image and assumed that of a family man, who was only interested in returning home.» ${ }^{34}$ Finally, although he did not seem to assign any responsibility to the government, major parties or the established media for Moro's death, he unconditionally expressed his conviction that the BR's action helped the DC above all:

[...] it is certain that the Red Brigades, inarticulate and fierce, while threatening Christian Democracy in the physical existence of their cadres, paradoxically guarantee them a kind of moral immunity, they help to postpone the examination of the responsibilities and faults [colpe] accumulated in thirty years of government and sub-government, [thus] which was called the sprocess' to the DC too quickly, but

32 Calvino 1995a, 2339; it.: «Se Moro è stato sequestrato per sconvolgere le istituzioni della Repubblica, l'azione, chiunque abbia concorso ad aspirarla, non poteva avere altra soluzione di quella che ha avuto. Volevano togliere di mezzo Moro, come uomo del difficile equilibrio tra DC e PCI. Ma non ucciderlo subito per evitare che la sua ultima operazione politica risultasse consacrata dal suo martirio. Comincia allora la fase più perversa del lavoro dei carcerieri: usare Moro contro sé stesso, contro il suo partito, contro la linea portata avanti fin là.»

33 Calvino 1995a, 2341; it: «[...] quel che Moro ha voluto o ha dovuto scrivere nel senso di una presa di distanza dagli uomini del suo partito, sembra studiato in modo da non danneggiare niente o nessuno, cosicché si può ben dire che Moro è restato fino in fondo essenzialmente un uomo di partito.»

34 Calvino 1995a, 2340; it: «[...] è stato chiaro che Moro rinunciava alla sua immagine pubblica e assumeva quella di un uomo di famiglia cui interessa solo che lo lascino tornare a casa.» 
which in reality means in particular the possibility of overcoming a serious crisis and the expulsion of the disease, of ex novo recovery. ${ }^{35}$

According to writer and literary critic Marco Belpoliti, this passage relates to Calvino's theory of power and violence and is based on the idea that «sacrifice is a sublimatory process and a mythical or mystical experience.» His arguments, Belpoliti notes, are similar to those of René Girard, «who is also Frazer's debtor for the figure of the scapegoat. ${ }^{36}$ Calvino refers to James George Frazer in an article entitled Il potere intercambiabile ( The Interchangeable Power»), written in 1974, in which he addresses the resignation of Nixon following the Watergate scandal. Calvino resumes the English anthropologist's theory of power, according to which in "primitive cultures» the reigning king was sacrificed as soon as he showed a decline in power in order to not break the balance between the natural cycle and the social cycle, fertility and social organization. In Calvino's reading of Frazer, power has a cost proportionate to the privileges related to it. In this sense, he understands the assassination of Moro as a natural outcome, the inevitable cost to pay for power. Moreover, in Calvino's thought the sacrifice of the king is nothing but a moment within the cycle through which power renews itself. ${ }^{37}$

This point of view leads him, in the final part in the article about Moro, to conceive good and evil as two opposing forces, both necessary in the great cosmic balance, and to reject the idea that goodness mingles with evil:

There is a philosophical process that is called dialectics, which consists in reversing the positive into the negative. But I do not believe in dialectics. I think that evil is nothing but evil. The accumulated Italian vices have led to the monstrousness of the Moro crime. This will result in more evil, which will be fought as evil, if possible, and reflected as evil, in any case. There is also a story of the good, mixed with the evil, but fundamentally separate, that one day may prevail for a lucky com-

35 Calvino 1995a, 2342; it.: «[...] è certo che le Brigate rosse, inarticolate e feroci, mentre minacciano la Democrazia Cristiana nell'esistenza fisica dei suoi quadri, le garantiscono paradossalmente una sorta di immunità morale, contribuiscono a rimandare l'esame delle responsabilità e delle colpe accumulatesi in trent'anni di governo e sottogoverno, quello che troppo in fretta fu definito il sprocesso) alla DC, ma che in realtà vuol dire soprattutto possibilità di superamento di una crisi grave, d'espulsione della malattia, di ripresa ex novo.»

36 Belpoliti 2001, 103.

37 See Belpoliti 2001, 101. 
bination of objective circumstances, and also a little for our will and intelligence. Maybe. ${ }^{38}$

Calvino basically says that he does not believe that the sacrifice of Moro can produce positive effects, that evil cannot produce something good, which is why his interventions can be considered a critique of sacrifice. However-and this is the key point-since he «naturalizes» sacrifice, conceiving it as related to the natural disposition of man towards violence, he finally conceives the sacrifice of Moro as a "cynical necessity», since «every powerful man knows that high commanders are exposed to the danger of violent death, so that the death of Moro, though it is execrable, confirms in a negative way the bond that unites death and exercise of power.» ${ }^{39}$ In other words, Calvino remains imprisoned in a mythological conception of history, as he basically conceives violence as intrinsically interlinked with exercising power, which guarantees and maintains social order.

Calvino's understanding of the relationship between power and sacrifice as indivisible and interdependent is also addressed in an article published in November 1978, in which he criticizes Leonardo Sciascia's L'affaire Moro, arguing that

The killing of a politician is a very serious fact $[\ldots]$; but we know that those who hold high positions of power are exposed to violent deaths [...], even in the most powerful and civil countries; this responds to a very ancient tradition that connects death with exercising power, and one cannot presume that this tradition will be interrupted in the very near future. [...] One can take the stest of firmness of the country for good, as does the official version of the facts with apologetic intent, and so does Sciascia with critical intent. I am more pessimistic, $[\ldots]$ as I believe that the hope of a happy ending was an illusion that it would be more pitiable not to cultivate. ${ }^{40}$

38 Calvino 1995a, 2343; it.: «C’è un procedimento filosofico che si chiama dialettica che consiste nel rovesciare il negativo in positivo. Ma io non credo nella dialettica. Credo che dal male non venga altro che male. I mali italiani accumulati hanno portato alla mostruosità del delitto Moro. Ne deriverà altro male, che andrà combattuto in quanto male, se possibile, e pensato come male, comunque. C'è anche una storia del bene, necessariamente mescolata a quella del male, ma sostanzialmente separata, che potrà un giorno riavere il sopravvento, per un fortunato concorso di circostanze obbiettive, e anche un po' per nostra volontà e intelligenza. Forse.».

39 Belpoliti 2001, 103.

40 Calvino 1995b, 2349-2352; it.: «L'uccisione di un uomo politico è un fatto gravissimo [...]; però sappiamo che chi ricopre alti posti di potere è esposto a morti vi- 
Laffaire Moro by Leonardo Sciascia is the most quoted and discussed text which addresses the events of spring 1978. The author describes the book as a "pamphlet»; the introduction, which Belpoliti describes as «one of the most beautiful pages of the entire post-war Italian literature» ${ }^{41}$, discusses a central topic in the author's entire literary work: the relationship between literature and the search for truth. «Literature [...] —Sciascia writes in Nero su nero-is the most absolute form that truth can take. ${ }^{42}$ Indeed, among the first chapters of Laffaire Moro, there is a concentration of literary references, among them references to Jorge Luis Borges, author of the short story Pierre Menard, autor del Quijote («Pierre Menard, Author of the Quixote»), which is written in the form of a literary review or critical piece about Pierre Menard, a fictional eccentric twentieth-century French writer. ${ }^{43}$ According to Sciascia, Borges was inspirited by Miguel de Unamuno's attempt to «rewrite» Cervantes masterpiece in his Vida de Don Quijote y Sancho (usually translated in English with «Our Lord Don Quixote»). Referring to Borges, Sciascia argues that any work of «copying» a certain sequence of words, even if the copy exactly reproduces the original, has a different signification than the sequence of words had in its original context or appearance. The Sicilian author points out that in the seventeenth century the assertion according to which history is «the mother of truth", as seen in Cervantes' Don Quixote, was a «mere rhetorical eulogy of history». The same assertion, rewritten in the nineteenth century assumed a completely different connotation, since it could now be understood as indicating the idea that history does not contain the truth, but is rather the origin of truth. In other words, the sentence was now expressing the belief that historical research is not research into truth but its foundations. The same change in meaning happened with what was said and written during or in the immediate aftermath of Moro's kidnapping and assassination. Sciascia provides the example of a description of Moro's interrupted path to parlia-

olente $[\ldots]$, anche nei paesi più potenti e civili; questo risponde ad una tradizione antichissima che collega la morte all'esercizio del potere e non è presumibile che questa tradizione si interrompa nel prossimo avvenire. [...] Si può prendere per buona la prova di fermezza del paese, come fa la versione ufficiale dei fatti con intenti apologetici e come fa Sciascia con intenti critici. Io sono più pessimista [...] pensando che la speranza di un lieto fine era un'illusione che sarebbe stato più pietoso non coltivare.

41 Belpoliti 2001, 3.

42 Sciascia 1991, 834; it.: «La letteratura [... è la più assoluta forma che la verità possa assumere.»

43 See Borges 2000, 88-95. 
ment the day of March 16 and emphasizes that such a description completely changed the meaning within only half a year (the approximate duration separating March 16 from the drafting of L'affaire Moro):

The center of gravity has shifted: from Mr. Moro [...] to the Chamber of Deputies, where Mr. Moro's absence would quickly produce what his presence difficultly would have achieved: namely the calmness and the concordance that allowed the approbation of the fourth government chaired by Mr. Andreotti without any debate. The drama of the abduction has been replaced [...] by the drama that the absence of Mr. Moro from Parliament, from political life, is more productive-in a certain direction - than his presence. ${ }^{44}$

After a few months, Sciascia argues, the relationship between words and things, acts and events changed, because the changed historico-political setting allowed for understanding words differently. In fact, after a few months it became clear that Moro's death had facilitated the consolidation of a certain type of government: not the government wanted by Moro, but Andreotti's government. His absence from politics was not productive in the direction wanted by Moro, but in the direction wanted by his political enemies. This conception of the performativity of language is fundamental to an understanding of Sciascia's hermeneutical approach to Moro's letter, the BR's communiqués and to the hegemonic discourse produced by the government and established media. Sciascia continually works to acquire even fragmentary elements in an attempt to reconstruct the «truth» by extrapolating details from language, form and style.

According to Sciascia, «Moro and the affair seem to have been generated by a certain type of literature.» ${ }^{45}$ Moreover, as already mentioned in the fifth chapter, he argues that Pasolini, when he wrote that Moro was the «least implicated of them all», already prefigured the «Moro affair» in 1975. The Sicilian author is particularly interested in Pasolini's expression «for an

44 Sciascia 1978, 26; it.: Si è come spostato il centro di gravità: dall'onorevole Moro [...] alla Camera dei deputati dove l'assenza dell'onorevole Moro avrebbe rapidamente prodotto quel che la sua presenza difficoltosamente avrebbe conseguito: e cioè quell'acquietamento e quella concordia per cui il quarto governo presieduto dall'onorevole Andreotti veniva approvato senza discussione alcuna. Al dramma del rapimento si è come sostituito [...] il dramma che l'assenza dell'onorevole Moro dal Parlamento, dalla vita politica, è più producente - in una determinata direzione - della sua presenza.»

45 Sciascia 1978, 27; it.: "Allo stesso modo che don Chisciotte dai libri di cavalleria errante, Moro e la sua vicenda sembrano generati da una certa letteratura.» 
enigmatic correlation»; in fact, he argues, «in this brief parenthetical element $[\ldots]$ there is something like the premonition, like the prefiguration of the «Moro affair). Now we know that the «correlation» was a «contradiction: and that Moro paid for it with his life.» ${ }^{46}$ Correlation is the relationship between two elements. What then is the enigmatic correlation affecting the Sicilian author? On the one hand, there is the correlation between power and sacrifice, which will be discussed later. On the other, there is the correlation between language and things, acts or events. ${ }^{47}$ Sciascia believes that literature has a privileged relation with «truth», because literature has the power to bring to light the correlation between language and things, act or events that, in different hermeneutic and pragmatic contexts, produce meaningfulness. In other words, literature uncovers the truth of the radical exteriority and contingency of language.

Before discussing the results of Sciascia's analysis, we need to reject from the outset the thesis according to which the Sicilian author is a dietrologo, namely one who advocates conspiracy theories. ${ }^{48}$ In fact, Sciascia does not argue that the assassination of Moro happened with the direct complicity of secret services, the government or occult organizations. Though he does not exclude a priori the possibility of such complicity, his thesis is another: the action of the BR responded to the interests of a certain political class that wanted to maintain (or increase) its power and for which the absence of Moro was more productive than its presence. In fact, he argues, despite the BR's efficacy in planning and executing the attack in via Fani,

The Red Brigades [...] are Italian. They are our thing [cosa nostra], whatever the relations they may have with revolutionary sects or secret services of other countries. [...] Their reason of being, their function, their «service〉 are solely in the shift of force relations: and of the forces that are already there. And to not shift them much, one has to add. Shifting them in the sense of «changing everything to change nothing> [...]. [It is] thus an operation of pure power. Which can only be carried out in that area between political parties where, in the shelter of ideological winds, power now lives. ${ }^{49}$

46 Sciascia 1978, 16; it.: «In questo breve inciso c’è un presentimento, come la prefigurazione dell'affaire Moro. Ora sappiamo che la «correlazione» era una «contraddiziones: e che Moro la pagata con la vita.»

47 See Belpoliti 2001, 8.

48 See Gotor 2008b, 192-195.

49 Sciascia 1978, 128-130; it.: «Le Brigate Rosse [...] sono italiane. Sono una cosa nostra, quali che siano gli addentellati che possono avere con sette rivoluzionarie 
Sciascia therefore does not say that the BR were directed by someone, but rather that their activities suited certain political interests, since they prepared the ground for the legitimization of the political and institutional status quo as absolutely necessary for the security and safety of Italian society. With «operation of pure power», the author does not intend to indicate a form of improbable direct complicity with the BR, but rather explain how Moro's kidnappers could operate with such great ease, why there was so much negligence with the investigations into finding Moro's prison, why the government spread a false communiqué, and finally why, from the outset, the government assumed an uncompromising position with regard to negotiations.

The capital error of the BR, Sciascia argues, was that they did not realize that their action produced the opposite effect of their intentions: to stop the political alliance between the PCI and the DC. They chose Moro precisely because "he was the creator of the return, after thirty years, of the Communist Party to the governing majority.» ${ }^{50}$ In other words, they wanted to imprison the highest representative of power, because they thought they could throw the entire Italian political system into crisis. It is worthwhile, at this point, to compare Sciascia's reflections with what was written by a great Italian writer about the BR, Umberto Eco. In an article published in La Repubblica on March 23, 1978, and republished in a collection of his texts in 1983, the famous semiotician lucidly analyzes the language and ideology of the BR one week after Moro's kidnapping, arguing that

We must have the courage to say that this «delusional message [the BR's first communiqué] contains a very acceptable premise and translates [...] a thesis that all European and American culture, from the students of the 1968 movement to the theorists of the Monthly Review, as well as the leftist parties have long been repeating. So if there is a sparanoia, it is not in the premises, but [...] in the practical conclusions that they draw from these premises. $[\ldots][\mathrm{N}] \mathrm{o}$ one can deny that global planetary policy is not determined by individual governments

o servizi segreti di altri paesi. [...] La loro ragion d'essere, la loro funzione, il loro 〈servizio〉 stanno esclusivamente nello spostare dei rapporti di forza: e delle forze che già ci sono. E di spostarli non di molto, bisogna aggiungere. Di spostarli nel senso di quel «cambiar tutto per non cambiar nulla [...]. Operazione di puro potere, dunque; che si può soltanto svolgere in quell'area interpartitica in cui, al riparo dai venti ideologici, il potere ormai vive.»

50 Sciascia 1978, 131; it.: «[...] è stato l'artefice del ritorno, dopo trent'anni, del partito Comunista nella maggioranza di governo.» 
but rather by a network of productive interests (and we can even call it a network of multinationals) $\left[\ldots . . .^{51}\right.$

The BR's mistake thus did not lie in their premise, but in the analysis of the function of power and the way they decided to counteract it:

The confused idea that drives terrorism is a very modern and very capitalist principle (with respect to which classical Marxism was unprepared) of the theory of systems. Large systems have no head, no protagonists, and are not even based on individual selfishness. This is why it is not possible to strike them by killing their Kings, but by making them unstable through disturbing gestures that rely on their own logic. [...] Modern terrorism pretends (or believes) to have meditated on Marx, but in fact, it meditated on Norbert Wiener on the one hand and science fiction literature on the other. The problem is that it did not meditate enough. Proof of this is that in all previous BR's propaganda they still talked of sstriking at the heart of the States, cultivating on the one hand the nineteenth-century notion of State, and on the other the idea that the adversary still has a heart or a head. [...] In the last leaflet, the BR abandon the idea of the heart, the State, the bad capitalist, the hangman $>$ minister. Now the opponent is the system of the multinationals, of which Moro is a committed follower, at most a depositor of information. [...] Once they have mastered the idea of large systems, they mythologize it again, believing that these systems have ssecret plans s of which Moro would be one of the depositors. The truth is that big systems have nothing to do with secrecy and we all know exactly how they work. ${ }^{52}$

51 Eco 1983, 109-110, it.: «Dobbiamo avere il coraggio di dire che questo «delirante» messaggio contiene una premessa molto accettabile e traduce [...] una tesi che tutta la cultura europea e americana, dagli studenti del Sessantotto ai teorici della Monthly Review, sino ai partiti di sinistra ripetono da tempo. E dunque se sparanoia c’è, non è nelle premesse, ma [...] nelle conclusioni pratiche che ne traggono. [...] $[\mathrm{N}]$ essuno si nasconde che la politica internazionale planetaria non è determinata dai singoli governi ma appunto da una rete d'interessi produttivi (e chiamiamola pure rete delle multinazionali) [...].»

52 Eco 1983, 110-111; it.: «Lidea confusa che muove il terrorismo è un principio molto moderno e molto capitalistico (rispetto a cui il marxismo classico si è trovato impreparato) di teoria dei sistemi. I grandi sistemi non hanno testa, non hanno protagonisti e non vivono neppure nell'egoismo individuale. Quindi non si colpiscono uccidendone i Re, ma rendendoli instabili attraverso gesti di disturbo che si avvalgono proprio della loro logica. [...] Il terrorismo moderno finge (o crede) di avere meditato Marx, ma in effetti, ha meditato Norbert Wiener da un 
The fundamental mistake of the BR was thus their belief that power «still has a heart or a head", that they could defeat an established power by kidnapping the one person they regarded as embodying and representing power. Moreover, they did not understand that their actions were functional to the maintenance and legitimization of what they called the «Imperialist State of the Multinationals»:

Terrorism is not the enemy of large systems but, on the contrary, their natural, accepted, and anticipated counterpart. The multinational system [...] accepts small local wars, which will, from time to time, be disciplined and reduced by astute international intervention, and on the other hand accepts terrorism. [...] Terrorism also serves to give a reason for being to police and armies, which, if they are made inoperative, demand to realize themselves in some other wider conflict. Lastly, terrorism serves to encourage disciplined action, where an excess of democracy renders the situation ungovernable. ${ }^{53}$

Eco's reflections are useful in clarifying the function of the «discourse of sovereignty» and the «mythology of the state». A general critique against the reintroduction of the concept of sovereignty in political theory as a paradigm of governance is that it is incompatible with the paradigm of governmentality. Different research fields have used the concepts of «governmentality», «discipline», the «microphysics of power» and «biopolitics» since Foucault introduced them in the 1970s. In particular, the idea of a

lato e la letteratura di fantascienza dall'altro. Il problema è che non l'ha meditata abbastanza. Prova ne sia che in tutta la propaganda precedente le BR parlavano ancora di «colpire il cuore dello Statos, coltivando da un lato la nozione ancora ottocentesca di Stato e dall'altro l'idea che l'avversario avesse ancora un cuore o una testa. [...] Nell'ultimo volantino le BR abbandonano l'idea di cuore, di Stato, di capitalista cattivo, di ministro 〈boia.) Adesso l'avversario è il sistema delle multinazionali, di cui Moro è un commesso, al massimo un depositario di informazioni. [...] Una volta colta l'idea dei grandi sistemi, li si mitologizza di nuovo ritenendo che essi abbiano (piani segreti di cui Moro sarebbe uno dei depositari. In realtà i grandi sistemi non hanno nulla di segreto e si sa benissimo come funzionano.»

53 Eco 1983, 111-112; it.: «ll terrorismo non è il nemico dei grandi sistemi, ne è al contrario la contropartita naturale, accettata, prevista. Il sistema delle multinazionali $[\ldots]$ accetta piccole guerre locali, che verranno di volta in volta disciplinate e ridotte da oculati interventi internazionali, e dall'altro lato accetta appunto il terrorismo. [...] Inoltre il terrorismo serve a dare una ragion d'essere alle polizie e agli eserciti, che a lascarli inoperosi chiedono di realizzarsi in qualche conflitto più allargato. Infine il terrorismo serve a favorire interventi disciplinati là dove un eccesso di democrazia rende la situazione ingovernabile.» 
government over life, in the form of an «anatomo-politics of the body» and «biopolitics of the population» has been employed productively in analyses of welfarist and neo-liberal programs of governance. ${ }^{54}$ However, despite assertions of the diminution in importance of the nation-state-through and alongside work on globalization and trans- and multinationals corporations-Giorgio Agamben's works on the sovereign ban and the state of exception highlight that the two paradigms of governmentality and sovereignty do not exclude each other. On the contrary, techniques of sovereignty and governmentality perfectly coexist. At the latest since the French Revolution, the modern democratic state has not been able to exercise violence without a moral justification, because it takes its legitimization from a reference to human and citizens' rights. What Benjamin calls «law-preserving» state violence can be justified only through the presence of an external threat. ${ }^{55}$ This is why terrorism is so convenient for the exercise of power through both sovereign and governmental techniques: the emergence of external, non-state violence allows not only the representation of state violence as necessary for the safety of the population, but also the production of docile subjects that accept all kinds of governmental techniques.

The coexistence of governmentality and sovereignty paradigms becomes even clearer by looking to the discursive practices through which Aldo Moro was first represented as a great statesman, reduced to mere life and finally declared a state martyr. As Sciascia masterfully describes, the kidnapping of Aldo Moro allowed for the reemergence of a national rhetoric. In fact, as the Sicilian writer notes, in the first days after the kidnapping and before his letters were published, the media began to represent Moro as the "great statesman», while before he was referred to simply as the leader or the President of the DC, as well as the weaver of political alliances. As discussed in the sixth chapter, this form of acclamation of sovereignty was accompanied, even before Moro died, by the first allocations of the martyr role. Moro was thus represented as both a great statesman and as a state martyr, almost indicating that Moro had to accept sacrifice, because he was the sovereign; but when Moro began to oppose this national rhetoric, expressly criticizing the «line of firmness» as an appeal to an abstract «reason of state», the situation changed:

54 Foucault 1978, 139.

55 Benjamin 2007, 284. 
An unexpected and immense state-idolatrous torchlight seems to have been attached to the Christian Democracy and possesses it. Moro, who continues to think as he always thought, is now an extraneous body: a kind of painful biliary calculus to be extracted - with the state-idolatrous ardor as an anesthetic-by an organism that, almost touched by the miracle, has acquired the movement and the use of the sense of the State. [...] Independent and party newspapers, illustrated weeklies, radio, and television: they are almost all there, in line to defend the State, proclaiming Moro's metamorphosis, his civil death. ${ }^{56}$

Influenced or persuaded, Moro now speaks like the Red Brigades: this is the thesis that as a huge tombstone falls on the living man, combative and sharp, which is still in the speople's prison', while [the government, parties and media] remember and celebrate the Moro that is already dead, the Moro to be monumentalized. ${ }^{57}$

Sciascia discloses a fundamental point here: Andreotti, Cossiga, the DC, or the government as a whole would not have been able to categorically reject negotiations for the liberation of Moro if a number of discursive practices produced by many social actors and diffused in different media had not transformed Aldo Moro into a homo sacer. Moro's voice had to be silenced, constructing the opposition between a good Moro-before the lettersand a bad Moro-the one who wrote the letters. Only after this procedure of discursive reduction to bare life, and after his death, could he again be acclaimed as a great statesman and finally glorified as a state martyr. This does not only corroborate Agamben's thesis, according to which «contemporary democracy is a democracy that is entirely founded upon glory, that is, on the efficacy of acclamation, multiplied and disseminated by the media beyond all imagination», but also demonstrates that power over mere

56 Sciascia 1978, 130; it.: «[...] un'inaspettata e immane fiaccola statolatrice sembra essersi attaccata alla Democrazia Cristiana e possederla. Moro, che continua a pensare come pensava, ne è ormai un corpo estraneo: una specie di doloroso calcolo biliare da estrare - con l'ardore statolatrico come anestetico - da un organismo che, quasi toccato dal miracolo, ha acquistato il movimento e l'uso del «senso dello stato.> [...] I giornali indipendenti e di partito, i settimanali illustrati, la radio, la televisione: sono quasi tutti lì, in riga a difendere lo Stato, a proclamare la metamorfosi di Moro, la sua morte civile.»

57 Sciascia 1978, 73; it.: "Suggestionato o convinto, Moro ormai parla come le Brigate Rosse: questa è la tesi che come un enorme pietra tombale scende sull'uomo vivo, combattivo e acuto che è ancora nella sprigione del popolo, mentre si ricorda e si celebra il moro già morto, il Moro da monumentare.» 
life is endorsed by the means of discursive practices. ${ }^{58}$ The discursive practices through which Moro was first excluded from the political sphere, then repeatedly represented as a state martyr, can be described as hegemonic procedures that regulate the formation of public opinion and political will. Without such discursive performances, there could be no justification for «sacrifice» and «martyrdom» for the state-no justification for the idea that individual life is an exchangeable commodity with which a society can buy its own welfare and security-since the rhetoric of sacrifice and martyrdom would otherwise appear to be what it is: a way to conceal the necessity of terrorist violence for the preservation of the status quo.

The strongest pages in Sciascia's book are probably those in which he addresses the situation of Moro in the " people's prison» and attempts to oppose or subvert the hegemonic discourse. Firstly, he highlights that Moro's rejection of the rhetoric of the "reason of state» and of the "sense of the state» in his first published letter is absolutely consistent with what Moro had been saying for years:

The Moro who formulates this proposition is perfectly coherent with the politician Moro and the teacher Moro that the Italians have known for thirty years: with his vision of life, of Italian things, the development of politics; with his sense of law and his sense of the State (and this time not in quotation marks, the sense of the State: that is to say, different from the ssense of the State that some, by deception, imposed on him). 59

In fact, Sciascia argues,

Aldo Moro, President of the Christian Democracy, had already said a few years ago that, between saving a human life and keeping faith in abstract principles, one had to force the legal concept of the state of necessity, so that it becomes the principle: the non-abstract principle of the [primacy of] the salvation of the individual against abstract principles. ${ }^{60}$

58 Agamben 2011, 256.

59 Sciascia 1978, 51; it.: «Il Moro che formula questa proposizione è in perfetta coerenza col Moro politico e col Moro docente che gli italiani hanno conosciuto per un trentennio: con la sua visione della vita, delle cose italiane, del corso della politica; col suo senso del diritto e col suo senso dello Stato (e questa volta non tra virgolette, il senso dello Stato: diverso, cioè, da quello che gli si è voluto, per impostura, imporgli).»

60 Sciascia 1978, 61; it.: «Cosi pensava Aldo Moro, presidente della Democrazia Cristiana, già qualche anno prima: che tra il salvare una vita umana e il tenere fede ad 
According to Sciascia, there is a passage in the second letter, which became public when it was published on April 5, 1978, that demonstrates how Moro himself had a premonition that he would not survive. In this passage, Moro admonished the PCI to remember that the kidnapping occurred the same day in which all other politicians were going to the Chamber of Deputies «for the consecration of the government", the same government that he himself had helped to realize. ${ }^{61}$ According to Sciascia, the use of the word «consecration» is

A lapse for a Catholic; a premonition for the man who feels himself a bit abandoned (and he meant completely). «Referring to human affairs — says the Catholic Tommaseo- no one should never use that great word ... Consecrating making sacred what was not sacred, with solemn words, acts, rites . Solemn words: the defense of the State. Rites: the massacre of five men, the execution of a death sentence. ${ }^{62}$

As previously mentioned, before his kidnapping Moro was known for his ability to use language instrumentally to defend his party from different accusations, but after the kidnapping, and after he saw the reaction to his letters, he began to use another language, a language that allowed him to become aware of and express the function of power. Commenting on Moro's letter to the DC, published on April 29, 1978, Sciascia highlights a sort of metamorphosis in Moro:

Here there is the word that for the first time he writes in the most atrocious nudity; the word finally revealed itself to him in its true, profound, and terrible sense: the word 〈power〉. «I do not want around me, I repeat, the men of powers. But in the previous letter he spoke of 〈State authority> and 〈party men»: it is only now that he has come to the right name, the frightening word. For power and from power he had lived until nine o'clock in the morning of that 16 March. He hoped to have it again: perhaps to return to take it fully, certainly to

astratti principi si dovesse forzare il concetto giuridico di stato di necessità, fino a farlo diventare principio: il non astratto principio della salvezza dell'individuo contro astratti principi.»

61 Moro 2008c, 13.; it.: «[...] per la consacrazione del Governo.»

62 Sciascia 1978, 64; it.: Un lapsus per un cattolico; un presentimento per l'uomo che si sente «un po' abbandonato» (e voleva dire del tutto). «Di cose umane»-dice il cattolico Tommaseo - «non si dovrebbe mai adoperare quell'alta parola ... Consacrarsi facendo sacro quello che sacro non era, con parole solenni, con atti, con riti.> Parole solenni. Difesa dello Stato. Riti: il massacro di cinque uomini, l'esecuzione di una condanna a morte.» 
avoid facing that death. But now he knows that others have the power: he recognizes in others its filthy, astonished, fierce face. ${ }^{63}$

Paradoxically or, as Sciascia says, tragically, imprisonment and the consequent discovery of the true face of power allowed Moro to «save» himself:

Moro begins, pirandellianamente [in the manner of author Luigi Pirandello], to get rid of form, since he tragically entered into life. From character to 〈lonely man', from lonely man> to creature: the steps that Pirandello assigns to the only one possible salvation. ${ }^{64}$

Here the fundamental difference between Sciascia and Calvino becomes manifest. The author of L'affaire Moro believes that, despite everything, even when Moro was in the "people's prison", reduced to bare life and to the status of a "creature», there was still the possibility of salvation. What kind of salvation did he have in mind? To answer this question, it is useful to quote what, in August 1978, three months after Moro's death, Sciascia stated in an interview with the French magazine Le Nouvel Observateur:

Yes. Aldo Moro by dying — despite all his historical responsibilitieshas acquired an innocence that makes us all guilty, then me too. [...] By dying, Aldo Moro was, so to speak, stripped of his Christian Democratic tunic. His body does not belong to anyone, but his death puts everyone on trial. ${ }^{65}$

63 Sciascia 1978, 110; it.: «[...] ecco, c’è la parola che per la prima volta scrive nella più atroce nudità, la parola che finalmente gli si è rivelata nel suo vero, profondo e putrido significato: la parola 〈potere.) (Io non desidero attorno a me, lo ripeto, gli uomini del potere.> Ma nella precedente lettera aveva parlato di <autorità dello Stato e <uomini di partitos: è soltanto ora che è arrivato alla denominazione giusta, alla spaventosa parola. Per il potere e del potere era vissuto fino alle nove del mattino di quel 16 marzo. Ha sperato di averne ancora: forse per tornare ad assumerlo pienamente, certamente per evitare di affrontare quella morte. Ma ora sa che c'è l'hanno gli altri: ne riconosce negli altri il volto laido, stupito, feroce.»

64 Sciascia 1978, 73; it.: «Moro comincia, pirandellianamente, a sciogliersi dalla forma, poiché tragicamente è entrato nella vita. Da personaggio a unomo solo), da «uomo solo» a creatura: i passaggi che Pirandello assegna all'unica possibile salvezza.»

65 Quoted in Balducci/Ferrara/Katz 1987, 155; it.: «Sì, Aldo Moro morendo - nonostante tutte le sue responsabilità storiche - ha acquistato una innocenza che rende tutti noi colpevoli, dunque anche me. [...] Morendo, Aldo Moro si è, per così dire, spogliato della tunica democristiana. Il suo cadavere non appartiene ad alcuno, ma la sua morte ci mette tutti sotto accusa.» 
As Sciascia highlights some months later in L'affaire Moro, this acquisition of innocence was not a reward obtained through sacrifice, but the result of the awareness of the function of power or, more precisely, of the performativity of the language of power. Paradoxically, the condition of mere life is the starting point from which it is possible to develop a language, a model of representation and narration, by which one can unveil, or demythologize the discourse of sovereignty and the mythology of the state. From this point of view, it can be said that Sciascia continues to develop the kind of subversive narrative Moro had started in his letters. The paired concepts of «innocence» and "guilt», as well as the idea of death that radically transforms the moral status of both the victim and of those who are held responsible for violence, recall and iterate the rhetorical structure of Christian martyrology. Some might argue that the allocation of innocence and guilt is also used in modern forensic and judicial discourses; but a closer observation reveals that this view is inconsistent. There is no legal system that «puts everyone on trial». Sciascia, by using the word «trial», does not want to refer to the process in which the ultimate form of judgment is the law of a country. What he has in mind, rather, is an analogy, however implicit, to the judgment of Christ at the end of time.

But one must not be fooled. Sciascia, as an atheist, surely does not want to say that on the Day of Judgment all Italians will have to take responsibility for what happened in the spring of 1978. Rather, he uses language units and rhetoric patterns in order to provoke an emotional response in the readers. As a Sicilian intellectual, Sciascia could not help but be aware of the performative power of Christian language; but, in the mind of Sciascia, there is no final judgment or redemption, but only historical guilt. In his representation, Moro is a weakened martyr, who accused, desacralized and delegitimized, but who «does not belong to anyone», not to the party, not to the state, not to the Church and not to the country. Moro's letters and Sciascia's book are attempts to propel people to become aware not only that there is collective guilt and responsibility, but there is also the possibility of collective salvation. It is salvation from the thanatopolitics that characterizes the function of modern and contemporaneous governmental practices that can be achieved by becoming aware of this function. Salvation can also be achieved by overcoming the correlation, within the hegemonic discourse, between politics, violence and sacrificial rhetoric, which is not a natural phenomenon, a discursive mirror image of a natural predisposition of man, but the result of a historical and cultural development. Only by forming a subversive discourse, by creatively developing discursive practices that appeal to individuals to empower themselves, to not accept 
the exercise of sovereign power with docility and to overcome the politics of fear on which this power is based, does it become possible to prepare a new a way of conceiving and organizing the political community.

\subsection{Moro's Image on Television and in Italian Cinema}

Every image or visual representation requires subjective positioning from the spectator. Each image portraying individuals or situations, even if the image documents a moment or gesture of daily life or if the individuals portrayed are already dead and their names have been erased from collective memory, potentially functions as an aid to remembrance. The famous photograph representing Moro's body in the trunk of a Renault 4, surrounded by police officers, carabinieri and journalists looking at the corpse, does not capture an everyday occurrence, but rather an exceptional event of death. It does not capture a man in his daily singularity, or in his personal way of existing in the world, but instead captures a collective event of historic significance. This image of Moro presents only the flesh, where he is only a void body alone and abandoned.

Different scholars point out that the photographs of Moro's corpse in the trunk, as well as those taken by the BR and delivered to the newspapers to prove he was alive, are forms of «degradation» of Moro. ${ }^{66}$ According to Christian Uva, the two photographs showing Moro in the «people's prison» were part of the propaganda strategy of the BR, which consisted not so much of proving that Moro was alive, but above all of forming a picture of Moro corresponding to that of the «naked king». ${ }^{67}$ Both Uva and Pezzini refer to Sciascia and describe this as the deprivation of Moro's political status. Undoubtedly, such images facilitated the operation by which Moro was reduced to mere, killable life, and which, as we saw in the two preceding chapters, in the spring of 1978 served to justify the line of firmness, to legitimate the established political authority and to reactivate national rhetoric. Similarly, the image of Moro's corpse was used to promote the image of Moro as a state martyr, as the one who died to save state institutions and Italian society, symbolically represented by the policemen, Carabinieri and journalists surrounding the dead man. However, these images were perceived, interpreted and used differently in the following years. In different cultural productions they were not used to point out the

66 See Pezzini 2012, 136.

67 See Uva 2011, 261. 
tragic inevitability of Moro's death. On the contrary, they were used to encourage people to remember Moro differently: as the man who within the «people's prison» managed to make his voice heard, criticizing a certain idea of the state, criticizing the operation by which he was represented as a finished man, deprived of all dignity.

The first television productions addressing the events of 1978 focused mainly on investigative journalism and historical divulgation. The emphasis was initially almost exclusively put on documentary and interview formats. The first broadcast dedicated to Moro's abduction was entitled Aldo Moro: Il giorno più lungo della Repubblica (RAI 1, IT 16.3.1979). The broadcast opens with a sequence of images and photographs of the assault on Moro's guards and the funeral of Domenico Ricci, Aldo Moro's driver. A speaker comments on the images and describes the four bodyguards as «symbols for those who oppose violence». The broadcast includes a series of interviews with political protagonists during Moro's captivity, in which Moro is described as «the man who had succeeded in realizing the policy of national solidarity» (Ugo La Malfa); «our highest intellectual, moral, and political guide» (Benigno Zaccagnini); and «one of the protagonists of the formation of the new majority» (Enrico Berlinguer). In the first anniversary of the attack in via Fani, the focus lies thus on the human and political qualities of Aldo Moro, and not yet on the responsibility of the political class or the mysteries related to the reconstruction of the event.

On March 21, 1988, after three trials (Moro-uno, Moro-bis and Moro-ter) on the tenth anniversary of via Fani, Rai 1 aired the newscast special Dopo il terrorismo, in which journalist Ennio Remondino interviews the former BR members Renato Curcio, Barbara Balzerani and Mario Moretti, of which the last two were directly involved in Moro's abduction. In this special program, all three declare that the «season of terrorism» is over, and assume all moral and political responsibilities for the attack in via Fani and the killing of Moro. After this first appearance, several members of the terrorist group repeatedly reappeared on television and acquired a certain celebrity status. For this reason, they were often accused of «mania of protagonism» and, in Miguel Gotor's words, of «keeping [Moro] prisoner today through an instrumental use of memory»: «A use that is necessarily functional for the current (judicial, political, moral, psychological, religious) needs of free men or those in search of freedom, but not for the historical reconstruction of what has happened, of a past on which they continue to exercise a monopoly and paradoxical dictatorship of testimony.» ${ }^{68}$ 
For this reason, Gotor considers it necessary to study Moro's letters, which he describes as «a living testimony to an ancient and perhaps unrepeatable thing, the last death of a Christian uprince». [...] Visible manifestation [...] of Christian faith, consolation, relief, redemption, martyrdom.» ${ }^{69}$ In other words, for Gotor the letters, like the Christian martyrologies, are living testimony that compensate for the lack of an «integral witness». ${ }^{70}$

One of the broadcasts on television that strongly contributed to the cementing of images of Aldo Moro as a martyr is undoubtedly the episode IL CASO Moro: dal SEQUeSTRO ALl'OMICIDIO - I 55 GIORNI CHE CAMBIARONO L'Italia (RAI 3, IT 10.5.2003) of the television program La STORIa Siamo NoI presented by Giovanni Minoli. ${ }^{71}$ The program reconstructs the events of the spring of 1978 by showing archive materials (videos broadcast during the 55 days of Moro's imprisonment), interviews with people who investigated the «Moro case» (the member of the first parliamentary commission of enquiry Sergio Flamigni, author Robert Katz, prosecutor general of the fourth Moro trial Antonio Marini, and historian Francesco Biscione), and excerpts from official videos of testimonies given by members of the BR as well as by Moro's wife in the trials. At regular intervals, the presenter Minoli summarizes the events of 1978 as well as the results of investigations and trials. The fifty-two-minute documentary addresses two themes. The first part (the first 30 minutes) addresses the alleged implications of the Masonic lodge Propaganda 2 (P2), the possibility that part of the state apparatuses could have thrown the inquiry off track, and the «foreign interests concerning Moro's fate», as Flamigni argues, who refers in particular to the presence of the American expert on international terrorism, Steve Pieczenik, as an adviser to the Italian government during Moro's imprisonment. The second part addresses the conflict between advocates of the «line of firmness» and those who promoted negotiations. The program devotes coverage to Aldo Moro's letters by alternating between images of the handwritten letters, the streets of Rome, photos of Moro and his wife Eleonora, and a video filmed from the front of a car and at the height of the plates, while a voice-over reads the letters. The first letter read aloud is the one addressed to then Minister of the Interior Cossiga (first published on March 30, 1978). The letter is read almost in full; after that the documentary shows an excerpt from the official video of Eleonora Moro's de-

69 Gotor 2008b, 348.

70 Gotor 2008a, xxii-xxiii.

71 http://www.lastoriasiamonoi.rai.it/puntate/il-caso-moro/381/default.aspx (accessed August 20, 2017). 
position at the first Moro trial, in which she expresses the conviction that the letters were written by her husband in the absence of any coercion. The same narrative strategy is used for the rest of the documentary, which alternates between the reading of Moro's letters and excerpts from the depositions in the fourth Moro trial of three former BR members who participated in the abduction (Anna Laura Braghetti, Barbara Balzerani and Valerio Morucci). All three of them say that if the state had negotiated, they would have freed Aldo Moro. While the speaker reads the letters, some of the rhetorically stronger or more controversial passages - such as «I die, if my party so decides, in the fullness of my Christian faith ${ }^{72}$-are accentuated with written words that cover almost half of the screen. The documentary ends with the reading of different passages of Moro's letters to his wife:

Someone should tell Giovanni [Moro's son] what political activity means. [...] And Zaccagnini? How can he remain quiet in his position? And Cossiga, who could not imagine any defense? My blood will fall upon them. But that's not what I want to talk about; but rather about you, who I love and will always love, about the gratitude I have for you, about the indescribable joy you gave me in life, about the little one [Moro's grandson] I loved to look at and who I will try to look at to the last. ${ }^{73}$

At this moment, I feel an infinite tenderness for you, the memory of everyone, a great love of seemingly insignificant but precious memories. [...] Kiss and caress all of them for me, face to face, eyes for eyes, hair for hair. [...] Kiss and caress Fida, Demi, Luca (so much Luca), Anna, Mario, the unborn little one, Agnese, Giovanni. I'm so grateful for what they did. Everything is useless when one does not want to open the door. ${ }^{74}$

72 Moro 20081, 143; it.: «Muoio, se così deciderà il mio partito, nella pienezza della mia fede cristiana [...].»

73 Moro 2008d, 32-33: it.: «Bisognerebbe dire a Giovanni che significa attività politica. [...] E Zaccagnini? Come può rimanere tranquillo al suo posto? E Cossiga che non ha saputo immaginare nessuna difesa? Il mio sangue ricadrà su di loro. Ma non è di questo che voglio parlare; ma di voi che amo ed amerò sempre, della gratitudine che vi debbo, della gioia indicibile che mi avete dato nella vita, del piccolo che amavo guardare e cercherò di guardare fino all'ultimo.»

74 Moro 2008m, 177-178; it.: "C’è in questo momento una tenerezza infinita per voi, il ricordo di tutti e di ciascuno, un amore grande grande carico di ricordi apparentemente insignificanti e in realtà preziosi. [...] Bacia e carezza per me tutti, volto per volto, occhi per occhi, capelli per capelli. [...] Bacia e carezza Fida, De- 
Now, suddenly, when some hope had come up, incomprehensibly comes the order of execution. Sweetest Noretta, I am in the hands of God and yours. Pray for me, and remember me gently. Caress the sweet little ones, everyone. God help you all. A kiss of love for you all, Aldo. ${ }^{75}$

This selection of passages from the letters clearly aims at producing an emotional response through a climax that begins with Moro's anathema against his party and against the government and ends with a declaration of love for and gratitude to his family. Although the term martyr is never used in the documentary-more often the term «sacrifice» is used by the people interviewed in reference to Moro's death-, it is clear that the documentary contributes to the formation of a hagiography of Moro, in which his death and letters assume the double meaning of a witness of love and faith and an accusation at the political class, the state authority. From this point of view, the documentary can, in all respects, be considered a martyrological representation. However, the martyr figure takes on a different role here, practically opposed to what he had and still has within hegemonic discourse. It is no longer functional to the discourse of sovereignty, but used to shape and reveal a discourse of rebellion that challenges the doxological way of representing Moro's death as a necessary sacrifice for the sake of national security and unity.

Sergio Zavoli's documentary series La notte della Repubblica similarly challenges the doxological representation of Aldo Moro as a state martyrr. $^{76}$ Zavoli's program blends excerpts from radio broadcasts, archive footage, scenes from films, television reports and ad hoc shots filmed specifically for the documentary, editing them in seamless sequences to produce contrasting effects. The program gives credence to the importance of oral testimony, individual memory as well as to «the figurative inscription of events on the body, which television manages to convey to the

mi, Luca (tanto tanto Luca) Anna Mario il piccolo non nato Agnese Giovanni. Sono tanto grato per quello che hanno fatto. Tutto è inutile, quando non si vuole aprire la porta.»

75 Moro 2008n, 179; it.: «Ora, improvvisamente, quando si profilava qualche esile speranza, giunge incomprensibilmente l'ordine di esecuzione. Noretta dolcissima, sono nelle mani di Dio e tue. Prega per me, ricordami soavemente. Carezza i piccoli dolcissimi, tutti. Che Iddio vi aiuti tutti. Un bacio di amore a tutti, Aldo.»

76 La notte della Repubblica: Caso Moro - Prima parte (RAI 2, IT 21.2.1990); La notte della Repubblica: Caso Moro - Seconda parte (RAI 2, IT 28.2.1990); La notte della Repubblica: Caso Moro - Terza parte (RAI 2, IT 7.3.1990). 
viewing public.» ${ }^{77}$ The program narrates Moro's abduction, imprisonment and murder, the discovery of Moro's corpse and the diverse reactions of social actors to these events. As Pezzini highlights, «Moro is re-evoked at length first as a physical absence from the topical sites of Italian political life (effectively portrayed in black and white in all their void monumentality); then as an image; intermittently as a shadow (the enigmatic figure appearing in archive footage, or in the famous photo the BR circulated as proof that the statesman was still alive); and finally in the picture of his corpse, unnaturally doubled over in the trunk of a red Renault $4 .{ }^{78}$ The program also devotes coverage to the recitation of Moro's letters, highlighting the banishment of Moro from political life and his attempt to be heard. After addressing the abduction, the documentary provides a portrait of Aldo Moro, which maintains a clear progression: «The image of Moro is defined gradually over the course of the programme [...] He goes from being a politician firmly positioned at the centre of power and of political life in Italy to a man abruptly placed outside that political life, relegated to a kind of anti-space. [...] At the end of the narrative, the role that is ultimately assigned to Moro is that of sacrificial victim, a role that is sealed by the words of Pope Paul VI [...] who, in the funeral eulogy, described Moro as buono, mite, saggio, innocente e amico [ ' good, mild, wise, innocent and friend $>.{ }^{79}$ However, although Moro is represented as a sacrificial victim, a role that the narrative progression renders almost predestined, Moro undergoes a metamorphosis from an observed object to a subject that poses questions and demands answers, challenges hegemonic discourse and requires an emotional, moral and political stance. Furthermore, the documentary shows both the politicians' "pilgrimage» to via Caetani as well as their presence at the official funeral in the absence of Moro's body (see figure 9). As Pezzini pointedly observes, the politicians' «queuing for Holy Communion seems to sanction their self-acquittal, their absolution, while the gaze of the viewer becomes one with that of Moro himself. The effect produced by the footage is that the body of Moro, doubly absent, is in fact present in the form of a gaze granted to him by the camera, a gaze which is united with that of the viewer.» ${ }^{80}$

77 Pezzini 2012, 143.

78 Pezzini 2012, 144.

79 Pezzini 2012, 146.

80 Pezzini 2012, 146-147. 


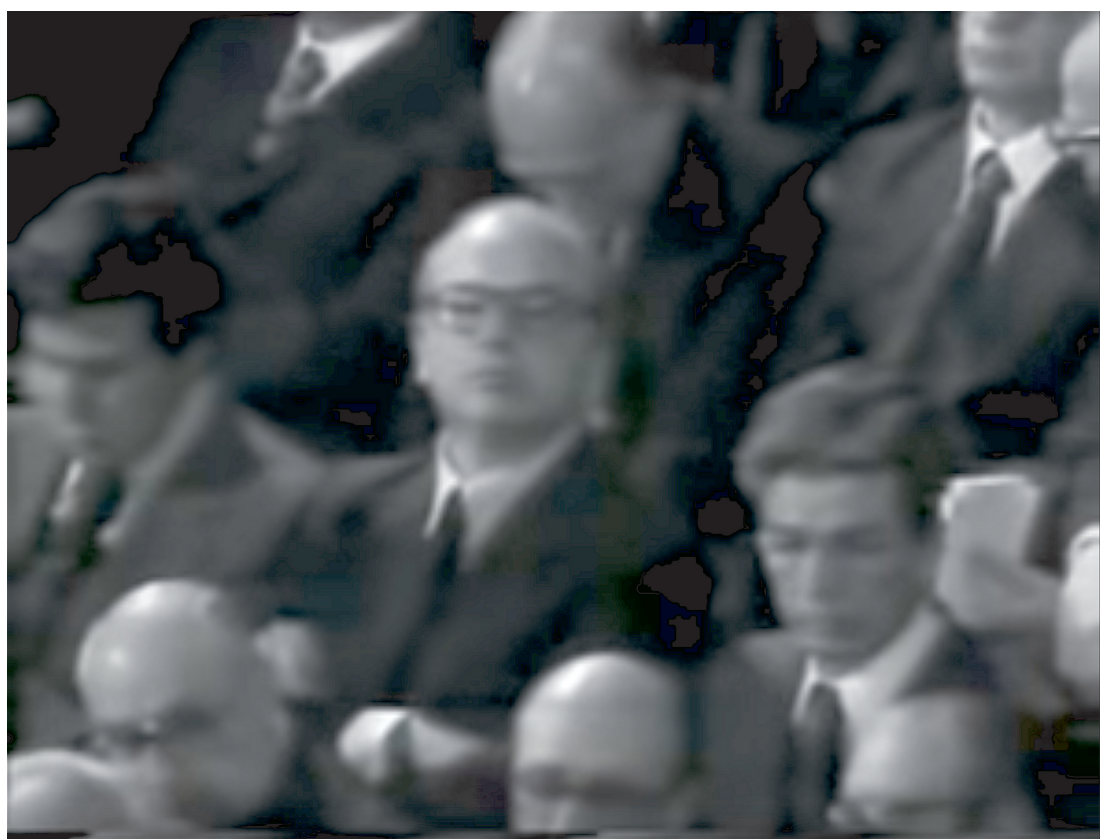

PICTURE 9: Bettino Craxi, secretary of the Italian Socialist Party, and Enrico Berlinguer, secretary of the Italian Communist Party, at the official funeral of Aldo Moro in the Archbasilica of St. John Lateran, Rome, May 13, 1978.

On different occasions, Sergio Zavoli's La notte della Repubblica uses film sequences from Giuseppe Ferrara's IL caso Moro (IT, 1986), which is based on Robert Katz's book Days of Wrath. The Public Agony of Aldo Moro. ${ }^{81} \mathrm{Katz}$ himself collaborated on the screenplay of the film. It is the first cinematographic production that explicitly addresses Moro's abduction and murder. ${ }^{82}$ The film pays particular attention to the involvement of the CIA and summarizes the findings of the police investigations, the court proceedings and the investigative exposés available at the time of its release. It is defined as a «docudrama» and contains many of the characteristics of

81 Katz 1980.

82 As Alan O-Leary points out, there are other films, in particular Ogro (Gilo Pontecorvo, E/IT/F 1979) and Maledetti vi Amerò (Marco Tulio Giorndana, IT 1980 ), that do not specifically adress the events of spring 1978, but which implicitly or implicitly refer to it. See O'Leary 2011, 34-45. 
television that is based on a true story. ${ }^{83}$ The thesis of the film is that the P2 Masonic lodge and the Italian secret services, sustained and influenced by Americans, ensured that the «line of firmness» would end with Moro's death. The film represents the DC as an instrumentalized party that, with its intransigence, was just as responsible for Moro's violent death as the jailers who left him dead in the trunk of a car. The central place of the Moro character, played by Gian-Maria Volonté in the role of a witness of truth and an accuser of the government and parties, distinguishes IL CASO Moro from the other Moro films. Volonté's choice is significant, since he previously played a main character in Elio Petri's Todo modo (IT, 1976), which was a parodic caricature of Moro. ToDo moDo is based on the homonymous novel by Leonardo Sciascia, who situates his protagonist, a painter, in the milieu of a religious retreat at the Hermitage Zafer. Sciascia's point of departure was Ignatius of Loyola's dictum: Todo modo para buscar y hallar la voluntad divina («One must use every means to seek and find the divine will»). ${ }^{84}$ Throughout the course of Ignatian Spiritual Exercises, several of the retreatants, all from various influential institutions, are mysteriously murdered. Don Gaetano, the retreat's master played by Marcello Mastroianni, is himself eliminated at the conclusion of the retreat, and a shroud of mystery hovers over the Hermitage as the novel ends.

Petri used this novel as a starting point to develop a highly politicized and caustic film, which explicitly attacks and criticizes the DC. To make his attack more explicit, Petri added specific details from the contemporary political scene. He chose the prominent political figure «M» as his protagonist, which is a specific reference to Aldo Moro. As Michalczyk observes, the portrait was sketched to cause maximum damage to Moro's image as well as to that of his party. ${ }^{85}$ In an interview, Petri recounted how strongly Volonté identified with the image of Moro as the true embodiment of power:

I scrapped the first two days of the making of ToDo моDo, in agreement with the producer and Volonté, because the resemblance of Gian Maria Volonté to Aldo Moro was nauseating, embarrassing, sickening to the stomach. In that picture there was all the insidiousness, the cunning of the political man. ${ }^{86}$

83 See O'Leary 2011, 51.

84 See Michalczyk 1988, 226.

85 See Michalczyk 1988, 228.

86 Manelli/Volonté 1998, 39; it.: «I primi due giorni di lavorazione di Todo MoDo furono cestinati da me, d'accordo col produttore e con lo stesso Volonté, perché 
Years later, Volonté provided completely different interpretations of the Moro figure, highlighting the process of metamorphosis that occurred in the media perception of the politician. Volonté's performances are interpreted as indicative of the responsibility felt by the left for the fate of the DC leader ${ }^{87}$ However, Volonté partially minimizes the difference between the images of Moro depicted in the two films:

In Todo MODo it [the image of Moro] was a mask, almost an imitation, within an allegory, so it was necessary to achieve a detachment, a continuous alienation. It was as if I had pulled the wires of that character, who was like a puppet, from the outside. In IL CAso Moro, instead, I wanted and had to look for internal paths, in the context of a dramaturgy that designed a progressive loss of power in a man and at the same time his descent into death: a fall. [...] But between the two characters, if their contents are well analyzed, there is not the enormous distance that someone wanted to indicate. In the Moro of Todo modo, there is an almost disturbing sense of premonition; and even in that movie, as a background, we choose to narrate the Christian Democracy. While Petri and Sciascia had chosen the key of allegory [...], on the other hand, the authors of IL Caso Moro [...] rightly chose the tragedy. [...] In IL CASO Moro we referred to a real human experience that had a recognizable conclusion in history, and for this very reference the viewer cannot escape the human appeal of this character. ${ }^{88}$

la somiglianza di Gian Maria Volonté con Aldo Moro era nauseante, imbarazzante, prendeva alla bocca dello stomaco. In quell'immagine risultava tutta l'insidiosità, l'astuzia dell'uomo politico.»

87 See O’Leary 2011, 52.

88 Balducci/Katz/Ferrara 1987, 19-20; it.: «In Todo modo si trattava di una maschera, quasi un'imitazione, all'interno di un'allegoria, quindi era necessario raggiungere un distacco, uno straniamento continuo. Era come se io tirassi dall'esterno i fili di quel personaggio che era come un burattino. In IL CAso Moro, invece ho voluto e dovuto cercare percorsi interni, nell'ambito di una drammaturgia che disegnava in un uomo la progressiva perdita del potere e contemporaneamente la discesa verso la morte: una caduta. [...] Ma tra i due personaggi, se si analizzano bene i contenuti, non c'è poi l'enorme distanza che qualcuno ha voluto indicare. Nel Moro di Todo modo c'è un senso di premonizione quasi inquietante; e anche in quel film, come fatto di fondo, si sceglie di raccontare la Democrazia Cristiana. Se da una parte Petri e Sciascia avevano scelto la chiave dell'allegoria [...], dall'altra gli autori de IL CAso Moro [...] hanno giustamente scelto la tragedia. [...] Ne Il CASo Moro noi ci siamo riferiti ad un'esperienza umana, reale, che ha avuto una sua conclusione riconoscibile nella storia, e 
The intention of showing Aldo Moro's humanity is explicit in the first scenes of the film, in which he is represented as a benevolent father and grandfather. In these scenes, he carefully asks his daughter Maria Fida if she will celebrate Easter with him and his wife and lovingly talks with his little grandson, Luca (see figure 10). The Moro we see here is fundamentally the same as the Moro we see in the "people's prison», where he tries to convince the BR that their vision of politics is simplistic, almost infantile (see figure 11). Moreover, it is the same Moro that tries to persuade the government and public opinion that undertaking negotiations for his liberation is both morally and politically necessary. So, as was already the case in Sciascia's L'affaire Moro and in the documentary La NOTTE Della RepubBLICA, the «humanization» of Moro does not correspond to the de-politicization of Moro's public image, but rather to the politicization of the man reduced to mere life, a man who, in spite of his captivity, tries to bear witness, accuse and appeal.

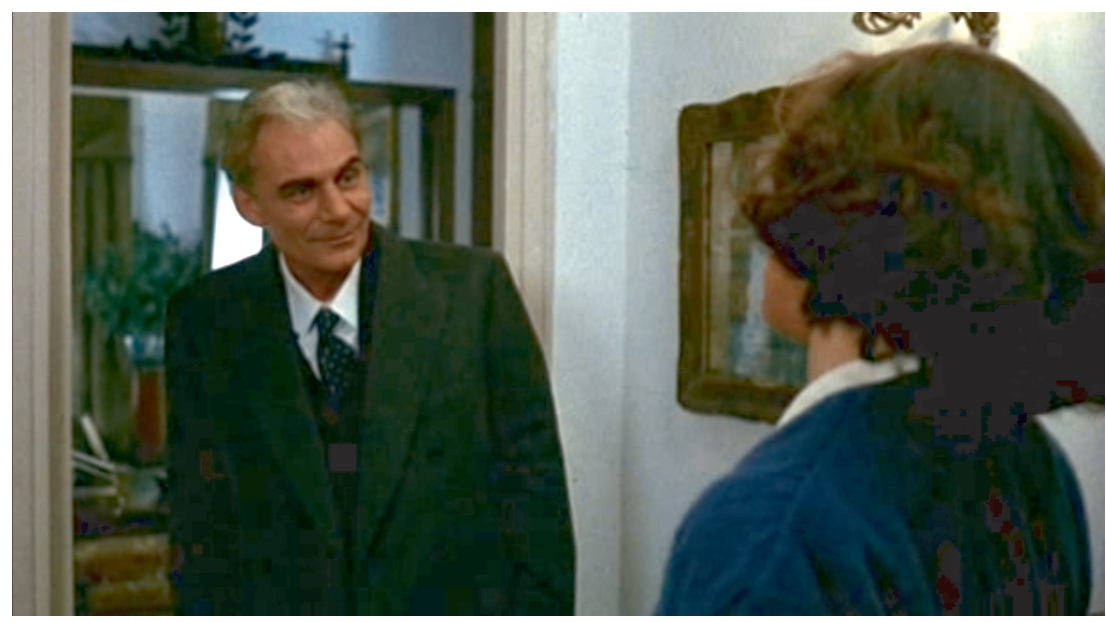

PICTURE 10: Aldo Moro (Gian Maria Volonté) speaking with his daughter Maria Fida (Daniela de Silva) in IL CASo Moro (Giuseppe Ferrara, IT 1986).

proprio per questo riferimento lo spettatore non riesce a sottrarsi al fascino umano di questo personaggio.» 


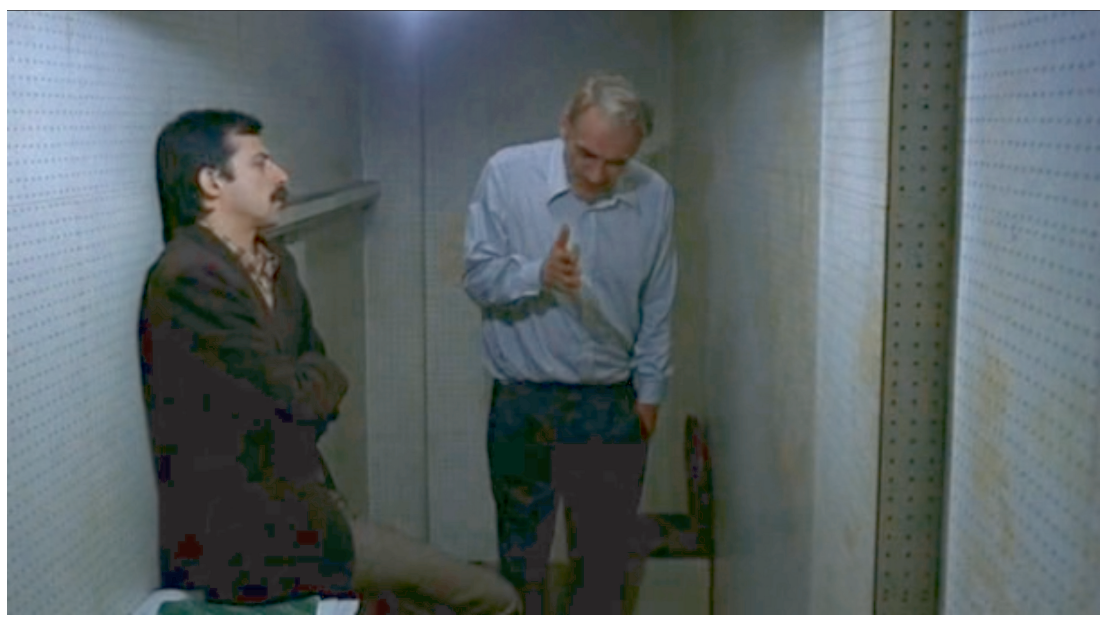

PICTURE 11: Aldo Moro (Gian Maria Volonté) speaking with one of the members of the Red Brigades (Mattia Sbragia) in IL CASO MORO (Giuseppe Ferrara, IT 1986).

Paolo Sorrentino's Il Divo (IT 2008), a biographical drama based on the figure of Giulio Andreotti, further demonstrates that the image of Moro underwent a metamorphosis. The film focuses on Andreotti's political activity and legal proceedings between the presentation of his seventh government in 1991 and the start of the Palermo trial against him for collusion with the Mafia in $1993 .{ }^{89}$ Although the actor who plays Moro (Paolo Graziosi) appears for only 14 seconds in the whole movie, his role in the film is essential (see figure 12). The film begins with a long series of murders and the alleged suicides of different personalities-journalist Carmine Pecorelli, General Carlo Alberto dalla Chiesa, judge Giovanni Falcone, bankers Roberto Calvi and Michele Sindona, lawyer Giorgio Anbrosoli and, last but not least, Aldo Moro-, insinuating, more or less explicitly, that Andreotti is somehow implicated in all of them. Moro's murder is hinted at only by a short shot of his body in the trunk of the famous Renault 4. After this montage of murders, we see Andreotti assuming, for the seventh time, the office of Prime Minister. An interesting scene appears

89 Andreotti was acquitted in the first instance on October 23, 1999. On May 2, 2003, he was judged and sentenced by the Palermo Court of Appeal for concorso esterno in associazione mafiosa. However, the offense committed was no longer punishable because of prescription. 
twenty minutes into the movie: the camera approaches slowly, moving downward toward the bed of Andreotti, who is lying on his back, reading. Once we see a close-up of the politician's face, the camera continues to move upward, where a painting depicting Karl Marx hangs over the bed. Immediately after, we hear the sound emitted by a recorded audiocassette reproducing the voice of Aldo Moro (played by Paolo Graziosi). This featured audiotape obliviously alludes to the hypothesis that emerged during the investigations, trials and parliamentary commissions of enquiry, according to which the recordings of the interrogations of Aldo Moro in the «people's prison» still exist, but have been hidden or concealed. However, the text that the voice recites is not invented, but a combination of excerpts from Moro's «Memorial» and one of Moro's letters to his wife:

What will they remember about you, honorable Andreotti? I do not intend to rake up your dull career. That's not a crime. What will they remember about you? A cold organizer: inscrutable, incapable of doubts or thrills, incapable of pity. What will they remember about you? Postscript: The Pope did ever so little; perhaps he will feel guilty. ${ }^{90}$

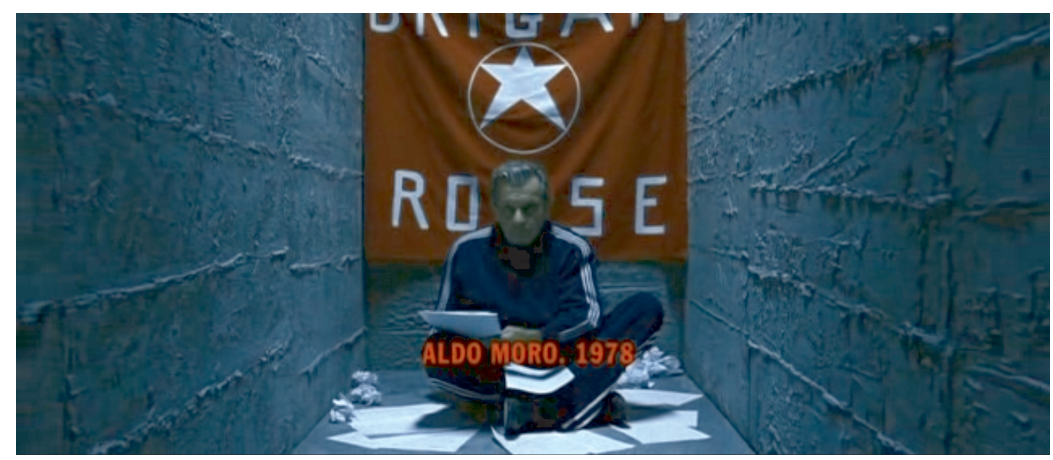

PICTURE 12: Aldo Moro as the accuser of Giulio Andreotti in the "people's prison» in IL DIVo (Paolo Sorrentino, IT 2008).

90 It.: "Che cosa ricordare di lei, onorevole Andreotti? Non è mia intenzione rievocare la sua grigia carriera. Non è questa una colpa. Che cosa ricordare di lei? Un regista freddo, impenetrabile, senza dubbi, senza palpiti, senza mai un momento di pieta umana. Che cosa ricordare di lei? Post scriptum: Il Papa ha fatto pochino. Forse ne avrà scrupolo» (21:00-21:43). See Flamigni 1997, 325, 356; Moro 2008m, 179. 
While the voice-over recites this text, we see Andreotti walking back and forth in a park or presumably in the garden of his residence in Rome. This leads the viewer to presume that the politician cannot sleep, perhaps due to feelings of guilt. Only after the voice pronounces the word "postscript», is there a sharp cut to a close-up of Moro; in the background stands the flag with the five-pointed star of the BR. He looks firmly in the direction of the lens or at the film's audience. The camera moves horizontally backwards until it reaches a frame that can be recognized by anyone who has seen the two Polaroid pictures shot by the BR. Here the scene, which lasts a little over a minute, ends. There are at least two aspects of this scene that can be highlighted. First, the prisoner is no longer represented here as a man deprived of his dignity, as the accused under trial in the «people's prison", but rather as an accuser who testifies in the trial where Andreotti is incriminated. Such an inversion was already emphasized by Sciascia, who in L'affaire Moro argues that in the BR's sixth communiqué, which could be considered as the "dispositive of a sentence», Moro looks more like a witness and an accuser than the accused. ${ }^{91}$ Second, the recited text emphasizes the theme of memory three times (although the phrase "what will they remember about you?» appears only once in Moro's «Memorial»). From this point of view, Andreotti is tried twice: once in the film in front of the court of Palermo, and a second time by the film in front of the film's audience. Here, the relationship between the narrative level and the performative or appellative intent of the film becomes manifest: just as it recounts the facts and events that are decisive for the accusation of collusion with the Mafia in the Palermo trial, the film constitutes itself as a second trial. This duplication is underlined at the end of the film, where we see Andreotti appear as the accused in the Palermo trial, which was held in the same bunker-courthouse where, between 1986 and 1992, 475 mafiosi were indicted in the so-called maxiprocesso. This is considered to be the biggest trial ever held in the world. ${ }^{92}$ While the camera is fixed on Andreotti's face as he sits in the dock, we hear the voice of Moro reciting the following text from the «Memorial» (see figure 13):

Andreotti remained indifferent, leaden, distant, cocooned in his dark dream of glory. He had to further his reactionary plan, not disappoint the Communists, the Germans, and who knows who else. What was the meaning, in the face of all this, of the inconsolable grief of an old

91 Sciascia 1978, 79.

92 See Giordano 2011, 68. 
spouse, the destruction of a family? What did all this mean for Andreotti, once he had achieved the power to do evil, just as he had always done evil in his life? All this meant nothing. ${ }^{93}$

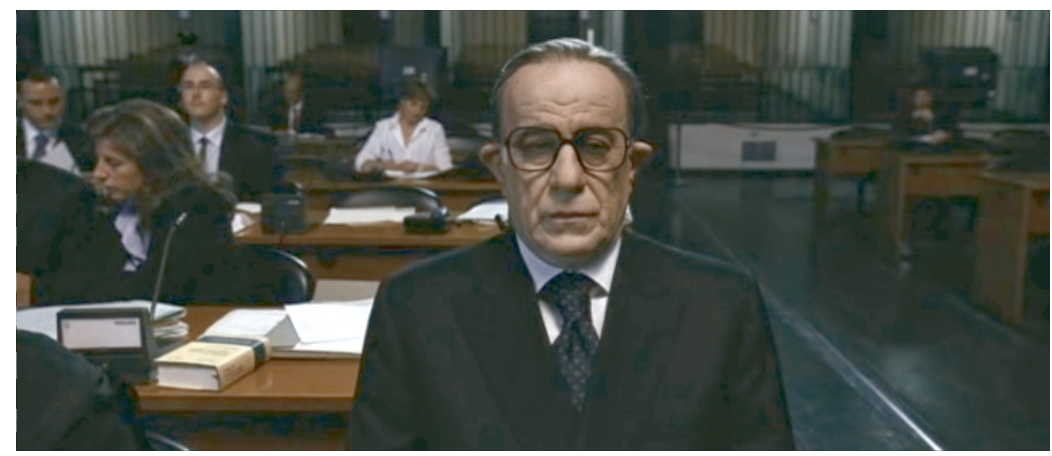

PICTURE 13: Giulio Andreotti accused of collusion with the Mafia at the maxiprocesso in front of the Palermo court in IL DIVo (Paolo Sorrentino, IT 2008).

Despite the metamorphosis of Moro's image described up to this point, the tendency to represent his death mythically as a sacrifice for the state also survives in recent cultural productions, as in the case of Marco Tullio Giordana's Romanzo di una STRAge (IT/F, 2012). The film, shot in Turin and Milan, deals with the reconstruction of the attack in piazza Fontana on December 12,1969, as well as with the various inquiries made by the judiciary about the death of Giuseppe Pinelli during the interrogation and subsequent killing of police commissioner Luigi Calabresi, who conducted the investigations. This film is based on the book Il segreto di Piazza Fontana by Paolo Cucchiarelli, in which he shares and enacts the thesis according to which two bombs were placed in the National Bank of Agriculture: the first by Anarchists as a demonstration attack, in which the bombs were meant to explode when offices were already closed; the second by Fascists

93 It.: «Andreotti è restato indifferente, livido, assente, chiuso nel suo cupo sogno di gloria. [...] Doveva mandare avanti il suo disegno reazionario, non deludere i comunisti, non deludere $\mathrm{i}$ tedeschi, e chissà quant'altro ancora. Che significava in presenza di tutto questo, il dolore insanabile di una vecchia sposa, lo sfascio di una famiglia? [...] Che significava tutto questo per Andreotti, una volta conquistato il potere per fare il male, come sempre ha fatto il male nella sua vita? Tutto questo non significava niente» (01:41:16-01:41:57). Cfr. Moro 1997f, 326. 
(who had infiltrated the Anarchists), which caused the massacre and aimed to make the attack appear as an act by leftist groups. It is not possible here to reconstruct the official results of the investigations and trials or the different conspiracy theories related to the massacre of Piazza Fontanawhich, as we have seen, is seen as the starting point of the «years of lead» and the «strategy of tension».94 The point of interest here is primarily the role attributed to Moro in the political management of the events of 1969 and the relationship that the film constructs between these events and the politician's murder in 1978.

The Moro character appears six times in the film: in a church in Rome; in the Palazzo del Quirinale, discussing the killing of a policeman during a demonstration in Milan with the then President of Italy, Giuseppe Saragat; in his office in Rome, discussing the threat of a coup d'état in Italy with the colonel of the Carabinieri, Pio Alferano; in Paris, recommending that the other members of the European Commission expel Greece from the Commission (because of the Greek military junta of 1967-1974); again in his office, where Alferano delivers the report on his investigation into the massacre of Piazza Fontana to him; and finally, again speaking with President Saragat. In this progression, Moro is represented as the politician who immediately realizes that the attack was organized and implemented by the Fascists, who opposes a series of repressive measures wanted by other members of government (Moro in that period was Foreign Minister), who investigates and finds out that part of the secret services and state apparatuses were involved, and who finally decides to keep information about the strage di Stato («massacre of the state») secret. In his last appearance, Moro submits Alferano's report to the President and, after the latter admonishes him not to make it public, he states:

If I made public what you just read, a civil war would break out, because for many people even the idea that some part of the state has covered or endorsed this horror would be intolerable. That is why we will

94 As noted in the fourth chapter, it was established that the right-wing group Ordine nuovo placed the bomb. In the "Memorial», Moro himself wrote that, when the attack was perpetrated, he immediately assumed that it had been carried out by right-wing groups in an attempt to «block certain political developments» [it.: «bloccare certi sviluppi politici»] and expressed the conviction that «the interest and the intervention were more foreign than national» [it.: «l'interesse e l'intervento fossero più esteri che nazionali»]. See Moro 1997c, 230-232. 
not do anything; we will force them to cover everything, like cats with their excrement. ${ }^{95}$

The most significant scene is undoubtedly the first one, which begins with Moro in the Church of Santa Chiara, where we see him speaking with a Catholic priest in what appears to be a confession, although the scene does not occur within the confessional but on the church's pew (see figure 14). Here, he says:

I wonder what role the Lord has assigned me in the midst of this stormy sea. I cannot understand it, Father. I cannot see it. I look at my fellow man and I see nothing but iniquity and vanity; I see wailing, no sense of community; no love except for their own reward; then cowardice and opportunism; violence instead of ideas. Sometimes I think that only things maintain dignity: trees, stones, nature. Sometimes I think that Italy needs a catastrophe destroying all that we have built to contrast [these things] — the ant's nest, cars, cement—in order to bring Italy back to the desert. To the bare earth it once was. So that nature can regain control and start again from the first form of life, from the first man, from the first fire. Here, of this cataclysm, Father, I feel ready to be the first victim. ${ }^{96}$

95 It.: «Se io rendessi pubblico ciò che le ho appena fatto leggere, scoppierebbe una guerra civile, perché per molti sarebbe intollerabile anche solo l'idea che una parte dello stato abbia coperto o avvallato questo orrore. Per questo non faremo nulla; li costringeremo a coprire tutto, come i gatti con gli escrementi» (01:15:2801:15:52).

96 It.: «Mi chiedo quale è il ruolo che il Signore mi ha assegnato in mezzo a questo mare in tempesta. Non riesco a capirlo, Padre. Non riesco a vederlo. Guardo i miei simili e non vedo che indisciplina e vanità; vedo furbizia; nessun senso della comunità; nessun amore se non per il proprio tornaconto. Poi viltà e opportunismo; violenza al posto delle idee. Alle volte penso che a mantenere un contegno siano rimaste soltanto le cose. Gli alberi, le pietre, la natura. Talvolta penso che all'Italia sia necessaria una catastrofe che distrugga tutto quello che vi abbiamo contrapposto: I formicai, le auto, il cemento, e la riporti al deserto. Alla nuda terra di prima. Così che la natura possa riprendere il sopravvento e ricominciare dalla prima forma di vita, dal primo uomo, dal primo fuoco. Ecco, di questo cataclisma, Padre, io mi sento pronto padre a essere la prima vittima» (05:54-06:50). 


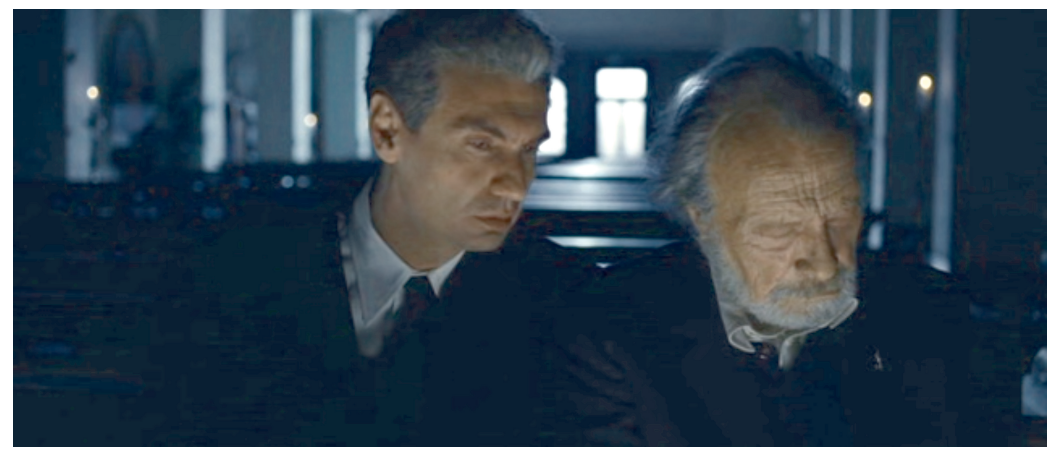

PICTURE 14: Aldo Moro's "confession» in RoMANZo DI UNA STRAGE (Marco Tullio Giordana, IT/F 2012).

In this scene, Moro basically expresses his willingness to accept martyrdom. The decision to set the scene in the same church where Moro went on the day of his abduction is obviously not accidental. The scene works with what Blumenberg calls «magic affirmation» (ger. magische Sicherung); that is, the narrative construction of a meaningful relationship between the juxtaposition of an event and another that precedes it. Moro's confession in the church in 1969 assumes the role of a premonitory sign, a prefiguration brought to a pathetic excess, of what happened on March 16, 1978. The film deploys the mythological conception already discussed above: Moro's death assumes the meaning of an expected sacrifice that is necessary to restore the balance of the natural and socio-political cycle of life and death, order and chaos..$^{97}$ Moreover, Moro's decision to maintain secrecy about the «massacre of the state» is denoted as a sort of «original sin», which can be expiated only by sacrifice. Sacrifice transforms guilt into innocence. This interpretation is corroborated by the fact that Moro's last appearance - the scene with Saragat-is preceded by a short sequence (nine seconds) in which we see him praying in church, and then followed by an intertitle stating «The Reason of State». The meaningful analogy constructed here is clear: the same «reason of state» that forced Moro into silence about what «really» happened in 1969 will force him to accept his sacrifice in 1978 . His choice had a price, as the final title informs the audience before the closing credits: «Aldo Moro was assassinated by the Red Brigades

97 As Alan O'Leary points out, the idea of the death of Moro as a sort of totemic sacrifice is already present in Marco Tullio Giorndana's MALEDETTI VI AMERò (IT 1980). See O'Leary 2011, 38-45. 
on May 9, 1978». In short: Romanzo DI UNA STRAGE is more proof of the widespread fascination with the mythical and sacrificial narrative model, since personalities such as director Marco Tullio Giordana and writer Italo Calvino, who are anything but naive and unprepared, failed to resist it.

In 2003, two films were released in cinemas that are quite different from each other: Piazza delle CinQue lune (Renzo Martinelli, IT/UK 2003) and Buongionno, notTe (Marco Bellocchio, IT 2003). The former is a thriller that brings the conspirational narrative plot to an unlikely and almost grotesque excess: twenty years after the Moro events, a judge on the cusp of retirement receives a film of the via Fani kidnapping from a mysterious figure and begins an investigation. The spectator comes to discover, after a series of revelations and twists, that Mario Moretti, the leader of the BR and principal architect of the Moro kidnapping, is a spy working for the CIA. ${ }^{98}$ As O'Leary observes, Piazza delle cinque lune is «not a Moro film at all», since «it invokes Moro both as a metaphor (for victimhood as such) and metonym (for the anni di piombo as a whole), but as a trope unhitched from its specific historical circumstances.» ${ }^{99}$ Moreover, the film does not pay attention to the «line of firmness» and to Moro's letters, which is why it has little relevance to this study. Much more interesting is the latter, since it explicitly addresses the problem of martyrological representation and the allocation of the martyr role. BuOngIORno, NOTTE is not interested in providing knowledge or explanations of the events or in revealing and conveying little known aspects that had been consigned to the dark corners of memory by media oblivion. The film combines historical reality and fiction, almost becoming a story of counterfactual fiction: Moro is symbolically «resurrected» to bring to fruition the hypothesis that Moro might be set free from his BR prison and walk away undisturbed.

BuONGIORNo, NOTTE is loosely based on the dramatic memoirs of the former BR member, Anna Laura Braghetti, who, according to her own account of the event, was a resident in the via Montalcini apartment throughout Moro's imprisonment. The film is conceived as a mixture of fiction and news reportage. ${ }^{100}$ For the most part, the story is told from the point of view of Chiara, the alter ego of the former female terrorist, who is eventually moved by the humanity of Aldo Moro and distances herself from the motives for the kidnapping and, above all, from the rationale of the death sentence. The camera follows her through her daily life, yet also

98 For a critique of conspiracy theory in this film, see O'Leary 2011, 48-59.

99 O'Leary 2011, 59.

100 See Braghetti/Tavella 1998. 
depicts her dreams and fantasies. In the non-dreamlike dimension of the film, the television is constantly on in the apartment where Moro is held prisoner, transmitting the news reports and other programs of the time. The original televisual images of the outside broadcasting from the location of the via Fani attack are fused with other images in the film. The dream sequences in the film also incorporate episodes of documentary cinema and, in particular, fragments of Dziga Vertov's Three Songs About LENIN (USSR 1934) showing highlights of the Soviet revolution.

An important topic of the film is the problem of the historical memorialization of the Resistenza. The reference to the partisan struggle is already present in one scene where Chiara attends a family reunion on April 25, the anniversary of the Resistenza, during which the older family members sing Fischia il vento, a popular song written in September 1943 at the inception of the partisan struggle; but the key scene in this regard is when Chiara reads one of Moro's letters to his wife, as already quoted above. ${ }^{101}$ As she reads the letter, we listen to the voice of Roberto Herlitzka, alias Aldo Moro, reciting the letter's content; after a while, his voice is replaced by another voice who reads a letter from a member of the Italian Resistance who is condemned to death. This scene is accompanied by Pink Floyd's song The Great Gig in The Sky and images of the atrocious executions of partisans from the final scenes of Roberto Rossellini's PaIsà (IT 1946) (see figure 15). ${ }^{102}$ We see, then, Chiara crying, as she realizes the analogy between Moro's and the partisans' ordeals. Moreover, the lyrics of the Pink Floyd song emphasize the theme of death and the courage when one is faced with death:

And I am not frightened of dying / Any time will do, / I don't mind. / Why should I / be frightened of dying? / There's no reason for it, / you've gotta go sometime. / I never said I was frightened of dying.

Undoubtedly, Bellocchio subverts and implicitly criticizes those who, as previously seen, in the spring of 1978, compared the partisans' letters and the letters by Moro to make the latter appear like a coward. Moreover, by combining fictional images of partisans' executions with the reading of a letter of a historical person who was actually executed, the director manages to construct a powerful analogy between Moro's letters and the partisans' letters and, at the same time, displays or unfolds the analogical construction. In a sense, the film invites the public to become conscious of the

101 See foodnote 73.

102 See Pezzini 2012, 147. 
performative mechanism of prefiguration. Within the film, the situation of the partisans condemned to death prefigures the situation of Moro within the "people's prison", allowing Chiara to become aware of the instrumentality of the BR's rhetoric and self-identification as legitimate heirs of the Resistenza, since she understands that they are acting just like the Fascists by condemning an innocent person or, at least, «the least implicated of them all» to death. The spectator is encouraged to become aware that historical memory is always the product of discursive practices. In other words, Bellocchio uses images and words poetically and not instrumentally, unveiling their historicity and exteriority.

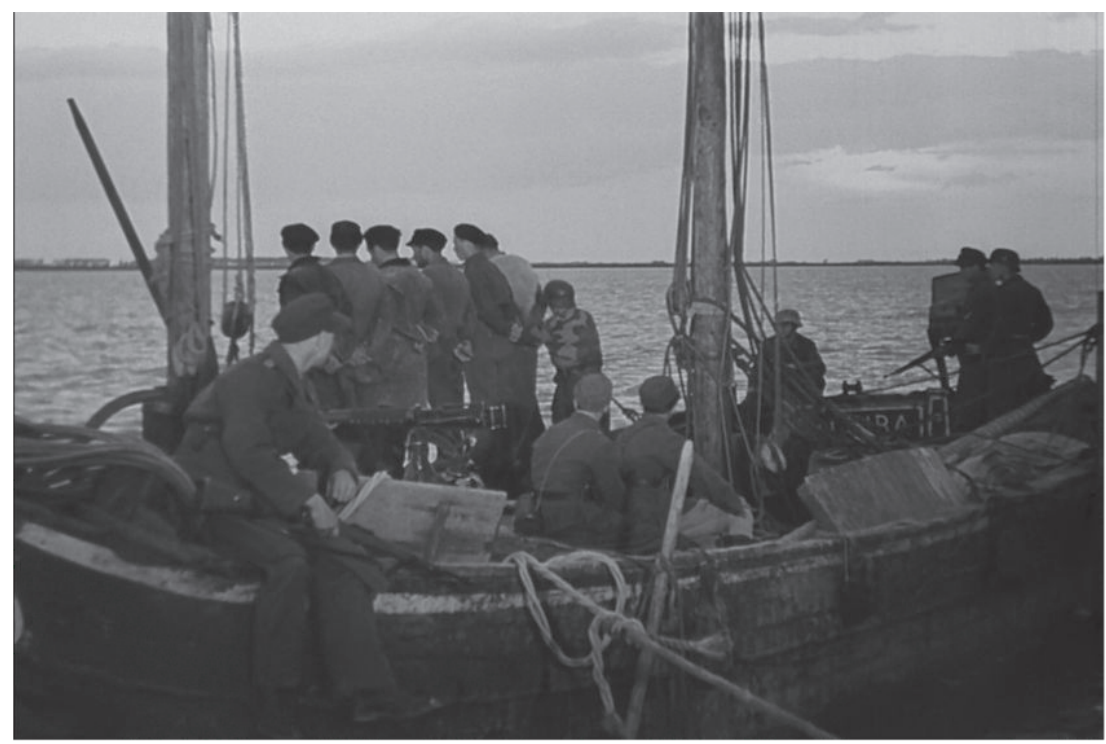

PICTURE 15: Execution of partisans in PAISÀ (Roberto Rossellini, IT 1946).

The same approach is used in relation to the martyr figure in a scene where Moro and Mariano (the name of a character that impersonates the Red Brigades' leader Mario Moretti) debate within the "people's prison». The scene begins with a close-up of Chiara's eye, who looks at the «interrogation» from a little hole in the wall that separates Moro's cell from the rest of the apartment and listens to what the prisoner and his jailer say:

Mariano: Are you afraid of death?

Moro: Why did you ask this? 
Mariano: Yet you believe in the afterlife.

Moro: Jesus was also frightened in Gethsemane.

Mariano: I remember that as a child I was so infatuated with religion that I hoped to die in order to go to heaven as soon as possible. So absurd!

Moro: Are you not afraid of dying?

Mariano: Every man one day has to die. But not all deaths have the same meaning. I believe our superiority consists in this: we are willing to die for our ideas. Communists are like that.

Moro: Like the first Christian martyrs. In the end yours is a religion, like mine. In fact, it is much more severe. For example, it despises the body far more than we Catholics do. Once also Christianity was like this, but now no more. The last crusade was in $1270 .{ }^{103}$

In just over a minute, the dialogue uncovers the historicity of the martyr figure and draws attention to its signatures. The Moro character highlights the analogy between Communists and the first Christian communities in their willingness to die for a «higher» cause. He thus draws attention to the fact that both Christianity and Communism are based on a messianic and eschatological conception of history. ${ }^{104}$ However, he also points out that the ideology of martyrdom was and is used as an instrument for the legitimization and justification of violence and war, as in the case of the crusades. In other words, Moro unveils, by the means of analogy, the instrumental use of memory: just as the crusaders understood themselves as the legitimate heirs of early Christians, the BR represented themselves as the legitimate heirs of Resistance fighters. The memory of early Christians and partisans, both willing to die for their ideas, is instrumentally used to legitimize the willingness to kill for ideas. The Moro character underlines the

103 It.: «Mariano: Hai paura di morire? / Moro: Perché me lo chiede? / Mariano: Eppure tu credi nell'aldilà? / Moro: Anche Cristo nell'orto del Getsemani ha avuto paura. / Mariano: Mi ricordo che da bambino ero talmente infervorato dalla religione che speravo di morire per andare in paradiso il più presto possibile. Che assurdità. / Moro: Lei non ha paura di morire? / Mariano: Ogni uomo un giorno deve morire. Ma non tutte le morti hanno lo stesso significato. Io credo che la nostra superiorità consista in questo: noi siamo disposti a morire per le nostre idee. I comunisti sono così. / Moro: Anche i primi martiri cristiani. In fondo la sua è una religione, come la mia. Anzi, è molto più severa. Per esempio disprezza il corpo, molto di più di quanto non facciamo noi cattolici. Un tempo il cristianesimo era così, ma ora non più. L'ultima crociata è del 1270» (47:00-48:08).

104 As far as the analogies between Christian and Communist eschatology are concerned, see Agamben 2005, 29-33. 
instrumentality of both practices of memorialization. From this point of view, it is correct to affirm that BuongionNo, NOTTE «is not a film about the Moro events as such, but about the representational means through which we construct our understandings of such events» and, more generally, of history. ${ }^{105}$

Although the film focuses on the deconstruction of the BR's rhetoric and language, it also challenges the hegemonic discourse produced by the government, major parties and established media. Again, it is the character of Aldo Moro that unveils the instrumental use of language and rhetoric. In the last dialogue before his death and resurrection, Moro tries to explain to his jailers why death will be extremely counterproductive for them:

Moro: Do you not understand that I will become a martyr? [Do you not understand that I will become] the idiot they will use to destroy you? When television - it does not take much to understand it! — when television and newspapers will show photos of my corpse, people will not understand. They will hate you. ${ }^{106}$

The role of the media during Moro's 55 days of imprisonment is constantly underlined in the film, showing how, out of the "people's prison", an uncompromising position with respect to negotiation emerged and spread quickly. Here, Moro essentially says to the BR that they are doing exactly what the government, media and parties expect of them; but this does not serve to convince the BR, except for Chiara, who expresses her disappointment since she cannot accept the idea of murder, and Ernesto, who seems to understand Moro's argument. In fact, speaking with Mariano, he states:

You heard what the president said. Think a little: Everybody wants him dead and we are going to kill him. We will be doing them a great service. We will kill him for them-do you realize that?107

105 O'Leary 2011, 61.

106 It.: Moro: «Ma non capite che diventerò un martire? L'idiota di cui si serviranno per annientarvi? Quando la televisione - non ci vuole molto a capirlo! - quando la televisione, i giornali, mostreranno le foto del mio cadavere la gente non potrà capire. Vi odierà» (01:26:06-01:26:21).

107 It.: «Hai sentito cosa ha detto il presidente. Ragiona: tutti lo vogliono morto e noi lo ammazziamo. Gli facciamo un gran servizio. Noi lo ammazziamo per loro, ti rendi conto?» (01:30:47-01:30:56). 
Mariano does not realize and continues to justify the homicide as necessary for the revolutionary cause:

If we kill him, we will prove that we are stronger because no pity can stop us. We only respond to the proletariat and the working-class. ${ }^{108}$

Here, the film clearly highlights what Umberto Eco had already noticed, namely that the BR's actions and ideology were functional to the same system they wanted to destroy.

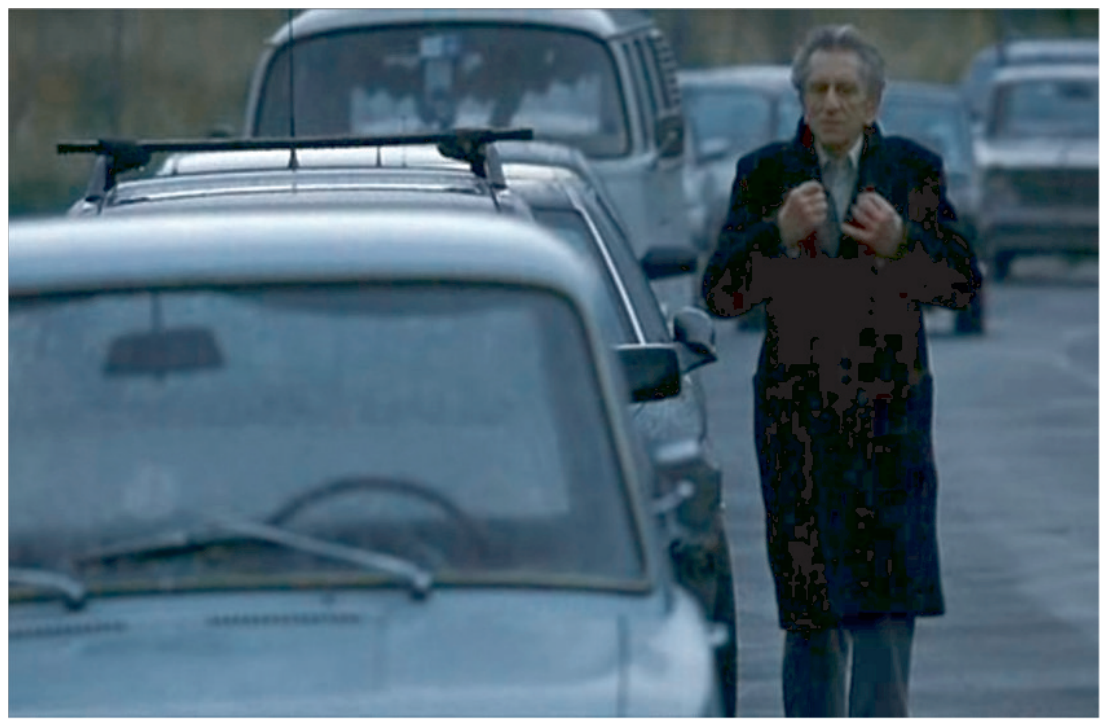

PICTURE 16: Alternative ending: Moro walking away from the "people's prison» in BUONGIORNo, NOTTE (Marco Bellocchio, IT 2003).

The final sequence of the film is a montage of two alternative outcomes of the kidnapping, united by Pink Floyd's song Shine On You Crazy Diamond (Part One) on the soundtrack. In the first scenario, the female terrorist falls asleep after taking a last look at the prisoner and opening the door of his cell. The prisoner then gets up and, while everybody sleeps, leaves the apartment and walks calmly out onto the street. In the second scenario, the

108 It.: «Se lo ammazziamo dimostriamo che siamo più forti perché nessuna pietà ci può fermare. Noi rispondiamo soltanto al proletariato e alla classe operaia» (01:30:56-01:31:03). 
woman falls asleep and Moro is led blindfolded from his cell with the sign «Buongiorno, notte», signaling the end. The film continues with a sequence of footage from the state funeral until the music changes: Schubert's Musical Movement in F accompanies the scene of Moro walking away into the open space of the city of Rome (see figure 16). As O'Leary observes, "the confusion between the poetic reconstruction of events and their revisionist reinterpretation in BuONGIORNO, NOTTE is deliberate», since «the jarring interpolation of sequences from other films, while illustrating Chiara's subjectivity, also force our attention to how film constructs our impression of history precisely through a rhetorical invocation and embellishment of the fact.» ${ }^{109}$ This is particularly evident in the way the film refers to the martyr figure: instead of using it instrumentally, it poetically uncovers its historical uses and abuses. Should Italian people consider Aldo Moro a hero, a saint, a martyr? The director Bellocchio, in a cameo appearance, takes pleasure in not answering this question by saying: «Was it true glory? Posterity will judge». ${ }^{110}$

\subsection{Beatification Process}

This reconstruction and deconstruction of memorializing representations and practices of the abduction and death of Aldo Moro cannot end without addressing a recent initiative: as reported firstly by the newspaper $\mathrm{La}$ Gazzetta del Mezzogiorno in September 2012, the Diocesan Tribunal of Rome approved an inquiry into the potential canonization and beatification of Aldo Moro. ${ }^{111}$ The initiative was launched in May of the same year by the Federazione dei Centri studi Aldo Moro and Renato Dell'Andro, led by the engineer Luigi Ferlicchia, who organized a collection of signatures in support of Moro's «fame of sanctity». The Postulator of the Cause, Nicola Giampaolo, provided the Supplice libello sulla fama di santita, that is, «Pleading Pamphlet on the Fame of Holiness», to Cardinal and Archbishop Agostino Vallini, Vicar of the Pope, who then addressed the statesman as Servo di Dio (Servant of God). After this, the President of the Diocesan tri-

109 O'Leary 2011, 67.

110 It.: «Fu vera gloria? Ai posteri l'ardua sentenza» (01:18:55-01:19:00).

111 See Sorino, Benedetto, "Moro beato, via alla causa - agli atti c'è un miracolo», La Gazzetta del Mezziorgiono, 22.9.2012, http://www.lagazzettadelmezzogiorno.it /news/home/397234/moro-beato-via-alla-causa-agli-attic-e-un-miracolo.html (accessed August 23, 2017). 
bunal of Rome introduced the cause by acquiring the acts of the Supplice libello sulla fama di santità.

The procedure of canonization and beatification is complex and can take years, if not decades. Moreover, it cannot begin unless at least five years have passed since the death of the person in question. ${ }^{112}$ Canonization is the act by which the Catholic Church declares that a person who has died is a saint; the person is included in the "canon", or list, of officially recognized saints and can be venerated in the «universal Church» (while beatification permits only veneration in "particular Churches», that is, in a certain diocese). The procedure of canonization has two phases: a Diocesan and a Roman phase. The beatification and canonization of Aldo Moro is still in the preliminary part of the first phase, called Inchiesta sull'eroicità delle virtù o sul martirio del servo di Dio (Inquiry into the heroic virtue or the martyrdom of the servant of God). ${ }^{113}$ The purpose of the inquiry is to collect documentary evidence and testimonies pro et contra beatification and canonization. People who lived with the potential saint and know about his or her work and lifestyle initiate the process of canonization: the community of the parish, the religious congregation, the community in which he or she worked, and so on. ${ }^{114}$ The «Actor»—-that is, the group of people initiating the process-charge a person they consider appropriate to submit a request to the competent bishop-the bishop of the diocese where the potential saint died-to open the Diocesan Inquiry into possible beatification. The person who submits the question is called the «Postulator of the Cause». The Postulator carries out investigations into the life of the «Servant of God» in order to know his «fame of holiness» and the ecclesial importance of the cause and to report this to the bishop. ${ }^{115}$ The goal is to verify the «heroic virtues» or the «martyrdom» of the dead person. As a legal representative of the "Actors», the Postulator prepares the Supplice libel$l o$, that is, the petition in writing with which he officially begins the Diocesan Inquiry. Along with this petition, the Postulator sends (a) a biography of the potential saint, (b) all the writings that the potential saint published or edited, (c) a list of «eyewitnesses» (de visu), that is, of texts that contribute to the verification of the virtues or martyrdom of the potential

112 See Congregazione delle Cause dei Santi 2004, 266.

113 See Congregazione delle Cause dei Santi 2004, 255.

114 See Sanctorum mater, Art.9-11, in: Congregazione delle Cause dei Santi 2004, 411.

115 See Sanctorum mater, Art. 12-19, in: Congregazione delle Cause dei Santi 2004, 412-413. 
saint. ${ }^{116}$ The bishop can accept the Supplice libello «after assessing the existence of the authentic and widespread fame of holiness or of martyrdom and of signs.» ${ }^{117}$ For this reason, he must consult with other bishops on the initiation of the cause as well as to «make known the petition of the postulator $[\ldots]$ with an edict, placed in a cathedral or published in the diocesan newspaper (bulletin).»118 In this edict, he invites all believers to provide useful information about the cause. Moreover, he must send a request to the Congregation for the Causes of Saints, asking for its nulla osta (nothing opposes).

In September 2016, Postulator Nicola Giampaolo declared to Radio Vaticana the following:

We are still gathering numerous postulations, testimonies of cardinals, bishops, convinced of the opportuneness of this cause, but also of common people, politicians and intellectuals. We hope to be soon able to request the 'nulla osta to proceed to the Italian Bishops' Conference. ${ }^{119}$

This means that the preliminary phase of the Diocesan Inquiry has not yet ended. Although the Supplice libello sulla fama di santità is not accessible to the public, some information on its contents was disclosed to the media by the Postulator. He declared three main arguments in favor of Moro's fame of holiness: his incontrovertible Christian and Catholic faith, his martyrium in odium fidei, and finally a miracle of intercession. According to the Postulator, the Red Brigades were a terrorist group led by Communist ideology in a war against Christianity, which is why Moro's death can be seen

116 See Sanctorum mater, Art. 37, in: Congregazione delle Cause dei Santi 2004, 418.

117 Sanctorum mater, Art. 40 - $\$ 1$, in: Congregazione delle Cause dei Santi 2004, 419; it.: «[...] il Vescovo diocesano o aperchiale potrà accettare il libello di domanda per l'avvio della causa dopo aver valutato l'esistenza di un'autentica e diffusa fama di santità o di martirio e di segni.»

118 Sanctorum mater, Art. 43 - $\$ 1$, in: Congregazione delle Cause dei Santi 2004, 420; it.: «Il Vescovo deve rendere nota la petizione del postulatore di iniziare la causa nella sua diocesi o perchia con un edito, affisso in catedrale o pubblicato sul giornale (bollettino) parrocchiale.»

119 Quoted in Zenit. Il mondo visto da Roma, "Aldo Moro. Il Vicariato di Roma avvia il processo di beatificazione», 24.9.2016, https://it.zenit.org/articles/aldo-moro-ilvicariato-di-roma-avvia-il-processo-di-beatificazione/ (accessed August 23, 2017); it.: "Attualmente stiamo ancora raccogliendo numerose postulatorie, testimonianze di cardinali, vescovi, convinti dell'opportunità di questa causa, ma anche di gente comune, politici e intellettuali. Quanto prima speriamo di poter richiedere il «nulla osta〉 per procedere alla Conferenza Episcopale italiana.» 
as a form of martyrdom. Moreover, he also referred to the witness of Monsignor Francesco Colasuonno, who is known for having organized the meeting between Gorbachev and Wojtyla and then being appointed Cardinal by John Paul II himself. Colassuonno recounted that, when he was in the Apostolic Nunciature in Mozambique in July 1978, a group of guerrillas attacked, destroyed and killed everyone they encountered. Closed in a room with a picture of Moro on the wall, Colasuonno began to pray, invoking his help. This is indicated as a miracle of intercession. ${ }^{120}$

For the purpose of this study, the second reason indicated by the Postulator is particularly interesting. A manual for the Postulators published by the Congregation for the Causes of Saints states that there are three fundamental elements that characterize «true Christian martyrdom»: «a) material martyrdom; b) formal martyrdom ex parte persecutoris, and c) formal martyrdom ex parte victimae.» ${ }^{121}$ The material element is violent death; however, for such a death to be regarded as martyrdom, «it is necessary that those who commit death carry out such action because of their hatred of faith or of a virtue related to the faith of God.» Moreover, the second necessary element is «the voluntary acceptance of death for the sake of faith». ${ }^{122}$ Martyrdom therefore demands that the cause of death be the faith or practice of a faith-related virtue. Recalling Saint Augustine's dictum non causa sed poena facit martyrem, the manual states: «martyrdom does not depend on the sufferance but on cause of this sufferance.» ${ }^{123}$

According to Monsignor Andrea Venezia, Presbyter of the Papal Archbasilica of St. John in Lateran, material and formal elements of martyrdom are fulfilled in the case of Moro's death. When interviewed by Radio Vaticana with the Postulator, Venezia stated:

The premise to open the cause of beatification was there, because if political activity is carried out according to the cardinal virtues of justice,

120 See Ferlicchia 2014, 559.

121 Congregazione delle Cause dei Santi 2004, 61; it.: «Sono tre gli elementi importanti che caratterizzano il vero martirio cristiano, ed ogni processo per un'eventuale canonizzazione dovrà raggiungere la certezza morale a questo riguardo: a) il martirio materiale ; b) il martirio formale ex parte persecutoris e )c) il martirio formale ex parte victimae.»

122 Congregazione delle Cause dei Santi 2004, 62; it.: «In primo luogo è necessario che chi infligge la morte compia tale azione per odio alla fede o a una virtù relazionata con la fede in Dio. [...] Il secondo elemento formale [...] è l'ccettazione volontaria della morte per amore della fede [...].»

123 Congregazione delle Cause dei Santi 2004, 64; it.: «[...] il martirio non dipende dalla pena che si subisce, ma dalla causa di questa pena.» 
fortune, temperance, sobriety, and service to the common good, but also in accordance with faith, it is the highest form of charity. For a Christian like Aldo Moro, baptized and raised as a young man in Christian consciousness, politics was certainly a charitable act that lived up to the effusion of blood. Moro was not only barbarously killed, as the images showing him as a «sacrificial lamb» show. But his end was also the conclusion of a testimony and that is why we can talk about martyrdom in his case. Not only did he testify to his faith with his gentle and peaceful approach to the things of politics and government activity, with his ability to listen, mediate, and reconcile opposites, but continued his testimony to the extreme consequences, to the point of death. His was not tactics; it was a model of government. And Moro was a politician also committed to a spiritual and transcendental ideal that is called Christian faith. ${ }^{124}$

For Venezia, Moro was killed due to the inspiration of Christian ideals and virtues in his political activity. Similarly, the Postulator Giampaolo argues this in a book published in 2015 when he describes the politician's «exercise of charity as an authentic and essential testimony of faith.» ${ }^{125}$ Moreover, according to the Postulator, Moro «was sacrificed for the salvation of so many $[. .$.$] .» Here, the voluntary acceptance of martyrdom is explicitly$ described as deriving from Moro's understanding of love as «agape, as a

124 Quoted in Zenit. Il mondo visto da Roma, «Aldo Moro. Il Vicariato di Roma avvia il processo di beatificazione», 24.9.2016, https://it.zenit.org/articles/aldo-moro-ilvicariato-di-roma-avvia-il-processo-di-beatificazione/ (accessed August 23, 2017); it.: «Le premesse per aprire la causa di beatificazione c'erano perché l'attività politica se svolta secondo le virtù cardinali di giustizia, fortezza, temperanza, sobrietà e come servizio al bene comune, ma anche nella fede, è la forma più alta di carità. Per un cristiano come Aldo Moro battezzato e cresciuto sin da giovane nella coscienza cristiana, la politica è stata certamente un atto di carità vissuto fino all'effusione del sangue. Non solo Moro fu ucciso barbaramente come testimoniano le immagini che lo mostrano come agnello immolato.> Ma la sua fine fu anche la conclusione di una testimonianza ed è per questo che nel suo caso possiamo parlare di martirio. Non solo testimoniò la fede con il suo approccio mite e pacato alle cose della politica e all'attività di governo, con la sua capacità di ascolto, mediazione, conciliazione degli opposti, ma portò avanti la sua testimonianza fino all'estreme conseguenze, andando incontro alla morte. Il suo non era tatticismo era un modello di governo. E Moro fu un politico impegnato anche per un ideale spirituale e trascendente che si chiama fede cristiana.»

125 Giampaolo 2015, 52; it.: «Aldo Moro ha cercato di esercitare il servizio della carità come una autentica ed essenziale testimonianza di fede.» 
gift of oneself to others.» ${ }^{126}$ We can find an explication in a book written by Luigi Ferlicchia, one of the main initiators of the procedure of beatification of Aldo Moro, of the first formal element of martyrdom, the hatred for faith. Here, he describes the reasons why the BR killed Moro:

Moro, with his political reasoning, all logical and concatenated into the strategy of attention, had foreseen and worked for the fall of Communism, and for this the epriests of international Communism> saw him as a danger that had to be eliminated with the armed struggle. The BR, who considered themselves the depositors of communist faith, in line with the Stalinist Communists of that time, came to the crazy gesture of eliminating him. As the priests of the temple entered into cahoots with «Roman power, through the game of parties, in order to sentence Christ to death, the same happened to Aldo Moro, when the BR, in the logic of the non-decision of the established power), killed him. [...] A martyr! And martyrdom immediately places him among the defenders of faith in Christian values. ${ }^{127}$

With the BR as the priest of the temple, and the Italian State as the Roman Empire, again, the mechanism of prefiguration is used to represent Aldo Moro as a martyr. Obviously, there is a certain ambiguity in this representation as well as, more generally, in the initiative for the beatification of Moro, since the cause of his death is indicated in his political activity as a statesman. Moro's death seems to assume here the connotation of martyrdom, a witness of faith in both the Italian State and the Church, in secular and religious power.

The initiative launched by Ferlicchia and carried by Postulator Giampaolo aroused some criticism and controversy in the press. To cite only one ex-

126 Giampaolo 2015, 52; it.: «Lamore egli lo intendeva e lo viveva come sagape», come dono di sé agli altri. E lui si è donato, si è sacrificato per la salvezza di tanti altri che non hanno riconosciuto il suo sacrificio.»

127 Ferlicchia 2014, 549; it.: «Moro con i suoi ragionamenti politici, tutti logici e concatenati sino alla strategia dell'attenzione, aveva previsto, intuito e operato per la caduta del comunismo, e per questo era visto dai «sacerdoti del comunismo internazionale come un pericolo che andava eliminato con la lotta armata. Le $\mathrm{Br}$ che si ritengono i depositari della fede comunista, in sintonia con i comunisti stalinisti dell'epoca, arrivano al folle gesto di eliminarlo. Come per Gesù Cristo i sacerdoti del tempio giungono in combutta con il spotere romano', attraverso il gioco delle parti, alla condanna a morte del Cristo così per Aldo Moro, le $\mathrm{Br}$ nella logica della non decisione del spotere costituitos, giungono alla sua eliminazione fisica. [...] Un martire! Ed il martirio subito lo pone fra i difensori della fede nei valori cristiani.» 
ample, in the right-wing newspaper Il Giornale, journalist Marcello Veneziani argued that

Moro was a politician and acted as a politician, [but] he was not a saint. His death still burns, but as Saint Augustine said, it is not the sufferance but the cause that makes martyrs. And I do not see Moro [as someone who was] moved by a Christian cause, but by [the cause of] Christian Democracy. Or should we sanctify all the Catholic victims of terrorism? True saints sacrificed themselves in the name of faith or devote their lives to works of charity or do miracles. Does Moro fall into these categories? There is already a political saint: it is Saint Thomas More. That's enough. God did not vote for the DC. ${ }^{128}$

This, like many articles and blog posts in favor of or against the beatification procedure, demonstrates that even today the politician Aldo Moro is controversial and that conflicting interpretations of the reasons, causes and interests that led to his kidnapping and death still remain. What seems to remain constant, within the various discursive and memorializing practices concerning Moro and his violent death, is the figure of the martyr. Whether the attribution and allocation of the martyr role is accepted or not, it continues to dominate public debates and cultural productions. This study shows how Aldo Moro has been constructed as a state martyr, and how alternative and subversive forms of representation have challenged this construction. In years, maybe decades, we will learn if the initiative will lead to the politician's beatification. For the moment, we can only observe that the battle through which different social actors tried and still try to take possession of the figure of the murdered politician, to represent and memorialize the events of 1978 in one way rather than in another, continues.

128 Veneziani, Marcello, «Tommaso, l'unico Moro vero santo», Il Giornale, 20.7.2012, http://www.ilgiornale.it/news/tommaso-lunico-moro-davvero-santo.h tml (accessed August 23, 2017); it.: «Moro fu un politico e si comportò da politico, non da santo. La sua morte brucia ancora, ma come diceva Sant'Agostino non è la pena ma la causa a fare i martiri. E non vedo Moro mosso da una causa cristiana, al più democristiana. $\mathrm{O}$ dovremmo santificare tutte le vittime cattoliche del terrorismo? I veri santi si sacrificano nel nome della fede o dedicano la loro vita a opere di carità o compiono miracoli. Moro rientra in questi canoni? Un Santo Moro politico c'è già: è San Tommaso Moro. Basta lui. Dio non votava Dc.» 


\section{How to Narrate and Represent Political Violence}

This study has identified and critically analyzed language units, narrative models and rhetorical patterns used, within different media and over the course of four decades, to represent and give meaning to a specific event of political violence: the kidnapping, imprisonment and assassination of the Christian Democrat politician Aldo Moro. Starting from the hypothesis of a connection between procedures of legitimization of political authority and power structures and the martyr figure, this study has addressed different discursive, cultural, and memorialization practices, through which Moro's death was successfully and effectively represented as a form of martyrdom necessary for the salvation of the Italian State and society. The study has sought to show that through the allocation of the state martyr role, Moro's death acquired the meaning of a (voluntary) witness to the absolute and meta-historical truth of human and citizens' rights as well as the necessity of the sovereign state to be the guarantor and defender of these rights. It has also drawn attention to the intrinsic relationship between collective identification processes, state martyrology and state mythology. Moreover, this study has pointed out that the martyr figure can be and has been used both poetically and instrumentally, that is: both as an instrument of protest against and as the concealment of established relations, structures and micromechanisms of power.

This chapter recapitulates the main insights and theses of the investigation. The first section addresses the theory and methodology of discourse and cultural analysis, highlighting their heuristic value when it comes to analyzing representations of political violence. The second section identifies the main theses concerning the emergence, signatures, and performativity of the martyr figure. The third section specifically addresses the insights gained from focusing on the Moro case as a paradigmatic example to understand state mythology in the modern and contemporary world. The final part of the chapter addresses the problematic relationship between practices of mythicization and de-mythicization, that is: between hegemonic and subversive representations. It thereby topicalizes the open-ended question that concerns both realms of ethics and aesthetics: How can we narrate and represent political violence? 


\subsection{Discourse and Cultural Analysis}

This investigation has made use of several tools of analysis and was inspired by different theories and authors. Its discourse analytical approach has made it possible to observe, describe and analyze both the historical emergence and changes of the martyr figuration, its diffusion, and its functionality within a particular pragmatic and hermeneutic context. Referring to the reshaping of discourse into cultural analysis as proposed by Stuart Hall, it has defined and analyzed discursive practices as cultural practices of representation capable of producing meaningfulness. In this way, the investigation was able to highlight and focus attention on the performative force and efficacy of different kinds of representations within different media. Following reflections exposed by both Foucault and Derrida, this study concentrated on the iterability, recognizability, materialization and manifestation of language units, narrative models and rhetorical patterns that refer to political violence, rather than on the intentionality of the acting subjects. It also referred to Louis Althusser's concept of interpellation to highlight the way in which discourse and cultural practices affect individuals, construct identity and subjectivity and shape their understanding of things and events. Furthermore, it has operationalized the distinction of instrumental and poetic uses of language, between hegemonic and subversive representations, in order to bring to light, compare and analyze different ways of iterating and recontextualizing the martyr figure. In this way, the discursive formation referring to the event of political violence, could be approached as a sort of battlefield in which hegemonic practices are challenged by other alternative and subversive practices, which try to expose and criticize the mechanism by which historical events are mythologized.

This approach has been very useful in allowing us to observe the emergence and use of the martyr figure from a specific perspective. In the first place, by focusing on the martyrological representation of political violence and not understanding violence primarily from the point of view of ritual theory, this study was able to analyze a concrete situation, in which the victim of violence clearly expressed his rejection of the allocation of the martyr role. Far from denying the relationship between rituality and performativity, this investigation has addressed the ritualization of the event of political violence-the construction and representation of the event as a ritual - as the product of discursive and cultural practices. Moreover, this perspective allowed for the observation and analysis of the production and function of discursive and cultural practices without postulating on the so- 
cial actors' consciousness of the instrumental dimension of their actions as producers and consumers of representations. The conceptualization, according to which language is used instrumentally when it conceals the historicity and exteriority of language, does not necessarily imply that subjects using language in this way are aware of what they are doing. On the contrary, the efficacy of the instrumental use of language lies exactly in its ability to conceal its function from both recipients and producers of discursive practices.

This approach has also made it possible to analyze the emergence of martyrological and sacrificial representations in their specific historicity without referring to universal assumptions. Ritual theories of sacrifice and self-sacrifice tend to consider the use of violence to be a fundamental trait of mankind, resulting in anthropological, universalistic and not historical explanations of political conflicts. This is the case, in particular, with Girard's scapegoat theory, which, despite its declared intention to overcome the mechanism of sacrifice it analyzes, fundamentally legitimizes the exercise of violence and other practices of coercion by so-called sovereign authority by basically considering them necessary for containing the everpresent threat of violence that "comes from the bottom» and which can, potentially, always destroy society. From this point of view, universalistic ritual theories in general and the scapegoat theory in particular, quiescently and covertly sustain the conceptualization of the state as a katechon, a force necessary to avoid the "war of all against all»: since the predisposition to violence is deeply-rooted in human nature, it is better that a sovereign monopolizes violence. Within this narrative, self-sacrifice is the price that individuals have to be willing to pay for the safety of society. By considering the sacralization connected with events of political violence as the product of discursive practices, the study was able to observe and analyze political violence as a fundamentally historical and thus contingent phenomenon. Violence, to put it simply, happens; it does not have a meaning per se, but always assumes meaning within a particular historical context. There is no universal function or reason for violence, but only discursive and cultural practices that construct violence as something meaningful.

\subsection{Performativity and Signatures of the Martyr Figure}

This study has demonstrated that the performative efficacy of martyrological representations lies in their ability to appeal to people and to signify events of political violence as sacrifices for a certain cause. Through marty- 
rological representation, violent death assumes the connotation of an act or event with which the dead person witnesses the absolute and meta-historical truthfulness of certain values, ideals and principles. Death then becomes a sort of truth-proof, which legitimizes the authority that the community experiences as sovereign. Furthermore, violent death assumes the connotation of an accusation of the political authority, which is responsible or is experienced as responsible for political violence. Moreover, this study has shown that the performative force of the martyr figure depends, on the one hand, on its stratifications of meaning, its residues of religious significance, its secret index and, on the other hand, on its spatial, temporal, multimedial diffusion and manifestation in the public space. With regard to this point, the study reconstructed the history of the martyr figure's signatures-the figure's transpositions from certain pragmatic and hermeneutic contexts to other contexts - at the end of which the state martyr figure emerged.

In its original context of appearance, the martyr figure was part of what has been defined as a narrative of rebellion, which is based on an eschatological understanding of history. Within this narrative, the martyr is the one who witnesses the truth of the soteriological power of Christ's death, resurrection and second coming at the end of time. The only authority that is experienced as sovereign is that of God, which operates in history through the Messiah, while the authority that subjugates the Christian community by the means of violence is experienced as illegitimate. In this context, martyrological representations appeal to people not as citizens within the borders of a certain territory, or as appertaining to a certain ethnic group, but fundamentally as part of a universal community of believers.

Through a long process of re-signification, the martyr figure has been incorporated into and «domesticated» by the modern narrative of sovereignty, which is functional to the construction of national identities and to the legitimization of political authority within national borders. The state martyr figure is thus intrinsically linked to the emergence of nation-states in modernity. The transcendental sovereignty of God is transformed into the immanent sovereignty of political authority, but maintains a sacral dimension. Within this narrative, this martyr is the one that witnesses the absolute necessity of the sovereign state to restrain the forces of evil that aim to destroy society and establish a situation of anarchic chaos, of war of all against all. Also, this narrative is based on an eschatological understanding of history, but inverts its original telos: the state itself assumes the connota- 
tion of a kathechon, a power that restrains the forces of absolute evil from destroying society and political order.

Within the messianic and eschatological narrative of rebellion, each individual life is considered sacred since it participates in the sacrality of the Christian community, which in turn participates in the sacrality of God by virtue of the soteriological power of Christ's death and resurrection. Martyrdom, intended as a self-sacrifice witnessing truth, is the act-event that, «repeating» the self-sacrifice of Christ, re-actualizes the sacrality of the community. Precisely because life, independently from its political recognition, from its participation in the public life of the polis, is sacred, martyrdom as self-sacrifice highlights the iniquity and profanity of the exercise of violence by political authorities. Conversely, within Greco-Roman cosmology, the life that has been excluded from the political sphere and thus belongs to the gods is sacred. Because of its exclusion from the profane sphere of politics and its inclusion in the sacred sphere of the gods, this mere life is no longer subject to the laws of the polis. The religious-political authority that has the power to decide over mere life, that is, to exclude it from the political sphere, is equally sacred, inasmuch as its decision transcends legality and, paradoxically, establishes it. Within this cosmology, both the sovereign and homo sacer are thus extra-legal figures, the former because it lives in the state of exception and the latter because it decides on the state of exception. This is why political authority permanently needs spectacles of violence to visualize and expose its power over mere life, thus demonstrating its sacredness. The radical subversiveness of the messianic and eschatological narrative of rebellion lies precisely in its ability to overcome this conceptualization of the sacred, to detach sacredness from the exercise of violence, revealing violence's contingency and iniquity. From this point of view, the martyr can be considered the one that, from within the state of exception, undermines the mechanism of the acclamation and glorification of power.

The modern narrative of sovereignty brings and binds together elements of Christian martyrology and eschatology with Roman procedures of acclamation, glorification and representation of power. If, within the narrative of rebellion, the martyrological representation has the function of revealing the iniquity of the spectacularization of violence, with which political authority exposes its power, the martyr figure assumes the function of concealing the utility of events of political violence for the perpetuation of the status quo of power relations within the narrative of sovereignty. A conditio sine qua non of this domestication of the martyr figure is the discursive construction of a perennial threat, of a sort immortal enemy, which can 
potentially destroy society and social order at any moment. This enemy is mankind itself, which, in the absence of a sovereign authority that monopolizes the exercise of violence, lives in a situation of permanent «war of all against all». It is for this reason that so-called sovereign states need myths in order to legitimize their power to decide on the state of exception. Within these myths, events of political violence appear as the unavoidable outcome of a cosmic and Manichean conflict between good and evil. This is why, ultimately, terrorism is the natural, accepted, anticipated, and often even promoted counterpart of bio- and thanatopolitics. In fact, the demonization of organized criminal groups, of gangsters of all stripes, is the most effective way of convincing people that they have to accept the political status quo. Whenever one or more members of these groups kill someone with firearms, bombs, airplanes, or anything else that can act as a weapon, there is a great opportunity to create a nation-state martyr, to represent events of political violence as unpleasant but necessary and expected outcomes of a cosmic struggle between good and evil.

Within the modern narrative of sovereignty, the Christian conception of the sacrality of individual life and the sacrality of both the homo sacer and the sovereign figure are bound together to the point of becoming indiscernible. This strange, yet historically very effective union became particularly blatant within this study when it came to analyzing the rhetoric of the «reason of state». The idea of the sacrality of individual life has survived, through and by the process of secularization, in the different declarations of human and citizens' rights. From this point of view, it does not seem hyperbolic to affirm that the idea of human rights and with it, modern constitutionalism, are the secular pendant of Christian personalism. From the French Revolution onwards, sovereign nation-states (the same goes for state leagues or multinational states) have been understood as the «natural» guarantors and defenders of human rights, and primarily of the right to life of every human being. In the course of the twentieth century, other bodies have emerged which, at least in theory, are supposed to guarantee human rights-primarily the European Union and United Nations. However, sovereign states remain the principal bodies that have the mandate to defend human rights and fight against their violation inside and outside their national borders. But because they are sovereign states, that is, geopolitical entities that have sovereignty over delimited geographic areas, they naturally tend to defend the rights and interests of their own citizensthough often not even those-and not of humanity as a whole.

The idea of the sovereign as the sacred authority that has the power to decide over mere life has been able to survive in modern political thought, 
because of the funding paradox of modernity, which lies in the fact that sovereign states have de jure the mandate to guarantee and defend human rights, but de facto are in a perpetual conflict with each other for economic and political hegemony. ${ }^{1}$ The performativity of contemporary state mythology lies in its ability to declare that every single human life is sacred and thus inviolable, but at the same time to declare that each human life is potentially expendable or, more precisely, can be excluded from the political sphere in order to guarantee the salvation, perpetuation and prosperity of society within the borders of nation-states. The rhetoric of the «reason of state» is based, ultimately, on a very simple mechanism: it makes people believe that the necessary price for guaranteeing the sacredness of individual life is the expendability of some «few» individuals. Or in other words: some humans have to be declared and treated as homine sacri, so that the sovereign state can guarantee the sacredness of individual life.

\subsection{The Moro Case}

My focus on the representation of the abduction, imprisonment and murder of Aldo Moro had the dual function of exemplifying and at the same time testing the heuristic value of these theses, their usefulness in analyzing and understanding discourses on political violence in contemporary world. In the first place, this study has demonstrated that the martyr figure played and still plays a central role in an enormous number of discursive, visual and memorializing practices that, since March 1978 onwards, have given meaning to the kidnapping, imprisonment and final assassination of Aldo Moro. It has thus highlighted that the allocation of the martyr role was and still is one of the main strategies of constructing meaning and signifying the event of political violence. Further, the study has shown that the martyr figure was used to justify the decision of not negotiating with the Red Brigades for the liberation of Aldo Moro or, more precisely, to make Aldo Moro appear as a martyr willing to die for the salvation of Italian society and its political system. Moreover, it has shown that martyrological representations, together with the rhetoric of the "reason of state», were intrinsically linked to a mythological narrative of the state, in which the Red Brigades were represented as absolute enemies who aimed only to

1 From this point of view, Carl Schmitt is perfectly right when he argues that at the very root of the concept of state sovereignty and autonomy there is the distinction between friend and enemy. See Schmitt 2002. 
destroy society and undermine political order and the state as absolutely necessary to restrain this manifestation of absolute evil.

By analyzing the representations of the event of political violence, rather than speculating about possible interferences, conspiracies and the direct responsibilities of intelligence services, foreign governments, representatives of political parties or secret organizations - that is, rather than focusing on what is obscure and unknown - the study has been able to focus on facts and events that are known, public, and accessible to everyone and has yet managed to maintain a critical approach. The actual knowledge about what happened in the spring of 1978 does not allow us to infer, with the necessary certainty and «beyond reasonable doubt», that there was a conspiracy by individuals or groups operating outside the organization of the Red Brigades seeking to eliminate Aldo Moro. Though it does not completely reject the possibility that there could have been different kinds of, still unknown, interference or false leads in the so-called «Moro affair». In fact, one of the main characteristics of the unknown, regardless of its probability or improbability, is that it cannot be falsified. This study demonstrates that it is not necessary to postulate on the existence of occult forces operating in history to highlight the instrumentalization of events of political violence. In fact, as we saw, even in the first days after the kidnapping, a discursive and rhetorical strategy was adopted, which de facto annihilated or at least minimized the possibility of saving Aldo Moro. The event of political violence was used to construct a state martyr figure, which was very useful for the maintenance of the political status quo and for the legitimization of established authority and power relations. In other words, this study has pointed out that martyrological representations of the event of political power became part of a strategy, which was functional to the preservation of power.

If Aldo Moro's letters had not become public, the process of his martyrologization, which began with his kidnapping, would have proceeded without problems. But Moro raised his voice and radically criticized and questioned the hegemonic representations produced by the government, major political parties and most of the established media. He rejected the allocation of the martyr role and even came to curse the government, the parties and the country for doing nothing for his salvation and, more importantly, for surreptitiously betraying the ethics of the sacredness of individual human life. In his letters, he subverted the rhetoric of the «reason of state» by clearly addressing the safeguarding of the dignity and rights of every single human being as the fundamental and, to some extent, unique true duty of the state. From this point of view, Aldo Moro did really act as 
a martyr, but not in the sense of someone who witnesses by dying, but in the sense of someone who witnesses with words the truth of the sacrality and dignity of each singular human life by raising his voice.

For this reason, Moro had to be silenced and his personal dignity annihilated. Within this study, the homo sacer theory has been implemented specifically to highlight the mechanism by which Aldo Moro was silenced and excluded from the public sphere. The sixth chapter highlighted the different strategies used to deprive Moro of his public role, to represent Moro, no longer as Moro the politician, but as a drugged person at the mercy of his kidnappers or, simply, as a coward who selfishly tried «only» to save his own life. But despite this attempt at annihilating Moro's voice-without which the government, the major political parties and the established media would not have succeeded in declaring him as expendable, representing his death as the necessary cost of the salvation of society and the preservation of social order-, Moro's voice and words grafted like the roots of a tree in the wall of hegemonic discourse. Precisely because Moro succeeded, in spite of everything, in making his voice heard in the public space, the task of silencing him and symbolically taking possession of his body was not completely successful.

Over the years, Moro's voice and words have found more and more people willing to listen to them and use them to shape and give form to subversive and alternative cultural and discursive practices with respect to hegemonic discourse. As shown in the seventh chapter, despite attempts to establish a shared and undisputed memory, especially through the occupation of the public space with memorial signs and institutionalized rituals of annual commemoration, Aldo Moro and the events of spring 1978 were and still are the subject of dispute and conflicting interpretations and representations. In fact, his letters became the point of departure of different cultural practices in which the martyr figure is used subversively and poetically. In these practices, Aldo Moro is not represented as the martyr who belongs to the state, to the party, to the nation, or to the Church, but as the one who, making use of the last liberty that he had-the freedom of using language subversively-radically rejected any instrumental appropriation of his person. In some cultural productions especially, Aldo Moro seems to assume, at least partially, the role that the martyr figure had in its original context of appearance, since it becomes a sort of spokesman for a radical critique not only of the Red Brigades' ideology of violence, but also and above all of the rhetoric of the "reason of state». It thus seems that even if the modern, mythical narrative of sovereignty has domesticated the martyr figure, it is still possible to use it in a subversive way, that is, to reintroduce 
it in what could be seen as a (post-)modern narrative of rebellion. The exemplarity of the Moro case lies precisely in this twofold usage of the martyr figure, in the fact that Aldo Moro was represented, remembered and constructed as a martyr who witnesses both for and against the necessity of sacrifice, who both conceals and reveals the mechanism by which power relations perpetuate themselves.

This last point is actually the main reason why this investigation focused on the cultural practices surrounding this particular and almost unique event of political violence in modern history. The case of the martyrological representation of Aldo Moro is, in some respects, what Agamben calls an example with a "paradigmatic character», that is, a case that cannot be explained by referring to the rule of a "generality preexisting the singular cases», but rather as a case that constitutes itself as a rule. ${ }^{2}$ Agamben argues that «a paradigm entails a movement that goes from singularity to singularity and, without ever leaving singularity, transforms every singular case into an exemplar of a general rule that can never be stated a priori.» ${ }^{3}$ The relationship between the rule and the example is not a logical one, where the movement from the rule to the case is called deduction and from the case to the rule induction. The heuristic value of a paradigm, of exemplarity, is not to exemplify a general rule but to expose its own singularity, which can then be used to make intelligible, and to analyze and interpret other cases by the mechanism of analogy: «its specific operation consists in suspending and deactivating its empirical givenness in order to exhibit only an intelligibility.» ${ }^{4}$ In other words, the analysis of the martyrological and sacrificial representation of Aldo Moro does not validate any general rule-for example: the martyr figure always functions in that way and not in another - but is useful, as a paradigmatic case, for understanding and explaining other cases of analogous representations of political violence.

\subsection{Towards an Aesthetics of Resistance}

If it is true that the martyr figure always returns, assuming new functions and engaging in new pragmatic and hermeneutic contexts, then a very important question arises, which concerns both the domain of ethics and aesthetics: What kind of representation of political violence might be able to

2 Agamben 2009, 21; see also Ferrara 2008.

3 Agamben 2009, 22.

4 Agamben 2009, 25-26. 
overcome both the deadly rhetoric of sacrifice and the mythology of the state? In other words, what kind of representation could be truly emancipatory, appealing to people to reject any kind of legitimization of violence? In a sense, it can be said that finding an answer to this question is the true telos that motivated and continues to motivate me in reflecting on the use and performativity of the martyr figure.

In the third chapter, I addressed the state martyr as a secularized figure, that is, as a figure that has been transposed from the pragmatic and hermeneutic context of Christianity and Christian theology in the late antiquity and medieval times to the context of modern political thought and society. In Agamben's words: «secularization acts within the conceptual system of modernity as a signature, which refers it back to theology.» ${ }^{5}$ What is at stake here is the way in which a certain «sign signifies because it carries a signature that necessarily predetermines its interpretation and distributes its use and efficacy.» ${ }^{6}$ The premise or axiom of the theory of signatures is that "pure and unmarked signs", which would signify and refer to something «neutrally», do not exist. ${ }^{7}$ Signs are never neutral but always marked by their signatures, that is, they are able to signify something only because they are used within a certain context and refer back to precedent uses within precedent contexts. It is thus by being performed, by being used in a specific context and at the same time referring to precedent performances, that signs are able to exert effects and thus appeal to people, to produce and induce a certain subjectivity and worldview. In fact, this is why Agamben also defines secularization as a «specific performance of Christian faith that, for the first time, opens the world to man in its worldliness and historicity. The theological signature operates [...] as a sort of tromp l'oeil in which the very secularization of the world becomes the mark that identifies it as belonging to a divine oikonomia.» ${ }^{8}$ From this point of view, the secularization of the martyr figure can be defined as a practice that transposes it into the domain of profane politics, which in turn assumes a sacral character.

Interestingly, in The Signature of All Things Agamben criticizes Hans Blumenberg, among others, for having not realized that secularization is not a concept but a signature. ${ }^{9}$ This «liquidation» does not do justice to Blumen-

5 Agamben 2009, 77.

6 Agamben 2009, 64.

7 Agamben 2009, 64.

8 Agamben 2011, 4.

9 See Agamben 2009, 76-77. 
berg's reflections on secularization, since I believe that there are, in the writings of the German philosopher, interesting considerations which can help us to understand the role of secularized Christian language in the modern and contemporary world, as well as to relate the topic of secularization to that of mythicization. The proximity of the concept of signature with Blumenberg's concept of prefiguration, which served as a heuristic tool for the analysis of the martyr figure, was already highlighted in the third chapter. In fact, one can say that the relationship of signatures to signs is analogous to that of prefigurations to figures: in the same way that signatures transpose signs, prefigurations transpose figures from one context to another. Despite the two philosophers using two different concepts, because they are referring to two different traditions of thought, I believe that both are pointing out the same phenomenon. While Agamben refers to the tradition of structuralism and post-structuralism, in particular to thinkers such as Lévi-Strauss, Derrida, and Foucault, Blumenberg refers instead to the tradition of German hermeneutics. Despite this proximity, I referred to both concepts because they highlight different aspects of the common phenomenon of language transposition. The concept of signature was useful in highlighting and describing the long process of perennial re-contextualization of the terms martyr and martyrdom, at the end of which the state martyr figure emerged, and in pointing out that their historical stratification affects their efficacy in the various contexts in which they appear. On the other hand, the concept of prefiguration was instead useful for drawing attention to the mechanism by which social actors used and still use the martyr figure to signify and refer to an event of political violence, in order to reduce the experienced contingency of the event and thus create meaningfulness. In other words, the former has served to explain the way in which the martyr figure could be secularized and yet maintain its efficacy, while the latter helped us to understand the reason why social actors have recurred to this figure.

In the third chapter, I mentioned Girard's scapegoat theory, which is based on the anthropological assumption whereby human beings act violently, because they always desire what other human beings desire, which results in a conflict between desiring parties. On the basis of this assumption, Girard argues that sacrifice is a form of ritualized violence with which social actors control their aggressive impulses by directing them on to a victim that serves as scapegoat. Now, I reject and criticize this theory, not because I generally dislike anthropological explanations, but simply because it is based on misleading anthropological assumptions, inasmuch as it hypostatizes and universalizes the meaning and function of violence. 
Moreover, this theory ultimately reproduces a mythological understanding of history, the same kind of mythological construction that this investigation has attempted to deconstruct. This is why I propose considering not violence per se, but rather the signification of violence as an anthropologically derivable and explainable phenomenon. It is therefore not in the phenomenon of violence that one has to search for and identify anthropological constants, but rather in the way in which human beings give meaning to violence, that is, in the relationship between human beings and the world, which is always mediated by a process of linguistic and symbolic construction. In other words, it is the need for the signification of violence, which is a historical and anthropological constant. From this point of view, the main question is not «why do human beings act violently?» but rather: why do humans need to make sense of what happens around them (especially when what happens occurs violently)? Hans Blumenberg's answer is relatively simple: because the human being is a «lacking being» (Mangelwesen) who compensates for this lack with action and, last but not least, with rhetoric action:

The fact that man is not biologically fixed to a particular environment can be understood as a fundamental lack of proper equipment towards the purpose of self-improvement or as an openness to the abundance of a world [...]. The human being is defined by what it lacks, or by the creative symbolism by which he resides in its own worlds. [...] Action is compensation for the indeterminacys [Unbestimmtheit, also indecisiveness)] of the human being, and rhetoric is the strenuous production of the consistencies [Übereinstimmungen] which compensate for the [lack] of a substantial pool [Fundus] of regulations, so that action is possible. From this point of view, language is not an instrument for the communication of knowledge or truth, but primarily for the establishment of understanding, approval, or acquiescence, on which the agent [the acting human being] is dependent. [...] The human being's lack of a specific disposition to reactive behavior in the face of reality $[\ldots]$ is the starting point for the central anthropological question, how does this being exist despite its biological indisposition. The answer can be reduced to the formula: by not engaging directly with this real- 
ity. Human reference to reality is indirect, laborious, decelerated, selective, and, above all, «metaphorical». ${ }^{10}$

On the basis of this sort of anthropological theory of rhetoric, it is possible to look at martyrological representations as rhetorical instruments that compensate for the radical indeterminacy and contingency experienced by humans when confronted with political violence and especially with violent death. The experience of death, especially of death inflicted by other human beings, reminds us of the incommensurability and unpredictability of what is happening in the world. The description of violence as what it is, that is, the simple and rather banal clash of living bodies in a certain space and time, resulting in the injury or annihilation of one or more of these bodies, is not able to produce that meaningfulness without which individuals are incapable of acting, thinking, choosing and deciding. The main and most powerful strategy of coping with contingency is the implementation of analogies and metaphors, whereby something seemingly inexplicable is explained by something else.

In the case of prefiguration, the analogical construction produces meaningfulness by referring to already known, historically stratified and conventionalized forms of representation, with which past events were represented and made intelligible. Moreover, the specificity of prefiguration is that it always refers to a past figure that, because of the meaning and even performative force attributed to it, serves as a representational model and as an «aid to decision-making» (Entscheidungshilfe): «What has already been done does not require $[\ldots]$ renewed consideration, confusion, perplexity, [because] it is pre-determined by the paradigm.» ${ }^{11}$ From this point of view, prefiguration can be defined as an analogical construction or metaphor that always concerns actions. As this study has exposed, social actors have represented the kidnapping, imprisonment and assassination of Aldo Moro by referring to a figure that was already used in the past to represent other events of political violence. Martyrological representation prefigured Moro's destiny as predetermined and thus unavoidable. "The prefiguration»-Blumenberg argues- «gives legitimacy to a decision that may be characterized by the utmost contingency» and in the case of Aldo Moro,

10 Blumenberg 2001, 406, 409, 415. Blumenberg refers to (and criticizes) Arnold Gehlen's famous work Der Mensch. Seine Natur und seine Stellung in der Welt, published in 1940.

11 Blumenberg 2014b, 9. 
the prefiguration served to legitimize the decision of not negotiating, of doing nothing for his salvation. ${ }^{12}$

Ultimately, the use of the term «martyrdom» to signify the occurrence of a violent death was metaphorical from the beginning: in the context of the first Christian communities, the event of death was signified with a term that previously, in antiquity, had been used to signify the speech act through which a person bore witness to something. The term underwent a signature through which events of death by the hands of the ruling political authority could be signified as acts of dying. Through martyrological representation, death assumed the meaning of a community-saving act, the witnessing of absolute truth and an accusation of political authority. Represented as martyrdom, death is no longer a simple, meaningless event, but a meaningful act, a way of doing something meaningful by dying. The success of this metaphor depends on its ability to constitute itself as a paradigm through regular and repetitive spatial, temporal, multimedial diffusion and manifestation. As soon as the metaphor became so strongly conventionalized that its previous use-let us call it pre-metaphorical-has been forgotten, it basically ceased to be a metaphor. At the end of this process of re-contextualization, which goes hand-in-hand with demetaphorization, the martyr established itself as one of the fundamental, and to some extent, almost irreplaceable figures for the representation of political violence.

Analogies, metaphors, and prefigurations are indispensable elements in mythicization, the bricks with which myths are constructed. The phenomenon of prefiguration especially, Blumenberg argues, "presupposes that the mythical form of thought as a disposition to certain functions is still virulent», since here «mythicization approaches the limit of magic, or even exceeds it as soon as the explicit act of repetition of a prefigure [Präfigurat] is associated with the expectation of the production of the identical effect.» ${ }^{13}$ This process of mythicization is basically omnipresent in modern and contemporary political discourses, especially when it comes to giving meaning to political violence. Within state mythology, violence always appears as the unavoidable outcome of the mythic struggle between good and evil forces. Now, if Blumenberg is right and the production of mythological narratives and the use of metaphors and prefigurations are anthropologically derivable phenomena, since human beings need strategies of complexity-reduction and meaning-construction in order to be able

12 Blumenberg 2014b, 10.

13 Blumenberg 2014b, 9. 
to act, to think and more generally to live in the world, then the question arises: is it possible to represent events of political violence without mythologizing them, without re-actualizing the myth that legitimizes the use of violence? If the human being cannot live and act without myths, is the mythicization of violence perhaps inevitable?

The «classic» approach in philosophy and cultural studies to counteract the appellative efficacy of myths is to deconstruct them and bring their function to light. Ultimately, philosophy was already a practice of demythicization since its inception. In twentieth century philosophy, the most paradigmatic attempt to deconstruct state mythology was perhaps made by Ernst Cassirer, who, at the end of The Myth of the State, published in 1946, argues that:

It is beyond the power of philosophy to destroy the political myths. A myth is in a sense invulnerable. It is impervious to rational arguments; it cannot be refuted by syllogisms. But philosophy can do us another important service. It can make us understand the adversary. In order to fight an enemy you must know him. That is one of the first principles of a sound strategy. To know him means not only to know his defects and weakness; it means to know his strength. All of us have been liable to underrate this strength. When we first heard of the political myths we found them so absurd and incongruous, so fantastic and ludicrous that we could hardly be prevailed upon to take them seriously. By now it has become clear to all of us that this was a great mistake. We should not commit the same error a second time. We should carefully study the origin, the structure, the methods, and the technique of the political myths. We should see the adversary face to face in order to know how to combat him. ${ }^{14}$

This study has taken Cassirer's warning seriously, trying to show that even after the Second World War, after the advent of the national myths of Fascism and Nazi-Fascism, political myths continue to determine how individuals and peoples represent and understand themselves, others and the world, particularly in situations of crisis and violence. In this sense, it can be said that this investigation was an attempt to deconstruct the myth of the self-sacrifice of the martyr-sovereign Aldo Moro by studying its origin, structure, methods and technique. As Cassirer argues, philosophy and critical cultural analysis cannot defeat political myths, but they can at least bring their function to light. However, I believe that only by means of ev- 
eryday subversive practices, alternative representations of what is happening in the world as well as of what could happen differently, can dangerous myths be opposed efficaciously. This does not reduce the margin of action of philosophical thought and social and cultural studies, but, on the contrary, opens the horizons for a dual task: philosophical, cultural and social research must not only criticize and deconstruct practices of mythicization, but also reflect on the structure and function of what in the second chapter of this study was defined as the poetic use of language, namely of forms of representations using language units, rhetorical patterns and narrative models without hypostatizing the relationship between words and things, acts or events.

If it is true that human beings are not able to act, decide, and orient themselves in the world without using metaphors, prefigurations and, more generally, rhetoric, then we have to accept that myths cannot be defeated in a definitive way. The poetic use of language can subvert conventional and instrumental uses of certain language units, rhetorical patterns and narrative models, revealing and unmasking their exteriority, historicity and contingency, only within certain delimited pragmatic and hermeneutic contexts, and therefore cannot prevent the same being re-incorporated and domesticated by hegemonic discourses in other contexts. For this reason, the poetic use of language - as a «bipolar gesture, which each time renders external what it must unfailingly appropriate»—should be regarded as something that has to be done constantly in all possible pragmatic and hermeneutic contexts. ${ }^{15}$

The distinction between instrumental and poetic uses of language can be compared, to some extent, with Roland Barthes' distinction between encratic and acratic discourses:

Adopting an old Aristotelian notion, that of the doxa (public opinion, the general, the sprobables, but not the strues, the scientifics), we shall say that the doxa is the cultural (or discursive) mediation through which power (or non-power) speaks: encratic discourse is a discourse that conforms to the doxa, subject to codes which are themselves the structuring lines of ideology; and acratic discourse always speaks out, to various degrees, against the doxa (whatever it is, acratic discourse is paradoxical). This opposition does not exclude nuances within each type; but, structurally, its simplicity remains valid as long as power and non-power are in their place; it can be (provisionally) blurred only in

15 Agamben 2015b, 86. 
the rare cases where there is a mutation of power (of the sites of power); thus, in the case of the political language in a revolutionary period: revolutionary language issues from the preceding acratic language; in shifting over to power, it retains its acratic character, as long as there is an active struggle within revolution; but once this struggle dies down, once the state is in place, the former Revolutionary language becomes doxa, encratic discourse. [...] Encratic language, supported by the state, is everywhere: it is diffused, widespread, one might say osmotic discourse which impregnates exchanges, social rites, leisure, the socio-symbolic field (above all, of course, in societies of mass communication). $[\ldots][\mathrm{A}]$ cratic $[\ldots]$ are all the languages which are elaborated outside the doxa and are consequently rejected by it [...]. By analyzing encratic discourse, we know more or less in advance what we shall find (which is why, today, the analysis of mass culture is visibly marking time; but acratic discourse is by and large our own (that of the researcher, the intellectual, the writer); to analyze it is to analyze ourselves as we speak: always a risky operation and yet one that must be undertaken. [...] [T] here is an inverted relation between the two systems of discursivity: patent/hidden, overt/covert. ${ }^{16}$

The two oppositional pairs of concepts poetic/instrumental and acratic/ encratic are not characterized by heuristic equivalency: the former serves to indicate two different discursive modes of relating and referring to non-discursive things, acts or events, while the latter illustrates the discursive practices' different positions and relation to each other within a certain field or context. Precisely because of their different heuristic value, both oppositional pairs are useful in making two final remarks on the possibility of subverting and opposing mythicization.

Firstly, subversive and alternative practices of representation always appear at the margin of hegemonic discourses or, as Barthes puts it, are always articulated outside of the doxa. This marginality or externality should not be considered an autonomous reality - this is why Barthes speaks of para-doxical and not anti-doxical discourse-but rather as a space, a field of action in which the same words, rhetoric and narratives used in hegemonic discourses are appropriate and to the same extent expropriated. Subversive and alternative practices, in other words, use language units, rhetorical patterns and narrative models to maintain their performativity-that is: their ability to appeal to people and to demand subjective positioning- 
without falling into the trap of mythicization. It is, ultimately, a use that exposes the historicity and exteriority of language without disempowering its performative force and efficacy. Secondly, any attempt to stop the spiral of history (to use Gianbattista Vico's beautiful metaphor) in order to consolidate and congeal a definitive and non-metaphorical language is illusory. Blumenberg calls this the Cartesian «ideal of full objectification», which corresponds to the ideal of «the perfection of a terminology designed to capture the presence and precision of the matter at hand in well-defined concepts.» ${ }^{17}$ This ideal is illusory because mythicization and de-mythicization are two sides within an agonistic and dynamic struggle, where the doxa is always changing. What, in a certain pragmatic and hermeneutic context, is used in a subversive and para-doxical way-as the term martyrdom in the first and especially second century $\mathrm{AD}$ or, to some extent, in the context of the French Revolution-in other contexts can become part of hegemonic discourses. In this sense, we can say that the struggle against mythicization cannot be won once and for all, but is something that must be undertaken continuously. This study wanted to bring to light the role of the martyr figure in this permanent struggle for hegemony and emancipation, for the concealment and disclosure of the relationship between power and violence, a struggle that cannot finish but will continue in the future.

17 Blumenberg 2010, 7. 


\section{List of Figures}

Figure 1:

https://it.wikipedia.org/wiki/Agguato_di_via_Fani\#/media/File:Via_Fani_Roma, _16_marzo_1978.jpg, AP-photo, public domain, accessed December 10, 2018.

Figure 2:

https://it.wikipedia.org/wiki/Caso_Moro\#/media/File:Aldo_Moro_br.jpg, public domain, accessed December 10, 2018.

Figure 3:

Photograph by Baldassare Scolari.

Figure 4:

https://it.wikipedia.org/wiki/Caso_Moro\#/media/File:Aldo_Moro3.jpg, public domain, accessed December 10, 2018.

Figure 5:

http:/www.ansa.it/sito/notizie/politica/2018/03/12/moro-da-via-fani-a-via-caetani -mappa-di-un-sequestro-_1434503e-c783-48ac-bcf9-77ac5474d775.html, ANSA, accessed December 10, 2018.

Figure 6:

Photograph by Baldassare Scolari.

Figure 7:

Screenshot, https://www.youtube.com/watch?v=vbcT711kt6Y\&t=20s, accessed December 10, 2018.

Figure 8:

Screenshot, https:/www.youtube.com/watch?v=ODNyR_tTH9c, accessed 10 December 2018.

Figure 9:

Film still, La notte della Repubblica: Caso Moro - Seconda parte, Rai 2, IT 21.2.1990, 00:59:38.

Figure 10:

Film still, Il caso Moro, Giuseppe Ferrara, IT, 1986: DVD (C) 1986 Columbia Pictures Italia (C) 2005 Cecchi Gori Editoria Eletronica Home Video, 00:04:25.

Figure 11:

Film still, Il Caso Moro, Giuseppe Ferrara, IT 1986: DVD (C) 1986 Columbia Pictures Italia @ 2005 Cecchi Gori Editoria Eletronica Home Video, 01:05:00.

Figure 12:

Film still, IL Divo, Paolo Sorrentino, IT 2008: DVD (c) 2008 Lucky Red, 00:21:48.

Figure 13:

Film still, IL Divo, Paolo Sorrentino, IT 2008: DVD (c) 2008 Lucky Red, 01:41:08. 
List of Figures

Figure 14:

Film still, Romanzo Di Una STRage, Marco Tullio Giordana, IT/F 2012: DVD (C) 201201 Distribution, 00:06:26.

Figure 15:

Film still, PaIsà, Roberto Rossellini, IT 1946: DVD (C) 2003 CG Entertainment SRL, 02:04:15.

Figure 16:

Film still, Buongionno, notTe, Marco Bellocchio, IT 2003: DVD (c) 2003 Filmalbatros and Rai Cinema (C) 2006 Wellspring Media, 01:34:19. 


\section{Bibliography}

Agamben, Giorgio, 1998, Homo Sacer. Sovereign Power and Bare Life, trans. Heller-Roazen, Daniel, Stanford: Stanford University Press.

Agamben, Giorgio, 2005a, State of Exception, trans. Attell, Kevin, Chicago: University of Chicago Press.

Agamben, Giorgio, 2005b, The Time That Remains. A Commentary on the Letter to the Romans, trans. Dailey, Patricia, Stanford: Stanford University Press.

Agamben, Giorgio, 2009, The Signature of All Things, trans. D'Issanto, Luca/Attell, Kevin, New York: MIT University Press.

Agamben, Giorgio, 2011, The Kingdom and the Glory. For a Theological Genealogy of Economy and Government, trans. Chiesa, Lorenzo/Mandarini, Matteo, Stanford: Stanford University Press.

Agamben, Giorgio/Deleuze, Gilles, 2012, Bartleby. La formula della creazione, trans. Verdicchio, Stefano, Macerata: Quodlibet.

Agamben, Giorgio, 2015a, Stasis. Civil War as a Political Paradigm, trans. Heron, Nicholas, Stanford: Stanford University Press.

Agamben, Giorgio, 2015b, The Use of Bodies, trans. Kotsko, Adam, Stanford: Stanford University Press.

Ali, Farhana/Post, Jerrold, 2008, The History and Evolution of Martyrdom in the Service of Defensive Jihad. An Analysis of Suicide Bombers in Current Conflicts, Social Research 75, 615-654.

Allen, Lori A., 2006, The Polyvalent Politics of Martyr Commemorations in the Palestinian Intifada, History and Memory 18, 107-138.

Allen, Lori A., 2009, Martyr Bodies in the Media. Human Rights, Aesthetics, and the Politics of Immediation in the Palestinian Intifada, American Ethnologist $36,161-180$.

Althusser, Louis, 2014, On the Reproduction of Capitalism. Ideology and Ideological State Apparatuses, trans. Goshgarian, G.M., London/New York: Verso.

Amara, Emanuel, 2009, Abbiamo ucciso Aldo Moro: Dopo trent'anni un protagonista esce dall'ombra, Roma: Cooper.

Amendola, Giovanni, 1953, Etica e biografia, Milano: Ricciardi.

Antonello, Pierpaolo/O'Leary, Alan, 2009, Introduction, in: Antonello, Pierpaolo/ O'Leary, Alan (eds.), Imagining Terrorism: The Rhetoric and Representation of Political Violence in Italy 1969-2009, Oxford: Legenda, 1-15.

Antonello, Pierpaolo, 2009, Narratives of Sacrifice. Pasolini and Moro, in: Antonello, Pierpaolo/O'Leary, Alan (eds.), Imagining Terrorism. The Rhetoric and Representation of Political Violence in Italy 1969-2009, Oxford: Legenda, 30-47.

Arendt, Hannah, 1998 (1958), The Human Condition, Chicago: University of Chicago Press. 
Arlati, Renzo/Magosso Roberto, 2003, Le carte di Moro. Perché Tobagi, Milano: Franco Angeli.

Assmann, Aleida, 2010, Re-Framing Memory. Between Individual and Collective Forms of Constructing the Past, in: Tilmans, Karin/van Vree, Frank/Winter, Jay (eds.), Performing the Past: Memory, History, and Identity in Modern Europe, Amsterdam: Amsterdam University Press, 35-50.

Austin, John L., 1962, How to do Things with Words, Oxford: Clarendon Press. van Baal, Jan, 1976, Offering, Sacrifice and Gift, Numen 23, 161-178.

Baliani, Marco, 2011, Body of State. The Moro Affair, A Nation Divided, trans. Marini-Maio, Nicoletta/ Nerenberg, Ellen/ Simpson, Thomas, Madison N.J.: Fairleigh Dickinson University Press.

Balducci, Armenia/Giuseppe Ferrara/Robert Katz (eds.), 1987, Il caso Moro, Napoli: Tullio Peronti.

Balzerani, Barbara, 1998, Compagna luna, Milano: Feltrinelli.

Barkan, Joanne, 1984, Visions of Emancipation. The Italian Workers' Movement since 1945, New York: Praeger.

Barbagallo, Francesco, 2008, Le lettere dalla prigione di Aldo Moro, Studi Storici 49, 261-267.

Barthes, Roland, 1989, The Division of Languages, in: Barthes, Roland, The Rustle of Language, Barkeley/Los Angeles: University of California Press, 111-124.

Barton, Carlin, 2002, Honor and Sacredness in the Roman and Christian Worlds, in: Cormack, Margaret (ed.), Sacrificing the Self: Perspectives on Martyrdom and Religion, Oxford: Oxford University Press, 23-38.

Battista, Pierluigi, 1999, Cultura e ideologie, in: Battista, Pierluigi/Vidotto, Vittorio (eds.), Storia d'Italia. L'Italia contemporanea dal 1963 a oggi, Vol. 6, Roma/Bari: Laterza, 439-539.

Baumeister, Theofried, 1980, Die Anfänge der Theologie des Martyriums, Münster: Aschendorff.

Benjamin, Walter, 1968, Theses on the Philosophy of History, in: Benjamin, Walter, Illuminations. Essays and Reflections, ed. Arendt, Hannah, trans. Zohn, Harry, New York: Schocken, 253-264.

Benjamin, Walter, 1995, Critique of Violence, in: Benjamin, Walter, Reflections: Essays, Aphorism, Autobiographical Writings, trans. Jephcott, Edmund, New York: Schocken, 277-300.

Bell, Catherine, 2009, Ritual. Perspectives and Dimensions, Oxford: Oxford University Press.

Bellah, Robert H., 1967, Civil Religion in America, Dædalus: Journal of the American Academy of Arts and Sciences 96/1, 1-21.

Belpoliti, Marco, 2001, Settanta, Torino: Einaudi.

Berlinguer, Enrico, 1975, Riflessioni sull'Italia dopo i fatti del Cile, in: Berlinguer, Enrico, La questione comunista: 1969-1975, Vol. 2, ed. Tato, Antonio, Roma: Editori Riuniti, 480-482. 
Bertham, Christopher, 2004, Routledge Philosophy Guidebook to Rousseau and the Social Contract, London/New York: Routledge.

Bianconi, Giovanni, 2001, Eseguendo la sentenza, Torino: Einaudi.

Bidussa, David, 2015, Introduzione, in: Pavone, Claudio/Bobbio, Norberto, Sulla guerra civile. La Resistenza a due voci, Torino: Bollati Boringhieri, vii-xxiii.

Bienk, Alice, 2008, Filmsprache: Einführung in die interaktive Filmanalyse, Marburg: Schüren, 2008.

Biscione, Francesco M., 1998, Il delitto Moro. Strategie di un assassinio politico, Roma: Editori Riuniti.

Biscione, Francesco M., 2003, Il sommerso della Repubblica: La democrazia italiana e la crisi dell'antifascismo, Torino: Bollati Borioghieri.

Biscione, Francesco M., 2012, Il delitto Moro e la deriva della democrazia, Roma: Ediesse.

Blumenberg, Hans, 1985, The Legitimacy of the Modern Age, trans. Wallace, Robert M., Cambridge MA/London: MIT Press.

Blumenberg, Hans, 2001, Anthropologische Annährung an die Aktualität der Rhetorik, in: Blumenberg, Hans, Ästhetische und metaphorologische Schriften, Frankfurt a.M.: Suhrkamp, 406-431.

Blumenberg, Hans, 2010, Paradigms for a Metaphorology, trans. Savage, Robert, Ithaca NY: Cornell University Press and Cornell University Library.

Blumenberg, Hans, 2014a (1979), Arbeit am Mythos, Frankfurt a.M.: Suhrkamp.

Blumenberg, Hans, 2014b, Präfiguration. Arbeit am politischen Mythos, Berlin: Surhkamp.

Bobbio, Norberto, 1980, Diritto e stato nell'opera giovanile di Aldo Moro, Il Politico 45/1, 7-26.

Bobbio, Norberto, 2015, Discorso sulla Resistenza [1965], in: Pavone, Claudio/ Bobbio, Norberto, Sulla guerra civile. La Resistenza a due voci, Torino: Bollati Boringhieri, 5-15.

Bocca, Giorgio, 1985, Noi terroristi. 12 anni di lotta armata ricostruiti e discussi dai protagonisti, Milano: Garzanti.

Bocca, Giorgio (ed.), 1978, Moro. Una tragedia italiana, Milano: Bompiani.

Boyarin, Daniel, 1999, Dying for God. Martyrdom and the Making of Christianity and Judaism, Stanford: Stanford University Press.

Borges, Jorge Luis, 2000, Pierre Menard. Author of the Quixote, in: Borges, Jorge Luis, Collected Fictions, trans. Hurley, Andrew, London: Penguin Books, 88-95.

Bowersock, Glen W., 2002, Martyrdom and Rome, Cambridge: Cambridge University Press.

Braghetti, Anna Laura/Tavella, Paola, 1998, Il prigioniero, Milano: Feltrinelli.

Brigate Rosse, 1978a, Comunicato numero 1, in: Bocca, Giorgio (ed.), Moro. Una tragedia italiana Milano: Bompiani, 34-36.

Brigate Rosse, 1978b, Comunicato numero 3, in: Bocca, Giorgio (ed.), Moro. Una tragedia italiana, Milano: Bompiani, 42-44. 
Brigate Rosse, 1978c, Comunicato numero 7, in: Bocca, Giorgio (ed.), Moro. Una tragedia italiana, Milano: Bompiani, 124-126.

Brigate Rosse, 1978d, Comunicato numero 8, in: Bocca, Giorgio (ed.), Moro. Una tragedia italiana, Milano: Bompiani, 131-133.

Brigate Rosse, 1978e, Comunicato numero 9, in: Bocca, Giorgio (ed.), Moro. Una tragedia italiana, Milano: Bompiani, 142-144.

Brigate Rosse, 1978f, Risoluzione della Direzione Strategica delle Brigate Rosse, in: Bocca, Giorgio (ed.), Moro. Una tragedia italiana, Milano: Bompiani, 49-112.

Bull Cento, Anna/Cooke, Philip, 2013, Ending Terrorism in Italy, New York: Routledge.

Butler, Judith, 1990, Gender Trouble. Feminism and the Subversion of Identity, New York/London: Routledge.

Butler, Judith, 1993, Bodies That Matter. On the Discursive Limits of Sex, New York/London: Routledge.

Butler, Judith, 2010, Performative Agency, Journal of Cultural Economy 3/2, 147171.

Butler, Judith, 2015, Notes Toward a Performative Theory of Assembly, Cambridge MA: Harvard University Press.

Calvino, Italo, 1995a, Le cose mai uscite da quella prigione. Quanto non potremo sapere su Moro, in: Calvino, Italo, Saggi, Milano: Mondadori, 2336-2343.

Calvino, Italo, 1995b, Moro ovvero una tragedia al potere, in: Calvino, Italo, Saggi, Milano: Mondadori, 2349-2352.

Cassierer, Ernst, 1946, The Myth of the State, London: Yale University Press.

Castelli, Elizabeth A., 2004, Martyrdom and Memory. Early Christian Culture Making, New York: Columbia University Press.

Cavanaugh, William T., 2009, The Myth of Religious Violence. Secular Ideology and the Roots of Modern Conflict, Oxford: Oxford Unversity Press.

Clarke, Joseph, 2007, Commemorating the Dead in Revolutionary France. Revolution and Remembrance. 1789-1799, Cambridge: Cambridge University Press.

Collotti, Enzo/Sandri, Renato/Sessi, Frediano (eds.), 2001, Dizionario della Resistenza. Luoghi - formazioni - protagonisti, Torino: Einaudi.

Colombo, Emilio, 1978, Rede, in: Gedenken an Aldo Moro, Strasburg: Europäisches Parlament, 5-6.

Congregazione delle Cause dei Santi, 2004, Le cause dei Santi. Sussidio per lo Studium, Roma: Libreria Editrice Vaticana.

Cook, David, 2007, Martyrdom in Islam, Cambridge: Cambridge University Press.

Cristi, Marcela, 2001, From Civil to Political Religion. The Intersection of Culture, Religion and Politics, Waterloo: Wilfried Laurier University Press.

Davidson, Arnold I., 2003, Über Epistemologie und Archäologie. Von Canguilhem zu Foucault, in: Honneth, Axel/Saar, Martin (eds.), Michel Foucault. Zwischenbilanz einer Rezepetion, Frankfurt a.M.: Suhrkamp, 192-211.

Deaglio, Enrico/Menapace, Lidia/Scalzone, Ernesto (eds.), 1978, Sulla violenza. Politica e terrorismo: Un dibattito nella sinistra, Roma: Savelli. 
Della Porta, Donatella/Rossi, Maurizio, 1984, Cifre crudeli. Bilancio dei terrorismi italiani, Bologna: Istituto Cattaneo.

Derrida, Jacques, 1988, Signature Event Context, in: Derrida, Jacques, Limited Inc, Evanston IL: Northwestern University Press, 1-24.

De Spiegeleer, Christoph, 2014, «The Blood of Martyrs Is the Seed of Progress». The Role of Martyrdom in Socialist Death Culture in Belgium and the Netherlands, 1880-1940, Mortality 19, 184-205.

Diaz-Bone, Reiner, 1999, Probleme und Strategien der Operationalisierung des Diskursmodells im Anschluß an Michel Foucault, in: Bublitz, Hannelore/ Bührmann, Andrea D./Hanke, Christine/Seier, Andrea (eds.), Das Wuchern der Diskurse. Perspektiven der Diskursanalyse Foucaults (Frankfurt a.M./New York: Campus, 119-135.

Didi-Hubermann, 2006, Survivance de lucioles, Paris: Minuit.

Dylan, Bob, 1967, I Dreamed I Saw St. Augustine, from the album John Wesley Harding.

Di Sivo, Michele (ed.), 2013, «Siate indipendenti. Non guardate al domani ma al dopo domani.» Le lettere di Aldo Moro dalla prigionia alla storia, Roma: Archivio di Stato.

Donati, Giuseppe, 1971, Il nostro programma politico-sociale, in: Angiulli, Nicola/de Antonellis, Giacomo (eds.), Giuseppe Donati cattolico antifascista, Milano: Cooperativa Editrice Donati, 139-140.

Drake, Richard, 1984, The Red and the Black. Terrorism in Contemporary Italy, International Political Science 5/3, 279-98.

Drake, Richard, 1995, The Aldo Moro Murder Case, Cambridge MA/London: Harvard University Press.

Drake, Richard, 1999, Italy in the 1960s. A Legacy of Terrorism and Liberation, South Central Review 16/17, 62-76.

Drake, Richard, 2001, Why the Moro Trials Have Not Settled the Moro Murder Case. A Problem in Political and Intellectual History, The Journal of Modern History 73/2, 359-78.

Drake, Richard, 2008, Catholics and the Italian Revolutionary Left of the 1960s, The Catholic Historical Review 94/3, 450-475.

Dreyfus, Hubert L./Rabinow, Paul, 1983 (1982), Michel Foucault: Beyond Structuralism and Hermeneutics, Chicago: University of Chicago Press.

Dunnage, Jonathan, 2002, Twentieth Century Italy. A Social History, Harlow: Pearson Education.

Eco, Umberto, 1983, Colpire quale cuore?, in: Eco, Umberto, Sette anni di desiderio, Milano: Bompiani, 109-113.

Fasanella, Giovanni/Sestieri, Claudio/Pellegrino, Giovanni, 2000, Segreto di Stato. La verità da Gladio al caso Moro, Torino: Einaudi.

Feltrinelli, Giangiacomo, 2012, Persiste la minaccia di un colpo di stato in Italia!, Milano: Feltrinelli. 
Fenske, Hans, 2003, Politisches Denken von der Französischen Revolution bis zur Gegenwart, in: Fenske, Hans/Mertens, Dieter/Reinhard, Wolfgang/Rosen, Klaus (eds.), Geschichte der politischen Ideen, Frankfurt a.M.: Fischer, 379-586.

Ferlicchia, Luigi, 2014, I tempi di Aldo Moro. Quando la politica era una vocazione, Bari: Federazione dei Centri studi Aldo Moro and Renato Dell'Andro.

Ferrara, Alessandro, 2008, La forza dell'esempio. Il paradigma del giudizio, Milano: Feltrinelli.

Fierke, Karin, 2013, Political Self-Sacrifice. Agency, Body and Emotion in International Relations, Cambridge: Cambridge University Press.

Flamigni, Sergio, 1988, La tela del ragno. Il delitto Moro, Milano: Kaos Edizioni.

Flamigni, Sergio (ed.), 1997, «Il mio sangue ricadrà su di loro.» Gli scritti di Aldo Moro prigioniero delle BR, Milano: Kaos.

Flamigni, Sergio, 1998, Convergenze parallele, Milano: Kaos.

Flamigni, Sergio (ed.), 2006, Le idi di marzo. Il delitto Moro secondo Mino Pecorelli, Milano: Kaos.

Flamigni, Sergio, 2015, Patto di omertà, Milano: Kaos.

Forlani, Alessandro, 2014, La zona franca. Così è fallita la trattativa segreta che doveva salvare Aldo Moro, Roma: Castelvecchi.

Formigoni, Guido, 2016, Aldo Moro. Lo statista e il suo dramma, Bologna: Il Mulino.

Foucault, Michel, 1966, Les mots et les choses. Une archéologie des sciences humaines, Paris: Gallimard.

Foucault, Michel, 1972, Archeology of Knowledge \& The Discourse on Language, trans. Sheridan Smith, A. M., New York: Pantheon Books.

Foucault, Michel, 1977, Nietzsche, Genealogy, History, in: Foucault, Michel, Language, Counter-memory, Practice: Selected Essays and Interviews, ed. Bouchard, Donald F., trans. Bouchard, Donald F./Simon, Sherry, Ithaca NY: Cornell University Press, 139-140.

Foucault, Michel, 1978, The History of Sexuality. Volume I: An Introduction, New York: Pantheon.

Foucault, Michel, 2002, Dits et écrits. Schriften, Vol. 2, Frankfurt a.M.: Suhrkamp.

Foucault, Michel, 2003, «Society Must Be Defended»: Lectures at the Collège de France, 1975-1976, ed. Bertani, Mauro/Fontana, Alessandro, trans. Macey, David, New York: Picador.

Foucault, Michel, 2007 (1997), What is Critique?, in: Foucault, Michel, The Politics of Truth, ed. Lotringer, Sylvère, trans. Hochroth, Lysa/Porter, Catherine, Los Angeles: Semiotext(e), 41-81.

Foucault, Michel, 2009, Security, Territory, Population. Lectures at the Collège de France, 1977-1978, ed. Senellart, Michel, trans. Burchell, Graham, New York: Picador.

Franceschini, Alberto/Buffa, Vittorio/Giustolisi, Franco, 1988, Mara Renato e io. Storia dei fondatori delle BR, Milano: Mondadori. 
Frend, William Hock Clifford, 1965, Martyrdom and Persecution in the Early Church. A Study of a Conflict From the Maccabees to Donatus, Oxford: Blackwell.

Fuller, Lon L., 1966, The Law in Quest of Itself, Boston: Beacon Press.

Galli, Giorgio, 2004, Piombo rosso. La storia completa della lotta armata in Italia dal 1970 ad oggi, Milano: Baldini Castoldi Dalai.

Gambetta, Diego (ed.), 2005, Making Sense of Suicide Missions, Oxford: Oxford University Press.

Gehering, Petra, 2004, Foucault. Die Philosophie im Archiv, Frankfurt a.M./New York: Campus.

Gentile, Emilio, 1993, Il culto del littorio. La sacralizzazione della politica nell'Italia Fascista, Roma: Laterza.

Giampaolo, Nicola, 2015, Aldo Moro. Un cristiano verso l'altare, Bari: Giuseppe Laterza.

Ginsborg, Paul, 1990, A History of Contemporary Italy: Society and Politics, 19431988, London: Penguin Books.

Ginzburg, Carlo, 1991, Il giudice e lo storico. Considerazioni in margine al processo Sofri, Torino: Einaudi.

Giordano, Alfonso, 2011, Il maxiprocesso venticinque anni dopo. Memoriale del presidente, Acireale: Bonanno.

Giovagnoli, Agostino, 2009, Il caso Moro. Una tragedia repubblicana, Bologna: Il Mulino.

Girard, René, 1979, Violence and the Sacred, trans. Gregory, Patrick, Baltimore: Johns Hopkins University Press, 1979.

Girard, René, 2001, Vedo satana cadere come la folgore, Milano: Adelphi.

Girard, René, 2011, Violenza e religione, Milano: Raffaello Cortina Editore.

Glynn, Ruth/Lombardi, Giancarlo, 2012, Introduction, in: Glynn, Ruth/Lombardi, Giancarlo (eds.), Remembering Aldo Moro. The Cultural Legacy of the 1978 Kidnapping and Murder, Oxford: Legenda, 1-17.

Glynn, Ruth/Giancarlo Lombardi/O’Leary, Alan (eds.), 2012, Terrorism, Italian Style. Representations of Political Violence in Contemporary Italian Cinema, London: Igrs Books.

Glynn, Ruth, 2009, Through the Lens of Trauma. The Figure of the Female Terrorist in Il Prigioniero and Buongiorno, notte, in: Antonello, Pierpaolo/O'Leary, Alan, Imagining Terrorism. The Rhetoric and Representation of Political Violence in Italy 1969-2009, Oxford: Legenda, 63-76.

Gobetti, Piero, 1969, Risorgimento senza eroi, in: Gobetti, Piero, Scritti storici, letterari e filosofici, ed. Spriano, Paolo, Torino: Einaudi.

Gotor, Miguel, 2008a, Premessa, in: Moro, Aldo, Lettere dalla prigionia, ed. Gotor, Miguel, Torino: Einaudi, xi-xxvi.

Gotor, Miguel, 2008b, La possibilità dell'uso del discorso nel cuore del terrore. Della scrittura come agonia, in: Moro, Aldo, Lettere dalla prigionia, ed. Gotor, Miguel, Torino: Einaudi, 185-389. 
Gotor, Miguel, 2011, Il memoriale della Repubblica. Gli scritti di Aldo Moro dalla prigionia e l'anatomia del potere italiano, Torino: Einaudi.

Hall, Stuart, 1993, The West and the Rest, in: Hall, Stuart/Gieben, Bram (eds.), The Formations of Modernity, Cambridge: Polity, 275-332.

Hall, Stuart, 1996, Who Needs Identity?, in: Hall, Stuart/du Gay, Paul (eds.), Questions of Cultural Identity, Los Angeles/London/New Delhi/Singapore/Washington DC: SAGE, 1-17.

Hall, Stuart, 2013a (1997), Introduction, in: Hall, Stuart/Evan, Jessica/Nixon, Sean (eds.), Representation, Los Angeles/London/New Delhi/Singapore/Washington DC: SAGE, xvii-xxvi.

Hall, Stuart, 2013b (1997), The Work of Representation, in: Hall, Stuart/Evan, Jessica/Nixon, Sean (eds.), Representation, Los Angeles/London/New Delhi/Singapore/Washington DC: SAGE, 2013, 1-59.

Hansen, Thomas Blom, 2006, Performers of Sovereignty. On the Privatisation of Security in Urban South Africa, Critique of Anthropology 26/3, 279-295.

Hanssen, Beatrice, 2000, Critique of Violence. Between Poststructuralism and Critical Theory, London: Routledge.

von Harnack, Adolf, 1905, Militia Christi. Die christliche Religion und der Soldatenstand in den ersten drei Jahrhunderten, Tübingen: Mohr/Siebeck.

Heywood, Paolo, 2009, The Two Burials of Aldo Moro. Sovereignty and Governmentality in the "Anni di Piombo", Cambridge Anthropology 29/3, 1-28.

Henninger, Joseph, 2005, Sacrifice [1987], in: Jones, Lindsay (ed.), Encyclopedia of Religion, Second Edition, Vol. 12, Detroit/New York/San Francisco/San Diego/New Haven CT/Waterville ME/London/München: Thomson Gale, 79978008 .

van Henten, Jan Willem, 1997, The Maccabean Martyrs as Saviours of the Jewish People. A Study of 2 and 4 Maccabees, Leiden: Brill.

van Henten, Jan Willem/Avemarie, Friedrich, 2002, Introduction, in: van Henten, Jan Willem/Avemarie, Friedrich (eds.), Martyrdom and Noble Death. Selected Texts from Graeco-Roman, Jewish, and Christian Antiquity, London: Routledge, $1-8$.

Hjelm, Titus, 2011, Discourse Analysis, in: Stausberg, Michael/Engler, Tihomir (eds.), The Routledge Handbook of Research Methods in the Study of Religion, London: Routledge, 134-150.

Hobbes, Thomas, 2003, Leviathan, Vol. 2, ed. Rogers, G. A. J./Schuhmann, Karl, Bristol: A\&C Black.

Hof, Tobias, 2013, The Moro Affair. Left-Wing Terrorism and Conspiracy in Italy in the Late 1970s, Historical Social Research/Historische Sozialforschung 38/1, $232-256$.

Horsch, Silvia/Treml, Martin (eds.), 2011, Grenzgänger der Religionskulturen. Kulturwissenschaftliche Beiträge zu Gegenwart und Geschichte der Märtyrer, Paderborn: Wilhelm Fink.

Hubert, Henri/Mauss, Marcel, 1964, Sacrifice. Its Nature and Functions, Chicago: University Of Chicago Press. 
Hung, Chang-tai, 2008, The Cult of the Red Martyr. Politics of Commemoration in China, Journal of Contemporary History 43, 279-304.

Imperi, Ilenia, 2016, Il caso Moro. Cronaca di un evento mediale, Milano: Franco Angeli.

Jäger, Sigfried, 2004, Kritische Diskursanalyse. Eine Einführung, Münster: UnrastVerlag.

Jamieson, Alison, 1989, The Heart Attacked. Terrorism and Conflict in the Italian State, London/New York: Marion Boyers.

Janes, Dominic/Houen, Alex, 2014, Introduction, in: Janes, Dominic/Houen, Alex (eds.), Martyrdom and Terrorism. Pre-Modern to Contemprorary Perspectives, New York: Oxford University Press, 1-22.

Jemolo, Arturo Carlo, 1978, Questa Repubblica. Dalla contestazione all'omicidio di Aldo Moro, Firenze: Le Monnier.

Juergensmeyer, Mark, 2008, Martyrdom and Sacrifice in a Time of Terror, Social Research 75, 417-434.

Kammler, Clemens, 2014a, Einführung. Konzeptualisierung der Werke Foucaults, in: Kammler, Clemens/Parr, Rolf/Schneider, Ulrich Johannes (eds.), Foucault Handbuch. Leben - Werk - Wirkung, Stuttgart: Metzler, 9-11.

Kammler, Clemens, 2014b, Archäologie des Wissens, in: Kammler, Clemens/Parr, Rolf/Schneider, Ulrich Johannes (eds.), Foucault Handbuch. Leben - Werk Wirkung (Stuttgart: Metzler, 2014), 51-62.

Katz, Robert, 1980, Days of Wrath. The Public Agony of Aldo Moro, London: Granada Publishing.

Keller, Reiner, 2008, Wissenssoziologische Diskursanalyse. Grundlegung eines Forschungsprogramms, Wiesbaden: Verlag für Sozialwissenschaften.

Kepel, Gilles, 2015, Terreur dans l'Hexagone. Genèse du djihad français, Paris: Gallimard, 2015.

Khalili, Laleh, 2007, Heroes and Martyrs of Palestine. The Politics of National Commemoration, Cambridge: Cambridge University Press.

Kippenberg, Hans G., 1983, Diskursive Religionswissenschaft. Gedanken zu einer Religionswissenschaft, die weder auf einer allgemein gültigen Definition von Religion noch auf einer Überlegenheit von Wissenschaft basiert, in: Gladigow, Burkhard/Kippenberg, Hans G. (eds.), Neue Ansätze in der Religionswissenschaft, München: Kösel Verlag, 9-28.

Kirwan Michael, 2009, Girard, Religion, Violence, and Modern Martyrdom, in: Clark, Peter B. (ed.), The Oxford Handbook of the Sociology of Religion, Oxford: Oxford University Press, 910-924.

Klausner, Samuel Z., 2005, Martyrdom [1987], in: Jones, Lindsay (ed.), Encyclopedia of Religion, Second Edition, Vol. 8, Detroit/New York/San Francisco/San Diego/New Haven CT/Waterville ME/London/München: Thomson Gale, 57375744.

Kohn, Hans, 1944, The Idea of Nationalism. A Study in Its Origins and Background, New York: Macmillan. 


\section{Bibliography}

Koselleck, Reinhard, 1999, Einleitung, in: Koselleck, Reinhard/Jeismann, Michael (eds.), Der politische Totenkult. Kriegerdenkmäler in der Moderne, München: Wilhelm Fink, 9-20.

Krass, Andreas/Frank, Thomas (eds.), 2008, Tinte und Blut. Politik, Erotik und Poetik des Martyriums, Frankfurt a.M.: Fischer.

Krass, Andreas, 2008, Sündenbock und Opferlamm: Der Märtyrer in kulturwissenschaftlicher Sicht, in: Krass, Andreas/Frank, Thomas (eds.), Tinte und Blut, Politik, Erotik und Poetik des Martyriums, Frankfurt a.M.: Fischer, 7-21.

Kress, Gunther R./van Leeuwen, Theo, 2001, Multimodal Discourse. The Modes and Media of Contemporary Communication, London: Arnold.

Lanata, Giuliana, 1973, Gli atti dei martiri come documenti processuali, Milano: Giuffrè.

Landwehr, Achim, 2008, Historische Diskursanalyse, Frankfurt/New York: Campus.

Lincoln, Bruce, 1989, Discourse and the Construction of Society. Comparative Studies of Myth, Ritual, and Classification, Oxford: Oxford University Press.

Lofoco, Nicola, 2015, Il caso Moro. Misteri e segreti svelati, Bari: Gelsorosso.

Lombardi, Giancarlo, 2009, Screening Terror. Political Terrorism in Italian Cinema, in: Antonello, Pierpaolo/O'Leary, Alan (eds.), Imagining Terrorism. The Rhetoric and Representation of Political Violence in Italy 1969-2009, Oxford: Legenda, 88-100.

Lombardi, Giancarlo, 2007, La passione secondo Marco Bellocchio. Gli ultimi giorni di Aldo Moro, Annali d'Italianistica 25, 397-408.

Mancino, Anton G., 2014, La recita della storia. Il caso Moro nel cinema di Marco Bellocchio, Milano: Bietti.

Manca, Vicenzo R., 2008, Moro un profeta disarmato: Dramma di un uomo - declino di un paese, Roma: KOINè.

Manelli, Valeria/Volonté, Gian Maria, 1998, L'immagine e la memoria, Ancona: Transeuropa.

Marinetti, Piero, 1923, Breviario spirituale, Milano: ISIS.

Marini-Maio, Nicoletta, 2012, Unbury that Body. The Tragic Palinode of a Generation in Marco Baliani's Corpo di stato, in: Glynn, Ruth/Lombardi, Giancarlo (eds.), Remembering Aldo Moro. The Cultural Legacy of the 1978 Kidnapping and Murder, Oxford: Legenda, 122-135.

Marini-Maio, Nicoletta/Nerenberg, Ellen, 2012, Critical Introduction, in: Baliani, Marco, Body of State. The Moro Affair, A Nation Divided, trans. Marini-Maio, Nicoletta/Nerenberg, Ellen/Simpson, Thomas, Madison: Fairleigh Dickinson University Press, 1-21.

Mario Banti, Alberto, 2000, La nazione del Risorgimento. Parentela, santità e onore alle origini dell'Italia unita, Torino: Einaudi.

Mario Banti, Alberto/Ginsborg, Paul, 2007, Per una nuova storia del Risorgimento, in: Mario Banti, Alberto/Ginsborg, Paul (eds.), Storia d'Italia. Annali 22. Il Risorgimento, Torino: Einaudi, xviii-xxxiv. 
Mauss, Marcel, 1896a, La religion et les origines du droit pénal d'après un livre récent, Revue d'histoire des religion 34, 269-295.

Mauss, Marcel, 1896b, La religion et les origines du droit pénal d'après un livre récent, Revue d'histoire des religion 35, 31-60.

Mecchia, Giuseppina, 2012, Moro's Body between Enlightenment and Postmodernism. Terror, Murder, and Meaning in Jean Baudrillard and Leonardo Sciascia, in: Glynn, Ruth/Lombardi, Giancarlo (eds.), Remembering Aldo Moro. The Cultural Legacy of the 1978 Kidnapping and Murder, Oxford: Legenda, 108121.

McWilliam, Neil, 1995, Monuments, Martyrdom, and the Politics of Religion in the French Third Republic, The Art Bulletin 77, 186-206.

Menkovic, Biljana, 1999, Politische Gedenkkultur. Denkmäler: die Visualisierung politischer Macht im öffentlichen Raum, Wien: Braumüller.

Michalczyk, John J., 1988, The Political Adaptation. Rosi and Petri Film Sciascia, Annali d'Italianistica 6, 220-230.

Middleton, Paul, 2006, Radical Martyrdom and Cosmic Conflict in Early Christianity, London: T\&T Clark.

Middleton, Paul, 2011, Martyrdom. A Guide for the Perplexed, London: Continuum.

Middleton, Paul, 2014, What is martyrdom?, Mortality 19/2, 117-133.

Mitchell, Jolyon, 2013, Martyrdom. A Very Short Introduction, Oxford: Oxford University Press.

Morcellini, Mario/Avallone, Francesco, 1978, Il ruolo dell'informazione in una situazione di emergenza. 16 marzo 1978. Il rapimento di Aldo Moro, Roma: RAI.

Moretti, Mario, 2000 (1994), Brigate rosse. Una storia italiana, interviewed by Mosca, Carla/Rossanda, Rossana, Milano: Baldini \& Castoldi.

Moro, Aldo, 1979, L'intelligenza e gli avvenimenti. Testi 1959-1978, ed. Fondazione Aldo Moro, Milano: Garzanti.

Moro, Aldo, 1997a, Mi rendo conto delle accuse, in: Flamigni, Sergio (ed.), «Il mio sangue ricadrà su di loro.» Gli scritti di Aldo Moro prigioniero delle Br, Milano: Kaos Edizioni, 227-228.

Moro, Aldo, 1997b, La stampa italiana, in: Flamigni, Sergio (ed.), «Il mio sangue ricadrà su di loro.» Gli scritti di Aldo Moro prigioniero delle $\mathrm{Br}$, Milano: Kaos Edizioni, 319-320.

Moro, Aldo, 1997c, I gravi fatti di piazza Fontana, in: Flamigni, Sergio (ed.), «Il mio sangue ricadrà su di loro.» Gli scritti di Aldo Moro prigioniero delle Br, Milano: Kaos, 229-233.

Moro, Aldo, 1997d, Per lo scandalo Lockhead, in: Flamigni, Sergio (ed.), «Il mio sangue ricadrà su di loro.» Gli scritti di Aldo Moro prigioniero delle $\mathrm{Br}$, Milano: Kaos, 273-274.

Moro, Aldo, 1997e, Strategia antiguerriglia della Nato, in: Flamigni, Sergio (ed.), «Il mio sangue ricadrà su di loro.» Gli scritti di Aldo Moro prigioniero delle $\mathrm{Br}$, Milano: Kaos, 301-302. 


\section{Bibliography}

Moro, Aldo, 1997f, Il futuro della DC e le dimissioni dal partito, in: Flamigni, Sergio (ed.), «Il mio sangue ricadrà su di loro.» Gli scritti di Aldo Moro prigioniero delle Br, Milano: Kaos, 321-328.

Moro, Aldo, 2006, Il diritto. Lo Stato. Lezioni di filosofia del diritto, Bari: Cacucci, 2006.

Moro, Aldo, 2008a, Lettere dalla prigionia, ed. Gotor, Miguel, Torino: Einaudi.

Moro, Aldo, 2008b, Lettera al ministro dell'Interno Francesco Cossiga, in: Moro, Aldo, Lettere dalla prigionia, ed. Gotor, Miguel, Torino: Einaudi, 7-9.

Moro, Aldo, 2008c, Lettera al segretario della Dc Benigno Zaccagnini (1), in: Moro, Aldo, Lettere dalla prigionia, ed. Gotor, Miguel, Torino: Einaudi, 13-15.

Moro, Aldo, 2008d, Lettera alla moglie Eleonora (1), in: Moro, Aldo, Lettere dalla prigionia, ed. Gotor, Miguel, Torino: Einaudi, 31-34.

Moro, Aldo, 2008e, Lettera sul senatore Paolo Emilio Taviani, in: Moro, Aldo, Lettere dalla prigionia, ed. Gotor, Miguel, Torino: Einaudi, 40-45.

Moro, Aldo, 2008f, Lettera alla moglie Eleonora (2), in: Moro, Aldo, Lettere dalla prigionia, ed. Gotor, Miguel, Torino: Einaudi, 59-62.

Moro, Aldo, 2008g, Lettera alla moglie Eleonora (3), in: Moro, Aldo, Lettere dalla prigionia, ed. Gotor, Miguel, Torino: Einaudi, 62-65.

Moro, Aldo, 2008h, Lettera al Papa Paolo VI, in: Moro, Aldo, Lettere dalla prigionia, ed. Gotor, Miguel, Torino: Einaudi, 68-69.

Moro, Aldo, 2008i, Lettera al segretario della Dc Benigno Zaccagnini (2), in: Moro, Aldo, Lettere dalla prigionia, ed. Gotor, Miguel, Torino: Einaudi, 71-76.

Moro, Aldo, 2008j, Lettera al segretario della Dc Benigno Zaccagnini (3), in: Moro, Aldo, Lettere dalla prigionia, ed. Gotor, Miguel, Torino: Einaudi, 98-103.

Moro, Aldo, 2008k, Lettera alla Democrazia Cristiana, in: Moro, Aldo, Lettere dalla prigionia, ed. Gotor, Miguel, Torino: Einaudi, 140-144.

Moro, Aldo, 20081, Lettera al Partito della Democrazia Cristiana, in: Moro, Aldo, Lettere dalla prigionia, ed. Gotor, Miguel, Torino: Einaudi, 140-146.

Moro, Aldo, 2008m, Lettera alla moglie Eleonora (4), in: Moro, Aldo, Lettere dalla prigionia, ed. Gotor, Miguel, Torino: Einaudi, 177-179.

Moro, Aldo, 2008n, Lettera alla moglie Eleonora (5), in: Moro, Aldo, Lettere dalla prigionia, ed. Gotor, Miguel, Torino: Einaudi, 179.

Moro, Alfredo Carlo, 1998, Storia di un delitto annunciato. Le ombre del caso Moro, Roma: Editori Riuniti.

Moss, Candida R., 2012, Ancient Christian Martyrdom. Diverse Practices, Theologies, and Traditions, New Haven CT: Yale University Press.

Moss, David, 1981, The Kidnapping and Murder of Aldo Moro, European Journal of Sociology 22/2, 265-295.

Moss, David, 1983, Analysing Italian Political Violence as a Sequence of Communicative Acts. The Red Brigades 1970-1982, Social Analysis: The International Journal of Social and Cultural Practice 13, 84-111.

Moss, David, 1989, The Politics of Left-Wing Violence in Italy. 1969-85, Basingstoke/London: MacMillan. 
Moss, David, 2009, Memorilization Without Memory. The Case of Aldo Moro, in: Antonello, Pierpaolo/O'Leary, Alan (eds.), Imagining Terrorism. The Rhetoric and Representation of Political Violence in Italy 1969-2009, Oxford: Legenda, 168-182.

Mosse, George L., 2015, Intervista su Aldo Moro, ed. Alfonsi, Alfonso, Soveria Mannelli: Rubettino.

Mouffe, Chantal/Laclau, Ernesto, 1985, Hegemony and Socialist Strategy, London: Verso.

Musurillo, Herbert, 1954, The Acts of the Pagan Martyrs. Acta Alexandrinorum, Oxford: Clarendon Press.

Niewiadomski, Józef (ed.), 2011, Opfer, Helden, Märtyrer. Das Martyrium als religionspolitologische Herausforderung, Innsbruck: Tyrolia-Verlag.

Noce, Celestino, 1987, Il Martirio. Testimonianza e spiritualità nei primi secoli, Roma: Edizioni Studium.

O'Leary, Alan, 2009, Moro, Brescia, Conspiracy. The Paraonid Style in Italian Cinema, in: Antonello, Pierpaolo/ O'Leary, Alan (eds.), Imagining Terrorism: The Rhetoric and Representation of Political Violence in Italy 1969-2009, Oxford: Legenda, 48-62.

O'Leary, Alan, 2011, Tragedia all'italiana. Italian Cinema and Italian Terrorisms, 1970-2010, Oxford/Bern/Berlin/Bruxelles/Frankfurt a.M./New York/Wien: Peter Lang.

O'Leary, Alan, 2012, Locations of Moro. The Kidnap in the Cinema, in: Glynn, Ruth/Lombardi, Giancarlo (eds.), Remembering Aldo Moro. The Cultural Legacy of the 1978 Kidnapping and Murder, Oxford: Legenda, 151-170.

Omodeo, Adolfo, 1946, L'età del Risorgimento italiano, Messina: Edizioni Scientifiche Italiane.

Omodeo, Adolfo, 1951, Difesa del Risorgimento, Torino: Einaudi.

Omodeo, Adolfo, 1970, Studi sull'età della restaurazione, Torino: Einaudi.

Palumbi, Nicola, 2003, Don Giovanni Minzoni. Educatore e martire, San Paolo: Cinisello Balsamo.

Pannewick, Friederike (ed.), 2004, Martyrdom in Literature. Visions of Death and Meaningful Suffering in Europe and the Middle East from Antiquity to Modernity, Wiesbaden: Reichert.

Pasolini, Pier Paolo/Amendola, Giorgio/Bocca, Giorgio/Calvino, Italo/Cattaneo, Giulio/Cittati, Pietro/Colombo, Furio/Cardelli, Franco/Debenedetti, Antonio/ Giolitti, Antonio/Lavagetto, Mario/Leonetti, Francesco/Manacorda, Giorgio/ Melograni, Piero/Pampaloni, Geno/Piccioli, Gian Luigi/Piovene, Guido/Siti, Walter/Valiani, Leo/Villari, Lucio, 1973, Otto domande sull'estremismo, Nuovi Argomenti 31, 5-101.

Pasolini, Pier Paolo, 1991 (1972), Nuove questioni linguistiche, in: Pasolini, Pier Paolo, Empirismo eretico, Milano: Garzanti, 5-24.

Pavone, Claudio, 2006, Una guerra civile. Saggio storico sulla moralità nella Resistenza, Torino: Bollati Boringhieri. 
Pavone, Claudio, 2015, La guerra civile [1986], in: Pavone, Claudio/Bobbio, Norberto, Sulla guerra civile. La Resistenza a due voci, Torino: Bollati Boringhieri, 24-65.

Pedazhur, Ami (ed.), 2006, Root Causes of Suicide Terrorism. The Globalization of Martyrdom, London/New York: Routledge.

Perona, Gianni, 2000, Stampa della Resistenza, in: Collotti, Enzo/Sandri, Renato/ Sessi, Frediano (eds.), Dizionario della Resistenza. Storia e geografia della liberazione, Torino: Einaudi, 291-299.

Peterson, Erik, 1937, Zeuge der Wahrheit, Leipzig: Jakob Hegner.

Pezzini, Isabella, 2009, Television and Terrorism in Italy. Segio Zavoli's La notte della Repubblica, in: Antonello, Pierpaolo/O'Leary, Alan (eds.), Imagining Terrorism. The Rhetoric and Representation of Political Violence in Italy 19692009, Oxford: Legenda, 77-87.

Pezzini, Isabella, 2012, Imago Moro. Medi-a(c)tion on Aldo Moro, in: Glynn, Ruth/ Lombardi, Giancarlo (eds.), Remembering Aldo Moro. The Cultural Legacy of the 1978 Kidnapping and Murder, Oxford: Legenda, 136-150.

Pollard, John Francis, 2008, Catholicism in Modern Italy. Religion, Society and Politics Since 1861, London/New York: Routledge.

Pombeni, Paolo, 1977, Socialismo e cristianesimo (1815-1975), Brescia: Queriniana.

Ponzo, Jenny, 2017, Procession as a Literary Motif. The Intersection of Religious and National Symbolism in Italian Narrative (Nineteenth-Twentieth Centuries), Journal of Religion in Europe 10/1-2, 107-146.

Pricoco, Salvatore, 2007, Dal concilio di Nicea a Gregorio Magno, in: Filoramo, Giovanni (ed.), Cristianesimo, Roma/Bari: Laterza, 55-104.

Rahner, Karl, 1958, Zur Theologie des Todes. Mit einem Exkurs über das Martyrium, Freiburg/Basel/Wien: Herder.

Recupero, 2011, Maria Grazia, Martirio. Elementi antropologici, politici e filosofico-simbolici, Massa: Transeuropa.

Reichel, Peter, 1995, Politik der Erinnerung. Gedächnisorte im Streit um die nationalsozialistische Vergangenheit, München/Wien: Carl Hanser.

Ricoeur, Paul, 1991, Mimesis and Representation, in: Valdés, Mario J. (ed.), A Ricoeur Reader. Reflection and Immagination, Toronto ON: University of Toronto Press, 137-156.

Rossi, Paola Elena, 1993, Untergrund und Revolution. Der ungelöste Wiederspruch für Brigate Rosse und Rote Armee Fraktion, Zürich: vdf-Hochschulverlag.

Rousseau Jean-Jacques, 1994, Discourse on Political Economy and the Social Contract, Oxford: Oxford University Press.

Satta, Vladimiro, 2003, Odissea nel Caso Moro. Viaggio controcorrente attraverso la documentazione della Commissione Stragi, Roma: EDUP. 
Schechter, Ronald, 2014, Terror, Vengeance, and Martyrdom in the French Revolution, in: Jenes, Dominic/Houen, Alex (eds.), Martyrdom and Terrorism. PreModern to Contemporary Perspectives, Oxford: Oxford University Press, 152178.

Sciascia, Leonardo, 1978, Laffaire Moro, Palermo: Sellerio.

Sciascia, Leonardo, 1991, Nero su nero, in: Sciascia, Leonardo, Opere 1971-1983, Milano: Bompiani, 823-942.

Schleiermacher, Friedrich D.E., 2012, Zur Hermeneutik (1805 und 1809/10), in: Schleiermacher, Friedrich D.E., Kritische Gesamtausgabe, Section II, Vol. 4, ed. Meckenstock, Günter/Arndt, Andreas/Dierken, Jörg/Käppel, Lutz/Selenczka, Notger, Berlin/Boston: De Gruyter, 5-34.

Schmitt, Carl, 1985, Political Theology. Four Chapters on the Concept of Sovereignty, trans. Schwab, George, Cambridge MA/London: MIT Press.

Schmitt, Carl, 1988, The Nomos of the Earth in the International Law of the Jus Publicum Europaeum, trans. Ulmen, G. L., New York: Telos Press Publishing.

Schmitt, Carl, 1996, The Leviathan in the State Theory of Thomas Hobbes. Meaning and Failure of a Political Symbol, trans. Schwab, George/Hilfstein, Erna, Westport CT/London: Greenwood.

Schmitt, Carl, 2002 (1932), Der Begriff des Politischen, Berlin: Duncker \& Humbolt.

Selva, Gustavo/Marcucci, Eugenio, 1978, Il martirio di Aldo Moro, Bologna: Cappelli.

Selva, Gustavo/Marcucci, Eugenio, 2003, Aldo Moro. Quei terribili 55 giorni, Soveria Menelli: Rubbettino.

Settembrini, Luigi, 1934, Ricordanze della mia vita, ed. Omodeo, Adolfo, Bari: Laterza.

Silj, Alessandro, 1978, Brigate Rosse-Stato. Lo scontro-spettacolo nella regia della stampa quotidiana, Firenze: Vallecchi.

Soboul, Albert, 1966, La rivoluzione francese, Vol. 1, Bari: Laterza.

Spriano, Paolo, 1975, Storia del Partito Comunista Italiano: la Resistenza. Togliatti e il partito nuovo, Torino: Einaudi.

Stuckrad, Kocku von, 2003, Discursive Study of Religion. From States of the Mind to Communication and Action, Method \& Theory in the Study of Religion $15 / 3,255-271$.

Stuckrad, Kocku von, 2010, Reflections on the Limits of Reflection. An Invitation to the Discursive Study of Religion, Method \& Theory in the Study of Religion 22/3, 156-169.

Stuckrad, Kocku von, 2013, Discursive Study of Religion. Approaches, Definitions, Implications, Method \& Theory in the Study of Religion 25/3, 5-25.

Sturzo, Luigi, 1965, Italia e Fascismo, Bologna: Zanichelli.

Sturzo, Luigi, 1967, Miscellanea londinese, Vol. 2, Bologna: Zanichelli. 


\section{Bibliography}

Taubes, Jacob, 1983, Statt einer Einleitung. Leviathan als sterblicher Gott, in: Taubes, Jacob (ed.), Der Fürst dieser Welt. Carl Schmitt und die Folgen, München/Paderborn/Wien/Zürich: Wilhelm Fink/Ferdinand Schöningh, 9-15.

Taubes, Jacob, 1987, Ad Carl Schmitt. Gegenstrebige Fügung, Berlin: Merve.

Taubes, Jacob, 2003 (1993), Die politische Theologie des Paulus, München: Wilhelm Fink.

Testa, Carlo, 2007, Film, Literature, and Terrorism. Mapping Italy's Political Landscape by Cinematic Means, Italica 84/4, 781-98.

Townshend, Charles, 2002, Terrorism. A Very Short Introduction, Oxford: Oxford University Press.

Tricomi, Antonio, 2009, Killing the Father. Politics and Intellectuals, Utopia and Disillution, in: Antonello, Pierpaolo/O’Leary, Alan (eds.), Imagining Terrorism. The Rhetoric and Representation of Political Violence in Italy 1969-2009. Oxford: Legenda, 16-29.

Uva, Christian, 2011, Tableaux Mourants. L'immagine di Aldo Moro tra fotografia, pagina scritta e cinema, The Italianist 31, 258-269.

Verdolini, Valeria, 2006, Profanazioni. la nuda vita tra violenza simbolica e violenza del simbolo nel terrorismo politico, Studi sulla questione criminale 1/3, 53-72.

Vincent, Andrew, 1987, Theories of the State, Oxford: Basil Blackwell.

Viroli, Maurizio, 2012, As If God Existed. Religion and Liberty in the History of Italy, Princeton: Princeton University Press.

Wagner-Pacifici, Robin Erica, 1986, The Moro Morality Play. Terrorism as Social Drama, Chicago/London: The University of Chicago Press.

Weigel, Sigrid, 2006, Souverän, Märtyrer und «gerechte Kriege» Jenseits des Jus Publicum Europaeum. Zum Dilemma Politischer Theologie, diskutiert mit Carl Schmitt und Walter Benjamin, in: Weidner, Daniel (ed.), Figuren des Europäischen. Kulturgeschichtliche Perspektiven, München: Wilhelm Fink, 101-128.

Weigel, Sigrid (ed.), 2007a, Märtyrer-Porträts. Von Opfertod, Blutzeugen und heiligen Kriegern, München: Wilhelm Fink.

Weigel, Sigrid, 2007b, Schauplätze, Figuren, Umformungen. Zu Kontinuitäten und Unterscheidungen von Märtyrerkulturen, in: Weigel, Sigrid (ed.), Märtyrer-Porträts: Von Opfertod, Blutzeugen und heiligen Kriegern, München: Wilhelm Fink, 11-37.

Whyte, Jessica, 2009, «I Would Prefer Not To». Giorgio Agamben, Bartleby and the Potentiality of the Law, Law and Critique 20, 309-324.

Wicker, Brian (ed.), 2006, Witnesses to Faith? Martyrdom in Christianity and Islam, Ashgate: Aldershot.

Wirth, Uwe, 2002, Der Performanzbegriff im Spannungsfeld von Illokution, Iteration und Indexikalität, in: Wirth, Uwe (ed.), Performanz. Zwischen Sprachphilosophie und Kulturwissenschaften, Frankfurt a. M.: Suhrkamp, 9-60.

Zampagni, Vera, 2000, Evolution of the Economy, in: McCarthy, Patrick (ed.), Italy since 1945, Oxford: Oxford University Press, 42-68.

Zavoli, Sergio, 1994, La notte della Repubblica, supplement of L'Unità, 22.11.1994. 


\section{Newspaper and magazine articles}

Alberoni, Francesco, «L'esercito dell'apocalisse», Corriere della Sera, 19.3.1978, 3.

Augias, Corrado, «Quell'apparente paradosso della sua azione politica», La Repubblica, 10.5.1978, 11-12.

Avanti!, «Le analogie con il caso Schleyer pongono inquietanti interrogativi», 17.3.1978, 10 .

Avanti!, «Forse Moro è stato drogato», 31.3.1978, 14.

Avanti!, «Uniti tutti i democratici - difendiamo la Repubblica», 10.5.1978, 1.

Barino, Mario, «Berna - Le BR hanno sbagliato i loro calcoli», Corriere della Sera, 10.5.1978, 10 .

Berlinguer, Enrico, «Berlinguer al popolo e agli elettori», L'Unità, 8.05.1978, 1.

Berlinguer, Enrico, «Unità e rigore», L'Unità, 17.3.1978, 1.

Biagi, Enzo, «Moro: Il suo stile è la tolleranza», Corriere della Sera, 17.3.1978, 3.

Bobbio, Norberto, «Per lo Stato democratico», La Stampa, 10.5.1978, 3.

Bocca, Giorgio, «A Milano gli operai tornano in prima fila», La Repubblica, 17.3.1978, 9 .

Bocca, Giorgio, "Al centro del dibattito c'è quel «prigioniero»", La Repubblica, 31.3.1978, 2.

Caputo, Sandro, «Il primo statista martire della libera Comunità europea», Il Popolo, 11.5.1978, 7.

Carbone, Fabrizio, «Prevenire subito», La Stampa, 21.3.1978, 1-2.

Carbone, Fabrizio/Mazzocchi, Silvana, «Doppio ricatto, contro lo Stato e la famiglia», La Stampa, 11.4.1978, 1.

Carraciolo, Lucio, «Un'inchiesta che sembra nata morta», La Repubblica, 25.3.1978, 4.

Carraciolo, Lucio, «Il giorno più lungo», La Repubblica, 6.04.1978, 2.

Cavedon, Remigo, «La «svolta〉 terroristica è nella logica delle BR», Il Popolo, 17.3.1978, 4.

Chierici, Maurizio, «Isolamento, droga, veglia prolungata. Ecco come si annienta la personalità, Corriere della Sera, 31.3.1978, 3.

Cianciullo, Antonio, «Un'azione alla tedesca che ricorda Schleyer», La Repubblica, 17.3.1978, 5 .

Conso, Giovanni, «Scambio Moro-BR nonsenso giuridico», La Stampa, 20.3.1978, 2.

Conso, Giovanni, «Il giurista Aldo Moro: «Gli interessi dello Stato devono essere prioritari su quelli individuali»», La Stampa, 10.5.1978, 3.

Corriere della Sera, «Moro rapito, cinque uomini della scorta massacrati - Il Paese rifiuta il ricatto delle «Brigate Rosse»», 17.3.1978, 1.

Corriere della Sera, "All'appello dei sindacati rispondono quindici milioni di Italiani», 17.3.1978, 1. 
Corriere della Sera, «Bonn - Si affaccia l'ipotesi che a Roma abbiano agito anche i terroristi tedeschi», 17.3.1978, 7.

Corriere della Sera, «Ma la Repubblica non sarà mai loro prigioniera», 30.3.1978, 1.

Corriere della Sera, «Ecco il testo dello scritto su Taviani. Gli amici: «Un Moro irriconoscibile»", 11.4.1978, 2.

Corriere della Sera, «La Repubblica non si baratta», 21.4.1978, 1.

Corriere della Sera, «Il delitto Moro», 10.5.1978, 1.

Corriere della Sera, «Bandiere bianche, rosse, verdi», 14.5.2017, 1.

Corriere della Sera, «Ma chi scrive quelle lettere?», La Repubblica, 26.4.1978, 1-2.

De Luca, Fausto, «Parole scritte sotto tortura», La Repubblica, 30.3.1978, 1.

De Rosa, Gabriele, «Il suo nome è impresso a caratteri indelebili nella coscienza civile di tutti i popoli amanti della libertà», Il Popolo, 11.5.1978, 5.

De Santis, Fabrizio, «Il dolore di Paolo VI dopo l'inutile appello - Il giornale vaticano: Dall'orrore alla speranza", Corriere della Sera, 10.5.1978, 5.

De Santis, Fabrizio, «Attorno al Papa si è trovato unito tutto il mondo politico italiano", Corriere della Sera, 14.5.1978, 2.

Di Bella, Franco, «È morto perché questa Repubblica viva», Corriere della Sera, 10.5.1978, 1 .

Donoghue, Denis, «The Hunger Strikes», The New York Review of Books, 22.10.1981, 29-31.

Fedi, Giuseppe, «D’improvviso la famiglia lo ha seppellito in segreto», La Stampa, 11.5.1978, 1 .

Firpo, Luigi, «Feroci e senza un futuro», La Stampa, 10.5.1978, 3.

Forcella, Enzo, «Bandiere rosse, bandiere bianche», La Repubblica, 24.3.1978, 6.

Forcella, Enzo, «Il martire che rifiutò di divenire un simbolo», La Repubblica, 19.3.1988, 1 .

Fortebraccio, «Uno che ha capito», L'Unità, 17.3.1978, 1.

Fortebraccio, «Ci vada piano», L'Unità, 15.4.1978, 1.

Fortebraccio, «Quello vero», L'Unità, 23.4.1978, 1.

Fossi, Giancarlo, «Roma: duecentomila lavoratori in piazza - Chiusi negozi e cinema, scioperi revocati», La Stampa, 17.3.1978, 3.

Gambescia, Paolo, «Una tragica lettera di Moro», L'Unità, 30.3.1978, 1.

Gilmozzi, Marcello, «Una guerra disperata», Il Popolo, 17.3.1978, 1.

Giuntella, Paolo, «Così disse condannando la violenza», Il Popolo, 17.3.1978, 3.

Grisi, Francesco, «La figura di Moro va al di là del rapporto con la cronaca: il suo discorso è metafisico e teologico", Il Popolo, 21.3.1978, 5.

Haberman, Clyde, «Evolution in Europe; Italy Discloses Its Web Of Cold War Guerrillas», New York Times, 16.11.1990, http://www.nytimes.com/1990/11/16/w orld/evolution-in-europe-italy-discloses-its-web-of-cold-war-guerrillas.html (accessed August 22, 2017). 
Jemolo, Arturo Carlo, «Adesso è indispensabile essere un popolo unito», La Stampa, 10.5.1978, 3 .

Lotta Continua, «Comunicato di Lotta Continua: Il sequestro di Macchiarini, dirigente alla Sit Siemens», 9.03.1972, 1.

Lotta Continua, «Rapito Moro, il gioco più pesante e sporco che sia mai stato provato sulla testa dei proletari italiani», 17.3.1978, 1.

Lotta Continua, «Non sarà un nuovo Stammheim», 17.3.1978, 10-14.

Lotta Continua, «Lo Stato continua», 18.3.1978, 1.

Lotta Continua, «Un appello», 19.4.1978, 1.

Lotta Continua, «Le adesioni all'appello», 20.4.1978, 1.

Lotta Continua, «In cerca di un martire»,18.4.1978, 1.

Mafai, Miriam, «Dodici killer per un massacro scientifico», La Repubblica, 17.3.1978, 1 .

Il Manifesto, «Il sequestro sanguinoso di Aldo Moro», 17.3.1978, 1.

Manetti, Clemente, «Scandalo e silenzi», Lotta Continua, 20.4.1978, 1.

Manfalotto, Rosario, «Andreotti alla Camera: «Non si può patteggiare con gente che ha le mani grondanti di sangue»", Corriere della Sera, 5.03.1978, 2.

Man, Igor, «Paolo VI e i delegati di cento paesi al solenne rito funebre in Laterano, La Stampa, 14.5.1978, 1.

Martelli, Claudio, «Perché non credere a quelle lettere?», Corriere della Sera, 1.05.1978, 3 .

Martinelli, Sergio, «Dieci storici giorni di passione», Corriere della Sera, 26.3.1978, 4.

Mazzocchi, Silvana, «Impossibile trattare per Moro, nel mirino c'era anche il PCI», La Repubblica, 31.3.2007.

Medail, Cesare, «Non scrive così per paura», Corriere della Sera, 26.4.1978, 1.

Mieli, Paolo, «Moro non voleva allearsi col PCI - Un compromesso (non) storico», Corriere della Sera, 13.11.2016, http://www.corriere.it/cultura/16_novembre_13/ moro-aldo-compromesso-storico-pci-dc-massimo-mastrogregori-salerno-comunis ti-democristiani-ff773f9a-a9c7-11e6-9e75-99cc0b521152.shtml (accessed August 12, 2017).

Mori, Anna Maria, «Una famiglia nell'angoscia però «col riserbo di Aldo»», La Repubblica, 17.3.1978, 6.

Munzi, Ulderico, «Nascosti due messaggi fra le righe delle pagine scritte dal prigioniero", Corriere della Sera, 31.3.1978, 1.

Narducci, Mario, «Così il papa ha vissuto la passione di Moro», Il Popolo, 10.5.1978, 3.

Nascimbeni, Giulio, "Quando Pallante sparò a Togliatti», Corriere della Sera, 17.3.1978, 3 .

Orfei, Ruggero, «La sofferenza di Aldo Moro è collettiva e una testimonianza nazionale alla cui lezione nessuno deve sottrarsi», Il Popolo, 19.3.1978, 4.

Pace, Giovanni Maria, «Tortura dura e raffinata ma senza l'uso di droga», La Repubblica, 31.3.1978, 5 . 
Padellaro, Antonio, «14.30: La disperazione entra nel palazzo di piazza del Gesù», Corriere della Sera, 10.5.1978, 4.

Pasolini, Pier Paolo, «Il vuoto del potere», Corriere della Sera, 2.2.1975, 1.

Pansa, Gianpaolo, «Ł̇̀ come se avessero rapito nostro padre e nella DC di Milano esplode la rabbia», La Repubblica, 17.3.1978, 7.

Pansa, Gianpaolo, «Moro sepolto in silenzio», La Repubblica, 11.5.1978, 4.

Pavone, Claudio, «Sparo, dunque sono. Il nodo della violenza», Il Manifesto, 6.05.1982, 7.

Pecorelli, Carmine, «Alla riscoperta dello Stato», Osservatore Politico, 4.04.1978. reprinted in: Flamigni, Sergio (ed.), 2006, Le idi di marzo. Il delitto Moro secondo Mino Pecorelli, Milano: Kaos, 255-266.

Pecorelli, Carmine, «Il Paese si può e si deve salvare», Osservatore Politico, 2.5.1978, reprinted in: Flamigni, Sergio (ed.), 2006, Le idi di marzo. Il delitto Moro secondo Mino Pecorelli, Milano: Kaos, 290-296.

Pellegrino, Michele, «La morte dell'innocente disegno misterioso di Dio», La Stampa, 10.5.1978, 3 .

Piazzesi, Gianfranco, «Aldo Moro: il suo ritratto è nei promessi sposi», Corriere della Sera, 13.3.1978, 3.

Piazzesi, Gianfranco, «Stoica dignità», Corriere della Sera, 19.3.1978, 1.

Piazzesi, Gianfranco, «La forza della dignità», Corriere della Sera, 7.04.1978, 1.

Piazzesi, Gianfranco, «La tregua», Corriere della Sera, 14.4.1978, 1.

Il Popolo, «Angoscia per Moro», 17.3.1978, 1.

Il Popolo, «Paolo VI: 〈profondo è il nostro dolore», 17.3.1978, 1.

Il Popolo, «Vogliono distruggere la figura di Moro», 26.4.1978, 3.

Il Popolo, «Aldo Moro assassinato», 10.5.1978, 1.

Il Popolo, «Il prezzo più alto», 10.5.1978, 1.

Il Popolo, «L'ultimo addio per un 〈giusto»», 14.5.1978, 1.

Reggiani, Stefano, «Aldo Moro, lo statista degli equilibri difficili», La Stampa, 17.3.1978, 5 .

Reichlin, Alfredo, «Perché l'hanno ucciso», L’Unità, 10.5.1978, 1.

La Repubblica, «Il rapimento di Moro - L'Italia ha reagito - sciopero generale, fiducia al governo", 17.3.1978, 1.

La Repubblica, «Hanno colpito il cuore dello Stato», 17.3.1978, 1.

La Repubblica, «Quelle parole non sono le sue», 30.3.1978, 1.

La Repubblica, «Sacrificare un uomo o perdere lo Stato», 21.4.1978, 1.

La Repubblica, L'assassinio di Moro - Il paese reagisce compatto alla sfida BR», 10.5.1978, 1 .

La Repubblica, «Messaggio di Leone al paese», 10.5.1978, 2.

Rizzo, Aldo, «Una linea ferma», La Stampa, 31.3.1978, 1.

Rodotà, Stefano, «Misure eccezionali», La Repubblica, 23.3.1978, 1-2. 
Roggi, Enzo, «La segreteria DC conferma la linea dell'intesa democratica», L'Unità, 30.3.1978, 8 .

Rossanda, Rossana, «L'album di famiglia», Il Manifesto, 2.4.1978, 1-2.

Russo, Giovanna, «La direzione Dc discute la linea da tenere nel caso di un ricatto», Corriere della Sera, 18.3.1978, 2.

Saba, Antonio, «Nel carcere del popolo la violenza psicologica fa desiderare la morte», La Repubblica, 31.3.1978, 4.

Sansa, Tito, «Bonn - Rapito come Schleyer», La Stampa, 17.3.1978, 4.

Scalfari, Eugenio, «Dio perdona ma Cesare castiga», La Repubblica, 23.4.1978, 1-2.

Scalfari, Eugenio, "Contro il terrore le leggi della Repubblica», La Repubblica, 10.5.1978, 1-2.

Scalfari, Eugenio, «Lo sgomento dopo 30 anni di potere», La Repubblica, 14.5.1978, $1-2$.

Scardocchia, Gaetano, «Si intravvede fra le righe un'inquietante domanda», Corriere della Sera, 30.4.1978, 2.

Senzani, Fiorenza, «Per Moro non potevamo trattare.> Andreotti replica al figlio dello statista - Cossiga: non leggerò il suo libro», Corriere della Sera, 15.10.2007, 21.

Sorge S.J., Bartolomeo, «Potenza della Risurrezione», Il Popolo, 26.3.1978, 1.

Sorino, Benedetto, «Moro beato, via alla causa - agli atti c'è un miracolo», La Gazzetta del Mezziorgiono, 22.9.2012, http://www.lagazzettadelmezzogiorno.it/ne ws/home/397234/moro-beato-via-alla-causa-agli-attic-e-un-miracolo.html (accessed August 23, 2017).

Spadolini, Giovanni, "Aldo Moro è il «tessitore» della nuova realtà italiana», La Stampa, 18.3.1978, 3.

Spadolini, Giovanni, «Difendo l'immagine di Moro», La Stampa, 27.4.1978, 1.

Spriano, Paolo, «La piazza e lo Stato», L'Unità, 18.3.1978, 1.

La Stampa, «Dopo il massacro, nessuna traccia di Moro - il Paese si è fermato: dice no al terrorismo", 17.03.978, 1.

La Stampa, «Le misure urgenti decise dal governo entreranno in vigore da mezzanotte», 21.3.1978, 2.

La Stampa, «È una delle figure più prestigiose ed umane», 17.3.1978, 5.

La Stampa, «Gli assassini come giudici», 19.3.1978, 1.

La Stampa, «Emozione, speranza alla sede della DC. Zaccagnini: Moro ne esce esaltato", 19.3.1978, 3.

La Stampa, «Quali farmaci possono usare le BR su Moro», 31.3.1978, 2.

La Stampa, «Una cieca violenza», 11.4.1978, 1.

La Stampa, «Perché lo Stato non può piegarsi a degli assassini», 21.4.1978, 1.

La Stampa, «Moro assassinato - Milioni di italiani scendono in piazza», 10.5.1978, 1

La Stampa, «Il discorso del Papa», 14.5.2017, 1.

La Stampa, «Solidarietà umana e politica», 14.5.2017, 1. 
Testori, Giovanni, «Il bisogno della speranza», Corriere della Sera, 26.3.1978, 1-2.

Tobagi, Walter, «Storia di oggi che ha radici in delitti lontani - Quel giorno ricordammo come ebbe inizio il martirio di Metteotti», Corriere della Sera, 10.5.1978, 8.

Tobagi, Walter, «Da Matteotti a Moro: due delitti contro la democrazia - Un martirio che non riuscì a fermare le trame del fascismo", Corriere della Sera, 10.5.1978, 6 .

Tornabuoni, Lietta, «Nelle mani delle BR un prigioniero fragile e fortissimo», Corriere della Sera, 24.3.1978, 1.

L'Unità, «Straordinario sussulto democratico - Gli italiani si stringono a difesa della Repubblica - Si è formata in Parlamento la nuova maggioranza», 17.3.1978, 1.

L'Unità, «Straordinario sussulto democratico», 17.3.1978, 1.

L'Unità, «Il linguaggio di Freda e quello delle BR», 27.4.1978, 1.

L'Unità, «Berlinguer: Assicuriamo al Paese l'impegno unitario e tenace del PCI», 17.3.1978, 1 .

L'Unità, «Commossi funerali dei cinque assassinati - I criminali si fanno vivi inviando la foto di Moro», 19.3.1978, 1.

L'Unità, «Un uomo torturato», 19.3.1978, 1.

L'Unità, «Fermezza», 31.3.1978, 1.

L'Unità, «Moro poteva essere sotto l'effetto di un ipnotico», 31.3.1978, 2.

L'Unità, «Una dichiarazione di Lucio Lombardo Radice», 21.4.1978, 3.

L'Unità, «Il prezzo vero», 21.4.1978, 1.

L'Unità, «L'assassinio di Moro - L'Italia si è fermata di colpo come il 16 marzo - Milioni di uomini mobilitati contro l'eversione», 10.5.1978, 1.

L'Unità, «La famiglia l'ha sepolto in silenzio nel paesino dove amava rifugiarsi», 11.5.1978, 2.

Valiani, Leo, «La democrazia ha altre armi per difendersi», Corriere della Sera, 20.3.1978, 1 .

Valiani, Leo, «Noi, nelle carceri del fascismo», Corriere della Sera, 11.4.1978, 1.

Veneziani, Marcello, «Tommaso, l'unico Moro vero santo», Il Giornale, 20.7.2012, http://www.ilgiornale.it/news/tommaso-lunico-moro-davvero-santo.html (accessed August 23, 2017).

Vinciguerra, Alfredo, «Come salvare il paese», Il Popolo, 17.3.1978, 3.

Vinciguerra, Alfredo, «Le mani armate di cuori disarmati», Il Popolo, 21.3.1978, 5.

Vinciguerra, Alfredo, «Un paese folgorato», Il Popolo, 10.5.1978, 3.

Viola, Sandro, «In 20 giorni hanno ucciso un leader», La Repubblica, 5.04.1978, 1.

Viola, Sandro, «Una voce stravolta dal carcere», La Repubblica, 11.4.1978, 1.

Willan, Philip, «US ssupported by anti-left terror in Italy». Report claims Washington used a strategy of tension in the cold war to stabilize the centre-right», The Guardian, 24.7.2000, 19. 
Zenit. Il mondo visto da Roma, «Aldo Moro. Il Vicariato di Roma avvia il processo di beatificazione», 24.9.2016, https://it.zenit.org/articles/aldo-moro-il-vicariato-di-ro ma-avvia-il-processo-di-beatificazione/ (accessed August 23, 2017).

Zucconi, Vittorio, «Le lettere: Strategia BR e resistenze di Moro», La Stampa, 30.4.1978, 2.

\section{Web pages}

http://www.adsnotizie.it/_dati_ante98.asp_(accessed May 6, 2016).

http://www.adsnotizie.it/_dati_DMS.asp (accessed May 6, 2016).

http://www.brindisiweb.it/monumenti/monumento_aldo_moro.asp_(accessed August 20, 2017).

http://www.brundarte.it/2014/05/07/monumento-a-virgilio-e-uno-sguardo-al-patrim onio-monumentale-contemporaneo/ (accessed August 20, 2017). 


\section{Filmography}

\section{Television programs}

La notte della Repubblica: Caso Moro - Prima parte (RAi 2, IT 21.02.1990), http://www.raiplay.it/video/2017/03/La-notte-della-Repubblica-Puntata-del-2102 1990-09f11b07-c32d-49dc-8351-bbec77557d22.html (accessed August 20, 2017).

La notte della Repubblica: Caso Moro - Seconda parte (RAI 2, IT 28.02.1990), http://www.raiplay.it/video/2017/03/La-notte-della-Repubblica-Puntata-del-2802 1990-8493b752-f295-4e55-8fb9-38b9620a61c2.html_(accessed August 20, 2017).

La notte della Repubblica: Caso Moro - Terza parte (RAI 2, IT 07.03.1990), http://www.raiplay.it/video/2017/02/La-notte-della-Repubblica-Puntata-del-0703 1990-7cd1f6e6-5920-4f83-9017-f394e7315fe9.html_(accessed August 20, 2017).

La STORIa Siamo NOI: Il CASO Moro: DAl SEQUeSTRO ALl'OMicidio - I 55 GIORNI CHE CAMBiarono L'ITALIA (RAI 3, IT 10.05.2003), http://www.lastoriasiamonoi.r ai.it/puntate/il-caso-moro/381/default.aspx (accessed August 20, 2017).

Aldo Moro: Il giorno più lungo della Repubblica (RAI 1, IT 16.03.1979), http:/ /www.raiplay.it/video/2016/09/watchfolder-TamTam-Il-giorno-piu-lungo-della-R epu-20160914181206--B-R-1800mp4-e6e3d116-eaa3-4ba5-8ac3-0f59032e458a.ht ml_(accessed August 20, 2017).

\section{Movies}

Buongionno, nOtTe (Marco Bellocchio, IT 2003).

IL CASo Moro (Giuseppe Ferrara, IT 1986).

IL Divo (Paolo Sorrentino, IT 2008).

Maledetti vi amerò (Marco Tulio Giorndana, IT 1980).

Piazza delle cinque lune (Renzo Martinelli, IT/UK 2003).

Paisà (Roberto Rossellini, IT 1946).

Romanzo di UNA STRAGE (Marco Tullio Giordana, IT/F 2012).

Three Songs About Lenin (Dziga Vertov, USSR 1934).

Todo мodo (Elio Petri, IT 1976). 


\section{Register}

absolutization 62, 63, 193

Agamben, Giorgio 32, 56, 62, 63, 94, 105, $193,327,328,372-374$

Alberoni, Francesco 225

Alferano, Pio 347

Allende, Salvador 146, 156

Althusser, Louis 79, 364

Amendola, Giovanni 135

Amnesty International 257, 263

Anbrosoli, Giorgio 343

Andreotti, Giulio 16, 156, 157, 173, 175, 177, 179, 203, 206, 207, 209-211, 215, $221,258,260,261,266,272,313,328$, 343-346

anthropology 28, 50, 92, 108, 240, 374, 376

Antonello, Pierpaolo 22, 23, 27, 28

apocalypse 104, 137, 225, 244

Arendt, Hannah 115, 129

Assmann, Aleida 306

Augias, Corrado 297

Augustine of Hippo 120, 359

Austin, John Langshaw 71-73, 75

Autonomia Operaia 164, 179, 261

Avenali, Marcello 308

Azione Cattolica 163, 241, 260

Azzolini, Lauro 183

Baliani, Marco 25, 27, 189, 287

Balzerani, Barbara 188, 334, 336

Barthes, Roland 379

Bartleby 192

Bartolomeo, Sorge 244

Barton, Carlin 113

Behemoth 50, 246, 280

Bell, Chaterine 94

Bellah, Robert N. 124

Bellocchio, Marco 25, 27, 316, 351, 356

Belpoliti, Marco 319, 321

Benjamin, Walter 52-55, 57, 281, 285, 327

Benvenuto, Giorgio 207

Berlinguer, Enrico 146, 147, 156, 157, 162, $170,217,226,227,232,334$

Berlusconi, Silvio 171

Biagi, Enzo 229

Biagi, Marco 20

biopolitics 282, 326, 368

Biscione, Francesco 142, 155, 175, 335

Blumenberg, Hans 50, 108, 349, 373-376, 381
Bobbio, Norberto 139, 140, 149, 260, 292, 294

Bocca, Giorgio 183, 217

Bodin, Jean 122

body politic 54, 55, 94, 189, 191, 297

Böll, Heinrich 260

Bonino, Emma 173

Bordiga, Amedeo 145

Borges, Jorge Luis 321

Borghese, Junio Valerio 147

Bowersock, Glen 109, 111

Braghetti, Anna Laura 336, 350

Brezhnev, Leonid 146

Brox, Norbert 109

Burgess, Anthony 317

Bush, George W. 52

Butler, Judith 58, 74, 79, 190

Cagol, Margherita 167, 168

Cain 294

Calabresi, Luigi 346

Calvi, Roberto 343

Calvino, Italo 27, 317, 319, 320, 331, 350

Caritas Internationalis 257, 265, 284

Carter, Jimmy 156

Cassirer, Ernst 378

Cercano, Giancarlo 205

Cervantes, Miguel de 321

Cervone, Vittorio 173

Charles I 317

Chenu, Marie-Dominique 260

Christ 27, 31, 104, 112, 114, 116, 148, 243, 361,367

- judgment 332

- martyrdom 55

- Passion 31, 54, 103, 113, 121, 237, 238, 240, 244, 267, 280, 293, 366

- resurrection 27, 55, 244, 366

- sacrifice 293, 367

- suffering 267

Christian Democracy 142, 143, 156

- and Fascism 195

- and Historic Compromise 16

- and Il Popolo 86

- and negotiation issue 17

- language 194, 215

- legitimacy crisis 217

- scandals 184, 194 
Christianity 30, 31, 125, 133, 135, 137, 138, 353,373

Church 110, 121, 195, 203

- Anglican 317

- Catholic 119, 137, 143, 144, 159, 160

Church of Santa Chiara, Rome 203, 348

CIA 173, 339, 350

Clark, Joseph 127

Coco, Francesco 167, 168

Colasuonno, Francesco 359

Colombo, Emilio 299

community

- Christian 31, 114, 117, 121, 182, 353, 366,367

- European 299

- national 33, 218, 278, 315

- political 15, 26, 30, 62, 93, 190, 280, 333

- universal 55, 366

consecration 92, 99, 101, 102, 105-107, $218,268,280,302,303,330$

Conso, Giovanni 292, 295, 296

conspiracy theory $22,173,323,370$

Constantine the Great 117

conventionality 73,74

Cossiga, Francesco 17, 173, 175, 177, 179, 204, 206, 207, 251, 253, 254, 269, 270, $272,313,328,335,336$

Craxi, Bettino 171, 179, 260, 286

Cristi, Marcela 124

Cromwell, Oliver 317

Cucchiarelli, Paolo 346

cultural analysis $15,26,364$

cultural practice $364,365,371,372$

Curcio, Renato 167, 209, 249, 254, 334

Curioni, Cesare 179

dalla Chiesa, Carlo Alberto 169, 250, 343

De Gasperi, Alcide 142-144, 151, 152, 157

De Lorenzo, Giovanni 147, 153

De Rosa, Gabriele 298

Deleuze, Giles 56

Derrida, Jacques 73-77, 364, 374

Di Bella, Franco 290

discourse

- acratic 379

- encratic 379

- hegemonic $61,322,329,332,337,338$, $354,371,380$

- of rebellion $34,43,45-48,50,137,139$, 337

- of sovereignty $34,43-45,47,48,51,60$, $106,137,326,332,337$

- subversive 332

discourse analysis $15,26,29,65,77,78,81$, $82,85,87,88,107,364$

discourse theory 64 discursive formation $66-68,75,80,82-85$, 87-89

discursive practice $30,41,42,44,60,62,63$, $65,66,68,71,72,74-80,82-88,96,106$, 193, 280, 327-329, 332, 352, 364, 365, 371,380

Donat-Cattin, Carlo 248

Donati, Giuseppe 136

Dossetti, Giuseppe 151

Drake, Richard 25, 151, 153, 163

Dumezil, Georges 44

Dunnage, Jonathan 159

Durkheim, Émile 125

D’Antona, Massimo 20

Easter 226, 240, 242, 244, 245, 280, 342

Eco, Umberto 324, 355

eschatology $31,46,114,115,121,123,225$, $353,366,367$

ethics 64, 182, 183, 192, 295, 296, 311, 370, 372

- Christian 149

European Union 368

exemplarity 282,372

faith $19,95,125,127,134,138,238,335$, $336,358,360,361$

Falcone, Giovanni 343

Fanali, Duilio 199

Fanfani, Amintore 151, 152, 156

Fasanella, Giovanni 175

Fassino, Piero 316

Federazione Universitaria Cattolica Italiana (FUCI) 260

Feltrinelli, Giangiacomo 158

Ferlicchia, Luigi 356, 361

Ferracuti, Franco 206

Ferrara, Giuseppe 339

Fierke, Karin 93

Firpo, Luigi 292, 293

Flamigni, Sergio 174, 335

Forcella, Enzo 218, 315

Formigoni, Guido 177, 255

Fortebraccio 231, 275

Fortini, Franco 218

Fossi, Giancarlo 216

Foucault, Michel 43-48, 63, 66, 67, 71, 74-79, 81-83, 85, 106, 282, 283, 364, 374

Foxe, John 121

Frajese, Paolo 206

Franceschini, Alberto 167, 171, 209

Frazer, James George 319

Freire, Pauolo 260

French Revolution 126, 132, 135, 306, 327, 368,381 
Galli, Giorgio 171, 176

Galloni, Giovanni 152, 223, 238

Garibaldi, Giuseppe 133

Gentile, Giovanni 140, 149

Giampaolo, Nicola 356, 358, 360, 361

Giansanti, Gianni 287

Ginsborg, Paul 153, 154, 157, 169

Ginzburg, Carlo 23

Gioberti, Vincenzo 133

Giordana, Marco Tullio 346, 349, 350

Giordani, Igino 136

Giralucci, Graziano 168

Girard, René 28, 92, 103, 104, 319, 365, 374

Gladio, NATO stay-behind organization 143,179

Glynn, Ruth 312, 313

Gobetti, Piero 135

Gotor, Miguel 178-180, 250, 334

governmentality $281,326,327$

Gramsci, Antonio 145, 197

Granelli, Luigi 248

Graziosi, Paolo 343, 344

Grisi, Francesco 241

Gui, Luigi 199-202, 254

Hall, Stuart 68, 69, 80, 83, 364

Herder, Johann Gottfried 132

Herlitzka, Roberto 351

Heywood, Paolo 281

Historic Compromise 16, 156, 169, 231

Hobbes, Thomas 50, 104, 123

homo sacer 32, 105, 107, 116, 242, 268, $280-283,303,328,367,368,371$

hot autumn 154, 162

Hubert, Henri 92, 101

human rights $32,33,128,327,368$

humanitarian 252, 254, 257, 261, 263, 265, 284-286

humanitarianism 263, 284, 285

Hus, Jan 120

hypostatization 63

identification $33,55,58,62,79,124$

identity $54,58,73,75,76,79,80,131,139$,

186, 190, 211, 215, 218, 221, 223,

226-229, 306, 366

Imposimato, Ferdinando 175

interpellation 79, 364

Italian Communist Party 142, 143, 145, 156

- and Historic Compromise 16

- and L'Unità 86

- and line of firmness 248

- and negotiation issue 17

- language 215, 227

- legitimacy crisis 217
Italian Constitution 32, 142, 162, 232, 261, 276, 281, 299

Italian Social Movement 160, 168, 188, 207

Italian Socialist Party 142

- and Avanti! 86

- and negotiation issue 185, 260, 261, 263

iteration $30,65,74,78,81,108$

Jemolo, Arturo Carlo 158, 292, 294

John Paul II 359

katechon 32, 51, 365

Katz, Robert 173, 335, 339

Khrushchev, Nikita 146

Kippenberg, Hans 64

Klausner, Samuel 92

Kohn, Hans 131

Koselleck, Reinhard 306

La Malfa, Ugo 207, 334

La Pira, Giorgio 151

Laclau, Ernesto 189

Ladu, Giovanni 175

Lago della Duchessa 257

Lama, Luciano 207

Landolfi, Antonio 179

language

- and meaning 68

- Christian 30, 332, 374

- eschatological 137

- game 96, 189

- Greco-Roman 117

- historicity and exteriority $323,365,381$

- instrumental 62-64, 193, 194, 197, 354, $364,365,379,380$

- legal 109, 187

- martyrological 118, 315

- performativity $57,71,73,74,82,322$

- poetic $62,64,193,364,379,380$

- political 69,202

- religious 15, 107, 108, 126

- revolutionary 380

- secularized 108

- technical 112

Lazzati, Giuseppe 151

Leccese, Valerio 287

Lefebvre, Antonio 199

legitimization $15,32,53,60,92,93,114$, $115,122,124,125,306,363,366,370$, 373

Leone, Giovanni 297

Lévi-Strauss, Claude 374

Leviathan 50, 56, 95, 246, 280

life

- eternal 301 
- mere/bare 32, 33, 53, 54, 56-58, 94, 95, 105-107, 266, 280, 282, 283, 285, 287, 288, 303, 327-329, 331, 332, 342, 367, 368

- political 268,322, 338

- sanctity/sacredness 37, 149, 170, 192, 248, 262, 263, 265, 283-285, 295, 368, 369,371

line of firmness 17, 19, 209, 252, 254, 259, $262,263,271,278,281,283,294$

Lockheed scandal 157, 199, 309

Lombardi, Giancarlo 312, 313

Lotta Continua (organization) 165

Louis XIV 132

Luther, Martin 120

Macario, Luigi 207

Macchi, Pasquale 179, 260

Macchiarini, Idalgo 166, 167

Man, Igor 301

Manca, Enrico 271

Marat, Jean-Paul 127

Marcucci, Eugenio 240

Marini, Antonio 335

Maritain, Jacques 144, 151

Maritano, Felice 168

Marshall Plan 143, 152

Martelli, Claudio 317

Martinelli, Renzo 350

Martinetti, Piero 137

Martini, Luigi 134

martyr

- Christian 27, 28, 31, 134, 264, 353

- cult 118, 127

- Maccabean martyrs 110

- martyrs of Belfiore 134, 307

- martyrs of Compiègne 127

- martyrs of the French Revolution 127

- martyrs of the Reformation 120

- martyrs of the Resistance 42, 307

- militarization 118

- national 126

- of the state $15,29,31,48,59,61,62,66$, $80,97,124,129,131,282,363,366$, 368,373

- remains 118

- republican 135

martyrdom

- and sovereignty 61

- and terrorism 42, 43

- as a spiritual conflict against Satan 119

- as act of self-sacrifice 92

- as act of witnessing 31,113

- as imitation of Christ 31

- Christian 110, 112, 359 martyrology

- Christian 23, 48, 103, 110, 182, 332, 335,367

- national 122

- republican 127, 128

Marx, Karl 151, 325, 344

Marxism 151, 163, 165, 240, 242, 325

Mastrogiacomo, Daniele 316

Mastroianni, Marcello 340

Mateotti, Giacomo 292

materiality $74,75,77,78$

Mauss, Marcel 92, 101, 105

Mazzini, Giuseppe 132

Mazzola, Giuseppe 168

mediality $74,75,77$

Melville, Herman 56, 192

memorial signs 306-308, 371

memorialization $45,306,313,315,316$, 351,354

memory

- collective 306

- instrumental use 334, 353

- political 306

- politicization 306

Menkovic, Biljana 306

Mennini, Antonello 179

metaphor 69, 70, 297, 350, 376, 377

Michalczyk, John 340

Middleton, Paul 90, 98, 110, 119, 121, 122 , 182

Milani, Lorenzo 163

mimetic desire 28

mimetic theory 92

Minoli, Giovanni 335

Minzoni, Giovanni 136

Moltmann, Jürgen 260

Montanelli, Indro 275

More, Thomas 362

Moretti, Mario 168, 179, 184, 185, 188, $205,334,350,352$

Moro, Aldo

- accusation of the Christian Democracy 261,266

- alliance between the DC and the PCI 147

- as accuser 345

- as Christian martyr 238, 299

- as defender of the Christian Democracy 199

- as great statesman $230,327,328$

- as legal scholar 148

- as martyr of democracy 292

- as martyr of liberty 298

- as martyr of the Christian Democracy 264 
- as martyr of the European community 299

- as president of FUCI 147

- as Prime Minister 153, 194

- as Secretary of the DC 152

- as sovereign-martyr 303, 304

- as state martyr 61, 193, 288, 289, 299, $327,328,333,337$

- as symbol 229, 231, 232, 279, 280, 288

- as witness 345

- assassination 18, 165, 169, 170, 286, 323

- beatification 19, 38, 289, 356, 357, 359, 361,362

- body 286-288, 297, 300, 303, 333, 338

- conception of Christianity 147

- conception of the law 149, 262, 296

- conception of the state 149, 192

- critique of liberalism and socialism 148

- critique of the line of firmness 252

- family $18,288,313$

- funeral 18, 36, 257, 266, 267, 288, 300, 302-304, 338

- image 316, 333, 338, 340, 342, 346

- interrogation 184

- kidnapping 15, 157, 188, 203, 334

- language 194, 195, 197, 199

- letters 16, 178, 250-252, 254-257, 260-262, 265-272, 274-280, 293, 294, $302,305,317,318,322,327-330,332$, $335-338,344,350,351,370,371$

- Memorial 178, 250, 251, 253, 256, 258, $273,344,345$

- on Jesus Christ 267

- on the reason of state 261

- photograph 233, 239, 258, 287, 333, 345

- private/public 279, 303, 371

- sacrifice 290, 292, 293, 299, 315, 320

Moro, Alfredo Carlo 174

Moro, Eleonora 335

Moro, Luca 342

Moro, Maria Fida 342

Moss, Candida R. 110

Moss, David 25, 313

Mouffe, Chantal 189

Mounier, Emmanuel 144

Müntzer, Thomas 120

myth $50,53,80,92,103,131,139,368,378$

mythicization $32,222,223,313,374,377$, 380, 381

narrative

- and history 23

- of rebellion 31, 49, 137, 366, 367, 372

- of sovereignty 49, 52, 366-368, 371

Nascimbeni, Giulio 216

nationalism 131, 132, 134, 136, 138
NATO 143, 156, 159, 172-175, 179

negotiation $170,179,199,209,211,220$, 228, 238, 246, 248, 249, 254, 256, 257, 259-261, 263, 265, 271, 272, 279, 280, 284, 290, 310, 324, 328, 335, 342, 369

New Testament 111, 243

Nixon, Richard 146, 319

Old Testament 293

Omodeo, Adolfo 137

Orfei, Ruggero 238

O'Leary, Alan 22, 23, 25, 350

Pace, Lanfranco 179

Palamara, Luca 175

parliamentary commission of inquiry 172 , 177, 196

Pasolini, Pier Paolo 153, 194-198, 322

Paul VI 16, 18, 185, 222, 250, 260, 300, 310, 338

Pavone, Claudio 139, 141, 164

Pecorelli, Carmine 157, 271, 343

Pellegrino, Giovanni 175

Pellegrino, Michele 292

performative force $15,30,59,61,62,68$, $75,76,238,364,366,376,381$

performativity $15,29,54,57,58,60,61,71$, $73-75,77,79,81,86,96,190,214,223$, 280, 322, 332, 369, 373, 380

Peterson, Erik 115

Petri, Elio 340

Pezzini, Isabella 316, 333, 338

Piano Solo 147

Piazza Aldo Moro, Bari 309

Piazza della Loggia bombing 21

Piazza Fontana bombing 21, 154, 155, 158, 166, 196, 346, 347

Piazza San Giovanni, Rome 206, 207, 217

Piazzesi, Gianfranco 237, 249, 273-275

Piccioni, Leone 241

Pieczenik, Steve 17, 207, 335

Pietrobelli, Romolo 241

Pinelli, Giuseppe 346

Pink Floyd 351, 355

Pinochet, Augusto 146

Piperno, Franco 179

Pirandello, Luigi 331

Pius XII 147, 160

political body 128, 191, 209, 223, 224, 231, 233

Ponzo, Jenny 135

prefiguration $108,117,138,187,198,216$, $226,237,240,242,246,264,268,280$, 292, 323, 349, 352, 361, 374, 376, 377

Propaganda 2 Masonic lodge 157, 172, 177, 335,340 
Radetzky, Josef 307

Radice, Lucio Lombardo 264

Rand Corporation 273

reason of state $29,192,202,250,252,253$, $282,283,310,311,316,327,329,349$, 368-370

Recupero, Maria Grazia 92, 118

Red Army Faction (RAF) 205, 219

Red Brigades

- acts of political violence 20

- and eschatological conception of history 225

- and prisoners exchange proposal 17

- and the hypothesis on foreign interference $173,219,313$

- and the Resistance 226, 353

- and violence 165

- as absolute enemies 369

- as beasts 69, 70, 235, 246, 274, 297

- as children of the Italian Communist Party 217, 223

- as common criminals 221, 222

- as Fascists 224

- as terrorists 42

- communiqués $16,18,24,183,185,187$, 209, 227, 233, 234, 248, 249, 251, 256-259, 261, 264, 265, 284, 286, 345

- conflict with the Italian State 246

- exclusion from collective identity 219

- first leaflet 167

- goal 177, 184-187, 190, 249

- history 167

- language 188, 226, 227, 324, 354

- leadership of Mario Moretti 168

- militarization 168

- propaganda strategy 333

- self-understanding 42, 183, 186, 190, 193

Reichel, Peter 306

religion

- and legitimization 115

- Christian 31, 117, 125, 128, 129, 133

- civil 124-126, 128, 135

- political 124-126, 128

- Roman 117

Remondino, Ennio 334

revolution $149,158,166$

Ricci, Domenico 334

Ricoeur, Paul 24

Ritschard, Willi 292

Rodotà, Stefano 208

Rossanda, Rossana 226

Rossellini, Roberto 351

Rousseau, Jean-Jacques 125-128, 133, 135

Rumor, Mariano 153 sacralization $32,94,95,102,103,105,107$, 124,365

Saragat, Giuseppe 296, 347

Satta, Vladimiro 176

Scaglia, Giovanni Battista 277

Scalfari, Eugenio 296, 304

Scalfaro, Luigi 174, 313

Scalzone, Oreste 221

scapegoat $27,28,92,103,254,365$

Schleyer, Hanns Martin 206, 220

Schmitt, Carl 51, 95, 104, 246

Schubert, Franz 356

Sciascia, Leonardo 23, 27, 173, 191, 198, 202, 221, 320-324, 327-333, 340-342, 345

secularization $30,31,107,108,124,128$, $129,280,368,373$

Segni, Antonio 147

Selva, Gustavo 240, 248

Sestieri, Claudio 175

Settembrini, Luigi 134

signature 29, 107, 353, 356, 363, 366, 373, 374,377

Signorile, Claudio 179

Silj, Alessandro 19, 222, 274, 281

Sindona, Michele 343

Smith, William Robertson 100

Soboul, Albert 127

Sorrentino, Paolo 343, 344, 346

Sossi, Mario 167, 168, 254, 256, 270

sovereign 303,367

- authority $365,366,368$

- body 302

- exception 284

- power $281,283,288,304$

- violence 31

sovereignty $122,281,326,327,366,368$

Soviet Union 35, 143, 146

Spadolini, Giovanni 230, 275

Spagnoli, Ugo 173

speech act 56, 64, 71-75, 93, 377

Spoeri, Tito 134

Stalin, Joseph 145

state of exception 51, 52, 95, 105, 281, 367, 368

state of nature 50

strategy of attention 154

strategy of tension $154,155,164,166,177$, 179,347

study of religion $15,64,65$

Sturzo, Luigi 136

subjectification $60,79,80$

Tambroni, Fernando 153, 160

Tanassi, Mario 199, 200

Tannassi, Mario 254 
Taubes, Jacob 52, 54, 55

Taviani, Paolo Emilio 167, 256, 257, 273

Taylor, Edward Burnett 100

Tazzoli, Enrico 134

terrorism 32, 41, 42, 52, 166, 196, 207, 217, $220,221,224,228,233,313,326$

Testori, Giovanni 218, 242

thanatopolitics $282,332,368$

theology 373

- Catholic 31

- Christian 31, 107

- Pauline 113

- political 51

Tobagi, Walter 292

Togliatti, Palmiro 145, 215

Tornabuoni, Lietta 239

Torres, Camilo 165

Torrita Tiberina 18, 300, 303

Tritto, Franco 287

truth $31,32,43,67,68,72,78,80,95,366$, 367

Turner, Victor 24

Unamuno, Miguel de 321

United Nations 284, 368

United States 35, 52, 155, 156, 172-174

Uva, Christian 333

Vallini, Agostino 356

van Baal, Jan 99

van Henten, Jan Willem 110

Venezia, Andrea 359

Veneziani, Marcello 362

Verdolini, Valeria 288

Vertov, Dziga 351

Vespa, Bruno 205

via Caetani, Rome 18, 286, 287, 311-315, 317,338

via del Forte Trionfale, Rome 203

via delle Botteghe Oscure, Rome 174

via Fani, Rome 16, 171, 185, 203, 206, 212, 214, 215, 217, 220, 221, 228, 232, 242, $245,312,313,315,350,351$

via Martiri di via Fani, Bari 309

via Montalcini, Rome 175, 350

via Monte Nevoso, Milan 250, 253

Vico, Gianbattista 381

Vinciguerra, Alfredo 232, 233, 240, 298
Viola, Sandro 272, 273

violence 164

- and power 43

- and sovereignty 106

- and terrorism 42

- divine 52-55, 57, 58

- Fascist 164

- law-preserving 281, 327

- lawmaking 281

- legitimization 51-53, 186, 193, 353

- monopoly 44, 48, 50, 104, 124, 129, 191

- mythical 52, 53, 55, 57

- passive 54

- political 15, 33, 41, 42, 91, 306

- representation 41, 44, 49, 372

- Resistance 164, 226

- spectacularization 367

Viroli, Maurizio 133, 139

Volonté, Gian-Maria 340, 341

von Harnack, Adolf 118

von Stuckrad, Kocku 65

Wagner-Pacifici, Robin Erica 24, 26, 27, 29 , $30,145,164,168,203,204,214,218$, $224,226,228,249,268,300$

war 43

- civil war 139, 188

- class war 139

- Cold War 143, 175, 176, 179, 220

- European wars of religion 120-122

- Greek Civil War 145

- Holy War 119

- of all against all 50, 368

- patriotic war 139

- Thirty Years War 123

- Vietnam War 163

- World War II 42, 144, 145, 155

Weigel, Sigrid 91, 95

Wittgenstein, Ludwig 96

Wycliffe, John 120

years of lead 22, 154, 155, 347

Zaccagnini, Benigno 18, 202, 238, 239, $255,256,261,265,266,275,276,292$, 300,334

Zama, Antonio 277

Zavoli, Sergio 26, 316, 337, 339 
